\title{
Digital Transformation and Public Services
}

Through a series of studies, the overarching aim of this book is to investigate if and how the digitalization/digital transformation process affects various welfare services provided by the public sector, and the ensuing implications thereof. Ultimately, this book seeks to understand if it is conceivable for digital advancement to result in the creation of private/ non-governmental alternatives to welfare services, possibly in a manner that transcends national boundaries. This study also investigates the possible ramifications of technological development for the public sector and the Western welfare society at large.

This book takes its point of departure from the 2016 Organization for Economic Co-operation and Development (OECD) report that targets specific public service areas in which government needs to adopt new strategies not to fall behind. Specifically, this report emphasizes the focus on digitalization of health care/social care, education, and protection services, including the use of assistive technologies referred to as "digital welfare." Hence, this book explores the factors potentially leading to whether state actors could be overrun by other non-governmental actors, disrupting the current status quo of welfare services.

The book seeks to provide an innovative, enriching, and controversial take on society at large and how various aspects of the public sector can be, and are, affected by the ongoing digitalization process in a way that is not covered by extant literature on the market. This book takes its point of departure in Sweden given the fact that Sweden is one of the most digitalized countries in Europe, according to the Digital Economy and Society Index (DESI), making it a pertinent research case. However, as digitalization transcends national borders, large parts of the subject matter take on an international angle. This includes cases from several other countries around Europe as well as the United States.

Anthony Larsson (Ph.D.) is a researcher at the Stockholm School of Economics Institute for Research (SIR), Sweden. He holds a Ph.D. from Karolinska Institutet, Sweden. He also holds an MBA and M.Sc. degrees in political science, social anthropology, and business administration and economics respectively, as well as an associate degree in psychology.

Robin Teigland (Ph.D.) is Professor of Management of Digitalization in the Entrepreneurship and Strategy Division at the Department of Technology Management and Economics at Chalmers University of Technology, Gothenburg, Sweden. She is also Professor of Business Administration with a specialization in strategic information systems management at the Stockholm School of Economics in Sweden and a member of the Royal Swedish Academy of Engineering Sciences. 


\section{Routledge Studies in the European Economy}

Crisis in the European Monetary Union

A Core-Periphery Perspective

Giuseppe Celi, Andrea Ginzberg, Dario Guarascio and

Annamaria Simonazzi

Rethinking Economic and Monetary Union in Europe

A Post-Keynesian Alternative

Philip B. Whyman

Central and Eastern Europe in the EU

Challenges and Perspectives Under Crisis Conditions

Edited by Christian Schweiger and Anna Visvizi

Greek Employment Relations in Crisis

Problems, Challenges and Prospects

Edited by Horen Voskeritsian, Panos Kapotas and Christina Niforou

Centrally Planned Economies

Theory and Practice in Socialist Czechoslovakia

Edited by Libor Žídek

SME Finance and the Economic Crisis

The Case of Greece

Alina Hyz

Russian Trade Policy

Achievements, Challenges and Prospects

Edited by Sergei Sutyrin, Olga Y. Trofimenko and Alexandra Koval

Digital Transformation and Public Services

Societal Impacts in Sweden and Beyond

Edited by Anthony Larsson and Robin Teigland

For a full list of titles in this series, please visit www.routledge.com/series/SE0431 


\section{Digital Transformation and Public Services}

Societal Impacts in Sweden and Beyond

Edited by

Anthony Larsson and Robin Teigland 
First published 2020

by Routledge

2 Park Square, Milton Park, Abingdon, Oxon OX14 4RN

and by Routledge

52 Vanderbilt Avenue, New York, NY 10017

Routledge is an imprint of the Taylor \& Francis Group, an informa business

(C) 2020 selection and editorial matter, Anthony Larsson and Robin

Teigland; individual chapters, the contributors

The right of Anthony Larsson and Robin Teigland to be identified as the authors of the editorial material, and of the authors for their individual chapters, has been asserted in accordance with sections 77 and 78 of the Copyright, Designs and Patents Act 1988.

The Open Access version of this book, available at www.taylorfrancis.com, has been made available under a Creative Commons Attribution-Non Commercial-No Derivatives 4.0 license.

Trademark notice: Product or corporate names may be trademarks or registered trademarks, and are used only for identification and explanation without intent to infringe.

British Library Cataloguing-in-Publication Data

A catalogue record for this book is available from the British Library

Library of Congress Cataloging-in-Publication Data

Names: Larsson, Anthony, editor. | Teigland, Robin, 1964- editor.

Title: Digital transformation and public services : societal impacts in

Sweden and beyond / edited by Anthony Larsson and Robin Teigland.

Description: Abingdon, Oxon ; New York, NY : Routledge, 2020.

Includes bibliographical references and index.

Identifiers: LCCN 2019026170 | ISBN 9780367333430 (hardback) |

ISBN 9780429319297 (ebook)

Subjects: LCSH: Public welfare-Sweden. |

Human services-Technological innovations-Sweden. |

Educational innovations-Sweden. | Medical care-Technological innovations - Sweden. | Public administration-Technological innovations - Sweden.

Classification: LCC HV338 .D55 2019 | DDC 361.609485-dc23

LC record available at https://lccn.loc.gov/2019026170

ISBN: 978-0-367-33343-0 (hbk)

ISBN: 978-0-429-31929-7 (ebk)

Typeset in Times New Roman

by Apex CoVantage, LLC 


\section{Contents}

List of figures viii

List of tables $\quad$ ix

Notes on contributors $\quad \mathrm{x}$

Foreword: digital transformation of public

services - how and why? $\quad \mathrm{xx}$

FRANCIS ANDREW GAFFNEY

Acknowledgments $\quad$ xxii

1 An introduction to digital welfare: a way forward? 1

ANTHONY LARSSON AND ROBIN TEIGLAND

PART I

Health and social care $\quad 13$

2 Telemedicine and the welfare state: the Swedish experience 15

MÅRTEN BLIX AND JOHANNA JEANSSON

3 Welfare services in an era of digital disruption: how digitalization reshapes the health care market

ANTHONY LARSSON, OLIVIA ELF, CORINNA GROSS, AND JULIA ELF

4 Centralization vs. decentralization on the blockchain in a health information exchange context

ANNA ESSÉN AND ANDERS EKHOLM

5 Digitalization of health in Sweden to benefit patients

JOHN ØVRETVEIT

6 Personalized predictive health care: how predictive AI

platforms will transform the health care industry

DANIEL WÄNN 
vi Contents

7 Digital dentistry: a solution to the dentistry crisis?

ANTHONY LARSSON AND DOMINIKA SABOLOVÁ

8 Solutions based on digital connected devices for social care and well-being

ANDRES LAYA AND JAN MARKENDAHL

\section{PART II}

Education

9 Educational technology (EdTech): unbounded opportunities or just another brick in the wall?

CORMAC MCGRATH AND ANNA ÅKERFELDT

10 Education at the intersection: a practitioner's view of the effect of digital transformation on public education STEPHEN MAHALEY

PART III

Citizen protection

11 Citizen protection: a capabilities and intentions framework MARK A. CONLEY AND EMILY NAKKAWITA

12 Societal security: how digitalization enables resilient, agile, and learning capabilities

ARNE NORLANDER

13 Digital identity - beyond verification: to a transparent (decentralized) system for data and identity monitoring and control

CLAIRE INGRAM BOGUSZ

\section{PART IV}

Future of the welfare state

14 Cashless: a dead end for Sweden?

BJÖRN ERIKSSON AND ULRIKA SANDHILL

15 Future consumption of welfare services: how the change in consumer expectations will affect offerings and business models in welfare 
16 The trust revolution: blockchain's potential to resolve institutional inefficiencies?

ALEJANDRO MORENO PUERTAS AND ROBIN TEIGLAND

17 The future of the nation-state: how the nation-state can find a way through digitalization

MATS LEWAN

18 Digitalization has changed the foundation of the democracy OLLE WÄSTBERG

19 Conclusion: digital welfare - now and forever?

ANTHONY LARSSON AND ROBIN TEIGLAND

Afterword: technology - the solution to all welfare challenges? NICHOLAS FORTUGNO

Index 


\section{Figures}

2.1 Number of telemedicine visits in Sweden, June 2016 to December 2017

2.2 Number of telemedicine visits according to age, June 2016 to December 2017, thousands

3.1 Governmental organizations responsible for Sweden's eHealth strategies

3.2 Forms of public-private collaboration

3.3 Market movement on the cold-hot continuum 41

$\begin{array}{lll}8.1 & \text { Research framework } & 131\end{array}$

11.1 Private and public "About Us" statements 182

12.1 Organizational agility as a product of chaos and order 201

12.2 A model of agile organizational capability 203

$\begin{array}{ll}12.3 \text { The agility value chain } & 205\end{array}$

13.1 How data are collected, cleaned, and sold in $2019 \quad 225$

15.1 The different scenarios and their main traits 261

$\begin{array}{lll}16.1 & \text { Blockchain investments } & 278\end{array}$

$\begin{array}{lll}17.1 & \text { The innovation loop } & 294\end{array}$ 


\section{Tables}

2.1 Examples of health care apps in Sweden, the UK, and the US

2.2 Share of telemedicine visits compared to population shares, 2016-2017

3.1 Overview of interview respondents 42

3.2 Obstacles to collaboration 49

4.1 List of interviewees $\quad 60$

8.1 Sources of primary data 130

8.2 Challenges to implementing digital services for social care in Sweden

9.1 Survey of digital learning strategies at a selection of Swedish universities

11.1 Citizen Protection LIWC dictionary 192

11.2 Military, armaments, and defense 192

11.3 National defense 193

11.4 Polling indicates low trust and confidence in government 193

12.1 Occurrences of performance degradation or failure of digitalization-enabled agility

13.1 Some typical digital identity verification services in use in 2019

13.2 Characteristics of commonplace digital identity management services

13.3 A comparison of the emerging models of data control, use, monetization, and interoperability

13.4 The characteristics of the existing "data-for-services" model, against the emerging "controlled model" of data use and control

15.1 List of participants 


\section{Contributors}

\section{Editors}

\section{Editor-in-chief}

Anthony Larsson (Ph.D.) is a researcher at the Stockholm School of Economics Institute for Research (SIR), Sweden. He holds a Ph.D. from Karolinska Institutet, Sweden. He also holds an MBA and M.Sc. degrees in political science, social anthropology, and business administration and economics respectively, as well as an associate degree in psychology. His recent work includes the books The Rise and Development of FinTech: Accounts of Disruption from Sweden and Beyond (2018), Too Big to Fail? A Case Study of the Rise and Fall of a Medical Research Infrastructure (2018) and The Digital Transformation of Labor: Automation, the Gig Economy and Welfare (2020), as well as a number of research papers. His research interests include innovation management, medical science, digitalization, customer loyalty, bank marketing, management, organizational behavior, organizational branding, stakeholder analysis, entrepreneurship, and qualitative research methods. A Routledge Featured Author, you may follow his research at www.routledge.com/authors/ i18347-anthony-larsson or via his Amazon.com author page at www.amazon. com/author/anthonylarsson.

\section{Editor}

Robin Teigland (Ph.D.) is Professor of Management of Digitalization in the Entrepreneurship and Strategy Division at the Department of Technology Management and Economics at Chalmers University of Technology, Gothenburg, Sweden. She is also Professor of Business Administration with a specialization in strategic information systems management at the Stockholm School of Economics (SSE), Sweden. She is also a member of the Royal Swedish Academy of Engineering Sciences. Robin has more than 20 years of research experience within social networks, strategy, innovation, entrepreneurship, and startup ecosystems. In particular, she is interested in how the convergence of disruptive technologies influences value creation in society as well as disrupting long-standing institutional structures. Robin is also an impact entrepreneur, having recently started 
a blue circular economy project and an ocean tech hub in Peniche, Portugal, that focuses on enabling regional development in coastal communities through digitalization. In 2017, 2018, and 2019 she was listed by the Swedish business magazine Veckans Affärer as one of Sweden's most influential women, primarily in technology. In her free time, she likes to "play" with her five kids as well as surf, and help run her surf school, Go4surf, at her favorite beach in Peniche.

\section{Contributors (in order of appearance)}

Francis Andrew Gaffney is Professor of Medicine (Emeritus) at Vanderbilt University School of Medicine in Nashville, Tennessee, USA. Since 2001, he has also served as a guest professor at the Department of Learning, Informatics, Management and Ethics (LIME) at Karolinska Institutet, Sweden. From 1984 to 1991, he served as a NASA astronaut. In June 1991, he participated as a payload specialist on the STS-40 mission and flew aboard the Space Shuttle Columbia, where he performed biomedical experiments during its nine-day mission. Simultaneous experiences as an academic cardiologist and NASA astronaut created a lifelong focus on combining medical informatics and highreliability organizational practices to make medicine both safer and more efficient. He currently has more than 80 publications in the areas of cardiovascular regulation and space physiology. In his spare time, he enjoys sailing and traveling. When not working or traveling, he divides his time between his homes in Berkeley and Nashville and his sailboat in Carloforte, Sardinia.

Mårten Blix (Ph.D.) is a research scholar at the Research Institute for Industrial Economics in Sweden. He is frequently invited to give seminars and has recently been interviewed by the New York Times, the Economist, and the Süddeutsche Zeitung. His work focuses on understanding the effects of digitalization and structural change. His recent work includes the book Digitalization, Immigration and the Welfare State (2017). He has a Ph.D. in Economics from Stockholm University and an M.Sc. in Econometrics and Mathematical Economics from the London School of Economics (LSE). He has held several senior management positions, including director for the division of budget totals in the Swedish Ministry of Finance, chief economist at the Ministry of Industry, and advisor at the Swedish Central Bank; he has also worked at the European Central Bank and been secretary to the Swedish Prime Minister in the Commission on the Future Challenges of Sweden.

Johanna Jeansson is an economist and macroeconomic expert at Sweden's leading business daily, Dagens Industri. She is a regular columnist in the paper, a recurring guest in Dagens Industri's TV studio, and a frequent participant in podcasts about macroeconomic trends, financial markets, and politics. She has written several articles about the effects of digitalization in Swedish health care. She holds a Master of Economics and a Master of Political Science from the University of Lund. She has worked as an analyst and economist, both in the private and public sectors, most recently at Nordea - the largest Nordic bank - the Swedish Ministry of Finance, and the Swedish Central Bank. 
Olivia Elf is a management consultant at McKinsey \& Company in Stockholm, Sweden. She holds an M.Sc. in International Business from Stockholm School of Economics and CEMS Master in Management from Copenhagen Business School, Denmark, with additional studies at Sciences Po, France. Her professional experiences include working in the financial sector and in consulting. Olivia is also an entrepreneur; in 2015, she founded her first company, "ObLa-Di Café," a café located in Paris, France (named "the best café in Paris" by various critics such as Vogue.com and LeFigaro.fr). She has previously founded a volunteering project in India, aimed at improving the social situation of women in small villages around Kanha National Park by donating and instructing the local women in using solar cookers. People, diversity, and education are some of the topics that motivate Olivia the most. In her spare time, Olivia enjoys travel, cooking, reading, and spending time in the forest. She keeps a keen interest in fitness and is an avid runner. As such, she has served as pacer for several run clubs over the years. Olivia is also a staunch Francophile and speaks French fluently.

Corinna Gross is an M.Sc. student in international business at the Stockholm School of Economics, Sweden, while simultaneously pursuing the renowned CEMS Master in International Management. She holds a B.Sc. in International Business from Maastricht University School of Business and Economics, where she graduated cum laude. She is broadly interested in understanding the impact of digital developments on organizations, industries, and societies. Still in the early stages of her career, she gained her first professional experiences by working in management consultancy as well as in the start-up scene. Originally hailing from the western part of Germany, Corinna developed a strong interest in exploring the world and foreign cultures at a young age. Thus far, she has lived and studied in six countries. In her spare time, Corinna enjoys traveling, skiing, and culinary delights.

Julia Elf is an industrial engineer from KTH Royal Institute of Technology with experience from the digital health care industry, and is currently working for the Boston Consulting Group (BCG) in Stockholm, Sweden. She holds an M.Sc. in Sustainable Power Generation, which she dedicated mainly to the field of e-mobility and energy as a service. Julia has a broad interest in technology, especially in the application of VR/AR in energy. To this end, she has helped arrange and has participated as keynote speaker at international conferences and several hackathons. She has received multiple talent awards and was one of the co-founders of a student organization at KTH Royal Institute of Technology that sought to foster innovation and entrepreneurship among students. In her spare time, Julia enjoys cooking and traveling. She is also an avid runner, and has served as a pacer for several run clubs through the years.

Anna Essén is Associate Professor at the Stockholm School of Economics, Sweden. Her research interest lies in how digital technology shapes what individuals and organizations find worthwhile to strive for and feel capable of 
achieving. She has published papers about the coevolution of national and global digital infrastructures and practices in health care in journals such as Human Relations, MIS Quarterly, Social Science \& Medicine, and Sociology of Health and Illness. Her current research projects concern the innovation of ecosystems in the autonomous transportation sector and the development of distributed governance models for digital health-data sharing platforms.

Anders Ekholm is Senior Advisor at the Institute for Futures Studies in Stockholm, Sweden. He has broad experience from working in the government offices of Sweden, where he mainly worked with quantitative economics, as well as serving as the Chief Analyst at the Ministry of Health and Social Affairs. In addition, Anders has worked at the Swedish Ministry of Finance, Employment and Education. His past experiences include development and analysis of microsimulation models, including a SESIM model where 300,000 statistically representative individuals live simulated lives, including demography, health, employment, education, taxes, and transfers. Anders has previous experience working as an IT project manager, working on such tasks as the state budget system, which distributes and monitors the state budget. Anders is also a frequently contracted speaker specializing in the areas of finding inspiration and new solutions to different problems in different sectors of society.

John Øvretveit (B.Sc. [Hons], M.Phil., Ph.D., C.Psychol., AFBPsS, C.Sci.) is Director of Research for the Medical Management Center (MMC) at Karolinska Institutet, Sweden, and serves as Professor of Health Improvement, Implementation, and Evaluation at that university. Previously, he was Professor of Health Policy and Management at Bergen University Medical School, Norway, for ten years and was also an appointed chair of health organization and management for 15 years at the Nordic School of Public Health, Gothenburg, Sweden. Translations of some of his 400 scientific papers and books have been made into eight languages. He was awarded the 2014 Avedis Donabedian International Quality Award for his work on quality economics. He is a founding member and board director of the Global Implementation Initiative and the Quality Improvement Research Network, and was a board director for 12 years of the Joint Commission International. He is currently a visiting professor with the Australian Institute of Health Innovation, Macquarie University, Kaiser Permanente RD\&E, Stanford Medical School, and CERC. John's work is based on the belief that organization and management can bring out the best and worst in people, and that the right organizational design is critical for effective health care. A theme underlying his work is how practical research can contribute both to better care for patients and to a "healthy work organization." He has pioneered action evaluation and partnership research methods for giving rapid feedback for service providers and policy-makers to improve their services, and for assessing the role of context in implementation.

Daniel Wänn is an entrepreneur, physician, and senior manager at Accenture, Stockholm, Sweden. He is a medical doctor (M.D.), having graduated from 
Uppsala University in 2005. He also holds an M.B.A. from Stockholm School of Economics, Sweden, having graduated in 2017. Daniel's work focuses mainly on the transformation of health care through digitalization. Daniel has extensive experience with entrepreneurship, especially in the field of digitalization, having launched his first company (a web design bureau) in 1996. He recently developed and released a mobile application for the Swedish market aimed at physicians, enabling mobile e-prescribing. Daniel has been a practicing general physician since 2005, although he has been less active in this field as of 2012, devoting most of his time and effort to health care transformation. Improved access to health care and quality of health care delivery are strong motivators for Daniel. He believes digitalization is the leverage necessary to accomplish change and strives to see a transformative process that seeks to improve how health care is organized and delivered. In his spare time, Daniel enjoys spending his time with his wife, their 2-year-old son, and their dog.

Dominika Sabolová is a doctor of dental medicine (Medicinae Dentalis Doctor). She graduated from Pavol Jozef Safarik University, Košice, Slovakia, in 2012. She practiced dentistry for two years in her native Slovakia before relocating to Sweden in 2014. She is currently a general dentist at the Swedish Public Dental Service (Swe: Folktandvården) in Linköping, Sweden, where she has been working since 2015 . Her main research interests concern digital dentistry, endodontics, periodontics, prosthodontics, and oral surgery. In her spare time, Dominika enjoys traveling, hiking, dancing, and horseback riding.

Andres Laya (Ph.D.) is Senior Researcher on Business and Consumer Aspects at Ericsson, Sweden. In 2009, he completed an M.Sc. degree in ICT from BarcelonaTECH (UPC), Spain. In 2017, he received a Ph.D. in Communication Services and Infrastructures from KTH Royal Institute of Technology, Sweden. He has been involved in Swedish and European projects in subjects related to the Internet of Things (IoT), service development, and advances in mobile communications. His research interests are consumer perception and business implications of connected devices in different industries.

Jan Markendahl is Associate Professor in Wireless Infrastructure Deployment and Economics at KTH Royal Institute of Technology, Sweden. After more than 20 years in the industry, Jan joined KTH 2003 as research program manager. He has a Ph.D. from 2011 in techno-economic analysis of wireless networks and services. Jan got the Docent degree in 2014, enabling him to be main advisor for Ph.D. students. So far, three Ph.D. and four Licentiate degrees have been awarded to his Ph.D. students. Jan has managed techno-economic research projects and tasks in EU and national projects. He has made research contributions in the following areas: low-cost wireless infrastructure, spectrum valuation, mobile payment and NFC services, IoT, and M2M communication services and analysis of business models and ecosystems. Currently he works with business aspects of IoT, digital platforms, smart cities, and the sharing economy. 
Cormac McGrath (Ph.D.) is a senior lecturer and academic developer at Stockholm University and Karolinska Institutet, Sweden, and has extensive experience working with change initiatives in higher education. He led the introduction of massive open online courses (MOOCs) in the Swedish context at Karolinska Institutet in collaboration with edx.org. His research interests relate to change agency and management, and learning in digital learning environments.

Anna Åkerfeldt (Ph.D.) is a researcher at Stockholm University, Department of Mathematics and Science Education, Sweden. She also works as a process manager of the development and research program called "Digital learning environments: equivalent education with remote and distance learning" at Ifous: innovation, research, and development in schools and pre-schools. Her research interests are educational technologies and how these are used for designs in and for learning and in assessment. Anna has a background as a producer and scriptwriter of custom-made e-learning applications and websites for various organizations and corporations. She has been involved in several research projects, including a longitudinal study of the implementation of oneto-one computing programs in primary education. She has been working with the Swedish National Agency for Education to develop online course materials for teachers. During 2016-2018, she received a postdoc scholarship where she investigated learning in digital environments and possibilities and consequences for teachers' formative assessment. She is also part of the research project "Programming Didactics," funded by the Marcus and Amalia Wallenberg Foundation.

Stephen Mahaley is the co-founder of Red Fern Consulting, an education consultancy in the USA. Based in North Carolina, Steve explores and works at the intersection of technology and education design to develop effective, engaging experiences that change people's lives for the better. For 20 years, his work has centered around leadership development, working for Duke University and then as a founding member of Duke Corporate Education - a global leader in providing customized management and leadership development programs. His current areas of interest include diversity, inclusion and belonging, virtual reality experience design and production, game-based learning, emotional intelligence, high-performance learning journey design, and advances in learning theory and neuroscience that inform better approaches for learning and development. Steve works on a wide array of projects globally and in a variety of capacities - from keynotes to learning experience design, to teaching onsite and online, and to serving on a variety of corporate and non-profit boards.

Mark A. Conley is Assistant Professor at the Stockholm School of Economics in the House of Innovation, Sweden. Mark measures motivation in strategic field settings and also experimentally manipulates motivation by inducing changes in perspectives. Mark's Ph.D. in Psychology is from Columbia University, USA, and his research demonstrates how motivational language affects key 
outcomes for organizations and individuals. He builds original linguistic measurement tools that measure motivations in organic communication and can also measure static documents and other archives. Mark's methodological contributions to innovation research demonstrate the importance of psychological and motivational variables.

Emily Nakkawita is a Ph.D. student in the Motivation Science lab at Columbia University, New York, USA. She is broadly interested in understanding the factors that lead to successful goal pursuit, with success defined in terms of both achievement and well-being. At the Higgins Lab, she studies how motivation and self-regulation in the pursuit of personal goals are affected by individual differences in the strength of primary motives like value, truth, and control, as well as the person's beliefs about how these motives should be prioritized. Prior to her graduate studies, Emily examined what motivates people through a career in brand marketing and advertising.

Arne Norlander (Ph.D.) has over 20 years of experience from senior and executive positions in strategic R\&D in crisis management, societal security, and defense. Based in Stockholm, Sweden, he is active as Senior Scientist and Research Director and is the author of numerous internationally recognized scientific publications. He is chairman of the Swedish Security \& Defense Industry Association Research \& Development Committee, and serves as an independent expert for the European Commission. Arne is a member of the the Swedish Society of Parliamentarians \& Scientists. He lectures frequently on scientific, technical, and policy-related topics. Arne's current research interests are complex adaptive systems, human factors, artificial intelligence, Internet of Things, cybersecurity, crisis management, business agility, innovation management, capability development, strategy, policy, and leadership. He holds Master's, Licentiate, and Doctoral degrees in Industrial Ergonomics and Computerized Automation from Linköping University and has studied strategic leadership and innovation management at the Stockholm School of Economics. He is also a graduate in crisis management and civil emergency planning at the Swedish Defense University Institute of National Defense \& Security Policy Studies. Arne is the founder and CEO of NORSECON, a consulting firm in science, engineering, capabilities development, strategic technology foresight, and innovation management.

Claire Ingram Bogusz (Ph.D.) is a postdoctoral researcher at the Department of Applied IT at the University of Gothenburg, Sweden, and an affiliated researcher at both the Forum for Reforms, Entrepreneurship and Sustainability (Fores) and the Stockholm School of Economics Institute for Research. She holds a Ph.D. from the Stockholm School of Economics, and was a visiting researcher at McGill University in Montreal, Canada. Her doctoral research into digital entrepreneurship in the field of finance was awarded the Börje Langefors Award (2018), the Peter Högfeldt Award (2019), and a Wallander postdoctoral scholarship. Prior to her Ph.D. studies, she worked in journalism 
and received a B.Soc.Sci. (Politics, Philosophy, and Economics, with distinction) and an L.L.B. (Law) from the University of Cape Town, South Africa. Her research interests include entrepreneurship, finance, FinTech, digital security, digitalization, and innovation policy. She has published work in journals such as the Journal of the Association for Information Systems (JAIS), Information Systems Journal (ISJ), and European Journal of Information Systems (EJIS). Her current research projects examine the effect of code-based artifacts on digital entrepreneurship and digital innovation, with particular focus on emerging technologies and how they affect social and organizational dynamics.

Björn Eriksson is a former governor of the Swedish province of East Gothland (Swe: Östergötland). He holds an M.B.A. from the Stockholm School of Economics and an honorary doctorate degree from Linköping University, Sweden. As a civil servant, Björn has held multiple positions in the public sector over the years, such as Budget Director within the Ministry of Finance, Director General of Customs, Director General of Coast Guard, and National Police Commissioner. He has also served as President for the World Customs Organization (WCO) as well as President for the International Criminal Police Organization (INTERPOL). During his career, Björn has led several governmental investigations covering various public affairs. In addition, he has been engaged as a board member and has served in various advisory roles for different companies in the private sector, ranging from small companies to large companies listed on the Stockholm Stock Exchange (Nasdaq Stockholm). Björn remains active as President for the Swedish Sports Confederation and as President for SäkerhetsBranschen, an association seeking to promote business for member companies and their clients in the security industry.

Ulrika Sandhill is a Stockholm, Sweden-based writer and business commentator, chiefly covering topics on IT and finance. Ulrika has previously held positions of Editor-in-Chief at the IDG publishing house and Managing Director at Mediearkivet, the largest digital media archive in the Nordics. Ulrika holds an M.Sc. in Business and Economics from Uppsala University, Sweden.

Charlotte Mattfolk is a senior strategic advisor within the fields of future analysis and strategy, business transformation, digitalization, sustainability, and entrepreneurship. She has held several roles as CEO or partner in larger management consulting firms as well as building up a consulting business from scratch. She holds an M.Sc. in International Economics from Uppsala University, Sweden, with undergraduate studies at Institut Supérieur de Gestion, France. With a solid vision and business acumen, she helps companies seeking to undergo digital transformation and become more sustainable. A credo Charlotte has carried with her throughout her career is the aspiration to break patterns, challenge truths, and dare to try new ways of doing things, to enable new levels of success. In a traditional industry, she has sought to encourage equality across all company levels and create business value with social responsibility. She has well-founded knowledge from the consulting world and a passion for all things digital, as well 
as an ability to create engagement in an innovative, inspiring, and creative way. Charlotte lives in Stockholm, Sweden, with her husband and three children.

Lina Emfeldt is a management consultant and head of marketing at the management consultancy firm Cartina in Stockholm, Sweden. Still in the early stages of her professional career, Lina has an M.Sc. in international marketing and management from Copenhagen Business School, Denmark, with additional studies at Middlebury Institute of International Studies in Monterey, California; the National University of Singapore; and Uppsala University, Sweden. Lina is particularly versed in helping companies develop future-proofed strategies by carrying out scenario-planning analyses. Sustainability is also close to her heart, and she strongly believes in the combination of digital and sustainable strategies. Lina has prior experience from future studies such as the report Future Consumption Patterns 2025, published by Cartina in 2017. Digital strategy, digital marketing, and customer experience are the competence areas that interest her the most. Lina lives in Stockholm, Sweden, but takes every chance she gets to travel the world, see new places, and enjoy new cultures.

Alejandro Moreno Puertas is a junior project manager at Tink, a data-driven company based in Stockholm, Sweden, specializing in providing back-end technology to banks and FinTechs. He currently co-leads the largest panEuropean PSD2 project that integrates all the major banks' APIs across 12 markets into a single platform. Alejandro holds a B.Sc. in Economics from Tilburg University, the Netherlands, and an M.Sc. in Finance from the Stockholm School of Economics. He has previously worked as a research assistant at the Stockholm School of Economics, where he coedited the book The Rise and Development of FinTech: Lessons from Sweden and Beyond (2018) and coauthored a report on RegTech and InsurTech, The Next Wave of FinTech (2018). Alejandro has spent many years of his life in China at various stages. He first moved there at a young age and later joined the Chinese boarding school Beijing Number 4 High School as the sole European student. He has also served as a representative of Sociedad Española de Negocios en Asia y America SL in Shanghai for their Chinese business development. Alejandro is proficient in English, Spanish, and Chinese. Besides traveling, he is passionate about FinTech, with a focus on open banking, machine learning, and blockchain.

Mats Lewan is an author, international keynote speaker, futurist, consultant, journalist, and research analyst focused on future and technology. He has been working for more than 15 years as a technology reporter for the leading Swedish technology magazine Ny Teknik. He also started the forward-looking Swedish digital magazine Next Magasin, for which he was Managing Editor. Previously, Mats worked internationally as a freelance journalist and as a reporter for CBS CNET News in San Francisco while attending the Innovation Journalism Program at Stanford University. Mats holds an M.Sc. degree in Engineering Physics from the Royal Institute of Technology (KTH) in Stockholm, 
Sweden. He is fluent in English and Italian, as well as in his native Swedish tongue. He lives with his wife and two children in Stockholm, Sweden.

Olle Wästberg is a former journalist, politician, marketing professional, and diplomat. He has served as a Swedish member of parliament, Liberal (1976-1982); State Secretary of the Ministry of Finance (1991-1993); Editor-in-Chief for the Swedish newspaper Expressen (1993-1995); Swedish Consul General to New York (1999-2004); Director General of the Swedish Institute (2005-2010); and, most recently, Chairman of the Governmental Democracy Commission (2014-2016) and Member of the Public Service Committee (2017-2018). He is also a member of several boards, among them the board of the Raoul Wallenberg Academy and of the Sweden America Foundation.

Nicholas Fortugno is a designer of digital and real-world games and co-founder of Playmatics, a game design company in New York City, USA. Nick has been designer, writer, and producer on dozens of games, serving as lead designer on the downloadable blockbuster Diner Dash, award-winning serious game Ayiti: The Cost of Life, CableFAX award-winning Breaking Bad: The Interrogation, and MUSE award winner Body/Mind/Change, as well as games with Red Bull, Disney, AMC, the Red Cross/Crescent, PBS, and USAID. Nick is co-founder of the Come Out \& Play street games festival, and teaches game design and interactive narrative at Columbia University and the School of Visual Arts. Nick holds an M.F.A. in Design and Technology from Parsons School of Design, New York City. 


\section{Foreword}

\section{Digital transformation of public services - how and why?}

Why read this book? Most of us are subjected to a flood of distressing national and international news. This creates a sense of being out of control with anxiety and concerns that our political leaders are not correcting the situation. The recent world refugee crisis reflects this phenomenon: millions of citizens are seeking safer, healthier environments for themselves and their families while citizens of the destination countries fear loss of life quality and opportunity. The absence of clear solutions to our national and international societal problems produces extreme political polarization and nationalistic governments. The only area of significant consensus is that major systemic social and governmental changes are needed. However, there is no agreement on what the changes should be, nor is there any agreement on how to achieve them. This book provides clear, logical answers to the question: What should societies be doing and how can they do it?

Digital Transformation of Public Services: Societal Impacts in Sweden and Beyond is a book based on extant experience and nascent progress in western digitalized societies, often drawing upon Sweden as a prime example of a country that has come far in its digital transformation across its society on multiple levels. By stressing equal access in implementation strategies, these countries' programs demonstrate how governmental and private organizations provide safe, effective, scalable, and affordable support services. Impressive, successful implementation of digitalization can be found in FinTech, E-commerce, social media, and medical informatics. Worldwide, digitalization access, quality, and extent vary widely. Economic development explains only part of the intercountry differences.

Even in highly developed countries, unintended consequences of digitalization are ubiquitous. These include identity theft affecting millions of individuals; unwanted disclosure of personal, financial, or medical information; direct or covert manipulation of democratic processes; and governments' use of surreptitious monitoring and controlling citizens. Cashless retail businesses and banks are common in northern Europe and emerging in certain parts of Asia. However, they are just entering the US market. Because of large disparities in income and access to banking, the Internet, and E-commerce in the United States, bans on cashless businesses have been proposed. Equitable implementation of integrated 
digitalized services in health care and social care, education, and citizen protection (both physical and digital safety) would improve accessibility while providing safer and less expensive services.

In each of these areas, the authors of this volume provide definitions, developmental history, current status, and paths to new practices and innovations, and discuss the potential impact of digitalization, including achievements and risks. The last section, "Part IV: Future of the Welfare State," builds on digital developments in these fundamental areas and discusses unexpected benefits and pitfalls. Extensive, equitable implementation of digitalization can be a powerful force for democratization.

The general approach discussed in this book includes creating and sustaining capacity for digitalization in implementing countries. Success in implementation of digital systems is, to a large extent, a matter of national "will and skill." Costs of digitalization are relatively small compared with other infrastructure investments (e.g., railroads, dams, ports, etc.). The extent to which Scandinavian digital innovations have been successfully implemented worldwide suggests that culture and system of government are much less important determinants of success. Implementation of widespread digitalization, as outlined in this book, could be a key solution to our current crisis.

Francis Andrew Gaffney

Professor of Medicine (Emeritus)

Vanderbilt University School of Medicine

Astronaut, NASA (Retired)

Guest Professor, Karolinska Institutet 


\section{Acknowledgments}

This edited volume constitutes the penultimate phase of the research project "The Innovative Internet," funded by the Internet Foundation in Sweden (IIS - Swe: Internetstiftelsen $i$ Sverige). Released as part of the same research project, this volume follows The Rise and Development of FinTech: Accounts of Disruption from Sweden and Beyond (ISBN hardback: 978-0-8153-7850-1; ISBN eBook: 978-1-351-18362-8), published under Open Access by Routledge in 2018. Initially, this phase of the project started out as a small-scale plan for a shorter report on the future of labor and the working conditions of tomorrow. We soon discovered a need to cover the future of welfare and the public sector as well, as this is an area that is seeing the rapid and profound effects of the digital transformation. Consequently, the project shifted focus, at least initially. However, the research project soon began expanding to also include the original plan of the digitalization of the labor market, and a decision was made to write and release two separate books. Hence, this book is followed by a companion piece titled The Digital Transformation of Labor: Automation, the Gig Economy and Welfare (2020) (ISBN hardback: 978-0-367-33070-5; ISBN eBook: 978-0-429-31786-6), also published by Routledge under Open Access.

We would like to take this opportunity to extend our deepest gratitude to IIS, and in particular to Danny Aerts and Jannike Tillå, who have supported us throughout the project while also allowing us full freedom to take ownership of our research and its direction. This volume would not have been possible without the experiences, insights, and expertise from our dedicated team of coauthors, consisting of academics, practitioners, and industry experts. To all the contributors we have had the privilege to lead and guide throughout this process, we wish to express our sincerest thanks for being the foundation for this book volume! We would also like to thank Johan Söderholm at the Stockholm School of Economics Institute for Research (SIR), as well as Kristina Abbotts and Christiana ("Chrissy") Mandizha, along with the rest of the assisting staff at Routledge/Taylor \& Francis for their help and support throughout every step in the making of this volume. We also wish to acknowledge the diligent work carried out by the copyeditors, typesetters, and indexers of this book, while extending a special thanks to Jennifer Bonnar and Kate Fornadel at Apex CoVantage, the project managers in charge of preparing our book for the printer. We would also like to extend our sincerest gratitude to 
IIS; Accenture; Cartina; Department of Education, Stockholm University; Magnus Bergvall's Foundation (Swe: Magnus Bergvalls stiftelse); Sven and Dagmar Saléns' Science and Culture Foundation (Swe: Sven och Dagmar Saléns Vetenskaps- och Kulturstiftelse), and all those who have generously contributed toward securing Open Access for this book.

Last, but not least, we would also like to extend our special gratitude to all of our family and friends for their unwavering and invaluable moral support throughout this process.

We hope that you, the reader, will have as much satisfaction in reading this book as we had in bringing it together. As an Open Access volume, we invite you to spread and redistribute this book freely to any and all interested parties you may encounter.

Stockholm, September 11, 2019 Anthony Larsson, Ph.D. Editor-in-Chief Robin Teigland, Professor 



\title{
1 An introduction to digital welfare
}

\author{
A way forward?
}

Anthony Larsson and Robin Teigland

\section{Introduction}

Increased "availability" and "individualization" are two of the most common demands from consumers in this day and age. This is a development that has gained a substantial foothold on the contemporary consumer market, whether the services lie in finance, insurance, retail, and/or transportation. The Internet, smartphones, and other technologies sprung from the digital age have helped people gain better insight into and awareness of what they expect from a service provider (Hardey, Loader and Keeble, 2009). To this extent, the welfare sector, just like other industries, also benefits from new technologies and digital innovations, as it seeks to drastically improve our everyday lives and help us create more sustainable societies.

It should at this point be noted that the welfare state as, we know it, has existed for approximately 100-150 years. While one may contend that the first welfare state was presented by the Islamic Caliphate under Umar (584-644), it did not exist in its modern concept until the late 19th-century Imperial Germany (18711918) under Chancellor Otto von Bismarck (1815-1898), when he established the social-welfare legislation that extended the privileges of some of the noble social classes to common Germans (Crone, 2005; Von Kersbergen and Vis, 2014). Still, the welfare sector is nowadays commonplace in most Western societies (albeit to varying degrees). However, digital solutions are often arduous to scale for the welfare sector. This is because the manner in which the welfare state is organized leads to various incentive structures that may hinder digital development. Traditionally, the incentive structure has been such that "the lower the benefit levels are in the compulsory systems, the stronger the incentives for citizens to add voluntary (market) solutions, in the form of private saving and private (individual or collective) insurance arrangements" (Lindbeck, 1996, p. 1). To this extent, the rapid development of digital technology poses a challenge to several of the extant structures, providing citizens with new options in areas where they see a need for something that is currently not provided for by the state. In return, new actors entering the welfare sector have prompted a counter-response from the state actors, in some cases coaxing these actors to expedite their digital evolvement in order to safeguard their market share against the new actors. This book 
will endeavor to explore the development in different welfare areas as outlined later in this introductory chapter.

Digital technology consists of many different concepts and components. As previously mentioned, the Internet has in many ways provided the backbone to much of this development, providing people with information access and flexibility in ways that were not possible in the past (Kienhues and Bromme, 2011). The development of smartphones has done much to forward digital advancement, providing people with Internet access virtually anywhere at any time (Amstutz, 2018). There are, of course, some other important developments that have done much to advance the digital age. Artificial intelligence (AI) (sometimes known as "machine intelligence") is a popular concept that has been defined in many different ways. In its broadest and simplest definition, it pertains to the description of a function wherein machines mimic human "cognitive" functions, such as "learning" and "problem-solving" (Russell and Norvig, 2009; Kaplan and Haenlein, 2019). The term "AI" is popularly attributed to computer scientist John McCarthy (1927-2011) in 1955 (McCarthy et al., 2006). McCarthy defined AI as "the science and engineering of making intelligent machines, especially intelligent computer programs" (McCarthy, 2007, para.2).

A closely associated concept is predictive analytics, which pertains to various statistical techniques, including data mining, predictive modeling, and machine learning, that analyze current and historical facts in order to make predictions about future events (Siegel, 2013; Kelleher, Namee and D'Arcy, 2015). Robotics is another broad concept that concerns the design, construction, operation, and use of robots. This also includes the computer systems needed for their control, sensory feedback, and information processing (Newton, 2018). While robots can take on any form or appearance, some are designed to resemble certain aspects of humans in order to help humans accept the robot's presence in carrying out certain replicative behaviors that are otherwise typically performed by people, such as attempting to replicate walking, lifting, speech, and cognition (Liu, Sheng and He, 2019). There is currently much debate regarding to what degree designers should aspire to design physical human characteristics on robots. The "uncanny valley" is a phenomenon in which humans may experience a feeling of discomfort when interacting with a robot that looks nearly, but not entirely, identical to a human being, while being more accepting of a robot designed with less humanoid features (Van Wynsberghe, 2015).

Terms like "digitization," "digitalization," and "digital transformation" are ever so often confused, as they are often used interchangeably in various settings. Nevertheless, there are distinct differences among the terms, which are important to bear in mind before going forward. The first term, "digitization," entails the conversion of analog material (such as images, video, and/or text etc.) into a digital format (Larsson and Viitaoja, 2017; Feldman, 1997; Brynjolfsson and McAfee, 2014). The second term, "digitalization," refers to a process wherein the use of digital/computer technology (also mobile applications) is adopted, or, alternatively, increased by an actor (Wachal, 1971; Castells, 2010). More often than not, the digital technology is implemented with the intent of establishing a 
communication infrastructure that connects various activities of the actor's various processes (Van Dijk, 2012; Larsson and Viitaoja, 2017). "Digital transformation" is a considerably broader term that signifies customer-driven strategic business transformation requiring far-reaching and cross-cutting organizational change in addition to the implementation of digital technologies (Bloomberg, 2018; Cochoy et al., 2017). Due to its scope, digital transformation is in reality not a matter of implementing one project, but rather a whole series of different projects, effectively necessitating the organization to deal better with change overall. In this way, digital transformation in and by itself essentially makes organizational change a core competency inasmuch that the venture seeks to become customer driven end to end (Bloomberg, 2018).

For this reason, digitalization and digital transformation are the two most useful/significant terms when explaining the changes and impact that digital technology has had on society at large. That is to say, intelligent algorithms make our day-to-day tasks easier, and it is in many cases nearly impossible to imagine how we could manage without them. The use of AI and robotics continues to gain momentum at a rapid pace. To this end, the idea of digitalizing welfare and the public sector has been seen as a way of providing a more efficient and costeffective solution in order to cater to the ever-growing demands of the population. Societal challenges, such as a growing and ageing population, along with population increase of chronic diseases and overall lingering financial constraints, have placed the public sector under pressure to find new ways of providing public services while keeping the costs down. The contention is that by using technology in welfare services, it can help secure the continued economic stability of the welfare state. Moreover, another possibility enabled by digital welfare is for the public sector to become more interconnected. Sharing information across the public sector is essential in order to shorten lead times, secure transparency, and ensure that the correct care is given to the right citizen.

To this extent, a 2016 Organization for Economic Co-operation and Development (OECD) report targets specific public-sector areas where governments need to adopt new strategies in order to ensure that they keep an even pace with societal development (OECD, 2016). Specifically, this report emphasizes the focus on digitalization of health care and social care, ${ }^{1}$ education, and protection services. The "smarter" use of well-proven assistive technologies in this context was referred to as "digital welfare." Hence, this book has sought to explore topics within these spaces, as these are areas in which the state actors potentially risk being overrun by other non-governmental actors, be they local or global. That is to say, the entry of new actors in these areas has the potential to cause a disruption of the current status quo of welfare services provided by national governments for their citizens, and it is likely this disruption that is escalated through the advancement of "digital welfare."

Ultimately, the discussion of technological advancements raises questions regarding the future role of the nation state in a fully digitalized world (Dasgupta, 2018; Schmidt and Cohen, 2013). Traditionally, the nation state has always been seen as the classic provider of security and basic well-being in exchange 
for citizens' loyalty. However, what will happen when new types of loyalties and associations begin to challenge the state's traditional role, that is, loyalties of kindred identities based on shared commercial, political, and/or other interests, rather than religious or ethnic identities? Such a development is not unproblematic for the current nation state. Many citizens, particularly in the West, work for or hold stock in commercial organizations that pay little to no regard to national tax and/ or regulatory agencies. To this end, nation states may more often than not adhere to models of welfare provision that increasingly disappoint their citizens and are, moreover, often unaffordable. Thus, the developed Western countries' high-cost, high-tax, high-benefits governance model is coming under an increasingly looming threat of disruption caused by global digitalization. To that end, this book will seek to explore the ramifications of such a societal development.

Moreover, this book seeks to provide an innovative, enriching, and controversial take on society at large and how various aspects of the public sector can be (and are) affected by the ongoing digitalization trend in a way that is not covered by extant literature on the market. While this book covers the welfare state in a broader, Western perspective, many cases covered in this book draw upon Swedish conditions. This is due to the fact that according to the Digital Economy and Society Index (DESI), Sweden (along with Denmark, Finland, and the Netherlands) is one of the most digitalized countries in Europe (European Commission, 2019). This means that the Swedish cases presented tend to reflect a development in a particular area that is, by international standards, often more advanced, as opposed to that seen in many other countries, making the Swedish cases pertinent to study, as they may bear relevance to the future development in other countries in this area. Still, much of the digitalization and digital transformation transcends national borders, and thus much of the subject matter takes on an international character and also includes cases from other countries around Europe and the United States, as it still houses some of the world's most innovative research institutions (Ewalt, 2016).

Following the aforementioned discussion, this book seeks to explore the following areas of the public sectors (and the society in which they exist) and how they are affected by digital welfare:

\section{Health care and social care}

- Telemedicine and its impact

- Blockchain in health care

- Digital developments in health care

- Social care and digitally connected devices

\section{Education}

- $\quad$ EdTech

- Digital transformation of public education 


\section{Citizen protection}

- Physical protection, both individual and societal

- Digital protection, data collection, and digital identity

\section{Future of the welfare state}

- Potential implications

- The future of cash in a digital welfare state

- New technological institutions

- The future consumption of welfare

- The changing democracy

The studies throughout the included chapters are methodologically and thematically multidisciplinary in nature, with some presenting empirical material and others more theoretical, while others are based on various forms of literature reviews or depart from the authors' personal, "best practice" experiences, and so forth. The book represents a collaborative effort between expert authors with representation from some of the most prominent research institutions and organizations in Europe and the United States, all contributing to a better understanding of the topic at hand. The authors have been instructed to look at the situation of their topic as how it has been, how it is now, and how it might be in the future. To this end, the chapters will base their assumptions in referenced facts, but they may also transcend the conventional academic comfort zone by offering some foresight in how their subject area could transpire based on the current and expected developments due to digitalization and/or digital transformation.

\section{Chapter overview}

The following section provides a brief overview of the themes and premises discussed in each of the chapters included in this volume.

\section{Part I Health and social care}

\section{Marrten Blix and Johanna Jeansson - Telemedicine and the welfare state: the Swedish experience}

This chapter uses the Swedish example of a vibrant economy and a large public sector as a case to analyze the implications of how digitalization reshapes the welfare services, with emphasis on how telemedicine is set to transform the primary health care services. 


\section{Anthony Larsson, Olivia Elf, Corinna Gross, and Julia Elf-Welfare} services in an era of digital disruption: how digitalization reshapes the health care market

This chapter takes a closer look at how public and private actors react to the emergent use of telemedicine, using the Swedish primary health care market as a case. The study utilizes original empirical data in order to investigate how the changes in the industry brought on by technological advancements affect the actors' perception of their role in the market and their relationship to one another.

\section{Anna Essén and Anders Ekholm - Centralization vs. decentralization on the blockchain in a health information exchange context}

Drawing upon interviews with individuals involved in the health care sector, this chapter discusses the availability of health data for learning by juxtaposing the governance arrangement of today's state-based health information exchanges (HIEs) with that of a potential decentralized (blockchain-based) HIE scenario.

\section{John Øvretveit-Digitalization of health in Sweden to benefit patients}

This chapter discusses the digital developments in Swedish health services for patients and citizens to date while also paying attention to the rapid changes expected to occur in the coming years. The chapter proposes that the disruptive potential of new digital services and technologies (DST) is partially dependent on patient advocacy movements and patient organizations and their dissatisfaction with traditional health care.

\section{Daniel Wänn-Personalized predictive health care: how predictive AI platforms will transform the health care industry}

This chapter looks at the prerequisites for creating a predictive, personalized, and preventative health care platform; how publicly financed health care would be affected; and the broader implications for society.

\section{Anthony Larsson and Dominika Sabolová - Digital dentistry: a solution to the dentistry crisis?}

The chapter looks at the anticipated impending dentistry crisis in the Western countries due to the shortage of new dentists in the workforce in addition to increasingly more unaffordable dental health care for low-income earners. This has effectively created a possible dental welfare deficit problem, which calls for new, radical solutions. The authors draw upon extant literature and "best-practice" experiences in order to investigate if and how digital dentistry could be used in the future to remedy this dental welfare deficit problem. 


\section{Andres Laya and Jan Markendahl - Solutions based on digital connected devices for social care and well-being}

This chapter considers two aspects of the development of solutions for social care and well-being in Sweden. Drawing upon a number of interviews with technology providers and municipalities, the authors investigate the business challenges preventing the development and uptake of new digital solutions. In addition, the authors discuss the implication of those challenges in terms of the emerging development patterns.

\section{Part II Education}

9 Cormac McGrath and Anna Akerfeldt-Educational Technology (EdTech): unbounded opportunities or just another brick in the wall?

This chapter considers to what extent educational technology has a disruptive or transformative influence on the educational environment today. For the purpose of this study, EdTech is used as an umbrella concept to define and identify a wide range of technologies that have been designed and developed with an outspoken purpose to be used for teaching and learning.

\section{Stephen Mahaley - Education at the intersection: a practitioner's view of the effect of digital transformation on public education}

This chapter seeks to review the history of public education in the United States through a combination of a literature review, a current event and policy analysis, and practical examples. The study then proceeds by looking at what is happening now with the increasing impact of digital technologies and finally examining the potential futures in terms of what lies ahead for this public good in particular.

\section{Part III Citizen protection}

\section{Mark A. Conley and Emily Nakkawita-Citizen protection: a capabilities and intentions framework}

This chapter conducts a linguistic analysis of the websites of US public and private security-focused organizations in order to analyze the safety and security concern across both groups. Top government contractors continue to apply digital innovations toward defense purposes, and according to polling, US citizens support an increasing private role along with a decreasing public role in delivering safety and security. As the authors argue, although public opinion indicates that taxpayers expect fewer defense capabilities from the government, these structures still broadcast their enduring intentions to provide citizen protection. To 
that extent, public-private partnerships are a modern standard in defense, and this relationship in the United States shows no sign of tilting away from government leadership, thus prompting a further analysis into their concern for safety and security.

\section{Arne Norlander - Societal security: how digitalization enables resilient, agile, and learning capabilities}

This chapter illustrates the relevance and potential impact of digitalization as an enabler of resilient, agile, and learning capabilities for societal security. The author argues that digitalization is essential in building organizations that can not only survive in complex and turbulent situations, but also excel in collective resilience, robustness, redundancy, and adaptability to ensure welfare, health care, food, water, energy, shelter, and security. The chapter explores how digitalization, in times of societal disruption, can add new and reinforce existing capabilities, while also generating vulnerabilities, in the protection of both society and its citizens.

\section{Claire Ingram Bogusz - Digital identity - beyond verification: to a transparent (decentralized) system for data and identity monitoring and control}

This conceptual chapter explores the existing models of digital identity verification and digital data management before juxtaposing them against emerging alternative solutions, and offering food for thought for policy-makers on how the tensions between digital integrity and data-driven innovation might be resolved using a digital identity management infrastructure. It then outlines some suggestions around how identity verification and data management - as distinct, but important, digital phenomena - might converge to allow individuals better dynamic control over which data are collected, by whom, and for what purposes.

\section{Part IV Future of the welfare state}

\section{Björn Eriksson and Ulrika Sandhill-Cashless: a dead end for Sweden?}

This chapter serves as an investigative commentary on the development of the cashless society in Sweden, the driving forces behind it, the outcome, and its ramifications on welfare. By doing so, the authors seek to provide some "best practice" insights using Sweden as a case in light of similar nascent developments across other digitalizing nations. 
15 Charlotte Mattfolk and Lina Emfeldt-Future consumption of welfare services: how the change in consumer expectations will affect offerings and business models in welfare

This chapter takes a qualitative approach in which the authors investigate the future consumption of welfare services to understand what scenarios may emerge given the rapid technological development, changing consumer behaviors, aging population, urbanization, and scarce human resources to cater to future needs. The empirical data have been collected from qualitative interviews and a workshop with representatives from both public and private sectors.

\section{Alejandro Moreno Puertas and Robin Teigland - The trust revolution: blockchain's potential to resolve institutional inefficiencies}

This chapter provides a qualitative analysis of the potential impact of blockchain on political institutions. The first section offers a brief explanation of blockchain technology, followed by how it relates to the emergence of trust in political institutions. The second section describes the problems that arise from centralizing power, while the third part focuses on blockchain's potential to mitigate some of them. The final section ventures into a discussion of the potential benefits of a blockchain nation.

\section{Mats Lewan - The future of the nation-state: how the nation-state can find a way through digitalization}

Building on a framework called the "innovation loop" developed by the author, the chapter considers societal evolution largely to be a continuous adaptation to changed conditions brought by innovations. The analysis traces the development of the modern nation-state from the perspective of major human inventions and addresses globalization and the changing role of the nation-state, with less autonomy on one hand but with a new position in an increasingly interconnected world on the other. Three fields where the nation-state needs to adapt are identified - efficiency of services, alternative providers of services, and the structure of the democratic process. The threat from supra-states, localism, and cosmopolitanism is also discussed.

\section{Olle Wästberg - Digitalization has changed the foundation of the democracy}

This chapter seeks to examine the role of digitalized communication in the US presidential election of 2016 and an exploration of how the digital revolution has changed Swedish politics. In the United States as well as in Sweden, the digital revolution is enabling individual voters to access masses of data and to act and react online, as all the while political parties are eroding. An apparent result of this process is a dramatic polarization of the political conversation. The author 
contends that political opinion formation and public information have largely been taken over by digital media.

\section{Note}

1 Social care entails the areas that countenance and develop care as an activity and set of relations lying at the intersection of state, market, and family (and voluntary sector) relations (Daly and Lewis, 2000). While distinct from health care, it is for the purposes of this book categorized alongside health care given the fact that it represents a smaller overall scope of the welfare sector as compared to the others mentioned.

\section{References}

Amstutz, L.J., 2018. Smartphones. Lake Elmo, MN: Focus Readers.

Bloomberg, J., 2018. Digitization, digitalization, and digital transformation: confuse them at your peril. [online] Forbes. Available at: <www.forbes.com/sites/jasonbloomb erg/2018/04/29/digitization-digitalization-and-digital-transformation-confuse-them-atyour-peril> [Accessed 11 Sep. 2019].

Brynjolfsson, E. and McAfee, A., 2014. The second machine age: work, progress, and prosperity in a time of brilliant technologies. New York, NY: W.W. Norton \& Company.

Castells, M., 2010. The rise of the network society: the information age: economy, society, and culture. 2nd ed. Chichester, UK: Wiley-Blackwell.

Cochoy, F., Hagberg, J., McIntyre, M.P. and Sörum, N., 2017. Digitalizing consumption: introduction. In: F. Cochoy, J. Hagberg, N. Sörum and M.P. McIntyre, eds. Digitalizing consumption: how devices shape consumer culture. London, UK: Routledge, pp. 1-19.

Crone, P., 2005. Medieval Islamic political thought. Edinburgh, UK: Edinburgh University Press.

Daly, M. and Lewis, J., 2000. The concept of social care and the analysis of contemporary welfare states. The British Journal of Sociology, 51(2), pp. 281-98.

Dasgupta, R., 2018. The demise of the nation state. [online] The Guardian. Available at: $<$ www.theguardian.com/news/2018/apr/05/demise-of-the-nation-state-rana-dasgupta $>$ [Accessed 11 Sep. 2019].

European Commission, 2019. The digital economy and society index (DESI). [online] Digital Single Market Policy. Available at: <https://ec.europa.eu/digital-single-market/en/ desi> [Accessed 11 Sep. 2019].

Ewalt, D., 2016. The world's most innovative research institutions. [online] Reuters. Available at: <www.reuters.com/article/us-innovation-rankings/the-worlds-most-innovativeresearch-institutions-idUSKCN0WA2A5> [Accessed 11 Sep. 2019].

Feldman, T., 1997. An introduction to digital media. New York, NY: Routledge.

Hardey, M., Loader, B.D. and Keeble, L., 2009. Introduction. In: B.D. Loader, M. Hardey and L. Keeble, eds. Digital welfare for the third age: health and social care informatics for older people. London, UK: Routledge, pp. 1-14.

Kaplan, A. and Haenlein, M., 2019. Siri, Siri, in my hand: who's the fairest in the land? On the interpretations, illustrations, and implications of artificial intelligence. Business Horizons, 62(1), pp. 15-25.

Kelleher, J.D., Namee, B. Mac and D’Arcy, A., 2015. Fundamentals of machine learning for predictive data analytics: algorithms, worked examples, and case studies. Cambridge, MA: MIT Press. 
Kienhues, D. and Bromme, R., 2011. Beliefs about abilities and epistemic beliefs: aspects of cognitive flexibility in information-rich environments. In: J. Elen, E. Stahl, R. Bromme and G. Clarebout, eds. Links between beliefs and cognitive flexibility: lessons learned. Dordrecht, Netherlands: Springer, pp. 105-24.

Larsson, A. and Viitaoja, Y., 2017. Building customer loyalty in digital banking? A study of bank staff's perspectives on the challenges of digital CRM and loyalty. International Journal of Bank Marketing, 35(6), pp. 858-77.

Lindbeck, A., 1996. Incentives in the welfare state: lessons for would-be welfare states. Working Paper No. 449. Stockholm, Sweden.

Liu, J., Sheng, L. and He, Z-Z., 2019. Liquid metal soft machines: principles and applications. Singapore, Singapore: Springer.

McCarthy, J., 2007. What is artificial intelligence?/Basic questions. [online] Available at: $<\mathrm{http}$ ://www-formal.stanford.edu/jmc/whatisai/node1.html> [Accessed 11 Sep. 2019].

McCarthy, J., Minsky, M.L., Rochester, N. and Shannon, C.E., 2006. A proposal for the Dartmouth summer research project on artificial intelligence, August 31, 1955. AI Magazine, 27(4), pp. 12-14.

Newton, D.E., 2018. Robots: a reference handbook. Santa Barbara, CA: ABC-CLIO.

OECD, 2016. Digital government strategies for transforming public services in the welfare areas. [online] OECD Comparative Study. Available at: <www.oecd.org/gov/digitalgovernment/Digital-Government-Strategies-Welfare-Service.pdf $>$ [Accessed $11 \mathrm{Sep}$. 2019].

Russell, S.J. and Norvig, P., 2009. Artificial intelligence: a modern approach. 3rd ed. Upper Saddle River, NJ: Prentice Hall.

Schmidt, E. and Cohen, J., 2013. The new digital age: reshaping the future of people, nations and business. London, UK: John Murray.

Siegel, E., 2013. Predictive analytics: the power to predict who will click, buy, lie, or die. Hoboken, NJ: Wiley.

Van Dijk, J.A.G.M., 2012. The network society: social aspects of new media. 3rd ed. London, UK: Sage Publications.

Van Wynsberghe, A., 2015. Healthcare robots: ethics, design and implementation. Farnham, UK: Ashgate.

Von Kersbergen, K. and Vis, B., 2014. Comparative welfare state politics: development, opportunities, and reform. New York, NY: Cambridge University Press.

Wachal, R., 1971. Humanities and computers: a personal view. The North American Review, 256(1), pp. 30-3. 



\section{Part I}

\section{Health and social care}





\title{
2 Telemedicine and the welfare state
}

\section{The Swedish experience}

\author{
Mårten Blix and Johanna Jeansson
}

\section{Introduction}

Health care in Sweden finds itself at a crossroads as regards digitalization. In this chapter, we will focus on one issue in particular that is causing consternation among primary care physicians: the rapid increase in popularity of telemedicine. Via smartphone apps, patients can at the press of a button make video calls directly with doctors, rather than having to wait days, or weeks, for a nonemergency meeting with a doctor at a physical care center. Apart from reducing waiting times, this development brings a host of other benefits for patients, such as removing the inconvenience of travel and lessening the risk of contagion at care centers (Mohr et al., 2018). Online consultations also use the physicians' time more efficiently. But the development is not without its predicaments, and one issue in particular stands out. The substantial government subsidy for primary care visits, in combination with vastly improved accessibility, could result in unsustainable cost increases for taxpayers. As we show in this chapter based on new, original data, the number of digital health consultations has already grown dramatically. Hence, it remains to be seen if this lessens the number of physical visits or simply adds volume and thus total health care costs.

Although the health care system is continuously undergoing change, the remuneration system in Swedish primary care is mostly through capitation (Anell, Glenngård and Merkur, 2012). But digitalization is now raising new issues. For one, the rules and governance of health care are increasingly at odds with what is possible and efficient through digitalization, where scale and network effects are important. Since Swedish health care lies under the responsibility of the 21 county councils, their legally mandated regional autonomy is increasingly in conflict with providing efficient digital health care available nationally. The county councils have the authority to tax citizens and shape health care, subject to some general government guidelines, but regional institutions lack the benefit of scale available at the national level. The county councils need to find a way to centralize - at least temporarily - some aspects of digital health care, such as price, remuneration, and best practices, while retaining autonomy in the choices that matter for its citizens. This will not be easy. 
To get a sense of how rapidly things are changing, consider that telemedicine in Sweden in its current form began in 2016 and that it had grown to represent almost 2 percent of all primary care visits by the end of 2017 (Blix and Jeansson, 2018). During this period, the Swedish Association of Local Authorities and Regions (commonly known as "SALAR," or "SKL" in Swedish), the organization that represents the autonomous regions, has been more or less forced to make some uncharacteristically quick changes to the recommended pricing of digital services.

Notably, in March 2018, the Board of Governors of SALAR endorsed a recommendation to the county councils to impose a minimum fee of SEK 100 $(\approx € 10)$ for telemedicine (SALAR, 2018). The reason was a peculiar combination of regional pricing and the borderless reach of digital services. One single county council representing just under 3 percent of the population in 2017 offers primary care free of charge (i.e., wholly subsidized by the taxpayers). Through a digital entrepreneur, gratis primary care suddenly became available in the whole country from January 1, 2018, a state of affair that created political tensions (Alskog, 2018). It only took 75 days before SALAR quickly introduced a recommended minimum fee for telemedicine, though the county council in question has delayed implementing the recommendation.

Going forward, the role of telemedicine hangs in the balance from the political choices made in the next few years. There is substantial need of reform in a system characterized by considerable inertia, but future decisions will likely prove more difficult. Addressing remuneration systems and how to triage patients between digital and physical care will be key issues. If digitalization is not well managed, it may lead to tensions that cause Swedish health care costs to hemorrhage. It could also lead to other challenges for health care, for example, in the skills needed in the profession, but these issues are beyond the scope of this chapter.

The rest of this chapter is structured as follows. First, we briefly discuss the persistent issue of poor accessibility to Swedish primary care. Next, we describe how digital doctors and telemedicine are transforming primary care, which age groups and regions are using the service, and the increased tensions telemedicine bring to the Swedish health care system. Finally, we conclude by discussing three reform areas that could improve the framework and pricing for telemedicine in Sweden.

\section{Pervasively low scores for health care accessibility}

Sweden's health care system is often acknowledged to deliver high-quality care even as the costs are among the higher in the OECD (apart from the United States). Measured per capita, or as a share of GDP, Sweden is one of the countries that spend the highest amount on health care (OECD, 2017). Based on various measures of quality, Sweden's rank is high in international comparisons:

- The mortality in cancer and the prescription of antibiotics are among the lower within the OECD (2017).

- There are more doctors and nurses per capita than in many other countries (OECD and European Observatory on Health Systems and Policies, 2017). 
- There is a low proportion of unmet health needs caused by cost constraints(OECD and European Observatory on Health Systems and Policies, 2017; OECD, 2017; The Commonwealth Fund, 2017).

At the same time, Sweden ranks as one of the worst countries when measuring quality based on patients' experience of care and waiting times (Vårdanalys, 2014). For example, Swedish health care is in the lower third of the OECD countries based on the amount of time a doctor spends with a patient during a visit and the level of transparency the patients receive in treatment (OECD, 2017). Senior citizens in Sweden (together with Germany and Canada) may also wait longer for care than in other Western countries (The Commonwealth Fund, 2017; Vårdanalys, 2017).

\section{Health care disruption}

\subsection{New health care providers: the emergence of telemedicine in Sweden}

In 2016, the digital entrepreneurs Kry and Min Doktor launched their respective telemedicine app. Since then, their popularity has steadily increased, as measured by a rapid increase in the number of digital visits (see Figure 2.1), with more companies entering the field. Also, Kry has expanded to other countries, notably to Norway and Spain, and has plans to enter other markets, notably France and the United Kingdom (Ram, 2018).

The novel element of the Swedish telemedicine apps is that they are designed to work seamlessly as part of the public welfare system. In contrast to other telemedicine companies, for example in the United States, the remuneration of telemedicine in Sweden is part of an existing mechanism put in place by the 21 county councils. The advantage is that patients (so far) pay the same fee as for a physical care visit and that the barriers for patients to access the service are minimal.

It works as follows: the patient accesses the app and their identity is confirmed via a mobile BankID. The mobile BankID is a stand-alone technology originally developed by the banks but has, in our judgment, become a de facto standard in Sweden for a host of other services outside the financial sector, including the tax authorities. Sweden has one mobile BankID that works for all applications, so users do not need to access multiple identification tools.

The design choice of integration with public welfare services means that the patient's access works smoothly, while all complicated interactions in regard to the technology and the health care bureaucracy occur in the background, out of sight.

The most notable of these complicated interactions is how costs are reimbursed. Within primary health care in Sweden, the primary funding is through capitation (Anell, Glenngård and Merkur, 2012). Each primary health provider receives funding based on the number of listed patients, with some adjustment for other factors, such as socioeconomic attributes and age. Telemedicine companies are not yet allowed to list patients. Instead, their remuneration is based on a legal 
construction known as out-of-county visits that is established in a legal bill (Sveriges Riksdag, 2017). All Swedish citizens have access to health care throughout the country, but the cost for each visit is borne by the home county council where the patient pays regional tax. For example, a person living in Stockholm utilizing care in the city of Malmö will pay the out-of-pocket fee established by the county council responsible for Malmö. Subsequently, that council will bill the Stockholm county council for a visit according to their own fee structure. Though such visits were not infrequent before telemedicine apps, the scope was too small to make it a contested political issue.

Telemedicine rests on this construction of out-of-county visits combined with the law of freedom-of-choice ("LOV") enacted in 2009-10 (Swedish Government, 2008). ${ }^{1}$ This freedom-of-choice law was a signature bill of the center-right coalition (2006-2014) to create private alternatives to publicly provided welfare services. It gave private health care actors the right to establish their services anywhere in Sweden as long as they fulfill the regulatory requirements. The same law forms the legal basis for telemedicine doctors. By the same token, just as for private health care providers, telemedicine doctors can also establish their services anywhere as long as they fulfill the same regulatory requirements. It is unclear - even unlikely - that this later development was foreseen by the legislators at the time.

In practical terms, the digital entrepreneurs Kry and Min Doktor connected their services to the county council of Jönköping, which represents slightly less than 2 percent of the national population. Formally, they are subcontractors to two private primary health care centers, Tranås and Wetterhälsan, supervised by the local authorities. Suddenly, starting in 2016, with this somewhat artificial construction, Sweden had a form of hybrid health care system; a national primary digital health care accessible for all, but with local regulators responsible for supervision and financing.

Essentially, the private providers were able to produce an innovative and popular service resting on top of existing regulation and rules. In itself, the emergence of telemedicine was only a matter of time. Video calls via the Internet have been available at least since Skype was launched in 2003, and in the United States, digital doctors have been using such technologies with paying insurance customers almost since smartphones were introduced. But the few Swedish county councils that have experimented with video calls have not had much impact, as the services have been awkward and not particularly user friendly. Instead, it took privately owned companies to take the decisive steps in developing a smooth and convenient service through smartphones.

\subsection{Digital transformation in primary health care}

Digitalization has already transformed many service sectors. Although health care is unique in many ways, there are fundamental similarities in two central aspects: network effects and scale. In one way or another, most of the strengths and benefits from digitalization stem from these two features (Brynjolfsson and McAfee, 
2016). The network effect implies that as more people use the service, the more useful it becomes. The scale effect means that the cost of the digital service is low and that the marginal cost of adding additional users is almost zero. These elements also have some bearing on telemedicine. Doctors can meet more patients in the same time-frame, and patients from far away can communicate with specialists who are locally unavailable.

The US physician Eric Topol has provided a perspective on these developments and argues that digitalization upsets the power balance between doctor and patients (Topol, 2015). The main argument is that digital technologies are providing patients with tools and information that were previously not available to them. In this way, digitalization makes health care more democratic. Patients can compare notes online with other patients displaying similar symptoms and diagnosis, even in instances when it occurs only rarely. Patients can also find information more easily and read up on treatments and side effects. This will likely increase the pressure on health care both in terms of volume and quality.

Telemedicine is part of this digital transformation. From a patient perspective, quality is improved as patients can await doctor's video call at a place of their own convenience (their home), instead of traveling to the care center or an emergency room. By the time the video call comes through, some of the bureaucracy in the identification and explaining of the symptoms have already been processed and both doctors and patients can spend their time more efficiently on medical questions rather than on administrative formalities. If a doctor writes a prescription, an electronic recipe makes it possible to visit any pharmacy to buy the medicine. Recently, it has also become possible to order home delivery of medicine, something especially useful for the elderly or those with mobility restrictions. But, as we have already mentioned, increased accessibility may raise costs, and there are also issues of regulating this new form of health care.

\subsection{Criticisms of telemedicine}

The most scathing comments against telemedicine come from within the medical profession. Perhaps this is no surprise. Health care has long-developed traditions and set hierarchies. As an added economic irritant to physical health care providers, some county councils reduce their remuneration for the physical care centers when their listed patients use telemedicine.

The criticism against telemedicine in Sweden can be summarized in three points (Andersson, Sjögren and Åsberg, 2017; Ahlzén et al., 2018):

- That diagnosis cannot be done by video call alone, but requires a physical examination

- That online doctors tends to overprescribe medicine, notably antibiotics, while underusing diagnostic tests

- That overconsumption of health care is encouraged, resulting in large volumes of trivial or unwarranted e-visits at the expense of patients with comprehensive needs 
Overprescription of antibiotics is a global problem, but much less of an issue in Sweden. Recommendations and some use of pay-for-performance incentives have also proved successful in Sweden (Ellegard, Dietrichson and Anell, 2018). With telemedicine doctors, the incentive may also yet again be stronger in Sweden to overprescribe antibiotics, since this what patients may demand, and they can shop around more easily for a doctor who may then be more prone to acquiesce. Indeed, there have been some alleged instances of oversubscription of antibiotics from medical doctors on behalf of the regulators (Lägermo and Bengnér, 2017a, 2017b, 2017c, 2017d), but the methodology and results have been criticized by the chief medical officer at Min Doktor (Cederberg, 2017). After these investigations, regulation and oversight have been strengthened. All aspects of regulating physical health care are also present in telemedicine, and it is important to maintain oversight so that the same standard is applied regardless of the format.

It is also clear that many diagnoses still require physical interaction between doctor and patients, for example, regarding ear and throat exams or when a bone may be broken. In regard to diagnosis, telemedicine doctors argue that much information about a patient can be learned from a video call (Schildt et al., 2017). Supporting their case is the fact that as technology advances, the range of diagnoses that may be feasible through telemedicine increases. For example, blood-pressure monitors can easily be connected to smartphones, as well as an expanding range of measuring and monitoring tools. As in other areas, increased competition and globalization also imply that lower costs for new medical instruments will make them more feasible for homeownership, which is especially vital for patients who often require access to health care. There are also promising results for using telemedicine to treat mental illness, and a literature review shows that there is no significant difference in diagnosis compared with physical visits (Hilty et al., 2013).

\subsection{Telemedicine and privatization of welfare services}

In Sweden, there are historical antecedents to the criticism against telemedicine in the private production of welfare services. While we will not try to summarize all arguments of this debate, we note that one motivating factor is the presumption that private producers boost demand in order to increase profit or reduce quality in order cut costs. The Swedish discussion has been ongoing with varying strength since the mid-1980s, and when the socialist-green coalition came to power in 2014, it resurfaced with renewed vigor.

The first, and by far the most vitriolic, conflict occurred not in health care, but in another area of welfare, namely that of preschool for children aged 1-6. In 1984, the private preschool Pysslingen met a storm of protests and legislation and the then-Prime Minister Olof Palme asked rhetorically if Sweden should allow "Kentucky-fried children" (sic), alluding to the alleged horrors of for-profit taxfinanced welfare services (Svanborg-Sjövall, 2013). Another example is elderly care, where, toward the end of the 1980s, political strife erupted around outsourcing in the municipality of Danderyd. Since then, private production has increased across most areas of welfare production from preschools and schools to health 
care. Today, private production plays an extensive role in health care in general and in primary health care in particular, where private providers account for 36 percent of all production as measured by the share of net cost in 2015 (Jordahl, 2013).

It is within this broader debate about profits within tax-financed welfare services that telemedicine may become even more controversial than today. During 2016-17, telemedicine providers were loss-making, as is often the case with start-ups. But at some point in the future, their private financiers will want to see a return on their investments. The stage is then set for more political conflict.

\section{Telemedicine use in Sweden}

Telemedicine is on the rise in many countries. It comes in many shapes and forms, from automated advice with avatars, as developed at the USC Center for Body Computing (Saxon, 2015), to video calls with online physicians. In Table 2.1, we illustrate some of the available apps.

Data on the total number, age, and region of residence of telemedicine users are available in Sweden. As can be seen from Figure 2.1, the number of visits has increased steadily since 2016, and in December 2017, they amounted to about 27,000 persons. In 2017 (December-December), the increase was almost 230 percent, albeit starting from a low level.

As expected, it is also apparent from Figure 2.1 that it is the most populous regions that account for most of the digital care visits during the period June 2016 to December 2017. Perhaps more surprising is how much the large regions dominate as a share of digital visits. Sweden's capital Stockholm, which accounts for 43 percent of all visits, is almost twice overrepresented relative to its population share of about 23 percent in 2017. On the other hand, residents from the other two big regions, Scania and Västra Götaland, consume digital care almost in parity with their respective population shares.

A relevant question in regard to the future of telemedicine is whether the previous figures are evidence of socioeconomic segregation, with high-income earners from the capital being the main beneficiaries of telemedicine, while other regions benefit less. While no data on socioeconomic characteristics are available, digital

Table 2.1 Examples of health care apps in Sweden, the UK, and the US

\begin{tabular}{lll}
\hline Sweden & UK & US \\
\hline Kry, Min Doktor, Doktor.se, & Babylon Health, Push & Doctor on demand, \\
Doktor24, A \& O i Vården, & Doctor, Dr Now, Vitality & LiveHealth Online, \\
Min Vård, Medicheck, & GP, Ada Personal Health & Teladoc, Amwell, \\
Närhälsan online, & Companion & HealthTap, MDLive, \\
Videmöte SLL, First Derm, & & American Well, \\
iDoc24, Medicoo & & StatDoctors, MeMD \\
\hline
\end{tabular}

Note: Some apps have limited functionality outside their respective country. 


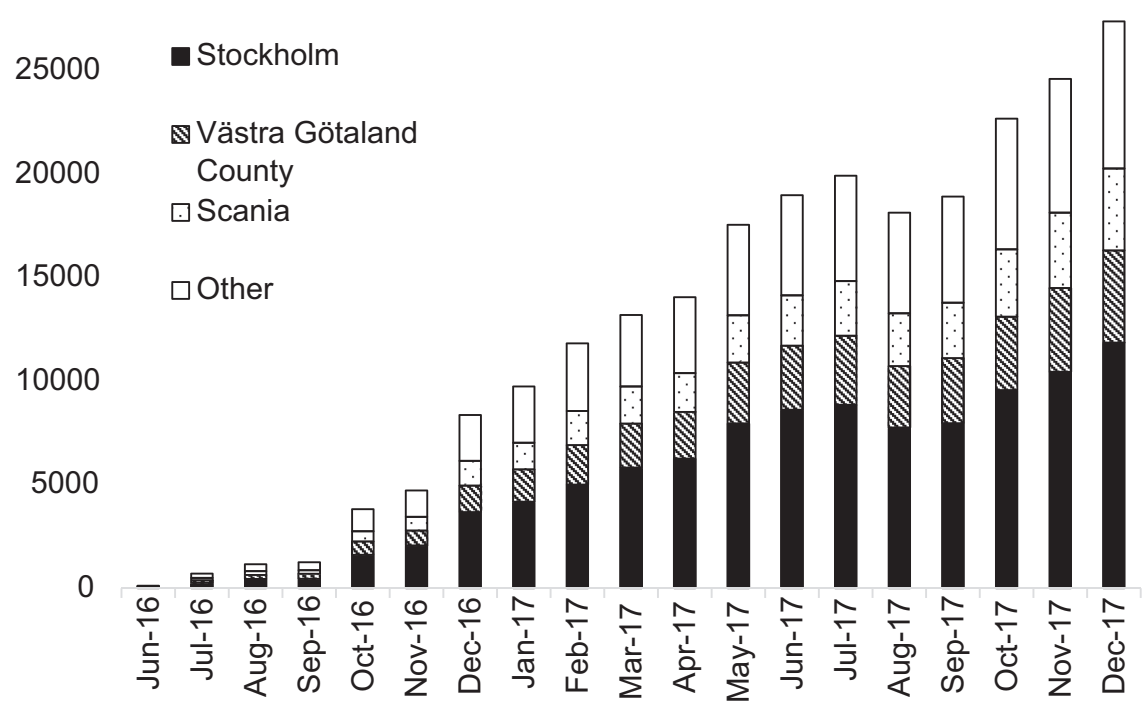

Figure 2.1 Number of telemedicine visits in Sweden, June 2016 to December 2017

Source: Unpublished data from Jönköping county council.

Note: The visits illustrate those recorded at Region Jönköping county council.

care is available on an equal footing to all citizens - low and high income earners alike. Such broad accessibility is a choice of design and was by no means inevitable. The digital entrepreneurs Kry and Min Doktor could have created a service accepting only insurance customers or those paying directly, such as in the United States (for some sense of how this is organized in other countries, see Hassan et al. (2018, p. 14). Instead, Kry and Min Doktor both target the whole population. Moreover, telemedicine also provides improved access compared with primary nonemergency care by upping the staff of doctors on evenings and weekends.

The increased use of telemedicine in Sweden, as well as international studies, suggests the service is appreciated by patients. All that is required for access is a smartphone or a reasonably modern computer with an Internet connection. And Sweden is one of the countries with the highest Internet penetration in the world. The ease of access should make telemedicine an attractive option for the elderly or for people with disabilities or chronic diseases, as well as those living in rural areas. Still, so far neither the elderly nor those in rural areas are especially frequent users of telemedicine.

Figure 2.1 shows that large cities dominate in numbers of digital visits. Table 2.2 and Figure 2.2 show that the elderly are underrepresented in regard to the age distribution of telemedicine use. Instead, young children aged 0-4 years are overrepresented, as they account for almost 20 percent of the visits but represent only about 6 percent of the population. Evidently, around toddler age and 
Table 2.2 Share of telemedicine visits compared to population shares, 2016-2017

\begin{tabular}{lllc}
\hline Age group & $0-19$ & $20-64$ & $65+$ \\
\hline Share telemedicine visits & 37.86 & 59.47 & 2.67 \\
Population share & 22.9 & 57.3 & 19.8 \\
\hline
\end{tabular}

Sources: Statistics Sweden's database www.scb.se and unpublished data from Region Jönköping.

Note: The population shares are dated November 2017. The number of telemedicine visits covers the whole period, starting from June 2016 to December 2017.

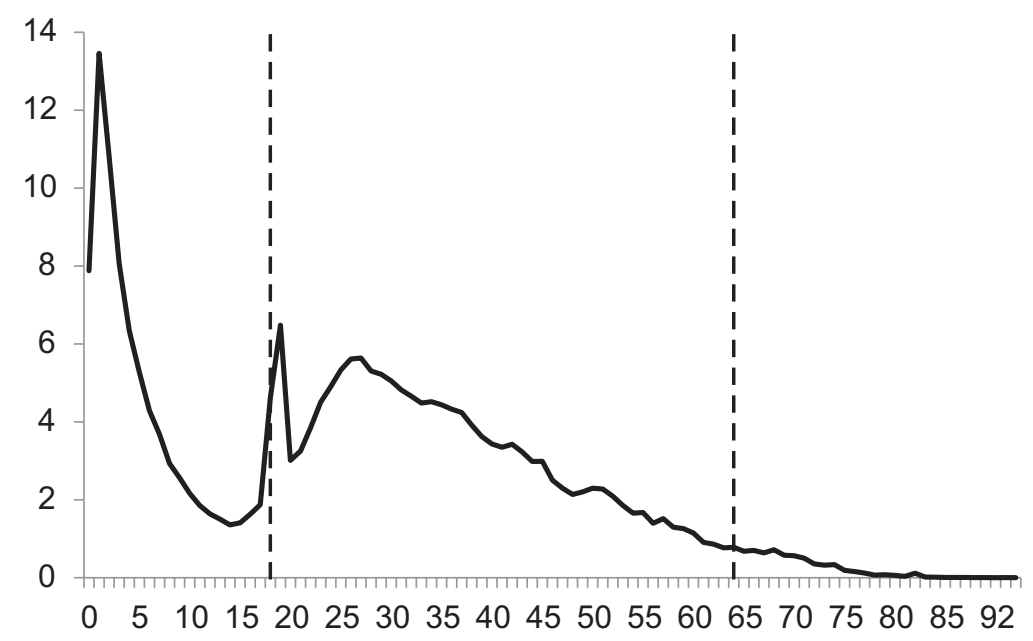

Figure 2.2 Number of telemedicine visits according to age, June 2016 to December 2017, thousands

Source: Unpublished data from Jönköping county council.

Note: The visits illustrate those recorded at Region Jönköping county council.

above, kids are sick more often. Moreover, the large share could reflect heightened parental worry for the smallest, more vulnerable children. It is rather the other end of the age spectrum that stands out in its own right. People above the age of 65 have a low level of use of digital care in relation to their (large) population share. This feature likely reflects the group's lower digital maturity. But as today's smartphone users age, it is reasonable to assume that the use of telemedicine will increase for the elderly and that the age distribution gradually will go from less of an "L" toward more of a "U" shape.

\section{Price, demand, and quality in telemedicine}

Swedish health care has long been struggling to achieve high-quality medical care that is both accessible and cost effective at the same time. A theme has been that health care should be based on medical need rather than being demand driven. 
One way of dampening demand is by calibrating the fee for health care. At the same time, studies show that the price sensitivity to health care fees in Sweden is low in the sense that the number of visits to doctors does not change much when the price changes (Jakobsson and Svensson, 2016). Also, the cap on medicine and health care spending for patients, above which the government subsidy costs, drastically reduces the importance of a fee. Those with outlays above the ceiling (in 2018 set to SEK 1100 over a 12-month period, or about $€ 107$ ) pay no fee at all. The same is true for children $0-19$ as well as those above the age of 85 . While we know how many young and old are exempt from health care fees, statistics on the number of patients benefiting from the ceiling is not centralized and therefore inaccessible.

Today, rationing of care is mostly done through longer waiting times, which probably explains the dissatisfaction with primary care availability.

\subsection{Increased tension in remuneration systems}

With telemedicine, the combination of easy access at today's low fees has led to rapidly increasing demand. As shown in Figure 2.2, small children represent a large share of digital primary care visits. This is not without benefits. Small children are often ill, and with digital visits, both they and their parents are spared the journey to the health center, where there may also be other infections. Moreover, the time gained from telemedicine eases the burden for children, parents, and employers and thus eventually also on public finances. The reason is the generous system of sick-pay available when children are sick and need parental supervision. To convey the magnitude of the sick-pay benefit in Swedish social security, consider that in 2016, a total of approximately 870,000 individuals, or about 20 percent of all employed, applied for compensation for temporary parental benefit from the Swedish Social Insurance Fund, and approximately SEK 7.2 billion $(\approx € 0.7$ billion) was paid for the care of sick children. With such a large amount, it can give significant cost savings if children are just a little healthier and the parents can spend a little more time at work.

Still, with virtually free-of-charge health care for children and improved accessibility, all constraints on rationing are essentially removed. In emergency care, there are already some indications that the treatment of those with extensive medical needs is neglected when parents and children seek care for less serious ills that could have been treated in primary care or at home (Ludvigsson, 2017).

When primary care is closed, telemedicine offers an attractive alternative to visiting the emergency room. But if the costs of telemedicine increase without alleviating the demand for primary care, there is an overt risk that the prioritization of care will deteriorate. But this is not the fault of telemedicine doctors. Apparently, they offer a medical service that patients demand.

The goal should be that primary care, emergency care, and digital care in its various guises form a coherent whole where the patient is matched to the appropriate level of care. There is, of course, an insight into these tensions at the county council, but little has happened. 


\subsection{Remuneration and future innovation}

In 2017, the total remuneration for telemedicine visits was set to SEK $650(\approx € 63)$, including the out-of-pocket patient fee that patients pay. Initially, the remuneration was more than three times higher, but SALAR in short order lowered the rate on two occasions. Without putting too much significance into these quick revisions, it still gives some indication of a system under pressure.

Indeed, it is fair to say that the construction of out-of-county visits, which rests on regulations intended for something else, has created additional administration. In principle, it is possible to track the new flows of payments between telemedicine providers and counties. The quantitative budgetary impacts, however, are more difficult to assess - even for the experts. The county councils themselves are responsible for their own budgetary systems, and we do not yet have a comprehensive analysis of how cost and compensation are affected by the developments that began in 2016. The remuneration flows are not exactly rocket science, but complicated enough to conclude that overall budget effects are not known and that lack of transparency is a concern.

As the use of telemedicine increases, the remuneration system will come under increased pressure. Digital care is being pushed onto an existing system operated through loose and mostly nonmandatory cooperation between the 21 autonomous county councils, and health care is a regional responsibility. This means there is a risk that reforms tend to be incremental and that mainly minimum resistance steps are possible.

Fees and remuneration for telemedicine are likely to grow in both economic and political importance. Profit for telemedicine introduces new complications. In other welfare services, county councils and municipalities set the standard for the level of compensation based on relevant comparisons. For schools, this comparison would be the cost of a student in a school operated by the municipality. Within health care, the relevant comparison would be a health care provider run by the county council. But as the country councils do not yet provide pure telemedicine, this standard is lacking. It is noteworthy, however, that the compensation for a digital visit is but one-third of the weighted average cost of a physical visit to a primary care center (which was SEK 1706 in 2016).

The challenge for reforming remuneration is that big profits in telemedicine would cause political anger and irritation among primary care physicians. But if profits are too small - or if there is an extended period of loss-making - private investors may lose patience and innovation could grind to a halt. Another risk is that the county council change the conditions to such an extent that the telemedicine doctors change their business model in order to focus only on private customers through insurance or fees. Already there are signs that advertising is increasing. Future innovation in telemedicine and its place in health care is thus hanging on a thread. It is essential that the county councils take this into account when considering reforms.

Today, digital care visits have quickly grown to almost 2 percent of all physical primary care visits, and within only a few years the share could edge up 
toward 10 percent. What happens to the remuneration system if telemedicine would account for 20,50 , or even 90 percent of primary care visits?

\subsection{Increased availability or overuse?}

A key issue is if telemedicine can reduce the burden on total primary health care by increasing efficiency or if it results in extra demand and therefore increases strain on the same resources. Studies show that the effects are greatly influenced by the way telemedicine is designed. A US study of 300,000 patients between 2011 and 2013 found a volume increase of 88 percent but only 12 percent relief on primary care (Ashwood et al., 2017). However, in a six-month pilot trial at Hurley Group, a group of health care centers in the United Kingdom, telemedicine led to nearly one-fifth of patients no longer feeling the need for a physical visit (Madan, 2014). The total time for visits to doctors also fell.

In the UK study, patients had access to digital solutions such as self-help guides, telephone counseling 24 hours a day, and e-consultation with their GP as a complement to the contact they already had with their primary health care center. The result showed more satisfied doctors and patients, where about 80 percent of the doctors wanted to implement the program and about 80 percent of patients would recommend online care to others. The results indicate that coordination and continuity are central aspects of improving the quality and cost effectiveness of health care by telemedicine. In Sweden today, however, telemedicine risks interrupting the continuity of care. This is partly because patients so far can only be listed with physical care centers, not with telemedicine doctors.

\subsection{Incentives and regulations determine the quality}

To start a telemedicine company, regulatory approval from the Health and Social Care Inspectorate (IVO) is required, but it is the county council where the online physicians are registered that is responsible for regular supervision.

An area that is under particular scrutiny is the prescription of antibiotics. Here, a review of a series of reviews of county council (Lägermo and Bengnér, 2017a, 2017b, 2017c, 2017d) showed that the telemedicine doctors had not followed the guidelines on diagnosis for pneumonia and throat infections. In a majority of cases, the region's criteria for diagnosis were not met, yet several doctors wrote prescriptions for antibiotics. Since then, Region Jönköping has implemented stricter rules. For example, restrictions are imposed on which diagnoses the telemedicine doctors can make and that more information about patient visits needs to be disclosed.

If guidelines are not followed, it is worrisome. To our knowledge, there is no compelling evidence of telemedicine providers generally being more likely to prescribe drugs or make erroneous diagnoses. A smaller American study comparing digital and physical visits showed no symptomatic oversubscriptions, although there were vast differences between health care providers (Schoenfeld et al., 2016). Research on Swedish data shows that some calibration in the 
compensation systems reduces the prescription of antibiotics (Ellegard, Dietrichson and Anell, 2018).

It is understandable that issues arise in the first phase of telemedicine, and supervisors and telemedicine doctors should draw lessons from this experience. Here it is important that the knowledge of best practice for digital care not stop at an individual county council and that the knowledge be conveyed to all. Better and aggregate statistics on telemedicine are therefore important. Although it is still early days for Swedish telemedicine, knowledge of how to conduct digital health care is improving fast and new digital tools are being developed. Perhaps in the future, visiting a physical health care center will be equally rare as a visit to the bank today.

Another pressing issue is that the lack of national coordination between county councils creates artificial barriers to digital care. For example, the requirements for laboratory tests vary, and there is no available national registry for patients. The combination of private telemedicine providers that have an incentive to as quickly as possible satisfy new patients, while there are bureaucratic obstacles in sending samples for analysis, can very well lead to under-utilization of diagnostics and overuse of medical prescriptions.

In comparing telemedicine to physical health care, it is also central that all be held to the same standard, be it private production or county council centers. There are examples of private providers that are kept to a higher standard than equivalent public-sector providers. Also, extensive distortion of competition occurs when county councils allocate more resources to their own care centers compared to what private actors receive, this according to the governmental agency responsible for competition in Sweden (Swedish Competition Authority, 2014). Despite this, more than half of the health care centers run by county councils are loss-making.

\section{Conclusions}

Telemedicine has the potential to alleviate the lack of accessibility of primary care. Video calls save time for patients, reduce the risk of infection during physical visits, and increase physicians' working time flexibility. Queues and waiting times can be shortened if digital care providers reduce the burden on physical primary and hospital care regarding simple diagnoses, prescriptions, and referrals. A digital solution can also be used for preventive purposes, to speed up referrals, to coordinate patient information, or to help health care providers improve their diagnoses. Finally, digitalization makes it possible for more care to be provided at home or remotely, which reduces the costs of hospital care and has the potential to improve access to care across the country. Better access to care in many sparsely populated areas of Sweden would be a considerable improvement. But so far, it is mostly children and metropolitan residents who have used telemedicine in Sweden. The elderly, those with chronic diseases, and rural residents should in the years ahead be able to benefit much more from telemedicine. 
At the same time, there is a significant risk that telemedicine will cause increased pressures in several dimensions. In part, public finances may suffer because the rationing of health care is weakened, and the bill is sent to the taxpayers. In part, there is a risk for health care as a whole since telemedicine practitioners may disrupt the continuity of care for those with multiple or complex needs. The latter is, in our view, an apparent risk as long as the digital care providers are not allowed to list their own patients and thus become fully responsible for them.

The dramatic increase in telemedicine visits since the beginning of 2016 clearly shows the dormant forces that have been released. Going forward, three key issues should be addressed for a better future with telemedicine:

1 There must be incentives for caregivers to provide coherent and preventive care and not encourage overuse. In order to avoid overuse and promote cost efficiency, remuneration systems should be reformed to induce care providers with greater cohesive responsibility for the patient. A simple first step is for existing physical health care providers to take much better advantage of existing digital innovations and integrate those tools into their own services. This can be done either through improved cooperation between existing physical and digital health care providers or as physical health care providers develop their own digital services. Coherence and cooperation between health care actors could increase if there were a model of sharing remuneration from listed patients and fees from telemedicine visits. The responsible political actors should launch an inquiry into how this could be done.

2 Primary care should no longer be free of charge for children when there is almost no barrier to access. Socioeconomically weak groups can instead be supported by better-designed cost ceilings. Increased digital accessibility already exacerbates the economic consequences of lack of overall coherence in the county system. While public finances may not exactly hemorrhage in the near term, the specter of dubious choices and priorities increases. A low fee for children's access to telemedicine at least restores a symbolic barrier with only minor reduction in accessibility. Whether telemedicine and physical health care visits should have the same fee is a difficult question. A higher fee for telemedicine could be motivated to reduce overconsumption of care. However, we believe that for the time being, the fee should be the same so as not to stifle innovation and the opportunities for telemedicine to reduce the burden on physical health care centers and emergency care. The remuneration system between county councils and telemedicine providers should also be reformed without the risk of holding back innovation - be that from the private or public sector.

3 More effort should be devoted to developing best practices for digital care. There is a need for better and more systematic knowledge about which forms of care can be provided by the telemedicine companies. Coordination among the 21 county councils in regard to experiences and protocols for 
telemedicine should be strengthened, preferably with a strong, but perhaps temporary, mandate for central control.

An example of a digital triage function has been developed by Min Doktor, which includes several questions to identify patients who have weak medical reasons to visit a doctor or who might better be supported in other parts of the health care system. This is a step in the right direction. Such functionality should be encouraged and developed further in order to improve matching of health care needs and resources. New technology has the potential to strengthen the chain of health care and help patients to the appropriate level of care. Done right, patients should be able to get more health care without significant cost increases. This is also the experience from other sectors, where the gains of digitalization are closely linked to scale and network effects.

It will also be necessary to strengthen regulation and supervision. Centralizing and analyzing data from digital care and telemedicine are key steps in this direction. Data collection should not only aim to improve telemedicine but also support research on medication and other effects for better health and prevention.

Some critical voices pejoratively dismiss the increase in telemedicine as "luxury consumption." It would be unfortunate if such an epithet were to gain ground because it implicitly implies a view of the "correct" amount of health care, while also suggesting that the current level of health care consumption is the appropriate one.

However, the benefits should not be taken for granted. They depend crucially on continued reform. If status quo remains, costs will increase, and the prioritization in health care will have more detrimental consequences for patients with comprehensive medical needs. It is the remuneration systems and supervision that should be reformed, not the patients' demand for more and better health care.

\section{Acknowledgments}

We would especially like to thank Peter Frykblom, Anna Häger Glenngård, and Charlotta Levay for comments on an earlier version of the text. We are also grateful to Agneta Rönn and Jonatan Vincent for providing background material, as well as for interviews with Livia Holm, Martin Lindman, and Daniel Persson representing Kry, Doktor.se, and Min Doktor, respectively. All opinions expressed are those of the authors. We are also grateful for research assistance from Charlotta Olofsson.

\section{Note}

1 The freedom of choice model ("LOV") was already established in five regions (Halland, Stockholm, Västmanland, Region Skåne, and Västra Götaland) out of 21 before the law was fully adopted. 


\section{References}

Ahlzén, R., Berggren, L., Metsini, A., Olsson, L. and Tegelberg, Å., 2018. Vetenskapligt stöd saknas för digitala diagnoser [Scientific evidence missing for diagnosis with video call]. [online] Dagens Nyheter. Available at: $<w w w . d n . s e / d e b a t t / v e t e n s k a p l i g t-s t o d-$ saknas-for-digitala-diagnoser $>$ [Accessed 2 Sep. 2019].

Alskog, J., 2018. SKL vill stoppa gratis digital vård i Sörmland [SKL want to stop free digital care in Sörmland]. [online] Altinget: Vård och hälsa. Available at: <www.altinget. se/vard/artikel/skl-vill-stoppa-gratis-digital-vaard-i-sormland $>$ [Accessed 2 Sep. 2019].

Andersson, O., Sjögren, J. and Åsberg, H., 2017. Nätläkarbolagen dränerar en underfinansierad primärvård [Telemedicine doctors drain resources from an underfunded primary care]. [online] Dagens Nyheter, March 2. Available at: $<$ www.dn.se/debatt/natlakarbola gen-dranerar-en-underfinansierad-primarvard $>$ [Accessed 2 Sep. 2018].

Anell, A., Glenngård, A.H. and Merkur, S., 2012. Sweden health system review. Health Systems in Transition, 14(5), pp. 1-159.

Ashwood, J.S., Mehrotra, A., Cowling, D. and Uscher-Pines, L., 2017. Direct-to-consumer telehealth may increase access to care but does not decrease spending. Health Affairs, 36(3), pp. 485-91.

Blix, M. and Jeansson, J., 2018. Synliga vårdbehov och osynliga kostnader [Visible care needs and invisible costs]. [online] Dagens Samhälle. Available at: <www.dagenssa mhalle.se/nyhet/synliga-vardbehov-och-osynliga-kostnader-21896> [Accessed 2 Sep. 2019].

Brynjolfsson, E. and McAfee, A., 2016. The second machine age: work, progress, and prosperity in a time of brillant technologies. New York: W.W. Norton \& Company.

Cederberg, J., 2017. Min doktor ger Jönköping skarp kritik [Min Doktor issues sharp criticism to Jönköping]. [online] Läkartidningen. Available at: <http://lakartidningen. se/Aktuellt/Nyheter/2017/05/Min-doktor-ger-Jonkoping-skarp-kritik> [Accessed 2 Sep. 2019].

The Commonwealth Fund, 2017. 2017 commonwealth fund international health policy survey of older adults in 11 countries. [online] Infographic. Available at: <www.com monwealthfund.org/publications/infographic/2017/dec/2017-commonwealth-fundinternational-health-policy-survey-older $>$ [Accessed 2 Sep. 2019].

Ellegard, L.M., Dietrichson, J. and Anell, A., 2018. Can pay-for-performance to primary care providers stimulate appropriate use of antibiotics? Health Economics, 27(1), pp. e39-e54.

Hassan, A., Dorsey, E.R., Goetz, C.G., Bloem, B.R., Guttman, M., Tanner, C.M., Mari, Z., Pantelyat, A., Galifianakis, N.B., Bajwa, J.A., Gatto, E.M. and Cubo, E., 2018. Telemedicine use for movement disorders: a global survey. Telemedicine and e-Health, 24(12), pp. 979-92.

Hilty, D.M., Ferrer, D.C., Parish, M.B., Johnston, B., Callahan, E.J. and Yellowlees, P.M., 2013. The effectiveness of telemental health: a 2013 review. Telemedicine and e-Health, 19(6), pp. 444-54.

Jakobsson, N. and Svensson, M., 2016. The effect of copayments on primary care utilization: results from a quasi-experiment. Applied Economics, 48(39), pp. 3752-62.

Jordahl, H., 2013. Välfärdstjänster i privat regi [Social welfare services in private production]. Stockholm, Sweden: SNS Förlag.

Lägermo, A. and Bengnér, M., 2017a. Bedömning av Läkarhuset Tranås/Krys följsamhet till Fakta avseende handläggningen av pneumoni respektive tonsillit vid 'digitala besök' under perioden 160701-170228 [Assessment of Läkarhuset Tranås/Kry’s adherence to 
facts regardign the processing of. . .]. Jönköping, Sweden [Unpublished Memo from Region Jönköping].

Lägermo, A. and Bengnér, M., 2017b. Bedömning av Wetterhälsan/Min Doktors följsamhet till Fakta avseende handläggningen av pneumoni respetive tonsilit vid 'digitala besök' under perioden 160701-170228 [Assessment of Wetterhälsan/Min Doktor adherence to facts regarding the processing. . .]. Jönköping, Sweden [Unpublished Memo from Region Jönköping].

Lägermo, A. and Bengnér, M., 2017c. Uppföljning av Läkarhuset Tranås/Krys följsamhet till Fakta avssende handläggning av tonsollit respektive pneumoni vid digitala vårdmöten under perioden 170601-0831 [Assessment of Läkarhuset Tranås/kry adherence to facts regarding the processing. . .]. Jönköping, Sweden [Unpublished Memo from Region Jönköping].

Lägermo, A. and Bengnér, M., 2017d. Uppföljning av Wetterhälsan/Min Doktors följsamhet till Fakta avseende handläggningen av pneumoni respektive tonsillit vid digitala vårdmöten under perioden 170601-0831] [Assessment of Wetterhälsan/Min Doktor adherence to facts. . .]. Jönköping, Sweden [Unpublished Memo from Region Jönköping].

Ludvigsson, J., 2017. Barnläkare: Ta betalt för barns besök på akuten [Pediatrician: introduce a fee for children's visit to emergency care]. [online] Svenska Dagbladet. Available at: <www.svd.se/barnlakare-ta-betalt-for-barns-besok-pa-akuten> [Accessed 2 Sep. 2019].

Madan, A., 2014. WebGP: the virtual general practice executive summary. [online] Available at: <https:/gpaccess.uk/wordpress/wp-content/uploads/2015/08/e-consult-pilotreport-2014.pdf $>$ [Accessed 2 Sep. 2019].

Mohr, N.M., Young, T., Harland, K.K., Skow, B., Wittrock, A., Bell, A. and Ward, M.M., 2018. Emergency department telemedicine shortens rural time-to-provider and emergency department transfer times. Telemedicine and e-Health, 24(8), pp. 582-93.

OECD, 2017. Health at a glance 2017: OECD indicators. Paris, France: OECD Publishing.

OECD and European Observatory on Health Systems and Policies, 2017. Sweden: country health profile 2017, state of health in the EU. Paris and Brussels: OECD Publishing, European Observatory on Health Systems and Policies.

Ram, A., 2018. The doctor will see you now - on your smartphone. Financial Times. [online] Available at: <www.ft.com/content/6e5f28ae-2948-11e8-9274-2b13fccdc744> [Accessed 2 Sep. 2018].

SALAR, 2018. Patientavgifter vid digitala vårdmöten [Fees for patients in telemedicine]. [online] Sveriges Kommuner och Landsting, 18/00003. Available at: <https:// skl.se/download/18.2819ed29162193bf8f26137e/1521195006266/05-2018-WEBBPatientavgifter-vid-digitala-vardmoten.pdf $>$ [Accessed 2 Sep. 2019].

Saxon, L., 2015. Center for body computing, USC. [online] Available at: <http://uscbody computing.org $>$ [Accessed 12 Aug. 2019].

Schildt, J., Flodin, J., Nilsson, M., Rodhe, A. and Stolt, R., 2017. Företrädare för Kry: "Videobesök spelar viktig roll i framtidens vård" [Representative for Kry: "Videocalls play an important role for the future of health care"]. [online] Dagens Nyheter. Available at: <www.dn.se/debatt/repliker/videobesok-spelar-viktig-roll-i-framtidens-vard> [Accessed 2 Sep. 2019].

Schoenfeld, A.J., Davies, J.M., Marafino, B.J., Dean, M., Dejong, C., Bardach, N.S., Kazi, D.S., Boscardin, W.J., Lin, G.A., Duseja, R., Mei, Y.J., Mehrotra, A. and Dudley, R.A., 2016. Variation in quality of urgent health care provided during commercial virtual visits. JAMA Internal Medicine, 176(5), pp. 635-42.

Svanborg-Sjövall, K., 2013. Kentucky fried children. Stockholm, Sweden: Timbro. 


\section{Mårten Blix and Johanna Jeansson}

Sveriges Riksdag, 2017. Hälso- och sjukvårdslag 2017:30 [Health-and sickness bill]. [online] Ministry of Health and Social Affairs. Available at: <www.riksdagen.se/sv/ dokument-lagar/dokument/svensk-forfattningssamling/halso-och-sjukvardslag_sfs2017-30> [Accessed 2 Sep. 2018].

Swedish Competition Authority, 2014. Etablering och konkurrens bland vårdcentralerOm kvalitetsdriven konkurrens och ekonomiska villkor [Establishment and competition among health care providers - About quality driven competition and economic conditions]. [online] Available at: <http://www.konkurrensverket.se/publikationer/ etablering-och-konkurrens-bland-vardcentraler--om-kvalitetsdriven-konkurrens-ochekonomiska-villkor> [Accessed 2 Sep. 2019].

Swedish Government, 2008. Vårdval i primärvården 2008/09:74 [Choice in primary care]. [online] Regeringen [Swedish government]. Available at: $<w w w . r i k s d a g e n . s e / s v /$ dokument-lagar/dokument/proposition/vardval-i-primarvarden_GW0374> [Accessed 2 Sep. 2018].

Topol, E., 2015. The patient will see you now: the future of medicine is in your hands. New York, NY: Basic Books.

Vårdanalys, 2014. Låt den rätte komma in [Let the right one in]. Stockholm, Sweden: Vårdanalys [Swedish Agency for Health and Care Services Analysis].

Vårdanalys, 2017. Vården ur patienternas perspektiv - 65 år och äldre [Health care from a patient perspective - 65 years and older]. Stockholm, Sweden: Vårdanalys [The Swedish Agency for Health and Care Services Analysis]. 


\title{
3 Welfare services in an era of digital disruption
}

\author{
How digitalization reshapes the \\ health care market
}

\author{
Anthony Larsson, Olivia Elf, Corinna Gross, \\ and Julia Elf
}

\section{Introduction}

\subsection{The digital transformation health care}

As industry after industry experiences digital disruption, the growing demands for digital solutions have in recent years stressed the needs of availability and personalization of services (Ihlström Eriksson, Åkesson and Lund, 2016). The welfare sector is no exception, as many researchers argue that the only way to accommodate the increase of citizens' demands in the coming years is through the utilization, and optimization, of so-called "digital welfare" (Urban, 2017; Cozza et al., 2018). In fact, a 2016 OECD report concluded that digital welfare will continue to expand and prompt new disruptive developments that may well undermine the public sector as we know it in order to make way for new solutions by different actors (OECD, 2016). At the heart of the matter lies the fact that the public sector, by and large, is an unwieldy beast that is slow to adapt and react to innovative solutions. This provides non-governmental actors with an opportunity to advance their positions and seek to claim new market shares in the welfare sector. Beyond the strictly technological challenges of undergoing digital transformation, the public sector also has to deal with various bureaucratic and political complexities, often including several different actors (Hartley, 2005).

Digital transformation is particularly present in the health care service industry, in no small part due to the opportunities provided by the use of mobile devices, which in turn has led to increased levels of disruption from other non-governmental actors (McLoughlin, Garrety and Wilson, 2017; Lapão, 2016). The use of such mobile devices in primary health care provision is commonly referred to as "telemedicine" (WHO, 2011). While it is easy to imagine the commercial possibilities for the new, non-governmental actors looking to promote themselves on the health care scene, it is more difficult to anticipate the long-term consequences that such a disruption would entail for the health care industry as we know it.

That is not to say that only non-governmental actors have an interest in digital transformation. OECD (2016) illustrates a counterpoint by anticipating that the digitalization of the health care sector may actually increase government productivity, 
as the demographic changes continue to bring about increases in health care expenditures. As such, digitalization of the public sector may in fact result in a trillionUS dollar productivity increase worldwide (Dilmegani, Korkmaz and Lundqvist, 2014). This implies high incentives for governments to further accelerate digital transformation in order to fully capitalize on these benefits.

Callon (1998) suggests that disruptive technological advancements can urge a re-evaluation of market frames. Assuming such a re-evaluation, how do the actors react to the market changes, and how do they view their roles within it? Examining the dynamics within this changing field comprising both public and private actors contributes to an improved understanding of how digitalization can affect industry actors' individual roles as well as their interactions.

\subsection{Health care digitalization in Sweden}

The effects of the digital transformation of public health care services have been a particularly pressing topic in Sweden, where the standard of health care has been historically held in high regard by the international community (SvanborgSjövall, 2014). Traditionally, the Swedish health care system has always rested on three tenets (Anell, Glenngård and Merkur, 2012, p. 9):

1 Human dignity - Everyone is entitled the same dignity, irrespective of their status in the community.

2 Need and solidarity - Those in greatest need must have priority for treatment.

3 Cost effectiveness - There must be equity between costs and benefit whenever making a decision.

Pressing upon the third tenet, a 2016 report contends that Swedish health care could save one-quarter of its health care costs, corresponding to some $€ 18 \mathrm{bn}$ (SEK180bn), merely by digitalizing health care service in an efficient manner (Hardy, Boldt-Christmas and Tyreman, 2016). Thus, digital transformation leads to more economical health care. To exemplify, a recent scientific study shows that the total economic cost of a digital medical consultation is roughly $€ 189$ (SEK1960), as opposed to $€ 324$ (SEK3348) for a traditional consultation at a health care clinic (Ekman, 2018).

Nevertheless, in a 2013 report, the OECD cautions that there are lingering governance issues that could threaten the excellence in Sweden's health and social care system if they are left unaddressed (OECD, 2013). Primarily, the report highlights potential difficulties in coordinating care between hospitals, primary care, and local authorities. While a statutory framework is decided nationally through the Ministry of Health and Social Affairs, health care in Sweden is managed (and for the most part funded) locally through income taxation (Anell, Glenngård and Merkur, 2012). As of 2010, every patient has a right to choose between a private and public primary care provider (Svanborg-Sjövall, 2014). In fact, primary care is provided by both public and private health care providers, and people can visit any accredited provider of their choice and be entitled to reimbursement. 
However, to complicate matters, Sweden's political system consists of 21 counties (Swe: län) and 290 municipalities (Swe: kommun). In charge of coordinating all county councils and municipalities is the Swedish Association of Local Authorities and Regions (SALAR), which also works as a communication bridge between the different levels (Anell, Glenngård and Merkur, 2012). In spite of this, the county councils have large degrees of autonomy, it is not uncommon for many of them to belong to a different political majority than the ruling party/parties of the national government, and their interest in implementing different reforms proposed by the national government may reflect party political interplay between the different political levels.

Private providers (constituting over 40 percent of all providers in 2017) receive public funding for their services if accredited by the local county council (Holmström, 2019; Ekonomifakta, 2017). Health care providers compete for registered patients, but since the county councils define fixed price levels for their entire region, they cannot compete on price. Moreover, county councils are responsible for ensuring that all health care providers deliver quality services.

According to WHO, 70 percent of the member states in the European region have worked on strategies that specifically refer to eHealth (Peterson et al., 2016). However, Sweden has been one of the forerunners in health care digitalization, with the official work on eHealth already starting in 2002, when the government published a report to increase the development of eHealth (Olsson and Jarlman, 2004; Wass, 2017). Subsequently, the eHealth strategy has been continuously updated and recently developed into the Vision for eHealth 2025, which states that "in 2025, Sweden will be best in the world at using the opportunities offered by digitalization and eHealth to make it easier for people to achieve good and equal health and welfare" (Government Offices of Sweden and SALAR, 2016, p. 9). As Wass (2017) explains, the implementation and coordination of Sweden's eHealth strategies have been managed by different governmental organizations throughout the years. This development is illustrated in Figure 3.1.

\begin{tabular}{|c|c|c|}
\hline $2000-2008$ & 2009-2013 & 2014-Today \\
\hline $\begin{array}{c}\text { Carelink: } \\
\text { The first official and } \\
\text { national organization for } \\
\text { eHealth was established by } \\
\text { the county council of } \\
\text { Sweden, SALAR, and the } \\
\text { Swedish Pharmacy and the } \\
\text { Association of Private } \\
\text { Care Providers. }\end{array}$ & $\begin{array}{c}\text { CeHis: } \\
\text { The Center for eHealth - } \\
\text { managed the development } \\
\text { and coordination of } \\
\text { eHealth. }\end{array}$ & $\begin{array}{c}\text { Inera: } \\
\text { Took over responsibilities } \\
\text { from CeHis. } \\
\text { The eHealth Agency: } \\
\text { Established with the aim of } \\
\text { driving the development of } \\
\text { eHealth in Sweden, } \\
\text { develop health care- } \\
\text { supporting infrastructures, } \\
\text { and providing eHealth } \\
\text { services. }\end{array}$ \\
\hline
\end{tabular}

Figure 3.1 Governmental organizations responsible for Sweden's eHealth strategies 
The accelerating rise of eHealth is enabling the entry of new players in the health care provider market, which is particularly noticeable in the telemedicine environment. To this end, mobile health, or "mHealth," has become increasingly present. As such, mHealth is a term used for the practice of medicine and public health supported by mobile devices (WHO, 2011). Globally, the number of health apps on iOS and Android has more than doubled in only 2.5 years, and the mHealth market worth USD 23 billion in 2017 is estimated to grow at a Compound Annual Growth Rate of more than 35 percent through 2019 (Cision, 2016; Deloitte, 2015). In Sweden's primary health care market, several telemedicine actors have in recent years made their entry onto the scene, including contemporary market leaders such as Kry and Min Doktor (Business Sweden, 2018).

As such, Sweden is a compelling case to study, partly due to its government relinquishing its public services monopoly of health care (Ranerup, Henriksen and Hedman, 2016; Ålander and Scandurra, 2015), and partly because Sweden lies at the forefront of digital health care innovation (Frid, Alsen and Robertson, 2017).

\subsection{Innovation in welfare services}

Although innovation in public services has increased in recent years, innovative capabilities in this space are typically incremental (Jalonen and Juntunen, 2011). Subsequently, there has been a dearth of disruptive innovations in health care services, a sector that has traditionally been governed by public services (Schulman, Vidal and Ackerly, 2009). This can be explained by the complexity of the environment in which public service organizations operate (Osborne et al., 2014; Antonsen and Jorgensen, 1997). Unlike private actors, public organizations are heavily embedded in society and subsequently evince differing drivers of innovation (Hartley, 2005). While commercial innovations are predominantly driven by competitive advantage, the public sector primarily acts on the motivation to increase public value (Moore, 1995; Hartley, 2005). Therefore, the evaluation of public-sector innovation tends to involve parameters of its usefulness to society and some notion of justice and fairness, in addition to the traditional criteria of efficiency and effectiveness (Bloch and Bugge, 2013; Bommert, 2010).

This embeddedness of welfare services affects the risk factors inherent in innovation practices (Albury, 2005). Not only are public-sector innovations exposed to higher levels of public scrutiny before they can be fully developed, the general risks to individual and community quality are also more substantial than for the private sector. Hence, it is important to stress that digital transformation of health care (and welfare services in general) be accompanied by complex challenges for policy and decision-makers (OECD, 2016). While the literature on public-sector innovation has to date mainly focused on the challenges hindering actors in going beyond incremental innovations, current disruptive digital developments raise several topics that have yet to receive any wider empirical attention. Thus, there exists little knowledge about the public sector's reaction to the entry of digital 
private companies in welfare, while, simultaneously, the increasingly blurring market boundaries call for insight in this space.

The social embeddedness of the welfare sector constitutes significant challenges for governments that are difficult to tackle unilaterally (Van Ham and Koppenjan, 2001). Dealing with this complexity, collaborations between the public and private sector have gained esteem as being an effective, legitimate mode of governance in recent years (Sørensen and Torfing, 2011) and showed increasing popularity in the health care sector (Jalonen and Juntunen, 2011). Still, such collaborations may give rise to complex controversies due to sometimes-conflicting values and rationales.

\subsection{Public-private collaboration in public-sector innovation}

In parallel to the increasing implementation of public-private collaborations (PPCs), a growing body of literature examining the phenomenon has developed. Schaeffer and Loveridge (2002) outline four forms of PPC, which is generally defined as the coordination of decisions between public and private actors.

As Figure 3.2 illustrates, in situations in which this coordination does not involve joint decision-making, the parties are involved either in a follower-leader or buyer-seller relationship. While the former is characterized by unequal power and/or resource conditions and well-defined problems, the exchange relationship between seller and buyer is open ended. Provided that the parties engage in joint decision-making and their efforts are dedicated toward a specific purpose over a

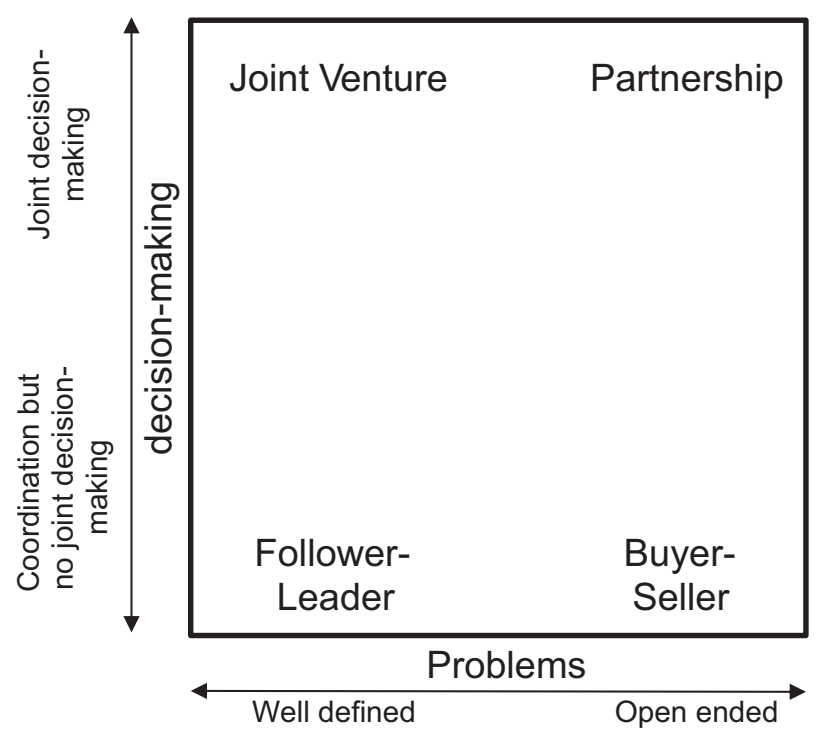

Figure 3.2 Forms of public-private collaboration

Source: Schaeffer and Loveridge, 2002, p. 182. 
limited time span, their collaboration is defined as a joint venture. That is, partnerships differentiate themselves from joint ventures by constituting an open ended agreement to work together (Schaeffer and Loveridge, 2002). This definition is congruent with Koppenjan (2005), who denotes public-private partnership as a durable PPC in which mutual products and/or services are developed and risk, costs, and benefits are shared.

By leveraging the resources, expertise, and ideas of both parties, PPCs represent a powerful tool for addressing the complex problems of the welfare environment and have the potential to result in increased innovation (Reich, 2002). However, it should be noted that PPCs generate intricate organizational interlacings, which may inhibit the realization of potential benefits (Jalonen and Juntunen, 2011). Since the parties do not share a common ownership structure, they tend to pursue different operating and strategic goals (Torchia, Calabrò and Morner, 2015). There are, of course, various reasons cooperation does not exist or does not turn out successfully. These include a lack of understanding and/or patience for the decision-making process in the public sector by private sector members, incompatible interests, and the existence of laws that prohibit cooperation (Schaeffer and Loveridge, 2002). Besides, actors exhibit differences in planning horizons, which further complicates successful collaboration (Van Ham and Koppenjan, 2001).

To understand the potential of PPC in the formation of the telemedicine market, it is therefore crucial to develop today's deficient understanding of which values and objectives the market parties act upon and how they perceive their own as well as the other's position.

\subsection{Synthesis and literature gap}

The rise of telemedicine is enabling new players to enter the primary health care market. While this is expected to be discernable in numerous national health care markets in the future, the phenomenon is already evident in Sweden, a leading market in health care digitalization and innovation. By selectively applying the research of various disciplines, the background and literature review examine previous contributions to provide a foundation for further empirical investigation.

Although there is extant fundamental research on public service innovation, there is a lack of knowledge about the disruption of welfare markets and the related entry by commercial players. The increasingly confounding market boundaries caused by technological developments in health care and other welfare services necessitate insights on how traditional providers perceive and react to the subversion of their historically stable, well-defined markets.

Moreover, public-private collaborations have been perceived as auspicious paths for welfare services. Yet, to entirely grasp the potential for collaborative actions in the shaping of the telemedicine market, it is crucial to understand both parties' interests and how they perceive each other's positions. Today's literature lacks insights on these aspects and is thus missing essential knowledge about building an understanding of the development of the market dynamics. While 
collaborative activities are considered powerful mechanisms in the shaping of the welfare sector, it is ambiguous whether the public and private actors perceive collaboration with one another in this way or if they indeed regard themselves as competitors or as merely "irrelevant" to one another.

In conclusion, existing research provides valuable starting points for understanding innovation in the welfare sector as well as incentives and challenges for collaborative efforts between public and private actors. However, extant research fails to fill the knowledge gap of how today's disruptive digital advancements reshape the health care industry and its market dynamics.

\subsection{Research questions}

To fill the outlined research gap, this study has formulated following research questions:

1 How do public-sector actors react to the emerging use of digital technology in the health care sector? Specifically, how do they perceive their role in a changing market?

2 How do public and digital private actors view potential collaborative efforts in the health care industry?

While the second research question applies to public and private actors, the first research question focuses solely on the reaction of the public sector. The underlying reasoning is that, together with traditional, long-established private players, the public sector is experiencing the market change, while digital private players embody the source of change rather than being subject to it.

\section{Theoretical discussion}

\subsection{Exploring market (re-)shaping from a socio-technological stance}

A notion heralded by Callon (1990) and Latour (1984) is that market actors are embedded in their social network, which in turn connects to the markets-aspractice theory on the formation of markets. As illustrated before, this is of particular significance for actors in the welfare sector, as this perspective describes markets as socio-technical arrangements made up of various human and nonhuman actor-networks that are linked through continuous translation processes.

Latour (1987) contends that it is important to explore situations in which science is still nascent rather than solely studying ready-made science. That is to say, it is not only relevant to look at how technologies enable new connections between people and organizations as passive intermediaries, but also at the ways in which they themselves might constitute new actors that actively alter the roles and identities within socio-technical arrangements. Thus, markets inevitably become sites of conflicting practices and interests that stimulate market actors 
to engage in strategic actions to shape the market to their advantage (Kjellberg and Helgesson, 2006; Santos and Eisenhardt, 2009). As Latour (2005) points out, to understand the shaping of a market, three crucial steps are involved. The first concerns how to deploy controversies so as to gauge the number of new participants in any future assemblage. The second step concerns the ability to follow how the actors themselves stabilize uncertainties by building formats, standards, and metrologies. The third and final step concerns how the assemblages gathered so far can renew the sense of still being part of the same collective. Opportunities to actively shape the emerging market are especially present in controversial and ambiguous environments, and these are sometimes characterized as "hot situations" (Rip, 2010; Callon, 1998).

\subsection{Ambiguity heating up the market environment}

Callon (1998) claims that interactions between different actors in the economy require frames that specify the context in which a particular set of relationships is ordered and made to make sense. However, those frames are regularly and inevitably disrupted by "overflows," which are tantamount to the economic parlance of "externalities." That is to say, an overflow or "externality" in this context refers to negative (or positive) outcomes that are not considered when agents calculate their courses of action and the associated outcomes (Tarim, 2013).

In today's fast-paced environment, technological advancements frequently put existing frames into question and call for fundamental re-evaluations (Kastberg, 2014; Overdevest, 2011). Callon (1998) distinguishes between "hot" and "cold" situations that emerge in scientific and technological development. That is, each constitutes the extreme end of a continuum on which any market situation can be placed (Donaldson et al., 2013). A "cold" situation is characterized by clearly identifiable actors, interests, preferences, and responsibilities and is easily framed and resolved. In contrast, "hot" situations exhibit a high degree of uncertainty, making the entire process controversial. Consequently, consensus and agreements become difficult, and framing becomes a chaotic process in which various actors compete to realize their respective descriptions of future world states by investing in metrological devices (Callon, 1998).

As illustrated in Figure 3.3, it can be argued that digitalization in the health care market triggers a movement toward the right on this cold-hot continuum. There are three reasons to exhibit such a movement. First, the topic is long and frequently debated in academia, as well as in various public outlets (Patel and Rushefsky, 2002). Second, the influx of new actors on the scene inevitably prompts questions about who might be considered part of the market and who might not (Gaynor, Mostashari and Ginsburg, 2017). Third and last, there is much ambiguity regarding the perceived roles, values, and objectives of the different parties (Castro-Sánchez et al., 2014; Panari et al., 2016). By studying the perceptions and attitudes of market actors, this chapter endeavors to elucidate the blurred market frames. As Kjellberg and Helgesson (2006) suggest, understanding ideas about a developing market allows for creating 


\section{The Past}

- Known actors and objectives

- Established practices are taken for granted

- Incremental innovations, easily framed

\section{The Present}

- New, unknown actors enter the market

- High levels of ambiguity about perceptions, roles, and objectives

- Highly controversial public debates

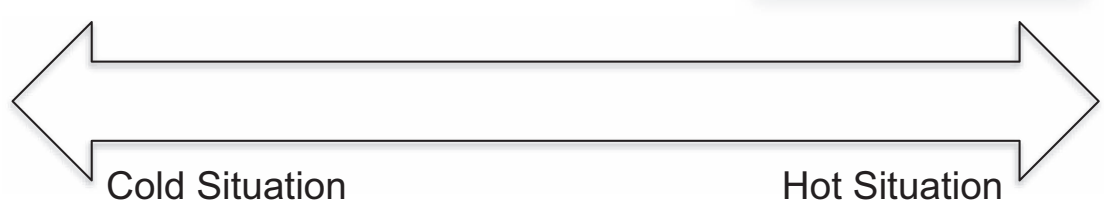

Figure 3.3 Market movement on the cold-hot continuum

Source: Authors' own depiction.

links to the conceptualization of market practice and is therefore congruent with understanding the world that is continuously being accomplished. This concept of performativity thus captures how the world of ideas and perceptions participates in shaping the market and becomes part of a circular causal relation over time.

\section{Methodology}

Attempting to investigate a nascent research field, this qualitative study employs an interpretative and inductive approach. Sweden was selected as a case for examining health care digitalization, as it is advanced in its use of digital technologies, thus providing an antecedent for other countries (Carter, 2015; Hardy, BoldtChristmas and Tyreman, 2016; OECD, 2018). The study used semi-structured interviews with actors involved in the digital transformation of health care, who were in turn selected by means of purposive sampling based on their competence and insight into the subject matter (Denscombe, 2017; Oliver, 2006). The included respondents were initially contacted by email or telephone, after which they were accepted to participate in the study.

Prior to the interview, the respondents were provided with information about the purpose of the study, the researchers, the interview outline, and 


\section{Anthony Larsson et al.}

other various practical details regarding the study. The respondents subsequently provided their informed consent to participating in this study. A semistructured interview guide was drawn up for the purposes of conducting the interviews.

The interviews were conducted between April 2018 and May 2018, with each interview ranging between approximately 30 and 60 minutes. The mode of interview was selected upon the interviewee's preference, resulting in some of the interviews being conducted face-to-face, while others were conducted via IP telephony (Skype) or regular telephone.

Table 3.1 illustrates the complete list of respondents used in this study.

Similar to the data collection method, the data interpretation also followed an iterative approach. This means that although the study's premise departed from certain theoretical discussions, as mentioned earlier in this chapter, the discerned themes yielded by the data analysis were successively uncovered rather than making use of predetermined themes based on pre-existing theoretical concepts. This ensured that the study could take part in new conceptual understandings that were grounded in empirical data (Welch et al., 2011).

Table 3.1 Overview of interview respondents

\begin{tabular}{|c|c|c|c|c|c|c|}
\hline Code & Company & Description & Position & Background & Duration & Type \\
\hline TEL1 & Min Doktor & $\begin{array}{l}\text { Private } \\
\text { telemedicine } \\
\text { company }\end{array}$ & $\begin{array}{r}\text { Managing } \\
\text { director } \\
\text { Nordics }\end{array}$ & Business & $45 \mathrm{~min}$ & Skype \\
\hline TEL2 & Kry & $\begin{array}{l}\text { Private } \\
\text { telemedicine } \\
\text { company }\end{array}$ & Co-founder & Business & $50 \mathrm{~min}$ & Phone \\
\hline ORG1 & ALMEGA & $\begin{array}{c}\text { Private industry } \\
\text { organization }\end{array}$ & $\begin{array}{l}\text { Political } \\
\text { advisor }\end{array}$ & Politics & $50 \mathrm{~min}$ & $\begin{array}{l}\text { Face-to- } \\
\text { face }\end{array}$ \\
\hline ORG2 & $\begin{array}{l}\text { Swedish } \\
\text { Medtech }\end{array}$ & $\begin{array}{c}\text { Private industry } \\
\text { organization }\end{array}$ & $\begin{array}{l}\text { Project } \\
\text { manager } \\
\text { innovation } \\
\text { and growth }\end{array}$ & $\begin{array}{l}\text { Medical } \\
\text { devices and } \\
\text { technology }\end{array}$ & $50 \mathrm{~min}$ & $\begin{array}{l}\text { Face-to- } \\
\text { face }\end{array}$ \\
\hline PUB1 & $\begin{array}{l}\text { Swedish } \\
\text { eHealth } \\
\text { Agency }\end{array}$ & $\begin{array}{l}\text { Governmental } \\
\text { agency }\end{array}$ & Strategist & Linguist & $30 \mathrm{~min}$ & $\begin{array}{l}\text { Face-to- } \\
\text { face }\end{array}$ \\
\hline PUB2 & $\begin{array}{l}\text { Swedish } \\
\text { eHealth } \\
\text { Agency }\end{array}$ & $\begin{array}{l}\text { Governmental } \\
\text { agency }\end{array}$ & $\begin{array}{l}\text { Head of } \\
\text { strategy and } \\
\text { coordination }\end{array}$ & $\begin{array}{l}\text { Medical } \\
\text { science and } \\
\text { informatics }\end{array}$ & $30 \mathrm{~min}$ & $\begin{array}{l}\text { Face-to- } \\
\text { face }\end{array}$ \\
\hline PUB3 & SALAR & $\begin{array}{l}\text { Governmental } \\
\text { association }\end{array}$ & $\begin{array}{l}\text { Coordinator } \\
\text { and strategist } \\
\text { eHealth }\end{array}$ & $\begin{array}{l}\text { Nurse/ } \\
\text { business }\end{array}$ & $45 \mathrm{~min}$ & Skype \\
\hline PUB4 & SALAR & $\begin{array}{l}\text { Governmental } \\
\text { association }\end{array}$ & $\begin{array}{l}\text { Project leader } \\
\text { welfare } \\
\text { technical } \\
\text { solutions }\end{array}$ & Nurse & $60 \mathrm{~min}$ & Skype \\
\hline
\end{tabular}




\section{Empirical discussion}

\subsection{Re-evaluation of the market frame}

The first research question aimed to investigate how public-sector actors react to the emerging use of digital technology in health care and how they anticipate potential change to their respective roles. In this section, we analyze the respondents' view of the current situation with Callon's (1998) notion of framing and overflows as a starting point. The responses yielded from the interviews suggest that the market is currently subject to a re-evaluation of its existing frames - what Callon describes as a "hot situation." Describing the emergence of telemedicine, TEL1 stated:

It is moving at a super high pace. Doctors, politicians, and decision-makers are not in control of things which they are not too happy about. With politicians you see that, while they had an extremely negative stance towards digital care just a year ago, now they are already working on legislations for digital services, which is really interesting and fun to observe.

The uncertainty about the market frames was further described by ORG1:

The new business model is challenging and changing the system. It has to adapt to the new situation, but there are so many discussions and questions regarding the digital doctors. Should they be allowed? What should they cost? Should we keep them away instead of integrating them?

This re-evaluation also implies that new actors previously not included within the market frame enter and challenge the hitherto stabilized conditions and knowledge base. PUB2 mentioned the importance of patients knowing which of the telemedicine apps will be part of the welfare system. This can be interpreted as an attempt to determine the number of new market participants - Latour's (2005) first step of market shaping. Another example of the increasingly vague barrier between the market and the outside world was expressed by PUB4:

Different perspectives are a good thing because we currently have this stereotype working within health care. We are stuck within our roles and all of a sudden, we can see that, for instance, a logistician is the one telling us the best way to transport staff to people in their homes. By adding digitalization, we also add knowledge of another workforce and are increasingly letting them take part of the control and the development to help us think in other ways.

The perceived roles of both traditional and private digital actors appear to be affected by the emergence of telemedicine. All respondents described telemedicine companies as challenging the public sector to innovate or adapt to the change. 
Expressions varied from "put pressure on" (TEL1) to "breaking through barriers and forcing county councils to follow" (ORG2). PUB2 viewed their role as twofold by being responsible for enabling efficient use of telemedicine and encouraging standards on the one hand, but, on the other hand, being responsible so that the health care industry does not become "technology driven." PUB2 added:

The question is whether the regulatory framework is supposed to follow in the same pace. Making a new law is a slow process. But that is for a purpose because the law is supposed to be long-term and stable and be able to regulate a market that needs to be regulated. The first question we ask ourselves is therefore: should we change the regulations? Is it helping or is it just making the health care technology driven? Is it supposed to be handled from the tech side or the health care side? We aim to focus on the health care side, so there is [sic] a lot of regulations and laws which are slow-paced for a reason but that is not easy to explain to the other actors.

PUB3 expressed a similar opinion, stating that: "[telemedicine] is going to transform the entire health care system, but it will take a while. Sometimes, that is not too bad, though - we must make sure that we have good quality."

However, the potential to adapt to changes is regarded differently by telemedicine actors, as in the following statement by TEL1:

What is significant for tech and telemedicine companies is that we can move pretty fast. If someone tries to shut one door, we will find some other way to do what we want to. We are set on the goal to make health care better and we are going to execute on that one way or another.

This statement further can be interpreted as pronouncement of investments shaping the market frame to their advantage.

\subsection{The desire for suitable metrological devices}

The data interpretation showed that the hot situation involves actors' desire for clarity in quantifying and comparing outputs within the evolving market frame. Public-sector respondents pointed toward an absence of 1) a regulatory framework that is adapted to the new situation and 2) measuring instruments and standards to ensure the quality of telemedicine services. In effect, this is analogous to Latour's (2005) second step of market shaping and to what Callon (1998) calls "metrological devices." Similarly, private respondents argued that without such institutional frameworks, they are unable to attain legitimacy in the market. ORG2 and TEL2 both emphasized that telemedicine actors are subject to a more severe scrutiny process than traditional actors. To this end, TEL2 stated:

We are helping SALAR to look into developing some sort of quality indicator for digital care. This would create standards for evaluating digital health care, 
but then there need to be compatible evaluation standards for physical health care. Often, when there is criticism about a digital health care provider, it is not compared to anything else but obviously there are errors made in normal health care as well.

The respondents had different views on how telemedicine actors could gain legitimacy, but independent clinical reports (mentioned by TEL2, ORG1, ORG2) and communication with the different actors in forums such as conferences (mentioned by TEL2, ORG1) are two means discussed. Such efforts to increase the understanding between actors and build a common ground can be considered a way to stabilize uncertainties in market formation and thus further illustrate Latour's (2005) second step.

ORG2 explained that there has been a recent evaluation by a regional health assessment center, which concluded that there is not enough evidence to prove the quality of telemedicine:

Usually when this happens, they tend to not use [the innovation] instead of making more studies. So it is really difficult when you are being evaluated too soon and not allowed the time to retrieve the data to prove the positive health care effects of your service. Thus, I think it is really important for these companies to work with researchers, academia, and the health care profession to actually make a solid research base for their products. The legitimacy has to come from the health care side and ... clinical studies will thus be essential.

\subsection{The blurring national borders of health care}

When encouraged to describe their role in the market, the respondents considered not only the Swedish health care market, but also reasoned beyond national borders. For instance, telemedicine respondents repeatedly discussed the enablers and challenges to scaling up internationally. TEL2 expressed the potential to optimize internationally in many ways because digitalization is not something local or regional - it is something national or international. Similarly, TEL1 described how digitalization allows for scalability to an unprecedented extent, which will encourage telemedicine companies to seek international opportunities. In terms of the theoretical discussion of this chapter, this may lead to an increasingly complex re-evaluation of the market frames due to the additional international actors and interests that then must be considered.

The public-sector respondents also believed that digitalization would challenge the national borders of primary health care. However, rather than scalability, the arguments centered chiefly on the benefits from a patient perspective, as well as various quality concerns. This perception is illustrated by the following quotations:

As a patient, I want to be where the knowledge is. And if there is someone in the world who is much better at providing a certain service, I want to be there. With digitalization this is possible. 
What I see as very interesting with digital solutions is that soon, there will not only be Swedish telemedicine companies on the Swedish market but also international companies that want to offer services to patients in Sweden. How will we then make sure that they give good quality?

Last, all actors expressed concerns that there may exist a conflict of interest between driving innovation in health care on the one hand and maintaining a conducive business environment on the other. This was exemplified by PUB1 stating:

We have the Vision for eHealth 2025, which aims to provide better and more equal health. Then we have the strategy for digitalization driven by the Ministry of Enterprise and Innovation, which aims for a driving market which enables you to sell your business in a Swedish context. So one part of the government wants to ensure that app developers within the EU are able to sell them here, but the health care strategy says that you should only be able to sell them if they provide better health. So, from a very high policy level, I think there are sometimes different goals.

\subsection{Insights on collaborative activities between the parties}

The aim of the second research question was to understand how public and private actors view potential collaborative efforts in the health care industry. To do so, data were collected on the perceptions of and expectations about the development of market dynamics (Section 4.4.1) and actors' views about underlying values and objectives of the market players (4.4.2), as well as obstacles to collaborative activities (4.4.3).

\subsubsection{The changing market dynamics}

The collected empirical data indicate that there are discernibly different perceptions about the current and future state of market dynamics between public actors and telemedicine companies. While all respondents generally agreed that there are and will be collaborations in the digitalized health care provision market, perceptions about the extent, forms, and use of collaborative activities diverged.

Telemedicine companies conveyed a competitive stance and regarded themselves as direct competitors to traditional health care providers. TEL2 explained that entering close partnerships with the public was considered in the early stages of their existence. Yet, they quickly distanced themselves from it due to different value sets and objectives (elaborated upon further in Section 4.4.2) and opted for the competitive route instead. Challenging the traditional method of health care provision, telemedicine companies viewed themselves as helping the welfare state improve its services, an attitude also supported by the public-sector representatives:

We are pushing the public sector to step up and take things to the next level. 
Because of the competition that the private sector gives the public sector, the public sector is getting better. The challenge that, for instance, Kry or Min Doktor are giving the public sector is a good challenge.

Nevertheless, it was expressed recurrently that not everyone in the public sector shared this level of appreciation. As ORG1 pointed out, small public clinics in particular were dismayed at losing money to digital actors.

While competitive, the telemedicine companies recognized that there did exist dynamisms that provided incentives to proceed with collaborative endeavors with the public. TEL2 explained that they previously collaborated with city councils to test their products in pilot studies, as well as a means of influencing the structure of the reimbursement system. Furthermore, they saw collaboration as another potential way to gain legitimacy. Hence, it is possible to surmise that the collaborative activities constitute strategic actions of telemedicine players to become part of the re-evaluated market frame.

The interviews with public-sector representatives indicated that all of them acknowledged the value of being challenged and driven by new entrants. Only PUB3 perceived the new players as an actively emerging threat to the traditional welfare system by recognizing that:

As public service providers, we should know that we are compared to the best service ... and if we do not take that in and learn from it, we will lose all the patients.

The other interviewees drew upon the fact that many public actors do not see their traditional health care provision as threatened by digital actors.

I cannot recall that I have seen any competition between the new and the old.

(PUB2)

It feels like you are perceiving it as if there was competition, but I do not see that. I mean, of course this is a hard time for the county councils, but that has more to do with the fact that the reimbursement system and other systems are not adjusted to digital solutions.

(PUB3)

The presence of these differing attitudes, even within the same organization, further demonstrates the ongoing re-evaluation of the market frame and the differing perceptions about future market states.

\subsubsection{Values governing behavior in the (Swedish) health care sector}

The importance and controversy surrounding whether the market actors act upon the same values and objectives was illustrated by PUB2, as they claimed that it was essentially their most pressing issue at the given time. 
Overall, the vast majority of respondents agreed that the overarching mission for all health care providers was the same, to provide safe and high-quality health care. However, some discernable differences remained. Specifically, three distinct values of private telemedicine companies were postulated:

\section{Strong user focus}

Mentioned by five respondents as separating digital health care providers from traditional health care providers.

\section{Accessibility}

In interactions with a county council, TEL2 found that they, contrary to digital providers, did not see accessibility as a real problem, but only as a perceived problem by the consumer.

\section{Flexibility}

As expressed by TEL2, this did not coincide with the rest of the health care system because less emphasis was put on prioritizing those patients with the greatest need.

An aspect emphasized by telemedicine actors and private industry organizations was that telemedicine companies felt widely misunderstood. This is typical in a "hot situation" where the actors can no longer take into account all actors' viewpoints within the existing frame. The following quotation by TEL1 provides an illustrative example.

I think that they [the public sector] do not feel like we share the same values. I get the feeling that they think we are capital hungry and greedy VC [venture capital]-funded parasites that want to earn as much money as we can in the shortest time possible. But they totally got this wrong. . . . Sometimes it feels like everyone is afraid that the technology companies want to replace doctors by computers but that is not really our intention. We want to build software that can make doctors much more efficient and health care safer.

However, the telemedicine respondents asserted that the public sector is slowly starting to show more understanding, as illustrated by PUB1:

The traditional answer would be "yes, the private sector is just there to make money." But having met a lot of these startups from the tech side, I know that they are always driven by something else. Personally, I am quite impressed by them because, of course, they have seen a business model somewhere, but they also seem to be driven by other things than money.

Besides the differences in values and strategic objectives, the information from the respondents suggested there were numerous other uncertainties and obstacles impeding collaborative activities between traditional and telemedicine actors. This in turn further illustrates the ongoing re-evaluation of the market frame. 


\subsubsection{Obstacles to collaborative activities}

Generally, obstacles to public-private collaboration were more explicitly stated by the telemedicine actors. By the same token, the public side was also aware that certain challenges had to be overcome. Recurrent obstacles, as expressed by the respondents, can be categorized into six different themes. These are illustrated in Table 3.2.

Table 3.2 Obstacles to collaboration

\begin{tabular}{|c|c|c|c|}
\hline Obstacle & $\begin{array}{l}\text { Mentioned } \\
\text { by }\end{array}$ & Explanation & Exemplary quotations \\
\hline Miscommunication & $\begin{array}{l}\text { TEL1, } \\
\text { ORG2 }\end{array}$ & $\begin{array}{l}\text { Parties feel } \\
\text { misunderstood. } \\
\text { Moreover, } \\
\text { contradictory } \\
\text { assertions are } \\
\text { communicated. }\end{array}$ & $\begin{array}{l}\text { "A very typical view is that the } \\
\text { public sector would say, there } \\
\text { is a tech push in that they are } \\
\text { asked to use tools and services } \\
\text { that are not adapted towards } \\
\text { their needs, that the tech } \\
\text { players need to know their } \\
\text { needs before they develop.... } \\
\text { Then the entrepreneurs say, } \\
\text { why do you not just tell us } \\
\text { your needs; can we please } \\
\text { come and see them? But then } \\
\text { some public parties will not } \\
\text { share their needs with them } \\
\text { after all." (ORG2) }\end{array}$ \\
\hline $\begin{array}{l}\text { Late involvement } \\
\text { of public } \\
\text { actors by tech } \\
\text { companies }\end{array}$ & $\begin{array}{l}\text { TEL1, } \\
\text { PUB3 }\end{array}$ & $\begin{array}{l}\text { The late involvement } \\
\text { of the public side } \\
\text { in the development } \\
\text { process nurtures } \\
\text { their skepticism } \\
\text { about the } \\
\text { services of digital } \\
\text { caregivers. }\end{array}$ & $\begin{array}{l}\text { "One lesson that we have } \\
\text { learned is that it would have } \\
\text { been beneficial to start the } \\
\text { interaction with the other } \\
\text { stakeholders at the same } \\
\text { time to make them part of } \\
\text { the things that we are doing } \\
\text { from the beginning and thus } \\
\text { have a smoother start so they } \\
\text { would be more confident } \\
\text { and comfortable about the } \\
\text { development." (TEL1) }\end{array}$ \\
\hline Lack of forums & $\begin{array}{l}\text { ORG1, } \\
\text { ORG2, } \\
\text { PUB2 }\end{array}$ & $\begin{array}{l}\text { Interactive forums } \\
\text { between digital } \\
\text { and traditional } \\
\text { caregivers } \\
\text { are missing. } \\
\text { Uncertainty } \\
\text { prevails about who } \\
\text { is responsible for } \\
\text { setting them up. }\end{array}$ & $\begin{array}{l}\text { "There is a lack of dialogues } \\
\text { and forums between the } \\
\text { new entrepreneurs and the } \\
\text { councils. SALAR has a } \\
\text { major role in making this } \\
\text { dialogue happen." (ORG1) }\end{array}$ \\
\hline
\end{tabular}


Table 3.2 (Continued)

\begin{tabular}{|c|c|c|c|}
\hline Obstacle & $\begin{array}{l}\text { Mentioned } \\
\text { by }\end{array}$ & Explanation & Exemplary quotations \\
\hline Different timelines & $\begin{array}{l}\text { TEL1, } \\
\text { ORG2, } \\
\text { PUB4 }\end{array}$ & $\begin{array}{l}\text { Digital caregivers are } \\
\text { required to work } \\
\text { on dual timelines } \\
\text { when interacting } \\
\text { with the public: (1) } \\
\text { fast, innovative, and } \\
\text { agile and (2) long- } \\
\text { term and strategic. }\end{array}$ & $\begin{array}{l}\text { "The implementation process } \\
\text { is so slow that you will } \\
\text { have multiple versions of } \\
\text { your product before its } \\
\text { implemented." (ORG2) }\end{array}$ \\
\hline $\begin{array}{l}\text { Structure of } \\
\text { Swedish health } \\
\text { care system }\end{array}$ & $\begin{array}{l}\text { TEL1, } \\
\text { TEL2, } \\
\text { ORG1, } \\
\text { PUB2 }\end{array}$ & $\begin{array}{l}\text { The fragmented } \\
\text { structure of the } \\
\text { health care system } \\
\text { complicates } \\
\text { communication } \\
\text { among parties } \\
\text { as well as the } \\
\text { procurement and } \\
\text { scaling of services. }\end{array}$ & $\begin{array}{l}\text { "Sweden does not operate in a } \\
\text { national health care system, } \\
\text { which makes scaling up } \\
\text { super difficult." (PUB2) } \\
\text { "It is very hard for a national } \\
\text { agency ... we are quite a } \\
\text { long step away from the } \\
\text { actual vendors, because we } \\
\text { are speaking to someone } \\
\text { representing the vendors and } \\
\text { not the vendors themselves." } \\
\text { (PUB2) }\end{array}$ \\
\hline $\begin{array}{l}\text { Protectionism of } \\
\text { public side }\end{array}$ & $\begin{array}{l}\text { ORG1, } \\
\text { PUB1, } \\
\text { PUB4 }\end{array}$ & $\begin{array}{l}\text { Threatened by the } \\
\text { new development, } \\
\text { some actors on the } \\
\text { public side become } \\
\text { protective and } \\
\text { express a "do-it- } \\
\text { yourself" attitude } \\
\text { by developing } \\
\text { their own solutions } \\
\text { rather than } \\
\text { collaborating. }\end{array}$ & $\begin{array}{l}\text { "The public side is often } \\
\text { reluctant to move forward in } \\
\text { integrating external digital } \\
\text { services. They are protective } \\
\text { and start their own solutions } \\
\text { instead." (ORG1) } \\
\text { "I know a lot of public } \\
\text { providers think the digital } \\
\text { caregivers are a bad thing ... } \\
\text { because they are not used } \\
\text { to them and they are doing } \\
\text { things differently." (PUB4) }\end{array}$ \\
\hline
\end{tabular}

\section{Analytical discussion}

\subsection{Discussion of main findings}

\subsubsection{RQ1}

Going back to Section 1.6 of this chapter, the first research question aimed to investigate how public actors react to the emerging use of digital technology in the health care sector (i.e., telemedicine) and how they perceive their role in the market that is about to change. The Swedish eHealth Agency has set an ambitious goal by formulating a vision for eHealth 2025. However, as Schulman, Vidal and Ackerly (2009) suggest, disruptive innovation is less likely to occur within 
health care, and the responses from the respondents used in this study suggest that the decentralized structure of the Swedish health care system further hinders a successful implementation of innovative digital solutions. The public-sector respondents acknowledged these obstacles by agreeing that private telemedicine companies challenge the entire sector to innovate and are thus essential for successful health care digitalization. For that reason, it is surmised that the public sector holds an overall positive attitude toward telemedicine companies entering the market. Still, the public-sector respondents did express some apprehension toward health care becoming solely technology driven rather than being propelled by other virtues and values. Following Albury's (2005) notion, the data analysis showed that this apprehension may affect the adoption of innovative efforts. As Albury (2005) illustrates, as innovations financed by public sector are exposed to more rigorous degrees of public scrutiny, there is added forethought to swiftly include innovations as part of the welfare system, a point raised by both publicand private-sector respondents. Moreover, the public sector acknowledges that market accommodations will have to be made in order to fit internationally dispersed primary health care providers.

Concerning the actors' perceived role in the changing market, public-sector respondents seemingly considered themselves less able to drive digital change or to shape market conditions compared to telemedicine companies. In other words, the public-sector respondents assume a reactive rather than a proactive stance, which follows a public-sector tradition of incremental introduction of innovations (Jalonen and Juntunen, 2011). They do consider themselves in power in relation to maintaining the old market frame by, for instance, changing the reimbursement system and hence shutting out telemedicine providers, but lack the control to form the new, re-evaluated frame. To gain and maintain the control of this re-evaluation and shape the market to their advantage, the telemedicine company respondents seek to 1) find metrological devices that can legitimize their actions and 2) convince the consumer of their worth.

\subsubsection{RQ2}

The second research question aimed to assess how traditional and telemedicine actors viewed potential collaborative efforts in the health care industry. Essentially, the study indicates that all parties consider each other as acting within the same, and not distinct, market frames in the future. This would require the current frame to be re-evaluated accordingly (by, for instance, adjusting the regulatory frameworks). Consequently, the potential paths for the development of the market dynamics amount to competition and/or collaboration.

While the different actors had different attitudes toward the means of doing so, the interviewees generally agreed on the fact that developing and strengthening some form of collaborative activities will be necessary to achieve the shared mission to provide the best care to people. On the one hand, the telemedicine actors convey a competitive attitude. However, they regard collaborative activities with the public sector as essential strategic means of establishing themselves as accepted 
and well-positioned players. On the other hand, traditional care providers credit the challengers with bringing advanced tools to the health care industry, thereby enabling and also pushing traditional care providers toward improving their own services. Yet, most respondents stated that they do not regard the challengers as competitive threats, but rather as collaborative opportunity. As discussed earlier in this chapter, PPCs are thought to serve as powerful tools in navigating within the complex environments of the welfare sector. However, the results of this study show that the actors' underlying value bases differ significantly in some areas. This effectively restricts the fruitful forms of future collaboration between the parties since it limits the activities requiring joint decision-making. Drawing upon Schaeffer and Loveridge's (2002) four forms of PPC mentioned in Section 1.4 of this chapter, this indicates that at the current stage, joint ventures, as well as partnerships, may be difficult to attain - at least to any successful extent.

\subsection{Practical implications}

Other than serving as an academic contribution to a nascent and rapidly growing concept of the health care market, the findings from this chapter also carry some practical implications. To the point, the development and implementation of metrological devices are essential in order to successfully adapt innovative practices in the health care sector. Without such measurements, telemedicine companies will have trouble gaining legitimacy. Furthermore, the public sector would not fully benefit from the innovations, and stabilized new market boundaries would be difficult to attain.

Moreover, it is important that such metrological devices, as well as pertinent changes in regulations, include international considerations, since the results of this study indicate that increased digitalization will lead to blurred national borders in primary health care. An example would be to ensure that international telemedicine companies operating in the Swedish market (and as part of the welfare system) are evaluated along the same quality measures.

Moreover, increased collaborative initiatives on the market can be anticipated in the near future. In order to help improve the prospects for such initiatives, it is important to overcome any perceived obstacles toward PPCs. The outcome of this study suggests that the most crucial aspect will be to secure improved means of communication between traditional and telemedicine companies. While digital disruption is yet in its early stage, it is paramount now to already start building the foundations to ensure optimized communication channels and a common knowledge base. Establishing effective forums for exchange will not only foster interaction between the parties but will also encourage the public to involve itself at an early stage and lessen its propensity toward protectionist tendencies. To this end, clear responsibilities must be communicated, agreed upon, and assigned across all involved parties.

\section{Conclusion}

This chapter has contributed to an increased understanding of how disruptive digital advancements, in particular regarding telemedicine, affect the perceived role 
of public and private actors within the Swedish health care sector. While the findings in this study are ultimately a representation of the respondents' own subjective perceptions of the subject matter, they still provide insight into the mindset of the rationale used to motivate their actions and/or inactions. To this end, the main findings can be summarized as follows:

1 Both public- and private-sector respondents expect telemedicine to have a large impact on the Swedish health care market.

2 Compared to the telemedicine company respondents, the public-sector respondents expressed a more reactive than proactive stance toward market shaping.

3 Public-sector respondents are generally positive to the emergence of telemedicine since it is regarded to enhance productivity and push the public sector to innovate at a higher speed.

4 There is some apprehension due to the concern that the development will ignore quality assurances, which results in an urge from both sides to introduce metrological devices, such as standardized quality measurements.

5 Parties encourage developing and strengthening collaborative efforts. These may, however, be difficult to attain due to perceived contrasting value bases as well as other obstacles, of which some can be productively counteracted, as suggested in the discussion of the main findings in Section 5.1 of this chapter.

While this study has chiefly sought to investigate the human experience of the respondents involved in this particular condition, the design of this study can be used analogously on similar examinations in other research settings. In regard to future research on the impact of health care digitalization, observational studies in forums of private-public interactions (such as conferences or joint projects) may yield additional insights to reinforce the understanding of the parties' values in action and hence further fill an additional research gap in areas where extant research is lacking. Moreover, similar studies may also be performed on welfare areas outside of the health care remit, for instance education and social care.

\section{References}

Ålander, T. and Scandurra, I., 2015. Experiences of healthcare professionals to the introduction in Sweden of a public eHealth service: patients' online access to their electronic health records. In: I.N. Sarkar, A. Georgiou and P. Mazzoncini de Azevedo Marques, eds., MEDINFO 2015: eHealth-enabled health: proceedings of the 15th world congress on health and biomedical informatics. Amsterdam, Netherlands: IOS Press, pp. 153-7.

Albury, D., 2005. Fostering innovation in public services. Public Money \& Management, 25(1), pp. 51-6.

Anell, A., Glenngård, A.H. and Merkur, S., 2012. Sweden health system review. Health Systems in Transition, 14(5), pp. 1-159.

Antonsen, M. and Jorgensen, T.B., 1997. The 'publicness' of public organizations. Public Administration, 75(2), pp. 337-57.

Bloch, C. and Bugge, M.M., 2013. Public sector innovation - from theory to measurement. Structural Change and Economic Dynamics, 27, pp. 133-45. 
Bommert, B., 2010. Collaborative innovation in the public sector. International Public Management Review, 11(1), pp. 15-33.

Business Sweden, 2018. Health - a brave new digital world. [online] Available at: $<$ https:// www.business-sweden.se/en/Invest/news-and-downloads/publications/health--a-bravenew-digital-world $>$ [Accessed 10 Sep. 2019].

Callon, M., 1990. Techno-economic networks and irreversibility. The Sociological Review, 38(S1), pp. 132-61.

Callon, M., 1998. An essay on framing and overflowing: economic externalities revisited by sociology. The Sociological Review, 46(S1), pp. 244-69.

Carter, J., 2015. The reasons why Sweden is a hotbed for digital innovation. [online] TechRadar. Available at: <www.techradar.com/news/world-of-tech/the-reasons-whysweden-is-a-hotbed-for-digital-innovation-1292681> [Accessed 10 Sep. 2019].

Castro-Sánchez, E., Charani, E., Drumright, L.N., Sevdalis, N., Shah, N. and Holmes, A.H., 2014. Fragmentation of care threatens patient safety in peripheral vascular catheter management in acute care - a qualitative study. PLOS ONE, 9(1), pp. e86167, 1-6.

Cision, 2016. The mHealth (mobile healthcare) ecosystem: 2017-2030 - opportunities, challenges, strategies \& forecasts. [online] Cision PR Newswire. Available at: $<$ https:/www.prnewswire.com/news-releases/the-mhealth-mobile-healthcare-eco system-2017--2030--opportunities-challenges-strategies--forecasts-300364008.html> [Accessed 10 Sep. 2019].

Cozza, M., Crevani, L., Hallin, A. and Schaeffer, J., 2019. Future ageing: welfare technology practices for our future older selves. Futures, 109, pp. 117-29.

Deloitte, 2015. Connected health - how digital technology is transforming health and social care. [online] Deloitte UK. Available at: <https://www2.deloitte.com/uk/en/pages/life-sci ences-and-healthcare/articles/connected-health.html $>$ [Accessed 10 Sep. 2019].

Denscombe, M., 2017. The good research guide: for small-scale social research projects. 6th ed. London, UK: Open University Press.

Dilmegani, C., Korkmaz, B. and Lundqvist, M., 2014. Public-sector digitization: the trillion-dollar challenge. [online] McKinsey \& Company. Available at: <www.mckinsey. $\mathrm{com} /$ business-functions/digital-mckinsey/our-insights/public-sector-digitization-thetrillion-dollar-challenge> [Accessed 10 Sep. 2019].

Donaldson, A., Lane, S., Ward, N. and Whatmore, S., 2013. Overflowing with issues: following the political trajectories of flooding. Environment and Planning C: Government and Policy, 31(4), pp. 603-18.

Ekman, B., 2018. Cost analysis of a digital health care model in Sweden. PharmacoEconomics - Open, 2(3), pp. 347-54.

Ekonomifakta, 2017. Vard och omsorg i privat regi [Care and social care in the private sector]. [online] Available at: <www.ekonomifakta.se/fakta/valfarden-i-privat-regi/ vard-och-omsorg-i-privat-regi> [Accessed 10 Sep. 2019].

Frid, A., Alsen, D. and Robertson, M., 2017. Digitizing Sweden: opportunities and priorities in five ecosystems. [online] McKinsey \& Company. Available at: <www.mckinsey. $\mathrm{com} /$ featured-insights/europe/digitizing-sweden-opportunities-and-priorities-in-fiveecosystems $>$ [Accessed 10 Sep. 2019].

Gaynor, M., Mostashari, F. and Ginsburg, P.B., 2017. Making health care markets work: competition policy for health care. [online] Brookings. Available at: $<$ www.brookings. edu/research/making-health-care-markets-work-competition-policy-for-health-care> [Accessed 10 Sep. 2019].

Government Offices of Sweden and SALAR, 2016. Vision eHealth 2025 - a common starting-point for digitalization in health and social care. [online] Available at: $<\mathrm{www}$ 
.government.se/4a3e02/contentassets/b0fd09051c6c4af59c8e33a3e71 fff24/vision-forehealth-2025.pdf> [Accessed 10 Sep. 2019].

Hardy, P., Boldt-Christmas, O. and Tyreman, M., 2016. Värdet av digital teknik $i$ den svenska vården [Digitizing healthcare in Sweden]. [online] McKinsey \& Company. Report. Available at: <www.mckinsey.com/industries/healthcare-systems-and-services/ourinsights/digitizing-healthcare-in-sweden $>$ [Accessed 10 Sep. 2019].

Hartley, J., 2005. Innovation in governance and public services: past and present. Public Money \& Management, 25(1), pp. 27-34.

Holmström, C., 2019. Vårdcentraler i privat regi [Health center in the public sector]. [online] Ekonomifakta. Available at: $<$ https://www.ekonomifakta.se/Fakta/Valfardeni-privat-regi/Vard-och-omsorg-i-privat-regi/vardcentraler-i-privat-regi $>$ [Accessed 10 Sep. 2019].

Ihlström Eriksson, C., Åkesson, M. and Lund, J., 2016. Designing ubiquitous media services: exploring the two-sided market of newspapers. Journal of Theoretical and Applied Electronic Commerce Research, 11(3), pp. 1-19.

Jalonen, H. and Juntunen, P., 2011. Enabling innovation in complex welfare service systems. Journal of Service Science and Management, 4(4), pp. 401-18.

Kastberg, G., 2014. Framing shared services: accounting, control and overflows. Critical Perspectives on Accounting, 25(8), pp. 743-56.

Kjellberg, H. and Helgesson, C-F., 2006. Multiple versions of markets: multiplicity and performativity in market practice. Industrial Marketing Management, 35(7), pp. 839-55.

Koppenjan, J.F.M., 2005. The formation of public-private partnerships: lessons from nine transport infrastructure projects in The Netherlands. Public Administration, 83(1), pp. 135-57.

Lapão, L.V., 2016. The future impact of healthcare services digitalization on health workforce: the increasing role of medical informatics. Studies in Health Technology and Informatics, 228, pp. 675-9.

Latour, B., 1984. The powers of association. The Sociological Review, 32(S1), pp. 264-80.

Latour, B., 1987. Science in action: how to follow scientists and engineers through society. Cambridge, MA: Harvard University Press.

Latour, B., 2005. Reassembling the social: an introduction to actor-network-theory. Oxford, UK: Oxford University Press.

McLoughlin, I., Garrety, K. and Wilson, R., 2017. The digitalization of healthcare: electronic records and the disruption of moral orders. Oxford, UK: Oxford University Press.

Moore, M.H., 1995. Creating public value: strategic management in government. Cambridge, MA: Harvard University Press.

OECD, 2013. OECD reviews of health care quality: Sweden 2013: raising standards. Paris, France: OECD Publishing.

OECD, 2016. Digital government strategies for transforming public services in the welfare areas. [online] OECD Comparative Study. Available at: <www.oecd.org/gov/digitalgovernment/Digital-Government-Strategies-Welfare-Service.pdf $>$ [Accessed $10 \mathrm{Sep}$. 2019].

OECD, 2018. OECD reviews of digital transformation: going digital in Sweden. Paris, France: OECD Publishing.

Oliver, P., 2006. Purposive sampling. In: V. Jupp, ed. The Sage dictionary of social research methods. London, UK: Sage Publications, pp. 244-5.

Olsson, S. and Jarlman, O., 2004. A short overview of eHealth in Sweden. International Journal of Circumpolar Health, 63(4), pp. 317-21.

Osborne, S.P., Radnor, Z., Vidal, I. and Kinder, T., 2014. A sustainable business model for public service organizations? Public Management Review, 16(2), pp. 165-72. 
Overdevest, C., 2011. Towards a more pragmatic sociology of markets. Theory and Society, 40(5), pp. 533-52.

Panari, C., Levati, W., Bonini, A., Tonelli, M., Alfieri, E. and Artioli, G., 2016. The ambiguous role of healthcare providers: a new perspective in human resources management. Acta Bio Medica Atenei Parmensis, 87(2-S), pp. 49-60.

Patel, K. and Rushefsky, M.E., 2002. Health care policy in an age of new technologies. Armonk, NY: M.E. Sharpe.

Peterson, C.B., Hamilton, C., Hasvold, P. and WHO, 2016. From innovation to implementation - eHealth in the WHO European region. Copenhagen, Denmark: World Health Organization.

Ranerup, A., Henriksen, H.Z. and Hedman, J., 2016. An analysis of business models in public service platforms. Government Information Quarterly, 33(1), pp. 6-14.

Reich, M.R., 2002. Introduction: public-private partnerships for public health. In: M.R. Reich, ed. Public-private partnerships for public health. Cambridge, MA: Harvard Center for Population and Development Studies, pp. 1-18.

Rip, A., 2010. Processes of entanglement. In: M. Akrich, R. Barbier, R. Barré, A. Barry, Y. Barthe, D. Boullier, G.C. Bowker, M. Callon, F. Cochoy, P. Cohendet, J-P. Courtial, H. Dumez, D. Foray, R. Garud, J. Gehman, A. Hatchuel, A. Hennion, J-A. Héraud, S. Jasanoff, A. Jeunemaître, P-B. Joly, P. Karnøe, P. Lascoumes, B. Latour, J. Law, L. Leydesdorff, C. Licoppe, P. Llerena, D. MacKenzie, A. Mallard, P. Miller, A. Mol, F. Muniesa, P. Mustar, H. Penan, D. Pestre, T. Pinch, A. Rip and N. Thrift, eds. Débordements Mélanges offerts à Michel Callon [Mixed overflows offered to Michel Callon]. Paris, France: Presses des Mines, pp. 381-92.

Santos, F.M. and Eisenhardt, K.M., 2009. Constructing markets and shaping boundaries: entrepreneurial power in nascent fields. Academy of Management Journal, 52(4), pp. 643-71.

Schaeffer, P.V. and Loveridge, S., 2002. Toward an understanding of types of public-pri vate cooperation. Public Performance \& Management Review, 26(2), pp. 169-89.

Schulman, K.A., Vidal, A.V. and Ackerly, D.C., 2009. Personalized medicine and disruptive innovation: implications for technology assessment. Genetics in Medicine, 11(8), pp. $577-81$.

Sørensen, E. and Torfing, J., 2011. Enhancing collaborative innovation in the public sector. Administration \& Society, 43(8), pp. 842-68.

Svanborg-Sjövall, K., 2014. Swedish healthcare is the best in the world, but there are still lessons to learn. The Guardian. [online] Available at: <www.theguardian.com/publicleaders-network/2014/jan/03/sweden-healthcare-coordinate-oecd $>$ [Accessed 10 Sep. 2019].

Tarim, E., 2013. Taking Michel Callon to the Istanbul stock exchange: frames, overflows and storytelling. In: B. Czarniawska and O. Löfgren, eds. Coping with excess: how organizations, communities and individuals manage overflows. Cheltenham, UK: Edward Elgar Publishing, pp. 81-98.

Torchia, M., Calabrò, A. and Morner, M., 2015. Public-private partnerships in the health care sector: a systematic review of the literature. Public Management Review, 17(2), pp. 236-61.

Urban, M., 2017. Embodying digital ageing: ageing with digital health technologies and the significance of inequalities. In: B. Heidkamp and D. Kergel, eds. Precarity within the digital age: media change and social insecurity. Wiesbaden, Germany: Springer, pp. 163-78. 
Van Ham, H. and Koppenjan, J., 2001. Building public-private partnerships: assessing and managing risks in port development. Public Management Review, 3(4), pp. 593-616.

Wass, S., 2017. The importance of eHealth innovations: lessons about patient accessible information. Doctoral Thesis. Jönköping University, Sweden.

Welch, C., Piekkari, R., Plakoyiannaki, E. and Paavilainen-Mäntymäki, E., 2011. Theorising from case studies: towards a pluralist future for international business research. Journal of International Business Studies, 42(5), pp. 740-62.

WHO, 2011. mHealth - new horizons for health through mobile technologies. [online] Global Observatory for eHealth Series - Volume 3. Available at: <www.who.int/iris/ handle/10665/44607> [Accessed 10 Sep. 2019]. 


\title{
4 Centralization vs. decentralization on the blockchain in a health information exchange context
}

\author{
Anna Essén and Anders Ekholm
}

\section{Introduction}

The potential of opening the global health data market has been discussed in the popular and academic literature for decades. If we could only enable a wider set of human and AI-based actors to learn from the growing amount of clinically, self-, and device-generated data about us, we could innovate new kinds of preventive, individualized, and fair health services, which may ultimately improve our health and well-being at a low cost, or so the argument goes (Inera, 2017; Government Offices of Sweden, 2016; Gilbert, Goldstein and Hemingway, 2015).

The above situation has raised questions about whether continuing the current development, that is, successively integrating more systems and new actors into the health information exchange (HIE) solutions of today, is a feasible way forward. That is, the technological infrastructure and governance of current HIEs have proven capable of attracting the actors (e.g., care providers, patients, researchers) that currently exchange clinical data. However, will the prevailing arrangement still be appropriate given the expected global exchanges between a whole new set of unknown actors, who in addition will exchange a range of new kinds of non-clinical but health-related data? Are the state-based governance and verification mechanisms of today's HIEs attractive and trustworthy in such contexts? Are they even legitimate?

Such doubts are increasingly indicated in discussions around blockchain technology (blockchain). In short, blockchain consists of a distributed ledger on which a network of computers store data and verify transactions, and on which distributed applications (e.g., smart contracts) that execute automatically can be built (Casey and Vigna, 2018). Many publications underline that such distributed solutions, which are allegedly maintained, hosted, and governed by the collective rather than any single actor, are more technically secure and cost efficient than today's platforms (Kuo, Kim and Ohno-Machado, 2017; Nicol, 2017; Gropper, 2016). Echoing the views of liberalists and anarchists (Hayek, 1948; Rothbard, 1978), some blockchain advocates even argue that because blockchain eliminates the need for intermediaries and vertical forms of coordination, they make representative democracy obsolete. Blockchain creates possibilities to form horizontal, stateless global direct democracies, in which self-sovereign identities can 
determine the rules of the game on a peer-to-peer contract basis (Casey and Vigna, 2018; Atzori, 2017). Whether these extreme blockchain-based scenarios will be realized, of interest is that they do foreground the predicament of how to combine decentralized and centralized features to create infrastructures that are not only technically capable but also perceived as legitimate in relation to the expanded health data transactions of the future.

The aim of the present chapter is to juxtapose the current infrastructure and governance of HIEs, focusing on the Swedish setting as an empirical example, with the completely decentralized blockchain-based HIE scenario that can be inferred from the blockchain debate. We discuss on what grounds the latter scenario may be questioned and outline several challenges that justify some form of centralized governance of the health data infrastructures of the future.

We approach this question humbly and acknowledge that it is a significant question that we will only be able to touch shallowly, especially considering our rudimentary technological and contextual knowledge. We do, however, find this endeavor relevant to stimulate the critical consideration of different avenues forward in relation to the move toward global health data exchanges. We also hope that the chapter will provide valuable input to the discussion of who should determine what aspects of the digitalization of welfare services and society in the future more generally.

\section{Premises}

\subsection{Theoretical points of departure}

Several different theoretical frameworks could be used to discuss views on blockchain in health care. Should we speak of technology as a "separate material" structure on its own? Or is this a futile attempt since what a technology becomes depends on how it is enacted - and "socially" constructed? These are debated issues in the information systems (IS) literature. In this chapter, we find it useful to analytically separate the material properties of digital infrastructures on the one hand and their affordances - the possibilities for action that they create - on the other (Essén and Värlander, 2018; Gibson, 2015; Leonardi and Barley, 2010). The assumption is that the material properties of technology matter but that they do not determine the outcomes. Technological properties can afford different things for different actors, depending on their goals and the ways in which they combine the various features of the technological artifact (Leonardi and Barley, 2010). The nature of and extent to which an affordance is actualized hence depends on the presence of a variety of releasing conditions, as well as environmental structures and values (Strong et al., 2014).

\subsection{Data sources}

We used online reports and published academic research to provide a brief overview of the current state of HIEs in Sweden and beyond. Given the lack of 
academic literature and "empirical evidence" on blockchain-based infrastructures in health care, we reviewed academic literature, books, and websites about the potential of blockchains and white papers describing specific proprietary/open source health care blockchain designs, noting that some are already implemented in pilot projects. Research on digital networks and artificial intelligence further provided input to the discussion. Finally, the first author engaged in conversations about the digital health infrastructure of the future with a few individuals working in the fields of HIEs, blockchain, e-health services, and digital services platforms in several countries from February to June 2018 (see Table 4.1).

Table 4.1 List of interviewees

\begin{tabular}{|c|c|c|c|}
\hline Country & Firm/organization & Individual/position & Blockchain involvement \\
\hline Sweden & $\begin{array}{l}\text { Inera, the organization } \\
\text { maintaining the } \\
\text { Swedish national } \\
\text { HIE. }\end{array}$ & $\begin{array}{l}\text { J. Eltes, chief } \\
\text { technology officer. }\end{array}$ & $\begin{array}{l}\text { No projects but scans the } \\
\text { area. }\end{array}$ \\
\hline Sweden & $\begin{array}{l}\text { Evimeria, IT vendor } \\
\text { that provides } \\
\text { Electronic Health } \\
\text { Record (EHR) } \\
\text { systems. 50-gruppen, } \\
\text { an association of } \\
\text { small e-Health firms. }\end{array}$ & $\begin{array}{l}\text { N. Hugosson, } \\
\text { business developer } \\
\text { at Evimeria, } \\
\text { spokesperson } \\
\text { 50-gruppen. }\end{array}$ & $\begin{array}{l}\text { No activity but scans the } \\
\text { area. }\end{array}$ \\
\hline Sweden & $\begin{array}{l}\text { General Electrics } \\
\text { Digital. }\end{array}$ & $\begin{array}{l}\text { L. Christensson, } \\
\text { strategic customer } \\
\text { engagements. }\end{array}$ & $\begin{array}{l}\text { The digital services platform } \\
\text { Predix offers a blockchain } \\
\text { service. }\end{array}$ \\
\hline Sweden & $\begin{array}{l}\text { iTeam, IT } \\
\text { development firm. }\end{array}$ & $\begin{array}{l}\text { C. Landgren, } \\
\text { president, founder. }\end{array}$ & $\begin{array}{l}\text { Provides AI, blockchain, } \\
\text { and other digitalization } \\
\text { solutions and services. }\end{array}$ \\
\hline Sweden & $\begin{array}{l}\text { CareChain, } \\
\text { blockchain } \\
\text { provider. }\end{array}$ & $\begin{array}{l}\text { S. Farestam and J } \\
\text { Sellström, founders. }\end{array}$ & $\begin{array}{l}\text { CareChain is a joint effort } \\
\text { to establish blockchain } \\
\text { infrastructure and personal } \\
\text { data management for } \\
\text { health. }\end{array}$ \\
\hline US & $\begin{array}{l}\text { BurstIQ, blockchain } \\
\text { provider. }\end{array}$ & $\begin{array}{l}\text { A. Heartley, business } \\
\text { developer. }\end{array}$ & $\begin{array}{l}\text { Provides blockchain-based } \\
\text { platforms for health care. }\end{array}$ \\
\hline UK & $\begin{array}{l}\text { General Electrics } \\
\text { Health Care } \\
\text { Partners. }\end{array}$ & $\begin{array}{l}\text { M. Jones, senior } \\
\text { consultant. }\end{array}$ & $\begin{array}{l}\text { Provides AI consulting } \\
\text { services and more. }\end{array}$ \\
\hline India & $\begin{array}{l}\text { Ohum Health Care } \\
\text { Solutions. }\end{array}$ & $\begin{array}{l}\text { T. Goyal and } \\
\text { U. Jayaram, } \\
\text { administrative } \\
\text { coordinator, } \\
\text { medical officer. }\end{array}$ & $\begin{array}{l}\text { Provides EHR and } \\
\text { blockchain-based } \\
\text { solutions. }\end{array}$ \\
\hline India & IBM India. & $\begin{array}{l}\text { P. Dey, customer } \\
\text { engagements, SME. }\end{array}$ & $\begin{array}{l}\text { IBM provides blockchain } \\
\text { solutions. }\end{array}$ \\
\hline Estonia & $\begin{array}{l}\text { Tallin University/ } \\
\text { Estonian National } \\
\text { HIE. }\end{array}$ & $\begin{array}{l}\text { J. Metsallik/lecturer, } \\
\text { IT architect of the } \\
\text { Estonian HIE. }\end{array}$ & $\begin{array}{l}\text { The Estonian National } \\
\text { HIE, often referred to as } \\
\text { blockchain based, although } \\
\text { this claim is criticized } \\
\text { (Kivimäki, 2018). }\end{array}$ \\
\hline
\end{tabular}




\subsection{Limitations}

We cover the operation of the current HIEs (focusing on the Swedish example) crudely, most likely omitting numerous development projects aiming to address many of the limitations that we mention. We further focus our discussion on the possibilities emphasized in the blockchain debate, though blockchain is only one among many potential future decentralized technologies that may disrupt health care. We discuss a few aspects of blockchain rather than covering all the design possibilities or their problems. For instance, the area of smart contracts is huge and impossible to capture within the scope of this chapter. Further, blockchain is still very much still in development. All claimed technological benefits have been questioned, and some aspects may be outdated in the near future. Our purpose is to discuss the possibilities and challenges raised by blockchain and the idea of decentralized infrastructures at a more general level. Finally, we provide a few (out of many possible) perspectives on how blockchains may afford decentralization as well as call for centralization, based on a limited number of interviews and selected readings, of which most were pro-blockchain biased. Numerous legal, financial, and psychological aspects remain to be explored.

\section{Results: data-driven health innovation - expanding the club}

We begin by outlining the arrangement of the health information exchanges of today, focusing on the Swedish example.

\subsection{The health information exchange of today}

Twenty years ago, most people understood health data to be the documentation performed by health care providers and stored in the care providers' various local electronic medical record (EMR) systems (Berg and Bowker, 1997; Berg, 1996). Transferring data between the different EMR systems was difficult if not impossible, and while patients in most countries enjoyed the legal right to request and view this documentation, this occurred only on a case-by-case manner, often with significant delays between a patient's order and receipt of the data. In early 2000, platforms, or health information exchanges, that enabled health care providers to share EMR data globally emerged (Greenhalgh et al., 2009). From around 2010 and onward, patients were also invited to join these platforms (Sellberg and Eltes, 2017). Today, patients in many countries can access all or parts of their EMR data through patient portals, which typically also provide other services such as EMR access logs, e-scheduling, e-prescriptions, and e-communication with their physician and/or nurse (Redelmeier and Kraus, 2018; Mold et al., 2015). The HIEs underlying these patient portals are often provided and maintained by statebased agencies that also run their respective underlying national HIE platform (see Essén et al. [2018] for an overview of different private/public arrangements). For example, the Swedish national HIE platform is maintained by the organization Inera, which is owned and governed by the 21 Swedish regional governments (county councils). 


\subsubsection{The current governance approach}

The rules of the HIEs in Sweden and beyond are designed at several levels. The national parliaments (as well as international organizations such as the EU) shape the prerequisites by providing regulations tied to medical record keeping and personal data. These regulations are typically abstract and allow care providers to share data in more as well as less "generous" ways - something we elaborate on more below (Essén et al., 2018). In Sweden, all 21 regional governments (county councils), however, mandate care providers in their region to make EMR data continuously available to the patient and other care providers through the national HIE. This means that data exchanges between care providers and patients are subject to the more specific rules of the national HIE.

Who, then, decides the rules of the national HIE? In Sweden, it is the national HIE board, which in turn consists of county council representatives. The national HIE board makes decisions about which technologies to use for authentication, exchange, and verification. For instance, the HIE board decided to allow BankID ${ }^{1}$ as an authentication method to allow actors to access data held in the original disparate systems through application programming interfaces (APIs), rather than, for instance, by creating a new central repository, and also to enable secure data integrity through the Exchange-index (Swe: engagemangsindex), a log of all transactions stored in the cloud. The national HIE board has also decided who is allowed to access and release data on the platform. Care providers have to fulfill specific requirements in order to receive permission to connect to the National Patient Summary (Swe: Nationell Patientöversikt NPÖ). Only then may they access other care providers' documentation about a patient and make data available to others (Inera, 2017). The national HIE board has further developed recommendations regarding which EMR data to release to which patients, for example, age restrictions, and when, for example, what is an accepted delay (Inera, 2016).

In summary, while a great deal of prestudies, anchoring work, and multiparty discussions have preceded all the decisions above, the Swedish county councils (the national HIE board) have heretofore assumed ultimate responsibility for ensuring that the national HIE infrastructure is technologically capable, that transactions are safe, and that data exchanges comply with national regulations. They have also decided who can "participate" in the HIE club, and what rules participants must follow or are recommended to follow. All of the Swedish interviewees emphasized that this governance model has been important to attract and make the current participants trust the national HIE. The interviewees, however, also pointed to the limitations tied to the current arrangement when looking ahead.

\subsubsection{Limitations tied to the current approach}

Several data legislation issues were raised as setting constraints around the Swedish HIE. For instance, interviewees referred to the current regulation's treatment of data as static records documented and stored by certain organizations, and the focus on protecting such data from, rather than ensuring its use by, external actors. 
They also pointed to the related uncertainty regarding individuals' and organization's opportunities and obligations to share digital data. For instance, according to Swedish legislation, care providers own the data they have entered into an EMR and they are allowed but not obliged to make that data continuously available to the patient or other care providers. There is further vagueness regarding individuals' rights and the rules tied to public e-services enabling individuals to release data that have been created by public care providers with third parties. ${ }^{2}$ Several interviewees stated that this ambiguity - or flexibility - regarding the "proper" interpretation of current legislation and the associated unpredictability regarding its enforcement have impeded the development of multisided health data exchanges in Sweden and beyond. According to several interviewees, it has created a "wait-and-see" culture in which the national HIE board as well as other actors/initiatives refrain from trying out new data-sharing structures in order to avoid being accused of doing something "illegal." The interviewees pointed to the tendency among actors to interpret the legislation in a conservative rather than in an entrepreneurial or "boundary-pushing" way. As argued by J. Eltes, "[The legislation] makes it difficult to radically change the terms of data ownership and data sharing" (J. Eltes, personal communication, February 2018). For more general discussions about the legal challenges in relation to digitalization, see Digitaliseringskommissionen (2016); Gulliksen, Persson-Stenborg and Backlund (2016); and Ekholm et al. (2016).

The Swedish interviewees also pointed to issues that were tied to the governance of the Swedish HIE rather than the legislation, though acknowledging that these are intertwined. They talked about the national HIE board's inclination to focus on "regional" rather than "global health data market" perspectives and on public care providers rather than private care and app providers. What also emerged from the interviews was the perceived lack of transparency and long lead-times characterizing the current governance model, which in turn slow down the incorporation of new technologies, data, and participants on the platform (cf. Vimarlund [2014]). Expensive waits and other entry barriers for new actors who want to join the platform are produced as a result, according to the interviewees. N. Hugosson noted this in the following way: "Not only paying the direct costs for joining but understanding what is actually required to join the national HIE, can be difficult if not impossible for a small actor."

Some of the interviewees argued that these tendencies will become increasingly problematic in relation to the envisioned large number of and dynamic participants in the HIE of the future. Problems were also foreseen in relation to the more varied types of data that the future HIE is expected to handle. For instance, numerous health-related data beyond EMR data (care consumption, income, sociodemographic, employment data, etc.) are currently stored locally by private and public social and health care providers and national agencies in Sweden (Digitaliseringskommissionen, 2016; Gulliksen, Persson-Stenborg and Backlund, 2016). There are also so called "open data" that are currently made available through various disconnected interfaces (OpenData, 2019). Add to this the data generated by every individual and their self-tracking devices, along with their global digital 
traces left behind when consuming and exploring online. It is neither the explicit responsibility of the Swedish national HIE, nor any other actor, to innovate, host, and govern services enabling individuals, public organizations, or external actors to share, access, combine, and use anonymized and aggregate data from these disparate sources in real time. As noted by the interviewees, the question is whose responsibility it should be.

The Swedish HIE (along with that of many other countries) is taking steps to enable greater exchanges and uses of data by making efforts to allow third-party actors to access and innovate services based on the EMR data that are currently only available to patients and care providers. There are even technological solutions for this end ready for implementation (J. Eltes, personal communication, February 2018). International efforts to enable global sharing of EMR and smart device data are also underway. For instance, EU projects (Pinto, 2018) attempt to develop gateways between national state-based HIEs. The interviewed actors applauded these efforts while recognizing that they address only a limited share of the various types of data that could in theory be exchanged. The tech-firm interviewees also worried about the more overarching limits that may be tied to the approach to simply expand the current setup in the future. As noted by C. Landgren, "Continuing on the current path would imply the endless addition of new specific integrations and service level and interoperability agreements between systems and actors." J. Metsallik pointed at this problem also in relation to the opening of the Estonian national HIE, "These kinds of national and international integration efforts add yet another layer of centralized governance, and it is already slow and expensive."

\subsubsection{Who should run the global health information exchange of the future?}

The interviewees' observations reflect the international debate, which has begun to discuss whether there may be limits to the types of data transactions under the current legislation and whether the different types of national HIEs are capable, appropriate, and legitimate platforms for them (Gropper, 2016; Peterson et al., 2016; Vest and Gamm, 2010). Health-related data are endless, bordering any data about an individual, the frequency and quality of one's social connections and environment, generated by the individual or by sensors embedded in one's body or environment. Who should create the rules regarding how to determine the quality of this kind of data, which will include but not be limited to what we currently think of as "health" and "identity" data, and who should decide who may access and use it? Neither completely state-based HIEs nor private firms are evident providers in this context. The need for more open and flexible platforms in combination with more nuanced and secure authentication mechanisms is discussed in this context, given the range of unknown actors that we may exchange data with in the future (Birch, 2014). It is against this background the decentralized blockchain scenarios may be understood. 


\subsection{Blockchain: enabling decentralized transactions}

Blockchain research is immature and mostly deals with cryptocurrencies and applications in the financial sector. Studies have identified several technical challenges with the Bitcoin blockchain (e.g., theft, scalability, structural problems), and solutions have been proposed (Nofer et al., 2017; Risus and Spohrer, 2017). Hence, the definition of "blockchain technology" is continuously changing. Most definitions, however, refer to the unlimited network of computers (nodes) that may participate in verifying and adding data transactions that occur on open blockchains. Each node stores a copy of the history of verified transactions tied to each data object, thus forming a decentralized and immutable memory (Casey and Vigna, 2018; Burniske and Tatar, 2017; Nakamoto, 2008). This distributed and decentralized characteristic, in combination with certain hashing and encryption mechanisms, purportedly makes the blockchain possess a higher degree of security (data provenance, immutable ledger, robust access) compared to centralized designs (Burniske and Tatar, 2017). As noted by Casey and Vigna (2018, p. 20), "The result is something remarkable: a record-keeping method that brings us to a commonly accepted version of the truth that's more reliable than any truth we've ever seen."

Because blockchain replaces a single centralized source of trust with network consensus, it allegedly eliminates the need for any intermediate or central function for verifying and storing transaction logs. Several analysts further claim that it would be more difficult for a malicious/noneligible actor to access and change a piece of data and to remove the traces of this breach on the blockchain compared to the current centralized/cloud-based infrastructures. Further, in contrast to centralized systems, the functionalities of the blockchain are said to persist even if particular nodes break down (Kuo, Kim and Ohno-Machado, 2017; Nofer et al., 2017).

\subsubsection{Eliminating the need for intermediaries and centralized functions}

Self-executing, distributed applications, also known as smart contracts, can be built on the blockchain. Smart contracts are thus replicated on the system and supervised by the network of computers that run the blockchain (Blockgeeks, 2016). Some blockchain advocates claim that the disintermediation enabled by smart contracts calls into question not only the centralized functions of traditional databases but also the role of any central institution. They argue that while centralized political organizations like the nation state, bureaucracy, and representative democracy have been a necessary response to the scaling problem, that is, for reaching consensus and coordination between heterogeneous or distant groups of people, such organizations imply a concentration of power in the hands of a few, which in turn implies inadequate responsiveness and risks tied to corruption, regulatory capture, and misuse of power. Dominant corporate giants such as Amazon, 
Facebook, Google, Twitter, PayPal, and eBay are subject to similar critiques in these discussions (Sparkes, 2014). The civil society could, however, organize itself and protect its own interests more effectively by replacing the traditional functions of the State and giant corporations with decentralized, open-source platforms, the argument goes (Buterin, 2014; Winfield, 2017). Such a decentralized system would produce benefits such as reduced overheads, improved security, and "removal of the weakest link of all - greedy, corruptible, fallible humans" (Sparkes, 2014, para.10). For an example of a stateless, DIY governance services entirely based on the blockchain, see Bitnation (2019).

This line of thought, often referred to as techno-libertarian, anarcho-capitalist, or market anarchist, echoes the anarchist view that coercive authority should be replaced by voluntary associations based on continuing consent and the idea that society best facilitates individual will in a free-market economy (Hayek, 1948; Rothbard, 1978; cf. Atzori, 2017). As noted by Bogost (2017, para.9), many blockchain-based scenarios depict a world where "neither states nor corporations are acceptable intermediaries. That leaves a sparsely set table. At it, individuals, the property they own, the contracts into which they enter to exchange that property, and a market to facilitate that exchange."

All the interviewees suggest more modest routes forward, a point to which we will return. At this stage, however, we find the extreme ideas useful as points of departure and comparison. Below, we will discuss how they could be applied in the HIE context.

\subsubsection{Applying blockchain ideas in the global health information exchange context}

Empirical research about blockchain in health care is scarce, to say the least. There is, however, a growing amount of development work and mobilization of interest in the area (see, for instance, the papers submitted to the US Office of National Coordination Blockchain challenge [Office of National Coordination, 2016] or posts on blogs and websites with blockchain content [Cryptoslate, 2018; Hashed Health, 2018; Bukstel, 2018]). The view emerging from this activity is that blockchain enables the creation of a protected lifelong record of one's health data. The record would handle (store and point to) ${ }^{3}$ all of an individual's health-related data and $\log$ everything done with it, at what time, and by what entity. This differs from the current situation, in which health-related data are stored and exchanged through multiple different devices and cloud hosted by a variety of public and private actors, requiring different authentication methods. The integrity of the blockchain record would surpass the robustness and integrity of current systems for storing and logging health transactions due to the large number of computers serving as nodes. Also, the record could be much more comprehensive, as it would be capable of including a wide set of health data transactions. The procedure of writing and reading data on and through the record would allegedly also be more lean, direct, and efficient than the procedures tied to current HIEs, as there would be no intermediary actors performing verifications or controls (BurstIQ, 2019; 
Carechain, 2018; Patientory, 2018; Lippman, Ekblaw and Halamka, 2017; Swan, 2015). A number of engineers and tech experts continue to emphasize the possibility to "bypass" the interoperability problem via blockchain. Different authors refer to technologies such as the representational state transfer (REST) application programming interface, which allows a variety of sources (including EMR data as well as embodied and environmental sensors) to write data to the blockchain (Bresnick, 2017). It is further argued that interoperability can be achieved by smart models with the ability to learn how to identify and interpret the meaning of patterns in data, even though it is expressed in different ways (post-structuration) (S. Farestam, personal communication, February 2018).

Through what mechanisms would actors "writing" and "reading" data identify themselves, then? Casey and Vigna (2018) argue that we need to reorient the discussion to how blockchains provide the mechanism to radically change the way digital identities are managed in this context. Similarly, Diakun-Thibault (2018) claims that the fact that blockchain makes it possible to construct new solutions for digital identity represents the most important affordance of blockchains. She notes, "Without identity (whether for humans or things), blockchain may remain on the periphery as a shiny object. Identity or identification is the quintessential piece that will make Blockchain perhaps the most important compound technology to date" (Diakun-Thibault, 2018, p. 2). To exemplify this point, consider how an individual "identifies" herself when using online eHealth services or wellness apps today. Most likely she uses a range of different accounts and credentials, provided by a set of different actors, and she may have more or less insight into where and by whom all her "identity data" are stored. Add to this the various paper-based proofs of her existence that she may store, for example, passport, population registration certificate, driver's license, ID card. This common state of affairs underlies the vivid debate about the "missing identity layer of the Internet" and the need to create an infrastructure enabling digital IDs that are secure, portable, and owned by the individual. Self-sovereign identities on blockchain infrastructures are presented as a means for achieving just that.

\subsubsection{Self-sovereign identities}

Self-sovereign identities (ssIDs) refer to solutions enabling you to be your own identity provider, thus making your digital existence independent of any single organization or state. No external party could claim to "provide" the identity for or take away the ID from you because it would be intrinsically yours. With an ssID, you would hence completely control and manage your digital identity. This includes being free to enter an identity-relationship with any other (Windley, 2018; Tobin and Drummond, 2017; Allen, 2016).

How would this work, then? There are several answers to this question. The general idea is, however, that you as an individual successively build your own ssID on a blockchain. Somewhere in the chain, you must most likely provide a physical proof of your existence. However, once you have a claim about your 
existence, you can then connect and disconnect various claims to it, which allows for pseudonymity (Birch, 2014).

In his blog, Lewis (2017, para.22) describes a scenario where you would have an identity wallet app: "Your identity wallet would start off empty with only a self-generated identification number derived from public key, and a corresponding private key. ... Y You then use this identification number, along with your identity claims, and get attestations from relevant authorities. You can then use these attested claims as your identity information." An ssID can hence be understood as a digital record or "container" of claims - statements - about you. The claims may concern attributes associated to your person (e.g., age, height, birth date, biometrics), attributes accumulated over time (e.g., medical information, preferences, communication metadata), and designated attributes (e.g., telephone number, email, passport number). You can add claims to your ID by writing claims yourself, by asking others to provide claims about you, and by accepting claims from any number of organizations. The fact that you accept a claim about you may, however, not be enough to make the claim trustworthy for others. Hence, the claim would be linked to attestations. An attestation refers to a "trusted" third party validating that according to their records, the claim is true by digitally signing pieces of info that are valid within certain time frames. For example, a university may attest to the fact that you studied there and earned a degree, a hospital may attest to the fact that you suffer from a specific diagnosis, and a governmental agency may attest that you were born in and a citizen of a specific country (Preukschat, 2018).

In this scenario, all transactions tied to your ID are broadcast and stored on the blockchain, which would allegedly reduce the risk of anyone reversing transactions regarding your identity, for example, eliminating or modifying a piece of your identity. Further, only you as the identity owner can tie the claims togetherthere is no external correlation between them unless you wish to reveal it, for example, by sharing claims from two different issuers with the same relying party. This reduces the risk of "oversharing" identity information. You will only release the claims relevant for a specific transaction, and the recipient will not need to be burdened by protecting sensitive identity data. Importantly, no single central agent makes all decisions regarding who can read and write claims or what is a piece of identity information. Anyone can write a claim, and it is up to the transaction parties to decide whether a claim and the attestations tied to it suffice for the exchange in question. Hence, authentication procedures will be determined in a decentralized way, through individual contracts. For an example of what a market of claims may look like, see the reputation economy suggested by Tobin and Drummond (2017). Furthermore, the Swiss town of Zug is, as of 2017, developing an offer to its citizens to use a blockchain-based digital identity (Vitaris, 2017). There are also EU Horizon 2020 initiatives such as "MyhealthData" (2018).

Analysts argue that the new kinds of granular and "need-to-know" transactions of claims mentioned above are enabled by smart contracts that will automatically execute the individual agreements and thus handle the authentication of the exchanging parties (Birch, 2014). These smart contracts may have access to both 
on-chain and off-chain information. For instance, if a research project wants to know if you have blood type A, the research project may send a question/transaction to your smart contract: "Are you blood type A?" Given that this is a question that your smart contract accepts since it is programmed only to respond to some questions, it will answer the question by looking up data on and off chain. ${ }^{4}$ Your smart contract would, however, not divulge private information about your name, date of birth, and so on, and the procedure would be direct, only involving the research project and you, as opposed to the current state where redundant identity information is often released per default, and where several intermediary functions are involved.

\subsubsection{Self-executing contracts operating on our behalf}

Given the possibility for smart contracts to efficiently handle authentication procedures, new service affordances emerge. The assumption is that you will perceive increased security regarding your health data transactions with ssIDs, for instance, worrying less about your data being used by someone else than the intended recipient or you being identified backward. The fact that blockchain enables "private" machine learning (i.e., allows models to train on sensitive data without revealing them) is also claimed to reduce the problem of derivation/secondary confidentiality in this context (Ehrsam, 2018). The point emphasized is that this will make you more willing to and will provide you with greater opportunities to make your data available to various parties and secondary uses (Birch, 2014).

The result would be possibilities that are often mentioned in scenarios of the future of health care more generally: integrating big health data streams (genomics, lifestyle, medical history, etc.) and running machine learning algorithms on them, which will yield insights used for wellness maintenance and preventive medicine. The constantly growing data will provide entirely new possibilities for actors to continuously monitor and learn about you, your things, and your environment's "normal" state, as opposed to the current situation in which data is generated at the point of care (at the clinic, for instance), when health problems have arisen, or at the "break-down" of things and environments. The knowledge will be used by actors to detect and act on early deviations, thus shifting the focus from reaction to prevention (Swan, 2015).

The blockchain community here envisions new global HIEs or data markets, completely run on and by several different dedicated blockchains. A range of different personalized services will be available on the markets, only you will be able to trade data, ideas, behavior, and identities with unknown actors and on new terms, not only with money (as we currently think of it) but also with data or other digital currencies, commodities, or goods (tokens), that is, "resources" that allow actors to do something. For a more in-depth discussion about the differences among cryptocurrencies, digital commodities, tokens, and finished digital goods, see Burniske and Tatar (2017). For instance, your personal AI agent may, based on data about you (your digital twin), identify the service that can help you achieve your specific health - or life - goal at the lowest cost, or it may constantly 
poll for research projects that fit your personal values and behavior and that need data about a body that has your characteristics. The agent may donate data to some prespecified types of projects (for instance, to data research commons with varying levels of openness/privacy) or sell your data to parties that pay well in order to earn tokens. Your AI agent may later invest the tokens in services or projects that you find worthwhile. Indeed, you may even allow your AI agent to make political propositions (suggesting, for instance, the modification of the rules or technological infrastructure of a health community) and invite certain human and non-human entities or communities to vote on them. A smart contract will then automatically execute the majority's decision. For more information about how to build "decentralized democracies," see Ethereum (2018). The idea is that this could stimulate the innovation of much more complex health services and health projects than today, which would ultimately lead to improved health outcomes benefitting both the individual and the society.

In the extreme scenario, the global HIE would be based on a permissionless technological infrastructure (as the Bitcoin blockchain is) and would be open for anyone to act as a node and to engage in transactions. The HIE would also be based on a decentralized and autonomous mode of governance, as smart contracts could coordinate and execute the peer-to-peer transactions without any centralized human curation at all.

Many blockchain voices, however, envision a future in which blockchain arrangements are coupled with centralized functions (Atzori, 2017). For instance, Swan (2015, p. 17) writes, "The end point is not lawlessness and anarchy, but that legal frameworks become more granular and personalized to the situation." Furthermore, in an interview, the blockchain advocate Antonopoulos states, "This is not some kind of libertarian manifesto, or anarchist manifesto, saying that we don't need mechanisms for achieving social cohesion. It's simply recognizing that we can create better mechanisms as we solve problems of scale. It's simply that we can make better governments when we don't concentrate power as much in the hands of a few people" (A. Antonopoulos, interviewed in Sparkes [2014, para.178]).

Below, we will elaborate on a few challenges associated with the establishment of expanded health data trades, which call for some element of centralization and some form of human governance.

\section{Discussion: challenges tied to the shift toward global health innovation clubs}

The idea of decentralized and autonomous infrastructures can be understood as a response to the limitations tied to current HIE arrangements. However, several needs may motivate some degree of centralized functions in the governance of the HIEs of the future. The needs discussed below are overlapping and nonexhaustive. They are, however, relevant to consider, in the presence as well as absence of blockchain-based HIE platforms. 


\subsection{Attracting participants}

Completely open infrastructures such as permissionless blockchains may provide effective means for creating secure transaction logs and flexible data exchanges. But would they be capable of creating systems that people trust? Consider the scenario where a community of unknown actors announces the availability of an open, blockchain-based HIE and tries to make potential users (care providers, patients, app developers, etc.) begin to write and read data on it. It seems reasonable to doubt that the technological design, including the "transparent ledger" and "smart contracts" of such a network, would suffice to attract users in the near future.

For one, the potential users may worry about the long-term survival of the infrastructure and its services. A decentralized blockchain could be dismissed by the actors providing computer power and/or data if not seen as attractive or remunerative anymore, as illustrated by the forking of the Bitcoin blockchain (Andersen and Ingram-Boguz, 2017; Gasser, Budish and West, 2015). This implies risks for lack of service continuity and preservation of data, with no delineation or liability (Reijers, Brochain and Haynes, 2016; DuPont and Maurer, 2015). In order to attract any users, a known, "trustworthy actor" may hence need to formally support the infrastructure underlying the health data market, in terms of providing an "OK stamp" on the actors that participate as nodes on it by guaranteeing its long-term stability and by ensuring the protection and preservation of certain shared values.

Consequently, the interviewees and many white papers suggest variants of permissioned technological blockchain designs for health care (BurstIQ, 2019; Carechain, 2018; Hashed Health, 2018; Patientory, 2018; Lippman, Ekblaw and Halamka, 2017). Permissioned blockchains are distributed and synchronized, but their network is restricted to few trusted nodes and members, identifiable by controlled access permissions (Buterin, 2015). ${ }^{5}$

Who, then, could constitute the central, trustworthy agent providing permission rather than a network of nodes and actors? One suggested answer is not one actor (which would imply little difference from today's setup), but several institutions, associations, and groups, joining in collaborative governance arrangements, such as private-public partnerships, eternal non-profit foundations, alliances, consortia, or cooperatives (see, e.g., Carechain [2018] and additional ideas from the organizational literature about the new forms of multi-actor governance [West and O'Mahony, 2008; Abbott, 2000; Paquet, 2000]). The idea of some blockchain advocates is that the current state-based boards of national HIEs could act as one among several participants in such consortia, which would also include other public, private, and non-profit actors, spanning sectors and national borders. As noted by one of the interviewees, "The crucial point will be to maximize participation and consensus while including actors diverse enough to prevent collusion of interests" (J. Sällström, personal communication, May 2018). That is, the support of state-based or private actors alone would not suffice to create trust in the platforms 
of the future, as there will be a need to find consensus-based solutions to problems spanning both sectors and national borders, a point to which we will return below.

\subsection{Realizing the societal value of data-based learning}

Large amounts of data available at low cost are often assumed in the scenarios of the future. As indicated above, current HIE setups in combination with abstract and ambiguous regulatory approaches have not generated any significant change in the release and use of data by individuals or public and private organizations. Indeed, what seems to emerge from HIE research across countries is that care providers' and patients' enthusiasm in "participating" in HIEs is growing but could be greater (Redelmeier and Kraus, 2018; Mold et al., 2015). The question is if a completely decentralized blockchain would be a more effective means for realizing the potential of data at societal level.

For one, a pure decentralized market would not be able to handle positive and negative externalities stemming from data use (Spiekermann et al., 2015). For instance, when deciding which data transactions to accept on a market, you may choose to ignore that the use of your data may yield insights that benefit not only you and the actor using the data, but larger groups in society. Similarly, you may refuse to release data about yourself, although this may limit not only your possibilities to receive individualized services but also the development of precision medicine for the population overall. This also applies to corporations. Overall, a market would encourage the view of data as a unique competitive advantage, which would create incentives to lock in, protect, and sell rather than freely sharing data, with resulting limitations on the degree to which actors could learn from the data (for a more elaborate discussion about the challenges related to the creation of data markets, see Spiekermann et al. [2015]).

The aim to maximize learning and innovation based on health data may hence motivate some form of centralized administration and regulatory changes. Insights from the AI community can be applied here, where analysts have proposed interventions such as time-restricted data monopolies as well as shared investment in and promotion of global data commons, donor banks, and gift-aid style schemes for data where there is value in secondary analysis. This is in order to create extended forms of what we currently think of as "open data," which would enable firms, governments, and individuals to contribute and reuse anonymous, aggregate datasets in new ways. Of course, creating such data philanthropy and making actors trust that they contribute to "the use of data for good" will be a challenge. Hence, efforts to enable and stimulate data generosity will need to be coupled with shared agreements regarding what kinds of uses are "for good" and what are not (UK Parliament, 2018; Naylor and Jones, 2017).

\subsection{Developing shared agreements to facilitate innovation "for good"}

The notion of decentralized health and identity data transactions can be seen as a response to the limited opportunities that individuals currently enjoy in terms 
of determining with whom and how to share health data. Some (new) forms of shared (rather than individual) agreements helping individuals to make decisions regarding their data (or nudging individuals to make a decision that benefits the society) may, however, be needed in the future.

As an example, given that a new culture of data use emerges, the number of agents wanting an individual's data for various purposes may become too numerous to count. Handling such data requests and providing consent on a case-by-case or individual contract level may not be tenable or desirable for a large share of the population. This may call for shared agreements regarding categories of agents and uses for the large scope of population that are not overly interested in these matters. Shared agreements may also be motivated in order to fully realize the value of data at a societal level. One could here imagine shared agreements regarding different dimensions of use and data ownership. As a basic example, the use of 1) non-identified data for research and model training could be differentiated from the use of 2) identified data for personalized intervention purposes. For the use of non-identified data, opt-out possibilities may be an alternative. Spiekermann et al. (2015) even discuss the alternative to remove the choice from individuals and make certain levels of non-identified data provision involuntary, given the aim to maximize health outcomes of data at societal level. For AI agents using multidimensional sets of data tied to an individual's identity in order to identify risks and deliver personalized interventions, opt-in possibilities may be an alternative. ${ }^{6}$ Obviously, endless degrees of nuance are possible here, and the path forward will involve balancing the need for simplicity versus flexibility and the freedom and responsibility of the individual in relation to the collective.

On a related note, the interviewees foresee a need for standards regarding the exchange of ID claims should the ssID-scenario materialize. While ssIDs are supposedly governed by the individual, it cannot be taken for granted that all individuals will be able and motivated to carefully delimit the claims they release. To prevent actors from connecting the dots and linking data to a specific individual (backward identification), a need for shared rules regarding, for instance, a maximum number of claim requests allowed is discussed (J. Sellström, personal communication, May 2018).

What these issues point toward is a shift in the target of data regulations, from a focus on the organization in which the data were documented to the situations in which the data will be used, updated, and extended. This will imply a need to ensure transparency and accountability in contexts of use that involve human as well as non-human actors and that span national jurisdictions (P. Dhey, personal communication, March 2018).

Finally, while blockchain enables a post-structuration approach to interoperability, the Swedish individuals interviewed here suggest a combination of preand post-structuring of data and metadata. Indeed, the variability of data formats and documentation patterns of today beg for pre-structuration, too, in order to facilitate the aggregations that are typically assumed. As pre-structuring standardization work cannot be solved on an individual-contract basis, this implies yet another motivation for some form of centralized governance unit. 


\subsection{Preventing hidden forms of power centralization}

The current HIE setups are criticized for not representing all participants in the future health ecosystem and for placing control in the hands of a few. However, the argument that blockchains will imply a decentralization of control may be deceptive. Research on networks based on distributed consensus show that they do exhibit centralized points of control, only in more subtle and hidden forms. For instance, centralization patterns have arisen in the Bitcoin blockchain due to the scalability problem and unequal knowledge distribution (Courtois, 2014; Gervais et al., 2014). Analysts have pointed to risks such as miner corporations and the likely dependency of private oligarchies, which may conduct mergers and gain considerable power on a global scale. This relates to research on infrastructures for distributed innovation, which points to the parallel existence of the "long tail" of specialized niche actors and the "giants" that achieve global dominance thanks to their ability to integrate diverse capabilities, combined with network effects (Brynjolfsson, Hu and Smith, 2010; Anderson, 2007). In short, digital networks of today often exhibit more or less subtle points of centralized control, resting with individuals (due to technical knowledge), firms (with resources), or foundations (with more insight into the network than others). Such actors may become de facto leaders but lack accountability and have not made any promise to serve public interests (for a more general critique against the dominance of today's corporate data giants, see, e.g., Bergstein [2017], Galloway [2017], and Taplin [2017]). There is no guarantee that principles such as diversity, inclusiveness, and equal access of care will be maintained by such groups (nor by smart contracts acting autonomously on a market). This presents additional charges for centralized functions: to prevent asymmetries, lower barriers to entry, and potentially develop new antitrust legislation to address data-based monopolies (UK Parliament, 2018). It will be equally important to ensure democratic values such as diversity and equal opportunity, and to protect groups that may be gaining the least, for instance, those who are data illiterate or generate data that are potentially less useful (Dahl, 1989).

\subsection{Securing a place for humans}

The scenarios in which AI agents learn to execute things on our behalf will increasingly raise ethical questions, which will be difficult to resolve on an individual-contract basis. For one, AI agents may be biased and may discriminate against actors (Frey and Osborne, 2017; Tegmark, 2017; Ananny, 2016; Harari, 2015; Newell and Marabelli, 2015). Note that this is a risk in relation to the inanity of today's narrow artificial intelligence, which may lead to AI being unable to recognize important dimensions of "the big picture" (Faraj, Pachidi and Sayegh, 2018). The risk is also relevant in relation to the potential "general" artificial intelligences, which may become "smarter" than we are and thus discriminate against us in undesirable ways, such as possibly not even including us in the "big picture" (Tegmark, 2017). 
Indeed, looking far ahead, Harari (2015) argues that technological developments in AI and biological and cyborg engineering may increase our ability to extend lifespans and even cheat death. Meanwhile, the redundancy of human labor, replaced by efficient machines, will generate an enormous "useless class," without economic purpose. In combination, this will lead to a society characterized by a universal faith in the power of algorithms, and in which individuals will become just a collection of "biochemical subsystems" monitored by global networks, which will inform us second by second how we feel. His book closes with the following questions: "What's more valuable - intelligence or consciousness?" and "What will happen to society, politics and daily life when non-conscious but highly intelligent algorithms know us better than we know ourselves?" (Harari, 2015, p. 402). Smart contracts will not provide the answer.

Ensuring that the systems of the future work toward our collective well-being hence requires us to be exceptionally lucid in our representations of the values we hold and the ways we want those values to be optimized and/or preserved (Yudkowsky, 2016). As noted by the UK Parliament (2018, p. 47): "Our ability to engage with philosophy and converge on ethical principles is starting to take on a dimension of significance that has not existed before." Needless to say, engaging in such philosophical and ethical questions will constitute a true challenge for the human governance layers of the HIEs of the future, blockchain based or not.

\section{Conclusion}

Health data available for learning at the global scale seem to be what most actors engaged in the digitalization of society hope for. Diverse views regarding how to achieve this state of affairs are, however, emerging. In an attempt to stimulate a discussion about alternative paths forward, we have juxtaposed the arrangement of today's HIEs with the decentralized (blockchain-based) HIE scenario. Based on our conversations with individuals involved in the field, we outline some question marks regarding the ability of current HIEs to enable the global data exchange and innovation envisioned. As one may expect, the decentralized (blockchain-based) scenario does not seem able to autonomously deal with these challenges. We conclude that a combination of decentralization and new forms of centralization will characterize the infrastructures of the future, be they blockchain based or not. Much effort will be required to reach agreement regarding how these infrastructures and governance models can serve the interests of both individuals and society.

\section{Acknowledgments}

We are immensely grateful for insights provided by the interviewees. Valuable conversations with Vivian Vimarlund also helped us forward. Warm thanks, finally, to Anthony Larsson and Robin Teigland for initiating this book project and for immaculate reviewing and editing work. 


\section{Notes}

1 BankID is a virtual certificate or ID that allows an individual to authenticate herself online. In Sweden, BankID is owned, maintained, and provided by Finansiell ID-Teknik BID AB, which is owned by several Swedish banks. BankID certificates are issued only to individuals with a personal social security number.

2 As an example, the Swedish eHealth Agency made an attempt to develop a personal health account (PHA) (Swe: Hälsa för mig) that would allow individuals to store health data from various sources (including EMR data) in a so-called "private space" (the Swedish legal term is "eget utrymme" [Bålman, 2017]). However, the Swedish Data Protection Agency found uncertainties regarding whether the setup regarding storage, processing, and exchange of the data actually complied with current data regulations in 2017 (Data Protection Agency, 2017). The Swedish administrative court (Swe: Förvaltningsdomstolen) subsequently ruled against the PHA on the basis that its design was not compliant with Swedish legislation, and the initiative was thus shut down in 2018 (Data Protection Agency, 2018).

3 There are different views regarding whether the actual health data should also be stored on or off chain. In the on-chain scenario, additional technologies are used to protect sensitive data stored on the blockchain, while the transaction data is kept open. In the off-chain scenario, the blockchain includes pointers to sensitive data stored off chain, and smart contracts fetch such off-chain data when necessary. Combinations are also possible.

4 While the transactions would be stored on chain, there are different views of where sensitive data and the private key should be stored, ranging from a personal off-chain device such as our smartphone, on a card and stored in a safe like we store passports, on a chip implanted in our bodies, in a space hosted by a trusted actor, and so on.

5 The number of nodes that may participate in these health care blockchains is hence smaller than permissionless blockchains. However, the nodes would still be higher in number than the nodes of the HIEs of today and thus make it more difficult for any central administrator to reverse the history of transactions. Since nodes are few, with no need for mining and computationally intensive proof-of-work, validations and propagation of data are further faster than permissionless blockchains.

6 While blockchain discussions often emphasize that data will be exchanged at a more fine-grained level and on a need-to-know basis, and even without revealing identified data, the possibility that some types of AI-based learning and innovation will require ("need-to-know") a horizontal, full view of all of your data cannot be excluded.

\section{References}

Abbott, F.M., 2000. Distributed governance at the WTO-WIPO: an evolving model for open-architecture integrated governance. Journal of International Economic Law, 3(1), pp. 63-81.

Allen, C., 2016. The path to self-sovereign identity. [online] Life with alacrity blog. Available at: <www.lifewithalacrity.com/2016/04/the-path-to-self-soverereign-identity.html $>$ [Accessed 4 Sep. 2019].

Ananny, M., 2016. Toward an ethics of algorithms. Science, Technology, \& Human Values, 41(1), pp. 93-117.

Andersen, J. and Ingram-Boguz, C., 2017. Patterns of self-organising in the Bitcoin online community: code forking as organising in digital infrastructure. In: Association for information systems AIS electronic library (AISeL) ICIS 2017 proceedings, pp. 1-20.

Anderson, C., 2007. The long tail: why the future of business is selling less of more. Journal of Product Innovation Management, 24(3), pp. 1-30. 
Atzori, M., 2017. Blockchain technology and decentralized governance: is the state still necessary? Journal of Governance and Regulation, 6(1), pp. 45-62.

Bålman, J., 2017. Promemoria 2017-09-29. Eget utrymme är numera accepterat i lagmotiv - frågor om legalitet och dataskydd återstår [Private space is accepted: questions about legality and data protection remains]. [online] Available at: <www.esamverka. se/download/18.3687e38a15e84632115c9b02/1506941988144/PM Eget utrymme.pdf $>$ [Accessed 4 Sep. 2019].

Berg, M., 1996. Practices of reading and writing: the constitutive role of the patient record in medical work. Sociology of Health \& Illness, 18(4), pp. 499-524.

Berg, M. and Bowker, G., 1997. The multiple bodies of the medical record: toward a sociology of an artifact. Sociological Quarterly, 38(3), pp. 513-37.

Bergstein, B., 2017. We need more alternatives to Facebook. [online] MIT Technology Review. Available at: <www.technologyreview.com/s/604082/we-need-more-alterna tives-to-facebook> [Accessed 4 Sep. 2019].

Birch, D., 2014. Identity is the new money. London, UK: London Publishing Partnership.

Bitnation, 2019. Enter Pangea. The internet of sovereignty. [online] Bitnation homepage. Available at: $<$ https://tse.bitnation.co $>$ [Accessed 4 Sep. 2019].

Blockgeeks, 2016. Smart contracts: the blockchain technology that will replace lawyers. [online] Blockgeeks blog. Available at: $<$ https://blockgeeks.com/guides/smart-con tracts $>$ [Accessed 4 Sep. 2019].

Bogost, I., 2017. Cryptocurrency might be a path to authoritarianism. The Atlantic. [online] Available at: <www.theatlantic.com/technology/archive/2017/05/blockchain-of-com mand/528543> [Accessed 4 Sep. 2019].

Bresnick, J., 2017. Exploring the use of Blockchain for EHRs, healthcare big data. [online] Health IT analytics. Available at: $<$ https://healthitanalytics.com/features/exploring-theuse-of-blockchain-for-ehrs-healthcare-big-data $>$ [Accessed 4 Sep. 2019].

Brynjolfsson, E., Hu, Y.J. and Smith, M.D., 2010. Long tails vs. superstars: the effect of information technology on product variety and sales concentration patterns. Information Systems Research, 21(4), 736747, pp. 1-20.

Bukstel, E., 2018. Competition for the healthcare blockchain. [online] Medium blog. Available at: <https://medium.com/@Connected_Dots/competition-for-the-healthcareblockchain-26a6f2bc09a4> [Accessed 4 Sep. 2019].

Burniske, C. and Tatar, J., 2017. Cryptoassets: the innovative investor's guide to bitcoin and beyond. New York, NY: McGraw-Hill.

BurstIQ, 2019. Connecting people: changing health. [online] BurstiQ homepage. Available at: <www.burstiq.com> [Accessed 4 Sep. 2019].

Buterin, V., 2014. An introduction to Futarchy. [online] Ethereum Blog. Available at: $<$ https://blog.ethereum.org/2014/08/21/introduction-futarchy $>$ [Accessed 4 Sep. 2019].

Buterin, V., 2015. On public and private blockchains. [online] Ethereum Blog. Available at: $<$ https://blog.ethereum.org/2015/08/07/on-public-and-private-blockchains $>$ [Accessed 4 Sep. 2019].

CareChain, 2018. The CareChain infrastructure consortium. [online] Available at: <www. carechain.io/files/CareChain_The_Infrastructure_Consortium.pdf $>$ [Accessed 4 Sep. 2019].

Casey, M.J. and Vigna, P., 2018. The truth machine: the blockchain and the future of everything. New York, NY: St. Martin's Press.

Courtois, N., 2014. On the longest chain rule and programmed self-destruction of crypto currencies. [online] Available at: $<$ https://arxiv.org/abs/1405.0534> [Accessed 4 Sep. 2019]. 
Cryptoslate, 2018. Healthcare cryptocurrencies. [online] Cryptoslate website. Available at: $<$ https://cryptoslate.com/category/cryptos/healthcare> [Accessed 4 Sep. 2019].

Dahl, R., 1989. Democracy and its critics. New Haven, CT: Yale University Press.

Data Protection Agency, 2017. Stopp for spridning av hälsotjänster från e-tjänsten hälsa för mig. [MyHealth halted]. [online] Data Protection Agency homepage. Available at: $<$ www.datainspektionen.se/nyheter/stopp-for-spridning-av-halsouppgifter-fran-e-tjan sten-halsa-for-mig > [Accessed 4 Sep. 2019].

Data Protection Agency, 2018. Domstol ger Datainspektionen rätt om Hälsa för mig. [The court supports the data protection agency concerning the personal health account]. [online] Data Protection Agency homepage. Available at: <www.datainspektionen.se/ nyheter/domstol-ger-datainspektionen-ratt-om-halsa-for-mig $>$ [Accessed 4 Sep. 2019].

Diakun-Thibault, N., 2018. Review: the truth machine in the age of cryptocurrency. [online] Available at: <www.researchgate.net/publication/323547090> [Accessed 4 Sep. 2019].

Digitaliseringskommissionen, 2016. Digitaliseringens effekter på individ och samhällefyra temarapporter [The effects of digitalisation on the individual and society - four thematic reports]. [online] Available at: <www.regeringen.se/rattsliga-dokument/stat ens-offentliga-utredningar/2016/12/sou-201685> [Accessed 4 Sep. 2019].

DuPont, Q. and Maurer, B., 2015. Ledgers and law in the blockchain. [online] Kings Review. Available at: <http://kingsreview.co.uk/articles/ledgers-and-law-in-the-block chain $>$ [Accessed 4 Sep. 2019].

Ehrsam, F., 2018. Blockchain-based machine learning marketplaces. [online] Medium blog. Available at: <https://medium.com/@FEhrsam/blockchain-based-machine-learn ing-marketplaces-cb2d4dae2c17> [Accessed 4 Sep. 2019].

Ekholm, A., Karim, J., Nilsson, F., Riggare, S., Markovic, D., Wetter, E., Wahlgren, J., Olsson, J., Krohwinkel, A., Winberg, H., Rognes, J., Ahrnell, B-M., Sundström, P., Lindencrona, F., Bokström, T. and Wieselgren, I., 2016. Bortom IT. Om hälsa i en digital tid [Beyond IT: on health in a digital era. [online] Institute for Future Studies. Available at: $<$ www.iffs.se/publikationer/if-rapporter/bortom-it-om-halsa-i-en-digital-tid $>$ [Accessed 4 Sep. 2019].

Essén, A., Scandurra, I., Gerrits, R., Humphrey, G., Johansen, M., Kiergegaard, P., Koskinen, J., Liaw, S., Odeh, S., Ross, P. and Ancker, J., 2018. Patient access to electronic health records: differences across ten countries. Health Policy and Technology, 7(1), pp. $44-56$.

Essén, A. and Värlander, S., 2018. How materiality enables and constrains framing practices: affordances of a rheumatology e-service. Journal of Management Inquiry, 28(4), pp. $458-71$.

Ethereum, 2018. How to build a democracy on the blockchain. [online] Etherium homepage. Available at: <http://web.archive.org/web/20190424032704/https://ethereum.org/ dao $>$ [Accessed 4 Sep. 2019].

Faraj, S., Pachidi, S. and Sayegh, K., 2018. Working and organizing in the age of the learning algorithm. Information and Organization, 28(1), pp. 62-70.

Frey, C. and Osborne, M., 2017. The future of employment: how susceptible are jobs to computerisation? Technological Forecasting and Social Change, 114(C), pp. 254-80.

Galloway, S., 2017. The four: the hidden DNA of Amazon, Apple, Facebook, and Google. New York, NY: Penguin.

Gasser, U., Budish, R. and West, S., 2015. Multistakeholder as governance groups: observations from case studies. [online] Available at: < https://papers.ssrn.com/sol3/papers. cfm?abstract_id=2549270> [Accessed 4 Sep. 2019]. 
Gervais, A., Karame, G., Capkun, S. and Capkum, V., 2014. Is Bitcoin a decentralized currency? IEEE Security and Privacy, 12(3), pp. 54-60.

Gibson, J., 2015. The ecological approach to visual perception. New York, NY: Psychology Press.

Gilbert, R., Goldstein, H. and Hemingway, H., 2015. The market in healthcare data. British Medical Journal, 351, pp. 1-5.

Government Offices of Sweden, 2016. Vision e-hälsa 2025 - gemensamma utgångspunkter för digitalisering $i$ socialtjänst och hälso- och sjukvård. [Vision e-Health 2025 - shared departure points for digitalization of social and healthcare]. [online] Available at: <www.regeringen.se/4a1f04/contentassets/79df147f5b194554bf401dd88e89b791/ vision-e-halsa-2025.pdf $>$ [Accessed 4 Sep. 2019].

Greenhalgh, T., Potts, H., Wong, G., Bark, P. and Swinglehurst, D., 2009. Tensions and paradoxes in electronic patient record research: a systematic literature review using the meta-narrative method. The Milbank Quarterly, 87(4), pp. 729-88.

Gropper, J., 2016. Powering the physician-patient relationship with HIE of one blockchain health IT. ONC/NIST use of blockchain for healthcare workshop. [online] Available at: $<$ www.healthit.gov/sites/default/files/7-29-poweringthephysician-patientrelationship withblockchainhealthit.pdf $>$ [Accessed 4 Sep. 2019].

Gulliksen, J., Persson-Stenborg, A. and Backlund, A., 2016. För digitalisering i tiden. Slutbetänkande av Digitaliseringskommissionen [Digitalisation today: final comments by the digitalisation committee]. [online] SOU 2016:89. Available at: <www.regeringen. se/4af25c/contentassets/f7d07b214e2c459eb5757cea206e6701/sou-2016_89_webb. pdf $>$ [Accessed 4 Sep. 2019].

Harari, Y., 2015. Homo deus: a brief history of tomorrow. London, UK: Harvill Secker, Penguim Random House.

Hashed Health, 2018. Press. [online] Hashed Health homepage. Available at: <https:// hashedhealth.com/media/press $>$ [Accessed 4 Sep. 2019].

Hayek, F.A., 1948. Individualism and economic order. Chicago, IL: University of Chigaco Press.

Inera, 2016. Ineras ramverk [Inera framework]. [online] Available at: $<$ https://www.inera. se/globalassets/om-inera/styrdokument-och-rapporter/ineras-ramverk.pdf> [Accessed 4 Sep. 2019].

Inera, 2017. Verksamhetsstrategi [Business strategy]. [online] Available at: <www.inera. se/tjanster/journalen/Journalen/journalen-nationellt-ramverk $>$ [Accessed 4 Sep. 2019].

Kivimäki, P., 2018. There is no blockchain technology in the X-Road. [online] Nordic Institute for Interoperability Solutions. Available at: < https:/www.niis.org/blog/2018/4/26/ there-is-no-blockchain-technology-in-the-x-road $>$ [Accessed 4 Sep. 2019].

Kuo, T.T., Kim, H.E. and Ohno-Machado, L., 2017. Blockchain distributed ledger technologies for biomedical and health care applications. Journal of the American Medical Informatics Association, 24(6), pp. 1211-20.

Leonardi, P. and Barley, S., 2010. What's under construction here? Social action, materiality, and power in constructivist studies of technology and organizing. Academy of Management Annals, 4(1), pp. 1-51.

Lewis, A., 2017. A gentle introduction to self-sovereign identity. [online] Bits on blocks blog. Available at: <https://bitsonblocks.net/2017/05/17/a-gentle-introduction-to-selfsovereign-identity> [Accessed 4 Sep. 2019].

Lippman, A., Ekblaw, A. and Halamka, J., 2017. The potential for blockchain to transform electronic health records. [online] Harvard Business Review online. Available at: 
$<$ https://hbr.org/2017/03/the-potential-for-blockchain-to-transform-electronic-healthrecords $>$ [Accessed 4 Sep. 2019].

Mold, F., De Lusignan, S., Sheikh, A., Majeed, A., Wyatt, J., Quinn, T., Cavill, M., Franco, C., Chauhan, U., Blakey, H., Kataria, N., Arvanitis, T. and Ellis, B., 2015. Patients' online access to their electronic health records and linked online services: a systematic review in primary care. British Journal of General Practice, 65(632), pp. e141-e151.

MyHealthData, 2018. A new paradigm in healthcare data privacy and security. [online] MyHealthData homepage. Available at: <www.myhealthmydata.eu $>$ [Accessed 4 Sep. 2019].

Nakamoto, S., 2008. Bitcoin: a peer-to-peer electronic cash system. [online] Available at: $<$ https://bitcoin.org/bitcoin.pdf $>$ [Accessed 4 Sep. 2019].

Naylor, A. and Jones, E., 2017. Intelligent sharing: unleashing the potential of health and care data in the UK to transform outcomes. [online] Future Care Capital. Available at: $<$ https://futurecarecapital.org.uk/wp-content/uploads/2017/07/Full-Report-Unleashingthe-potential-of-health-and-care-data.pdf $>$ [Accessed 4 Sep. 2019].

Newell, S. and Marabelli, M., 2015. Strategic opportunities (and challenges) of algorithmic decision-making: a call for action on the long-term societal effects of 'datification.' Journal of Strategic Information Systems, 24(1), pp. 3-14.

Nicol, P., 2017. The power of blockchain for healthcare: how blockchain will ignite the future of healthcare. Newington, CT: Author.

Nofer, M., Gomber, P., Hinz, O. and Schiereck, D., 2017. Blockchain. Business \& Information Systems Engineering, 59(3), pp. 183-7.

Office of National Coordination, 2016. News. [online] Office of National Coordination homepage. Available at: <http://wayback.archive-it.org/3926/20170128063822/www. hhs.gov/about/news/2016/08/29/onc-announces-blockchain-challenge-winners.html> [Accessed 4 Sep. 2019].

OpenData, 2019. Den nationella dataportalen för öppna data [The national portal for open data]. [online] National portal for open data. Available at: $<\mathrm{https}$ ://oppnadata.se $>$ [Accessed 9 Aug. 2019].

Paquet, G., 2000. The new governance, subsidiarity and the strategic state. [online] Available at: $<$ http://citeseerx.ist.psu.edu/viewdoc/summary?doi=10.1.1.580.8542 $>$ [Accessed 4 Sep. 2019].

Patientory, 2018. Your health at your fingertips. [online] Patientory homepage. Available at: $<$ https://patientory.com $>$ [Accessed 4 Sep. 2019].

Peterson, K., Deeduvanu, R., Kanjamala, P. and Boles, K., 2016. Mayo Clinic: a blockchainbased approach to health information exchange networks. [online] Available at: $<$ www. healthit.gov/sites/default/files/12-55-blockchain-based-approach-final.pdf $>$ [Accessed 4 Sep. 2019].

Pinto, L., 2018. OpenNCP introduction. [online] Open NCP homepage. Available at: $<$ https:/ec.europa.eu/cefdigital/wiki/display/EHNCP/OpenNCP+Introduction $>$ [Accessed 4 Sep. 2019].

Preukschat, A., 2018. Self-sovereign identity - a guide to privacy for your digital identity. [online] Medium blog. Available at: <https://medium.com/@AlexPreukschat/self-sov ereign-identity-a-guide-to-privacy-for-your-digital-identity-5b9e95677778> [Accessed 4 Sep. 2019].

Redelmeier, D. and Kraus, N., 2018. Patterns in patient access and utilization of online medical records: analysis of MyChart. Journal of Medical Internet Research, 20(2), e43, pp. 1-9. 
Reijers, W., Brochain, F. and Haynes, P., 2016. Governance in blockchain technologies \& social contract theories. Ledger Journal, 1, pp. 134-51.

Risus, M. and Spohrer, K., 2017. A blockchain research framework: what we (don't) know, where we go from here, and how we will get there. Business \& Information Systems Engineering, 59(6), pp. 385-409.

Rothbard, M., 1978. For a new liberty: the libertarian manifesto. Rev. ed. For a new liberty. New York, NY: Collier Books.

Sellberg, N. and Eltes, J., 2017. The Swedish patient portal and its relation to the national reference architecture and the overall eHealth infrastructure. In: M. Aanestad, M. Grisot, O. Hanseth and P. Assilakopoulou, eds., Information infrastructures within European health care. Paris, France: Springer, pp. 225-44.

Sparkes, M., 2014. The coming digital anarchy. [online] Telegraph online. Available at: $<$ www.telegraph.co.uk/technology/news/10881213/The-coming-digital-anarchy.html> [Accessed 4 Sep. 2019].

Spiekermann, S., Acquisti, A., Böhme, R. and Hui, K., 2015. The challenges of personal data markets and privacy. Electronic Markets, 25(2), pp. 161-7.

Strong, D., Johnson, S., Tulu, B., Trudel, J., Volkoff, O., Pelletier, L., Bar-On, I. and Garber, L., 2014. A theory of organization-EHR affordance actualization. Journal of the Association for Information Systems, 15(2), pp. 53-85.

Swan, M., 2015. Blockchain: blueprint for a new economy. Sebastopol, CA: O'Reilly Media.

Taplin, J., 2017. Move fast and break things: how Facebook, Google, and Amazon cornered culture and undermined democracy. New York, NY: Little, Brown and Company.

Tegmark, M., 2017. Life 3.0: being human in the age of artificial intelligence. New York, NY: Knopf Publishing Group.

Tobin, A. and Drummond, R., 2017. The inevitable rise of self-sovereign identity. [online] Available at: <https://sovrin.org/wp-content/uploads/2017/06/The-Inevitable-Rise-ofSelf-Sovereign-Identity.pdf $>$ [Accessed 4 Sep. 2019].

UK Parliament, 2018. Written evidence volume: AI in the UK: ready, willing and able? [online] Available at: <www.parliament.uk/business/committees/committees-a-z/lordsselect/ai-committee/publications> [Accessed 4 Sep. 2019].

Vest, J. and Gamm, L., 2010. Health information exchange: persistent challenges and new strategies. Journal of the American Medical Informatics Association, 17(3), pp. $288-94$.

Vimarlund, V., 2014. Sociala innovationer $i$ välfärden - Förutsättningar för ett E-hälsokonto. [Social innovations in welfare - prerequisites for an e-Health account] [online] Available at: <http://entreprenorskapsforum.se/wp-content/uploads/2014/06/UV_rap port_7_Vimarlund_webb.pdf $>$ [Accessed 4 Sep. 2019].

Vitaris, B., 2017. Swiss cryptovalley to create digital identities for its citizens on the Ethereum blockchain [online] Bitcoinmagazine online. Available at: $<$ https://bit coinmagazine.com/articles/swiss-crypto-valley-create-digital-identities-its-citizensethereum-blockchain $>$ [Accessed 4 Sep. 2019].

West, J. and O'Mahony, S., 2008. The role of participation architecture in growing sponsored open source communities. Industry and Innovation, 15(2), pp. 145-68.

Windley, F., 2018. How blockchain makes self-sovereign identities possible. [online] Computerworld online. Available at: <www.computerworld.com/article/3244128/security/ how-blockchain-makes-self-sovereign-identities-possible.html $>$ [Accessed 4 Sep. 2019]. 


\section{Anna Essén and Anders Ekholm}

Winfield, A., 2017. Blockchain: libertarian, authoritarian, or somewhere in between? [online] Forbes online. Available at: <www.forbes.com/sites/sap/2017/07/07/blockchainlibertarian-authoritarian-or-somewhere-in-between/\#2bdff0922e64> [Accessed 4 Sep. 2019].

Yudkowsky, E., 2016. AI alignment: why it's hard, and where to start. [online] Machine Intelligence Research Institute homepage. Available at: < https://intelligence.org/2016/12/28/ ai-alignment-why-its-hard-and-where-to-start> [Accessed 4 Sep. 2019]. 


\title{
5 Digitalization of health in Sweden to benefit patients
}

\author{
John Øvretveit
}

\section{Introduction}

\subsection{Brief definition and history}

This chapter considers the digitalization of health and health care in Sweden and other countries. The scope is digital health technologies (DHTs); digital services and technologies (DSTs); and how data are collected, analyzed, and used for different purposes. Sweden is used as an example because it is advanced in its use of digital technologies and gives lessons for other countries (Carter, 2015; Hardy, Boldt-Christmas and Tyreman, 2016; OECD, 2018). After a brief history, the chapter gives examples of DHTs and DSTs in Sweden, only some of which are potentially disruptive of traditional services. It discusses explanations for why digitalization in health has been slower than in other industries and more limited in the areas where it has been applied. It introduces the concept of "co-care" and describes services and devices that can empower patients to make decisions and perform self-management either independently from public-sector services or in cooperation with their publically employed clinicians and public services.

Swedish health care is mostly tax based, publically funded, and publically provided by local county councils within a national regulatory framework, with national grants to the counties to reduce inequities. The independence of counties is similar in some respects to that of the 16 German Länder and to the US and Australian state governments, and significant health reforms are made at both a county and national level. The 18 Swedish county councils, plus two regional bodies and one island municipality, referred to here as the 21 counties, are responsible for providing health services (primary, secondary, and public health) and for a good standard of health in their populations.

In 1992, the responsibility for long-term inpatient health care and care for older people was transferred to local municipalities, and, in 1996, so was care for the physically disabled and people with long-term mental illnesses. These directly run or contract nursing homes or home care services. In addition, the 290 municipalities provide social services, financial assistance, childcare, school health services, and environmental health, as well as non-health services for roads, water, sewerage, and energy. Both the county councils and municipalities raise tax from 
residents. Health care is financed 59 percent from county taxes, 23 percent from national insurance and state grants, 11 percent from patient charges, and 7 percent from payment by communes to county councils for some functions they have taken over (Anell, Glenngård and Merkur, 2012).

\subsubsection{Terms used in this chapter}

Co-care: shared decision-making and self-care supported by help from others, including clinicians and family (Øvretveit and Keel, 2014).

Digital services and technologies (DSTS): services provided over the Internet and technologies that collect and use digital data in different ways, including different types of software and hardware.

Digital health technologies (DHTs): DSTs used in health services for different financial, management, and clinical purposes; for promoting and maintaining health; or for preventing, treating, or caring for illness (Øvretveit, 2017).

Digital technology application (DTA): a device, service, or software program applied to meet a particular need of a user (Øvretveit, 2017).

Electronic medical record (EMR): an electronic record of health-related information on an individual that can be created, gathered, managed, and consulted by authorized clinicians and staff within one health care organization (NAHIT, 2008).

Electronic health record (EHR): a repository of information regarding the health status of a subject of care in computer-processable form, stored and transmitted securely, and accessible by multiple authorized users (ISO, 2005).

Patient-accessible electronic health record (PAEHR): termed "patient portal" if the patient accesses a health system record or "personal health record" for separate patient systems that often do not connect with the EHR (Øvretveit, 2017).

Digitally enabled learning health system: a health system that collects, stores, analyzes, and presents clinical and other data at the time and place that users require the data, and in a way that enables better-informed everyday decision-making. Such systems also support longer-term learning and improvement through research and quality improvement projects (Øvretveit, Nelson and James, 2016a).

\section{History}

Sweden is relatively advanced in its implementation of DHTs. Partially this is due to public investment in digital infrastructures such as broadband and hardware in the mostly publically funded and owned health care services. Partially it is due to a computer-literate and educated public citizenry and clinician workforce. Sweden was one of the countries with high take-up and early use of personal 
computers (PCs), Internet, and smartphones. People were ready for digital health information services and surprised by the slow deployment within public health care compared to other industries such as banking.

One of the earliest and most substantial uses of DHT was for electronic medical and health records. In the 1970s and 1980s, a number of physicians used PCs, but it was not until the 1990s that different hospital departments began to adopt PCs and networked EMRs. The first Swedish hospital to introduce a hospital-wide system was a 190-bed hospital in southern Sweden (Kajbjer, Nordberg and Klein, 2011). Many small commercial EHRs were developed, but most vendors went out of business because adoption was limited and problematic.

Cloud computing and developments by the larger EMR vendor systems led to a rapid take-up of EMRs in hospitals and primary care in the first decade of the millennium. This involved integrating into the system the physician medical records and the records for nursing and other health professions to construct an EHR. However, there was and still is limited shared patient data, especially between hospitals and primary health care, which often used different systems that could not be connected. One study on primary health care in Sweden in 2006, repeated in 2016, found limited used of the functionalities of an EHR compared to the United States (Øvretveit et al., 2007, Øvretveit et al., 2016b).

In 2009, the Swedish National Patient Summary initiative was launched in stages. Uppsala county was an early pilot site and, in 2012, became the first in Sweden to make EHRs accessible to patients (PAEHR). Later developments saw both clinical and welfare professions having authorized access to limited patient data. Research has found that some of the early EMR systems were unpopular with physicians (Boonstra and Broekhuis, 2010). Recent studies have identified one source of physician burnout and stress to be the demands of EMRs and other health information technologies. Many were not well designed to enable clinical practice and demanded extra time and effort to operate, even after physicians had become familiar with the systems (Wright and Katz, 2018).

A widely used security method was for authorized users to insert a credit card with a programmed chip into a chip reader that connected to the facility IT system and allowed and recorded the user's access to the patient's record. The Swedish patient data privacy law required the organization to register as a "data user" and to nominate a staff member as a data privacy officer to run monthly audits to check for unauthorized access.

Another significant development was the digitalization of the country's national clinical registers. As of 2016, there were 106 national clinical "quality registers." One example is the national orthopedic register that collects and stores data on hip and knee replacements, including data about the patient, procedure, prosthesis, and patient-reported outcomes (Larsson et al., 2012). Analysis of the data over a number of years led to the discontinuation of some hip replacement implants that showed unusually high re-operation rates due to implant deficiencies (Larsson, Lawyer and Silverstein, 2010). 


\section{The situation now}

\subsection{Digital health technologies and services in the public and private sector in Sweden}

A growing range of digital services and technologies are currently used by Swedish patients, clinicians, managers, and others to meet their different needs. Most of the examples below are small pilot schemes, limited to one county, or separately provided by private organizations. Some DSTs are used by patients only, and some functions are shared with others, especially patient data collection and analysis services, and this includes researchers and other health organizations.

\subsection{Target high-need/at-risk populations}

Over the last 20 years, more data from public national census surveys have been digitalized or entered directly into digital databases. These data and the software to analyze the data are used by health service planners, clinicians, managers, and researchers for a number of purposes. One example is software that presents geovisual displays to highlight geographical areas associated with high need (e.g., high rates of hospital admissions for heart attack from one local area). These data can direct attention to assessing causes (e.g., few health care services, unemployment, low income) and then to targeting interventions.

\subsection{Display actionable information}

Primary care physicians in some Swedish health centers can call up on their computer screens a list of their patients and see the current health data and status of each. Lists of patients are displayed with each patient's recent blood pressure rates, blood glucose, and other test results under different columns, so that a physician or nurse can quickly see which patients to follow up. Similarly, many nurses or social workers visiting patients at home can call up on cell phones or on mobile computer tablets basic data about their patients or clients and see alerts about tests, tasks, or help needed during the visit.

\subsection{Patient data collection for more effective actions}

Staff visiting patients at home can enter data about the patient directly into the patient's record to update and provide these data to other care workers at the same time. They can record the medications the patient is taking and receive any relevant alerts from the software that checks this entry against what the doctor has prescribed. In other situations, when a patient visits some clinics or emergency departments, these services provide patients with computer tablets that present a series of questions for the patient to fill in while waiting to see the physician or nurse (Zakim, 2016). The tablet uses a computer program that records the data for each question and provides the clinician with a printed history and recommended 
diagnosis that is often more accurate than that made by physicians without this computer-assessed method.

\subsection{Peer sharing and patient experiences}

The growth of patient associations is relatively recent in Sweden and has been accompanied by Swedish or overseas services that enable patients to share experience and information with other patients. The longest-running and largest is the UK PatientsLikeMe website that some Swedish patients also use. These patientrun and patient-directed sharing sites are developing rapidly and independently from health care services, although some are partnering with researchers and clinicians to enable patients to contribute their data for health research, such as CN3 (2018).

\subsection{Patient information and consults}

The first digital services to be offered to patients were information websites, and many exist in Sweden and are also based overseas. "Patient portals" are another channel for patients to health information provided by or authorized by health systems: the Swedish 1177 care guide system provides patients with different services and access to its patient portal with information about tests and appointments and functionalities such as appointment booking systems (Stockholm County Council, 2016a). As of 2018, patients in Sweden have limited or no online access to health professionals' notes or the ability to read or correct lists of their medications. In 2017, a pilot was started in Stockholm by the county council to allow patients to buy, at a subsidized rate of USD30, a consult with a privately contracted primary care doctor. This is one example of a potential disrupter being integrated into the public health system. In England in 2016, the national quality regulator found 24 of 28 online providers did not meet standards. A number did not confirm patient identity before prescribing drugs or communicate adequately with the patients' registered GPs (Care Quality Commission, 2018).

\subsection{Patient monitoring, feedback, and co-care}

A rapidly growing number of consumer devices and applications are available to the Swedish public from within Sweden and overseas, one example being a continuous glucose monitoring device for people with diabetes to track their changing blood sugar levels minute to minute. The accuracy and effectiveness of monitoring devices appears to vary widely, but there is little research into their use, value, and limitations, including the dangers of inaccurate devices. Two forefront Swedish approaches are Parkwell (for Parkinson's disease) and Genia, described in a later section of this chapter (OpenRatio, 2018; Genia, 2016). One service in use and under testing in different rural remote communities in Sweden is virtual health rooms, which are physical facilities that patients can use without assistance, but are physical facilities with devices for teleconsultations, self-administered blood 
testing, blood pressure, heart rate, blood glucose tests, and Coumadin tests linked remotely to the patient's EHR (Näverlo et al., 2016).

\subsection{Adherence}

Enabling some patients consistently to take prescribed medications and follow lifestyle practices to prevent ill health and remain healthy are two of the biggest behavioral health issues facing health care, especially for people with chronic illnesses such as diabetes or heart failure or at high risk of such illness. Nonadherence leads to health deterioration, avoidable suffering, and high cost in terms of unnecessary use. Many influences contribute to nonadherence beyond an individual's control, but reminders delivered by phone in text messages and smartphone apps can be effective for improving adherence. Various pill-box digital devices that send alerts when not opened at the required dose times, as well as "smart pills," are useful for enabling patient adherence to medications.

\subsection{Enhanced care management}

Care management is the coordination of different carers that the patient needs at different times. It involves multi-professional assessment of needs and care planning with goals of treatment, ideally involving the patients and their close carers (Øvretveit, 1993). The work of needs assessment, goal planning, monitoring, and coordination of care and visits is greatly assisted by an integrated care management digital health system with easy access by the patient and authorized persons giving services (Øvretveit, 2017). A common model is for an IT system only for care managers because of the complications of connecting this to the IT systems used by other providers, but this is of limited use. Future systems that can connect to other providers are used by some US integrated health systems (Øvretveit, 2017).

\subsection{Software for detecting potential adverse events and artificial intelligence}

There is increasing use of machine learning and artificial intelligence software in health care. One early and simple application is software that checks prescribed medication in EHRs and gives alerts for drug interactions, wrong doses, and allergy alerts (Wong et al., 2018). Later, more sophisticated software systems scan all EMRs for possible predictors or indications of medical error or adverse events such as surgical site infections (Savitz et al., 2014). Another example in Sweden is a patient history-taking system that uses a digital tablet to take a patient with chest pain through a series of questions and to assess the data for risk of heart attack and present a likely diagnosis and history to the clinician. This reduces time to diagnosis and assists in accuracy of diagnosis. In addition to this function, the system runs machine learning algorithms on data from each patient, which include data on the patients' subsequent health to improve predication and 
diagnosis (Zakim, 2016). Other examples are the use of machine learning for detecting pathology in images.

Will AI lead to specific services or devices that disrupt traditional health care service delivery? How advanced are these health care services in developing and applying AI for different purposes? At present only a few health care systems in Sweden and abroad are aggressively using AI, in part because of concerns about lack of independent evaluation of the accuracy and effectiveness of such systems.

\subsection{Faster emergency response}

It is difficult to imagine an emergency dispatch center or an emergency vehicle without an array of DHTs and DSTs. One example in Sweden is the ambulance services for stroke care, which include telemedicine connections to an emergency doctor and allow the health care staff to assess and authorize immediate treatment on the road as necessary.

\subsection{Patient flow improvement}

Many hospitals are using quality improvement methods to streamline the flow of patients through different services and departments along "patient pathways." Radio frequency identification and other types of sensors attached to the patient transmit data that can be displayed on screens to track where the patient is located and to improve the flow. The data are then aggregated and displayed on management dashboards and used in different ways to improve short- and long-term management of patient pathways and hospital performance.

\subsection{Surgery}

One of the earliest digitally assisted devices used in surgery was the addition of digital technologies to laparoscopic surgery systems for gallbladder and other types of keyhole surgery. Many other systems are in use, including the da Vinci system for more accurate surgery and tele-surgery performed by a surgeon in one place guiding surgery directly on a patient's body in another location using remote systems, as well as simulation systems (Wee Sim et al., 2016).

\subsection{Robots}

The physical surgery systems noted above are one type of robot, but perhaps more common are different material-transporting robots in hospitals. These are connected to systems that automatically detect low supply levels of materials in nursing and other units and collect and deliver supplies autonomously to different parts of the hospital (Stockholm County Council, 2016b).

The above only noted some of the more common DHSs and DSTs used in Sweden: the next section considers the disruption potential of different DSTs. Some of the issues that may limit rapid spread and adoption of these by both public 
and private services are concerns about evidence of effectiveness and about cost effectiveness, data security and privacy, increased workload for clinicians, and other unintended negative consequences such as safety issues and dependence on and cost of maintaining a system, and, for private suppliers and services, support might no longer be available in the future. There are also concerns about increasing inequities in access and in health when some older, less educated, or less digitally literate patients may not be able to use online services, and that health care providers in wealthy areas would be more able to apply DHTs to improve their services, thus also increasing digital disparities.

\section{The concept of co-care disrupts traditional relationships between patients and health care}

\subsection{Factors influencing the disruptive potential of digital services and technology}

The above summarized a variety of both digital services and technologies in Sweden, provided by public-sector health organizations, independent private organizations, or private-public partnerships. The following now considers DSTs that may disrupt traditional physician-patient relationships and services and also disrupt the way in which public health care services in Sweden have traditionally been funded, organized, and run.

Some DSTs may be taken up by clinicians because of their convenience, time saving, or contribution to the quality of the services that they are able to provide. They may be used by clinicians in response to patient demands, such as exchanging emails with patients outside of their formal health informatics systems, even though this may be prohibited practice. In many cases, clinicians may lead the development of disruptive DSTs: sometimes their frustration with a lack of support by the public health system for their digital innovations has led to them to develop and offer such innovations independently from the public health system, as happened in the past with some non-digital medical devices and technologies. Some DSTs may be taken up by patients for different reasons, and most use medical information websites, either publically provided, publically approved, or other international public or private sites.

The following advances a theory that an important and neglected factor contributing to the disruption of health care by some DSTs is patient wishes for self-determination and control over their own health and health data, as summarized in the concept of "co-care" discussed below. This wish is fueled by patient experience of the convenience and usefulness of other digital services and by patient advocacy movements as well as other cultural trends. The following proposes that patient advocacy movements, patient organizations, and the rise in support by politicians for patient involvement in their health and health care is a background factor creating a precondition for the disruptive potential of new DSTs. This, in turn, relates to changing attitudes regarding the role of the individual and the state, which, in Sweden, has shifted over 
the last 30 years from collectivism to more individualism with a wish for more choice and autonomy.

\subsection{Co-care, digital services and technologies, and disrupting the patient-provider power balance}

"Co-care" is shared decision-making and self-care supported by help from others, including clinicians and family (Øvretveit and Keel, 2014). Shared decision-making is one type of co-care where "clinicians and patients share the best available evidence when faced with the task of making decisions, and where patients are supported to consider options, to achieve informed preferences" (Elwyn et al., 2010). Research has shown the benefits of self-care, especially for patients with chronic illness or at risk of such illness, as well as the benefits of shared decision making (Da Silva, 2012). Modern person-centered integrated care (PCIC) recognizes that most care is self-care, supported by family members and friends ("close carers"), and that the person must be at the center of the integration model, with health care providers supporting them and their close carers (Scholl et al., 2014; Redding, 2013; Goodwin, 2016; PAF, 2018; Øvretveit, 2017).

Another concept driving these changes is "expert patient knowledge": the knowledge that patients have about their symptoms and about "what works for me," which are the strategies that they use that help them to manage their symptoms and their health. More patients are sharing and learning from other patients about such strategies (PatientsLikeMe, 2018; The Health Foundation, 2018). This individual and collective patient knowledge is different from a clinical professional's knowledge about disease and treatment effectiveness, much of which relates to "the average patient" (Kent and Hayward, 2007). Patient knowledge is also about the activities and life goals that are now important to them after their diagnosis and experiencing the effects of their illness. Patient-driven care and treatment are choosing treatments, care, and self-care strategies that enable patients to perform the activities and achieve the life goals that are important to them at different times (Øvretveit and Degsell, 2020). Patient capacity for sharing care and self-care can be developed into competences for these activities, especially for patients classified as being from a disadvantaged group (Olry de Labry Lima et al., 2017).

In Sweden, a number of DHSs are being used to enable patients to perform selfcare, to support shared decision-making, and to implement co-care in different services. Some are being developed in private-public partnerships, while some are being developed privately and independently of the public health system. One is a symptom-monitoring tool used by patients to enhance the everyday management of cystic fibrosis (CF). This tool was developed by the chair of Cystic Fibrosis Association, who funded the company that owns and distributes the tool (Genia, 2016). The CF Association organizes networking, collaboration, and shared learning among CF patients. The CF Association works with all CF Centres of the six university hospitals in Sweden to help develop the use of the CF national clinical registry and the Genia tool. 
Another self-tracking tool is the ParkWell smartphone application, developed by a patient-engineer in collaboration with the company Cambio, which tracks patients' medication administration and related short-term motor symptoms (OpenRatio, 2018).

A third tool is the patient evaluation of co-care survey (PECS). This is a tool for patients to assess how much the service they have received has assisted them in performing the activities they now wish to achieve and that are made more difficult by their health condition (Degsell and Øvretveit, 2018).

A further patient-driven innovation that relies on an Internet platform for sharing information and providing education are the site and applications associated with Swedish "Recovery Colleges." These follow the examples established in the National Health Service in England (The Health Foundation, 2018). Those colleges aim at increasing people's self-confidence in their self-management of their mental health and well-being. It is believed to help persons experiencing mental ill health to take control of and overcome or manage the challenges posed by their mental health difficulties.

One criticism of co-care is that it may meet the wishes of educated and wealthier patients, but may disadvantage some patients who are limited in the extent of shared decision-making and self-care that they can undertake by socio-economic and educational factors. A compromise approach is that more self-care by the privileged might release resources to invest in support for those more challenged to perform self-care.

\subsection{Will co-care and patient power contribute significantly to disruption by some digital services and technologies?}

The above-described co-care is one approach that epitomizes features of the patient advocacy and consumer movements that are increasingly being supported by politicians in Sweden. The section described digital services and technologies driven by these influences and being applied to implement co-care in patients' everyday lives. It noted the challenges that routine health care services face in integrating the functions and data from these services into health care services.

Disruption questions are whether these innovations are subsequently integrated into the public health system after their development outside or are widely taken up and become a separate - and alternative - health service, or part of one, at a price and convenience that challenge the public-sector services. The latter may happen with private medical consultation services over the Internet. This then presents challenges for coordinating care, especially if many patients and clinicians are using a set of independent services and data that are not integrated: a situation similar to patients using alternative medicines and treatments in addition to their public health care treatments. Options for public health care are to contract such services and to integrate their data and establish ways to coordinate care with them, or to copy the services and to offer patients the benefits of integration and supposedly greater data security and privacy. The former model is under testing in Stockholm for patient-doctor video consultation, and 
the latter model appears to be the one chosen by the English NHS (Marshall, Shah and Stokes-Lampard, 2018).

The integration of these devices and systems, the most rapidly growing sector being health-monitoring devices, depends in part on clinicians' motivation and capacity to use the patient data and functions as part of a broader change toward more patient-centered care. Other factors affecting whether these DSTs develop into significant disruptions is patient trust in the security of their data, and also whether the public health care technical systems can interface effectively with the data systems of these DSTs. Perhaps as significant is the number of patients that take up active and sustained use of these DHTs: it is possible that the patient early adopters, who tend to be more educated and digitally literate, will remain the main users and that other patients will find it difficult to use these DSTs, thus also raising concerns about increasing health inequities and the growth of a digital divide.

\section{Conclusion}

There are general conclusions for other countries from this example. Electronic health records and patient health records are examples of the many digital services and technologies that were developed independently of public health care services. More recently, public services have taken up this particular DHT on a large scale. However the connection of different EHR systems and also other DHSs to enable integrated care is a slow process, and the limited functionality of patient portals and their poor ease of use has meant that few patients use many public sector-provided services. Overall, the slow take-up of digital technology and services by the public sector has led to some clinicians and patients independently developing services and applications. Some remain stand-alone services provided by private organizations in Sweden or internationally. Some are being developed in public-private partnerships, such as subsidized primary care remote physician consultations.

Patient advocacy and patient organizations are advancing a patient-centered model of care and co-care that is driving the creation and take-up of independently developed DSTs. These DSTs, combined with these social movements and growing patient power, may lead to parallel systems and/or disruption of public health care services in ways that, for example, alternative medicine has not. We have yet to see if take-up and support of these systems by the more wealthy and educated patients will lead to lower-cost and easier-to-use systems that attract use by a larger majority or whether a growing digital divide may result. The potential for disruption is perhaps less for other devices and systems requiring significant investment: to date, private investors have not viewed the return on investment as sufficient to offset the risk and uncertainty of approval by regulators. Disruption may also be constrained by the concerns of patients and citizens about the security of health data and privacy issues. Whether justified or not, patients in Sweden are trusting of public health services to maintain their privacy, and this is one factor restricting disruption, especially by non-Swedish DSTs. 


\section{Acknowledgments}

I acknowledge the assistance of the book editor Anthony Larsson in revising the chapter.

\section{References}

Anell, A., Glenngård, A.H. and Merkur, S., 2012. Sweden health system review. Health Systems in Transition, 14(5), pp. 1-159.

Boonstra, A. and Broekhuis, M., 2010. Barriers to the acceptance of electronic medical records by physicians from systematic review to taxonomy and interventions. $B M C$ Health Services Research, 10(1), pp. 231-9.

C3N, 2018. About C3N project. [online] C3N Project. Available at: $<\mathrm{http} / / /$ web.archive. org/web/20180901235300/http://c3nproject.org/about-c3n-project> [Accessed 2 Sep. 2019].

Care Quality Commission, 2018. Online primary care inspection programme. [online] Available at: <www.cqc.org.uk/publications/themes-care/online-primary-care-inspec tion-programme $>$ [Accessed 2 Sep. 2019].

Carter, J., 2015. The reasons why Sweden is a hotbed for digital innovation. [online] TechRadar. Available at: <www.techradar.com/news/world-of-tech/the-reasons-whysweden-is-a-hotbed-for-digital-innovation-1292681> [Accessed 2 Sep. 2019].

Da Silva, D., 2012. Helping people share decision making. [online] The Health Foundation. Available at: $<$ https://www.health.org.uk/publication/helping-people-share-deci sion-making $>$ [Accessed 2 Sep. 2019].

Degsell, E. and Øvretveit, J., 2018. Patient evaluation of co-care survey (PECS). Stockholm, Sweden: Karolinska Institutet. Unpublished Survey (Available upon Request from MMC, Karolinska Institutet).

Elwyn, G., Frosch, D., Volandes, A.E., Edwards, A. and Montori, V.M., 2010. Investing in deliberation: a definition and classification of decision support interventions for people facing difficult health decisions. Medical Decision Making, 30(6), pp. 701-11.

Genia, 2016. Genia application and services. [online] Available at: <www.genia.se/home page> [Accessed 2 Sep. 2019].

Goodwin, N., 2016. Towards people-centred integrated care: from passive recognition to active co-production? International Journal of Integrated Care, 16(2), pp. 15, 1-2.

Hardy, P., Boldt-Christmas, O. and Tyreman, M., 2016. Värdet av digital teknik $i$ den svenska vården [Digitizing healthcare in Sweden]. [online] McKinsey \& Company. Report. Available at: <www.mckinsey.com/industries/healthcare-systems-and-services/ourinsights/digitizing-healthcare-in-sweden $>$ [Accessed 2 Sep. 2019].

The Health Foundation, 2018. The power of peer support at the Severn \& Wye Recovery College. [online] The Power of People. Available at: <www.health.org.uk/content/ power-peer-support-severn-wye-recovery-college $>$ [Accessed 2 Sep. 2019].

ISO, 2005. ISO/TR 20514:2005. [online] Health informatics - electronic health record definition, scope and context. Available at: <www.iso.org/standard/39525.html > [Accessed 2 Sep. 2019].

Kajbjer, K., Nordberg, R. and Klein, G.O., 2011. Electronic health records in Sweden: from administrative management to clinical decision support. In: J. Impagliazzo, P. Lundin and B. Wangler, eds. History of Nordic computing 3. HiNC 2010. IFIP advances in information and communication technology, vol 350. Heidelberg, Germany: Springer, pp. $74-82$. 
Kent, D.M. and Hayward, R.A., 2007. Limitations of applying summary results of clinical trials to individual patients: the need for risk stratification. JAMA, 298(10), pp. 1209-12.

Larsson, S., Lawyer, P., Garellick, G., Lindahl, B. and Lundström, M., 2012. Use of 13 disease registries in 5 countries demonstrates the potential to use outcome data to improve health care's value. Health Affairs, 31(1), pp. 220-7.

Larsson, S., Lawyer, P. and Silverstein, M.B., 2010. From concept to reality putting valuebased health care into practice in Sweden. [online] Boston Consulting Group. Available at: <www.bcg.com/documents/file64538.pdf> [Accessed 2 Sep. 2019].

Marshall, M., Shah, R. and Stokes-Lampard, H., 2018. Online consulting in general practice: making the move from disruptive innovation to mainstream service. $B M J, 360$, pp. k1195, 1-5.

NAHIT, 2008. The National Alliance for Health Information Technology report to the Office of the National Coordinator for Health Information Technology on defining key health information technology terms. [online] Available at: <www.himss.org/nationalalliance-health-information-technology-report-office-national-coordinator-health> [Accessed 2 Sep. 2019].

Näverlo, S., Carson, D.B., Edin-Liljegren, A. and Ekstedt, M., 2016. Patient perceptions of a virtual health room installation in rural Sweden. Rural and Remote Health, 16(4), pp. $3823,1-8$.

OECD, 2018. OECD reviews of digital transformation: going digital in Sweden. Paris, France: OECD Publishing.

Olry de Labry Lima, A., Bermúdez Tamayo, C., Pastor Moreno, G., Bolívar Muñoz, J., Ruiz Pérez, I., Johri, M., Quesada Jiménez, F., Cruz Vela, P., de los Ríos Álvarez, A.M., Prados Quel, M.Á., Moratalla López, E., Domínguez Martín, S., Lopez de Hierro, J.A. and Ricci Cabello, I., 2017. Effectiveness of an intervention to improve diabetes selfmanagement on clinical outcomes in patients with low educational level. Gaceta Sanitaria, 31(1), pp. 40-7.

OpenRatio, 2018. Enterprise-mobility. [online] Parkwell. Available at: <www.openratio. com/category/enterprise-mobility/page/2 > [Accessed 2 Sep. 2019].

Øvretveit, J., 1993. Coordinating community care: multidisciplinary teams and care management in health and social services. Buckkingham, UK: Open University Press.

Øvretveit, J., 2017. Digital technologies supporting person-centered integrated care - a perspective. International Journal of Integrated Care, 17(4), pp. 6, 1-4.

Øvretveit, J. and Degsell, E., 2020. Implementing patient and carer participation in self-care and co-care in Sweden: policy, practice and the future of person-centered care. In: M-P. Pomey, J-L. Denis and V. Dumez, eds. Patient engagement how patient-provider partnerships transform healthcare organizations. Basingstoke, UK: Palgrave Macmillan (Forthcoming).

Øvretveit, J. and Keel, G., 2014. Summary of the evidence review of the Swedish rheumatoid registry-supported care and learning systems. Stockholm, Sweden: LIME, MMC, Karolinska Institutet. Unpublished.

Øvretveit, J., Nelson, E. and James, B., 2016a. Building a learning health system using clinical registers: a non-technical introduction. Journal of Health Organization and Management, 30(7), pp. 1105-18.

Øvretveit, J., Ramsay, P., Shortell, S.M. and Brommels, M., 2016b. Comparing and improving chronic illness primary care in Sweden and the USA. International Journal of Health Care Quality Assurance, 29(5), pp. 582-95.

Øvretveit, J., Scott, T., Rundall, T.G., Shortell, S.M. and Brommels, M., 2007. Improving quality through effective implementation of information technology in healthcare. International Journal for Quality in Health Care, 19(5), pp. 259-66. 


\section{John Øvretveit}

PAF, 2018. Home - National Patient Advocate Foundation. [online] National Patient Advocate Foundation. Available at: <www.npaf.org > [Accessed 2 Sep. 2019].

PatientsLikeMe, 2018. A chance to change the future of personalized health. [online] Available at: $<$ www.patientslikeme.com $>$ [Accessed 2 Sep. 2019].

Redding, D., 2013. The narrative for person-centred coordinated care. Journal of Integrated Care, 21(6), pp. 315-25.

Savitz, L.A., Moore, S.L., Biffl, W., Price, C. and Gilmartin, H., 2014. A participatory research approach to reducing surgical site infections (SSIs). [online] Development of an Automated SSI Surveillance Tool. Agency for Healthcare Research and Quality, Rockville, MD. Available at: <www.ahrq.gov/professionals/quality-patient-safety/ patient-safety-resources/resources/advances-in-hai/hai-article17.html $>$ [Accessed 2 Sep. 2019].

Scholl, I., Zill, J.M., Härter, M. and Dirmaier, J., 2014. An integrative model of patientcenteredness - a systematic review and concept analysis. PLOS ONE, 9(9), pp. e107828, 1-9.

Stockholm County Council, 2016a. New in Sweden - healthcare. [online] Available at: $<$ http://web.archive.org/web/20171128122850/https://www.1177.se/Stockholm/Otherlanguages/New-in-Sweden---healthcare/English--Engelska> [Accessed 2 Sep. 2019].

Stockholm County Council, 2016b. Pratande robotar sköter logistiken på Nya Karolinska Solna [Talking robots to handle logistics at the new Karolinska hospital]. [online] Available at: <www.sll.se/verksamhet/halsa-och-vard/nyheter-halsa-och-vard/2016/04/Pra tande-robotar-skoter-logistiken-pa-Nya-Karolinska-Solna $>$ [Accessed 2 Sep. 2019].

Wee Sim, K., Baker, B., Amin, K., Chan, A., Patel, K. and Wong, J., 2016. Augmented and virtual reality in surgery - the digital surgical environment: applications, limitations and legal pitfalls. Annals of Translational Medicine, 4(23), pp. 454, 1-10.

Wong, A., Amato, M.G., Seger, D.L., Rehr, C., Wright, A., Slight, S.P., Beeler, P.E., Orav, E.J. and Bates, D.W., 2018. Prospective evaluation of medication-related clinical decision support over-rides in the intensive care unit. BMJ Quality \& Safety, 27(9), pp. 718-24.

Wright, A.A. and Katz, I.T., 2018. Beyond burnout - redesigning care to restore meaning and sanity for physicians. New England Journal of Medicine, 378(4), pp. 309-11.

Zakim, D., 2016. Development and significance of automated history-taking software for clinical medicine, clinical research and basic medical science. Journal of Internal Medicine, 280(3), pp. 287-99. 


\title{
6 Personalized predictive health care
}

\author{
How predictive AI platforms will \\ transform the health care industry
}

\section{Daniel Wänn}

\section{Introduction - from population to personal}

The past few years have seen a wide application of big data technology, including health care. Data from large populations drive analytics that have become better at defining public health conditions. Data analysis is used to better understand populations' health challenges based on geography, age, race, gender, socio-economic background (Cooper et al., 2001; Mackenbach et al., 2015), and so on, as well as for public health surveillance (Brownstein, Freifeld and Madoff, 2009). Big data holds great promise to deliver vastly improved health outcomes at significantly lower costs but has yet to show full realization (Groves et al., 2013).

These are powerful tools in their own accord and have the potential to change how public health care can be managed and improved. However, population data have disadvantages that limit their usability. Collection of health care data is rarely done in "real time." This means that any conclusions are based on data from past events, which is too late for individual intervention. It is not possible to prevent what has already happened, and predictive powers are limited to probability for groups of people, not individuals. Any conclusions regarding a subpopulation are only as good as the stratification used and will not necessarily predict the health outcome for any single individual therein. From the single individual's perspective, population health is merely abstract statistics that are easy to ignore; that is, "this does not affect me." Consequently, efforts to improve the health of a specific subpopulation risk becoming inefficient and/or a waste of resources.

In order to become relevant to the individual human being, big data must become personal. This means further developing the analytical powers of data analysis using deep learning algorithms, commonly known as artificial intelligence, and expanding the number of data sources used for analysis while carrying a strong sense of consumer focus. In the example below, Richard is a consumer of a predictive and personalized health care analysis platform.

It had been another long day at work, and Richard was commuting back home in the evening. The day had been full of meetings he barely had control over; firefighting activities with belligerent participants and unclear responsibilities. He mostly enjoyed his job, but the past six months had been worse than 
usual, requiring him to refocus his time and spend more of it on work issues, bringing work home and even into bed with him, answering emails before going to sleep and first thing in the morning even before getting up. It was temporary, he told himself, as he gradually reprioritized his daily schedule to make more time for work - his gym membership was paid for, but he hadn't been there for months; he'd been eating more fast food or skipping meals altogether, and less time had been spent with his family.

Richard's smartphone suddenly flashed a "red alert" on his health-tracking app. For months, the health tracker had been sending him weekly reminders about exercise, meditation, and sleeping habits, which he'd been ignoring. It had been telling him about his degrading sleep patterns, and that his pulse and blood pressure had become elevated, indicating increased physiological stress levels. Combining data about his activity levels from movement sensors, his nutritional choices from his meal tracking app, and his changes in habits from his calendar app, the tracker had warned him about the negative aspects of his lifestyle changes. Through the patient portal app, genetic data showing a predisposition for cardiovascular disease had been combined with family history data about his father and paternal grandfather both suffering myocardial infarctions before the age of 55. His latest blood tests from the company physical four months ago had shown increased levels of the stress hormone cortisol, micro-elevation in myocardial biomarkers, and a slight decrease in glucose sensitivity - although all falling within normal intervals, together indicating increased health risk. In the background, a powerful health care AI was constantly comparing his combined health data with that of tens of millions of others, looking for patterns in the vast sea of data.

"Warning: compared to peers in your population, your health data indicate that you are at 93 percent risk of developing a myocardial infarction within four weeks. Your primary health care provider has been alerted and an appointment for preventative intervention has been scheduled for tomorrow. Your calendar has been updated. Click here for details."

In the vaguely futuristic example above, Richard had permitted access to his private health data to be used not only for his own sake but also for the benefit of a much larger population. By enabling access to the huge amounts of data that could be realized through this type of pooling, it will be possible to apply AI to look for patterns in the data of a larger population, unbound by national borders. In Richard's case, the specific pattern had already been identified in the larger population but, until that moment, the conditions for matching him with the pattern had not attained a sufficiently high probability. Once the prerequisites had been achieved and the risk for an adverse health event identified, the platform could respond with automated medical advice and by integrating with Richard's health care provider, even providing a suitable intervention.

By focusing on the individual and using data unique to that person, it will be possible to predict health and disease to a high degree of specificity. Through AI analysis of population data, it is possible to identify unknown patterns that can 
be used to predict adverse health events for single individuals, as in the example above. The information is personalized and of higher relevance to the individual since it is based on their data. Information on personal health tailored to an individual has greater impact on behavioral change, which is key to health improvement and risk reduction (Celis-Morales et al., 2016). The requirement for such a platform to work, however, is access to patient and individual data in enormously larger amounts than previously possible.

As we will see below, advances are being made in several fields, including wearables and genomics, but these are all being developed within their own data silos. For personalized, predictive, and preventative health care to become reality, multiple data sources - including medical history, genomics, behavioral data, and real-time data from medical devices - will need to be harvested and combined across a large population and analytical results served back to the individual together with actionable medical advice (Flores et al., 2013).

This study looks at the prerequisites for creating a personalized, predictive, and preventative health care platform and how publicly financed health care would be affected by its emergence. The study takes its starting point in existing technology and ongoing initiatives, and then extrapolates, speculating on the prospective platform development, considering that we are at least a decade away from seeing the described platforms emerge.

\section{Discussion - building the platform}

Richard's story highlights some of the requirements for any system to provide personalized health care diagnostics and medical advice based on population data. In his work on systems medicine, Hood (2013) describes a system where medicine is personalized, participatory, predictive, and preventative, called $P 4$ medicine. In the coming medical revolution, knowledge of how to diagnose and treat disease will not be based on the population as a whole, but on peers - the part of the population "like you" - using far more granular characteristics than age and gender. In order for this to become reality, it will be necessary to create a platform bringing together three major functionalities: gathering data on individuals from a large number of disparate data sources, with four main types of data sources identified; analyzing the data in the context of each individual as well as for the population as a whole, extracting predictions based on the patterns identified; and, finally, offering actionable medical advice back to the individual. The four data source types and the three functionalities are further defined below.

Setting patient health care data free - patient data, locked into a large number of siloed electronic medical records systems, need to be set free. Every EMR uses its own data models and nomenclature, making data interoperability challenging. Collected data will need to be cleaned and translated to a common nomenclature. Examples of data include medical records, radiological diagnostics, interventions, pathology reports, diagnoses, and medication history.

Involving the individual - moving from reactive, event-driven health care to proactive, participatory health care will require large-scale transformation, not 
least of all to shift from only treating patients to also focusing on consumer behavior. It will require motivating healthy individuals to get involved in their own well-being far before any illnesses or symptoms, encouraging them to share data that otherwise would be considered beyond the scope of traditional health care: nutritional habits, workouts and activity levels, lifestyle choices, social media presence, education, work information, and so on.

Incorporating DNA - genomics is rapidly becoming available to the general population due to decreasing costs of DNA sequencing and increasing knowledge of individual genes' effect on health and well-being. Historically, genetic information about an individual would be part of a person's medical record, but this is quickly being eclipsed by the large number of people using publicly available sequencing services.

Measuring everything, now - wearable sensors are becoming far more prevalent due to decreasing prices and improving design. A bracelet can now contain sensors that measure heart rate, movement, sleep, workouts, and more. Other biosensors enable the measurement of blood glucose levels, oxygen saturation, respiration, body temperature, body weight, and more. These data are often locked within their own data systems and seldom used for anything outside their strict area of use. It will be crucial to enable the real-time exposure of sensor data.

Predictive diagnostics - combining data from the above sources will provide a rich insight into each individual's life and preconditions. Using AI, it is then possible to analyze the combined datasets for the entire population for patterns in health, illness, and well-being. These can in turn be used to identify individuals matching these patterns, but who have not yet had an adverse health event, such as in the previously illustrated example of Richard.

From prediction to advice - the final requirement for the system is being able to combine predictive diagnostics with medical advice. Initially, third-party providers of health care could be utilized to provide medical advice, to be replaced later with an AI advisor. The main source for medical advice today is based on the vast amount of medical studies available. It would be possible to train an AI to parse medical literature to create a set of best-practice recommendations, but in addition, AI could also analyze health care outcomes from peers in the population that have received treatment, identifying which treatments were more effective and carried with them better health care outcomes. The combination of these two sources - literature and population outcomes - would create the basis for personalized actionable medical advice.

In the next sections, we will look at each of these prerequisites in greater depth, discuss the most likely market actors involved, and examine the possible consequences of this type of platform and how this will affect publicly funded health care.

\subsection{Setting patient health care data free - the personal health record}

A key obstacle to creating health care data platforms is the lack of access to health care data. Data protection regulations ensure privacy but also mean that health 
care data are usually only available within the confines of organizational boundaries of health care providers, such as single hospitals or single counties/regions. Health care data from traditional sources, such as EMRs, as well as newer sources, such as medical devices, are estimated to globally grow from 153 exabytes (= 153 billion gigabytes) in 2013 to a staggering 2314 exabytes in 2020, the amount of data doubling each year (Stanford Medicine, 2017). Many health care providers and payers are looking to use health care analytics to make sense of their data to improve operations efficiency and the health of their population under treatment. The global health care analytics market is predicted to reach USD18.7 billion by 2020, up from USD5.8 billion in 2015 (Singh, 2016). However, the analytics conducted have limitations: the datasets are often too small to train AI for other purposes than general administrative automation and simpler predictive powers such as determining probable length-of-stay or risk of readmission in 30 days (Cohen, 2017).

EMRs contain information that answers the "what" in health care. Health care data provide a rich background of diagnostic data in the form of radiological imaging, laboratory tests, pathology tests, and clinical observations. Of equal importance, the records contain information on outcomes - what the patient was diagnosed with, what the treatment was, and what the outcome was. The information is, in itself, enough to start the process of training AI to spot patterns on clinically produced data alone. Unfortunately, EMR data are siloed by proprietary data models with low interoperability, and health care providers are often unable to exchange anything more than rudimentary patient information across organizational boundaries.

An AI-driven predictive health care platform would require a huge amount of data records to become meaningful, often much more than what is found within a single county or region. For countries with a limited population size such as the Nordics, this would require gathering data at a national level. From a national perspective, a government agency would need to be appointed with responsibility of developing a national EMR platform. Historically, this has been challenging, with low participation by counties and with unclear use cases. Trying to enlarge scope would entail amendments to the laws regulating health care data privacy, which would be challenging.

An alternative is to move ownership of and access to health care data to the patient through what is called a personal health record (PHR). Patients can grant direct access to their health care data to any party they see fit. This is an elegant solution to the problems of data privacy, since in the case of a PHR, the patient is in control of the data, thereby bypassing patient data laws. It therefore comes as no surprise to see collaborations such as between Apple and 12 US hospitals announced in January 2018 (Apple, 2018). Through Apple's Health Record, patients are able download, synchronize, and access their medical records data in a PHR on the Apple device platform. Through the PHR, patients are able to grant access to their data to a third party, such as Apple, enabling access to medical data that were previously legally inaccessible. This was made possible through Apple's 2016 acquisition of Gliimpse (Farr and Sullivan, 2016), a company that developed 


\section{Daniel Wänn}

PHR software that can scrub medical records for medical data, populating a PHR with meaningful and correct data. Making the health care data interoperable is a crucial step - without interoperability, it would not be possible to collate an individual's data from multiple EMR sources, and neither would it be possible to compare data between individuals with data from different sources. The two steps of setting patient data free and making them interoperable are therefore instrumental to succeed at any kind of meaningful analysis of health care data.

\subsection{Involving the individual - behavioral data}

If medical data, as described above, are the answer to "what," behavioral data are part of the answer to "why." The majority of acquired diseases are caused by a varying mix of nature (genetics) and nurture (background and behavior). Involving the individual will allow us to capture data directly from users, as well as providing communication with the user to convey results and advice.

It is well known that cardiovascular disease is at least partly influenced by behaviors associated with nutritional habits (Bazzano et al., 2002), physical exercise (Mora et al., 2007), and psychological factors such as stress (Kivimaki et al., 2002), as well as loneliness (Valtorta et al., 2016). Similarly, behavioral factors have been linked to many other forms of disease, including diabetes type 2 (Spruijt-Metz et al., 2014), certain types of dementia (Rakesh et al., 2017), and various forms of cancer (Khan, Afaq and Mukhtar, 2010).

An individual's behaviors are expressed in a multitude of ways in the digital world. To understand the individual, we do not even have to have access to the data describing traits or behaviors directly: correlative data can be utilized to infer certain traits and behaviors indirectly, for example, with users' choice of social media profile pictures, which could be used to accurately determine personality (Liu et al., 2016).

Already now, digital users are using applications for recording a large amount of behavioral data. These include recreational social media with images and information on peers and social events, professional social media with information on education and work information, fitness apps for logging exercise, calendar applications with information on schedules and time allocation, and nutrition/diet apps for logging dietary data.

As more people start using these applications in their daily lives, and as the applications continue evolving to become more user friendly, the information gathered through them will become more valuable. In a similar way to how patients can permit access to their medical data through a PHR, these applications can be leveraged to provide behavioral data, enabled by users permitting the use of their data.

\subsection{Incorporating $\mathrm{DNA}$ - genomics}

Genomics is rapidly becoming available to the general population due to the decreasing cost of DNA sequencing. From an initial cost of approximately 
USD300 million for whole-genome sequencing of the first full human genome completed in June 2000, the cost for whole-genome sequencing had dropped below USD1000 in 2016 (National Human Genome Research Institute, 2016), an astounding decrease in cost. There are multiple companies now offering genetic analysis aimed directly at consumers without a specific diagnostic purpose, including companies such as 23 andMe (2018) and myDNA (2018). Many of these services enable customers to download the raw genetic data, and there are even third-party services offering further genetic analysis using genetic data generated from other providers, for example, Promethease (2018).

This is highly advantageous since it means that access to genetic data is already enabled within the industry. The data models describing genetics are well understood, and genetic variations and their correlation with disease are being identified at a rapid rate. Having users upload their genetic data to the platform will create a huge pool of genomic information for a very large population. Combining these data with medical records and behavioral data will provide a complete picture of an individual's historic and present health and well-being, enabling AI analytics for pattern recognition.

\subsection{Measuring everything, now - wearables}

We are currently seeing the rapid emergence of generally accessible medical technology (MedTech) devices that were previously only available to health care institutions. MedTech devices would often be large, cumbersome, and complicated to use; the results difficult to interpret; and expensive to purchase, making it all but impossible for consumers to acquire privately. Now, practically anyone can buy digital devices with biosensors to measure blood pressure, pulse, movement, oxygenation, sleep patterns, caloric output, electrocardiogram (ECG), and much more. With the more advanced MedTech on offer, data are automatically collected, stored to the cloud, combined with previous data, and analyzed, and the results interpreted and delivered back to the user in accessible graphical interfaces. Additional services are combining results with medical recommendations or can be used to trigger other services such as alarms.

A recent example is the device Coala Heart Monitor by the Swedish company Coala Life (2018), which offer users the ability to self-monitor their heartbeat in the form of a simplified ECG. Together with the app on a smartphone and a service subscription, the user is alerted to any abnormalities and given recommendations depending on the result. Abnormal results can also be automatically relayed to a health care specialist for personalized advice. Another example is the use of wearable devices with an accelerometer for use among the elderly to detect falls, which has shown high specificity and sensitivity (Kangas et al., 2008). Reducing the time from fall to intervention decreases rehabilitation time. Yet another example is continuous blood glucose monitors for type 1 diabetics that automatically take measurements, helping users identify trends and better calibrate their insulin treatment (McGill and Ahmann, 2017). Treatment can also be simplified using an insulin pump instead of manual injections. There are recent 
advances in developing combined devices known as sensor-augmented insulin pumps (Steineck et al., 2017). The first devices have already been approved by regulatory agencies for medical use (US Food \& Drug Administration, 2018), but the technology is still in an early phase and subject to debate in regard to device security (Klonoff, 2015).

The wearable MedTech devices market is expected to grow from USD6.22 billion in 2017 to USD14.41 billion in 2022 (Research and Markets, 2018). There is also rapid innovation and development of recreational wearable devices, which are becoming far more ubiquitous. Traditional MedTech companies are under increasing competitive pressure by newer actors such as Apple, with its market entry of the Apple watch.

The criticism against recreational MedTech devices is that they are unsuitable for the medical monitoring of high-risk individuals. Trusting a workout bracelet with the task of monitoring individuals with, for example, a serious heart condition would clearly be in error, but this does not invalidate the use of the devices or the data they produce. Quite the opposite: for the purpose of generating the enormous amounts of vitals data necessary for training health care AI, it is necessary to accept and encourage the widespread use of recreational MedTech devices. In time, the commercially available sensors will develop in quality and further drop in price, as well as new biosensors becoming available as the market grows.

It also makes sense to approach the issue from a perspective of prolonged wellbeing instead of monitored disease. High-risk patients are few compared to the large number of healthy individuals. Their data are also generated after disease onset: to find disease onset patterns in populations, it is better to study healthy people falling ill rather than retrospectively looking at already ill people who cannot supply data from before illness onset.

\subsection{Predictive diagnostics - artificial intelligence}

The previous four sections have mainly been concerned with from where and how data can be gathered. As we have seen, it is through the users that data can be accessed - users give the platform permission to the various data sources for genomics, wearables, and behavioral and medical records. Even without a full complement of data sources for all users, it would still be possible to apply AI and start looking for patterns. Still, more data sources, more users, and more data will provide a better basis for precise pattern recognition: a case of more is more. Through continuous learning, patterns recognition is constantly being improved in both sensitivity and specificity, against which identified users' data are tested. Where a positive match is found, the user can be alerted to predicted diagnoses for the individual.

Medical records contain information on diagnoses that have been previously established: the platform $\mathrm{AI}$ is trained to recognize patterns that are common for diagnosis outcomes, which establishes the "what." Data from both the medical record as well as the other data sources are used by the AI to elucidate the "how" and "why." The more data available, the more precise the AI can become in its 
predictive capacity. Unfortunately, due to the nature of how deep learning works, it is not possible to understand the reasoning as to why the AI matches users with a specific outcome. To this end, it is only possible to test if the AI is accurate in its predictions.

The intrinsically alien mechanisms of how AI operates present a challenge to both users, consumers and clinical staff. A profound shift in how health care operates is necessary, where users, despite not understanding the reasoning behind predictive diagnostics, still trust the conclusions enough to act on the information.

Predicting diagnoses is only part of the predictive capabilities of an AI trained on platform data. AI can also be applied to understand treatment and intervention data in a far more complex way than today. For example, the majority of pharmaceutical studies are performed with a minimum of simultaneous medications to try to isolate the effects of the drug under observation. However, in real populations, patients with chronic illnesses often have a broad array of medications, so-called "polypharmacy." AI can analyze the underlying population data for a multitude of concurrent variables and better understand which treatment options might exist, precisely selecting the best option based on an individual's background.

\subsection{From prediction to action}

The final step for a personalized, predictive, and preventative platform is going from new knowledge to creating a compelling argument for action based on best practice, available evidence, and knowledge of the individual. It is through action of the individual that prevention can be achieved. Information on a predicted health outcome is not enough - the platform must also provide the user with persuasive advice on how to act on this knowledge.

The two major hurdles to providing AI-driven medical advice are regulations regarding medical responsibility, and trust from users. Can an AI be trusted? Can an AI be held responsible if we do not understand how it works? These questions are difficult to answer and almost philosophical in nature. They will almost certainly require clarification or amendment to the current legal system if fully automated medical advice would become a reality.

For these reasons, it is likely that the first versions of predictive platforms will limit themselves to providing health insights and advising users to contact their regular health care provider if any alarming matches are made. This is similar to how paramedical services (genomics, wearables) are offered today. The platform could simplify this process by offering users contact with thirdparty health care providers integrated through video chat, such as Kry (2018) or Min Doktor (2018).

The next phase of development would be providing paramedical advice, mostly relating to behavior. This type of advice is usually not considered medical treatment and therefore not regulated under health and medical services laws. Typically, this type of advice will focus on diet, sleep, and exercise. Again, third-party providers could be able to offer this type of advice through the platform. However, behavioral advice could also be generated using the AI to quantify behavioral 
change achieved by peers on the platform. The AI could identify behavioral commonalities among the peers that have had successful outcomes, reducing risk for illness, and presenting this as a possible course of action to the user.

Finally, and most challenging, the platform could offer the user medical advice on potential treatment options to decrease risk of identified possible adverse events. There are a number of regulative challenges that need to be met, such as in the opening questions above. This step would also require more intimate cooperation with local health care providers since the system would directly be responsible for creating demand for health care. Health care providers would need to be involved to understand how the system operates and how to handle users who have been given recommendations. There is also the question of what happens when medical professionals disagree with the diagnosis or recommended treatment (as further discussed in Section 2.8.2).

More so challenging, the AI would need to be able to act as a medical professional. Clinicians will, based on their experience and medical literature known to them, advise patients on the best course of action, using information on the patient's specific set of circumstances. The choice between several possible treatments is thus based on very different sources of information: research, experience, and patient background. However, clinicians face a problem of their own, which AI could help solve: digesting the immense number of medical studies available, which continue to grow at a daunting rate (Jinha, 2010). In 2016 alone, 870,000 new medical citations were added to MEDLINE, ${ }^{1}$ or about 1.6 citations added per minute (MEDLINE, 2018). Even if only 1 of every 1000 citations were to have direct relevance to a clinician, it would still require reading two published papers every day of the year to keep abreast of current research. An AI trained on medical literature could be potentially developed by a third party and offered as a service through the predictive platform. Together with the medical advice based on the AI trained on population health outcomes, the two sets of advice could be combined to give the best possible advice to each patient, based on the specific circumstances.

Given the complexities involved, however, it would be overly optimistic to believe that an AI would be giving unassisted medical advice within the next ten years. Far more likely is that the two AI platforms will be developed separately, and primarily offered to health care providers, so clinicians can offer better support to patients.

\subsection{Assembling the pieces}

In the previous sections, we have looked at the three major functionalities needed to build a platform that would enable personalized, predictive, and preventative health care: data collection from a large number of disparate sources, pattern recognition using AI to predict health outcomes, and finally leveraging medical knowledge to generate actionable medical advice. Understanding the challenges, we can now look more closely at which market actors are most likely to have the necessary capabilities and infrastructure to be involved in the creation of a platform. 
There are five main arguments about why we should expect large technology companies, rather than nationally owned initiatives, to build a predictive platform. These are: 1) technological experience, 2) speed of innovation, 3) required population size, 4) past initiatives, and 5) regulatory compliance.

1 Technological experience - any market actor hoping to create a robust, comprehensive platform for a large number of disparate data sources would need the knowledge and experience of how to plan and build large-scale data aggregation platforms. They would also need to have deep experience of AI and how to implement an AI system for pattern recognition. Typically, regional or national authorities do not possess this experience, and in the few cases where large-scale platforms have been created, external knowledge and expertise are brought in. More likely, it will be large technology companies with access to large digital infrastructure and previous AI experience that could develop a platform.

2 Speed of innovation - simply put, governmental agencies are not known for either innovation or speed of implementing new technology. It is unlikely that radically transformative change will emanate from within the health care sector itself, or any agencies linked to them.

3 Population size - to gain a large enough dataset to use for analysis, it will probably be necessary to go beyond regional boundaries, possibly beyond national boundaries. There is no method of knowing exactly how much data are needed to train an AI, but generally nonlinear algorithms such as AI, complex data, and complex patterns all require more data. In addition, as more data are added, the precision of pattern recognition will improve in both specificity and sensitivity, making the platform more valuable. With the sizeable number of variables for pattern recognition in the dataset - medications, diagnostics, genetics, wearables, behaviors - the dataset would likely need to be in excess of the possible number of users within the population of any single Nordic country. A market actor with the capability of acting across national boundaries is more likely to gather a large enough user base. The complexities involved in setting up a cooperative initiative between governmental agencies make such a solution unlikely. Private companies have more agile organizations and could therefore more easily solve the problem of gaining an international user base.

4 Past initiatives - all the Nordic countries have at least one national initiative with the purpose of providing a national, common patient health care record. Focus for the initiatives has mostly been health care providers, more seldom direct to consumers. Experience has shown that these initiatives have been cumbersome and often do not achieve the goals set. In Sweden, there have been two large-scale initiatives, Nationell patientöversikt (NPÖ), a national longitudinal patient record (Inera, 2018), and Hälsa för mig, a PHR (E-Hälsomyndigheten, 2018). The longitudinal patient record is geared toward health care providers and aims to collect patient medical records from health care providers across the country. Currently, all 21 counties/regions in Sweden have integrated with the service, even though the level of use varies markedly. In some counties, the system is updated for every patient visit. In other counties, the integration requires manual synchronization. In addition, private health care providers are not necessarily included. The system 
has not become widely popular despite having launched in 2009, possibly because of the low number of patients moving across county boundaries, and probably also because it is impossible to know if the information available shows a complete record or not. The launch of the PHR Hälsa för mig was initially delayed for several years due to regulatory issues regarding patient data laws (Datainspektionen, 2018). In October 2018, the responsible agency abandoned the project altogether after the Swedish administrative court (Swe: Förvaltningsdomstolen) ruled that the platform's data-sharing policy was in violation of patient data laws (E-Hälsomyndigheten, 2018). Both cases show that there are considerable barriers to creating large patient data platforms, and that governmental agencies might have additional challenges because of their assignment, unlike private companies, who are unaffected by such challenges.

5 Regulation compliance - a key obstacle to gaining access to data are the policies and laws regulating patient data. Most countries, especially in the Nordics, have regulations prohibiting sharing patient data across county/regional boundaries, unless specifically permitted by the patients themselves on a case-by-case basis. It would be impossible to create a data-driven predictive platform with these limitations. It is therefore necessary for two things to happen: the individual must take ownership of the data (both medical and personal), and the individual must permit the use of his or her data by the platform for general purposes. Health care organizations would not be permitted to operate a platform based on these regulations. An alternative would be a national agency with the assignment to create a platform, similar to the PHR solution covered in the previous section. This places the agency in the same position as any private company, however, and existing technology giants already have considerable experience in handling data privacy and security, placing them at a distinct advantage.

We can see that it would be far more likely for a successful platform to be created and operated by one or more large technology companies. However, publicly funded initiatives still have an important role to play in enabling their success, for example, through innovation funding, support from national agencies, and amending national regulations to ease access to data and cross-border data movement.

\subsection{Consequences}

The creation of a personalized, predictive, and preventative health platform will fundamentally change how health care is consumed. First, health care utilization will likely increase as accessibility and availability of health care increase (van Loenen et al., 2015). To a large extent, medically related questions that can be answered through knowledge alone could be provided through the platform itself, or through third-party providers offering medical advice through the platform. Second, analysis predicting the need for medical treatment would create demand for additional diagnostics such as radiography or laboratory, which would affect both private and public health care by driving costs. Third, if a need for medical intervention is confirmed, the individual would need to receive treatment - a core 
competency of publicly funded health care. Together, these factors affect both supplier-induced and consumer-induced demand on health care (Feldstein, 2012).

We can define five separate groups of market actors that would be affected by the transformation generated by a predictive platform: 1) consumers/users, 2) health care providers, 3) health care payers, 4) government and agencies, and 5) platform operators and third-party actors. Each of these groups faces distinct challenges and opportunities.

\subsubsection{Consumers/users}

Maybe the largest opportunity offered by a predictive platform is the empowerment stemming from users owning their data, being able control its use, and gaining real benefit from sharing it. Users would become more independent from health care providers since they would be able consume nonphysical health care through the platform and associated third-party providers. By having access to health care recommendations based on a holistic picture of their data, users would be able to make better-informed decisions regarding their own health and wellbeing. AI would be able to compare treatment outcomes based on the same type of pattern recognition as for prediction of health issues. This could be used to support the patient with recommendations on both what treatments to look for, as well as which health care providers are best at delivering care.

Of course, decisions based on data produced by an individual cannot be better than the quality of data provided. The platform would need to rely on data generated by wearables and biosensors that are beyond qualitative control of the platform. Because of this, there is risk of false positive and false negative matches, resulting in both overdiagnosis and underdiagnosis. Some of this risk can be mitigated through requirements on participatory devices and manufacturers but cannot be fully avoided. Consequences include risk for unnecessary diagnostics and treatments that might even cause more harm than they avert. Worse still, false negatives might mean completely missing diagnoses and unnecessarily delaying treatments.

Health care providers will need to adopt new strategies in how to meet expectations of users seeking diagnostic confirmation or treatment for a predicted diagnosis. Due to personal experience and knowledge, clinicians might arrive at conclusions contradictory to those of the predictive platform. Assuming a high level of sensitivity and specificity of the AI predictions - which will improve over time as more data are collected - clinicians will need to learn to understand the AI. From the perspective of the platform, this means exposing patient data and contextual decision support to the clinicians. It also means that clinicians will need to become technology and data literate to understand the information provided by the platform, knowing when to question or trust predictions.

There is also a risk of increasing inequality of access to health care. Since platforms most likely will be operated by private enterprise, there will be some kind of cost associated with use of the platform. This means that financially enabled consumers could have better access to the services provided, while less fortunate 
individuals might not be able to afford using the service. This becomes even more apparent if we also factor in the cost of genetic testing and various wearables providing detailed health data, costs the users must carry themselves. Lower digital literacy would also be a probable barrier to use, further increasing inequality as these groups - often uneducated, lower-income, and/or elderly - would likely benefit the most from participation (Choi and DiNitto, 2013).

The discussion about inequality in health care and well-being will become even more important as digital services evolve. Inequality carries a high societal cost when creating groups of haves and have-nots; research has shown that with increased equality in society, health becomes better for all social groups (Pickett and Wilkinson, 2009). It will be up to citizens and politicians to decide what type of society to build.

\subsubsection{Health care providers}

Health care providers are perhaps the organizational market actors that will be most profoundly affected by the transformative changes that a predictive platform could provide. Today, health care providers are accustomed to being in charge they control patient data, they control the domain knowledge, and they decide what patients need, effectively controlling diagnostics and treatment. When individuals are empowered with medical knowledge about themselves, they will be on more equal terms with health care, being able to place greater demands on providers. Since data on treatment outcomes will become available, users will also be able to make better choices about where to go for specific treatments. In many ways, this is what health care providers have been talking about for years putting the patient first - but it is unlikely that providers are prepared for the transformation required to succeed. Patients will need to be treated as customers and consumers first, rather than patients without choice. For example, this will require removing the use of queues as a barrier to health care. Another effect of empowered patients is that providers will need to improve their health care outcomes in order to stay relevant as a choice for patients. This will decrease variation in health care outcomes, improving quality in care at a domestic and possibly even international level (The NHS Confederation, 2004).

These same factors could also risk driving costs through unnecessary diagnostics and perhaps even unnecessary treatments. Besides possibly causing harm to the patients, this also increases the risk for inequality between patient groups, where vulnerable groups ${ }^{2}$ might be outcompeted for health care resources (Chang et al., 2004; Waisel, 2013).

A risk that a data-based analytical platform might induce is that of treatment suboptimization. At any point in time, the data available will only contain information on existing treatments, and treatments that are well established will have more data available. There is therefore the risk that these treatments will be overrepresented in the data, falsely showing better outcomes compared to new or novel treatments, where there typically is a learning curve. This imbalance could introduce a barrier to newer and better treatments to enter the market. The role of 
health care providers will become important in judging if a given patient would have better outcomes using a new technique rather than the common option; clinicians face a difficult task, sometimes needing to convince the patient of the need to act contrary to the advice of the platform.

\subsubsection{Health care payers}

With the introduction of a personalized platform, health care payers can look forward to the opportunity of decreasing the cost of health care by a sizable amount. Decreased costs would come about through two separate ways: first, by shifting some of the cost of health care to the consumer through subscriptions and selftreatment, and second, through decreasing the need for resources such as first-line health care providers, as this service could be offered through the platform.

For countries with a publicly funded universal health care system, this could introduce a risk of decreased willingness to pay high levels of tax, such in Sweden and the Nordics. As more users start paying for health care advice outside of the regular health care system, more people will question the validity of the current organization and funding of health care.

For systems with private insurance health care, there are risks that the payers could cherry-pick customers, turning away those they identify as carrying too high risk/cost. This does not represent a real difference to insurance companies' current business models, but the effect would become far more pronounced given powerful and reliable predictive tools. For consumers, it would therefore be important to understand how their health care data are used and who has access to them.

\subsubsection{Government and agencies}

In countries with universal health care insurance, such as the Nordics, decisions on resource allocation are based on available knowledge of the population's needs. The enormous amounts of health care data pooled by the platform will provide a rich dataset for understanding the needs of the population, and therefore also provide the tools for better resource management. Pattern recognition could provide advance warning for changes in population health such as influenza outbreaks, or slower changes such as increasing prevalence of chronic illnesses. Similarly, analysis of health care data could provide better understanding of the population under care, allowing for better segmentation so that health care initiatives could be properly targeted for maximum impact.

There are some challenges in that data might not be easily accessible to authorities wishing to make use of it. If the platform with collected data is operated by a private enterprise, access to data might be regulated and limited, especially if the platform is international. Authorities would likely need to collaborate with the platforms, possibly even becoming part of the revenue model.

Possibly, the largest challenge lies in preventing inequalities in access to health care that might become exaggerated through a participatory platform. As noted in the section on consumers, it is through a user's active participation, and therefore 


\section{Daniel Wänn}

through their digital literacy, that an individual user can gain the most from the platform. Vulnerable groups may not have the capacity to make use of these services.

\subsubsection{Platform operators and third-party actors}

The creation of a personalized, predictive, and preventative platform will provide the basis for an ecosystem of associated third-party actors and services. The market for wearable devices and biosensors will explode as demand for continuous monitoring equipment increases. Depending on the openness of the platform, it will be possible for third-party analytical services to offer medical advice and services directly to consumers. Anonymized data could be used for medical research in for example epidemiology, providing researchers with a far larger data source that previously ever available. It is likely, as noted above, that health care providers, health care payers, and governmental agencies all will become part of the ecosystem - either providing data or medical advice or extracting analytics.

\section{Conclusion}

Technological development is pointing in the direction of ever more complex systems where AI will become the central nervous system. Both Tegmark (2017) and Kurzweil (2005) argue that an AI-driven future is closer than we think, and that every aspect of human life will be changed by it. Health care organizations are generally resistant to change, so it is likely that changes in health care will be forced through changed consumer behavior (Edwards and Saltman, 2017). In the story at the beginning of this chapter, we could see how Richard, through personal use of technology, was empowered by his own data to act preventatively to improve his own health and avoid serious illness. The demand for health care was driven by a consumer-powered, automated system relying on AI to deliver predictive, preventative, and actionable advice directly to the end user, an extension to P4 medicine as described by Hood (2013).

The first steps toward building a personalized and predictive platform are already underway, with technology giants such as Apple and Microsoft heavily investing in the creation of PHR platforms, allowing patients to open up access and share their health care data. As the user base increases, more data sources will be added - such as genomics, wearables, and behavioral data - focusing on consumer needs. As consumer health care data are aggregated, the platform operators can apply their considerable expertise in the area of AI to identify patterns in the data, training the systems to predict adverse health events before they occur. The platforms will attract a large number of third-party providers, looking to offer health care advice and additional analytics. This ecosystem of providers will offer consumers high-quality monitoring and advice at low cost and without the cumbersome qualities of the current physical health care system, exhibiting long waiting times and low consumer satisfaction scores. Publicly funded health care will need to transform their business models, as the platforms will outcompete some 
services, such as acute primary care, and will complement others, such as treatment of patients with chronic conditions.

A possible solution to several of the challenges noted in this chapter would be to form partnerships between platform providers and national agencies governing health care payers and providers. Although disrupting current models of health care, a personalized, predictive, and preventative platform would provide benefits to all sides.

Eventually, the platforms will become sufficiently advanced to the point of being able to automate medical advice, although such scenarios are beyond the next decade.

\section{Notes}

1 MEDLINE is a journal citation database containing over 25 million references to biomedical and life sciences journal articles dating back to 1946, gathered from more than 5200 scholarly journals published around the world.

2 In this setting, "vulnerable groups" refers to population groups that have either an impairment of decision-making capacity, are unable to defend their rights to health care, or are unable to make use of modern information technology. Examples include the very young and the very old, individuals with serious mental disabilities including dementia, and individuals without equal access to information technology including the socioeconomically disadvantaged and individuals with literacy or language barriers.

\section{References}

23andMe, 2018. 23andMe homepage. [online] Available at: <www.23andme.com> [Accessed 4 Sep. 2019].

Apple, 2018. Apple announces effortless solution bringing health records to iPhone. [online] Available at: <www.apple.com/newsroom/2018/01/apple-announces-effortlesssolution-bringing-health-records-to-iPhone> [Accessed 4 Sep. 2019].

Bazzano, L.A., He, J., Ogden, L.G., Loria, C.M., Vupputuri, S., Myers, L. and Whelton, P.K., 2002. Fruit and vegetable intake and risk of cardiovascular disease in US adults: the first national health and nutrition examination survey epidemiologic follow-up study. The American Journal of Clinical Nutrition, 76(1), pp. 93-9.

Brownstein, J.S., Freifeld, C.C. and Madoff, L.C., 2009. Digital disease detection - harnessing the web for public health surveillance. New England Journal of Medicine, 360(21), pp. 2153-57.

Celis-Morales, C., Livingstone, K.M., Marsaux, C.F.M., Macready, A.L., Fallaize, R., O’Donovan, C.B., Woolhead, C., Forster, H., Walsh, M.C., Navas-Carretero, S., SanCristobal, R., Tsirigoti, L., Lambrinou, C.P., Mavrogianni, C., Moschonis, G., Kolossa, S., Hallmann, J., Godlewska, M., Surwiłło, A., Traczyk, I., Drevon, C.A., Bouwman, J., van Ommen, B., Grimaldi, K., Parnell, L.D., Matthews, J.N.S., Manios, Y., Daniel, H., Martinez, J.A., Lovegrove, J.A., Gibney, E.R., Brennan, L., Saris, W.H.M., Gibney, M. and Mathers, J.C., 2016. Effect of personalized nutrition on health-related behaviour change: evidence from the food4me European randomized controlled trial. International Journal of Epidemiology, 46(2), pp. 578-88.

Chang, B.L., Bakken, S., Brown, S.S., Houston, T.K., Kreps, G.L., Kukafka, R., Safran, C. and Stavri, P.Z., 2004. Bridging the digital divide: reaching vulnerable populations. Journal of the American Medical Informatics Association, 11(6), pp. 448-57. 


\section{Daniel Wänn}

Choi, N.G. and DiNitto, D.M., 2013. The digital divide among low-income homebound older adults: internet use patterns, eHealth literacy, and attitudes toward computer/internet use. Journal of Medical Internet Research, 15(5), pp. 1-15.

Coala Life, 2018. Coala life homepage. [online] Available at: <www.coalalife.com> [Accessed 4 Sep. 2019].

Cohen, J.K., 2017. Efficiency in hospital operations can tackle length of stay - how AI can help. [online] Becker's Healthcare. Available at: <www.beckershospitalreview.com/ artificial-intelligence/efficiency-in-hospital-operations-can-tackle-length-of-stay-howai-can-help.html $>$ [Accessed 4 Sep. 2019].

Cooper, R.S., Kennelly, J.F., Durazo-arvizu, R., Oh, H., Kaplan, G. and Lynch, J., 2001. Relationship between premature mortality and socioeconomic factors in black and white populations of US metropolitan areas. Public Health Reports, 116(5), pp. 464-73.

Datainspektionen, 2018. Datainspektionen [The Swedish data protection authority]. [online] Available at: <www.datainspektionen.se/nyheter/domstol-ger-datainspek tionen-ratt-om-halsa-for-mig $>$ [Accessed 4 Sep. 2019].

E-Hälsomyndigheten, 2018. Välkommen till Hälsa för mig [Welcome to health for me]. [online] Hälsa för mig [Health for me]. Available at: <www.halsaformig.se $>$ [Accessed 4 Sep. 2019].

Edwards, N. and Saltman, R.B., 2017. Re-thinking barriers to organizational change in public hospitals. Israel Journal of Health Policy Research, 6(1), 8, pp. 1-11.

Farr, C. and Sullivan, M., 2016. Apple acquires personal health data startup gliimpse. [online] Fast Company. Available at: <www.fastcompany.com/3062865/apple-acquirespersonal-health-data-startup-gliimpse $>$ [Accessed 4 Sep. 2019].

Feldstein, P.J., 2012. The demand for medical care. 7th ed. Health care economics. Boston, MA: Cengage Learning.

Flores, M., Glusman, G., Brogaard, K., Price, N.D. and Hood, L., 2013. P4 medicine: how systems medicine will transform the healthcare sector and society. Personalized Medicine, 10(6), pp. 565-76.

Groves, P., Kayyali, B., Knott, D. and Van Kuiken, S., 2013. The 'big data' revolution in healthcare: accelerating value and innovation. [online] Available at: $<\mathrm{https} / / \mathrm{www}$. ghdonline.org/uploads/Big_Data_Revolution_in_health_care_2013_McKinsey_ Report.pdf $>$ [Accessed 4 Sep. 2019].

Hood, L., 2013. Systems biology and P4 medicine: past, present, and future. Rambam Maimonides Medical Journal, 4(2), pp. 1-15.

Inera, 2018. Nationell patientöversikt - NPÖ [National patient overview - NPÖ]. [online] Available at: <www.inera.se/tjanster/nationell-patientoversikt-npo $>$ [Accessed 4 Sep. 2019].

Jinha, A.E., 2010. Article 50 million: an estimate of the number of scholarly articles in existence. Learned Publishing, 23(3), pp. 258-63.

Kangas, M., Konttila, A., Lindgren, P., Winblad, I. and Jämsä, T., 2008. Comparison of low-complexity fall detection algorithms for body attached accelerometers. Gait \& Posture, 28(2), pp. 285-91.

Khan, N., Afaq, F. and Mukhtar, H., 2010. Lifestyle as risk factor for cancer: evidence from human studies. Cancer Letters, 293(2), pp. 133-43.

Kivimaki, M., Leino-Arjas, P., Luukkonen, R., Riihimäi, H., Vahtera, J. and Kirjonen, J., 2002. Work stress and risk of cardiovascular mortality: prospective cohort study of industrial employees. BMJ, 325(7369), pp. 857-61.

Klonoff, D.C., 2015. Cybersecurity for connected diabetes devices. Journal of Diabetes Science and Technology, 9(5), pp. 1143-7. 
Kry, 2018. Kry homepage. [online] Available at: $<$ https://kry.se $>$ [Accessed 4 Sep. 2019].

Kurzweil, R., 2005. The singularity is near: when humans transcend biology. New York, NY: Penguin Books.

Liu, L., Preotiuc-Pietro, D., Samani, Z.R., Moghaddam, M.E. and Ungar, L.H., 2016. Analyzing personality through social media profile picture choice. In: M. Strohmaier and K.P. Gummadi, eds. Proceedings of the tenth international AAAI conference on web and social media (ICWSM 2016). Cologne, Germany, pp. 211-20.

Mackenbach, J.P., Kulhánová, I., Bopp, M., Deboosere, P., Eikemo, T.A., Hoffmann, R., Kulik, M.C., Leinsalu, M., Martikainen, P., Menvielle, G., Regidor, E., Wojtyniak, B., Östergren, O. and Lundberg, O., 2015. Variations in the relation between education and cause-specific mortality in 19 European populations: a test of the 'fundamental causes' theory of social inequalities in health. Social Science \& Medicine, 127, pp. 51-62.

McGill, J.B. and Ahmann, A., 2017. Continuous glucose monitoring with multiple daily insulin treatment: outcome studies. Diabetes Technology \& Therapeutics, 19(Supplement 3), pp. 3-12.

MEDLINE, 2018. Citations added to MEDLINE by fiscal year. [online] 10 Sept. Available at: <www.nlm.nih.gov/bsd/stats/cit_added.html> [Accessed 4 Sep. 2019].

Min Doktor, 2018. Min Doktor homepage. [online] Available at: <https://mindoktor.se> [Accessed 4 Sep. 2019].

Mora, S., Cook, N., Buring, J.E., Ridker, P.M. and Lee, I-M., 2007. Physical activity and reduced risk of cardiovascular events: potential mediating mechanisms. Circulation, 116(19), pp. 2110-18.

MyDNA, 2018. myDNA homepage. [online] Available at: <www.mydna.life > [Accessed 4 Sep. 2019].

National Human Genome Research Institute, 2016. The cost of sequencing a human genome. [online] Available at: <www.genome.gov/27565109/the-cost-of-sequencing-ahuman-genome $>$ [Accessed 4 Sep. 2019].

The NHS Confederation, 2004. Variation in healthcare - does it matter and can anything be done? [online] Available at: <https://www.nhsconfed.org/-/media/Confederation/ Files/Publications/Documents/Variation-in-healthcare.pdf $>$ [Accessed 4 Sep. 2019].

Pickett, K.E. and Wilkinson, R.G., 2009. Greater equality and better health. BMJ, 339(b4320), pp. 1154-5.

Promethease, 2018. Promethease homepage. [online] Available at: <https://promethease. com> [Accessed 4 Sep. 2019].

Rakesh, G., Szabo, S.T., Alexopoulos, G.S. and Zannas, A.S., 2017. Strategies for dementia prevention: latest evidence and implications. Therapeutic Advances in Chronic Disease, 8(8-9), pp. 121-36.

Research and Markets, 2018. Wearable medical devices market by device (diagnostic (heart, pulse, bp, sleep), therapeutic), application (sport, fitness, rpm), type (smartwatch, patch), distribution channel (pharmacy, online) - global forecast to 2022. [online] Available at: <https://www.researchandmarkets.com/research/n699wt/global_ wearable? $\mathrm{w}=5>$ [Accessed 4 Sep. 2019].

Singh, S., 2016. Healthcare analytics market worth $\$ 18.7$ billion by 2020. [online] WhaTech Medical Market Research. Available at: <www.whatech.com/market-research/ medical/archive/192126-healthcare-analytics-market-worth-18-7-billion-by-2020> [Accessed 4 Sep. 2019].

Spruijt-Metz, D., O’Reilly, G.A., Cook, L., Page, K.A. and Quinn, C., 2014. Behavioral contributions to the pathogenesis of type 2 diabetes. Current Diabetes Reports, 14(4), pp. 475-85. 


\section{Daniel Wänn}

Stanford Medicine, 2017. Stanford Medicine 2017 health trends report - harnessing the power of data in health. [online] Available at: <https://med.stanford.edu/school/ leadership/dean/healthtrends.html $>$ [Accessed 4 Sep. 2019].

Steineck, I., Ranjan, A., Nørgaard, K. and Schmidt, S., 2017. Sensor-augmented insulin pumps and hypoglycemia prevention in type 1 diabetes. Journal of Diabetes Science and Technology, 11(1), pp. 50-8.

Tegmark, M., 2017. Life 3.0: being human in the age of artificial intelligence. New York, NY: Alfred A. Knopf.

U.S. Food \& Drug Administration, 2018. FDA approves automated insulin delivery and monitoringsystemforuseinyoungerpediatricpatients. [online]FDANewsReleaseAvailable at: <www.fda.gov/NewsEvents/Newsroom/PressAnnouncements/ucm611475.htm> [Accessed 4 Sep. 2019].

Valtorta, N.K., Kanaan, M., Gilbody, S., Ronzi, S. and Hanratty, B., 2016. Loneliness and social isolation as risk factors for coronary heart disease and stroke: systematic review and meta-analysis of longitudinal observational studies. Heart, 102(13), pp. 1009-16.

van Loenen, T., van den Berg, M.J., Faber, M.J. and Westert, G.P., 2015. Propensity to seek healthcare in different healthcare systems: analysis of patient data in 34 countries. BMC Health Services Research, 15(1), pp. 465-75.

Waisel, D.B., 2013. Vulnerable populations in healthcare. Current Opinion in Anaesthesiology, 26(2), pp. 186-92. 


\title{
7 Digital dentistry
}

\section{A solution to the dentistry crisis?}

\author{
Anthony Larsson and Dominika Sabolová
}

\section{Introduction}

The concept of digital dentistry pertains to the dental technologies used to incorporate digital, or digitally controlled, components to perform dental procedures as opposed to using mechanical or electrical tools (Ito, Hamid and Ichikawa, 2016). The purpose of using digital dentistry is that it is more efficient than mechanical tools in conducting dental procedures. This applies to restorative as well as diagnostic purposes. Digital dentistry was developed as a means of meeting the increasing demands among patients for a faster, more secure, and more conformable experience. Digital dentistry has also been developed as a means of dealing with the shortage of resources in primary care. For instance, in the United States, this primary care shortage has led to an increased need to improve health care by increasing the utilization of existing health care providers (Giddon et al., 2013). Specifically, Petterson et al. (2012) forecast that the United States will require approximately 52,000 more primary care doctors by 2025 , of which the majority $(33,000)$ are required due to population growth. Other factors such as aging and insurance expansion will require an additional 10,000 and 8000 , respectively (Fodeman and Factor, 2015). Needless to say, this creates an unsustainable situation, as shortage of primary health care workers may compromise the quality of patient care. Smith (2019, para.3) states that "each primary care physician is estimated to spend more than 17 hours each day in the provision of acute, chronic, and preventative health care." Moreover, this is not a problem that is restricted merely to the United States, but is rather a challenge that has become prevalent worldwide as similar trends and developments have been observed across Europe, Asia, and other regions as well (Wu and Lam, 2016; Kuhlmann et al., 2015; Committee on Pediatric Workforce, 2015).

What is more, in recent years, the shortage of dentists has become even more prevalent internationally, and various outlets are now calling the situation a "crisis" (Minjarez, 2017; Beek and Davidson, 2016). This is likely to have even more detrimental consequences in geographic areas that are already underserved and where the incentive for a market-driven solution to the dentist shortage is low (Voinea-Griffin and Solomon, 2016). This is of particular concern, as the role of dentistry has often been overlooked in the overall discourse on health care 
(Giddon et al., 2013). This is in spite of the fact that dentistry is one of the world's oldest medical professions, harkening as far back as 7000 BC (American Dental Education Association, 2019). Much like primary care, it is predicted that in the United States, increases in dentist supply will not meet the increases in demand for dentists. This will, in turn, lead to an exacerbation of the existing shortage, and it is anticipated that the entire United States will experience a dentist shortage by 2025 (US Department of Health and Human Services, Health Resources and Services Administration and National Center for Health Workforce Analysis, 2015).

Just like with primary care, this dentistry situation is reflected in several other countries worldwide as well. For instance, in the Netherlands, the workforce of practicing dentists is rapidly decreasing due to aging. In 2017, there were approximately 10,000 dentists working in the Netherlands. From this selection, only 29 percent were younger than 40 years of age (Schreijer, 2018). Beyond that, 56 percent of those dentists under 40 were female (Schreijer, 2018; Van der Zande et al., 2015). In the Netherlands, it is not uncommon for women to combine their careers with their families by working part-time (Pieters, 2018; Kalmijn and Luijkx, 2006). This means that the effective amount of full-time employed dentists is not enough to saturate the market consisting of an ageing workforce. Moreover, the annual number of new dentists graduating and entering the profession (roughly less than 240) is not in parity with the number retiring each year (approximately 300) (DutchNews, 2019). On this account, it should be noted that approximately 78 percent of all Dutch people visit the dentist at least once a year, and out of this group, each person will visit their clinic about 2.7 times per year on average (Versteeg, 2016).

In the United Kingdom, the British Dental Association (BDA) figures published in 2018 indicated that 68 percent of National Health Service (NHS) practices in England struggled to fill vacant posts, which was an 18 percent rise on the 2016 figure (British Dental Association, 2018). In past few years, it has been reported the recruitment crisis at the United Kingdom's largest provider, Mydentist (with 10 million patients on its books), has become so dire it has left thousands of Britons unable to see NHS dentists (British Dental Association, 2019). This resulted in patients having to wait several months to see a dentist (Ford, 2019; Gupta, 2017). While there are a few countries in Europe where the number of recruited dentists has increased in the past few years (such as Lithuania), several other countries have shown a downward trend (including Greece, Denmark, France, etc.) (Fedcar, 2017).

A 2017 study showed that a lingering consequence following the 2008 European financial crisis is that fewer people with low incomes tend to visit the dentist today (Elstad, 2017). The same study also concluded that Ireland, Spain, and Switzerland were among the countries with the worst insurance coverage of health services, while several Eastern European countries, such as Slovakia, Slovenia, and the Czech Republic, had the best dental coverage. The reason for this is that these countries have to a large extent preserved much of the staterun health system that was present during the Cold War era (Elstad, 2017; Balci, 2017). These countries do not face the same projected population growth as many 
of the Western European countries, and introducing a similar type of state-run health system in the rest of Europe will likely be impossible for political and market reasons. Moreover, many of the state-run subsidies only cover routine visits and check-ups. In Slovakia, for instance, dental care is chiefly private, with dentists being paid on a fee-for-service basis, and specialized dental treatment (e.g., crowns and bridges) will cost the patients extra. To exemplify, depending on the material used, a cavity treatment can in itself cost up to $€ 80$ (EURACTIV Slovakia, 2012). The situation in the Czech Republic follows a similar pattern, with dental insurance largely covering basic dental care. This entails limited numbers of the most usual treatment measures, with those wishing to pay out of their own pocket being more likely to gain access to more advanced dental equipment (Manski et al., 2015). Moreover, in some European countries, such as Germany, the dental health service is to a large extent included in the normal health service insurance schemes. In other countries like in Norway, most adults would need to fund their regular dental health services entirely out of their own pocket, even though private insurances may provide a solution to some people who have a subscription (Balci, 2017).

One may thus conclude that the dental welfare deficit is a twofold problem. On the one hand, there is the matter of a shrinking dentistry workforce. On the other hand, there is a matter of unaffordable dental care for large parts of the population in many parts of the world. Thus, the situation would seemingly call for a new and radical approach to address these problems. To this end, arguments have been raised in regard to digital dentistry and its potential to stem the tide. Specifically, the contention is that the application of digital dentistry could take some of the workload off dentists for less complex procedures, as these could then be handled by midlevel providers, which in turn results in more accessible dental care at lower cost. Hence, by discussing extant literature and best-practice developments in the area, this chapter aims to investigate the potential for digital dentistry to address the dental welfare deficit problem in its aspiration of providing more effective and more affordable dental care in the future.

\section{The origins of digital dentistry: computer-aided design/computer-aided manufacturing}

In the words of Schleyer (1999, p. 1713), the aim of digital dentistry is to develop "a cadre of experts in dental informatics, relying on sound research principles, effectively disseminating best practices and developing strategic objectives for the implementation of technology." At bedrock, digital dentistry is in itself not a new concept per se, as computer-aided design and computer-aided manufacturing (CAD/CAM) had already been invented in 1973 and implemented in practice more regularly during the 1980s (Ritter, Boushell and Walter, 2019; Lin, 2018). While there is no question that dental CAD/CAM revolutionized dentistry, it was in its early stages considered to be somewhat of a unwieldy novelty, as it required a disproportionate amount of time to produce a viable product due to slow speeds and a cumbersome interface (Tang, Medioni and Duret, 1998). 
The purpose behind the development of the CAD/CAM was that, before its inception, it was difficult for dentists to construct crown and bridge structures, as this requires capacity to freely design a three-dimensional crown form, that is, full occlusal proximal, labial (buccal), and lingual surfaces, freely (Ueda and Yamaguchi, 2017). In time, use of CAD/CAM became the quintessential way to support the processing method and workflow. Dental CAD/CAM systems have continued to advance rapidly, and nowadays 3D model scanners and dental CAD/ CAM systems are used worldwide (Ueda and Yamaguchi, 2017). Today there are a multitude of different chairside and laboratory-based CAD/CAM systems, such as Procera (Nobel Biocare), Lava (3M ESPE), Cercon (DENTSPLY Ceram-co), CEREC (Sirona), and E4D (D4D Technologies), just to name a few examples. These systems are used to design and manufacture metal, alumina, and zirconia frameworks, as well as all-ceramic and composite full-contour crowns, inlays, and veneers (McLaren, Culp and White, 2008).

\section{The next steps in digital dentistry}

Nowadays, digital dentistry has evolved far beyond the mere use of CAD/CAM, and several other digital technologies are currently used by dentists all over the world. For instance, intraoral cameras (IOCs) are cameras used by dentists to show a patient the interior of their mouth, rather than using a mirror. They were first developed in the late 1980s as oversized mobile units, and have through the decades shrunk to pocket-sized lightweight wands (Darby and Walsh, 2015). An advantage of using these is that they have the ability to magnify teeth 40 to 60 times their original size, making it possible for the dentist to identify defects within the oral cavity.

In more recent years, however, there have been particular advancements in the development of 3D printing and virtual reality (VR) and augmented (AR) reality. Three-dimensional printing, for instance, has been hailed as a disruptive technology that will change the very essence of manufacturing. Three-dimensional printing has a particular resonance with dentistry, with its use including everything from "the production of drill guides for dental implants, the production of physical models for prosthodontics, orthodontics and surgery, the manufacture of dental, craniomaxillofacial and orthopedic implants, and the fabrication of copings and frameworks for implant and dental restorations" (Dawood et al., 2015, p. 521). In other words, 3D printing may be used to for a variety of different procedures, such as printing physical models of digital images taken with intra-oral scans, making appliances, temporaries, surgical guides, and so on (Oberoi et al., 2018). Essentially, 3D printing in dentistry can be used for anything from repairing broken teeth to making dental flossing easier.

\subsection{Three-dimensional printing}

It should be stressed that in dentistry, there is a need for 3D printers to be particularly accurate. This means that the most common technologies used are 
stereolithography (SLA) and digital light processing (DLP) (Hay, 2019). The advantage of 3D printing is that it may be used in the dentist's office as well as in labs. Hence, it brings a new level of speed and ease to old procedures. Also, the advantage of using a 3D model in dentistry as opposed to a plaster model is that a 3D model is more stable, durable, and precise (Borgwardt, 2017). While 3D printing is still a comparatively new phenomenon in dentistry, it is still in a growing and developing stage, while also being a multimillion-dollar industry (McCue, 2017; Haria, 2017). Hence, there should be a future incentive for the market to continue investing in dental $3 \mathrm{D}$ printing.

While there are seemingly infinite ways for dentists to use dental 3D printers, there is still a need for a "community of practice" and common standards that is thus far largely bereft from dentistry, although it can be expected that such will emerge in the coming decade. Also, although 3D printing carries many advantages, there are some additional disadvantages. Specifically, 3D printing carries a considerable cost of running, in addition to the cost of materials, maintenance, and skilled operators. This technology also places new demands on postprocessing as well as adherence to strict health and safety protocols. There may also be some additional environmental concerns, as 3D printing tends to consume exorbitant amounts of electricity and may lead to harmful emissions (Pearson, 2018).

\subsection{Virtual reality and augmented reality}

An even newer phenomenon is the occurrence of VR and AR in dentistry. Both technologies are useful for educational purposes, that is, training new dentists. In this way, both of these technologies are likely to radically alter the future clinical training of dentistry and encourage the use of reflective forms of assessment. This may include having dentistry students undertaking greater degrees of self-assessment procedures in order to identify individual learning needs and self-directed learning. In that way, VR and AR may serve to lower the costs of the educational process, thereby enabling the funding of more dental students. These technologies may also to increase educational quality by providing new tool to dental schools so that future dentistry graduates may perfect their skillsets and aptitudes further (Roy, Bakr and George, 2017; Dutã et al., 2011; Huang et al., 2018).

Notwithstanding, VR and AR are not exclusive only to dental students, as the technologies may also continue to have practical usefulness during patient interaction. To the point, the VR technology inherently requires a large headpiece that covers the eyes, thus "inserting" users in a virtual world where they can interact with their new surroundings. In dentistry, the advantages can be seen primarily in the enhancement of the patient experience. For instance, VR can in some cases be used to help ease patient anxieties or even offer pain relief, as studies have shown that VR can lessen the perception of pain (Benham, Kang and Grampurohit, 2019; Wiederhold et al., 2014). VR thus allows for patients to become immersed in an interactive experience, thereby distracting them from the dental procedure.

$\mathrm{AR}$, on the other hand, is distinguishable from VR in the sense that it provides not only virtual information, but also interacts with the environment that 
surrounds the user. AR provides the user with a great degree of freedom, and unlike VR, it does not need to cover the user's eyes and does not necessitate any unwieldy, bulky pieces of equipment. While VR provides for a greater sense of immersion in a given, set scenario, AR allows users to practice procedures regardless of where they are. As such, AR in dentistry is chiefly concentrated within the surgery realm (Kwon, Park and Han, 2018; Huang et al., 2018). To this end, dentists can practice complex procedures with no risk to patients and with minimal costs, as no material (save for some electricity) is disposed of during the practice runs, making it a cost-efficient solution.

Just like with VR, AR can also be used to enhance the patient experience for certain procedures. For instance, with AR, rather than taking a cast of the patient's mouth, sending it off to a dental lab, and waiting for it to be processed and sent back, the dentist has the advantage of giving the patient an immediate visual representation of the completed proposed treatment (Jain, 2017). This may include orthodontics, crown and bridgework, implants, and so on. This saves both time and money for the patient as well as the dentist and the welfare system (if funded via that route) while also proving the patient with a greater sense of what to expect.

\section{Concluding discussion}

This chapter set out to discuss if and how digital dentistry could offer a solution to the impending dental welfare deficit problem. The problem is in part caused by the sheer number of diminishing active dentists in the workforce, and in part by the unaffordable dental care that is keeping large parts of the population from seeking dental care. In answering these questions, this chapter has investigated some of the most prominent new technologies found in digital dentistry, with an emphasis on 3D printing as well as VR and AR.

The future applications of said technologies are for all intents and purposes limitless.

Three-dimensional printing could provide for the possibility of instantaneous manufacturing of needed products, effectively eliminating, or at least heavily reducing, the need for processing casts and imprints and so on at specialist labs. In that way, the automation process also reduces the likelihood of human errors, ensuring a greater degree of predictability in the final results. It may also allow for greater precision and higher quality of dental appliances manufactured. Assuming that the $3 \mathrm{D}$ printer is operated by someone with the right competency, it should be less labor intensive than other techniques. This means that manufacturing models and appliances would become a fully automated, unsupervised process. This, in turn, will save the dentist much valuable time.

Moreover, if a dentist were to be able to take instantaneous virtual scans of patient's mouth, or even if patients would have the technological means to take scans of their own mouths, after which custom-built pieces could be manufactured, dentistry as we know it would be a thing of the past. Seeking initial dental care would in many cases be no more cumbersome than standing in line at the grocery store. Keeping the length of each appointment as short as possible, while 
keeping the number of required repeat visits to a minimum, is in the best interest for both patients as well as dentists. If digital dentistry can help shorten lead times, much time may be saved, which may help lower fatigue rates among practitioners, or alternatively increase patient volume.

Other potential advantages brought forth by digital dentistry are the possibilities of having an overlay of information displaying a wider range of patient data and metrics for monitoring during dental procedures. Another possibility would be for dental students to digest information more rapidly with an AR-supported course that could provide helpful illustrations and/or interactive visuals along with the lecture.

If these technologies were utilized in a way that made it possible to make them work together, it would increase efficiency, lower costs, and enhance the patient experience profoundly. Nevertheless, while digital technology can present the physical means of addressing the dental welfare deficit problem, the problem will never get resolved unless there is also a political as well as a market incentive to do so. For instance, using digital dentistry to cut costs and save resources during dental education programs could provide schools with the means to accept more students each year. By reducing waste of time and resources in dentistry, dentists may find themselves in a less stressful environment while also being able to see more patients. By being able to craft the necessary material needed for dental procedures through 3D printing, it is easier to estimate costs and the amount of resources needed. This should in turn provide for more affordable dental care. Still, these areas are by and large to a large extent governed by regulation as well as by market incentives. Once the technology is perfected and in place, it is therefore important to raise awareness among policy-makers so that the technology will be utilized in an optimal fashion that benefits dentists, patients, and society at large.

\section{References}

American Dental Education Association, 2019. History of dentistry. [online] ADEA GoDental. Available at: <www.adea.org/GoDental/Health_Professions_Advisors/His tory_of_Dentistry.aspx $>$ [Accessed 10 Sep. 2019].

Balci, S., 2017. Low-income earners skip going to the dentist. [online] ScienceNordic. Available at: <http://sciencenordic.com/low-income-earners-skip-going-dentist> [Accessed 10 Sep. 2019].

Beek, M. Van and Davidson, J., 2016. Dental therapists: a proposal to expand access to dental care in Michigan. [online] Texas Public Policy Foundation. Available at: $<$ www. texaspolicy.com/dental-therapists-a-proposal-to-expand-access-to-dental-care-in-mich igan> [Accessed 10 Sep. 2019].

Benham, S., Kang, M. and Grampurohit, N., 2019. Immersive virtual reality for the management of pain in community-dwelling older adults. OTJR: Occupation, Participation and Health, 39(2), pp. 90-6.

Borgwardt, E., 2017. Great benefits of using 3D-printing and digital models in the dental industry. [online] ELOS Medtech. Available at: <https://elosmedtech.com/great-bene fits-of-using-3d-printing-and-digital-models-in-the-dental-industry> [Accessed $10 \mathrm{Sep}$. 2019]. 
British Dental Association, 2018. NHS dentistry facing recruitment crisis. [online] Press Release. Available at: <https://bda.org/news-centre/press-releases/nhs-dentistry-facingrecruitment-crisis $>$ [Accessed 10 Sep. 2019].

British Dental Association, 2019. 75\% of NHS dental practices now struggling to fill vacancies. [online] Press Release. Available at: <https://bda.org/news-centre/pressreleases/75-per-cent-of-nhs-dental-practices-now-struggling-to-fill-vacancies $>$ [Accessed 10 Sep. 2019].

Committee on Pediatric Workforce, 2015. The use of telemedicine to address access and physician workforce shortages. Pediatrics, 136(1), pp. 202-9.

Darby, M.L. and Walsh, M., 2015. Dental hygiene: theory and practice. 4th ed. St. Louis, MO: Elsevier.

Dawood, A., Marti, B.M., Sauret-Jackson, V. and Darwood, A., 2015. 3D printing in dentistry. British Dental Journal, 219(11), pp. 521-9.

Dutã, M., Amariei, C.I., Bogdan, C.M., Popovici, D.M., Ionescu, N. and Nuca, C.I., 2011. An overview of virtual and augmented reality in dental education. OHDM, 10(1), pp. 42-9.

DutchNews, 2019. More foreign dentists are filling the gap as dentist shortage grows. [online] Available at: <www.dutchnews.nl/news/2019/03/more-foreign-dentists-arefilling-the-gap-as-dentist-shortage-grows $>$ [Accessed 10 Sep. 2019].

Elstad, J.I., 2017. Dental care coverage and income-related inequalities in foregone dental care in Europe during the great recession. Community Dentistry and Oral Epidemiology, 45(4), pp. 296-302.

EURACTIV Slovakia, 2012. Social situation in Slovakia still a painful issue. [online] Available at: <www.euractiv.com/section/eu-priorities-2020/news/social-situation-inslovakia-still-a-painful-issue $>$ [Accessed 10 Sep. 2019].

Fedcar, 2017. Updated figures on practising dentists in Europe: no general shortage. [online] Available at: <http://fedcar.eu/en/news/europe/2017/02/updated-figures-onpractising-dentists-in-europe $>$ [Accessed $10 \mathrm{Sep}$. 2019].

Fodeman, J. and Factor, P., 2015. Solutions to the primary care physician shortage. The American Journal of Medicine, 128(8), pp. 800-1.

Ford, J., 2019. Thousands of new patients unable to get dentist appointment on NHS, according to survey. [online] East Anglian Times. Available at: <www.eadt.co.uk/ news/thousands-of-people-unable-to-get-an-nhs-dental-appointment-in-suffolk-surveyreveals-1-5876727> [Accessed 10 Sep. 2019].

Giddon, D.B., Swann, B., Donoff, R.B. and Hertzman-Miller, R., 2013. Dentists as oral physicians: the overlooked primary health care resource. The Journal of Primary Prevention, 34(4), pp. 279-91.

Gupta, R., 2017. Some new dentists unable to do NHS work, say British Dental Association. BBC News. [online] Available at: <www.bbc.com/news/health-38534758> [Accessed 10 Sep. 2019].

Haria, R., 2017. How 3D printing has changed dentistry, a billion dollar opportunity. [online] 3D Printing Industry. Available at: $<$ https://3dprintingindustry.com/news/3dprinting-impact-on-dentistry-121284> [Accessed 10 Sep. 2019].

Hay, Z., 2019. Dental 3D printing - all you need to know in 2019. [online] All3DP. Available at: $<$ https://all3dp.com/2/dental-3d-printing-all-you-need-to-know $>$ [Accessed 10 Sep. 2019].

Huang, T-K., Yang, C-H., Hsieh, Y-H., Wang, J-C. and Hung, C-C., 2018. Augmented reality (AR) and virtual reality (VR) applied in dentistry. The Kaohsiung Journal of Medical Sciences, 34(4), pp. 243-8. 
Ito, T., Hamid, R.A. and Ichikawa, T., 2016. Collaborative design and manufacturing of prosthodontics wire clasp. In: M. Borsato, N. Wognum, M. Peruzzini, J. Stjepandić and W.J.C. Verhagen, eds. Transdisciplinary engineering: crossing boundaries: proceedings of the 23rd ISPE Inc. International Conference on Transdisciplinary Engineering, 3-7 October. Amsterdam, Netherlands: IOS Press, pp. 421-8.

Jain, R., 2017. Augmented reality dentistry will show you how your teeth look posttreatment. [online] International Business Times. Available at: <www.ibtimes.com/aug mented-reality-dentistry-will-show-you-how-your-teeth-look-post-treatment-2586615> [Accessed 10 Sep. 2019].

Kalmijn, M. and Luijkx, R., 2006. Changes in women's employment and occupational mobility in the Netherlands: 1955 to 2000. In: H-P. Blossfeld and H. Hofmeister, eds., Globalization, uncertainty and women's careers: an international comparison. Cheltenham, UK: Edward Elgar Publishing, pp. 84-114.

Kuhlmann, E., Groenewegen, P.P., Batenburg, R. and Larsen, C., 2015. Health human resources policy in Europe. In: E. Kuhlmann, R.H. Blank, I.L. Bourgeault and C. Wendt, eds. The Palgrave international handbook of healthcare policy and governance. London, UK: Palgrave Macmillan, pp. 289-307.

Kwon, H-B., Park, Y-S. and Han, J-S., 2018. Augmented reality in dentistry: a current perspective. Acta Odontologica Scandinavica, 76(7), pp. 497-503.

Lin, Y-M., 2018. Digitalisation in dentistry: development and practices. In: Y-C. Kim and P-C. Chen, eds. The digitization of business in china: exploring the transformation from manufacturing to a digital service hub. Cham, Switzerland: Palgrave Macmillan, pp. 199-217.

Manski, R., Moeller, J., Chen, H., Widström, E., Lee, J. and Listl, S., 2015. Disparity in dental coverage among older adult populations: a comparative analysis across selected European countries and the USA. International Dental Journal, 65(2), pp. 77-88.

McCue, T.J., 2017. 3D printing moves align technology toward $\$ 1.3$ billion in sales. [online] Forbes. Available at: <www.forbes.com/sites/tjmccue/2017/09/14/3d-printingmoves-align-technology-toward-1-3-billion-in-sales> [Accessed 10 Sep. 2019].

McLaren, E., Culp, L. and White, S., 2008. The evolution of digital dentistry and the digital dental team. Dentistry Today. [online]. Available at: <www.dentistrytoday.com/restora tive-134/1789-sp-1323704604> [Accessed 10 Sep. 2019].

Minjarez, J., 2017. America's dental crisis is happenin: here is the solution. [online] RealClear: Health. Available at: <www.realclearhealth.com/articles/2017/08/24/americas_den tal_crisis_is_happening_here_is_the_solution_110712.html $>$ [Accessed 10 Sep. 2019].

Oberoi, G., Nitsch, S., Edelmayer, M., Janjić, K., Müller, A.S. and Agis, H., 2018. 3D printing - encompassing the facets of dentistry. Frontiers in Bioengineering and Biotechnology, 6, pp. 172, 1-13.

Pearson, A., 2018. 10 Disadvantages of 3D printing technology. [online] 3DInsider. Available at: $<$ https://3dinsider.com/3d-printing-disadvantages $>$ [Accessed 10 Sep. 2019].

Petterson, S.M., Liaw, W.R., Phillips, R.L., Rabin, D.L., Meyers, D.S. and Bazemore, A.W., 2012. Projecting US primary care physician workforce needs: 2010-2025. Annals of Family Medicine, 10(6), pp. 503-9.

Pieters, J., 2018. Young Dutch women work least hours in Europe. NL Times. [online] Available at: <https://nltimes.n1/2018/01/22/young-dutch-women-work-least-hourseurope $>$ [Accessed 10 Sep. 2019].

Ritter, A.V., Boushell, L.W. and Walter, R., 2019. Sturdevant's art \& science of operative dentistry. 7 th ed. St. Louis, MO: Elsevier. 
Roy, E., Bakr, M.M. and George, R., 2017. The need for virtual reality simulators in dental education: a review. The Saudi Dental Journal, 29(2), pp. 41-7.

Schleyer, T.K.L., 1999. Digital dentistry in the computer age. The Journal of the American Dental Association, 130(12), pp. 1713-20.

Schreijer, S., 2018. There is a shortage of dentists in Holland-and it's growing. [online] BGB Dentistry. Available at: <www.dentistinholland.com/there-is-a-shortage-of-den tists-in-holland-and-its-growing $>$ [Accessed 10 Sep. 2019].

Smith, Y., 2019. Strategies to improve shortage of primary health care. [online] News medical: life sciences. Available at: <www.news-medical.net/health/Strategies-toImprove-Shortage-of-Primary-Health-Care.aspx $>$ [Accessed 10 Sep. 2019].

Tang, C-K., Medioni, G. and Duret, F., 1998. Automatic, accurate surface model interference fo dental CAD/CAM. In: W.M. Wells, A. Colchester and S. Delp, eds. Medical image computing and computer-assisted intervention - MICCAI'98: first international conference, Cambridge, MA, 11-13 October, Proceedings. Heidelberg, Germany: Springer, pp. 732-42.

Ueda, Y. and Yamaguchi, T., 2017. History of and current situation regarding dental CAD/ CAM systems and future perspectives. Hokkaido Journal of Dental Science, 38(Special issue), pp. 104-10.

US Department of Health and Human Services, Health Resources and Services Administration and National Center for Health Workforce Analysis, 2015. National and state-level projections of dentists and dental hygienists in the U.S., 2012-2025. [online] Available at: $<$ https://bhw.hrsa.gov/sites/default/files/bhw/nchwa/projections/nationalstatelevel projectionsdentists.pdf $>$ [Accessed 10 Sep. 2019].

Versteeg, A., 2016. Dutch dentistry: trends \& developments. [online] BGB Dentistry. Available at: <http://web.archive.org/web/20170512204041/http://www.dentistinholland. com/dutch-dentistry-trends $>$ [Accessed 10 Sep. 2019].

Voinea-Griffin, A. and Solomon, E.S., 2016. Dentist shortage: an analysis of dentists, practices, and populations in the underserved areas. Journal of Public Health Dentistry, 76(4), pp. 314-19.

Wiederhold, B.K., Gao, K., Sulea, C. and Wiederhold, M.D., 2014. Virtual reality as a distraction technique in chronic pain patients. Cyberpsychology, Behavior, and Social Networking, 17(6), pp. 346-52.

Wu, D. and Lam, T.P., 2016. Underuse of primary care in China: the scale, causes, and solutions. Journal of the American Board of Family Medicine: JABFM, 29(2), pp. 240-7.

Van der Zande, M.M., Gorter, R.C., Aartman, I.H.A. and Wismeijer, D., 2015. Adoption and use of digital technologies among general dental practitioners in the Netherlands. PLOS ONE, 10(3), pp. e0120725, 1-13. 


\title{
8 Solutions based on digital connected devices for social care and well-being
}

\author{
Andres Laya and Jan Markendahl
}

\section{Introduction}

In this chapter, we discuss the structure of the Swedish social care sector and explore how different ventures handle this structure in the development of solutions for social care and well-being. By looking at the current structure, it is possible to highlight challenges that emerging services face. We present how social care is structured in Sweden and what the enabling forces and driving factors are behind the development of solutions based on the Internet of Things. Second, we investigate the business challenges preventing the development uptake of new solutions based on digital connected devices. Finally, we discuss the implication of those challenges in terms of the recommendations for development of solutions.

We argue that the social care structure in Sweden has intrinsic challenges that prevent the uptake of solutions based on digital connected devices. However, these services could improve quality of life and reduce costs; patients can monitor their status regularly and get a comprehensive view of what affects a disease activity and how effective medication and self-care are (Ahlen, 2016). The drive to achieve the potential gains is resulting in distinctive development patterns to overcome, or circumvent, the existing barriers. The implications show how innovative initiatives are addressing the existing challenges. There are three distinctive development patterns in different sectors that are followed by emergent new services in Sweden - 1) the public sector, 2) the private sector, and the 3) wellbeing sector.

The convergence of information and communication technologies (ICT) and social care industries can be considered a nascent market, considering that it still lacks formal rules and awareness governing business relations among competitors, suppliers, and customers (Fligstein and Calder, 2015). Digital solutions to improve the delivery of social care have been considered a nascent market since the mid-90s, but only recently are the benefits becoming evident.

One reason for the slow adoption of ICT in social care and well-being are organizational models and revenue models (Vannieuwenborg et al., 2014; Fife and Pereira, 2011), which still remain a challenge and open research topics (Barry, 2013; European Commission, 2014; Steinhubl, Muse and Topol, 2015). The complex and vague environment of actors that are the subject of intense collaboration 
results in unclear, and unbalanced, distribution of costs and benefits: "often is the investing actor not the one which will benefit the most" (Vannieuwenborg et al., 2014, p. 3). Forsstrom (2013) and Labrique et al. (2013) highlight the need to promote horizontal models with open and shared approaches, rather than vertical solutions developed in isolation for niche markets. Along the same lines, Källander et al. (2013) conclude that the main challenge is still to move from pilot projects to national scalable programs that engage workers and communities.

Our approach to studying the convergence between social care and ICT is to explore the existing business ecosystem for health and social care services in Sweden. This context represents an area of interest since the phenomenon of services based on connected devices is emerging in abundance (Eisenhardt, 1989). In this setting, it is possible to observe multiple examples and extract recurrent patterns (Granqvist, Grodal and Woolley, 2013). The term "business ecosystem" is commonly used and has been widely adopted in the high technology community (Moore, 2006). Moore (2006) defines business ecosystems as networks of buyers, suppliers, and makers of products or services within a socio-economic environment that includes institutional and regulatory framework. It includes how the contribution of each actor will be modularized and which type of firm will provide particular elements (Ozcan and Santos, 2015; Moore, 2006). As synthesized by Anggraeni et al. (2007), a business ecosystem stresses the interconnectedness and interdependence of economic agents, with a focus on the relationships between firms and the business network around them.

ICT have been part of social care services for decades, but the recent trend to move from health care interventions to become proactive in health has increased the focus on preventive care and improving physical and mental performance (Schraefel and Churchill, 2014; Rozenfeld, 2015; Free et al., 2013). Services based on the IoT and connected devices are beginning to play a key role in preventive health care; they can provide remote connectivity and access to relevant patient information. In this sense, they are related to social care and well-being.

\section{Method}

We use qualitative data to show the underlying reasons, opinions, and motivations to innovate in social care and well-being based on digital connected devices, and present recurrent challenges affecting innovation in the context of Sweden. The aim is to uncover patterns in opinions and development of new solutions. The strategy is exploratory in nature, in that is divergent and open to varied inputs and sources.

Due to the emerging nature of services covered, we consider an extended scope that allows the inclusion of any digital service in the context of well-being and social care. Given the nature of the services considered in this chapter, we do not limit the study to predefined labels or claims (Granqvist, Grodal and Woolley, 2013). Therefore, we include services and solutions based on the use of digital technologies, which to date include labels such as remote care, telehealth, electronic health (eHealth), mobile health (mHealth), smart devices, and wearable devices (Iyawa, Herselman and Botha, 2016). 
We use a longitudinal cumulative case study research strategy to explore the recurrent challenges and innovation paths for services based on connected devices. Cumulative case studies aggregate data from several sources at different times (Mann, 2006; Davey, 1991).

For the review of challenges, we use stylized facts to accumulate published knowledge based on empirical data (Jurisch, Wolf and Krcmar, 2013; Loos et al., 2011; Houy, Fettke and Loos, 2015), pointing at empirical regularities (Helfat, 2007). The aim is to accumulate evidence from different sources that follow qualitative and quantitative methods in order to represent relevant patterns in empirical data (Heine, Meyer and Strangfeld, 2005; Houy, Fettke and Loos, 2015; Helfat, 2007).

We consider a business ecosystem study to develop an organizational map and find suggestions on the way forward to develop solutions for health care based on connected devices. This map is important because there are diverse views and no clear boundaries in the emerging market.

The sources of primary and secondary data include semi-structured interviews; research projects with focus groups on challenges for innovation in health care, business models, and collaboration in solutions based on the IoT; and attendance at industry conferences focused on social care and welfare technologies; primary data sources are presented in Table 8.1. Based on data collection activities, we uncover recurrent challenges and recommendations on how to overcome such challenges in the creation of digital service, following the framework shown in Figure 8.1.

\section{Challenges and current conditions affecting the development of solutions}

\subsection{Overview}

Canning and Eamonn (2015) infer, compared to previous innovation in social care, that there is an emerging approach based on multisector ecosystem solutions supported by availability of information, including mobile phones, social media, cloud computing, data analytics, and the IoT. Nevertheless, there are key challenges affecting the development and adoption of these solutions in Sweden, which are presented next, and correspond to (Laya, 2017):

1 The social care structure and governance

2 Public-sector barriers

3 Unclear incentives and reimbursement models

4 Interoperability and coordination

The social care structure and governance in Sweden is decentralized, which allows each region to implement solutions based on its own needs, but it had led to interoperability issues among systems and regions (Falan, 2016, para.1; Axelsson, 2000). For example, it is argued that decentralization at the county council level creates additional costs because 20 different organizations perform some of 


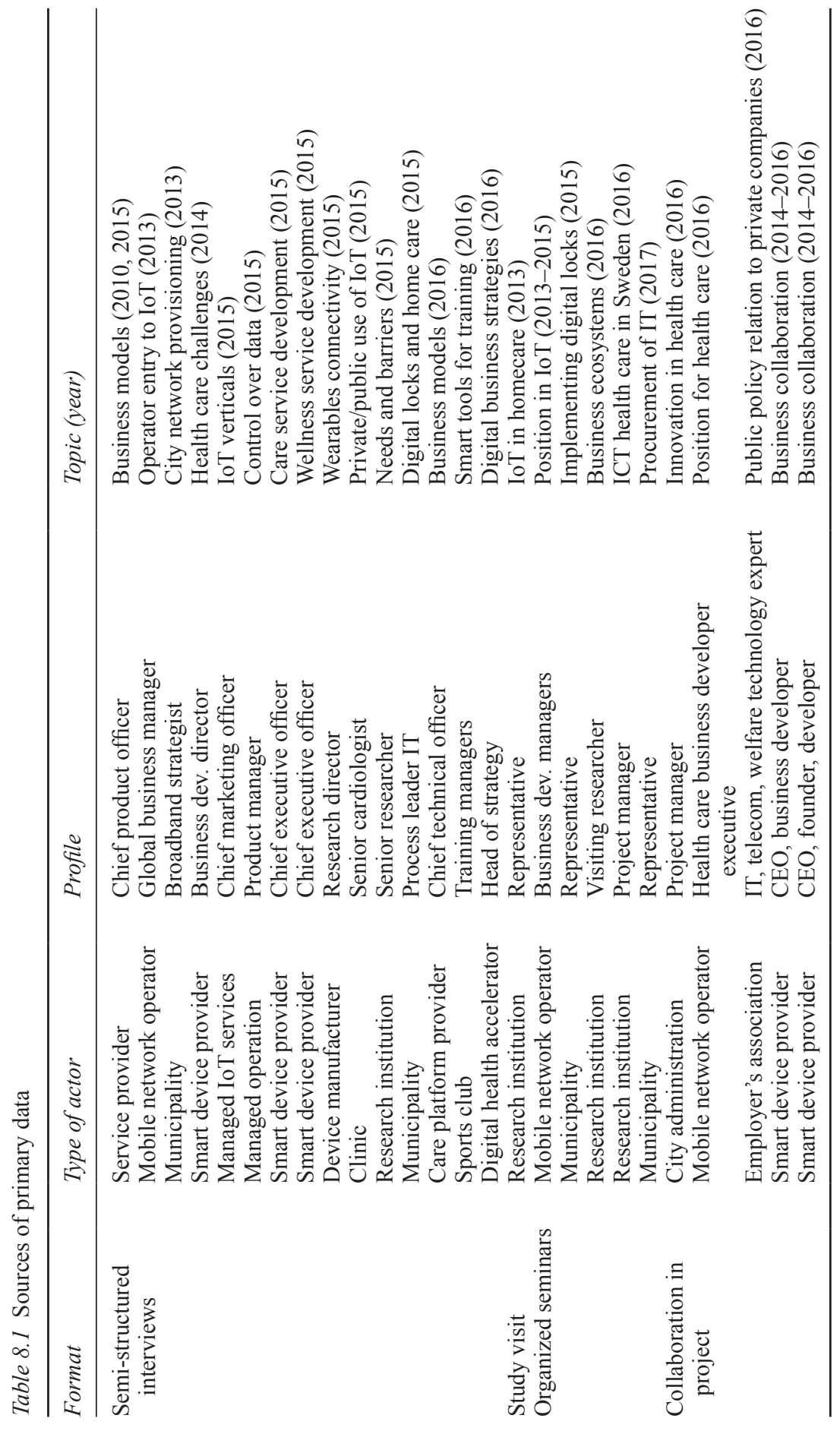




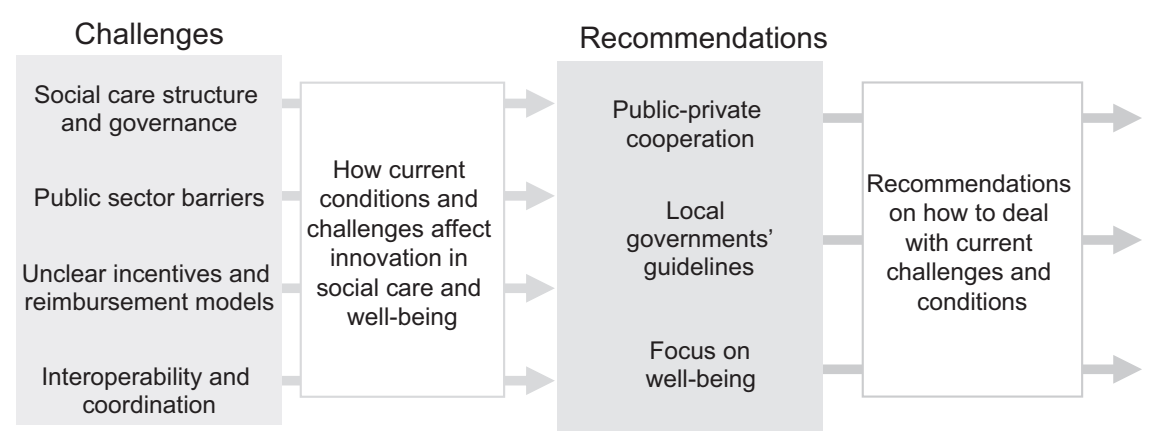

Figure 8.1 Research framework. The identification and description of each challenge is presented in Section 3. Recommendations for different actors are presented in Section 4.

the same work, resulting in sharply expanding administration costs for care providers (Friberg et al., 2015; Axelsson, 2000); this is in addition to the substantial resources and expertise needed to meet the requirements for procurement and development at 20 different county councils (Friberg et al., 2015).

There is an extensive network of actors in Sweden collaborating in the establishment of guidelines (Laya, 2017). The aggregated work is evident; however, it is not clear who is providing the guidelines to set the structure and who is appointing the infrastructure. The management of social care is fragmented, and the division of roles between the different actors is unclear and subject to reinterpretation based on what benefits their operations (Friberg et al., 2015).

Public-sector barriers for innovation in social care can be discussed as early digitalization phases, since they relate to a lack of competence and awareness of the available technologies and their benefits (Dahlberg, 2015, p. 9). In addition, there a long procurement processes and a resistance to adopt new technology that has not been used on a large scale since it is perceived as a risk factor. A problem with public procurement is that there are always appeals. Some incumbents use the appealing process to exhaust the resources of smaller providers. It is always possible to find something to appeal on a public procurement process, "if they don't win, they will appeal." It creates delays and increases the costs for everyone. Small companies cannot bear several procurement processes.

Unclear incentives and reimbursement models are a factor impeding the adoption of digital solutions in social care, the main reason being that payback periods for digital technologies are longer than public budgeting cycles (Laya, 2017). Currently, just a few county councils and municipalities can prescribe digital services (in the form of eHealth services). The lack of appropriate reimbursement models for these services prevents their widespread use (Widén and Haseltine, 2015, p. 15).

In Sweden, every county council uses a combination of reimbursement models. There is a trend to replace the fixed and variable costs with bundled payments, that is, payments per diagnosis. This provides an incentive to increase efficiency 
(European Commission, 2017, p. 21), but it could reduce the quality of the service. Nevertheless, the patient's freedom of choice in Sweden will counteract and incentivize providers to improve the quality (Högberg and Lindvall, 2012, p. 17). A study by Högberg et al. (2012) reviews the health care reimbursement models in different counties. They show the move toward quality indications and outcomes. This will allow a transition from fee-for-service payments to capitation or bundled payment without affecting the quality of the service.

Interoperability and coordination are a recurrent challenge since most solutions are developed using a vertical approach. The vertical, or siloed, approach to innovation has hindered the ability of achieving more sustainable and efficient health and social care delivery (European Commission, 2017). "Lack of interoperability is both a reason and a result of market fragmentation. It perpetuates market fragmentation and creates significant barriers to entry, especially for innovators and SMEs" (European Commission, 2017, p. 24).

Even if some developers follow standard specifications, there are over 45 interoperability standards for health care information management, according to the StandIN project (Nordgren et al., 2016); the main issue is a lack of awareness and unclear requirements demanded from the customer side. Without clear requirements on standards adoption and guideline specifications, the result is usually lock-in effects and high maintenance costs, particularly when deciding to integrate different solutions.

\subsection{Recapitulation and synopsis of the challenges}

A summary of the challenges is presented in Table 8.2, synthetizing the main findings and suggesting the negative implications that each challenge poses to the actors affected by it. We see a close relation among some of the challenges previously presented; however, their origins and implications highlight different sides that explain the struggles to provide innovative solutions. For instance, the existence of bespoke solutions for specific localities is closely related to social care structure and governance. These two aspects can be regarded as the cause of interoperability issues. However, structure and governance point to the lack of guidelines to foster innovation in the public sector, while the challenge of interoperability and coordination points to the lock-in effects and scalability issues raised by solutions developed in isolation, without considering integration with other systems and solutions.

We stress the side of newcomers with innovative solutions as the main type of actor affected by these challenges. However, it is evident that other actors are also affected. For instance, local governments with limited budget allocation for social care might see the potential of new solutions, but there are no clear guidelines on how to properly assess the benefits and risk of adopting new solutions. Along the same lines, individuals requiring complex assistance from municipality social care often encounter a lack of coordination among public entities.

The challenges are described from the public-sector perspective. Even if many solution providers understand the clear benefits of being part of the approved 
Table 8.2 Challenges to implementing digital services for social care in Sweden

\begin{tabular}{|c|c|c|c|}
\hline Challenge & Description & Main affected & Implication \\
\hline $\begin{array}{l}\text { Social care } \\
\text { structure and } \\
\text { governance }\end{array}$ & $\begin{array}{l}\text { Fragmented coordination } \\
\text { Unclear guidelines } \\
\text { No leader (ecosystem } \\
\text { integrator) }\end{array}$ & $\begin{array}{l}\text { Newcomers with } \\
\text { innovative } \\
\text { solutions }\end{array}$ & $\begin{array}{l}\text { Slow uptake } \\
\text { Negative } \\
\text { fragmentation }\end{array}$ \\
\hline $\begin{array}{l}\text { Public-sector } \\
\text { barriers }\end{array}$ & $\begin{array}{l}\text { Innovation implies risks } \\
\text { Risks are avoided in } \\
\text { public health and } \\
\text { social care structures }\end{array}$ & $\begin{array}{l}\text { Newcomers with } \\
\text { innovative } \\
\text { solutions }\end{array}$ & $\begin{array}{l}\text { Slow uptake } \\
\text { while structure } \\
\text { changes }\end{array}$ \\
\hline $\begin{array}{l}\text { Unclear } \\
\text { incentives and } \\
\text { reimbursement } \\
\text { models }\end{array}$ & $\begin{array}{l}\text { No clear incentives to } \\
\text { improve efficiency } \\
\text { with digital } \\
\text { technologies }\end{array}$ & $\begin{array}{l}\text { Providers that } \\
\text { require long } \\
\text { times to see } \\
\text { return on } \\
\text { investment }\end{array}$ & $\begin{array}{l}\text { Lack of } \\
\text { attractiveness } \\
\text { for innovation in } \\
\text { the public sector }\end{array}$ \\
\hline $\begin{array}{l}\text { Interoperability } \\
\text { and coordination }\end{array}$ & $\begin{array}{l}\text { Bespoke solutions } \\
\text { prevent integration at } \\
\text { the national level } \\
\text { Lock-in effect from } \\
\text { providers }\end{array}$ & $\begin{array}{l}\text { Vendors cannot } \\
\text { scale } \\
\text { Municipalities } \\
\text { with lock-in } \\
\text { effects }\end{array}$ & $\begin{array}{l}\text { Slow uptake } \\
\text { unless clear } \\
\text { push for } \\
\text { common } \\
\text { international } \\
\text { standards }\end{array}$ \\
\hline
\end{tabular}

Source: Adapted from Laya (2017).

service providers in the public sector, it is a cumbersome process to reach that stage. Some ventures take alternative routes toward the same objective, depending on their actual offer, resources, and expertise.

\section{Discussion}

In this section, we bring up implications of the challenges for innovation in social care. We do it using examples and cases from Sweden and focus on how this can be of value for practitioners. We have identified three themes that we will discuss below:

1 Public-sector cooperation with private companies

2 Local government guidelines

3 Focus on well-being for innovation

\subsection{Public-sector cooperation with private companies}

In an environment with digitalized home care, public actors need stronger cooperation with private companies to provide new services. Private companies target focus on value-driven solutions and bring flexibility to public-sector services. Hence, one strategy is to innovate within the public sector to overcome interoperability and coordination challenges. This type of initiatives can be driven 
by authorities and coordination bodies such as the Swedish Association of Local Authorities and Regions (Swe, Sveriges Kommuner och Landsting - SKL). We have identified some examples of this.

The municipality of Västerås was early in the introduction of e-home care services. The initial driver was to improve the quality of the elderly, but it soon turned out that the different initiatives resulted in substantial improvements of working efficiency and reduction of costs (Marklund, 2012; Dahlberg, 2015). According to an industry expert:

[The case of] Västerås is not private investment or private ideas, is something that they wanted to do and it has not been done in the private sector. The municipality had people with good ideas and good management that wanted to try them.

Other pilots in Sweden have shown the potential of digital health solutions. The Connected for Health project in the Swedish city of Hudiksvall had the task to develop and test a social care alarm system to send event messages. ${ }^{2}$ The alarm system showed considerable cost savings for the municipality, based on staff efficiency (European Commission, 2016). Taking into account demographic changes and shortage of "young people," a local authority said:

In the homecare staff; people are expensive and in short supply. It is not on how to replace them, but how to utilize them in the best way.

Yet another example of how to exploit the contacts with technology providers is how the Swedish municipality of Nacka procured IT new systems for IT services for home care. Instead of buying separate technical functions or solutions for elderly (e.g., alarms, messaging, and night cameras), they employed an overall approach. Key components in this approach were:

- To make scenarios and use cases looking to the daily life of the elderly.

- To put together interested providers (i.e., also competitors) to brainstorming sessions.

- To make the specifications for procurement based on brainstorming sessions; here, a key result was that all interested actors were aware of the process and requirements.

In summary, there are many examples where municipalities and county councils interact closely with companies to specify, test, and deploy new solutions. We believe that this is different from the large industry approach with phases like technology research, standardization, development, and large-scale production. It is not that "one size fits all"; the technical solutions also need to include organizational and working process aspects. 


\subsection{Local government guidelines}

Local governments should follow clear development guidelines; otherwise, public social care providers will encounter challenges and obstacles related to the introduction of new technology. Examples of this are:

- $\quad$ Lock-in effects from technology suppliers

- Scalability and integration challenges after initial deployments

We have identified examples illustrating that municipalities in many cases have understood the need to change conditions, organization, and/or roles in order to fully exploit the benefits of new solutions.

Again, using Västerås as a case, there is an example of the role of the municipality in provisioning e-home care (Forsstrom, 2013; Markendahl and Laya, 2013). The traditional broadband provider had problems being the Internet service provider (ISP) for e-home care, mainly due to issues with support and helpdesk functions. Then, the municipality IT department stepped in and took the ISP role. They act as system integrator and service provider and take full responsibility for the technology package for e-home care services.

Other insights can be gained from the stories told at the event MVTe $2015^{3}$ by two Swedish municipalities about the strategy for introduction of digital locks in home care. In one town, the key-free home service works quite satisfactorily after some years, but it could work better. The introduction of key-free home services had a tight schedule, focusing on time registration of home care and not on key management. Six years of experience have led to many ideas about what we would do instead if we were to introduce it today. If we compare the two towns, the first one introduced the new services on top of existing organization and processes. This is in contrast with the other town, which created a new organization in order to fully support the new IT functions and working processes. Examples are dedicated IT technicians being part of the digital lock team and a new process for storing the old locks that were removed (and later to be restored) when new digital locks were installed.

The municipality of Linköping made an attempt to foster the adoption of ICT by social care service providers. The approach was to include assignment of digital technology implementation in the procurement process for service providers. Many of the potential supplies fulfilled the digital technology points in their bids, but solutions were often quite basic and without technical novelty. An expert commented:

We wanted to introduce a new demand in our requirements that you should use new technology. And that will be scored, not so high, but it will give you some kind of points. And everyone did answer on that requirement, but it was very low tech and nothing new.

We can see that agencies and organizations like the Swedish eHealth Agency, Inera ${ }^{4}$ and SALAR are trying to coordinate efforts and initiatives at the national 
level. For example, they are driving national coordination in the creation of guidelines to select standards and increase technical interoperability within health and social care. Also, cooperation within the other Nordic countries has been launched to jointly develop the standardization of welfare technologies (eHälsomyndigheten, 2016).

To summarize, we can see both efforts and insights from municipalities and national bodies to be proactive in the procurement and implementation of new technology for social and home care services. This includes both stepping up and being active in issues related to standards and interoperability as well as being prepared to identify the need to change the organization and/or working processes.

\subsection{Focus on well-being for innovation}

The restrictive regulatory frameworks in the public sector have pushed innovation in sport and well-being areas (Laya, 2017). This has had the effect of pushing small innovative companies outside the public care system, even if some of them have a long-term goal to be part of the social and health care market. By focusing on well-being and sports, it is possible to show the potential of digital solutions while avoiding some of the challenges of addressing the public sector.

One consideration is that, to avoid additional regulation, some solutions must reduce theirs claims to avoid being labeled as a health care device and becoming subject to additional regulation. In Sweden, the Medical Products Agency abstains from regulating general products in the wellness area. The head of strategy of a startup incubator in the area commented:

Digital care companies are targeting consumer market directly because it is easier. Many of the developers come from the gaming industry, and they do not really know how to deal with the regulatory aspects and are used to develop directly to end-consumers.

The well-being focus is also instrumental in avoiding the long-term validation and procurement processes, while interoperability is achieved by following frameworks provided by incumbent IT companies such as Microsoft, Samsung, Apple, and Sony. This last point has also been presented as an advance by newcomers, suggesting that while the regulatory challenges are lower, there is an immediate possibility to reach a global market.

In summary, the well-being focus targets the end-consumer market. A clear motivation for small companies is to be able to initiate tests, show potential, and gain experience, even if the long-term goal is to enter procurement processes in the public sector and access the public health and care system.

\section{Conclusion}

We have discussed how the current structure of the social care sector results in challenges limiting innovation based on digital solutions for social care in Sweden. 
With the identified challenges, we present recommendations for the development of new solutions, based on how different actors are currently dealing with the existing challenges. What we see in Sweden is not that non-governmental actors will overrun anyone when it comes to social care services. Looking at established services, collaboration between private companies and providers of innovative solutions is required. This is partly due to regulation, but it will also combine know-how.

From a research perspective, all these cases, insights, and findings clearly illustrate the fact that innovation in the social care sector is not only a matter of fixed buyer-seller relations and discussion about ready-made solutions. Most of the services that have been set in place are the result of joint efforts involving actors from different parts of the ecosystem, in several cases through research and academic projects together with municipalities or social care service providers. What is important to highlight is that innovative services for social care in Sweden tend to emerge from alignments between needs identified by the public sector and solutions developed to target those specific needs, usually provided by flexible and small-sized companies. Finally, we stress how newcomers are focusing on providing solutions in sports and well-being in order to avoid regulatory hurdles and long procurement processes. In the future, these solutions will become reliable sources that should be integrated into public systems; that is, this sector will create external pressure to adopt and accept innovation in the public sector.

\section{Notes}

1 Based on expert opinion given at a roundtable discussion on the VINNOVA project on IoT ecosystems, help, and KTH Royal Institute of Technology in Stockholm, Sweden, in the spring of 2016 .

2 In Sweden, the industry refers to safety or security alarm. In the rest of Europe, it is referred to as social alarm.

3 Meeting place for welfare technology and e-health (Swe: Mötesplats välfärdsteknologi och e-hälsa-MTVe) 2015, held in Stockholm, Sweden.

4 Inera is a company owned by the county councils, which provides independent public eHealth development. It coordinates the county council and region collaborations for eHealth.

\section{References}

Ahlen, H., 2016. Personligt hälsostöd till alla! [Personal health assistance to all!]. [online] Alfa Bravo. Available at: <http://alfabravo.com/2016/06/personligt-halsostod-till-alla $>$ [Accessed 4 Sep. 2019].

Anggraeni, E., Hartigh, E. Den and Zegveld, M., 2007. Business ecosystem as a perspective for studying the relations between firms and their business networks. In: ECCON 2007 annual meeting 19/10/07. TVA, Veldhoven, pp. 1-28.

Axelsson, R., 2000. The organizational pendulum: healthcare management in Sweden 1865-1998. Scandinavian Journal of Public Health, 28(1), pp. 47-53.

Barry, J., 2013. Next generation European ambient assisted living innovation alliance: D3.2 business model analysis. [online] AALIANCE. Available at: <http://www.aaliance.eu/ 
sites/default/files/files_list/AA2_D3.2_Business_Model_Analysis_rev1.4_20140314. pdf $>$ [Accessed 4 Sep. 2019].

Canning, M. and Eamonn, K., 2015. Business ecosystems come of age. [online] Deloitte University Press. Available at: <https:/www2.deloitte.com/content/dam/insights/us/ articles/platform-strategy-new-level-business-trends/DUP_1048-Business-ecosystemscome-of-age_MASTER_FINAL.pdf $>$ [Accessed 4 Sep. 2019].

Dahlberg, Å., 2015. Is the use of welfare technology profitable? Welfare technology conference 2015. ACCESS Health International.

Davey, L., 1991. The application of case study evaluations. Practical Assessment Research \& Evaluation, 2(9), pp. 1-2.

eHälsomyndigheten, 2016. Nationell kontaktpunkt för e-hälsa [National contact point for e-health]. [online] Available at: <www.ehalsomyndigheten.se/globalassets/dokument/ regeringsuppdrag/rapportering2016/regeringsuppdrag-s2016_03789_fs_nationell-kon taktpunkt-for-e-halsa.pdf> [Accessed 4 Sep. 2019].

Eisenhardt, K.M., 1989. Building theories from case study research. The Academy of Management Review, 14(4), pp. 532-50.

European Commission, 2014. Green paper on mobile health ('mHealth'). [online] Digital Single Market. Available at: <http://ec.europa.eu/digital-agenda/en/news/green-papermobile-health-mhealth $>$ [Accessed 4 Sep. 2019].

European Commission, 2016. Four Nordic eHealth pilots achieve lasting results. [online] Digital single market. Available at: <https://ec.europa.eu/digital-single-market/en/news/ four-nordic-ehealth-pilots-achieve-lasting-results> [Accessed 4 Sep. 2019].

European Commission, 2017. Blueprint digital transformation of health and care for the ageing society. [online] Digital Single Market. Available at: $<$ https://ec.europa.eu/dig ital-single-market/en/blueprint-digital-transformation-health-and-care-ageing-society> [Accessed 4 Sep. 2019].

Falan, S., 2016. EHR records in Sweden and what the future brings. [online] Salus Digital. Available at: <http://web.archive.org/web/20171210003308/http://illinois.nef2. com/ehr-records-in-sweden-and-what-the-future-brings-salus-digital-future-of-ehr $>$ [Accessed 4 Sep. 2019].

Fife, E. and Pereira, F., 2011. Digital home health and mHealth: prospects and challenges for adoption in the U.S. In: 2011 50th FITCE congress - 'ICT: Bridging an Ever Shifting Digital Divide', 31 Aug.-3 Sept. 2011. Palermo, Italy: Institute of Electrical and Electronics Engineers (IEEE), pp. 1-11.

Fligstein, N. and Calder, R., 2015. Architecture of markets. In: R.A. Scott and S.M. Kosslyn, eds. Emerging trends in the social and behavioral sciences: an interdisciplinary, searchable, and linkable resource. Hoboken, NJ: John Wiley \& Sons, pp. 1-14.

Forsstrom, P., 2013. BoIT 2.0. Lokala projekt 2012 [BoIT 2.0. Local projects 2012]. [online] SABO [pptx Presentation]. Available at: <http://slideplayer.se/slide/2603893> [Accessed 4 Sep. 2019].

Free, C., Phillips, G., Galli, L., Watson, L., Felix, L., Edwards, P., Patel, V. and Haines, A., 2013. The effectiveness of mobile-health technology-based health behaviour change or disease management interventions for health care consumers: a systematic review. PLoS Medicine, 10(1), e1001362 pp. 1-45.

Friberg, P., Halmin, M., Löfmark, R., Makdessi, L., Sallin, K. and Sjögreen, J., 2015. En Värdefull Vård - en hälso- och sjukvård med människan i centrum [A valuable carehealth services with people first]. [online] The Swedish Society of Medicine. Available at: <www.sls.se/contentassets/9ae913327d5742e6bb01b663f56b05fd/evv20remiss20hu vuddokument202201506261.pdf> [Accessed 4 Sep. 2019]. 
Granqvist, N., Grodal, S. and Woolley, J.L., 2013. Hedging your bets: explaining executives' market labeling strategies in nanotechnology. Organization Science, 24(2), pp. 395-413.

Heine, B.O., Meyer, M. and Strangfeld, O., 2005. Stylised facts and the contribution of simulation to the economic analysis of budgeting. Journal of Artificial Societies and Social Simulation, 8(4), pp. 1-34.

Helfat, C.E., 2007. Stylized facts, empirical research and theory development in management. Strategic Organization, 5(2), pp. 185-92.

Högberg, M. and Lindvall, S., 2012. Ersättningssystem inom hälso- och sjukvård [Reimbursement systems in health care]. [online] Forum för Health Policy [Forum for Health Policy]. Available at: <http://healthpolicy.se/wp-content/uploads/2016/07/FORUM Staffan_och_Michael_REVIDERAD_120314.pdf> [Accessed 4 Sep. 2019].

Houy, C., Fettke, P. and Loos, P., 2015. Stylized facts as an instrument for literature review and cumulative information systems research. CAIS (Communications of the Association for Information Systems), 37(1), pp. 225-56.

Iyawa, G.E., Herselman, M. and Botha, A., 2016. Digital health innovation ecosystems: from systematic literature review to conceptual framework. Procedia Computer Science, 100, pp. 244-52.

Jurisch, M.C., Wolf, P. and Krcmar, H., 2013. Using the case survey method for synthesizing case study evidence in information systems research. In: Nineteenth Americas conference on information systems, 15-17 August. Chicago, IL, pp. 1-8.

Källander, K., Tibenderana, J.K., Akpogheneta, O.J., Strachan, D.L., Hill, Z., ten Asbroek, A.H., Conteh. L., Kirkwood. B.R. and Meek, S.R., 2013. Mobile health (mHealth) approaches and lessons for increased performance and retention of community health workers in low- and middle-income countries: a review. Journal of Medical Internet Research, 15(1), e17, pp. 1-13.

Labrique, A.B., Vasudevan, L., Kochi, E., Fabricant, R. and Mehl, G., 2013. mHealth innovations as health system strengthening tools: 12 common applications and a visual framework. Global Health, Science and Practice, 1(2), pp. 160-71.

Laya, A., 2017. The internet of things in health, social care, and wellbeing. KTH - Royal Institute of Technology. Doctoral Thesis in Information and Communication Technology.

Loos, P., Fettke, P., Weißenberger, B., Zelewski, S., Heinzl, A., Frank, U. and Iivari, J., 2011. What in fact is the role of stylized facts in fundamental research of business and information systems engineering? Business \& Information Systems Engineering, 3(2), pp. $107-25$.

Mann, B.L., 2006. Case study research on web-based learning: types, typologies and thesis research. In: B.L. Mann, ed. Selected styles in web-based research. Hershey, PA: IGI Global, pp. 70-80.

Markendahl, J. and Laya, A., 2013. Business challenges for Internet of Things : findings from e-home care, smart access control, smart cities and homes. In: The 29th IMP conference. Atlanta, GA, pp. 1-22.

Marklund, M., 2012. Att införa e-hemtjänst: Erfarenheter från Västerås stad [To introduce e-home care: the experience of the city of Västerås]. [online] Hjälpmedelsinstitutet [Swedish Institute of Assistive Technology]. Available at: $<$ http://docplayer.se/3130398Att-infora-e-hemtjanst-erfarenheter-fran-vasteras-stad.html $>$ [Accessed 4 Sep. 2019].

Moore, J.F., 2006. Business ecosystems and the view from the firm. The Antitrust Bulletin, 51(1), pp. 31-75.

Nordgren, H., Sandell, R., Johannesson, R., Gillespie, C., Ehn, G., Spanne, C., Wallin, S-B., Lundell, K-H., Jerlvall, L., Lindén, F., Andersson, M. and Linnarsson, H., 2016. 
Common framework of standards for interoperability and change management. [online] Medtech4Health. Available at: <https://medtech4health.se/report-standards-interopera bility-standin-sweden $>$ [Accessed 4 Sep. 2019].

Ozcan, P. and Santos, F.M., 2015. The market that never was: turf wars and failed alliances in mobile payments. Strategic Management Journal, 36(10), pp. 1486-512.

Rozenfeld, M., 2015. What you wanted to know about wearables. [online] IEEE - The Institute. Available at: <http:/origin.www.theinstitute.iee.org/ieee-roundup/members/ achievements/what-you-wanted-to-know-about-wearables> [Accessed 4 Sep. 2019].

Schraefel, M.C. and Churchill, E.F., 2014. Wellth creation: using computer science to support proactive health. Computer, 47(11), pp. 70-2.

Steinhubl, S.R., Muse, E.D. and Topol, E.J., 2015. The emerging field of mobile health. Science Translational Medicine, 7(283), 283rv3 pp. 1-7.

Vannieuwenborg, F., Van Auwermeulen, T., Van Ooteghem, J., Jacobs, A., Verbrugge, S., Colle, D. and Pickavet, M., 2014. Smart home care platforms: where is the added value? In: 25th European regional conference of the international telecommunications society. Brussels, Belgium: ITS, pp. 1-27.

Widén, S. and Haseltine, W.A., 2015. eHealth technologies and the future of healthcareinterview with Henrik Ahlen. [online] ACCESS Health International. Available at: $<$ https://accessh.org/resource/ehealth-technologies-and-the-future-of-healthcare-inter view-with-henrik-ahlen $>$ [Accessed 4 Sep. 2019]. 


\section{Part II}

\section{Education}





\title{
9 Educational technology (EdTech)
}

\author{
Unbounded opportunities or just \\ another brick in the wall?
}

\author{
Cormac McGrath and Anna Akerfeldt
}

\section{Introduction}

Sweden is among the European countries with the best access to bandwidth and connectivity and has a high student-to-computer ratio (Wastiau et al., 2013). Ninety-three percent of Swedes between the ages of 16 and 85 have access to the Internet in their homes (SCB, 2017). Furthermore, Sweden is the home of a wide range of technology- and software-based companies (Teigland et al., 2018). Entering in third place, Sweden, together with Denmark and Finland, are the top three countries for advanced digital economies according to The Digital Economy and Society Index (European Commission, 2019). As such, the Nordic countries are well placed to avail themselves of new and emerging educational technologies. EdTech is an emerging concern in the broader European context, too, demonstrated not least by the establishment of the European Institute of Innovation \& Technology (EIT) in 2008. In 2018, the European Commission launched a digital education action plan that acknowledges the importance of supporting the use of technologies in education (European Commission, 2018b).

Disruptive innovations have the potential to unlock and create new markets, or radically change the ways in which current markets operate, displacing established market-leading practices and products (Christensen, Raynor and McDonald, 2015). Common examples of such innovations include the personal computer, which disrupted the development of mainframe computers, rendering them almost obsolete. In a similar way, mobile phones have made fixed-line telephony almost a thing of the past. Educational technologies have the potential to cause disruptions in the educational sector with a view to providing key services for governance, services that provide new ways of interacting with educational material, but also through services providing new ways of certification, both in compulsory and higher education. While we acknowledge that some EdTech innovations have the potential to be somewhat disruptive, the traditional Christensen, Raynor and McDonald (2015) definition does not translate well to the scope of compulsory and higher education sectors. Disruption in the educational sector comes slowly for a number of reasons, for example, path dependency in public infrastructure, laws regulating public procurement of services, and also data regulation laws. This chapter presents a number of potentially disruptive or transformational 
innovations and considers the conditions needed for EdTech to play a part in displacing and transforming current practices. In doing so, we consider the difference between digitization and digitalization and acknowledge the transformative nature digitalization of practice could potentially involve. Finally, we present and discuss three different EdTech-oriented themes, artificial intelligence, digital exams, and global content providers, which extend across the educational sectors, and comment on how they could have a transformative effect on educational practice.

\subsection{EdTech as the grand narrative of modernity}

EdTech is often sold as offering unbounded possibilities and a grand narrative of modernity. A positively oriented EdTech discourse is one that comes with the promise to replace a rigid education system with fast-moving technological developments, where insights into technology will have fundamental effects on how people learn. This juxtaposition of new and modern with old and antiquated is often touted from within the EdTech industry itself and should perhaps therefore be treated with skepticism by policy-makers and educators. For example, in AOL's TechCrunch magazine, one could recently read:

For the past 150 years or so, most learning models - especially regarding children - have barely changed: A teacher or lecturer stands at the front of the classroom explaining ideas or introducing facts while students sit and listen with the learning materials being mostly physical textbooks or printouts. Now, however, digital technologies are starting to transform today's classrooms. More students are using computers or tablets, and teachers are increasingly using screens to illustrate aspects of their lessons. Physical textbooks are being replaced by online, interactive services that are more up-todate and in-depth, which allows learners to explore and learn at their own pace. This is important because of two contributing factors. First, students are born with digital DNA.

(Bainbridge, 2016, paras.10-12)

Other notions, such as digital nomads and digital natives, are projected in the media landscape, further enhancing the apparent and almost existential shift that is occurring through the advancement of technology-enhanced education. Advances driven by EdTech are, in reality, much more modest, where we, at times and at best, can identify some more or less strong correlations between learning in the classroom and the use of EdTech (Linderoth, 2016). Still, the grand narrative of disruptive EdTech is one that returns at regular intervals; in the early 2000s, flipped classroom instruction was going to have a profound impact on the classroom; 2012 was the year of the massive open online course (MOOC), when MOOCs were predicted to have an irreversible impact on how education was offered; and currently, we are in the midst of a hype of expectations with reference to how AI, big data, and learning analytics will affect how we teach and 
learn. Only recently, a Swedish EdTech company claimed to be able to utilize AI to closely personalize content to the needs of each student. This promise is made at a time when access to user learning patterns is poorly documented, when public access to learner data is becoming increasingly restricted, for example, because of the new General Data Protection Regulation (GDPR). To confound matters even more, when user data are documented, they are rarely shared and aggregated or put to use in conventional learning contexts to systematically develop teaching (EU GDPR Portal, 2019; European Commission, 2018a).

\section{An overview of EdTech in the school setting}

In Swedish schools, teachers and students have access to and use digital resources on a daily basis in the classroom. Common arguments from the municipalities for implementing new technologies include such notions that education needs to keep up to date with the technological developments in society, and the argument that one can draw advantages from the possibilities to improve the pupils' performance is also often invoked (Tallvid, 2010; Hylén, 2013; Grönlund, 2014). However, it is difficult to establish a clear relationship between increased access to new technologies, leading to their increased use, and improved performance and grades (Lei, 2010). For example, if we consider the results from the International Program for Student Assessment (PISA) from 2012, in countries that use technology on a daily basis, students' results declined between 2000 and 2012 (OECD, 2015). One reason for the decline in students' achievement could be the lack of adequate teaching methods when using technologies in the classroom (OECD, 2015). In other words, previous research can identify some specific advances in learning, but it is difficult to identify causal relationships and "a general fix" for education using EdTech. As such, EdTech does not offer a panacea to student learning and achievement, but there are still many good reasons to use it. EdTech might not facilitate and in itself make learning and teaching more efficient. However, technologies can affect the way teaching, learning, and assessment are perceived and conducted in schools and universities (Åkerfeldt, 2014a). For example, the possibility to store, retrieve, edit, and collaborate when writing a text challenges the notion of writing if we compare writing with using pen and paper only (Åkerfeldt, 2014b). Writing using different technologies has increased in schools and higher education, and a recent investigation identified Google Docs as one of the mostused EdTech tools in the classroom in the United States today alongside YouTube and Google Drive (Molnar, 2017).

Previous research on technology and education suggests that the most successful tools, when it comes to implementation of software and digital systems, are those that have been developed to align with teachers' established teaching methods (Kennewell, 2017), but in reality this is perhaps is not always the case. For example, one example of a digital tool that has been widely adopted in the United Kingdom during the beginning of the 21 st century is the interactive whiteboard (IWB). The implementation of the IWB was not based on research; instead, the initiative was driven by policy-makers in the hope of modernizing educational 
settings and introducing new and innovative teaching methods. Moss and Jewitt (2010) studied the implementation of IWBs, and their findings suggest that some of the teachers were using the IWB as a traditional blackboard. Many teachers did not use features, such as saving and sharing content created on the IWB, with learners. Moss and Jewitt (2010, p. 32) find that the "ways in which teachers use technology is strongly shaped by their existing pedagogic practice, the context of the school, and the demands of particular school subject areas and topics." Thus, the promise that IWBs would bring about a transformation of pedagogy and revitalize classroom teaching was far from being realized in the classroom.

\section{Digitization and digitalization}

The example of the IWB above acts as an introduction to a discussion on the difference between digitization and digitalization. Digitization, we postulate, is an evolutionary process of replacement, involving the creation of a digital version of analogue or physical artifacts. Examples include keyboards replacing pens and paper or computers replacing paper documents and physical books. Analogous to health care, when you transfer patient data to digital health cards, in education you can transfer student's performance data or admission data to digital "cards" or files. As a result of a move toward a digital society, companies are offering schools and municipalities the possibility to accommodate new digital solutions to old analogous problems. Such needs include the digital signing of certificates or offering digital exams, replacing practices that were previously performed on pen and paper, or offering software for a wide range of uses. These practices may not constitute a disruption of practice akin to the introduction of the mobile phone, but instead they may constitute a natural evolution of practice toward digitization, offering minor tweaks as opposed to radically changing the marketplace.

Conversely, we argue that the digitalization of education practice has a transformative nature. So, for example, when introducing digital technology in the classroom or incorporating digital tools in the classroom, there is a need to consider the basis for how educational and information technology can best service the learner and the teacher. Digitalization prompts questions such as: "What does the digital tool afford the teacher and the learner that the analogous version did not?" and "How can the digital tool enhance learning?" and so on. First, after answering these and other related questions, new digitally oriented pedagogies or new approaches can be developed that enhance learning.

\subsection{EdTech as a tool for transforming teaching and learning}

Transforming teaching and learning does not come solely by introducing digital technology into education settings. The transformative process is made up of different layers, conceptual and practical, depending on how one views learning, teaching, and assessment. As the printed text moves to the screen with the possibilities to provide visual and auditory modes, these modalities, in turn, offer 
specific ways of interacting with the learning material. The move from printed text to the screen has the potential to reshape content and therefore also the meaning of printed text. Jewitt (2002) shows in her study how the novel Of Mice and Men by Steinbeck was perceived by students both when represented as a printed text and on the screen. The findings suggest that the characters were conceptually reshaped differently by the students, depending on which media form was used for reading the novel. Furthermore, the characters' relations to each other and even the narrative in the novel communicated different meanings. "The electronic reorganization of the original text into the CD-ROM became fractured, the narrative was disrupted" (Jewitt, 2002, p. 20). The findings suggest that using technology to facilitate learning can involve a deeper transformation of how learners shape their meaning through different modes and media, which might have consequences for teachers' practice when using EdTech solutions in the classroom. However, as the IWB example above demonstrates, a practice-oriented transformation does not occur just because of the implementation of technology. So, how could EdTech have a disruptive or transformative effect in the context of teaching and learning, both in compulsory and higher education? That is the focus of the next section.

\section{EdTech as a potential game changer: three examples}

As mentioned above, technological advances continue to play a central part in most forms of education and have an impact on how people interact with subject content, through the introduction of digital tools and platforms offering students at different levels of education access to vast amounts of knowledge and access to peers across the globe. EdTech innovations also have the possibility to play a more disruptive or transformative role in how educators engage with their students and how students engage in their learning processes, but also how EdTech providers could play a key role in the nexus between teaching and learning. Below, we identify three different EdTech-driven themes and consider further how the different types of EdTech solutions might constitute a transformative change in practice for teachers and learners.

\subsection{AI-enhanced learning solutions}

We are currently witnessing the emergence of a number of AI-oriented solutions with specific relevance to the educational sector, for example, recently the results of AI research have been translated into a tool used to identify and determine reading difficulties in children. In Stockholm's municipality, a large project has been started in which more than 15,000 students, spread across the municipality's primary schools, will carry out eye-screening tests to determine and identify students with reading disabilities. The test is currently offered at a low cost and is projected to be time effective, as it promises to take only two minutes for each student to complete. As early as 2016, four Stockholm schools were part of a study that tested the new AI tool developed with researchers from Karolinska 
Institutet (KI) (Nilsson Benfatto et al., 2016). The new AI tool is not a diagnostic tool per se that can determine the cause of reading and writing difficulties; instead, the tool identifies the reading difficulties. Students read a short text on a computer screen while their eye movements are recorded by a camera. The eye movements are understood to represent cognitive processes in the brain, the results for each student are compared with a large database containing reference material, and the results are analyzed with the help of artificial intelligence (Nilsson Benfatto et al., 2016). The students who show deviating eye movements may have some form of reading or writing difficulties. Traditionally, testing could take half a day for each student, but the new tool promises to finish the test in two minutes per student. Once a student has been found to have problems with the help of the screening, special education interventions may be offered with support measures specific to each student's needs (Jällhage, 2017).

This is just one example of a transformative innovation on a relatively small scale, identifying specific problems in the educational context. The innovation has a potentially transformative effect on one category of teachers in the sense that special educators can devote their time to implementing measures instead of conducting the tests. The tool also means that testing can now be done at a scale with many students, addressing a second issue in the Swedish educational context, namely the lack of special-ed teachers.

Other examples of AI in the education context include using machine learning and neural network software to make predictions based on a participant's scores on diagnostic tests, where individual learning patterns can be identified and proposed. The Swedish company referred to above recently won a global AI competition, beating other AI platforms in predicting mistakes that language learners would make based on their previous errors, and was able to suggest unique learning trajectories for individual learners. These advancements in AI and learning pathway prediction offer some interesting insights into potential possibilities for EdTech in the future. At the same time, there is a significant difference between learning language via an app and the reality of a school environment that is socially and culturally situated and that follows conventional assumptions about meaning-making and methods of information delivery.

\subsection{Digital exams}

There is a current and widespread emergence of digital exam vendors in the Swedish context. In their simplest form, digital exams constitute a form of digitization whereby conventional exams are migrated to digital spaces and tools (LlamasNistal et al., 2013). Digital exams offer a tool or a range of tools; for example, when students log on to a platform via a computer, the system can be configured so that it locks down other elements of the computer, meaning that the student can only focus on the digital exam. The research on digital exams is still nascent at the moment, but there is ongoing research into automatic correction of open-response tests. This field of research combines natural language processing and artificial intelligence techniques, but empirical results are still scarce. Digital exams 
also afford teachers a legible reading experience, and as a bonus if connected to a single-sign-on system, the results can be registered digitally, thus reducing the time for teachers to document students' results. Computer-based assessment such as digital exams, multiple choice quizzes (MCQs), single best answer (SBA), and other online tests are commonly used to assess students' knowledge. Computer-based assessment can, for example, reduce the teacher's workload, as the students' answers can be corrected automatically (currently limited to the preresponse selection type of questions such as MCQs). Moreover, it is possible to randomize the questions, and it is also possible to increase reliability, as the exams can be taken and corrected anonymously. In an interview study with 33 university teachers, the teachers stated that online MCQs were used as they saved time and they felt a pressure to adopt more efficient forms of assessment, even though some teachers questioned whether this was good practice (Bennett et al., 2017). The use of video and simulations was also mentioned as a technology that could offer efficiency. Simulation was used to assess students' practical skills, for example, in paramedics when students worked with simulated patients. However, creating new forms of assessment was perceived as time consuming and challenging. Conversely, teachers wanted to discuss foremost students' achievement rather than starting directly to implement technologies in their assessment practices. In this sense, the pedagogy and technology were disconnected (Bennett et al., 2017).

In Sweden, the national tests for compulsory and secondary school will be digitized by the end of 2022. In doing so, the government argues that the tests will be delivered digitally, corrected fairly, and provide reliable data (Government Offices of Sweden, 2017). Through digitization, all students will be subject to the same test. Testing reliability, it is argued, can be obtained when the students' answers are anonymized and are corrected by another teacher than the one that has been teaching the student. Previous investigations show that teachers tend to be more generous in their assessment and grading if they teach the student than if they do not know the student (Begler and Bremberg, 2012).

The digitization and digitalization of exams offer entirely new opportunities that utilize digital exam systems, but in ways that require a transformative approach to teaching and learning. Another aspect of the digitalization of assessment practices is that it can potentially transform how assessment is carried out in schools. In contexts where technologies are used on a daily basis for teaching and learning, assessment practices are changing and moving toward assessment for learning (Erstad, 2008) instead of assessment of learning. Through the use of learning management systems, educators have the possibility to follow students' learning and knowledge progress over time. Teachers using technologies in their classroom claim that they can determine students' grades before the students have handed in the final assignment. The teachers feel that they have been informed through the digital systems about the students' learning process (Hernwall et al., 2018).

New ways of approaching exams in a digital fashion are needed today; for example, it is not uncommon for large student cohorts in medicine, law, and computer science to do pen-and-paper exams, as there are no exam facilities for digital 
exams for large groups in many of Sweden's university cities $(\mathrm{n}=300-500)$. The solution to this problem, however, is not to provide 500 computers or tablets to the students; instead, new ways of conceptualizing and practically implementing changes are needed that take advantage of digitization and use EdTech as a catalyst for digitalization. Here, EdTech can offer solutions; however, the question remains: Are schools and universities open and able to capitalize on the new opportunities?

\subsection{EdTech as global content provider}

In this section, we identify EdTech as a content provider, that is to say, specific EdTech companies offer courses or content material. We acknowledge that there are a wide range of forms of content providers on the marketplace that provide service and target compulsory education as well as higher education, both in Sweden and globally. However, in this part of the chapter, we will focus specifically on MOOCs as an EdTech phenomenon. MOOCs are not a specific EdTech innovation per se; instead, they are an aggregation of different educational technologies cohosted on a platform. MOOCs often offer tools that are broadly accessible and commonplace already, such as video-recorded lectures, multiple-choice questions, and discussion forums. Other innovations used in MOOCs are 3D modeling and virtual patients. This chapter uses the MOOC phenomenon to illustrate different views on how EdTech could be used in the context of higher education to disrupt current practices, and gives comments on developments so far.

MOOCs are courses that are hosted on globally accessible platforms. Initially MOOCs were open to everyone who had access to a computer and an Internet connection, and a certificate of participation was offered to students who passed courses. However, as business models have developed, it has become increasingly common for MOOC vendors to differentiate between audiences, offering some content for free (without certification), certification of participation for a fee (ca. USD 50), and corporate-specific education at a higher fee (starting at, for example, around USD 200 per one-week course). MOOCs came to wide public attention in 2012 and brought the promise of being a new force in higher education, promising to revolutionize but also disrupt traditional higher education (Ross et al., 2014; Yuan and Powell, 2013; McGrath et al., 2017). However, even though MOOCs offer the promise of open education resources (De Freitas, Morgan and Gibson, 2015; Czerniewicz et al., 2017), the broad transformative and previously promised revolutionary effects on higher education learning have yet to materialize (Eisenberg and Fischer, 2014; Siemens, 2015; Stöhr et al., 2019).

Arguably MOOCs could be a disruptive force in a number of ways, for example, they could empower a change in the demographics of higher education, enabling nontraditional students to gain access to higher education. MOOCs could, given their massive outreach, bring about a change in the certification of higher education credit, they could afford universities new ways of addressing learners' needs, and they could also involve university teachers in new ways of practicing and teaching their subjects. 
In the Swedish context, the response to MOOCs thus far has been moderate. Some of the larger universities, for example KI, the Royal Institute of Technology (KTH), and Chalmers University of Technology all provide MOOCs via the edx platform, and Lund University offers courses on the Coursera platform. The current courses are either offered as introduction courses or as highly specialized courses, often requiring a good pre-understanding and several years of previous study.

Data on MOOC participants suggest that while there is wide geographical diversity - for example, KI's course on urology had participants from 172 countries (Henningsohn et al., 2017) - most MOOC participants already had a college or university degree (Breslow, 2016). In other words, the MOOCs themselves are not disrupting the traditional pathways to higher education studies but instead seem to be attracting and offering continued education to well-educated professionals, providing opportunities for them to solidify or refresh their knowledge. At the same time, research suggests that lay people and students alike can benefit from MOOCs, (Henningsohn et al., 2017; Stöhr et al., 2019).

MOOCs, given their specific attention to online learning and mass participation, could also allow universities to provide mass education in basic introductory courses traditionally offered by universities. In doing so, it would be possible to allow many people to attend "MOOCified" versions of introductory courses in medicine, engineering, and law, just to name a few. Georgia Tech has MOOCified one of its master's programs (McKenzie, 2018). Some initial data suggest that:

- An enrollment of 6365 makes it the largest master's degree program in computer science in the United States.

- New categories of people are attending the program. The typical applicant to the online program is a 34-year-old midcareer American, while the typical applicant to the in-person degree is a 24-year-old recent graduate from India.

- Students admitted to the online program had slightly lower academic credentials than those admitted to the in-person program; online students performed slightly better in identical and blind-marked final assessments.

- Tuition to the MOOC program costs USD 6630, which is one-sixth of the cost of the in-person program.

MOOCs could also afford universities new ways of addressing learners' needs. Given the mass participation, MOOCs provide higher education institutions with large datasets that could be used to better optimize the learning of certain subjects using learning analytics to identify gaps in student learning for on-campus students. However, a quick look at the MOOC strategies of KI, KTH, and Chalmers reveals that none of the universities have active policies for exploring how learning occurs in MOOCs. Instead, the research done on MOOCs is conducted on the same competitive grounds as other research and is self financed. Given the high costs associated with developing MOOCs (a one-week MOOC costs between SEK 350,000-700,000 to produce), it is interesting that the universities do not employ learning analysts to understand how MOOCs can be translated into a 
return on investment in terms of educational practice and financial responsibility. It is clear to us that MOOCs could break open the higher education sector, offering access to higher education to new categories of students. Such digital learning resources could also change the way in which we select students for advancement through higher education. MOOC introductory courses could be used as a way of providing students with access to continued studies. This could mitigate concerns raised by the Swedish National Agency for Education (2018) that secondary school grades are not always the best predictor for successful university studies. By allowing students to attend the same MOOC, then performance scores on the MOOC could act as better predictors of performance in higher education. However, Swedish universities have a well-defined and path-dependent infrastructure that is based on quasi-meritocratic grounds. A loosening up of this system could have far-reaching consequences that may be more or less desirable and predictable, such as, for example, disturbing merit-based approaches to university access.

\section{EdTech as a disruptive force - looking ahead}

So far, we have considered the difference between digitization and digitalization, and we introduced the idea of transformation as a key concept when considering the disruptive nature of EdTech. The chapter has also presented a number of different EdTech-oriented innovations that extend across the broader educational sector from preschool to higher education, and we have commented on how they may or may not constitute a transformative effect on educational practice. We endeavored to acknowledge a distinction between what may constitute disruptions of the education sector and what otherwise might be viewed as opportunities to transform, in more or less radical ways, educational and learning practices. Our focus on transformation of educational practice is driven by our experiences as practitioners and researchers in education.

In this final section, three strands are presented that will form a starting point for a discussion about the use of EdTech in education: 1) IT education strategies are needed on several levels; 2) challenges when new technologies face policy, laws, and regulations need to be addressed; and 3) collaboration between researchers, teachers, and EdTech ventures can lead to mutual benefit.

We emphasize a need for strategy as a key feature when considering the digitization and digitalization of the education sector. Consequently, and for the purposes of this chapter, we conducted a mini-survey of a few Swedish higher education institutions, asking two brief questions related to digital learning strategies. The two questions were directed to the central communications departments at the universities and do not provide an adequate examination of how the universities approach digitalization and learning, but the results may be of interest, nonetheless. The questions were:

- Do you have a strategy document for IT with a view on education practice within your university?

- Does your university have a chief digital officer? 
The outcomes are listed in Table 9.1.

None of the universities consulted reported having a dedicated digital learning strategy at this point in time. In the cases where there are strategies, they are part of wider IT infrastructure strategies. The fact that some of Sweden's foremost universities do not have digital learning strategies is perhaps not surprising - after all, Sweden's first chief digital officer (CDO), Åsa Zetterberg, was only recently (2018) appointed - but it does suggest that EdTech may not really play a disruptive part in the near future, at least simply for the reason that strategies may be needed to drive financial investments and strategies are run by key people within the organization. Looking ahead, we see a need for municipalities and universities to have digital learning strategies that are aligned to data-sharing laws and that are user focused. In addition, they must also have a strategy for developing university teachers' digital competence.

We identify that laws regulating public procurement of services and also data regulation laws constitute major obstacles to EdTech ventures, and we argue that strategies along a number of lines are needed. Laws regulating the public procurement of services may also act as obstacles, at least initially, to the development of the new, previously unthought-of services. The public procurement act regulates the way in which public bodies, universities, and municipalities conduct procurement and stipulates that a public procurement contest must be organized that is open to all and arranged by a contracting authority with the aim of acquiring a plan or design selected by a jury. Other restrictions entail no one contractor being treated more favorably during the procurement process. Such a process makes sense from the viewpoint of authorities' legal obligations via-à-vis the law. Still, we wonder if this may in some ways act as an obstacle to the development of specific new innovations in the public sector. The implementation of the new dataprotecting regulations (GDPR) also means that vendors may be more restricted when collecting data from learners in the context of the EdTech industry. This

Table 9.1 Survey of digital learning strategies at a selection of Swedish universities

\begin{tabular}{|c|c|c|}
\hline University & $\begin{array}{l}\text { Do you have a strategy } \\
\text { document for IT with a view on } \\
\text { education practice within your } \\
\text { university? }\end{array}$ & $\begin{array}{l}\text { Does your university have a } \\
\text { chief digital officer? }\end{array}$ \\
\hline $\begin{array}{l}\text { Stockholm } \\
\text { University }\end{array}$ & No & No \\
\hline $\begin{array}{r}\text { Karolinska } \\
\text { Institutet }\end{array}$ & No & No \\
\hline $\begin{array}{l}\text { KTH, The Royal } \\
\text { Institute of } \\
\text { Technology }\end{array}$ & No response within time frame & $\begin{array}{l}\text { No response, but KTH has a } \\
\text { digitalization officer }\end{array}$ \\
\hline Lund University & $\begin{array}{l}\text { There is no overall digital } \\
\text { learning strategy, but Lund } \\
\text { University has an IT strategy }\end{array}$ & No \\
\hline Umeå University & No response within time frame & No response within time frame \\
\hline
\end{tabular}


presents a major challenge, not least for the development of personalized learning solutions and also for researchers and practitioners in the educational field.

We believe that there is a lack of experience and knowledge about how researchers can collaborate with EdTech ventures. However, there are attempts to bridge this gap between research and ventures. For example, universities in Sweden have created software in order to encourage researchers to think about how they could commercialize their research and create new innovations with companies, or how they could start their own business. Researchers are paired with a business mentor who supports the researcher for one year to think more in terms of commercialization of their research findings. One challenge that the participants in the program faced was that the academic organization did not have the appropriate "knowhow" about business models, laws, intellectual property, copyright, and so on.

In conclusion, we acknowledge that EdTech has a prominent place in the Swedish educational context, and we identify many middle-way transformative outcomes that use EdTech to drive a change in practice; such examples include flipping the classroom and other blended learning techniques. We have shown how open-source software circumvents the procurement law, enabling students to access and learn code and coding. "Scratch" is an example of an open-source web-based application, where the user through block-based programming can create, for example, stories and games. However, we also acknowledge that these advances do not come quickly, nor are they adopted radically or systematically, but occur more sporadically. Furthermore, closer partnerships with end users are needed to promote mutual benefit.

In this chapter, we did not address corporate learning, where companies and global corporations may have a more direct decision-making process and whereby they could potentially have a very strong financial drive toward implementing AI in their corporate educational programs. Similarly, we have not discussed how other forms of continued professional development could be enhanced by educational technology.

Finally, we should consider the value that teachers and educators provide to students' learning experience, and offer a word of caution. Teachers and educators offer unique experiences to students at all levels of the education system, and offer critical voices that act as a counterbalance to many taken-for-granted ideas. They also act as creators of knowledge, by breaking knowledge down into intelligible bits and pieces that are shared, critiqued, and used to build further knowledge in our society. Are we willing to embrace the full effects of educational technology? If so, then what is the role for educators? Will they be reduced to curators of content created by artificial intelligent systems in Silicon Valley? We believe there is an inherent value that educators are cocreators of intellectual output and on-demand solutions that enhance their own teaching efforts and the efforts of the students they meet and engage with.

\section{Acknowledgments}

We would like to express our gratitude to Dr. Christian Stöhr and Dr. Eva Insulander for comments on early drafts of this chapter. 


\section{References}

Åkerfeldt, A., 2014a. Didaktisk design med digitala resurser: En studie av kunskapsrepresentationer $i$ en digitaliserad skola [Didactic design with digital resources: a study of representations of knowledge in a digitalised school]. Sweden: Stockholm University.

Åkerfeldt, A., 2014b. Re-shaping of writing in the digital age: a study of pupils' writing with different resources. Nordic Journal of Digital Literacy, 9(3), pp. 172-93.

Bainbridge, D., 2016. Edtech is the next fintech. [online] TechCrunch. Available at: $<$ https:// techcrunch.com/2016/08/13/edtech-is-the-next-fintech > [Accessed 4 Sep. 2018].

Begler, A-M. and Bremberg, G., 2012. Lika för alla? Omrättning av nationella prov $i$ grundskolan och gymnasieskolan under tre år [Equal for all? recorrrection of national tests in primary school and high-school during three years]. Stockholm, Sweden: The Swedish Schools Inspectorate.

Bennett, S., Dawson, P., Bearman, M., Molloy, E.K. and Boud, D.J., 2017. How technology shapes assessment design: findings from a study of university teachers. British Journal of Educational Technology, 48(2), pp. 672-82.

Breslow, L., 2016. MOOC research: some of what we know and avenues for the future. In: E. De Corte, L. Engwall and U. Teichler, eds., From books to MOOCs? Emerging models of learning and teaching in higher education. London, UK: Portland Press, pp. 57-68.

Christensen, C.M., Raynor, M.E. and McDonald, R., 2015. What is disruptive innovation? Harvard Business Review, 93(12), pp. 44-53.

Czerniewicz, L., Deacon, A., Glover, M. and Walji, S., 2017. MOOC - making and open educational practices. Journal of Computing in Higher Education, 29(1), pp. 81-97.

De Freitas, S.I., Morgan, J. and Gibson, D., 2015. Will MOOCs transform learning and teaching in higher education? Engagement and course retention in online learning provision. British Journal of Educational Technology, 46(3), pp. 455-71.

Eisenberg, M. and Fischer, G., 2014. MOOCs: a perspective from the learning sciences. In: J.L. Polman, E.A. Kyza, D.K. O'Neill, I. Tabak, W.R. Penuel, A.S. Jurow, K. O’Connor, T. Lee and L. D'Amico, eds. Learning and becoming in practice: 11th international conference of the learning sciences (ICLS) 23-27 June. Boulder, CO: ICLS, pp. 190-7.

Erstad, O., 2008. Changing assessment practices and the role of IT. In: J. Voogt and G. Knezek, eds. International handbook of information technology in primary and secondary education - part one. Berlin, Germany: Springer, pp. 181-94.

EU GDPR Portal, 2019. Site overview. [online] Available at: <www.eugdpr.org > [Accessed 4 Sep. 2019].

European Commission, 2018a. 2018 reform of EU data protection rules. [online] Justice and fundamental rights. Available at: $<$ https://ec.europa.eu/commission/priorities/jus tice-and-fundamental-rights/data-protection/2018-reform-eu-data-protection-rules_en> [Accessed 4 Sep. 2019].

European Commission, 2018b. Communication from the commission to the European parliament, the council, the European economic and social committee and the committee of the regions on the digital education action plan. [online] Available at: $<$ https://eur-lex.europa. eu/legal-content/EN/TXT/?uri=COM\%3A2018\%3A22\%3AFIN $>$ [Accessed 4 Sep. 2019].

European Commission, 2019. The digital economy and society index (DESI). [online] Digital Single Market Policy. Available at: <https://ec.europa.eu/digital-single-market/en/ desi> [Accessed 4 Sep. 2019].

Government Offices of Sweden, 2017. Nationella prov - rättvisa, likvärdiga, digitala (Proposition 2017/18:14) [National tests - fair, equal, digital (Government Bill 2017/18:14)]. [online] Available at: <www.regeringen.se/rattsliga-dokument/proposi tion/2017/09/prop.-20171814> [Accessed 4 Sep. 2019]. 
Grönlund, Å., 2014. Att förändra skolan med teknik: Bortom 'en dator per elev' [To change the school with technology: Beyond 'one computer per pupil']. [online] Available at: $<$ http://urn.kb.se/resolve?urn=urn:nbn:se:oru:diva-34389> [Accessed 4 Sep. 2019].

Henningsohn, L., Dastaviz, N., Stathakarou, N. and McGrath, C., 2017. KIUrologyX: urology as you like it - a massive open online course for medical students, professionals, patients, and laypeople alike. European Urology, 72(3), pp. 321-2.

Hernwall, P., Insulander, E., Åkerfeldt, A. and Öhman, L., 2018. Bedömning av multimodala elevarbeten - lärares uppfattning om bedömning [Assessing multimodial student work - the teacher's perception of assessment]. In: K. Nygårds and T. Raymond, eds. Navigera i den digitala samtiden - En antologi om den nya lärarrollen [Navigating in the digital era - an antology regarding the teacher's new role]. Stockholm, Sweden: Lärarförlaget, pp. 55-70.

Hylén, J., 2013. Digitalisering i skolan - en kunskapsöversikt [Digitalization in schoola knowledge overview]. [online] Available at: $<\mathrm{https} / / \mathrm{kfsk} . \mathrm{se} / \mathrm{larandeocharbetsliv/wp-}$ content/uploads/sites/8/2015/01/Ifous-Digitalisering-i-skolan-2013-1.pdf $>$ [Accessed 4 Sep. 2019].

Jällhage, L., 2017. Stockholmselever screenas för läs- och skrivsvårigheter [Stockholm students are screened for reading and writing difficulties]. [online] Lärarnas tidning. Available at: <https://lararnastidning.se/stockholmselever-screenas-for-las-och-skrivs varigheter> [Accessed 4 Sep. 2019].

Jewitt, C., 2002. The move from page to screen: the multimodal reshaping of school English. Visual Communication, 1(2), pp. 171-95.

Kennewell, S., 2017. Changing rationales for computers in education: from liberation to involvement. In: A. Tatnall and M. Webb, eds. Tomorrow's learning: involving everyone. Learning with and about technologies and computing. WCCE 2017. IFIP advances in information and communication technology, vol. 515. Cham, Switzerland: Springer, pp. 3-12.

Lei, J., 2010. Conditions for ubiquitous computing: what can be learned from a longitudinal study. Computers in the Schools, 27(1), pp. 35-53.

Linderoth, J., 2016. Lärarens återkomst: Från förvirring till upprättelse [Return of the teacher: from confusion to vindication]. Stockholm, Sweden: Natur \& Kultur.

Llamas-Nistal, M., Fernández-Iglesias, M.J., González-Tato, J. and Mikic-Fonte, F.A., 2013. Blended e-assessment: migrating classical exams to the digital world. Computers \& Education, 62, pp. 72-87.

McGrath, C., Stenfors-Hayes, T., Roxå, T. and Laksov, K.B., 2017. Exploring dimensions of change: the case of MOOC conceptions. International Journal for Academic Development, 22(3), pp. 257-69.

McKenzie, L., 2018. Online, cheap - and elite. [online] Inside Higher Ed. Available at: $<$ www.insidehighered.com/digital-learning/article/2018/03/20/analysis-shows-georgiatech's-online-masters-computer-science $>$ [Accessed 4 Sep. 2019].

Molnar, M., 2017. 40 most popular ed-tech tools in K-12 identified in new analysis. [online] EdWeek Market Brief. Available at: <https://marketbrief.edweek.org/marketplace-k12/40-popular-ed-tech-tools-k-12-identified-new-analysis> [Accessed 4 Sep. 2019].

Moss, G. and Jewitt, C., 2010. Policy, pedagogy and interactive whiteboards: what lessons can be learnt from early adoption in England? In: M. Thomas and E. Cutrim Schmid, eds. Interactive whiteboards for education: theory, research and practice. Hershey, PA: IGI Global, pp. 20-36.

Nilsson Benfatto, M., Qvist Seimyr, G., Ygge, J., Pansell, T., Rydberg, A. and Jacobson, C., 2016. Screening for dyslexia using eye tracking during reading. PLOS ONE, 11(12), e0165508, pp. 1-16. 
OECD, 2015. Students, computers and learning: making the connection. Paris, France: OECD Publishing.

Ross, J., Sinclair, C., Knox, J., Bayne, S. and Macleod, H., 2014. Teacher experiences and academic identity: the missing components of MOOC pedagogy. MERLOT Journal of Online Learning and Teaching, 10(1), pp. 57-69.

$\mathrm{SCB}, 2017$. IT bland individer [IT among individuals]. [online] Available at: $<\mathrm{http}: / / \mathrm{web}$. archive.org/web/20180620153432/www.scb.se/hitta-statistik/statistik-efter-amne/lev nadsforhallanden/levnadsforhallanden/it-bland-individer> [Accessed 4 Sep. 2019].

Siemens, G., 2015. The role of MOOCs in the future of education. In: C.J. Bonk, M.M. Lee, T.C. Reeves and T.H. Reynolds, eds., MOOCs and open education around the world. New York, NY: Routledge, pp. xiii-xvii.

Stöhr, C., Stathakarou, N., Mueller, F., Nifakos, S. and Megrath, C., 2019. Videos as learning objects in MOOCs: a study of specialist and non-specialist participants' video activity in MOOCs. British Journal of Educational Technology, 50(1), pp. 166-76.

Swedish National Agency for Education, 2018. Från gymnasieskola till högskola - en registerstudie [From high-school to college - a register study]. Stockholm, Sweden.

Tallvid, M., 2010. En-till-en: Falkenbergs väg till Framtiden? [One-to-one: Falkenberg's road to the future]. Falkenberg, Sweden: The Municipality of Falkenberg.

Teigland, R., Siri, S., Larsson, A., Moreno Puertas, A. and Ingram Bogusz, C., 2018. Introduction: fintech and shifting financial system institutions. In: R. Teigland, S. Siri, A. Larsson, A. Moreno Puertas and C. Ingram Bogusz, eds., The rise and development of fintech: accounts of disruption from Sweden and beyond. London, UK: Routledge, pp. 1-18.

Wastiau, P., Blamire, R., Kearney, C., Quittre, V., Van de Gaer, E. and Monseur, C., 2013. The use of ICT in education: a survey of schools in Europe. European Journal of Education, 48(1), pp. 11-27.

Yuan, L. and Powell, S., 2013. MOOCs and open education: implications for higher education. Bolton, UK: Cetis Publications. 


\title{
10 Education at the intersection
}

\author{
A practitioner's view of the effect \\ of digital transformation on public \\ education
}

Stephen Mahaley

\section{Introduction}

The objective of this chapter is to explore the ongoing evolution of public education in the United States, with a particular focus on the risks and rewards of digital transformation. There are a number of dimensions of public education that merit review: funding, access, content, methods, teacher qualifications, and infrastructure, to name a few. Arguably there are no institutions, formal or informal, that are immune to the effects of widespread technological innovation - from the dawn of the Internet through the rapid proliferation of digital connections in the early 2000s, to today's deeply ethical considerations of the potential impact artificial intelligence, gene editing, robotics and automation, and data sharing and analytics, among other manifestations.

Education will be argued as a core and abiding component of viable democratic economies and societies, and the current range of digital transformations (and related policies) stand to either bolster the public good that quality education can create, or further damage and divide public education in ways that exacerbate existing disparities. I will be examining public education in the United States only, with references to global comparative data where applicable and available. It is my hope that the reader gain some useful information from this chapter and ask questions about the state of digital influence on this particular public good and what she or he can do to direct investments, programming, policies, and conversations in ways to support it.

\section{Material}

\subsection{A brief history of public education in the United States}

At the turn of the 20th century, the United States was poised at the edge of an educational crisis: the industrial revolution was in full swing, yet there were not nearly enough workers who had basic skills to run machines and participate in the booming assembly-line industries expanding across the country. The federal government established the Department of Education, and each state in the union was given some budget and latitude to levy its own taxes for public education, and to 
interpret and implement federal education guidelines. Over the years, states determined their own methods of funding public schools - either through management at the state level (with funding through state taxation), through localized counties or districts (with funding largely based on property taxes), or some combination of both.

Times were tumultuous, given the racially divided country, stemming from a century or more of subjugation of African Americans. Brown v. Board of Education, a landmark ruling of the US Supreme Court decided in 1954, called for all states to integrate their schools, and while the legal intent was there at the federal level, many states were slow to implement the guidance (taking more than a decade), leaving a legacy of great disparity in the funding of schools, largely based on the populations they serve. In many cases, school districts were formed around zones of wealth and districts organized around neighborhood schools, such as in the state of Connecticut. Combine that with the fact that the largest portion of public school funding in Connecticut comes from local property taxes, and we see large disparities in levels of funding for local schools, with poor students attending dilapidated schools (CT School Finance, 2018). For more on the Connecticut example, see Thomas and Kara's 2017 report (Thomas and Kara, 2017).

The importance of the Brown v. Board ruling and the realities of state-level funding policies should be held in consideration as we think further below about the implications for equal funding and access to modern educational tools. As Chief Justice Warren stated in the ruling in 1954:

We conclude that in the field of public education the doctrine of 'separate but equal' has no place. Separate educational facilities are inherently unequal.

(United States Courts, 2018, para.15)

As we will see below, these funding disparities have a direct effect on how digital transformation is evolving in this sector.

Public education in the United States has been undergoing a digital transformation for decades, and that transformation, since the advent of the Internet, has accelerated with a host of new technologies available. The Internet, born out of early sharing of research data between US governmental agencies and academic institutions, was a key turning point for education, affecting everyone involved from teachers, to students, to content producers, to school building designers, and of course to governance and financial managers.

As a former public school teacher, I began my teaching career in the 1980s using the same technologies that I had had experience with as a student decades before: overhead projectors, filmstrip projectors, the occasional vinyl record or tape, and of course plenty of mimeographed copies to go with well-worn textbooks and chalkboards. This was the state of learning technology at start of the 1990s, and it looked like it could stay that way forever - until the expansion of personal computers.

In the mid-90s, I was there to open the first boxes of hardware that arrived at my public elementary school. Owing to thin budgets, I volunteered my time 
to learn all about databases, email servers, networking protocols, HTML, and hardware installation. This was a radical time, as everyone - parents, teachers, administrators, and students - wandered into the web to figure out what it was and what it could mean. After having corralled a group of parent volunteers together to run a "Net Day" at our school in which we ran wires to the classrooms and connected as many computers as possible, it became clear that the "soft side" of this transformation needed just as much care and attention. The teachers needed help understanding what this new world would mean and how to integrate the rapidly growing toolset into their instructional practices, evaluation methods, and curriculum design.

And now, as the 21 st century has begun, the pace of technological innovation has accelerated from the boom at the end of the 20th, placing traditional educational practices and structures in the crosshairs of potential innovation. Examples of this innovation include rising student access to digital learning resources (DLR) and the incorporation of those tools and resources into the educational experience. Access, however, does not necessarily equate to increased performance, and the United States may be falling behind. According to the National Center for Education Statistics' (NCES) 2017 report, US teenagers, solving problems in a technology-rich environment, performed at a lower level than the OECD average (Hussar and Bailey, 2014).

Certainly multiple factors (income levels, access to resources, parental educational levels, etc.) have come into play. In 2015, only 62 percent of households had Internet access in the state of Mississippi (Hussar and Bailey, 2014). If there is an expectation that students access online tools, content, and experiences, equal access to the Internet will need to be resolved. This history of digital transformation, coupled with federal and local policy-making, has placed public education squarely in the intersection. Will there be equitable and democratic access to highquality public education, powered by technologies? Let's take a closer look at how these factors are playing out today.

\subsection{The current state of digitalization of education}

Over the past ten years, the open Internet and the proliferation of digital tools have not delivered the degree of democratization of education that we once predicted. Some great examples of this democratization do exist, to be sure: Salman Khan and his Academy (www.khanacademy.org), the genesis and proliferation of massively open online courses, the wide use of live webinar platforms, opensource learning management systems (e.g., Moodle), and myriad digital learning experience and content authoring tools. During this time we've seen educational business models evolve, including the purely digital "freemium" models for online coursework as well as an expansion of for-profit colleges and universities (e.g., University of Phoenix as a prime example). Based on NCES data, we can expect today a total of 27 to 28 million students enrolled in post-secondary schools in the United States (NCES, 2019). This is indeed a large market to be served. 
What has failed to keep up, however, are smart regulations that ensure that infrastructure is equally available across school systems and that options are available for the many students who do not have reliable (or any) Internet or computer access outside of school. Nowhere is this more pronounced, perhaps, than at the $\mathrm{K}-12^{1}$ level, where the United States has seen a significant relaxation of regulations regarding the number and structures of charter and private schools. While these schools promote the benefits of "choice" in schools, those choices are rarely available to the populations who arguably most need them - namely the underserved, lower middle class, and poor communities. Charter and private schools are typically exempt from providing transportation, meals, or special services for children with exceptional needs, and the result is a further widening of the gap between those who have choice and access to well-funded schools and those who do not.

What is more, the data on performance do not typically bear out the promises: in a 2016 study of school performance in Louisiana, charter and private schools, on average, underperformed their public school counterparts (Mills et al., 2017). Additionally, there are widely varying governance structures and standards: many private or charter schools do not require their teaching staff to have any formal education or qualifications in instruction or child development. Frequently there is little to no recourse for parents if their students are underserved; these students eventually find their way back into the public school stream.

This is not to say that all charter or private schools fail to provide quality education. This is, however, to bring focus on a critical piece of the overall landscape to consider as we look at digital transformation and examine the arguments for school choice that present deeper funding challenges for public schools (Walker, 2016). With potentially more limited funding reaching public schools, and greater concentrations of wealth in fewer school districts, there is a growing concern for equal access to the latest that digital tools and methodologies can offer.

We have also seen a lack of accountability and standards with regard to the quality of many privatized, online education providers, often leaving students with incomplete educations and a significant pile of debt. Examples of failed for-profit universities abound, and the number of current and former students struggling with a mountain of student loans to repay is staggering. Forbes, the Brookings Institution, and others have reported on the perversion of higher education toward revenues and shareholder returns, resulting in what is now 1.3 trillion dollars of debt owed by students - many (35-47 percent, depending on source) of whom will default (Simon, 2018). Public and for-profit universities have been offering increasing numbers of distance education courses and garnering a growing share of student participation - totaling nearly 30 percent of all students in 2015 (Seaman and Seaman, 2017). The digital wave may have brought new possibilities for access to education, but in too many cases educational outcomes have been limited due to mounting debt.

While we in the United States continue to struggle with these issues of affordability and access, there are still great examples of digital innovation that illustrate the right blend of educational design and technology integration. There are better 


\section{Stephen Mahaley}

and better learning apps that provide not just another boring channel for pushing content, but that connect content to context. The University of Adelaide's Allan Carrington has integrated the SAMR model (substitution, augmentation, modification, and redefinition) along with Bloom's Taxonomy to identify over 125 apps that can be used on the iPad for instructional purposes (Carrington, 2016). For example, there are apps that deliver content based on geolocation or through the use of beacons, giving learners relevant information, questions, and tools for a particular place in the world - be that in an art gallery or during onboarding at a new office job.

We have also seen the early growth of virtual and augmented reality tools in teaching, learning, and performance support applications. Apps, on tablets or phones, now incorporate augmented reality tools - just point the camera at an object, a map, or a photo and a contextual overlay appears. Surgeons have used augmented and virtual reality views of a patient's heart muscle to identify particular approaches to correcting a blocked artery - in the operating theatre (Zhang, 2018). There are many, many applications of augmented reality - through headsets or handheld devices - that provide learners and workers real-time guidance during particular procedures, be that in the automotive garage or on an oil rig out at sea. Students at Georgia Tech University enrolled in Professor Ashok Goel's Interactive Computing course have their online questions fielded by Jill Watson, an artificial intelligence engine that functions as a virtual teaching assistant (Maderer, 2017). And this has been going on since 2015.

These immersive experiences are but one aspect of positive impact of digital transformation today. There is also the improving use of online platforms, powered with data analytics, that allows for greater insights into student performance, engagement, and smart suggestions for further, personalized, study paths. We have seen the disaggregation of some services to allow for interoperability - with many thanks to standardization on using xAPI technology to create links between content warehouses, LMS activities, and online learning events. Systems are now linking up, and learning can (with the right hardware and access) happen just about anywhere.

Today's reality for digital transformation in education is part of a larger context, of course. Here in the United States, there is an ongoing debate about net neutrality. Recent actions by some of the service providers have sought to split up service levels of Internet access, providing more opportunities for these companies to charge for their services. If you have a large dataset or rich streaming media experience you want to access, that could require greater levels of payment. As we think about the benefits of immersive education (gaming, virtual reality, live streaming, etc.) and the role of public education as a potentially equalizing force in our democracy, these debates over net neutrality ${ }^{2}$ will hopefully result in fair access for all students, irrespective of their income (Hitlin, Olmstead and Toor, 2017).

\subsection{Considerations for the future}

Projected enrolment in 2022 in public elementary and secondary schools in the United States is expected to be at 53 million students (Hussar and Bailey, 2014), 
according to the National Center for Education Statistics (US). This is just around the corner. What will children and high-schoolers' experience be? How will digital transformation show up for them?

Will campuses be ready? According to a 2018 article by EDUCAUSE President and CEO John O'Brien (2018, para.6):

digital transformation is affecting the entire higher education enterprise, of course. Yet evidence from EDUCAUSE research shows that comprehensive approaches to digital transformation are not evenly distributed. Around onethird of institutions . . . show clear signs of campus-wide digital strategy either already in place (3\%) or exerting a 'major influence' $(28 \%)$ on their emerging IT strategy.

Looking into the future is, of course, a guessing game. Disparities in access have been outlined above, and other trends that are disrupting our "today" may be themselves disrupted and supplanted by others in quick order. We can, however, take the directionality of the previous storylines and some data from current economic projections and extrapolate on a few points.

First, let us consider the "why" of education in the future. Many are arguing now that the combination of artificial intelligence (pulling big data from an Internet of Things) and robotics will revolutionize many industries, destroying long-held jobs (and career paths), creating new ones, and therefore spawning an entire wave of new learning and development requirements. The Pew Research Center's report (Rainie and Anderson, 2017, para.5) summarizes current expectations nicely, and points out that:

A central question about the future, then, is whether formal and informal learning structures will evolve to meet the changing needs of people who wish to fulfil the workplace expectations of the future.

With artificial intelligence managing the paperwork and assessing the best cases and points of law from thousands of sources in hours rather than weeks, many legal jobs stand to disappear. With routinized work such as welcoming guests at hotels, processing paperwork at doctors' offices, and performing quality controls on assembly lines in the AI crosshairs, many more jobs are at risk.

From an educator's perspective, I think there are big opportunities here, as well as risks. First, let us consider the pedagogy of technology and how that will shift as some tasks are automated with smart systems and perhaps even some forms of robotics. Artificial intelligence will continue to evolve to power such smart learning systems and to provide increased predictive tools for high degrees of personalization in the learner's experience. To some extent, "curricula" will become detached from standard process, and an individual will, with these enhanced systems, be able to demonstrate success at his or her own pace. And with different methodologies available based on their preferences, the learning experience of "courses" will be much more individualized. Granted, there will always be a need to understand processes and procedures in a standardized fashion (thinking 
about medical training, for example), but for many other topics, content, and skill development areas, the future will be highly differentiated thanks to these new technologies.

And as jobs themselves become more specialized, so too will the role of those smart recommendation engines be for the ongoing learning and development of individuals in many different fields. Consider radiology: there are already nearly a dozen subspecialties in this field, each with its own evolving set of technologies, procedures, and protocols. It is not far-fetched to imagine much of this work being performed by machines, with interpretation of results informed by an AI entity that quickly compares vast data sources to the very specific profile of the patient in question to produce a potentially greater accuracy in assessments. The jobs of the future may well be in the specialization of AI and data analytics for radiology, along with innovation in technologies that perform the various tests. Will this mean fewer lab coats? More data engineers?

From the side of learning administration and credentialing, there is likely to be a shift to the use of artificially intelligent systems that recommend courses and modules based on preparatory testing and/or learner habits and expressed interests. This will be a more widespread application of what we are currently experiencing as "recommendation engines." I can easily imagine these recommendation engines having a presence like Amazon's Alexa or Apple's Siri, speaking and interacting with the learner to further personalize the experience.

This shift is going to happen either by design or by default. As individuals gain access to greater resources online, tracking of completion of various coursework and qualifications may no longer reside in formal institutions, but in individually held, publicly recognized repositories. This is where blockchain technology and learning record management will become services that individuals and institutions depend on and subscribe to, and that provide continuity of verified learning from academics and expert systems, from formal educational processes through ongoing, employment-based and job-specific development. The learner will control her credentials and "own" them - we may actually see the waning of the diploma as the ultimate credential and the waxing of the badged portfolio of learning and work experience, secured and verified through blockchain-powered services.

We may see an expansion of individual contractor teaching staff, who depend on these independent systems to track their own reviews, ratings, and qualifications, and who rely on more technologies to deliver live and recorded learning lessons, experiences, and coaching. We already have services such as Teachable and Thinkific that are turn-key solutions for individual instructors and educational service providers. Other content and teaching aggregation services such as Gooru and Khan Academy will likely expand and diversify, offering more and more vetted, well-designed content and services to individuals and institutions of learning.

And even if not an individual contractor, the classroom of this future may be a much more blended environment, including more distributed students real time, in a highly interactive, collaborative, and data-rich setting. Virtual and augmented reality technologies will become commonplace as tools for connecting and interacting. New display technologies; expanding distribution of high-speed 
networks; and better, smaller, faster cameras could revolutionize "being there" as virtual field trips place students in the moment, creating new immersive learning experiences.

Another potential future shows the rise of platforms such as LinkedIn as career managers. What we already have seen is the purchase of Lynda.com by LinkedIn, and the service is following the "freemium" approach to offer paid assistance in being the Match.com of careers. I can see additional potential here, as LinkedIn or other platforms continue to acquire content, knowledge, education, and career management services. Marrying this idea with the aforementioned need for independent and validated housing of learning records, I can easily imagine LinkedIn (or something similar) becoming the one-stop shop for learning from grade school through late-stage careers.

From a topical level, science, technology, engineering, and mathematics (STEM) has been the focus for the early part of the 21 st century, owing to the growing need for students and workers with skills in these areas to become the authors of computer code, developers of apps and hardware, and managers of data. With the expansion and eventual standardization of artificial intelligence communication (much like XAPI in recent years), systems will become self maintaining, and many of those jobs that required hard technical skills will begin to go away.

I foresee a time when a return to human sciences occurs, especially as the operational side of human existence becomes more automated and deeper philosophical and ethical questions emerge. We are already seeing the beginning of this with the move to extend general data protection regulations to preserve individuals' privacy and agency over data shared across networks and devices. Deep and shared understanding of human factors, ethics, history, social constructs, and so on will be in great demand as technologies expand in reach and potentially threaten our ability to understand and empathize with others, leading to what Sherry Turkle (2011) describes as a situation of being "alone, together."

Public policy will need to evolve in sync with new technologies, bearing in mind the greater good and supporting not just a nation-state level of health and well-being, but also a global and integrated perspective that reflects the interconnectedness of economies, access to core services, digital trade flows, and of course education and skill development. Internet service providers may continue to challenge net neutrality, and if they win, we may be in for a further bifurcated world of haves and have-nots, and this will have a direct impact on the quality and availability of education. We may also see advanced applications of bio-hacking, embedding technologies that are designed to monitor, send, and receive data connected to learning and performance. This will open up its own set of concerns as we think about health factors, data privacy, and related issues.

And while all this is going on, learning science will advance, and organizations will further increase their focus on connecting learning to performance, spawning an increase in the number of digital tools available to bridge the knowledge to application gap. We have already seen the development of learning platforms designed to create this bridge. Those platforms, in the future, will be augmented 


\section{Stephen Mahaley}

with all manner of data capture and reporting mechanisms, owing to the Internet of Things and the eventual shakeout of standards for interoperability. And, while content and platforms will expand to meet a growing opportunity for online, ubiquitous learning and development, a premium will be placed on the creation of immersive learning experiences. What we postulated as a possible future in our work in virtual worlds ten years ago will become a vivid reality, accessible through lightweight, multisensory virtual reality gear. We can easily imagine a version of Ernest Cline's (2011) Ludus from Ready Player One - a virtual galaxy of three-dimensional locations where simulations of all forms are developed and experienced.

\section{Conclusion}

Education as a public good sits squarely in the intersection of digital innovation and economic and social policy. We cannot consider the design, development, and implementation of new technologies in educational settings without also considering factors relating to equal access and quality assurance. The current ongoing debate and legislation related to privatization of education is critically important to this: The World Economic Forum has stated that education is a human right (Brende, 2015), and if we are to meet the needs of the millions of learners globally, young and old, we will need to advocate for policies that ensure access for all to the many benefits of digital transformation.

\section{Conflict of interest}

To the writer's knowledge, there are no conflicts of interest of the writer with regard to any of the subject matter above. It is solely of the writer's views and interpretations of source materials and direct experience. At the time of this work, the writer was employed by Align Technology, but was not under any compensatory contract with any of the data sources mentioned.

\section{Notes}

$1 \mathrm{~K}-12=$ kindergarten to 12 th grade. That is, primary and secondary free education for publicly supported school from kindergarten all the way up to 12th grade.

2 This is a highly politicized debate in the United States, and the attempts to garner public comment on the issue were stymied by hacking. Fifty-seven percent of comments submitted to the Federal Communications Commission, through online forms, were made from duplicate or temporary email addresses.

\section{References}

Brende, B., 2015. Why education is the key to development. [online] World Economic Forum. Available at: <www.weforum.org/agenda/2015/07/why-education-is-the-keyto-development $>$ [Accessed 4 Sep. 2019].

Carrington, A., 2016. The padagogy wheel. [online] Education Technology Solutions. Available at: <https://educationtechnologysolutions.com.au/2016/06/padagogy-wheel> [Accessed 4 Sep. 2019]. 
Cline, E., 2011. Ready player one. London, UK: Arrow Books.

CT School Finance, 2018. Frequently asked questions. [online] Connecticut School Finance Project. Available at: $<$ http://ctschoolfinance.org/faqs $>$ [Accessed 4 Sep. 2019].

Hitlin, P., Olmstead, K. and Toor, S., 2017. Public comments to the federal communications commission about net neutrality contain many inaccuracies and duplicates. [online] Pew Research Center. Available at: <www.pewinternet.org/2017/11/29/publiccomments-to-the-federal-communications-commission-about-net-neutrality-containmany-inaccuracies-and-duplicates> [Accessed 4 Sep. 2019].

Hussar, W.J. and Bailey, T.M., 2014. Projections of education statistics to 2022. [online] National Center for Education Statistics. Available at: <https://nces.ed.gov/ pubs2014/2014051.pdf> [Accessed 4 Sep. 2019].

Maderer, J., 2017. Jill Watson, round three. [online] Georgia Tech News Center. Available at: <www.news.gatech.edu/2017/01/09/jill-watson-round-three> [Accessed 4 Sep. 2019].

Mills, J.N., Wolf, P.J., Greene, J.P., Zamarro, G., Kisida, B., Cowen, J., Figlio, D., Gill, B., Carruthers, C. and Barrett, N., 2017. The effects of the Louisiana scholarship program on student achievement after three years. [online] Education Research Alliance. Available at: $<$ https://educationresearchalliancenola.org/publications/the-effects-of-thelouisiana-scholarship-program-on-student-achievement-after-three-years $>$ [Accessed 4 Sep. 2019].

NCES, 2019. Trend generator. [online] National Center for Education Statistics. Available at: $<$ https://nces.ed.gov/ipeds/TrendGenerator/\#/answer/2/2> [Accessed 4 Sep. 2019].

O'Brien, J., 2018. Digital transformation and technology narratives. [online] EDUCAUSE Review. Available at: <https://er.educause.edu/articles/2018/3/digital-transformationand-technology-narratives $>$ [Accessed 4 Sep. 2019].

Rainie, L. and Anderson, J., 2017. The future of jobs and jobs training. [online] Pew Research Center. Available at: <www.pewinternet.org/2017/05/03/the-future-of-jobsand-jobs-training $>$ [Accessed 4 Sep. 2019].

Seaman, J.E. and Seaman, J., 2017. Distance education state almanac 2017. [online] Digital Learning Compass. Available at: <www.onlinelearningsurvey.com/reports/almanac/ national_almanac2017.pdf $>$ [Accessed 4 Sep. 2019].

Simon, C., 2018. For-profit colleges'teachable moment: 'terrible outcomes are very profitable.' [online] Forbes. Available at: <www.forbes.com/sites/schoolboard/2018/03/19/ for-profit-colleges-teachable-moment-terrible-outcomes-are-very-profitable $>$ [Accessed 4 Sep. 2019].

Thomas, J.R. and Kara, J., 2017. The state of CT's public schools in charts. [online] The CT Mirror. Available at: $<$ https://ctmirror.org/2017/09/28/the-state-of-cts-public-schoolsin-charts $>$ [Accessed 4 Sep. 2019].

Turkle, S., 2011. Alone together: why we expect more from technology and less from each other. New York, NY: Basic Books.

United States Courts, 2018. History - Brown v. Board of Education re-enactment. [online] Available at: <www.uscourts.gov/educational-resources/educational-activities/historybrown-v-board-education-re-enactment $>$ [Accessed 4 Sep. 2019].

Walker, T., 2016. 'School choice' mantra masks the harm of siphoning funds from public education. [online] NEA Today. Available at: $<$ http://neatoday.org/2016/01/22/schoolchoice $>$ [Accessed 4 Sep. 2019].

Zhang, C., 2018. Chinese doctors are using virtual reality to help perform operations thousand of miles away. South China Morning Post. [online]. Available at: <www. businessinsider.com/chinese-doctors-are-using-virtual-reality-to-help-perform-opera tions-2018-1> [Accessed 4 Sep. 2019]. 



\section{Part III}

\section{Citizen protection}





\section{Citizen protection A capabilities and intentions
framework}

Mark A. Conley and Emily Nakkawita

\section{Introduction}

Citizens evaluating domestic security might ponder two aspects of their trust in the government. First, does my government have the capability to protect me? Second, do I trust my government's intention to protect me? These assessments of a state's capacity and motivations are fundamental to citizen perceptions of internal security, with consequences for private responses. Due to wide-ranging, accelerating technological advancement, digital innovation has enabled effective and extensive private efforts with the potential to disrupt traditional governmental roles. Herein, we study how digitalization has affected historical citizen protection functions using a capabilities and intentions framework. This framework does not assume any baseline trust levels, and it is important to emphasize that we do not assume that citizens automatically trust their governments. We measure citizen trust with public opinion polls, and present this evidence alongside a time series analysis of other sources of public trust.

First, we broadly define citizen protections and summarize their historical origins in the United States and their recent evolution. We hypothesize that private government contractors - all with a major digital component that bolsters citizen security - signal increasing concern with threats, vigilance, and protection in the age of digitalization. However, during the same time period, public institutions charged with citizen protection have also pursued and exhibited these same concerns and intentions. After highlighting extensive public-private collaboration across a wide range of protective functions, we identify important considerations that this hybrid model raises in the coming years. This chapter addresses serious structural and moral issues inherent to large government efforts, but we avoid diverting into lengthy treatments on civic topics that merit entire library sections. We therefore balance tension between terseness and tedium in order to emphasize our argument that citizen protection roles have evolved recursively between public and private institutions in this age of digitalization.

\subsection{Defining citizen protection}

We define citizen protection as the work of institutions aimed at minimizing public harm and ensuring enumerated fundamental rights, including: inalienable 
rights such as "life, liberty and security of person" (UN General Assembly, 1948); human rights to private property and self-defense (Barnett, 2004); and legal rights including a fair trial (The Constitution of the United States, Amendment VI). Due to its size and global influence, we focus this analysis on US public security institutions and the accompanying industrial complex; however, the interpretation and conclusions transcend national boundaries and government structures. These data describe how digitalization affects citizen protections and welfare both within and beyond any country's public security apparati.

Within the broad realm of citizen protection are three key distinctions that clarify the structure and function of organizations and their general missions. ${ }^{1} \mathrm{We}$ explore each dimension below.

\subsubsection{International vs. intranational protection}

Security requires parallel efforts - international and intranational protection - each with different sets of responsibilities and legal constraints. International security encompasses protection from hostile foreign actors. In the United States, this duty belongs primarily to well-known public defense and intelligence organizations: the Department of Defense, the Central Intelligence Agency, and the National Security Agency. Intranational security efforts safeguard citizens from internal actors (i.e., other individuals within the state). Intranational security has primarily been led by public entities, including the police and courts, though in many parts of the United States, there remains a strong custom of self-protection via firearm ownership that is rooted in US history and values, including "culture of honor" norms and the primacy of rights to liberty (Cohen et al., 1996; Kocsis, 2015).

Guarding against both inter- and intranational threats is an evolving challenge in the digital age. In a digital world war, national boundaries are practically irrelevant to an enemy that plans attacks and recruits fighters worldwide (Ullah, 2017). Instead of focusing on the characteristics of these resilient and amorphous enemies, this chapter focuses on public and private efforts to guard against them.

\subsubsection{Public vs. private protection}

Traditionally, citizen protection efforts have fallen under the purview of local, state, and federal government entities. However, beyond the historic use of hired soldiers in armed conflicts (Avant, 2004), beginning in the early 20th century, governments began to collaborate with private entities in their efforts to promote citizen security for reasons ranging from financial efficiency to technological superiority (Markusen, 2003). Today, governments stand at a critical juncture where new technology is evolving at a rapid pace and financial incentives have changed, such that the consumer market for innovation has surpassed the public sector. As a result, governments are no longer the primary drivers of the innovation agenda (FitzGerald and Parziale, 2017). In this changing landscape, citizen protection efforts are distributed across a public-private continuum, and the lines between public and private efforts are blurring. This trend, rooted in the 
development of digital technology, has augmented private entities' capabilities to play a larger - perhaps, even leading - role in citizen protection. Some defense scholars have suggested that private capabilities will continue to grow such that they eventually supersede the power and relevance of public structures (Leander, 2005; Minow, 2005; Singer, 2005, 2008). We explore those claims with data: markers for protective capabilities and intentions across both public and private institutions. We proceed to interpret those trends and speculate about the future of this public-private collaboration.

\subsubsection{Direct vs. indirect protection}

We focus on direct protection: citizen protections from physical threats that directly imperil rights to life and immediate "security of person" (UN General Assembly, 1948). This definition excludes many indirect protections, and in some cases, makes distinctions on certain security tactics depending on their ultimate aim. For example, this chapter's scope includes online surveillance by technology organizations who attempt to prevent imminent terrorist attacks, but excludes organizations who aim to protect citizens from hate speech on the Internet. Distinctions like these narrowed the list of public and private organizations we studied (see Section 2: "Methods").

\subsection{Overview of citizen protection structures in the United States}

The US government is a model hierarchical bureaucracy, consisting of delineated departments with complementary missions. Among 15 cabinet departments within the executive branch (agriculture, commerce, defense, education, energy, health and human services, homeland security, housing and urban development, interior, justice, labor, state, transportation, treasury, and veterans affairs), five departments pursue citizen protection as a primary mission: the Departments of Defense (DOD), Homeland Security (DHS), State (DOS), Justice (DOJ), and Energy (DOE). ${ }^{2}$ In addition to these cabinet departments, we review the protective functions of intelligence agencies, the US judiciary branch (i.e., public courts), and local law enforcement. Appendix A briefly sketches out the histories, functions, and counterparts to these direct citizen protection structures.

\subsection{Evolution of citizen protection in the United States}

Although public entities have delivered protection to citizens since the country's founding, more recently, non-governmental actors have augmented the government's capabilities. Since the 1950s, public structures (see Appendix A) have been transformed by privatization, primarily resulting from expectations of cost efficiencies and greater technological prowess (which, in recent decades, has included digital technology). Despite the increased ability of private entities to engage in citizen protection, we propose that the acceptance of such an 
arrangement depends on citizens' beliefs about public and private capabilities and intentions.

\subsubsection{Evolution of international protection}

In this section, we highlight growing privatization within various forms of international protection, including the nation's armed forces and intelligence efforts. In the United States, this privatization has generally taken the form of public-private partnerships. Although private companies play increasingly important protective roles, they typically work in close collaboration with public entities.

Military and diplomatic protection: international defense endeavors comprise a major portion of the US annual budget, chiefly via the DOD. Until recent decades, the most significant technological advances within citizen protection in the United States were driven by the public entities reviewed in Appendix A, whether directly (i.e., technologies developed within government agencies) or indirectly (i.e., through government-sponsored grants) (FitzGerald and Parziale, 2017). However, today private contractors play important and growing roles in international citizen protection, as evidenced by a US defense contractor workforce that had expanded to 3.7 million by 2015 (Light, 2017; Prem, 2018). The extent of this privatization is somewhat unique to citizen protection: Security-related agencies and departments, including the Departments of Defense and Energy, rely more heavily on outsourcing than other public entities (Markusen, 2003). In fact, a review of 1996 data revealed that, by this date, five contract and grant jobs existed for every DOD role, with a ratio of only 1.5-to-1 in areas of government not dedicated to citizen protection (Light, 1999). Similarly, the share of defense roles accounted for by private contractors grew to 50 percent in 2000 from 36 percent in 1972, whereas military and Pentagon (i.e., the US DOD Headquarters) civilian employees' share decreased from 64 percent to 50 percent during the same period (Markusen, 2003). There is much more privatization within the citizen protection sector.

Explanations for this shift to privatization are often rooted in claims about the greater efficiency and expertise of private entities; their operations are seen as more agile and less costly than similar efforts would be if managed publicly (Rosenberg, 2016; Markusen, 2003). Since the 1970s, the scope of work outsourced to contractors has grown, and these entities have responded to increasing calls for less "bloated" government by expanding their offerings to provide a wider range of services, from troop training to base maintenance (Abrahamsen and Williams, 2009; Markusen, 2003). This is a recursive process by which governments have a need, private organizations respond to that need by expanding their offerings, and government structures come to rely on those broadened skillsets. Over time, this partnership expanded from garrison services to combat operations.

However, cost efficiency is not the only driver of security privatization; digitalization and technological aspirations also play an important role in this process. As an example, consider the advancement of military capabilities: In the first half of the 20th century, thanks to the emergence of new technology (air warfare), the 
US government looked to the private sector for the development of advanced aircraft (Markusen, 2003). Following private success in developing ballistic missiles in the 1950s, the Air Force's strategic reliance on private contractors prevailed over the Army's preference for public research and development (Kelsey, 1982). In the decades that followed, the majority of weapons development has been led by private entities contracted by government forces (Markusen, 2003). This trend is also reflected in the US nuclear program: Although a wide range of public entities both oversee the country's nuclear arsenal (e.g., the DOE) and work to prevent the spread of such technology (e.g., the Bureau of International Security and Nonproliferation) (Holgate, 2018), private contractors play a leading role in the development and production of these weapons. This public-private partnership enhances the government's effectiveness in maintaining a strong nuclear program, as these private entities' capabilities are superior to the public's (Cole and Vermeltfoort, 2018).

Beyond weapons technology, privatization within international citizen protection has also been driven by research and innovation more broadly. In their review of DOD commercial activities programs, Tighe et al. (1996) found that military research, development, testing, and evaluation (RDT\&E) increasingly relies on the work of private entities; for example, the Navy outsourced only 30 percent of RDT\&E activities in 1970, and by 1996, this share had grown to 50 percent. Public security reliance on private technology is even more evident when examining the financial growth of companies with government contracts, such as Computer Sciences Corporation, whose defense sales exceeded USD 1 billion by 1997 (Berteau, 1998); for a more modern perspective, Leidos's defense contracts exceeded USD 6.8 billion in 2016 (Washington Technology, 2017). Though some citizens have raised concerns about this privatization of international security, the outcry has not been loud enough to prompt any change (Leander, 2005).

Evidenced by little resistance to public-private partnerships, citizens appear to consider defense contractors trustworthy enough. Americans indicate positive feelings toward technology firms that are likely responsible for digitalization: 71 percent indicate that tech companies have a "positive effect on the way things are going in the country" (Doherty et al., 2015). Beyond the greater capabilities of these private organizations, this strong privatization trend may also reflect citizens' mistrust in the motivations of public entities. Public opinion studies have tracked American sentiments toward defense with polls depicting tenuous confidence in public protection. From 2002 to 2012, public opinion on defense spending showed a reliable trend of more people thinking that the United States spends too much and fewer people thinking that the United States spends too little (Corman et al., 2015). Other polls confirm waning trust in the US government; in 2015 only 19 percent of Americans reported trusting the government always or most of the time, as compared to a peak of 77 percent in 1964 (Doherty et al., 2015). These public-private hybrids thrive in times of waxing and waning government trust alike. Taken together, these two poll investigations indicate that trust in US government institutions has been generally lower than trust in its private defense industry and indicates taxpayer openness to joint public-private 
protection efforts. Citizens generally do not deconstruct, it appears in these polls, which exact aspects of public-private hybrids are trustworthy; if either component appears trustworthy, that quality bestows citizen trust upon the whole unit.

Digital surveillance: this reliance on public-private partnerships extends into cyberspace. US intelligence agencies have worked closely with private organizations to cultivate citizen protection via digital surveillance of foreign actors. For example, through its PRISM program, the NSA partners with the FBI and CIA (with oversight from the DOJ and the Judiciary) to collect digital data on foreign intelligence targets from private Internet service providers (Director of National Intelligence, 2013). This public-private collaboration is no surprise: Given that these companies own the technology platforms and data that individuals around the globe use to browse, learn, and communicate (Blumenthal, 2018), public entities will be most successful in identifying potential threats through public-private partnerships, as the private entities' capabilities are vastly superior.

Despite the strong protection of individual rights for US citizens, these international protection efforts (whether public or private) do not extend those individual privacy rights to foreign actors. Warrantless surveillance against noncitizens is approved through the Foreign Intelligence Surveillance Act (FISA) section 702 (Pulver and Medina, 2018), and while some groups have voiced concerns over these tactics (Weber, 2015), more than half of Americans find it acceptable for the US government to conduct digital surveillance of foreign actors (Rainie and Madden, 2015). Similarly, as of 2016, the Pew Research Center found that US citizens were more concerned with protection from terrorism (49 percent) vs. civil liberties (33 percent) (Doherty, Kiley and Johnson, 2016). These trends suggest that US citizens trust the capabilities and intentions of these hybrid public-private entities regarding international surveillance.

\subsubsection{Evolution of intranational protection}

In the United States, despite the existence of strong public institutions with citizen security responsibilities, the realm of intranational security has historically included a considerable private component thanks to the country's revolutionary foundation and strong protections for individual firearm ownership. Be that as it may, similar to the international space, intranational protection has evolved to place even stronger emphasis on private security thanks to the emergence of digital tools. These technologies have bolstered the capabilities of private entities and have better positioned those entities to play a larger role in citizen protection. In addition, powerful, readily available, and relatively inexpensive digital technology has increased citizens' personal protection capabilities relative to traditional law enforcement.

Private commercial security: the commercial use of private security forces has grown in recent years, as evidenced by the presence of uniformed guards in seemingly innocuous establishments from supermarkets to shopping malls. Today the United States is the world's largest private security market, employing 1.5 to 2 million individuals; nearly three private contractors exist for every single 
member of the public police force (Abrahamsen and Williams, 2009). Interestingly, in this age of relative peace, these private security companies often work in alignment with public entities, forming a loosely organized group of actors Abrahamsen and Williams term "global security assemblages" (2009). The relative lack of public protest against this trend suggests citizen trust in the capabilities and intentions of these private guards. US students view private security officers' professionalism and goals positively (Nalla and Heraux, 2003). These positive citizen perceptions of private security appear even stronger among students in countries in "emerging" and "flawed" democracies; perhaps in such systems where a lack of confidence in public institutions is common, the intentions of private contractors are viewed as more trustworthy by comparison (Nalla, Maxwell and Mamayek, 2017).

Private home security: beyond this growth in the commercial security market, digital technology has also increased citizens' own protection capabilities. This protection takes several forms, including the rise of a private home security market. Following an increase in crime after World War I, the notion of home security systems, installed and managed by private companies, grew in popularity (Electronic Security Association, 2018). Despite the industry's modest beginnings in which human "door shakers" would confirm that customers' doors were locked each evening, by the 1940s, the American District Telegraph company had installed the first automated burglar system connected via telephone to a central monitoring center (ADT, 2018). The availability of improved camera technology in the 1970s sparked the widespread installation of what are now considered modern home security systems, complete with video surveillance (Electronic Security Association, 2018). Today, an ever-growing number of mobile- and WiFi-based home security options are available to consumers, from the Ring video doorbell and security camera, to the wireless SimpliSafe home security system, to former NSA contractor (also former CIA staff) employee Edward Snowden's Haven app, which converts any Android smartphone into a mobile surveillance tool (Greenberg, 2017). Additionally, despite falling crime rates, the home security market is growing (NextMarket Insights, 2014), suggesting that consumers trust both the capabilities and intentions of these purveyors of private security.

Private individual protection: advocates purport that widespread private gun ownership serves a citizen protection function (Kleck and McElrath, 1991; Lott Jr. and Landes, 1999). Also, see Hemenway (1997) and McDowall (2005) for rigorous rebuttals. Those claims follow from the US Constitution's suggestion that gun ownership is a necessary structure for security: "A well regulated militia, being necessary to the security of a free state, the right of the people to keep and bear arms, shall not be infringed" (The Constitution of the United States, Amendment II). Centuries after its writing, that security structure was reinforced by a US Supreme Court decision that interpreted the Second Amendment to guarantee gun ownership at the level of the individual (District of Columbia v. Heller, 2008). It is remarkable that this form of citizen protection is the only structure that delegates security tasks to the individual citizen. The explicit rights in the Second Amendment in effect hire out part of the government's otherwise robust citizen protection 
role to private citizens. Unlike most government contracts, however, the labor is unpaid; in fact, the security providers purchase and maintain their own equipment. It appears that gun owners accept the government's mandate; gun owners cite defense as their primary reason for gun ownership, not recreation or hunting (Dimock, Doherty and Christian, 2013). Beliefs about the benefits of gun ownership parallel this trend: 79 percent of gun owners find that owning a gun makes them feel safer, and only 7 percent report that it makes them feel uncomfortable (Dimock, Doherty and Christian, 2013).

This unusual protection structure has been resistant to digital transformation. Many technological advances in guns are traditional improvements to ballistics, harmonics, and optics. Some proposed new technologies are digital transformations; biometric trigger lock devices are fingerprint identification surfaces that would allow only a specific person, ostensibly the adult owner of the gun, to access the trigger. This digital technology affects firearms only until these locks are disabled; after that, the firearms function as usual. There are a variety of analog locks and safes that perform the same function; biometric trigger locks are not an innovation that have transformed citizen protection functions as much as they are an innovation aimed to prevent accidents (Kloepfer et al., 2018). Also, see Mossberg, Kluwe and Kinion (2001) for a similar digital innovation.

Like other methods of protection we have reviewed, steady support for private self-protection appears to be driven by a lack of trust in public entities' capacity and motivation to carry out their protective duties. For example, in rural areas where law enforcement response times are greater (indicating a deficiency in the public capability to protect), citizens support Second Amendment rights more strongly (Parker et al., 2017). This perspective appears related to a construct called legal cynicism, in which people view law enforcement as incapable of executing its protective duties: "unresponsive, and ill equipped to ensure public safety" (Sierra-Arévalo and Crowther-Dowey, 2016). Legal cynicism in this domain is also summarized blithely, "When seconds count, police are minutes away." Among gun owners, negative perceptions of police correlate positively with seeking private gun ownership as a defense alternative (Sierra-Arévalo and Crowther-Dowey, 2016). Independent of opinions toward police, perceptions of the state of the world can drive gun ownership. Gun owners are sensitive to diffuse threats that the world is inherently dangerous (Stroebe, Leander and Kruglanski, 2017; Ziegenhagen and Brosnan, 1990; Parker et al., 2017).

Case study: school shooting prevention efforts: consider the first paragon of a school shooting in America - the Columbine massacre - and compare that with the most recent notorious school shooting (at the time of this writing) in Parkland, Florida. The perpetrators of both crimes wrote prolifically about their intent. The Columbine shooters scrawled ink into private notebooks; the Parkland shooter uploaded his dark musings to YouTube for anyone on the Internet to access. Digitalization has transferred even male teenage written angst that precedes deadly violence from private to public view. Private citizens read the Parkland shooter's comment, "Im [sic] going to be a professional school shooter" on YouTube, and 
reported him to authorities, including local sheriffs and the FBI (Goldman and Mazzei, 2018). Those private citizens certainly acted with intent for citizen protection, but whether public authorities were capable of delivering that protection is debatable. These macabre examples portray how digital tools may augment the both private and public capabilities for citizen protection. Private citizens noticed the threat; public security forces were incapable of executing to deter the threat. Despite this catastrophe, it is reasonable to hope that the sequence of events in this case will inform future public citizen protection procedures. If so, both private and public capabilities for citizen protection will be enhanced by digital tools.

\subsection{Behind the evolution}

Broad acceptance of changes to citizen protection structures, roles, and responsibilities should depend on widespread perceptions of the capabilities and intentions of both the public entities typically tasked with this protection and the private organizations that may support or supplant them. If citizens find their governments' capabilities to be deficient or motives to be questionable, and they also believe that private companies can not only fill those roles but also act with benevolent intentions, citizens will allow public-private defense partnerships to thrive with taxpayer support. To this end, private companies use digital tools to tout their capabilities and reinforce their protective intentions.

For these reasons, understanding the role of digitalization in citizen protection requires the present capabilities and intentions framework. In the "Methods" section below, we describe our linguistic measurement tool that captures the degree to which organizations signal their ability to protect and their benevolent motivation. In keeping with our framework, we constructed a robust sample of private and public citizen-protection entities and tested for differences in their communication of protective capabilities and intentions over time.

\section{Methods}

\subsection{Overview}

This chapter's arguments rest upon the proposed capabilities and intentions framework for understanding the roles of different actors in the citizen protection landscape. For this reason, we operationalized the signaling of protective capabilities and intentions using a modern linguistic analysis. Organizations, both public and private, communicate their ability to protect citizens effectively, as well as their positive motivations, in the way they outwardly describe themselves. In the digital age, organizations disseminate these self-descriptions on their websites particularly on their "About Us" web pages. We aimed to measure the amount of protective language on those pages among public vs. private organizations. This linguistic analysis quantifies the extent to which private and public entities each signal their concerns for citizen protection. 


\subsection{Data and sample}

The government departments and agencies discussed in Appendix A comprise our sample of public organizations. Every government entity with a primary mission for citizen protection is included in the sample. We compare those defenseoriented government organizations with the top government contractors - private companies with citizen-protection capabilities. Although the top 100 government contractors are publicly available in ranked order (Washington Technology, 2017), we constrained this sample to organizations with a 2017 government contract over USD 500M. This constraint limited the size of the private sample to 40 organizations to compare to 12 public entities. Each of these private organizations performs its roles using digital tools, strives for digital advances, and capitalizes on digital transformations.

\subsection{Measures}

The Linguistic Inquiry and Word Count (LIWC) is a text analysis program that measures valuable psychological content in digitalized written samples (Pennebaker et al., 2015b; a). For example, LIWC can measure markers for analytic thinking and emotions (Ritter, Preston and Hernandez, 2014), motivations and risk (Gamache et al., 2015), and even fear and aggression (Soroka, Young and Balmas, 2015). For the purposes of the present analysis, we constructed a dictionary that is sensitive to written markers that signal concern for citizen protection. We adapted the motivational LIWC dictionary (Gamache et al., 2015) to also measure common military and defense terminology (US Department of Defense, 2018).

\subsubsection{Independent variable}

To measure increasing communication of citizen protection, we used time as our predictor variable to show the evolution of concerns for threat manifested in company descriptions. We mined the Internet for a historical record of organizations' self-descriptions over time using the Internet Archive's Wayback Machine (available at https://archive.org). This website allowed us to capture the language each organization used to describe itself every year dating back to its inaugural website (beginning in the year 1996, when the Internet Archive was founded). For standardization, we attempted to capture all text-based content contained in the first available snapshot of each organization's "About Us" page for each calendar year. For the many cases where the website for any given year was unavailable, we proceeded forward in time to the closest available update. The dates for each observation, and the sample text we analyzed, are available on the Open Science Framework at https:// osf.io/xj843, and within a public Github repository here: https://github.com/ mac2393/CitizenProtection. 


\subsubsection{Dependent variables}

The Citizen Protection LIWC dictionary yields a continuous measure that is a ratio of key citizen protection words to the total word count in the sample text. As a result, we analyzed 1077 scores from the text of 52 entities (40 private organizations and 12 public entities), from the present back to 1996 , where available. Given that the "About Us" page of an organizational website is intended to convey the entity's strategic positioning and capabilities to the public (both potential government clients and private citizens alike), each of those scores serves as a proxy for the organization's intention to signal its capacity and motivation for engaging in protective efforts at that moment in history. This continuous outcome measure allows for the detection of change over time.

\subsubsection{Control variables}

Our analyses controlled for protection-focused investment, measured using publicly available annual contract sizes for every private defense contractor and annual budgets for every public entity (both from the most recent available calendar year). The three statistical models presented below include budget size as a covariate. All reports hold at the same significance level with and without this covariate included in the regression model.

\section{Results}

Three notable trends emerged. First, concerns for citizen protection have been reliably increasing, creeping upward, among private defense firms $(t=8.35$, $p<.001)$. Further, this same trend is detectable among US government security entities $(t=5.37, p<.001)$. Importantly, and perhaps surprisingly, testing for differences between those slopes reveals that the government's concerns are growing significantly more rapidly, approximately twice the rate of its private contractors $(t=4.09, p<.001)$. Figure 11.1 reflects increasing private and public concerns for citizen protection, and also shows their significantly different slopes side by side.

\section{Discussion}

\subsection{Findings}

These results indicate increased signaling of protective capabilities and intentions by both public and private entities from 1996 to 2018. Based on this pattern of data, it appears that the organizations within our sample are increasingly concerned with conveying their interest in citizen protection to individual citizens (across both organization types) and, potentially, clients within public entities 


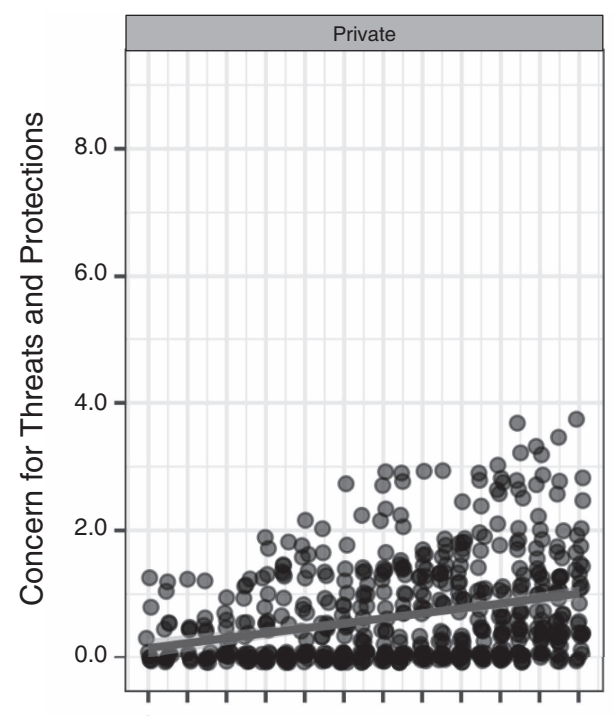

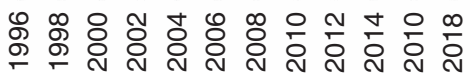

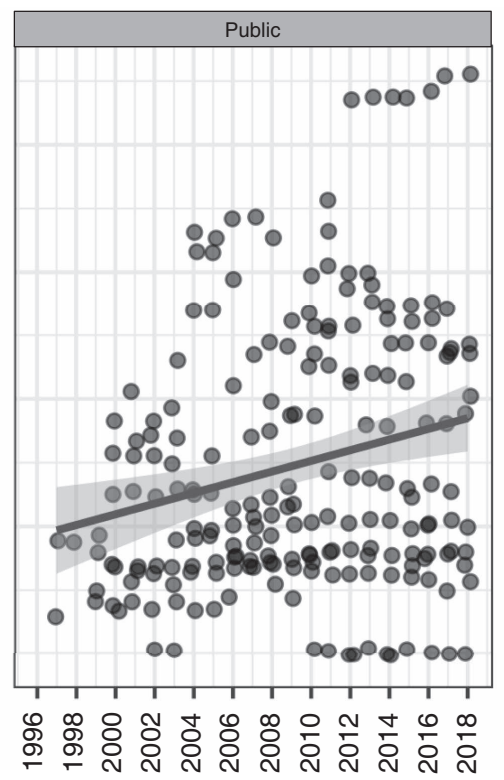

Figure 11.1 Private and public "About Us" statements. Although both continue to signal growing concerns for citizen protection, public institutions outpace private organizations.

responsible for awarding government contracts (in the case of private organizations' websites). Combined with the general evolution of citizen protection in the direction of public-private collaboration, these data suggest that this hybrid approach to citizen protection can be expected to persist.

\subsection{Key considerations}

Despite some doubts about the capabilities and motivations of the government, 94 percent of Americans still report believing that the government should play a major role in a particular type of citizen protection: "keeping country safe from terrorism" (Doherty et al., 2015). Public views of private institutions have also improved: when comparing 2015 to 2010, the percentage of Americans believing small businesses had a positive effect on the country grew by 11 percentage points, and large corporations by 8 percentage points (Doherty et al., 2015). These numbers suggest an environment ripe for more frequent and extensive public-private partnerships. With this in mind, we identify several challenges this hybrid approach will pose to protective entities in the coming years. 


\subsubsection{Key consideration \#1: navigating borderline cases}

Despite apparent public support for privatization and digitalization within certain domains, the distinctions between intranational and international citizen protection have blurred and thus create a wide range of potential "gray areas." For example, consider the protection of citizens from terrorists within the state: What is the appropriate balance between maintaining citizen security and yet still adhering to domestic privacy norms? Further, given that these efforts will certainly involve digital surveillance, what might be considered a responsible level of data encryption, whereby law-abiding citizens' rights to privacy are upheld yet the activities of potentially dangerous actors can be monitored? Similarly, consider the protection from the state within the state (an issue that underlies the right to bear arms within the US Constitution): To what extent should Second Amendment rights allow citizens to prepare a defense against their own government, digitally or physically, should it turn tyrannical? This line of inquiry also raises questions about private oversight of the state: To what extent should private citizens be privy to military plans, operations, and spending information (an especially timely question given the prevalence of digitally facilitated leaks)?

We propose that when the distinctions between inter- and intranational protection are unclear, as illustrated in the examples above, privatization efforts should be accompanied by extensive oversight safeguards, audits, and reviews revisited often. This recommendation becomes even more important when tactics typically assigned to international security (which may fail to uphold individual privacy rights, for example) would be used for the purposes of domestic protection. The importance of this distinction is illustrated by recent events, in which the New York police department shared plans in 2012 to use terahertz ("T-Ray") imaging technology that facilitates long-distance gun detection, enabling public police officers to detect if an individual is carrying a gun under their clothing (Parascandola, 2017). This technology was originally developed by the Department of Defense for international security purposes: specifically, to detect suicide bombers carrying explosives. Though this technology might help police officers identify potential offenders at vulnerable events, it also conflicts with strong privacy protections in the United States ensuring that no citizen or their property can be searched without reasonable cause and a warrant (The Constitution of the United States, Amendment VI). Not surprisingly, the New York Civil Liberties Union pushed back on the adoption of this technology, and the police department subsequently decided to abandon its use (Parascandola, 2017). This example acts as a useful case study for future protective initiatives that cross the inter- vs. intranational divide; proactive engagement with respected civil libertarian groups prior to the adoption of new technology may enable protective entities to identify digital solutions that simultaneously pursue citizen security and uphold fundamental civil rights. 


\subsubsection{Key consideration \#2: maintaining necessary oversight of private entities}

As citizen protection structures grow ever more complex through a wide range of public-private partnerships, it naturally becomes more challenging for any "central" public entity to maintain oversight of the associated network of organizations. One important type of oversight relates to the coordination of work among entities that share responsibility for a specific protective function. Given that each involved organization maintains its own internal hierarchy, which indirectly connects with similar hierarchies within partner organizations, the ultimate chain of command across various entities is necessarily more convoluted (and contains additional points of potential failure) than if a single entity were responsible for the same work (Markusen, 2003). If not carefully managed, a complicated crossorganizational structure may also create a lack of transparency within which corruption can thrive. Further, various working groups within this cross-organizational team may suddenly vanish, for all intents and purposes, if the scope of work changes or entities' management cannot align on or adhere to a contract, creating a great deal of operational risk for the "central" entity. Managing these risks and maintaining contingency plans requires substantial oversight, a burden that must be balanced against the apparent benefits of such public-private partnerships.

A second and important type of oversight relates to the assumed cost savings of privatization. Research into the financial realities of public-private partnerships suggests that the cost efficiencies that often drive privatization are ultimately specious; the long-term contracts underlying these partnerships are written in order to impede competition from other firms and flexibility within the scope of work (Avant, 2004). Further, given the limited number of large prime contractors in each realm today, some speculate that these organizations function as an oligopoly and likely engage in some price collusion (Markusen, 2003). This challenge seems only likely to grow given the steep degree of technological expertise required to compete as a contractor within modern weapons development and digital surveillance. Due to these challenges, public entities should maintain vigilant oversight, conducting frequent audits to ensure that partner organizations are delivering the benefits promised.

\subsubsection{Key consideration \#3: ensuring equitable protection for all citizens}

A third challenge for privatization (particularly as it pertains to intranational protection) relates to the unequal distribution of resources inherent in private markets. In its report on Citizen Security and Human Rights, the Inter-American Commission on Human Rights (2009) warns that the privatization of protective functions jeopardizes a nation's ability to guarantee fundamental rights. The report argues that privatization reduces citizen protection to a product that can be retained only by those with the resources to purchase it. Beyond these demand-side challenges to equitable citizen protection, private intranational security solutions are also likely to proliferate within larger and wealthier markets where greater profit margins 
can be expected. Thanks to these supply-side differences, rural and low-income areas may experience a dearth of private interest and, as a result, the citizens of these regions may find themselves with diminished access to protection vs. their more affluent, urban-dwelling counterparts (Isima, 2009). For these reasons, it is critical that public organizations maintain a focus on ensuring democratic access to citizen security. In many cases, this emphasis on equal protection will constrain the extent to which these intranational functions can be privatized.

\subsubsection{Key consideration \#4: aligning public and private objectives}

Finally, public entities may find that, at some point, their objectives are no longer aligned with those of their private counterparts. Markusen (2003, p. 490) shares a well-considered list of challenges in her paper arguing against the privatization of international protection:

What happens when a firm's home government's interest and its employers' interest diverge? How will the potential to sell army and air force modernization advice worldwide affect the proliferation of conventional weapons and techniques? Might not these private arrangements alter the career strategies of members of the armed services? These questions begin to convey the extraordinary challenges facing a world in which the best Western military training and experience is offered for sale on the private market.

In the past 15 years, those predicted challenges have come to fruition. As governments today embark on extensive partnerships with private organizations, they should and can now measure the long-term implications of their collaborations. Specifically, the DOD should track publicly available information on defense contractors: what percentage of their revenue comes from which nations; what percentage of the work in these companies is devoted to the United States compared to all other nations. To address Markusen's third question above, the DOD can capture in exit surveys the proportion of military retirees who have been hired by a defense contractor and conduct more research on whether that opportunity compelled them to leave active duty. Since noncompete agreements are valid between government contractors, would such agreements be tenable between the government and defense contractors? The government might care about the answer to that question only to the extent that it deems the loss of experienced military officers into private employment deleterious to the government's capabilities. This concern would be intensified in a public-private model where the intentions of the private organizations are less trustworthy.

\section{Conclusion}

The growing public-private hybrid model where private organizations master digital innovations and apply them toward public citizen protection missions shows 
no sign of fading and no sign of tilting heavily toward either side. The relationship is symbiotic and recursive, and is supported by public opinion; citizens trust government capabilities and intentions. The borderline cases where governments face dilemmas in order to deliver protection, the challenges of oversight, the concerns for equity, and the tenuous alliance all make these public-private partnerships one of the most important issues in the defense industry.

The sturdiness and longevity of public-private hybrids foment interest in the potential dangers they pose. Consider this contrived scenario that depicts a publicprivate partnership gone awry where the public entity loses some capability to protect its citizens, while the private component's intentions are unknown. Imagine a government funding a private organization to build a particularly destructive weapon or capability. Perhaps that contractor and its employees could wrest control of material capabilities from any government oversight, access, or failsafe procedures onsite. The government has lost control of the weapon, the capability, and the private aspect of the hybrid might be able to wield that new threat against the government or against the citizenry. Alternatively, the private organization might offer to protect the citizenry against the government with these hijacked capabilities.

Many practical realities undermine the plausibility and dampen the severity of these or similar scenarios. First, a government with military competence enabled by digitalization is likely to deter any rogue takeovers. Next, the decentralization of public-private partnerships would benefit the government in this scenario, where that rogue private organization would represent just one of many capabilities, with the other security relationships intact. Most important, digital communication tools would enable that government to maintain citizen trust. The implausibility of the above scenario underscores and offers some explanation for the endurance of public-private hybrids. Simply put, the size and scope of the existing security apparati in developed countries acts as a check to the dangers new hybrid ventures pose.

As digitalization increases government capabilities, whether in isolation or via partnerships, dangerous scenarios become less, not more, of a legitimate potential danger. Public institutions are incrementally bolstered by the results of these hybrids, and those reinforcements discourage disruptions to the recursive capabilities and intentions framework. Despite these serious concerns, digital innovators secure large government contracts and expand their defense capabilities, but the government is still leading the public-private hybrid model for citizen protection.

\section{Acknowledgments}

Members of the motivation science lab and affiliated scholars helped us to create the Citizen Protection LIWC dictionary using their knowledge of regulatory focus theory. We especially thank Maya Rossignac-Milon and Katherine Zee. 


\section{Appendix A \\ International citizen protection structures}

This appendix provides a cursory description of key US government citizen protection entities. These brief illustrations of mission sets, histories, and interoperability notes may serve to familiarize readers from outside the United States, and may spark recognition of the roles and responsibilities of parallel ministries and departments within other governments.

\section{The US Department of Defense}

The DOD is the largest and longest-standing US government agency, with a primary mission to "provide the military forces needed to deter war and ensure our nation's security" (US Department of Defense, 2019, para.1). The DOD lists on its website that it was founded in conjunction with the American Revolution (US Department of Defense, 2019). The site describes that although the Army, Navy, and Marine Corps were created before the country's official founding, in 1789 the War Department was established. However, the website notes that all branches of military remained under separate direction and, despite several reorganizations, were not unified under a single department until the creation of the National Military Establishment in 1947, and formalized as the Department of Defense (along with the newly formed Air Force) under the National Security Act in 1949. Today, the DOD's website notes that it is responsible for the training and deployment of all branches of the US military. Many nations around the world have a Ministry of Defense that is similar in structure and mission set to the US DOD.

\section{The US Department of State}

The DOS leads US diplomatic efforts. The department's website notes that its mission is to "lead America's foreign policy through diplomacy, advocacy, and assistance" (US Department of State, 2019a, para.2). The site describes that the DOS underwent a similar pattern of expansion and reorganization to the DOD since its founding, also in 1789. Primary drivers of the department's expansion were the two world wars in the first half of the 20th century and the ending of the Cold War in the second half; the accompanying changes in the world prompted the United States to enhance its abilities to diplomatically respond to issues ranging from the 
new global economy to terrorism (US Department of State, 2019b). Importantly, the DOS also contains dedicated groups with specific citizen protection roles. For example, the Bureau of International Security and Nonproliferation prevents global threats relating to Weapons of Mass Destruction (US Department of State, 2018a). The Bureau of Consular Affairs warns citizens about country-specific threats through its travel alerts and warnings, found on the Bureau's Travel Advisories webpage as well as on its network of embassy and consulate websites (US Department of State, 2018b). Many nations around the world have a Ministry of Foreign Affairs that is similar in structure and mission set to the US DOS.

\section{The US Department of Energy}

The DOE website describes that the department aims "to ensure America's security and prosperity by addressing its energy, environmental and nuclear challenges through transformative science and technology solutions" (US Department of Energy, 2019c, para.1). The department's role within citizen protection encompasses the maintenance and security of the country's nuclear arsenal, efforts to protect against threats to critical energy infrastructure, and oversight of emergency energy supplies such as the Strategic Petroleum Reserve (US Department of Energy, 2019d). Since launching the Manhattan Project in 1939, the DOE has played a leading role in both the development of nuclear technologies in the United States and their regulation around the globe (US Department of Energy, 2015). Similar to the DOS, the DOE maintains several organizations with a focus on citizen security. For example, the Office of Nuclear Energy is dedicated to the use of nuclear power as an energy resource, and its focus on citizen protection resides in both promoting the country's energy security and minimizing the risks associated with the proliferation of nuclear technology (US Department of Energy, 2019b). Conversely, the National Nuclear Security Administration (NNSA) was founded in 2000 to oversee military applications of nuclear energy, including oversight of the country's stockpile of nuclear weapons (US Department of Energy, 2019a). The analogous department in some other countries is the Ministry of Energy.

\section{The US Department of Homeland Security}

The DHS website describes that the department was established in 2002 following the September 11, 2001, attacks on the World Trade Center in New York, combining 22 distinct federal agencies and departments into a single department with the objective of coordinating the country's homeland security efforts (US Department of Homeland Security, 2016). The site lists DHS goals as "preventing terrorism and enhancing security; managing our borders; administering immigration laws; securing cyberspace; and ensuring disaster resilience" (US Department of Homeland Security, 2016, para.2). The Ministry of the Interior in many countries performs roles similar to the US DHS. 


\section{The US Central Intelligence Agency}

The CIA describes on its website (2013) that the agency was founded in 1947 under the National Security Act with the purpose of collecting and evaluating intelligence (often with a special focus on human intelligence) to ensure national security. In support of this mission, the CIA indicates on its website that it invests in the development of technology for intelligence purposes. The site also describes that the agency has established dedicated teams with specific citizen protective roles: "nonproliferation, counterterrorism, counterintelligence, international organized crime and narcotics trafficking, environment, and arms control intelligence" (US Central Intelligence Agency, 2013, para.10). Almost every nation around the world has a similar primary intelligence service.

\section{The US National Security Administration and Central Security Service}

Established in 1952 following World War II, during which time the country's code-breaking abilities proved critical, the NSA works with its CSS colleagues within the armed forces on the United States' cryptology efforts (US National Security Administration, 2016). Collectively, these organizations serve two primary missions: signals intelligence, the collection of digital intelligence required for national security purposes, and information assurance, the protection of vital United States digital systems from violence and theft (US National Security Administration, 2016). Very few countries perform citizen protection with a robust signals intelligence comparable to the scale and scope of the NSA.

\section{Intranational citizen protection structures}

\section{The US Department of Justice (DOJ)}

The DOJ's website describes its mission as "[t]o enforce the law and defend the interests of the United States according to the law; to ensure public safety against threats foreign and domestic; to provide federal leadership in preventing and controlling crime; to seek just punishment for those guilty of unlawful behavior; and to ensure fair and impartial administration of justice for all Americans" (US Department of Justice, 2019, para.1). The site further describes that although the Office of the Attorney General was created as a single position in 1789 as part of the Judiciary Act, the DOJ was not officially established until 1870. This new department was intended to oversee both criminal and civil cases with federal interests at stake. Since then, the DOJ has evolved structurally to become "the world's largest law office and the chief enforcer of federal laws" (US Department of Justice, 2019, para.6). Ministries of Justice in other countries perform similar protection roles. 


\section{The US judiciary}

The judiciary consists of the federal court system, including the Supreme Court, and is primarily responsible for interpreting the meaning of laws in regard to individual cases and determining if laws violate the Constitution (US Government, 2019). Meanwhile, the judiciary was founded with the establishment of the Supreme Court "under Article III of the Constitution to administer justice fairly and impartially, within the jurisdiction established by the Constitution and Congress" (US Judicial Branch, 2019a, para.1). Beyond the Supreme Court, with the Judiciary Act of 1789, the broader federal court system was established with a structure that has broadly remained intact today (The Library of Congress, 2017). Though they share a similar name, the judicial branch is distinct from the DOJ, and these two structures work closely together; for example: "The Department of Justice, which is responsible for prosecuting federal crimes and for representing the government in civil cases, is the most frequent litigator in the federal court system" (Eastern District of Washington, 2018, sec.1.4).

\section{The US Federal Bureau of Investigation}

The FBI was established in 1908 as the first federal organization dedicated to addressing national law enforcement (US Federal Bureau of Investigation, 2019a). Since the founding of the FBI Laboratory in 1932, the Bureau has led the use of the latest scientific and technological advances in promoting national security, which originated in practices including fingerprint and handwriting analysis (US Federal Bureau of Investigation, 2019c). Today, the FBI strives to protect American citizens from threats within the country, including terrorism, cyberattacks, civil rights violations, large crime organizations, and "significant" violent crime (US Federal Bureau of Investigation, 2019b). The Ministry of the Interior in many countries performs roles similar to the FBI.

\section{US state courts}

In the United States, state courts hear both civil and criminal cases, including tort cases, contract cases, and family cases (US Judicial Branch, 2019b). They are also responsible for interpreting state laws and constitutions (US Judicial Branch, 2019 b). As it concerns citizen protection, these courts work with law enforcement officers within the criminal justice system in the trial and judgment of individuals who commit crimes.

\section{Police power}

Police in the United States are responsible for local law enforcement, based on states' authority to enforce lawful regulation of citizen behavior (Barnett, 2004). Importantly, the police force is distinct from the military because military forces are not trained to manage citizen security, which has unfortunately led to human 
rights violations in certain circumstances (Inter-American Commission on Human Rights, 2009).

Though an important and public-facing component of citizen protection on the local level, police power is not specifically delegated within the United States Constitution and was applied inconsistently within writings from the period of the country's founding (Barnett, 2004). In his seminal treatise on states' legislative power, Michigan Supreme Court Justice Cooley (1871, p. 572) described the police as an entity that seeks:

not only to preserve the public order and to prevent offences against the State, but also to establish for the intercourse of citizen with citizen those rules of good manners and good neighborhood which are calculated to prevent a conflict of rights, and to insure to each the uninterrupted enjoyment of his own, so far as is reasonably consistent with a like enjoyment of rights by others.

Other scholars have conceived of police power more broadly, which has important implications when weighing individuals' rights (e.g., to privacy) vs. promotion of the "common good" - even if this means prevention of crimes that may or may not take place (Barnett, 2004). 


\section{Appendix B}

\section{Citizen Protection LIWC dictionary}

Table 11.1 Citizen Protection LIWC dictionary. This word list facilitated quantitative measurement of protective language signaled by public and private organizations

\begin{tabular}{llll}
\hline Prevention motivational dictionary & Additional words: citizen protection \\
\hline Accuracy & Loss & Attrition & Mitigate \\
Afraid & Obligation & Avert & Monitor \\
Careful & Ought & Constrain & Patrol \\
Anxious & Pain & Counter & Preserve \\
Avoid & Prevent & Curb & Recover \\
Conservative & Protect & Deny & Regulate \\
Defend & Responsible & Deport & Rescue \\
Duty & Risk & Duress & Restrict \\
Escape & Safety & Evacuate & Retain \\
Escaping & Security & Guard & Safeguard \\
Evade & Threat & Hostage & Save \\
Fail & Vigilance & Inhibit & Shield \\
Fear & & Keep & Stave \\
& & Limit & Ward \\
& & Maintain & \\
\hline
\end{tabular}

Table 11.2 Military, armaments, and defense. More Americans think the US spends "too much" on military, armaments, and defense, while fewer Americans think the US spends "too little"

\begin{tabular}{lrrrrrr}
\hline & 2002 & 2004 & 2006 & 2008 & 2010 & 2012 \\
\hline Too little & 32 & 35 & 25 & 24 & 27 & 25 \\
About right & 46 & 39 & 33 & 33 & 38 & 43 \\
Too much & 22 & 26 & 41 & 43 & 35 & 32 \\
$N$ & 1324 & 1367 & 1442 & 965 & 986 & 965 \\
\hline
\end{tabular}

Source: Adapted from Corman et al., 2015, p. 169. 
Table 11.3 National defense. More Americans think the US spends "too much" on defense, while fewer Americans think the US spends "too little"

\begin{tabular}{lrrrrrr}
\hline & 2002 & 2004 & 2006 & 2008 & 2010 & 2012 \\
\hline Too little & 36 & 33 & 28 & 27 & 25 & 26 \\
About right & 44 & 39 & 34 & 37 & 41 & 43 \\
Too much & 20 & 28 & 38 & 37 & 35 & 31 \\
$N$ & 1348 & 1371 & 1445 & 980 & 981 & 934 \\
\hline
\end{tabular}

Source: Adapted from Corman et al., 2015, p. 169.

Table 11.4 Polling indicates low trust and confidence in government

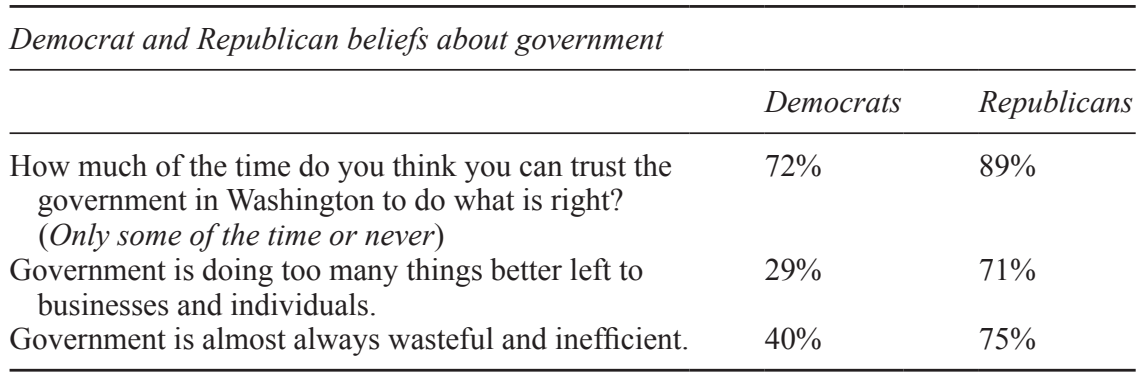

Source: Adapted from Doherty et al., 2015, pp. 9, 39, 112.

\section{Notes}

1 Beyond these three key distinctions, other scholars have called attention to the difference between preventive vs. reactive protection and positive vs. negative protection. We believe the first is self-explanatory; for more detail on the second, see the Report on Citizen Security and Human Rights (Inter-American Commission on Human Rights, 2009).

2 Although the Department of Energy may not be readily categorized as a protectionfocused organization, security and protection feature prominently in the DOE mission statement.

\section{References}

Abrahamsen, R. and Williams, M.C., 2009. Security beyond the state: global security assemblages in international politics. International Political Sociology, 3(1), pp. 1-17.

ADT, 2018. Our history. [online] ADT. Available at: <www.adt.com/about-adt/history> [Accessed 4 Sep. 2019].

Avant, D., 2004. The privatization of security and change in the control of force. International Studies Perspectives, 5(2), pp. 153-7.

Barnett, R.E., 2004. The proper scope of the police power. Notre Dame Law Review, 79(2), pp. 429-95.

Berteau, D., 1998. Defense conversion in information technology service industries. In: G.I. Susman and S. O'Keefe, eds. The defense industry in the post-Cold War era: corporate strategies and public policy perspectives, technology, innovation, entrepreneurship, and competitive strategy series. Oxford, UK: Pergamon. 
Blumenthal, P., 2018. Facebook and Google's surveillance capitalism model is in trouble. Huffington Post. [online] Available at: <https://www.huffingtonpost.com/entry/ facebookgoogle-privacy-antitrust_us_5a625023e4b0dc592a088f6c $>$ [Accessed 4 Sep. 2019].

Cohen, D., Nisbett, R.E., Bowdle, B.F. and Schwarz, N., 1996. Insult, aggression, and the southern culture of honor: an 'experimental ethnography.' Journal of Personality and Social Psychology, 70(5), pp. 945-59.

Cole, C. and Vermeltfoort, R., 2018. The private military industry. In: U.S. government contractors and human trafficking, springerbriefs in criminology. Cham, Switzerland: Springer International Publishing, pp. 9-16.

The Constitution of the United States, Amendment II.

The Constitution of the United States, Amendment VI.

Cooley, T., 1871. A treatise on the constitutional limitations which rest upon the legislative power of the states of the American union. 2nd ed. Boston, MA: Little, Brown \& Co.

Corman, J., Harris, K., Levin, D., Schulte, J. and Shanks, B., 2015. Support for defense and military spending. Public Opinion Quarterly, 79(1), pp. 166-80.

Dimock, M., Doherty, C. and Christian, L., 2013. Why own a gun? Protection is now top reason. Washington, DC: Pew Research Center.

Director of National Intelligence, 2013. Facts on the collection of intelligence pursuant to section 702 of the Foreign Intelligence Surveillance Act. [online] Available at: <www. dni.gov/index.php/newsroom/press-releases/press-releases-2013/item/871-facts-on-thecollection-of-intelligence-pursuant-to-section-702-of-the-foreign-intelligence-surveil lance-act> [Accessed 4 Sep. 2019].

District of Columbia v. Heller [2008] 554 US 570.

Doherty, C., Kiley, J. and Johnson, B., 2016. 15 years after 9/11, a sharp partisan divide on ability of terrorists to strike US. Washington, DC: Pew Research Center.

Doherty, C., Kiley, J., Tyson, A. and Jameson, B., 2015. Beyond distrust: how Americans view their government. Washington, DC: Pew Research Center.

Eastern District of Washington, 2018. Educational resources. [online] US Courts. Available at: <www.waed.uscourts.gov/educational-resources $>$ [Accessed 4 Sep. 2019].

Electronic Security Association, 2018. The history of home security. [online] Alarm.org. Available at: $<$ https://alarm.org/the-history-of-home-security $>$ [Accessed 4 Sep. 2019].

FitzGerald, B. and Parziale, J., 2017. As technology goes democratic, nations lose military control. Bulletin of the Atomic Scientists, 73(2), pp. 102-7.

Gamache, D.L., McNamara, G., Mannor, M.J. and Johnson, R.E., 2015. Motivated to acquire? The impact of CEO regulatory focus on firm acquisitions. Academy of Management Journal, 58(4), pp. 1261-82.

Goldman, A. and Mazzei, P., 2018. YouTube comment seen as early warning in shooting left little for F.B.I. to investigate. New York Times, 15 Feb.

Greenberg, A., 2017. Snowden-backed app 'Haven' turns your phone into a home security system. Wired. [online] Available at: $<$ www.wired.com/story/snowden-haven-app-turnsphone-into-home-security-system $>$ [Accessed 4 Sep. 2019].

Hemenway, D., 1997. Survey research and self-defense gun use: an explanation of extreme overestimates. Journal of Criminal Law and Criminology, 87(4), pp. 1430-45.

Holgate, L.S.H., 2018. The enduring challenge of nuclear security coordination. [online] Arms Control Association. Available at: <www.armscontrol.org/act/2018-01/features/ enduring-challenge-nuclear-security-coordination $>$ [Accessed 4 Sep. 2019].

Inter-American Commission on Human Rights, 2009. Report on citizen security and human rights. Washington, DC: Organization of American States. 
Isima, J., 2009. The global marketplace and the privatisation of security. IDS Bulletin, 40(2), pp. 113-20.

Kelsey, B.S., 1982. The dragon's teeth? The creation of United States air power for world war II. Washington, DC: Smithsonian Institution Press.

Kleck, G. and McElrath, K., 1991. The effects of weaponry on human violence. Social Forces, 69(3), pp. 669-92.

Kloepfer, K.T., Stapley, B.D., Haymond, B.R. and Seiter, P.D., 2018. System and method for authenticating an identity for a biometrically-enabled gun. U.S. Pat. 9,857,133.

Kocsis, M., 2015. Gun ownership and gun culture in the United States of America. Essays in Philosophy, 16(2), pp. 154-79.

Leander, A., 2005. The power to construct international security: on the significance of private military companies. Millennium: Journal of International Studies, 33(3), pp. 803-25.

The Library of Congress, 2017. Judiciary act of 1789: primary documents of American history. [online] Web Guides by the Library of Congress Digital Reference Section. Available at: <www.loc.gov/rr/program/bib/ourdocs/judiciary.html > [Accessed 4 Sep. 2019].

Light, P.C., 1999. The true size of government. Washington, DC: Brookings Institution Press.

Light, P.C., 2017. The true size of government. [online] The Volcker Alliance. Available at: $<$ https://www.volckeralliance.org/publications/true-size-government $>$ [Accessed 4 Sep. 2019].

Lott Jr., J.R. and Landes, W.M., 1999. Multiple victim public shootings, bombings, and right-to-carry concealed handgun laws: contrasting private and public law enforcement. University of Chicago Law School, John M. Olin Law \& Economics Working Paper, No. 73. Chicago, IL: University of Chicago.

Markusen, A.R., 2003. The case against privatizing national security. Governance, 16(4), pp. 471-501.

McDowall, D., 2005. Review: John R. Lott, Jr.'s defensive gun brandishing estimates. The Public Opinion Quarterly, 69(2), pp. 246-63.

Minow, M., 2005. Outsourcing power: how privatizing military efforts challenges accountability, professionalism, and democracy. Boston College Law Review, 46(5), p. 989.

Mossberg, J.E., Kluwe, G.E. and Kinion, K.F., 2001. Magnetic tag firearm safety enhancement system. U.S. Pat. 6,219,952.

Nalla, M.K. and Heraux, C.G., 2003. Assessing goals and functions of private police. Journal of Criminal Justice, 31(3), pp. 237-47.

Nalla, M.K., Maxwell, S.R. and Mamayek, C.M., 2017. Legitimacy of private police in developed, emerging, and transitional economies. European Journal of Crime, Criminal Law and Criminal Justice, 25(1), pp. 76-100.

NextMarket Insights, 2014. The smart home security market: market analysis, vendor profiles \& forecast. [online] Available at: $<\mathrm{http} / /$ web.archive.org/web/20181118183554/www. shield-security.com/hs-fs/hub/208616/file-1882657287-pdf/Smart_Home_Security_ Report_pdf $>$ [Accessed 4 Sep. 2019].

Parascandola, R., 2017. NYPD's 'T-Ray' gun sensors sit idle, but that's OK with cops. New York Daily News, 21 Feb.

Parker, K., Horowitz, J., Igielnik, R., Oliphant, B. and Brown, A., 2017. America's complex relationship with guns. Washington, DC: Pew Research Center.

Pennebaker, J.W., Booth, R.J., Boyd, R.L. and Francis, M.E., 2015a. Linguistic inquiry and word count: LIWC 2015 [computer program]. [online] Available at: <https:// s3-us-west-2.amazonaws.com/downloads.liwc.net/LIWC2015_OperatorManual.pdf> [Accessed 4 Sep. 2019]. 
Pennebaker, J.W., Boyd, R.L., Jordan, K. and Blackburn, K., 2015b. The development and psychometric properties of LIWC2015. Austin, TX: University of Texas.

Prem, B., 2018. Who am I? The blurring of the private military and security company (PMSC) category. In: O. Bures and H. Carrapico, eds., Security privatization: how nonsecurity-related private businesses shape security governance. Cham, Switzerland: Springer International Publishing, pp. 51-76.

Pulver, A. and Medina, R.M., 2018. A review of security and privacy concerns in digital intelligence collection. Intelligence and National Security, 33(2), pp. 241-56.

Rainie, L. and Madden, M., 2015. Americans' privacy strategies post-Snowden. [online] Pew Research Center: Internet, Science \& Tech. Available at: <www.pewinternet. org/2015/03/16/americans-privacy-strategies-post-snowden $>$ [Accessed 4 Sep. 2019].

Ritter, R.S., Preston, J.L. and Hernandez, I., 2014. Happy tweets: Christians are happier, more socially connected, and less analytical than atheists on Twitter. Social Psychological and Personality Science, 5(2), pp. 243-9.

Rosenberg, M., 2016. At Booz Allen, a vast U.S. spy operation, run for private profit. [online] The New York Times. Available at: $<$ https://www.nytimes.com/2016/10/07/us/ booz-allen-hamilton-nsa.html> [Accessed 4 Sep. 2019].

Sierra-Arévalo, M. and Crowther-Dowey, C., 2016. Legal cynicism and protective gun ownership among active offenders in Chicago. Cogent Social Sciences, 2(1), 1227293, pp. $1-21$.

Singer, P.W., 2005. Outsourcing war. Foreign Affairs, 84(2), pp. 119-32.

Singer, P.W., 2008. Corporate warriors: the rise of the privatized military industry. 2 nd ed. Cornell studies in security affairs. Ithaca, NY: Cornell University Press.

Soroka, S., Young, L. and Balmas, M., 2015. Bad news or mad news? Sentiment scoring of negativity, fear, and anger in news content. The Annals of the American Academy of Political and Social Science, 659(1), pp. 108-21.

Stroebe, W., Leander, N.P. and Kruglanski, A.W., 2017. The impact of the Orlando mass shooting on fear of victimization and gun-purchasing intentions: not what one might expect. PLOS ONE, 12(8), e0182408, pp. 1-15.

Tighe, C.E., Kleinman, S.D., Jondrow, J.M. and Trunkey, R.D., 1996. Outsourcing and competition: lessons learned from DOD commercial activities programs. Occasional Paper, October. Alexandria, VA: Center for Naval Analyses.

Ullah, H., 2017. Digital world war: Islamists, extremists, and the fight for cyber supremacy. New Haven, CT: Yale University Press.

UN General Assembly, 1948. The universal declaration of human rights. Paris, France: United Nations.

US Central Intelligence Agency, 2013. About CIA. [online] US Central Intelligence Agency. Available at: $<$ https://cia.gov/about-cia $>$ [Accessed 4 Sep. 2019].

US Department of Defense, 2018. DOD dictionary of military and associated terms. [online] Available at: <www.jcs.mil/Portals/36/Documents/Doctrine/pubs/dictionary. pdf?ver=2018-09-28-100314-687> [Accessed 4 Sep. 2019].

US Department of Defense, 2019. Our story. [online] US Department of Defense. Available at: <www.defense.gov/Our-Story> [Accessed 4 Sep. 2019].

US Department of Energy, 2015. History of the energy department's role in nuclear security. [online] US Department of Energy. Available at: <www.energy.gov/articles/historyenergy-departments-role-nuclear-security> [Accessed 4 Sep. 2019].

US Department of Energy, 2019a. About NNSA. [online] US Department of Energy. Available at: <www.energy.gov/node/2764052/timeline> [Accessed 4 Sep. 2019]. 
US Department of Energy, 2019b. About us (ONE). [online] US Department of Energy. Available at: <www.energy.gov/ne/about-us > [Accessed 4 Sep. 2019].

US Department of Energy, 2019c. Mission. [online] US Department of Energy. Available at: <www.energy.gov/mission> [Accessed 4 Sep. 2019].

US Department of Energy, 2019d. National security \& safety. [online] US Department of Energy. Available at: <www.energy.gov/national-security-safety> [Accessed 4 Sep. 2019].

US Department of Homeland Security, 2016. Mission. [online] US Department of Homeland Security. Available at: <www.dhs.gov/mission> [Accessed 4 Sep. 2019].

US Department of Justice, 2019. About DOJ. [online] US Department of Justice. Available at: <www.justice.gov/about> [Accessed 4 Sep. 2019].

US Department of State, 2018a. Bureau of international security and nonproliferation $(I S N)$. [online] US Department of State. Available at: $<$ www.state.gov/t/isn $>$ [Accessed 4 Sep. 2019].

US Department of State, 2018b. Travel advisories. [online] US Department of State. Available at: <https://travel.state.gov/content/travel/en/traveladvisories/traveladvisories. html $>$ [Accessed 4 Sep. 2019].

US Department of State, 2019a. About the U.S. Department of State. [online] US Department of State. Available at: <www.state.gov/aboutstate $>$ [Accessed 4 Sep. 2019].

US Department of State, 2019b. Department history. [online] Office of the Historian. Available at: $<$ https://history.state.gov/departmenthistory $>$ [Accessed 4 Sep. 2019].

US Federal Bureau of Investigation, 2019a. A brief history. [online] Federal Bureau of Investigation. Available at: <www.fbi.gov/history/brief-history> [Accessed 4 Sep. 2019].

US Federal Bureau of Investigation, 2019b. Mission \& priorities. [online] Federal Bureau of Investigation. Available at: <www.fbi.gov/about/mission> [Accessed 4 Sep. 2019].

US Federal Bureau of Investigation, 2019c. The FBI and the American gangster, 19241938. [online] Federal Bureau of Investigation. Available at: <www.fbi.gov/history/ brief-history/the-fbi-and-the-american-gangster $>$ [Accessed 4 Sep. 2019].

US Government, 2019. Branches of government. [online] USA.Gov. Available at: <www. usa.gov/branches-of-government $>$ [Accessed 4 Sep. 2019].

US Judicial Branch, 2019a. About federal courts. [online] United States Courts. Available at: <www.uscourts.gov/about-federal-courts> [Accessed 4 Sep. 2019].

US Judicial Branch, 2019b. Comparing federal \& state courts. [online] United States Courts. Available at: <www.uscourts.gov/about-federal-courts/court-role-and-structure/ comparing-federal-state-courts $>$ [Accessed 4 Sep. 2019].

US National Security Administration, 2016. Frequently asked questions about NSA. [online] US National Security Administration and Central Security Service. Available at: <www.nsa.gov/about/faqs/about-nsa-faqs.shtml\#about11> [Accessed 4 Sep. 2019].

Washington Technology, 2017. 2017 top 100. [online] Washington Technology. Available at: <https://washingtontechnology.com/toplists/top-100-lists/2017.aspx > [Accessed 4 Sep. 2019].

Weber, R.H., 2015. The digital future - a challenge for privacy? Computer Law \& Security Review, 31(2), pp. 234-42.

Ziegenhagen, E.A. and Brosnan, D., 1990. Citizen recourse to self protection: structural, attitudinal and experiential factors. Criminal Justice Policy Review, 4(2), pp. 91-104. 


\title{
12 Societal security \\ How digitalization enables resilient, agile, and learning capabilities
}

\author{
Arne Norlander
}

\section{Introduction}

Digitalization-enabled agility and learning concepts are important for the conduct of emergency response, but not only that; they are critical to the development of effective societal security capabilities that are able to meet future challenges and set clear objectives and requirements for the society in its broadest sense. Collaborative research in digitalization is essential. Sweden needs extensive knowledge building and investments in digitalization research, development, and innovation to secure its societal security capabilities. This chapter addresses two central research questions:

RQ 1: How does digitalization affect society and its societal security capabilities?

RQ 2: How do we create and organize Sweden's collective digitalization knowledge base that leads toward necessary future societal security capabilities?

\subsection{Brief definition and history}

Swedish society depends on a steady and reliable welfare state, but the distribution of resources and responsibilities between commercial entities on the one hand, and government and municipal agencies on the other hand, has changed drastically since the beginning of the 1990s (Government Offices of Sweden, 2017). These changes are due to both public and market sector deregulation, wideranging changes in geopolitical affairs, and the information revolution. Swedish society is neither structured nor organized as before. The population is more educated than ever but lacks basic skills to cope with the hardship of long-term crises.

\subsection{Current state of digitalization of societal security}

Digitalization brings great efficiency benefits in peacetime, but it also introduces vulnerabilities and risks. Digitalization can be both a strength and a weakness in that the very same, highly efficient, digitalized infrastructure, systems, and services normally used to serve and assist the population, can also - by their design - have inherent weaknesses that may expose these systems to the risks of 
unanticipated vulnerabilities and specific antagonistic exploitation of these vulnerabilities. Digitalization has brought extensive changes to society and has an impact on our daily lives. An extensive body of international research provides both deep and broad insight in the realm of digitalization and its current manifestations, for example, financial technologies, artificial intelligence, and machine learning. On December 20, 2017, the Swedish Defense Commission presented its annual report (Government Offices of Sweden, 2017). The Defense Commission notes that the Swedish civil and total defense must, in principle, be built up from the ground.

\subsection{Potential future impact of digitalization on societal security}

New concepts for national resilience, robustness, and redundancy need to be developed to ensure welfare, health care, food, water, energy, shelter, and security in times of hostilities or societal disruption or during naturally caused disasters (Swedish Civil Contingencies Agency, 2018). The Swedish Civil Contingencies Agency has also defined five future scenarios as part of its long-term strategic foresight (Wahlberg, Jonsson and Lindberg, 2013). The Swedish Defence Research Agency (FOI) highlighted societal weaknesses and threats in a scenario description to be used in Sweden's national preparedness planning (Johnsson, 2018). The Swedish government has analyzed experiences from emergency response missions, antiterrorism operations, natural disasters, critical events in health care, and collapses in the global financial system (Government Offices of Sweden, 2017). This analysis indicates that Sweden's national security and protection system must possess a range of agile capabilities, enabled by strategic level digitalization. In 2018, the global dimensions of digitalization - AI in particular - were studied and analyzed by a network of universities and research institutes, ranging from the Future of Humanity Institute to the University of Oxford, along three distinct security domains: digital security, physical security, and political security (Brundage et al., 2018). They illustrate possible changes to threats within these domains through representative scenarios in which digitalization-enabled capabilities could be used for malicious purposes in each of the digital, physical, and political security domains. Consequently, the authors of this project propose a number of recommendations to be acted upon today:

- Analyzing and (where appropriate) experimenting with novel openness models

- Learning from the experience of other scientific disciplines

- Multistakeholder dialogues on the risks in particular domains

- Accelerating beneficial research on promising defenses

\section{Methods}

A review of selected business agility literature and models is presented, as well as the latest developments within military studies of organizational agility. The 
relevance and impact of digitalization on agile and learning organizations is applied to four real-world scenarios. Discussion and conclusions on the impact of digitalization on societal security are presented.

\subsection{Agility in management theory: the business perspective}

The term "agility" was introduced in business studies and industry by Nagel and Dove (1991) at the Iacocca Institute, Leigh University. Since then, the concept has been used in several studies and its definition has been developed. Agility is defined as dynamic, context specific, growth oriented and aggressively embracing change. It is less about increased effectiveness or diminished costs. Instead it is about success, market share, and customers in the very heart of competition and conflict. Dove (1994) states that being agile means mastery of change - enabling an organization to do whatever it wants whenever it wants.

The definition was further developed by Nelson and Harvey (1995), who declared agility to be a capability; it is the organization's capacity to quickly and effectively seize unforeseen opportunities and to proactively develop solutions for potential needs.

Kidd (1995) characterized agility as a rapid and proactive adaptation of enterprise elements to unexpected and unpredicted changes, which represents a new and radically different business model. Holbrook (2003) concluded that change is perpetual and that the agile enterprise must be able to nimbly adapt to and exploit emerging opportunities.

Based on a review by Sherehiy, Karwowski and Layer (2007), the following main attributes for an agile enterprise can be distinguished:

1 Flexibility and adaptability

2 Responsiveness

3 Speed

4 Integration and low complexity

5 Mobilization of core competences

6 High quality and customized products

7 Culture of change

Prince and Kay (2003) regard agility as the capability of a firm to reconfigure itself in response to sudden change in a manner that is effective, opportune, robust, and with broad reach. Sharifi and Zhang (2001) view agility as encompassing two major elements: 1) to respond to changes (foreseen or unexpected) in appropriate and opportune ways, and 2) to exploit changes and turn them into opportunities.

According to Tsourveloudis and Valavanis (2002, p. 330), agility is more formally defined as "the ability of an enterprise to operate profitably in a rapidly changing and continuously fragmenting global market environment by producing high-quality, high-performance, customer-configured goods and services."

The predominant concepts and theories in business studies and research address different approaches to managing the ever-changing and unpredictable business 
environment. This stance affects how we view change and leads to making a distinction between episodic change (that we always have been accustomed to in business studies) and continuous change (that has emerged through the latest studies on managing complexity and organizational learning).

\subsubsection{Dynamic and agile organizations}

Dyer and Shafer (1998) suggested a model of organizational agility that they define as a necessary core competence for organizations operating in dynamic external environments. Agile organizations strive to develop a built-in capacity to shift, flex, and adjust, either alone or with alliance partners, as circumstances change, and to do so as a matter of course. The goal is to keep internal operations at a level of fluidity and flexibility that matches the degree of turmoil in external environments, a principle known as requisite variety. Ashby (1956) formulated the widely used concept of requisite variety, and Weick and Quinn (1999) made a well-researched distinction between change that is episodic, discontinuous, and intermittent and change that is continuous, evolving, and incremental.

Dyer and Shafer (2003) cite Dee Hock, the former president of Visa International, who described agile organizations as "chaordic," a combination of chaotic and ordered in order to be agile. According to this concept, in an agile organization, it is possible to release as much innovation and initiative as possible (chaos) while still having the means for coordination and cooperation (order). Arranged in a matrix (Figure 12.1), the agile organization would be the one with the highest degree of "direction, stability, and order" while simultaneously presenting the highest degree of "experimentation, discovery, and flexibility."

How organizations hold competitive advantage on the marketplace was investigated by Dyer and Shafer (2003). They suggest that dynamic organizations (DOs) compete through organizational and marketplace agility and point at strategic human resource management (SHRM) as a critical success factor. Dyer and Shafer $(2003$, p. 3) state that "Marketplace agility requires that employees at all

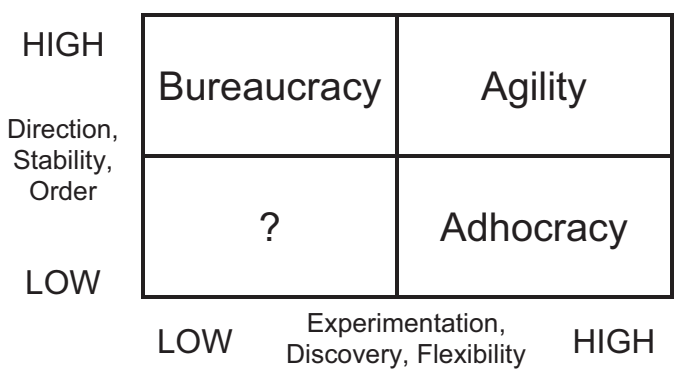

Figure 12.1 Organizational agility as a product of chaos and order

Source: Adapted from Dyer and Shafer, 1998, p. 7. 
levels engage in proactive, adaptive, and generative behaviors, bolstered by a supportive mindset" and identify four critical success factors of agile organizations:

1 Reading the market, intended as the ability to scan the external environment, locate and analyze emerging developments, and quickly turn the resulting information into actionable decisions.

2 Mobilizing rapid response, as the capacity to quickly and easily make decisions and translate these decisions into action. In some cases, this involves little more than making a series of relatively small-scale accommodations to evolving customer needs or competitors' initiatives. In others, it involves making major adjustments in product or service offerings or critical business processes. In either case, the key to success seems to lie in two factors: mindset and resource mobility.

3 Exploiting temporary advantage, which refers to the capacity to quickly and easily enter new markets and to deliver competitively priced products or services to these markets as long as, but not longer than, they remain the most attractive options on the horizon.

4 Embedding organizational learning, as the creation, adaptation, and replication of knowledge to improve organizational performance. The authors refer to the two types of learning: adaptive, or single loop, and generative, or double loop.

\subsubsection{Dyer and Shafer's model of organizational agility}

The critical success factors above are essential to meet the demands of maintaining competitive advantage. The authors developed a model of how these organizational competencies are developed, introducing a criterion that is critical to the issue of sustainability: organization and organizational capability. Dyer and Shafer's (1998) suggested model of organizational capability (the systemic interaction of key components, of which people are but one) for an agile organization is depicted below, with a relatively stable inner core and a constantly moving frame that consists of reconfigurable components. Dyer and Shafer suggest that the inner core, almost paradoxically, thanks to its stability, provides the energy that allows constant change, because it is grounded in an expansive vision and including change and adaptability as key performance metrics. The outer ever-moving ring becomes the place where continuous evolution, experimentation, discovery, and adaptation are operationalized.

Dyer's and Schafer's original agile organizational capability model is depicted in Figure 12.2.

\subsection{Agility in military thinking: a complementary perspective}

Crisis management operations (CMO) span a broad and diversified spectrum of conflicts, with very different characteristics. The capability to shift between different approaches to manage each sort of crisis situation is critical to maintain 


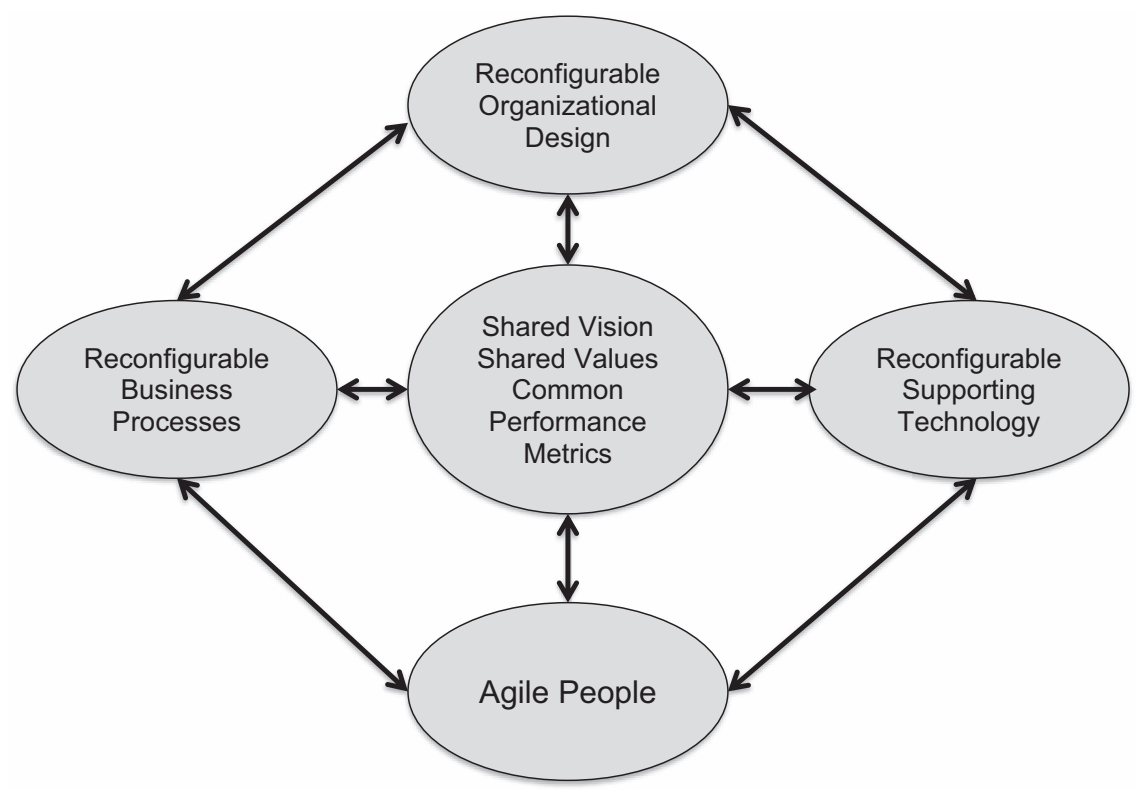

Figure 12.2 A model of agile organizational capability

Source: Adapted from Dyer and Shafer, 1998, p. 11.

operational effectiveness. Deployed forces need to rely on interaction and collaboration within and between different organizational cultures; between people with different backgrounds, education, and experience; and on managing and maintaining technological and doctrinal effectiveness and interoperability.

$\mathrm{CMO}$ - be they military missions, counterterrorism, or emergency response comprise complex, laborious, and dangerous tasks, requiring resolute and determined teamwork under extreme conditions (Worm, Jenvald and Morin, 1998). Deployed units must be able to operate independently and with little support while still ensuring operational security and mission efficiency without risking excessive resource depletion.

New technology will offer extensive support in every aspect of CMO. The potential of digitalization, including high-capacity information processing and real time interaction in distributed, dynamic mission environments, is yet to be fully exploited (Norlander, 2011). Future decisions will be made in situations where operational and system characteristics are highly dynamic and nonlinear, that is, minor events or actions might have irreversible consequences on the entire mission.

Additionally, success in future military and emergency response missions requires highly capable understanding, based on a correct perception and interpretation of a particular situation in order to provide the context, insight, and 
foresight required for effective decision-making (Norlander, 2011). Every commander and operator must develop a capability for sense-making to enable a comprehensive appreciation of the situation and a detailed system insight, leading to safe and efficient mission accomplishment (Weick, Sutcliffe and Obstfeld, 2005).

Finally, the circumstances around CMOs can often be characterized as a "wicked" environment, where adopting an approach that is appropriate for "tame" problems might be, at least, misleading, and often counterproductive. The term "wicked problem" was introduced by Rittel and Webber (1973). They found traditional planning methods to be inadequate for the ill-structured problems they encountered in city planning. Conklin (2006) states that situations often involve a combination of tame elements and wickedness. Conklin also generalized the concept of problem wickedness to areas other than planning and policy. Conklin's defining characteristics of wicked problems are:

1 The problem is not understood until after the formulation of a solution.

2 Wicked problems have no stopping rule.

3 Solutions to wicked problems are not right or wrong.

4 Every wicked problem is essentially novel and unique.

5 Every solution to a wicked problem is a "one shot operation."

6 Wicked problems have no given alternative solutions.

Based on these findings, building an agile and adaptive organization begins with recognizing and accepting the complexity and wickedness of the enterprise and its circumstances, and letting go of the idea that it can be tamed and controlled. This requires a major shift in mind-set, at both individual and organizational levels, and embracing digitalization as an enabler of agile and adaptive behavior; the implementation of new methods, procedures, or organizational charts would not be sustainable without this major shift in attitude. This, in turn, requires support at policy level, an organizational culture based on flexibility, openness to change and tolerance for error (a learning culture), and an organizational design that supports and enhances such properties, rather than mortifying them (as it is often the case). An agile and adaptive enterprise needs these competencies in any department and at any level of command, and it needs to be strongly sustained by the adequate leadership, doctrine, and policy.

Alberts (2011, p. 190) defines agility as "the capability to successfully effect, cope with and/or exploit changes in circumstances." The phrase "changes in circumstances" has strong connotations of situations arising or events unfolding over time, not only external but also internal ones. A NATO research task group defined six enablers of agility, listed as enablers 1 to 6 below (NATO, 2014).

Dodd (2011) complemented this agility model with three additional enabling concepts: proactivity, learning, and collaboration, listed as enablers 7 to 9 . The complete list of agility enablers is found below:

Enablers of agile capabilities are:

1 Resilience - able to recover from or adjust to misfortune, damage, or a destabilizing perturbation in the environment 
2 Responsiveness - able to react to a change in the environment in a timely manner

3 Versatility - able to maintain effectiveness across a range of tasks, situations, and conditions

4 Adaptability - able to change the organization and/or work processes

5 Flexibility - able to employ multiple ways to succeed and having the capacity to move seamlessly between them

6 Innovativeness - able to do new things or able to do old things in new ways

7 Proactivity - able to conduct proactive and preemptive actions to drive and shape change or protect continuity

8 Learning - able to learn and unlearn from experience and develop and utilize continuously evolving procedures and cooperation structures

9 Collaboration - among people, technology, and organizations with a readiness to capitalize on the benefits of emerging information age technologies

The enablers of agility constitute an "agility value chain" that includes the set of links that connects various entity characteristics and behaviors to entity agility. Figure 12.3 depicts agility to be a function of the enterprise, the entities, and the circumstances of the mission and mission environment.

The following operational scenarios are authentic examples ranging from accidents and natural disasters to deliberate antagonistic influence and coercion, all exacerbated or in some cases even directly enabled through dysfunction or failure

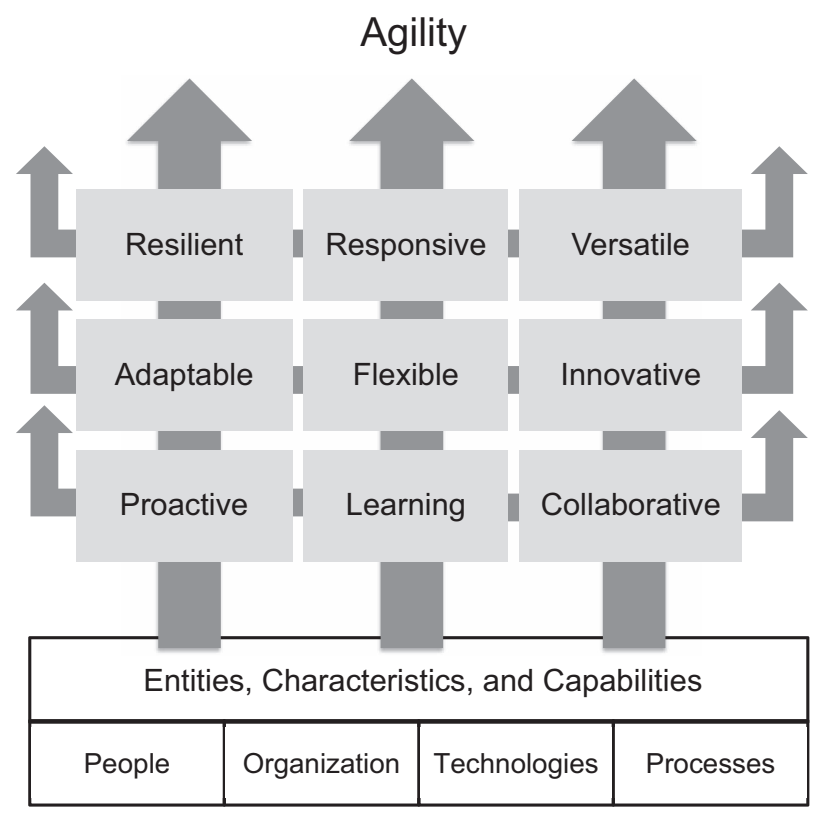

Figure 12.3 The agility value chain - the agility value chain is not a simply a string of links, but is in reality a mesh or network of interdependent variables 
of digitalized capabilities. Each case was analyzed using the nine agility characteristics and rating to what degree they were accomplished, and how human, technological, and organizational agility in some cases have been reshaped and improved to better respond to the requirements for different dimensions of societal security.

\subsection{Autonomous vehicle operating within a non-supportive infrastructure}

The increased use of autonomous vehicles presents risks that might cause collisions due to changes in the traffic environment, its information, or other circumstances. This scenario involves a fatal car crash involving a car with a built-in vehicle automation suite that collided with a heavy semi trailer. The car's recognition algorithms did not recognize the turning semi trailer as a dangerous object and continued at the same speed and direction, killing the car driver (NTSB, 2017). The interpretation of a traffic sign or a difficult traffic situation can become different or inconclusive due to specific alterations or disturbances in the vehicle's sensors or through a malfunctioning automated situation recognition and response system in the vehicle. This could be caused by either poorly designed algorithms or by an antagonist hacker to cause traffic interference and injury. A healthy human driver would easily recognize a damaged traffic sign as still a traffic sign, or interpret complex, dynamic traffic situations correctly, and steer away from the danger. The US National Transportation Safety Board (NTSB) recommends a vehicle-to-vehicle (V2V) communication system, transmitting warnings and basic safety information (speed, position, heading, brake status, etc.) to all other vehicles in the surrounding traffic environment; a system like this would generate complex requirements, and draw unprecedented economic resources into road-based networked critical infrastructure. The scenario showed agility deficiencies in responsiveness, adaptability, proactivity, and collaboration from both the human operator and the technology perspectives.

\subsection{Digitized networks and procedures in an electronic intensive care unit}

Another example is the recent communications failure of the medical electronic intensive care unit (EICU) system at the New Karolinska Hospital near Stockholm, Sweden, which experienced several breakdowns of the internal EICU network during the fall of 2017 and early in 2018, seriously affecting patient safety and hospital resource management. EICU nurses had to leave several of their ordinary duties of monitoring and responding to patients via the Karolinska Hospital EICU network to take on manual management and coordination tasks, with little or insufficient training. An investment in network infrastructure is often motivated by increased efficiency but often generates costs of time, effort, and resources for training EICU nurses and physicians in the networking procedures. In fact, it is not unusual that digitalization in health care can cause negative effects on patient 
safety. Digitalized systems introduce the need for resilience, adaptation, learning, and collaborative capabilities. Professional physicians and nurses, having thorough experience, knowledge, and skills for the medical specialist responsibility, will have to acquire skills as managers and coordinators of distributed teams, working in a digital health care management system. This paradox is thoroughly described by Anders et al. (2007). The scenario showed agility deficiencies in resiliency, versatility, adaptability, learning, and collaboration from all perspectives: human, technological, and organizational.

\subsection{Crisis response and command and control in a large forest fire}

As part of a government evaluation of a forest fire in Västmanland, central Sweden, in 2014, Johansson, Trnka and Berggren (2016) conducted a study where an assessment template developed by a research group in NATO's Science and Technology Organization (NATO, 2014) was used to identify, collect, and analyze evidence concerning the manifestation of agility of the capabilities deployed in the fire-fighting operation. The fire evolved in a rapid and complex pattern due to unusual weather conditions. Hundreds of firemen, soldiers of the Swedish home guard, and volunteers worked around the clock to fight the fire, which at its most critical point spread over two kilometers per hour. More than 20 helicopters and airplanes assisted the ground force. The fire raged for nearly two weeks before the incident commander could report that the fire was under control. One person was killed and one person was badly burned, 13,800 hectares of forest were destroyed, and the total cost of the emergency operation and damages was estimated to be at least SEK 1 billion.

The large number of engaged agencies and other organizations, each one with its specific command structure, mandate, and responsibilities, faced a number of complex management and command challenges (Uhr et al., 2016). The analysis emphasized the need to be prepared for scenarios that are not commonly encountered (Worm, Jenvald and Morin, 1998). The deployed organizations failed to reach the appropriate levels of performance, mainly due to agility deficiencies in responsiveness, adaptability, flexibility, and collaboration during the initial and intermediate phases of the firefighting mission. The unusual and challenging conditions of the forest fire contributed to the failure, but it also underscored the need for a capacity to activate and create supporting capabilities to be able to achieve proper shared situational awareness with support from a common operational picture. This capacity proved insufficient throughout the operation.

\subsection{A campaign of influence and coercion on a digitized society}

Estonia has, since its independence from the Soviet Union, invested heavily and broadly in digitalization; Estonia's strategy and its implementation, called E-Estonia, is the most ambitious project in technological governance today, including all 
members of the government and affecting every citizen's daily life. The normal services that government is involved with, legislation, voting, education, justice, health care, banking, taxes, policing, and others, have been digitally linked across one platform, connecting the nation.

In 2007, the Estonian government attempted to relocate a Soviet-era war memorial to a military cemetery outside of the city center of its capital, Tallinn. This decision met aggressive protests from the Russian minority in Estonia, the Russian government, and Russia-friendly media. Estonia had recently joined NATO at that time, and a foreign cyberattack against Estonia was launched, aiming at projecting foreign power and influence over the Estonians and sending a broader message to countries neighboring Estonia warning them of the consequences if they also joined NATO. Estonia was attacked in several operational dimensions, including physical, psychological, and cyber. Street riots flamed up, and Nashi (a Russian political youth movement) instigated a siege of the Estonian embassy in Moscow during which the Estonian ambassador was physically harassed. Russian authorities have denied any involvement.

Estonia's digitalized society, designed to simplify and streamline every citizen's daily life, had weaknesses that could be exploited by an antagonist, but the weaknesses were continuously identified and mitigated.

This type and form of attack showed Estonia's national agility deficiencies in adaptability, innovativeness, proactivity, and resiliency; the Estonians had no procedures for dealing with this kind of situation, and at the time of the attack, Estonia lacked a national digitalization and cybersecurity strategy. However, Estonia drafted and approved its first strategy for national cyber protection in 2008. Based on its experiences, Estonia now has set up a voluntary civilian cyberdefense force as a complement to its national military defense force. Estonia is also reinforcing its capabilities to meet a full-scale cyberattack through other safeguards. Estonian government agencies have invested in shared situational awareness and a common cyber-operating picture for analysis and response in real time, and in a dynamic exploratory manner, with support from national and international organizations, such as the Computer Emergency Response Team for Estonia (CERT-EE), Ministry of Defense (MoD), NATO, and national and international information technology experts. The Estonian government has created a server capability in Luxembourg, containing a backup of its national systems. It is created using the same body of international law as a physical embassy, locating the servers and their data (virtually but still legally) on Estonian soil. Whether digitally or physically attacked, Estonia's governance will shift to a mirror site abroad.

\section{Results and discussion}

The study results from the four scenarios described above shows that digitalizationenabled agile capabilities can be seriously affected by situational dynamics and mission complexity to the level of severe degradation or failure in all cases. A summary is found in Table 12.1. 
Table 12.1 Occurrences of performance degradation or failure of digitalization-enabled agility

\begin{tabular}{|c|c|c|c|c|}
\hline \multirow{2}{*}{$\begin{array}{l}\text { Digitalization-enabled } \\
\text { agility characteristic }\end{array}$} & \multicolumn{4}{|c|}{ Operational scenario $1-4$} \\
\hline & $\begin{array}{l}\text { Autonomous } \\
\text { vehicle } \\
\text { operating within } \\
\text { a non-supportive } \\
\text { infrastructure }\end{array}$ & $\begin{array}{l}\text { Digitized } \\
\text { networks and } \\
\text { procedures in } \\
\text { an electronic } \\
\text { intensive } \\
\text { care unit }\end{array}$ & $\begin{array}{l}\text { Crisis } \\
\text { response and } \\
\text { command and } \\
\text { control in a } \\
\text { large forest } \\
\text { fire }\end{array}$ & $\begin{array}{l}\text { A campaign of } \\
\text { influence and } \\
\text { coercion of a } \\
\text { digitized society }\end{array}$ \\
\hline Resilience & & $\mathbf{X}$ & & $\mathbf{X}$ \\
\hline Responsiveness & $\mathbf{X}$ & & $\mathbf{X}$ & \\
\hline Versatility & & $\mathbf{X}$ & & \\
\hline Adaptability & $\mathbf{X}$ & $\mathbf{X}$ & $\mathbf{X}$ & $\mathbf{X}$ \\
\hline Flexibility & & & $\mathbf{X}$ & \\
\hline Innovativeness & & & & $\mathbf{X}$ \\
\hline Proactivity & $\mathbf{X}$ & & & $\mathbf{X}$ \\
\hline Learning & & $\mathbf{X}$ & & \\
\hline Collaboration & $\mathbf{X}$ & $\mathbf{X}$ & $\mathbf{X}$ & \\
\hline
\end{tabular}

The impact and value of digitalization for both society and its citizens can be increased by 1) expanding the number and variety of approaches an entity can choose among (a larger, more diverse organizational and technological "toolkit"); 2) enabling entities to select and adopt the most appropriate approach to specific needs and circumstances; and 3) making individual approaches and the systems that support them more responsive, versatile, flexible, and resilient, enabling citizens and organizations to be more adaptive and innovative.

\subsection{Research questions revisited}

Each of the concepts and scenarios described above, whether from the business or government/public domains, provides insight and presents specific elements that can be critical to achieving digitalization-enabled agility. The two research questions were a useful vehicle for directing and analyzing the scenarios. We consider RQ 1 to be answered to a certain extent in that the scenarios show the impact of digitalization from a societal security perspective. The essence of RQ 1 is the effect on society's capabilities and its consequences for the individual citizen. Hence, the scenarios lead to the conclusion that digitalization's impact is profound and will indeed be of a revolutionary character. Citizen protection will be both enhanced and jeopardized by digitalization, and an interdisciplinary, overarching approach to digitalization is fundamental. Nearly every capability component and dimension of society will be affected by digitalization, and agility and adaptation will be significant and critical characteristics of all digitalized solutions. Regarding RQ 2, we found it difficult to answer in a straightforward 
and coherent manner. The main point of RQ 2 resides not in implementation or effects but in policy and strategy. Building a digitalization knowledge base on a national level means integrating policy areas, commercial interests, and societal needs, and will depend on political accord. A central part of RQ 2 is the common underlying requirement of continuous learning and adaptation, both central enablers of agile capabilities but on a different level than that of RQ 1. We conclude that the truly agile and adaptive organization is not the one that can handle the problems of today, but the one that is able to be evolutionary to manage the problems of tomorrow. Not because the agile and adaptive organization tries to foresee what the problems of tomorrow will be, but because it is prompt and quick in learning about them as they rise, and adapts accordingly. It implies an evolutionary way of being, encompassing all aspects of the organization. Theories of organizational change have highlighted the difficulty and various forms of resistance to change, also when accepted and advocated, not only at the individual, but also at the organizational and strategic level.

\subsection{The importance of policy and organizational culture}

As organizational culture is the personality of the organization, we are advocating agility and learning as a way of being, and organizational culture plays a major role in this issue. A learning organization requires a culture of curiosity and dynamism, where initiative is rewarded and the bar is set high for excellence. Policy sets the framework for these issues and, not the least, for decision-making. In fact, decisions are only made within the realm of what is seen and accepted. In this sense it could be stated that decisions are made at the policy level, as this is where the conditions and circumstances are determined, whereas within the organization, decisions are taken (within the framework set by the policy level). An organization where there is no place for new ideas or constructive criticism is far from evolutionary, and doomed to failure.

\section{Conclusions}

Societal security is a complex endeavor, where operational and system characteristics are highly dynamic and nonlinear; that is, minor events or actions might have irreversible consequences for the entire mission. Based upon an analysis of the empirical evidence from case studies, supported by organizational agility theory, our first conclusion is that it is imperative to increase agility and learning in societal security capabilities, because doing so improves the likelihood of mission success. An organizational entity's increased agility and learning contribute to mission success by facilitating entities to adopt more appropriate approaches to societal security in more situations and to adjust their approaches as the mission and circumstances change. Digitalization enables this because

1 The concepts of agility and learning have proven to be critical factors in societal security, and digitalization can offer significant improvements. 
2 Organizational agility in societal security and the variables that impact it are observable, are measureable, and can be influenced, shaped, and controlled by digitalization.

Given the variety of situations and circumstances, collectives of entities must be able to meet these challenges. Agility, learning, and collaboration are at the core of organizational culture; there is no "one-size-fits-all" approach to societal security. Hence, organizations need to be able to employ more than one approach, understanding when different approaches are appropriate, and have the ability to efficiently transition between approaches in a timely manner.

\section{Acknowledgments}

The Swedish Armed Forces, the Swedish Defence University, the Swedish Defence Research Agency, The Swedish Civil Contingencies Agency, and the Swedish National Foundation for Strategic Research supported this work in collaboration with Linköping Institute of Technology and Stockholm Royal Institute of Technology.

\section{References}

Alberts, D.S., 2011. The agility advantage: a survival guide for complex enterprises and endeavors. Washington DC: DoD Command and Control Research Program.

Anders, S., Patterson, E.S., Woods, D.D. and Ebright, P., 2007. Projecting trajectories for a new technology based on cognitive task analysis and archetypal patterns: the electronic ICU. In: K. Mosier and U. Fischer, eds. 8th annual naturalistic decision making conference. Pacific Grove, CA: NDM, pp. 1-12.

Ashby, W.R., 1956. An introduction to cybernetics. London, UK: Chapman \& Hall.

Brundage, M., Avin, S., Clark, J., Allen, G.C., Flynn, C., Farquhar, S., Crootof, R. and Bryson, J., 2018. The malicious use of artificial intelligence: forecasting, prevention, and mitigation. Oxford, UK: Future of Humanity Institute.

Conklin, J., 2006. Dialogue mapping: building shared understanding of wicked problems. Chichester, UK: John Wiley \& Sons.

Dodd, L., 2011. Task 10 C2 agility, work package 1: top-down review of current agility research, sub-package WP1.1: academic literature review [Unpublished Report]. Shrivenham, UK: UK Defence Academy.

Dove, R., 1994. The meaning of life and the meaning of agile. Production Magazine, 106(11), pp. 14-15.

Dyer, L. and Shafer, R.A., 1998. From human resource strategy to organizational effectiveness: lessons from research on organizational agility. CAHRS Working Paper, No. 98-12. Ithaca, NY.

Dyer, L. and Shafer, R.A., 2003. Dynamic organizations: achieving marketplace and organizational agility with people. CAHRS Working Paper, No. 03-04. Ithaca, NY.

Government Offices of Sweden, 2017. Motståndskraft: Inriktningen av totalförsvaret och utformningen av det civila försvaret 2021-2025 [Resilience: the total defence concept and the development of civil defence 2021-2025]. [online] Ministry of Defence. Available at: <www.regeringen.se/rattsliga-dokument/departementsserien-och-promemo rior/2017/12/ds-201766> [Accessed 4 Sep. 2019]. 


\section{Arne Norlander}

Holbrook, M.B., 2003. Adventures in complexity: an essay on dynamic open complex adaptive systems, butterfly effects, self-organizing order, coevolution, the ecological perspective, fitness landscapes, market spaces, emergent beauty at the edge of chaos, and all that jazz. Academy of Marketing Science Review, 2003(6), pp. 1-181.

Johansson, B., Trnka, J. and Berggren, P., 2016. A case study of C2 agility in the 2014 Västmanland forest fire. Linköping, Sweden: Swedish Defence Research Agency.

Johnsson, D.K., 2018. Typfall 5: Utdragen och eskalerande gråzonsproblematik [Scenario 5: prolonged and escalating gray zone issues]. Stockholm, Sweden.

Kidd, P.T., 1995. Agile manufacturing: a strategy for the 21st century. In: IEE colloquium on agile manufacturing (Digest No. 1995/179). Coventry, UK: IET.

Nagel, R.N. and Dove, R., 1991. 21 st century manufacturing enterprise strategy: an industry-led view. Bethlehem, PA: Diane Publishing.

NATO, 2014. C2 agility - task group SAS-085 final report (STO-TR-SAS-085). [online] Task Group SAS-085 Final Report. Available at: <www.dodccrp.org/sas-085/sas-085 report_final.pdf $>$ [Accessed 4 Sep. 2019].

Nelson, A. and Harvey, F.A., 1995. Technologies for training and supporting your agile workforce: in creating the agile organization: models, metrics and pilots. In: J.J. Barker, ed. 4th agility forum annual conference. Atlanta, GA: Angus \& Robertson.

Norlander, A., 2011. Cognitive systems modeling and analysis of command \& control systems. In: T.E. Pinelli and L.S. Bullock, eds., Proceedings of the MODSIM world 2011 conference and Expo, 11-14 October. Virginia Beach, VA: National Aeronautics and Space Administration (NASA).

NTSB, 2017. NTSB/HAR-17/02 PB2017-102600 notation 56955 adopted September 12, 2017 highway accident report collision between a car operating with automated vehicle control systems and a tractor-semitrailer truck near Williston, Florida, 7 May 2016. Washington, DC.

Prince, J. and Kay, J.M., 2003. Combining lean and agile characteristics: creation of virtual groups by enhanced production flow analysis. International Journal of Production Economics, 85(3), pp. 305-18.

Rittel, H.W. and Webber, M.M., 1973. Dilemmas in a general theory of planning. Policy Sciences, 4(2), pp. 155-69.

Sharifi, H. and Zhang, Z., 2001. Agile manufacturing in practice - application of a methodology. International Journal of Operations \& Production Management, 21(5-6), pp. 772-94.

Sherehiy, B., Karwowski, W. and Layer, J.K., 2007. A review of enterprise agility: concepts, frameworks, and attributes. International Journal of Industrial Ergonomics, 37(5), pp. 445-60.

Swedish Civil Contingencies Agency, 2018. Nationell risk- och förmågebedömning 2018 [National risk and capability assessment 2018]. [online] MSB1221. Available at: $<$ https://www.msb.se/sv/publikationer/nationell-risk--och-formagebedomning-2018> [Accessed 4 Sep. 2019].

Tsourveloudis, N.C. and Valavanis, K.P., 2002. On the measurement of enterprise agility. Journal of Intelligent and Robotic Systems, 33(3), pp. 329-42.

Uhr, C., Johansson, B.J., Landgren, J., Holmberg, M., Bynander, F., Koelega, S. and Trnka, J., 2016. Once upon a time in Västmanland - the power of narratives or how the 'truth' unfolds. In: ISCRAM16. Rio de Janeiro, Brazil: ISCRAM.

Wahlberg, M., Jonsson, O. and Lindberg, A., 2013. Five challenging future scenarios for societal security. [online] Swedish Civil Contingencies Agency (MSB). Available at: 
$<$ https://www.msb.se/sv/publikationer/five-challenging-future-scenarios-for-societalsecurity> [Accessed 4 Sep. 2019].

Weick, K.E. and Quinn, R.E., 1999. Organizational change and development. Annual Review of Psychology, 50, pp. 361-86.

Weick, K.E., Sutcliffe, K.M. and Obstfeld, D., 2005. Organizing and the process of sensemaking. Organization Science, 16(4), pp. 409-21.

Worm, A., Jenvald, J. and Morin, M., 1998. Mission efficiency analysis: evaluating and improving tactical mission performance in high-risk, time-critical operations. Safety Science, 30(1-2), pp. 79-98. 


\title{
13 Digital identity - beyond verification
}

\author{
To a transparent (decentralized) \\ system for data and identity \\ monitoring and control
}

\section{Claire Ingram Bogusz}

\section{Introduction}

In recent years, we have become accustomed to everything from emails that "phish" for our passwords to the use of our individual data on social media sites being used for purposes we did not explicitly consent to - and even being sold to third parties. We have even gotten so used to the ubiquitous "cookies" notice in our browser that we seldom stop to think about the data that are being collected.

Digital trace data, or data that are generated as a result of interactions online, have come to be used from everything to optimizing advertisements to detecting fraud, and more (Ingram Bogusz, 2018b). In fact, it is almost a paradox that although we know that data are used to solve problems and create products - both useful and sinister - we are often unaware, and cannot keep track of, our own data in these processes. As a result of the ubiquity of these data, and their use, policy-makers and the public sector have become increasingly interested in how these data are collected, monetized, and managed. This chapter provides an overview and some analysis of this emerging phenomenon with policy-makers in mind. In particular, it considers the role of the public sector in this phenomenon.

The aim of this chapter is to explore the existing models of digital identity verification and digital data management before analyzing and contrasting some existing solutions and offering food for thought for policy-makers as this phenomenon moves forward. It then outlines some suggestions around how these two distinct, but important, phenomena might converge to allow individuals better dynamic control over which data are collected, by whom, and for what purposes.

Parallel to the development of data-driven problem-solving and products, both public and private actors have developed digital identity verification systems for use by individuals and firms across the globe. Some of the best known are digital identities used to access bank services, for instance, through mobile IDs, one-time passwords, and smart cards. Others include the use of digital biometric data, for instance, in passports and civic identity cards.

Moreover, with the rise in these digital ways of verifying one's identity has come an increased awareness from individuals that their data are being used - as 
well as a rise in digital identity theft and fraud. Both individual demand and the potential for exploitation point to the need for us to have more control over both our identities and our data online, and potentially even be compensated for these data. This movement from digital identity verification to digital data management, with identity verification a key element, has led to the emergence of several nascent solutions - but comprehensive data management nevertheless faces a number of challenges and risks.

\subsection{Tackling the tension between commerce and control}

Data, as part of a broader move toward digitalizing both private and public services, have come to be seen as lifeblood of many competitive economies. Indeed, the collection of data and the development of new services and products reliant on data has been likened to an "oil rush" (The Economist, 2017).

Smartphones and the internet have made data abundant, ubiquitous and far more valuable. Whether you are going for a run, watching TV or even just sitting in traffic, virtually every activity creates a digital trace - more raw material for the data distilleries. As devices from watches to cars connect to the internet, the volume is increasing: some estimate that a self-driving car will generate 100 gigabytes per second. Meanwhile, artificial-intelligence (AI) techniques such as machine learning extract more value from data. Algorithms can predict when a customer is ready to buy, a jet-engine needs servicing or a person is at risk of a disease. Industrial giants such as GE and Siemens now sell themselves as data firms.

(The Economist, 2017, para.4)

However, even as more and more data are collected, so, too, is there competition between firms to collect as much data as possible - and many countries see facilitating access to data, whatever the cost, as fueling innovation. This has led to what the Financial Times calls an "arms race": not only are Internet giants racing to collect and control the most data, whether they can use it or not, but governments have found themselves unsure how to balance the lure of the innovation promised by easy access to large volumes of data against individuals' calls for limitations and protections (Financial Times, 2018).

What has emerged is a polarization of approaches: on the one hand, one has an approach championed by countries within the European Union and exemplified by the General Data Protection Regulation (Regulation (EU) 2016/679). Such approaches place requirements around the need for firms not only to get specific, limited, and informed consent from individuals around both how data are collected and what those data are used for, but also to get rid of data that have not been used within a certain time frame - and to obtain new consent if they wish to use old data for a new purpose. On the other hand, one has the deliberately laissez-faire approach exemplified by the likes of China; not only are there few limitations on what data can be collected and for what purposes, but a cultural 


\section{Claire Ingram Bogusz}

acceptance of oversight in exchange for convenience and innovation has emerged (The Economist Intelligence Unit, 2017).

This difference in policy and cultural approaches also highlights a policy conundrum. Individuals have expressed and are often perceived to have the right to have some control over the data about them that are collected and how they are used. However, firms and governments often argue that better access to individuals' data not only drives innovation and entrepreneurship, but also value creation more generally.

Today, it is unclear to see how to reconcile these two approaches. This is especially in light of the fact that data is often treated as a by-product of online activity, rather than a product in its own right (Ingram Bogusz, 2018a).

Thus, digital identity solutions today are only infrastructures for confirmation and consent. Few have records of the consent, and only a small number, mostly pioneered by start-ups, have built infrastructures that confirm identity, tag and trace data related to that identity, and offer a dynamic management infrastructure for individuals to revoke consent at a later date.

This chapter will examine how digital identities are being used today before presenting the case for an expansion of the digital identity verification model to a fine-grained digital data use and management system and offering some nascent examples. Last, it presents some areas for consideration by public actors as we approach the possible integration of the two.

\section{Data identity and data management}

The first step toward management of an individual user's data is for that individual to be considered a distinct user on the Internet. In other words, not only must data be collected, but it needs to be connected to a unique user - with a unique identity and the ability to control that identity through verification and control. This kind of unique identity is what is called an "identity verification" system, and a functioning identity verification system - whatever form it might take - is a prerequisite for better management of digital data online.

\subsection{Static, restricted, and binary}

Management consulting firm McKinsey \& Company estimates that the market for identity verification services was, in 2018, close to USD10 billion. They predict that it has the potential to create economic value worth between 3 and 13 percent of global GDP by 2030, with developing countries like Nigeria and India set to benefit most (White et al., 2019). When they talk about identity verification services, what they refer to are services that 1) verify that an individual is a person and not, for example, a bot, and 2) that they are who they say they are. While identity verification is relatively frictionless in the offline world, in the digital world it can be cumbersome - and different alternatives have emerged. These are summarized in Table 13.1. 
Table 13.1 Some typical digital identity verification services in use in 2019

\begin{tabular}{|c|c|c|}
\hline Verification type & Commonly used by & Examples \\
\hline Identity Verification & $\begin{array}{l}\text { Governments and banks, and } \\
\text { linked to national registries } \\
\text { (for example, of identity } \\
\text { numbers) }\end{array}$ & $\begin{array}{l}\text { BankID application } \\
\text { linked to a verified } \\
\text { phone number }\end{array}$ \\
\hline $\begin{array}{l}\text { Multifactor } \\
\text { Identification }\end{array}$ & $\begin{array}{l}\text { Online services to confirm that } \\
\text { person attempting to log into } \\
\text { an account is the same as the } \\
\text { one who set up the account, } \\
\text { via a pre-verified device }\end{array}$ & $\begin{array}{l}\text { Text message } \\
\text { identification by } \\
\text { Google, Facebook sent } \\
\text { to a verified mobile } \\
\text { phone number }\end{array}$ \\
\hline $\begin{array}{l}\text { Dynamic Knowledge- } \\
\text { Based Identification }\end{array}$ & $\begin{array}{l}\text { Online services to confirm that } \\
\text { person attempting to log into } \\
\text { an account is the same as the } \\
\text { one who set up the account, } \\
\text { through a number of pre- } \\
\text { verified questions }\end{array}$ & $\begin{array}{l}\text { Pre-verified questions } \\
\text { asked to ascertain } \\
\text { individual's knowledge } \\
\text { of the answers (and } \\
\text { thus identity) }\end{array}$ \\
\hline
\end{tabular}

Source: Author's summary.

The first of these, often used by banks and similar, links your digital identity to documents that show your identity in the real world. In many countries, this means sending a scanned copy of a driver's license or identity card. In the Nordic countries, digital verification takes the form of a service in which one can use one's identity number and a pin code to identify oneself; in Sweden this is known as BankID. In this kind of identity verification system, what is important is not just that you have signing rights over a particular account, but also that you are a real person - for example, so that you can open a bank account. These verification services are often therefore used as a form of control to avoid fraud and money laundering.

In contrast, the second and third forms of identity verification verify not that you are a real person, but that you have the right to access the account in question. These services include both two-step verification procedures, for example, when you are sent a pin code every time you try to log in to a website, and dynamic knowledge-based identification, for instance, where you answer a predetermined question. These services verify that you have access to the right device and knowledge, respectively, to confirm that you have the right to access an account. Some examples from both the public and private sector are discussed in this section before the strengths and weaknesses of existing models are discussed.

\subsection{Examples from the Nordics}

Nordic countries are known for their high levels of digitalization; this digitalization extends beyond just the willingness to execute transactions online, to 


\section{Claire Ingram Bogusz}

provision of services to support safe transactions in various sectors. Among the most lauded of these are the e-Identity in Estonia and BankID in Sweden.

\subsubsection{Estonia}

Estonia offers three forms of digital identity - some only to physical residents, and others to so-called "e-residents." These include a digital ID card, a Mobile ID, and a Smart ID. The ID card operates not only as a form of legal identification when, for example, traveling elsewhere in Europe, but also allows holders to identify themselves online, for example at a bank, to submit tax returns, or to check medical records. This card carries embedded and encrypted files, and works together with a card reader and a PIN code that is unique to each care. It is the combination of the card, code, and reader that allows an individual to use a card that exists in the physical world for digital purposes.

The Mobile ID offers a similar system - through a dedicated sim card. Like the ID card, it can be used to access secure web and public services, as well as sign documents, but does not require a card or card reader. Instead, it only requires a pin code and a working smart phone. Mobile phone operators (e.g., Tele2, Telia, and Elisa) provide the sim card, and it costs an individual $€ 10$ to sign up, and a further $€ 1$ per month to maintain the service.

A Smart ID works in much the same way, through an app-based, rather than sim-based system. In other words, it relies on an application being run on a mobile phone, not a unique SIM card contained within the phone. Unlike the Mobile ID, however, the Smart ID is free. According to e-Identity service providers, as of November 2018 it has the same legal status as both the ID card and Mobile ID (SK ID Solutions, 2018). However, while the ID card can also be used as a form of physical identification, the latter two cannot.

\subsubsection{Sweden}

BankID in Sweden is said to boast eight million users, or close to 100 percent of the adult population (BankID, 2019; Statistics Sweden, 2019). This system was developed as a collaboration between the large banks in Sweden in the early 2000s and, as such, is not linked to a single actor or authority. Like Estonia's e-Identity, the Swedish system offers both mobile and online versions of their service. However, they do not offer a card version. Also like Estonia, the system relies on an individual first verifying their identity with reference to a state identity document like a passport or driving license before they can be issued a digital identity. The system is centrally controlled by a limited liability firm in the country, and provides services to banks, as well as to both other private companies and state agencies after a rigorous compliance process.

However, lack of understanding by individuals has led to weaknesses in this system through mistakes at the point of use: BankID is often exploited through scammers asking people to identify themselves over the phone, leading to losses through illicit transactions. This pattern of exploitation has been perpetuated 
because there is no transparent way for users to identify, track, or manage how their identity (and any associated data) have been verified and used.

Other examples include the use of Ethereum to build land registries and streamline new registrations, as the Swedish Land Survey has done. However, there seem to be few end-to-end digital identity management systems being developed by states; rather, these are being implemented by private actors.

\subsection{Examples from digital giants}

Over and above password methods, to which few of us need any introduction, private firms make use of a number of tools to enable us to identify ourselves. The overwhelming majority of these services, whether they offer simple passwords or more complex - and therefore secure - alternatives, are linked to a single service. That is, they are restricted to a certain service (e.g., a web platform) or service provider (e.g., Google's services). Many of them have developed application programming interfaces ${ }^{1}$ or a platform with a standardized code base and rules for ease of access. This means that you can use your credentials from one service to identify yourself in another (e.g., by using Facebook to log into a third-party application), making them less restricted. They are, nevertheless, still static.

Many Internet services (among them Google, Amazon Web Services) use what is called a "time-based one-time password algorithm" (TOTP) to support two-step authentication. This is a system whereby a single-use password is generated that can only be used for a certain amount of time, and where the times on the user's (receiving) device and the server from which the password is sent are roughly the same.

However, although all of these approaches have their merits and are well established in what has thus far been a digital economy in which users have little control over their data, they are largely inadequate on their own when it comes to a digital economy that includes elements of individual data management.

\subsection{Toward alternatives}

These services have three characteristics, summarized in Table 13.2. First, they are static; that is, they allow an individual to give consent through identity verification only at a single, fixed point in time. Although many keep records of when consent has been given, it cannot be revoked once given. ${ }^{2}$

Second, they are restricted; that is, they either support a single service (for example, Google), or are offered as a service only to prescreened parties. Last, they are binary; that is, they either allow for consent or nonconsent, not partial consent or other kinds of more nuanced interactions.

With the rise of smart phones, it is expected that digital data - and with it digital identity - are only likely to increase in volume and important. The World Bank, for instance, anticipates that 4.8 billion smartphone devices will come online by 2020 , many of these in developing countries where few digital services are provided by governments today (Bujoreanu, Mittal and Noor, 2018). 
Table 13.2 Characteristics of commonplace digital identity management services

\begin{tabular}{|c|c|c|}
\hline & Description & Problems \\
\hline Static & $\begin{array}{l}\text { Consent through identity } \\
\text { verification at a single, } \\
\text { fixed point in time }\end{array}$ & $\begin{array}{l}\text { Consent cannot be revoked } \\
\text { digitally, once given }\end{array}$ \\
\hline Restricted & $\begin{array}{l}\text { Either support a single service } \\
\text { (for example, Google), or } \\
\text { are offered as a service only } \\
\text { to prescreened parties }\end{array}$ & $\begin{array}{l}\text { Only certain verification services } \\
\text { work in certain contexts; there } \\
\text { are no universal services }\end{array}$ \\
\hline Binary & $\begin{array}{l}\text { Allow for either consent or } \\
\text { nonconsent }\end{array}$ & $\begin{array}{l}\text { Users cannot give partial or limited } \\
\text { consent, or agree to certain } \\
\text { contract terms but not others }\end{array}$ \\
\hline
\end{tabular}

Source: Author's analytical summary.

Having discussed what kinds of identity management systems have emerged, and how existing systems suffer from shortfalls that make new identity management desirable - and even likely - this chapter turns now to discussing data management, which relies upon a functioning digital identity service. Of note is that some identity management systems are implicit in data management systems, but may equally exist independently of them.

\section{Selective and decentralized data control}

Thus, three parallel shifts mean that digital identity verification services need to shift. The first of these is the rise of smartphone use, and with it the need for digital identity services that support digital identities that are not restricted to certain geographies or services. The second of these is a rise in data generation and data collection - and with it demand for data, with or without individuals' consent. The last of these is an existing pattern of behaviors among digital firms, wherein they collect data without thought for how they will be used, how they will be stored, or whether consumers might be concerned that their data are being collected.

In response to these developments, new forms of data controls have arisen. These have typically taken the form of products and services developed by private firms (e.g., Civic and Datacoup), although the Mydata model (2018) from Finland is unique in that it was developed in response to requests and support from the Finnish government.

Below, this chapter classifies these models into three nonexhaustive and nonexclusive categories, namely self-sovereign identities, data marketplaces, and new infrastructures. It then analyzes how they allow for more dynamism in how data are controlled than existing digital verification systems. These exist over and above the centralized, often state-managed, digital identity systems already described above. 


\subsection{Self-sovereign identities}

So-called "self-sovereign" identities are digital identity services individual users create and manage themselves, which do not rely on a central organization or authority, and which can, in principle, be used in either the digital or the physical world.

Many of the self-sovereign identities that exist today rely on public key cryptography; users have a private key that should be kept secret and is paired with a public key. Both are unique to each individual user. The public key is visible to others, like a finished signature or address, but can only be "signed" through using the secret, private key. In other words, a person can sign a document such that a public key is visible to others by using the private key. Indeed, the ability to generate the public key from the private key is the "proof of ownership" that makes this form of identity self-sovereign.

Public keys are then typically linked to other identifiers, for instance, one's bank or university. A registry of public keys and associated identifiers is then maintained, in most cased using blockchain technology. This decentralized maintenance not just of public-private key pairs, but also other associated identifiers, allows for a system wherein data about individuals cannot be altered without their consent (because there is no central authority), and where changes are verified at scale through blockchain verification mechanisms (Böhme et al., 2015). ${ }^{3}$ The work of both conducting maintenance of the database and verifying changes is typically rewarded within the system, making the whole thing self sustaining.

Thus, the overall picture is of a digital (and physical) identity that is 1) decentralized, and therefore not subject to control by either a single government or a single-point hacking attack; 2) permissionless - and therefore equally open to everyone with Internet access; and 3) self sustaining, and therefore not reliant on any single company, country, or individual for its survival. Instead, incentive systems mean that users of the system either directly pay maintainers (through payments for verification), or algorithms in the system generate tokens that have market value, with which maintainers are paid.

Of note is the fact that many of these otherwise decentralized systems allow a user to create a new public-private key pair should they, for example, lose their private key. Although this makes practical sense given how often individuals forget or misplace their passwords, it presents a weakness in the system in that it could allow for an individual's identity to be hijacked, depending on the methods involved to create this new pair and link them to a pre-existing digital identity or set of identifiers.

Examples of these kinds of identities include Civic and LifeID. Of note is the fact that the most simple self-sovereign identities are typically static and binary. However, they are typically not restricted at the point of delivery - but being able to use a self-sovereign identity at, for example, a public library, will require that that library accept the identity and have the digital infrastructure to process and verify it. 
However, many point to the fact that a self-sovereign identity, while internally coherent, does not necessarily link back to the physical world. That is, although the digital elements of the identity may point to an individual with a single set of permissions, this does not mean that the individual is who they say they are - or even that they are a real person; they could be a company, another person, or even a bot.

\subsection{Data marketplaces, cooperatives, and new infrastructures}

The twin problems of identity verification, on the one hand, and data control and monetization on the other, have been approached in three main ways: first, by the creation of marketplaces for data, second by the creation of data cooperatives, and last through whole new infrastructures that allow for both control over identity and data. These different approaches, and examples of each, are discussed below.

\subsubsection{From industry to personal data marketplaces}

Another way in which the details of our data are being managed differently include those conducted through data marketplaces. These marketplaces provide an interface through which data providers and data consumers can buy and sell data from one another. The use of business data marketplaces, wherein companies buy and sell industry data, is well established and relatively uncontroversial. Such marketplaces are common when it comes to, for example, recent investment activities, insurance claim statistics, or price data in different markets.

Among industry data marketplaces, data are typically taken from multiple different sources; sometimes the data are bought from the different sources, with the aim to combine the data and thus make them collectively more valuable, or preventing data from being lost or wasted. ${ }^{4}$ They further take unstructured data and, by structuring them, make it easier for other organizations to use - whether for comparisons, machine learning, or less complex analytics. In other words, they break down silos, standardize data flows, and facilitate price-setting for otherwise hard-to-price information. Some examples of these in the international context include Bloomberg, which sells company and financial data, and CKAN, which releases data from national and regional governments, for example, around the operation of public transport and other public utilities.

However, many of these marketplaces rely on repositories of data that, while not standardized, are nevertheless fairly structured from the outset. One of the main problems with data linked to individual identities is that they are so distributed: individual data are generated across multiple contexts (e.g., multiple social media sites), multiple devices (e.g., smartphones, computers and tablets), and for completely different purposes (e.g., cookie data on a news site, or search data through a search engine). The task of building a personal data marketplace with standardized flow of data that breaks down silos is therefore a more challenging one - but perhaps more valuable for it. 
There are many nascent examples of personal data marketplaces, and many of the marketplaces that offer portals to personal data also provide access to organizational data. Some examples include Openprise, which serves as an integration platform that structures data from other sources. While it offers organization integration, for instance by allowing users to integrate Salesforce data, it also links up to other repositories of individual-level data, like Kickfire and Zoominfo, which sell individuals' contact details. While Openprise does not standardize or set prices for data, it does integrate and make data comparable across multiple datasets. Crucially, it does not allow individuals to sell or control their own data, however.

In contrast, Datacoup is an example of a data marketplace that allows individuals to sell data generated from their different social media profiles through a single marketplace. This service matches firms looking for granular data - more granular than the contact details sold by many data resellers today - with individuals looking to sell their data. Individuals' personal data are collected from existing applications, like Facebook or LinkedIn, through APIs controlled by those firms. Multiple data sources are then integrated by the platform, subject to a price setting mechanism, and then sold on.

Analysts expect that "data as a service," or a subscription model for access to data, will be a USD10.4-billion market by 2021 (Tang et al., 2018). These services are just the tip of the iceberg when it comes to selling individuals' data. However, many services rely on existing APIs - or do not allow individual-level control of where, and to whom, data are sold. This is largely a consequence of the fragmented nature of data generation and data collection on the Internet today - a set of problems that new data infrastructures seek to overcome.

\subsubsection{Data cooperatives}

Still another model is that of the data cooperative. This model is often used in science and in niche industries, and is typically reciprocal and not-for-profit. Unlike data marketplaces, the focus of data interaction is on standardization and integration, allowing for the provision of aggregate-level data, with less emphasis on price setting and data sales. Often, but not always, cooperatives work with data collected by multiple organizations - but some niche platforms also work with individual data.

Take, for instance, the health data cooperative Midata (2019). This Swiss data cooperative not only allows individuals to gather all of their data securely in one place (standardization), but also allows individuals to work with different doctors and medical teams - and even share their individual-level data (in whole or in part) with, for example, medical researchers. Another cooperative is one for investment data, the European Data Cooperative, which not only collects and standardizes data about industry activities around investments, but also makes these data more broadly available - and even conducts analysis itself (Invest Europe, 2018). 


\subsubsection{New, decentralized infrastructures}

One way in which identity and data control have been tackled has been through the creation of typically blockchain-based systems that track the data that users generated, link that data to a self-sovereign identity, and then provide an access control system for the individual user to control (and potentially monetize) that data. Instead of being hosted by a single centralized server, this system relies on decentralized or distributed computational and storage "work" by users through the blockchain, in what has come to be known as the "decentralized Internet."

One example of this is Blockstack, which is a blockchain-based ecosystem that, once a user has created a Blockstack identity (ID), through the Blockstack browser, allows them to collect the data that are generated by their online activities - and store them on their own computer. This data could then be accessed, with permission, by Blockstack-based applications. These applications, called DApps, connect not to a centralized API to collect data, but rather to individual users' APIs - through which a user's identity can be accessed and authorized, and their data accessed. ${ }^{5}$

According to proponents of the decentralized Internet, the use of this kind of system solves resource problems for both users and developers. On the user side, not only do users regain control and ownership of their data (through the use of a self-sovereign identity), but web developers no longer have to worry about servers, hosting data, or protecting individuals' privacy. ${ }^{6}$ Instead, users maintain the decentralized equivalent of a server and release their data when and if they want to. Currently, it does not seem as though users can sell the data. Instead, one legacy of the existing Internet system remains: trading data for service/DApp access.

However, there is no shortage of other solutions that have built decentralized data marketplaces that build on the same tenets as above: identity creation, authorization, data collection and standardization, and individual data sale. Some of these include Ocean Protocol (2019), which additionally bundles data for training machine learning algorithms; Wibson (2018), which is aimed at individual monetization; and Enigma Data Marketplace (2018), which aims not only to provide a data marketplace, but monetize the computing power of individual users, beyond just their data.

A widely admired model for data control is the Finnish Mydata model. This model emphasizes standardization, control, and interoperability: individual users create an identity, and they use it to authorize the use of their data by third parties. According to their white paper, "The primary function of a MyData account is to enable consent management - the data itself is not necessarily streamed through the servers where the MyData account is hosted." This leaves a certain amount of flexibility around where the data are securely stored: users could store the data themselves or allow a trusted third party to do so. Either way, the intention of this model is to facilitate better user control over their data.

\subsection{From standardization and scaling to control}

Overall, the move toward both greater control over one's online interactions, and with it better control over the data generated, gathered, and ultimately used, has 


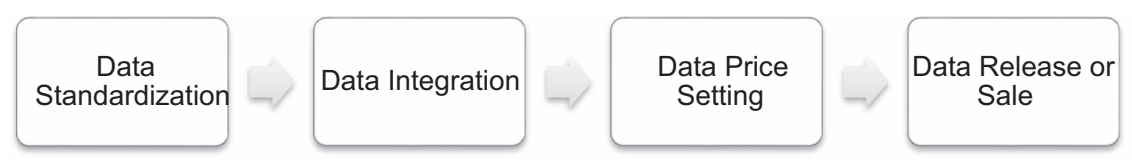

Figure 13.1 How data are collected, cleaned, and sold in 2019, typically through data marketplaces and cooperatives

Source: Author's summary.

moved apace. Although data marketplaces and data cooperatives are well established, new technologies and demands - notably enabled by the blockchain - have given rise to the creation of self-sovereign identities, and with them the creation of decentralized infrastructures.

Overall, the commodification of data has involved four main steps, namely the collection of data in a standardized format, the integration of data so that it can be aggregated or used at scale, the setting of data prices (per user or for aggregate databased), and a central platform for data release or resale. These steps are summarized in Figure 13.1.

While data marketplaces and cooperatives have made the collection of individual (and activity) data both commonplace and easily monetized, the need for standardization and scale has meant that these activities have required the presence of a central actor. These central actors have not only reaped rewards from their activities, their presence has also meant that those to whom the data pertain do not always have full control over them - which has legal, ethical, and security implications.

However, the advent of decentralized infrastructures, and with them better possibilities to create identities that are not centrally controlled - but which nevertheless are interoperable with the non-digital world - has given rise to new possibilities around data control and its subsequent release and sale (see Table 13.3).

Not only that, the digital nature of the chains of control means that we can move beyond static, restricted, and binary controls over data to allowing for changes to consent over time (non-static consent), interoperability (non-restricted consent), and partial consent or subset consent (non-binary consent). Having discussed both the background to the need for changes to how, and by whom, data are collected and sold, I now turn to discussing the hurdles and opportunities implicit in implementation of these new systems, before concluding and raising some policy concerns.

\section{The risks, opportunities, and policy concerns in implementation}

Both entrepreneurs and public actors have made inroads into the implementation of systems not only whereby data can be shared and sold, but where this sharing and sales can be done dynamically and with a clear trail of consent. Implementation, however, is still emerging: although state-controlled identity and consent systems, on the one hand, and data marketplaces and cooperatives, on the other 
Table 13.3 A comparison of the emerging models of data control, use, monetization, and interoperability

\begin{tabular}{|c|c|c|c|c|}
\hline & Data control & Data use & Monetization & Interoperability \\
\hline $\begin{array}{l}\text { Data } \\
\text { marketplaces }\end{array}$ & Centralized & $\begin{array}{l}\text { Works with } \\
\text { existing APIs }\end{array}$ & $\begin{array}{l}\text { Individual- } \\
\text { level, price } \\
\text { setting } \\
\text { through } \\
\text { market } \\
\text { mechanisms }\end{array}$ & $\begin{array}{l}\text { Compatible } \\
\text { with existing } \\
\text { infrastructures }\end{array}$ \\
\hline Data cooperatives & Shared & $\begin{array}{l}\text { Works with } \\
\text { existing APIs }\end{array}$ & $\begin{array}{l}\text { Aggregation, } \\
\text { often } \\
\text { reciprocal or } \\
\text { for science }\end{array}$ & $\begin{array}{l}\text { Compatible } \\
\text { with existing } \\
\text { infrastructures } \\
\text { and standards }\end{array}$ \\
\hline $\begin{array}{l}\text { Self-sovereign } \\
\text { identities }\end{array}$ & Decentralized & Agnostic & Varied & $\begin{array}{l}\text { Designed to } \\
\text { be interface/ } \\
\text { application } \\
\text { agnostic }\end{array}$ \\
\hline $\begin{array}{l}\text { Decentralized } \\
\text { infrastructures }\end{array}$ & Decentralized & $\begin{array}{l}\text { Need for new } \\
\text { APIs and } \\
\text { infrastructures }\end{array}$ & $\begin{array}{l}\text { Individual } \\
\text { level, } \\
\text { built-in } \\
\text { incentive } \\
\text { mechanisms, } \\
\text { market } \\
\text { price-setting }\end{array}$ & $\begin{array}{l}\text { Typically } \\
\text { require new } \\
\text { infrastructures, } \\
\text { but often built } \\
\text { using existing } \\
\text { standards }\end{array}$ \\
\hline
\end{tabular}

Source: Author's depiction.

hand, are commonplace, they typically have not been integrated. Moreover, the nascent attempts at integration, notably by combining self-sovereign identities with decentralized infrastructures, are still in the very early stages.

This section therefore delves into the possibilities associated with the idea of individuals' management of their data, and decentralized infrastructures in particular, and the obstacles that their implementations are likely to face. Of note is the fact that all of these areas are typically areas in which policy-makers operate, generally to mitigate negative externalities or support market conditions. These hurdles and opportunities fall into three broad categories, namely 1) networks effects, 2) externalities, and 3) interoperability and value. The section immediately after discusses the implications of this chapter, provides some concluding analysis, and discusses whether states or private actors are best placed to provide dynamic, end-to-end data management services.

\subsection{Network effects}

The single biggest hurdle that any new system, irrespective of its benefits, will have to cross is that there are already existing systems whereby data are shared, used, and harvested. Notably, these systems are of the data-for-a-service model; firms like Google and Facebook collect individuals' data through their web 
presence and standardize and use it. In exchange, users obtain access to services, for instance, social media and search engines, for free. For most people, this model works reasonably well. In fact, many of us barely think about the trade that we are making: data for services. Moreover, the reach of firms like Google and Facebook means that large numbers of individuals already use their services, the services are well developed and interdependent, and they have already collected significant volumes of data.

One often talks about the importance of network effects when it comes to platforms; in the case of existing data-for-service models, there are network effects on both sides. Take, for instance, Google. Google runs a number of interdependent services, from their Search tool to Gmail and word-processing tools. From the perspective of users, the fact that so many people use these tools means that 1) search results are already well tuned to their needs - they have already been trained on one's own, and others', data; 2) the fact that many people already use and are familiar with these tools makes them easy to use for collaboration; and 3) given that the tools work well and are well integrated with one another, there is little incentive to switch; that is, there are switching costs.

From the perspective of the platform, the reach of these tools means that: 1) they do not have to suffer the "cold start" of attracting new users; 2) they do not have to assess who provides useful data and who does not - they can offer the same services to all users, and aggregate the data for maximum value; and 3) access to volumes of data and existing models means that they can easily finetune services to suit users (and advertisers), giving them a competitive advantage.

\subsection{Externalities}

Moreover, the switch from existing exchanges of data (without control) for services to data (with control, and potentially even remuneration) for services introduces a host of possible externalities.

The first of these is that disruption of existing business models - wherein advertisers pay for user data/optimized advertising that cross-subsidizes services - will come under threat. This will likely mean that advertising on the Internet will decline, undermining sales for advertisers, and thus with knock-on effects for regional and global firms reliant on sales.

The second of these is, in response to the collapse of the advertising model, should we expect to pay for services? From the perspective of users today, data for services is a straight trade; if we switch over to a model wherein we can control and sell - our data, should we also expect access controls and costs to arise when it comes to the provision and use of online services like those already provided by the likes of Facebook and Google?

Third, there is nothing to guarantee the veracity of the data for sale. With increased control and awareness, and with them the possibility of getting paid, the rewards for data create incentives to "game" the system, at one extreme, or just to tweak one's data to make them more desirable. When it comes to manipulating the system, it is likely the data "bots" that create data and sell them are likely 
to become commonplace - undermining the veracity of the system as a whole. Moreover, when individuals are more aware that they are being watched, they are more likely to change their behavior, in what is known as the "Hawthorne Effect" (Adair, 1984).

Last, what is there to prevent a so-called "Tragedy of the Commons" (Hardin, 1968)? While many self-sovereign identity services and data markets generate income from their services, most of those providing whole new decentralized infrastructures do so for ideological - not financial - reasons. Without clear financial models to support the development, scaling, and security needs of these services, the risk is that they are used without being maintained, threatening their long-term viability.

\subsection{Interoperability and value}

One of the benefits of data collection and use being better controlled - and better tracked - is that it is likely to generate new signals of value, for better or for worse. For instance, where there are standardized forms of data, standardized APIs, and better connections between different data repositories and services, this would not only undermine the stranglehold that existing digital giants have on Internet services, but allow for the creation of new services.

Among these new signals of value are records of individuals' social and data networks, the volume of data that they generate, and the veracity of the data generated. Take, for instance, an individual who regularly generates large volumes of data that are largely internally consistent - pointing to repeated patterns of interest and behavior about that person. Not only do they become a "valuable" source of data, but their interactions with other users ("data sources") might become important points of reference in relation to those users, too.

This could be both positive and negative. On the one hand, the risk is that this creates a tiered system of data users: those who create lots of consistent data are valuable, while those who do not (or who opt out) are seen as less valuable.

Moreover, increased interoperability also brings with it the risk of increased oversight: not only can private firms get better views of (consenting) datagenerating users, but so too can governments. One of the benefits of decentralized infrastructures is that they limit the ability of governments to influence data collection systems or force reporting. However, as with the signals of private value discussed above, should interoperable data systems become a reality, failure to opt in could also raise concern from government officials.

\section{Conclusion}

Overall, the case for a move from users "paying" for services with their data on a case-by-case basis to the creation of infrastructures for better individual control of their data is a complex one. On the one hand, there is no question that the existing ways of exchanging data for services work: they have led to the creation of valuable firms, free services that are nearly universally accessible, and personalized 
communications services through, for example, social media. However, there remain problems with this system: the first of these is that there is no way for individual users to limit what data are collected, and there is little transparency to where the data go once they have been collected. Although laws and ethics across the globe increasingly mean that users have to give informed consent to the collection and use of their data, this consent is given at a single point, is all or nothing, and cannot easily be amended or revoked after the fact. Moreover, under the existing ways of doing things, data are often siloed and cannot be transferred from one service to another. Further, individuals increasingly feel - rightly or wrongly - that if their personal data are so valuable, they should be financially remunerated for their collection and use, especially when digital giants are making profits off the back of these data.

In contrast, a model of data control that allows for better control over when, by whom and to what extent users' data are collected and used offers a number of benefits. These include improved interoperability across services, the potential for the creation of new signals of value, incentives for the creation of more data, and - crucially - a more nuanced approach to data management, including more transparency. A comparison of the existing data-for-services model and the emerging controlled model is summarized in Table 13.4.

However, much depends on the form that the controlled model takes, and whether it relies on a self-sovereign or public identity service. In parts of northern Europe, like Sweden and Estonia discussed above, it has become the norm for

Table 13.4 The characteristics of the existing "data-for-services" model, against the emerging "controlled model" of data use and control

\begin{tabular}{|c|c|c|}
\hline & Data-for-services model & Controlled model \\
\hline Access to services & $\begin{array}{l}\text { Free services are nearly } \\
\text { universally accessible }\end{array}$ & $\begin{array}{l}\text { Access to services may become } \\
\text { more limited - and possibly } \\
\text { even pay-to-use }\end{array}$ \\
\hline Consent & $\begin{array}{l}\text { Given at a single point } \\
\text { All or nothing } \\
\text { Cannot easily be amended } \\
\text { or revoked after the fact }\end{array}$ & $\begin{array}{l}\text { Nuanced consent models likely, } \\
\text { depending on the controlled } \\
\text { model that comes to dominate }\end{array}$ \\
\hline Transparency & Little to no transparency & $\begin{array}{l}\text { Likely to be more transparent, } \\
\text { depending on dominant model }\end{array}$ \\
\hline Interoperability & $\begin{array}{l}\text { Limited interoperability } \\
\text { Interoperability determined } \\
\text { by data collector }\end{array}$ & $\begin{array}{l}\text { Likely to be interoperable by } \\
\text { design }\end{array}$ \\
\hline Identity & $\begin{array}{l}\text { Does not rely on any } \\
\text { identity system }\end{array}$ & $\begin{array}{l}\text { Could rely on either a state or } \\
\text { self-sovereign identity system }\end{array}$ \\
\hline Risks & $\begin{array}{l}\text { Model has become standard } \\
\text { and is well-understood, } \\
\text { continues to dominate } \\
\text { due to network effects }\end{array}$ & $\begin{array}{l}\text { Risks of: } \\
\text { - Data becoming unreliable } \\
\text { - Undue pressure and oversight } \\
\text { - Two-tier access to services }\end{array}$ \\
\hline
\end{tabular}

Source: Author's depiction. 
identity control and verification to become a public service. However, people in countries with governments that either are known for less professionalism in their public service delivery, or for using civil services for political ends, might prefer for centralized versions of these services to be privately controlled and therefore subject both to better oversight by courts and to market forces.

Culture and history aside, there are a number of areas for consideration when it comes to assessing whether a digital identity management system should be state or self-sovereign. One of the main benefits of a self-sovereign system is that it offers a system that prioritizes interoperability over all else. As a result, data control (and identity as a service) can be scaled across multiple industries, and even multiple countries. This is important when one considers how important digital identity is likely to become beyond the scope of data management: a 2015 Swedish survey suggested that 91 percent of businesses believed that digital identity services facilitated business transactions and relationships (Hyborn, 2015).

Further considerations include questions around how to pay for maintenance and development of the identity service, and with it any data management services. Swedish and Estonian service providers, by making digital identity services public, have dealt with this problem by paying for them from state coffers - meaning that these services are free at the point of use and thus available to all. Selfsovereign identities, depending on their business models, may not be free at the point of use - or may come with other strings attached. Unfortunately, because of the risk of the "Tragedy of the Commons," discussed above, free digital identity services seem not unlikely to emerge, but undesirable.

Overall, the benefits and risks associated with if, and how, identity verification services and data management services converge on a new model for dynamic data control will depend on implementation. Indeed, while there are clear calls for better data management in places like the European Union, it is not clear that the hurdles described above can be overcome at all. Should users prioritize control and transparency over convenience, then the possibility exists that data management systems that are more interoperable and nuanced than what we have today are likely to emerge. However, much depends on what kinds of business models prevail: which kinds of data management systems, and how data are controlled and potentially monetized. Moreover, given that there are already so many established players in the market, the space for new entrants is small. In particular, the costs of bringing a broad product that competes with the likes of Facebook and Google to the market are prohibitive: as outlined above, network effects mean that these services tough to compete with.

However, should these kinds of management systems come to exist, it seems likely that it will be possible to overcome the tension between commerce and control described earlier in this chapter: not only will it be possible for firms to make use of individuals' data to, for example, train algorithms, but users will have better oversight over how, and by whom, their data are being used. And maybe even get paid in the process.

For public actors and policy-makers, there is considerable food for thought: the path forward when it comes to identity management is full of opportunities for 
individuals, but also numerous areas in which effective policy - and even state service provision - could affect the future of identity management solutions. In particular, many states have a long history of correcting for externalities and supporting markets for services deemed to be in the public interest; identity management services are among these services.

\section{Notes}

1 An API defines a standardized way, including coding languages and access points, for a developer to write a program that requests services from an operating system (OS) and/ or other application.

2 That is, once data have been obtained through an identity, it cannot easily be reclaimed or permission revoked retrospectively. Future use of the person's data, or prospective revocation, is, however, often possible.

3 For a detailed discussion of how blockchain-distributed database maintenance and verification occur, please see Nakamoto (2008).

4 Over 99 percent of all generated data are thought to be either lost or unused (White et al., 2019).

5 See Blockstack (2019).

6 All increasingly important considerations in light of regulations like GDPR in the European Union.

\section{References}

Adair, J.G., 1984. The Hawthorne effect: a reconsideration of the methodological artifact. Journal of Applied Psychology, 69(2), pp. 334-45.

BankID, 2019. BankID. [online] Available at: <www.bankid.com/en> [Accessed 5 Sep. 2019].

Blockstack, 2019. Frequently asked questions. [online] Available at: $<$ https://blockstack. org/faq $>$ [Accessed 5 Sep. 2019].

Böhme, R., Christin, N., Edelman, B. and Moore, T., 2015. Bitcoin: economics, technology, and governance. Journal of Economic Perspectives, 29(2), pp. 213-38.

Bujoreanu, L., Mittal, A. and Noor, W., 2018. Demystifying technologies for digital identification. [online] The World Bank. Available at: <https://blogs.worldbank.org/voices/ demystifying-technologies-digital-identification> [Accessed 5 Sep. 2019].

The Economist, 2017. The world's most valuable resource is no longer oil, but data. [online] The Economist. Available at: <www.economist.com/leaders/2017/05/06/theworlds-most-valuable-resource-is-no-longer-oil-but-data $>$ [Accessed 5 Sep. 2019].

The Economist Intelligence Unit, 2017. Plugging in: mobile payments in China. [online] The Economist Intelligence Unit. [online] Available at: <http://web.archive.org/ web/20180628064512/www.eiu.com/industry/article/915926475/plugging-in-mobilepayments-in-china/2017-11-13> [Accessed 9 Aug. 2019].

Enigma Data Marketplace, 2018. Enigma data marketplace homepage. [online] Available at: $<$ https://enigma.co/marketplace $>$ [Accessed 5 Sep. 2019].

Financial Times, 2018. China and US compete to dominate big data. Financial Times. [online] Available at: <www.ft.com/content/e33a6994-447e-11e8-93cf-67ac3a6482fd> [Accessed 5 Sep. 2019].

Hardin, G., 1968. The Tragedy of the Commons. Science, 162(3859), pp. 1243-8. 


\section{Claire Ingram Bogusz}

Hyborn, D., 2015. Okta: identity for the connected economy. [online] Computer Sweden. Available at: <https://computersweden.event.idg.se/wp-content/uploads/sites/11/2015/ 10/cloud-confessions-okta.pdf $>$ [Accessed 5 Sep. 2019].

Ingram Bogusz, C., 2018a. Digital trace data: which data should we collect, and what should we do once we have it? In: P. Andersson, S. Movin, M. Mähring, R. Teigland and K. Wennberg, eds. Managing digital transformation. Stockholm, Sweden: Stockholm School of Economics Institute for Research, pp. 115-31.

Ingram Bogusz, C., 2018b. Digital traces, ethics and insight: data-driven services in fintech. In: R. Teigland, S. Siri, A. Larsson, A. Moreno Puertas and C. Ingram Bogusz, eds. The rise and development of fintech: accounts of disruption from Sweden and beyond. London, UK: Routledge, pp. 207-22.

Invest Europe, 2018. European data cooperative (EDC). [online] Available at: $<$ www. investeurope.eu/research/about-research/european-data-cooperative $>$ [Accessed 5 Sep. 2019].

Midata, 2019. My data - our health. [online] Available at: $<$ www.midata.coop $>$ [Accessed 5 Sep. 2019].

MyData, 2018. Mydata homepage. [online] Available at: $<$ https://mydata.org $>$ [Accessed 5 Sep. 2019].

Nakamoto, S., 2008. Bitcoin: a peer-to-peer electronic cash system. [online] www.bitcoin. org. Available at: <https://bitcoin.org/bitcoin.pdf $>$ [Accessed 5 Sep. 2019].

Ocean Protocol, 2019. A decentralized data exchange protocol to unlock data for AI. [online] Available at: $<$ https://oceanprotocol.com $>$ [Accessed 5 Sep. 2019].

Regulation (EU) 2016/679 of the European Parliament and of the Council 27 April 2016 on the protection of natural persons with regard to the processing of personal data and on the free movement of such data, and repealing Directive 95/46/EC (General Data Protection Regulation). Available at: <https://eur-lex.europa.eu/eli/reg/2016/679/oj> [Accessed 5 Sep. 2019].

SK ID Solutions, 2018. Smart-ID's security was recognized on the highest possible level. [online] Available at: $<$ https://sk.ee/en/News/smart-ids-security-was-recognized-on-thehighest-possible-level $>$ [Accessed 5 Sep. 2019].

Statistics Sweden, 2019. Summary of population statistics 1960-2018. [online] Available at: <https://www.scb.se/en/finding-statistics/statistics-by-subject-area/population/pop ulation-composition/population-statistics/pong/tables-and-graphs/yearly-statistics--thewhole-country/summary-of-population-statistics> [Accessed 5 Sep. 2019].

Tang, D., Fujii-Hwang, J., Colwill, E., Arora, S., Shah, A., Mendizabal, A. and Callejas, R., 2018. Value of data: the dawn of the data marketplace. [online] Accenture. Available at: $<$ www.accenture.com/us-en/insights/high-tech/dawn-of-data-marketplace $>$ [Accessed 5 Sep. 2019].

White, O., Madgavkar, A., Manyika, J., Mahajan, D., Bughin, J., McCarthy, M. and Sperling, O., 2019. Digital identification: a key to inclusive growth. [online] McKinsey Global Institute. Available at: <https://www.mckinsey.com/ /media/mckinsey/featured insights/innovation/the value of digital id for the global economy and society/mgidigital-identification-a-key-to-inclusive-growth.ashx $>$ [Accessed 5 Sep. 2019].

Wibson, 2018. Wibson homepage. [online] Available at: <https://wibson.org $>$ [Accessed 5 Sep. 2019]. 


\section{Part IV}

\section{Future of the welfare state}





\title{
14 Cashless
}

\section{A dead end for Sweden?}

\author{
Björn Eriksson and Ulrika Sandhill
}

\section{Introduction}

The payment market is undergoing a digital revolution. Sweden is a country that has always been eager to build an image of being a trailblazer of digitalization at large, and has therefore also endeavored to take on a pole position in this particular digital race. With a widespread shift to digital payments and rapidly diminishing cash services in banks across the country, the existence of cash is quickly dwindling from Swedish society (Rogoff, 2016). Some predict a totally cashless society in less than a decade (Arvidsson, 2018; Alderman, 2015). The idea that Sweden will eventually become cashless has taken root on many fronts, including private individuals, businesses, and public organizations. Sweden is often held up as a model for the move toward a cash-free society as a success story in cutting costs and reducing crime (Olsen, 2018; Rogoff, 2016). In reality, however, the development has been far less utopian. Many are now asking whether the transformation has benefited society at large or just the bottom line of the large banks. For instance, in February 2018, the Swedish National Bank's (Swe: Riksbanken) governor, Stefan Ingves, called for new legislation in order to secure public control over the payment system, contending that the ability to make and receive payments is a "collective good" (Crouch, 2018).

We, the authors, Björn Eriksson and Ulrika Sandhill, have long been following the development of the cash issue in Sweden. The aim of this investigative commentary is to look at the development of the cashless society in Sweden, the driving forces behind it, the actual outcome, and its ramifications on the overall welfare, thus providing some "best-practice" insights using Sweden as a case in light of similar nascent developments across the digitalized nations.

\section{The concept of money then and now}

Cash is probably one of the world's most sophisticated inventions. We have made a collective agreement that paper notes and metal pieces hold a special value, which we can exchange between us for goods and services. For more than 2000 years, cash has been a legal means of payment, but is now increasingly substituted for digital ones (Weatherford, 1997; Koblitz and Menezes, 2016). Until just a few 
decades ago, the value of the money supply in Sweden and in other developed countries was backed by the equivalent value of some sort of asset. For instance, up to 1931, the Swedish National Bank employed a system of "gold standard," that is, owning gold equivalent to its money supply, but had to abandon the system in the aftermath of World War I (Haavisto and Jonung, 1999). After that, Sweden attempted to tie the Swedish krona to other types of values, such as the US dollar or other currencies of EEC countries, until ultimately surrendering the idea of a fixed exchange rate in 1992. This was following a desperate attempt to defend the krona against currency speculation. Today, the Swedish krona is a floating currency, meaning that it is not backed by gold or assets, and its value fluctuates due to supply and market expectations (Jonung, 2000).

To control the money supply, the Swedish National Bank is exclusively entitled by law to issue and cancel banknotes and coins. However, this law has never been updated to consider digital money, and the amount of hard cash today is exceedingly small compared to digital cash. In fact, estimates show that only roughly 8 percent of the entire money supply exists in physical form, whereas the rest is electronic (Buntinx, 2017; Price, 2016). Commercial banks actually create large amounts of money by issuing digital credits when approving loans to their customers (Focardi, 2018). The Swedish National Bank therefore no longer controls the money supply. When commercial banks lend money, they only need to cover a small fraction thereof with equity. Even if the capital adequacy requirement has become higher after the recent financial crisis, banks lend significantly more than they have - a risk that the global central banks, including Swedish National Bank, and societies globally obviously accept (Cervenka, 2017).

In recent decades, indebtedness has increased exponentially, both at an individual and at a country level. At the same time, there has been a shift in how we perceive money; it is no longer obvious, for example, that a debt must be repaid. Some speculate that we are living in an economic bubble. Nobody truly knows, and so far, money and debt keep growing. Still, the fact remains that the banking system would go immediately bankrupt if, for some reason, trust were to be disturbed and droves of people were to rush to the ATM network with withdrawal requests. In this light, cash represents a threat to the banking system as we know it.

\section{Forgotten public service ambitions in the deregulation era}

In Sweden, the disassembly of the payment system started in 2005. That year, the Swedish National Bank - which had previously been responsible for cash management through its depots throughout the country - decided to outsource the cash management process to the four major commercial banks present at the time (Forskning.se, 2013). It was the golden age of liberalization, and trust in market forces soared. If the market could handle it all unaided, why should the State bear the cost and responsibility for cash management?

In hindsight, it is obvious that handing over the responsibility of cash management from the public to the private sector in reality meant entrusting the fox to 
guard the henhouse. Since cash carries significant handling and storage costs, the commercial banks almost immediately developed a strategy aimed at ridding them of these costs. A common deposit system and ATM system were established. In reality, a monopoly situation was created, which has allowed the banks to use their pricing power to shift payment flows from cash to digital payments. At present, the banks are shutting down ATMs, closing down branches, and raising the price of cash deposits and withdrawals. The ultimate goal is to have customers carry out banking services by themselves from their homes. For the banks, this is a win-win situation: They can cut back on staff and office space, while gaining control of all transactions, which opens up a plethora of opportunities, such as introducing new fees and enabling surveys of various kinds. They also conjure away the risk of bank runs, given that customers no longer - at least in theory can withdraw their money from the bank.

Having said that, the actions of the banks are in no way surprising or unexpected. As private companies, they are expected to put the shareholders' interests before that of the well-being of society. If delivering cash or financial services to disadvantaged groups in rural areas are not profitable, for example, they will simply "drop the ball." In retrospect, it appears surprising that no one had seriously contemplated the consequences of placing an infrastructure that is essential to the country in the hands of private actors. On the other hand, at the early stages of the Internet era, no one could have predicted that the liberalization reform would have meant that our citizens would be left without cash.

\section{Cashlessness affects the civil society and the countryside}

In our work, we are often contacted by people who feel abandoned by the banks. Retirees, people living in parts of the country with poor or no mobile phone coverage, immigrants, disabled people with difficulties in using digital tools, tourists, market traders, small businesses - many are those who are disappointed and upset about the situation. It is becomes evident that the glue holding the civil society together evaporates when people can no longer pay for a waffle at the market, deposit the earnings from a lottery ticket, or hand out a few bucks to the guy who mows their lawn. For some, the situation creates no more than a minor annoyance and inconvenience in their everyday life, while for others it threatens the survival of their entire communities.

Researchers and experts engaged in heated debates claim that these issues are temporary, because the elderly will eventually die off and there will soon be broadband coverage across the whole of Sweden (Eriksson and Olofsson, 2016; Swedish Government Official Reports, 2016). In our view, the argument is not just cynical, but it is also not true. The elderly do not just "pass away." The population ages continuously and new individuals will lose their cognitive abilities. If one adds rapid technology development on top of that, the picture becomes even clearer. The problems will persist, albeit in different forms and with new people. Also, relying solely on digital solutions without a functioning backup plan 
is naïve. To this end, cyber-experts have attested that if someone really wants to hack into a system, they will sooner or later be successful (Skarec, 2017; Waldrop, 2016; Snyder, 2018).

\section{Digitalization creates vulnerabilities}

There is some contention that Swedes appear to be somewhat "peace-damaged" (New Eastern Europe, 2015). As a people, we Swedes may have forgotten that we are vulnerable because we have been consistently spared from crises and wars. When the Berlin Wall fell, we thought that was the last threat standing. Eternal peace was bound to reign supreme, making armies and civil defense a nuisance to do away with - as we did (Wieslander, 2017; Platen, 2015).

History, however, keep unfolding. Today, serious global concerns persist, and Russia, our eastern neighbor, has made its ambition felt. At the same time, globalization and digitalization interweave our societies. An increasing number of organizations have emerged with branches in numerous countries and integrated IT systems, endless chains of subcontractors, and information stored in different cloud services. While this arrangement proves effective when it works, it also makes our society exceptionally vulnerable.

Major parts of our critical infrastructure, that is, energy, transport, drinking water supply, payment systems, health care - stand firmly in cyberspace. This makes it harder to draw boundaries between internal and external security, to understand what threats look like and from where they come. Future attacks will be carried out by keystrokes on computers. In Sweden there have already been several occurrences involving extensive hacking, an example of which was the disastrous attacks on the Transport Agency's IT-system in 2017 (Government Offices of Sweden, 2018a). In that case, the procurement favored a low-cost approach to secure data management under the self-deceiving mantra: "What could possibly go wrong?", in spite of various Swedish authorities having been subjected to repeated similar hacker attacks since 2012, that is, following the outsourcing of data to private companies (Crona, 2017).

The fact that all digital transactions are visible and traceable also makes us vulnerable at an individual level. While some fail to see that as a problem, others regard privacy as a human right. In any event, we should be aware of the risks attached. Prescription of medicine, hotel bills, liquor purchases, and contributions to communities and political organizations are examples of information that can be assembled into detailed patterns of data about specific individuals. As such, consequences may be indeed dire should it fall into the wrong hands, as this could entail anything from extortion to bringing about new political scenarios.

\section{On the frontier of technical development or simply naïve?}

In other countries, cash is perceived as self evident and necessary (Anderson, 2017; Cerulus and Contiguglia, 2018). Therefore, many people from abroad look 
to Sweden in awe. What's going on up there, in the small country in the north? Up to this point, we have met with many enquiring journalists. ${ }^{1}$ Their opinions are nearly unanimous: Swedes seemingly have an unprecedented confidence in the state in addition to their perception of "benevolent authorities." Many journalists have living historical references to oppressive regimes and have been sincerely wondering about the seemingly naïve Swedish approach to the matter. "The Stupid Swedes" was heard a few times during our meetings with these journalists. In their view, Swedes are unwittingly rushing head-first into a cashless transformation experiment, without stopping to question the potential consequences of abolishing the only safe and privacy-friendly means of payment available to the population.

Perhaps the cash issue will divide the population into two camps (a development we are already witnessing). That is, global digital "natives" on the one side, and those who experience the emerging society as exclusionary on the other side. The latter group will ultimately end up in a dependency position of the former group, as their freedom and independence erode. Brexit, the 2016 United States presidential election, and new populist winds in European politics can be part of the same phenomenon, expressing resentment against the "establishment," against the politicians and decision-makers who are seemingly snubbing their citizens. Perhaps the wrath in people's minds has actually forced the hand of those purporting that cash is an analog contingency to safeguard the people?

\section{Conclusions - the tide is turning?}

Now, there are some signs that the tide is turning. Issues about security and cybercrime are now being highlighted by researchers and experts in Sweden. More and more people seem to realize that security is of strategic value, and thus the operation of essential IT systems should not be jeopardized for short-sighted cost reasons. Following this logic, we also must have a secure payment system in the event of a crisis or war.

The Swedish Civil Contingencies Agency's (MSB) 2018 publication "If Crisis or War Comes" suggests that Sweden's inhabitants must stock up on cash in crisis situations (Swedish Civil Contingencies Agency, 2018). In its publication, the MSB states that analog technology that is not interconnected is the most robust technology available. While digital payments rely on electricity, telecommunications, and IT systems to work, cash works regardless of the existence of electricity or who wields political power. The ability to pay with cash offers a permanent, physical security no matter the crisis or emergency situation. The laissez-faire attitude toward the development is clearly being substituted for a greater awareness of the consequences of going cashless. It is becoming more obvious that the digitalization of the payment system creates an unwanted and unexpected shift of power, both from individuals and from the state, to global, private banks and financial institutions.

A clear sign of this awareness is the parliamentary investigation that has been proposed at the time of writing, which suggests that banks above a certain turnover 
should be mandated to handle cash (Government Offices of Sweden, 2018b). Another sign is that the Swedish National Bank, as the first national bank in the world, is now is looking into creating its own e-currency as a means of defending itself from the threat of having a system of payment solutions that is solely owned and managed by private big banks without government influence. As such, the use of an e-currency is a means of reclaiming the power over the money production and supply from the private banks back to the Swedish National Bank (2018).

Thus, if private companies are able to consolidate power over the state by means of digitalization, the government and the Swedish National Bank own the political arsenal to steer the markets adequately. Time will tell whether the government and the Swedish National Bank are swift and cunning enough to stop the scramble for a cashless society before it is too late.

\section{Note}

1 The corresponding author of this chapter, Björn Eriksson, has conducted over 50 interviews on the subject with reporters from all over the world.

\section{References}

Alderman, L., 2015. In Sweden, a cash-free future nears. The New York Times. [online] Available at: <www.nytimes.com/2015/12/27/business/international/in-sweden-a-cashfree-future-nears.html $>$ [Accessed 4 Sep. 2019].

Anderson, E., 2017. Vast majority of Germans never want to give up cash, poll shows. [online] The Local.de. Available at: <www.thelocal.de/20170518/vast-majority-of-ger mans-never-want-to-give-up-cash-poll-shows $>$ [Accessed 4 Sep. 2019].

Arvidsson, N., 2018. The future of cash. In: R. Teigland, S. Siri, A. Larsson, A. Moreno Puertas and C. Ingram Bogusz, eds., The rise and development of fintech: accounts of disruption from Sweden and beyond. London, UK: Routledge, pp. 85-98.

Buntinx, J.P., 2017. Around 8\% of the money supply exists in cash, the rest is just faithbased currency. [online] News BTC. Available at: <www.newsbtc.com/2017/04/17/ around-8-money-supply-exists-cash-rest-just-faith-based-currency> [Accessed 4 Sep. 2019].

Cerulus, L. and Contiguglia, C., 2018. Central bankers warn of chaos in a cashless society. [online] Politico. Available at: <www.politico.eu/article/central-bankers-fear-cybersecu rity-chaos-in-a-cashless-society> [Accessed 4 Sep. 2019].

Cervenka, A., 2017. Vad gör en bank [What does a bank do]. Stockholm, Sweden: Natur \& Kultur.

Crona, M., 2017. Personuppgifter läckte från outsourcad myndighetsdata redan 2012 [Personal data leaked from outsourced authority data already in 2012]. [online] SVT Nyheter. Available at: <www.svt.se/nyheter/inrikes/inte-helt-olikt-den-stora-lackan-2012> [Accessed 4 Sep. 2019].

Crouch, D., 2018. 'Being cash-free puts us at risk of attack': Swedes turn against cashlessness. The Guardian. [online] Available at: <www.theguardian.com/world/2018/apr/03/ being-cash-free-puts-us-at-risk-of-attack-swedes-turn-against-cashlessness $>$ [Accessed 4 Sep. 2019].

Eriksson, B. and Olofsson, K., 2016. Kör inte över folket - säkra kontanterna [Do not steamroller the people - secure the cash]. [online] Aftonbladet. Available at: 
<www.aftonbladet.se/debatt/a/e1e40R/kor-inte-over-folket-sakra-kontanterna> [Accessed 4 Sep. 2019].

Focardi, S., 2018. Central-bank digital currencies: toward a cashless society? [online] The Conversation. Available at: <https://theconversation.com/central-bank-digital-cur rencies-toward-a-cashless-society-93903> [Accessed 4 Sep. 2019].

Forskning.se, 2013. Avregleringar ledde till finanskrisen 1990 [Deregulations led to the financial crisis of 1990]. [online] Available at: <www.forskning.se/2013/04/25/avregler ingar-ledde-till-finanskrisen-1990> [Accessed 4 Sep. 2019].

Government Offices of Sweden, 2018a. Brister i Transportstyrelsens hantering av ITupphandling [Deficiencies in the transport agency's IT procurement]. [online] Press Statement. Available at: <www.regeringen.se/pressmeddelanden/2018/02/brister-itransportstyrelsens-hantering-av-it-upphandling > [Accessed 4 Sep. 2019].

Government Offices of Sweden, 2018b. Tryggad tillgång till kontanter [Secured access to cash]. [online] SOU 2018:42. Available at: <www.regeringen.se/rattsliga-dokument/ statens-offentliga-utredningar/2018/06/sou-201842> [Accessed 4 Sep. 2019].

Haavisto, T. and Jonung, L., 1999. Central banking in Sweden and Finland in the twentieth century. In: C-L. Holtfrerich, J. Reis and G. Toniolo, eds. The emergence of modern central banking from 1918 to the present. Aldershot, UK: Ashgate Publishing Limited, pp. 111-43.

Jonung, L., 2000. Från guldmyntfot till inflationsmål - svensk stabiliseringspolitik under det 20:e seklet [From gold standard to inflation target - Swedish stabilization politics under the 20th century]. Ekonomisk Debatt, 28(1), pp. 17-32.

Koblitz, N. and Menezes, A.J., 2016. Cryptocash, cryptocurrencies, and cryptocontracts. Designs, Codes and Cryptography, 78(1), pp. 87-102.

Kontantupproret, 2018. Välommen till kontantupproret [Welcome to the cash rebellion]. [online] Available at: <www.kontantupproret.se> [Accessed 4 Sep. 2019].

New Eastern Europe, 2015. A peace-damaged country. [online] Available at: $<$ http://new easterneurope.eu/old_site/interviews/1725-a-peace-damaged-country $>$ [Accessed 4 Sep. 2019].

Olsen, K.A., 2018. A cash-free society: whether we like it or not. Lanham, MD: Rowman \& Littlefield.

Platen, M. von, 2015. Bedräglig känsla av evig fred [Deceptive feeling of enternal peace]. [online] Realtid.se. Available at: <www.realtid.se/bedraglig-kansla-av-evig-fred $>$ [Accessed 4 Sep. 2019].

Price, T., 2016. Investing through the looking glass: a rational guide to irrational financial markets. Hampshire, UK: Harriman House.

Rogoff, K.S., 2016. The curse of cash: how large-denomination bills aid crime and tax evasion and constrain monetary policy. Princeton, NJ: Princeton University Press.

Skarec, M., 2017. Vi är inte redo för det kontantlösa samhället [We are not ready for the cashless society]. [online] Aftonbladet. Available at: <www.aftonbladet.se/debatt/a/ ORLkE/vi-ar-inte-redo-for-det-kontantlosa-samhallet> [Accessed 4 Sep. 2019].

Snyder, C., 2018. A cybersecurity expert showed us how hackers can tap into an office phone and listen to everything you're saying. Business Insider. [online]. Available at: <www. businessinsider.com/hackers-can-turn-office-phone-into-remote-listening-devicecybersecurity-hack-cisco-spying-tap-2017-11> [Accessed 4 Sep. 2019].

Swedish Civil Contingencies Agency, 2018. If crisis or war comes. [online] Available at: $<$ https://www.msb.se/sv/publikationer/om-krisen-eller-kriget-kommer--engelsk-ver sion> [Accessed 4 Sep. 2019].

Swedish Government Official Reports, 2016. Tillgång till betalkonto med grundläggande funktioner [Access to payment account with basic functions]. [online] Delrapport 2 


\section{Björn Eriksson and Ulrika Sandhill}

från 2015 års betaltjänstutredning (Fi 2015:02) [Interim Report 2 from the 2015 Payment Service Investigation (Fi 2015:02)]. Available at: <www.sou.gov.se/wp-content/ uploads/2015/04/Delrapport-2.pdf $>$ [Accessed 4 Sep. 2019].

Swedish National Bank, 2018. Ingves: E-kronan och framtidens betalningar [Ingves: e-currency and future payments]. [online] Available at: $<$ www.riksbank.se/sv/press-ochpublicerat/tal-och-presentationer/2018/ingves-e-kronan-och-framtidens-betalningar> [Accessed 4 Sep. 2019].

Waldrop, M.M., 2016. How to hack the hackers: the human side of cybercrime. Nature, 533(7602), pp. 164-7.

Weatherford, J., 1997. The history of money: from sandstone to cyberspace. New York, NY: Three Rivers Press.

Wieslander, A., 2017. Världen vid en brytpunkt - vår framtida säkerhet [The world at an inflection point - our future security]. [online] Folk och Försvar. Available at: $<$ www2.folkochforsvar.se/artiklar/vaerlden-vid-en-brytpunkt-var-framtida-saekerhet. html?page_n51 $=6>$ [Accessed 4 Sep. 2019]. 


\title{
15 Future consumption of welfare services
}

\author{
How the change in consumer \\ expectations will affect offerings \\ and business models in welfare
}

\section{Charlotte Mattfolk and Lina Emfeldt}

\section{Introduction}

Welfare was originally a term that described citizens' prosperity and is nowadays often used as a collective term when talking about the social security system and welfare services like education, health care, and social care. In this regard, Sweden makes for a relevant case to study, given that its welfare services are well established and integrated into the welfare state inasmuch that they aim to promote prosperity and individual autonomy. Likewise, the welfare policy is based on universal principles that all citizens should have access to high-quality welfare services (Government Offices of Sweden, 2016; Nationalencyklopedin, 2017).

\subsection{Background}

The public sector in Sweden has served an important purpose in making services such as education and health and social care, as well as civil contingencies and protection services, available to all citizens. With digitalization, consumption of services in the public sector is likely to merge with consumption of any other service. The sector faces new user demands. At the same time, global and regional development is putting an increased pressure onto service providers. If the world is to find solutions to the global sustainability challenges, including climate change, water, and sanitation, we need ten times the speed of innovation to be successful (Cartina, 2018). Given societal challenges such as an increasingly aging Swedish population, fewer young people to finance care for the elderly people (SCB, 2018), and the transformation into a fossil-free society, it is obvious that the public sector will have to find ways to increase resource efficiency and accessibility through for example automation and innovation of services (European Commission, 2011; IVA, 2016).

In the future, would we perhaps be able to receive the same public services, but from other, more niche and specialized players? Or might we even be serviced by large global actors built upon substantial economies of scale? Will the public sector even be fit to compete with those players in terms of relevance, quality, customization, value for money, and efficiency? The logic of digital services 
implies both cost efficiency and a high level of quality and relevance - opposite the traditional competitive edge built on either price or quality. Digital players have already shown their strength in competing in the business world, causing industry borders to blur and with a firm focus on meeting consumer demand with an ecosystem approach, rather than sticking to traditional definitions of industries.

Our life is full of digital services: we communicate with our friends, family, and colleagues; read the news and search for information; book our travels, restaurants, haircuts, or any other appointments. Consumers spend almost four hours a day online, in the digital world. In the next five to ten years, these consumers will lift their heads from 2D screens and will most likely interact with devices in a much more complex way, including using all senses and a much wider array of technologies than today (IIS, 2016; Porter and Heppelman, 2017). This all will enable the shift.

In the future, consumers will no longer be willing to waste time waiting for a doctor's appointment, and they will demand getting instant access to the education they want, accessible for anyone from anywhere. No one will be willing to wait for months or years for bureaucratic processes to handle simple matters that could be solved swiftly by an algorithm. However, at the same time, the human resources available to cater to the needs of the older population will be scarce. Automatization and data-driven services are therefore a must. The future society will not be able to shoulder the cost of a welfare model like the one we apply today (Vartiainen, 2017). In the future, we will most certainly face home care staff that are humanoid robots.

Not only robots will become humanized, humans will become roboticized, too (Cartina, 2018). Some argue that we will be upgraded by technology and that our human abilities will be enhanced. A technology like this has the potential to make us all smarter, healthier, and more efficient, but it might also increase our fears, make us more vulnerable, and even kill us if we do not manage to master the ethical aspects of this development. Until now, technology has demanded much from us in terms of understanding how to use it properly. In the years to come, technology will be more like an extension of ourselves, demanding less interpretation and enabling much more precision in how we do things. Shared values and a common view on ethics, responsible behaviors, and rights and wrongs will be the key to preventing technology from working against us.

In the future welfare system, the overarching currency will be data. Consumers tend to lean toward either wanting a high degree of control over personal data, making well-thought-through decisions with a high level of perceived control - or they lean toward a convenient approach where personal data is the main facilitator in their life, freeing up time when their service provider already knows their preferences and makes services available with a very limited need for decisionmaking and choice.

The future welfare services must meet the demand from citizens expecting the same level of innovation, simplicity, efficiency, transparency, and accessibility to welfare services as with any other service. Although global initiatives, such as recommendations from the OECD in 2016, are pushing Sweden and other countries 
to work harder toward a digital transformation of the public sector, we are still only in the beginning of this journey. The recommendations that governments should develop and implement digital strategies and use digital technologies to create open, inclusive, and trustworthy public sectors needs further attention, as do initiatives to bring governmental and non-governmental actors together to achieve national development and long-term sustainable growth (OECD, 2016). Important steps have been taken in the Swedish market lately. The Swedish government appointed a Minister of Housing and Digital Development in 2016, a Chief Digital Officer for the nation in 2017, and a new public agency to maintain the digital infrastructure and capital in 2018. Sweden also established an eHealth Agency in 2017 (OECD, 2018).

\subsection{Aim and research question}

The aim of this project is to describe four scenarios encompassing different future outcomes. These scenarios are in turn contingent in part on which players in the market are most dominant, which players succeed in offering the best services, and what consumer behavior emerges as the most prevalent. Our approach is iterative. This means that the approach follows a theoretical framework wherein a scenario planning method (known as the "four scenarios") will be developed, the outcomes of which are built upon the result of the study. All four scenarios are likely to co-exist, but the different scenarios are based on trends and drivers that may be stronger or weaker over time. For the purposes of this study, all scenarios are presented in forecast of the year 2030. This was done in order to serve as a thought-provocative prognostication of the future market, as well as to allow adequate time for the forecasted changes to become fully implemented in practice.

Key questions to be answered in this study:

- What scenarios can best describe the main possible differences in consumption of welfare services from the citizens' point of view?

- In each scenario, we will describe:

- What are the main characteristics of the expectations that a citizen has of the welfare system?

- Which players are successful?

- Which business models and offerings do we see?

- What is the role of the state?

- What is the purpose of public welfare services?

\subsection{Methodology}

This study is based on a scenario analysis conducted in Sweden during October 2016 to June 2017 named "The Future of Consumption Patterns 2025" (Cartina, 2017). This is an extension of the same study focusing on the public sector and how future consumption patterns will affect how Swedish citizens might want 
to consume welfare services in the future. The general scenario planning logic from the original study is kept intact, but we will add the perspective of how future consumption of welfare services would change in the different scenarios.

This qualitative study was conducted through a series of face-to-face interviews and workshops and built upon scenario methodology and design thinking, developing the four previously mentioned alternative future paths of development. The respondents/participants came from both the public and private sector and represented both small ( $<50$ employees), medium ( $<250$ employees), and large $(<1000$ employees) companies with a disruptive business model, where innovative new services have been developed. Experts within digital and sustainable business development also participated in interviews and workshops.

All participants cited in the study have given their informed consent to appear with their names and the companies they represent.

Table 15.1 shows all participants in interviews, workshops, and discussions in the study.

Table 15.1 List of participants

\begin{tabular}{|c|c|c|c|}
\hline Name & Title/position & Company & Industry \\
\hline $\begin{array}{l}\text { Ahlquist, } \\
\text { Magnus }\end{array}$ & $\mathrm{CEO}$ & Securitas & Security \\
\hline Berg, Ylva & $\begin{array}{l}\text { VP Head of Digital } \\
\text { Development }\end{array}$ & $\begin{array}{l}\text { Coor Service } \\
\text { Management }\end{array}$ & Service management \\
\hline $\begin{array}{l}\text { Bergström, } \\
\text { Fredrik }\end{array}$ & $\mathrm{CEO}$ & Länsförsäkringar & Insurance \\
\hline Ehle, Petra & $\begin{array}{l}\text { Head of Business Unit } \\
\text { Mail }\end{array}$ & PostNord & Logistics \\
\hline Ekstedt, Anders & CEO & $\begin{array}{l}\text { Svensk } \\
\text { Kommunrating }\end{array}$ & Economy \\
\hline $\begin{array}{l}\text { Farestam, } \\
\text { Stefan }\end{array}$ & Co-Founder & CareChain & IT and healthcare \\
\hline $\begin{array}{l}\text { Ferndahl, } \\
\text { Torbjörn }\end{array}$ & Managing Director & Säkerhetsbranschen & Security \\
\hline $\begin{array}{l}\text { Forslund, } \\
\text { Daniel }\end{array}$ & Innovationslandstingsråd & $\begin{array}{l}\text { Stockholms läns } \\
\text { landsting }\end{array}$ & Public services \\
\hline Gejke, Jenny & $\begin{array}{l}\text { Head of Digital Channel } \\
\text { Development }\end{array}$ & SJ & Transport \\
\hline $\begin{array}{l}\text { Gerger, } \\
\text { Magdalena }\end{array}$ & CEO & Systembolaget & Retail \\
\hline Golan, Jonas & Health Care Lead & Microsoft Sweden & Computer software \\
\hline Grandt, Anna & $\begin{array}{l}\text { Head of Digital } \\
\text { Experience \& } \\
\text { Communication, } \\
\text { Digital Banking }\end{array}$ & SEB & Bank \\
\hline $\begin{array}{l}\text { Gullström, } \\
\text { Annelie }\end{array}$ & $\begin{array}{l}\text { Head of Business } \\
\text { Development }\end{array}$ & AMF Fastigheter & Real estate \\
\hline $\begin{array}{l}\text { Hafstad, } \\
\text { Joachim }\end{array}$ & Director of Operations & KRY & Health \\
\hline
\end{tabular}




\begin{tabular}{|c|c|c|c|}
\hline Name & Title/position & Company & Industry \\
\hline Hellqvist, Linda & $\begin{array}{c}\text { Senior Director Global } \\
\text { Digital Acceleration }\end{array}$ & Oriflame & Consumer products \\
\hline $\begin{array}{l}\text { Holgersson, } \\
\text { Tom }\end{array}$ & $\begin{array}{l}\text { Head of Fintech \& } \\
\text { Financial Services } \\
\text { Nordics }\end{array}$ & Enterprise Ireland & $\begin{array}{l}\text { Government } \\
\text { organization }\end{array}$ \\
\hline $\begin{array}{l}\text { Jarnemark, } \\
\text { Tommy }\end{array}$ & $\mathrm{COO}$ & AcadeMedia & Education \\
\hline $\begin{array}{l}\text { Källsholm, } \\
\text { Joachim }\end{array}$ & Country President & Securitas & Security \\
\hline Kanter, Theo & $\begin{array}{l}\text { Professor in Computer } \\
\text { Science }\end{array}$ & $\begin{array}{l}\text { Stockholm } \\
\text { University }\end{array}$ & Education \\
\hline Kernell, Daniel & Co-Founder \& CCO & Doktor24 & Health \\
\hline Krés, Ulrica & Head of Marketing & Swedbank & Bank \\
\hline $\begin{array}{l}\text { Lindstedt, } \\
\text { Monica }\end{array}$ & Founder & Hemfrid & Household services \\
\hline $\begin{array}{l}\text { Melander, } \\
\text { Helen }\end{array}$ & $\begin{array}{l}\text { Associate Professor in } \\
\text { Education, Department } \\
\text { of Education }\end{array}$ & Uppsala University & Education \\
\hline $\begin{array}{l}\text { Nybell, Karl- } \\
\text { Johan }\end{array}$ & $\begin{array}{l}\text { VP \& Global Customer } \\
\text { Unit Head }\end{array}$ & Ericsson & Telecommunication \\
\hline $\begin{array}{l}\text { Salmeling, } \\
\text { Merete }\end{array}$ & $\begin{array}{l}\text { Head of Digital and } \\
\text { Innovation }\end{array}$ & Landshypotek Bank & Bank \\
\hline $\begin{array}{l}\text { Sellström, } \\
\text { Johan }\end{array}$ & Co-Founder & CareChain & IT and health care \\
\hline $\begin{array}{l}\text { Stenberg, } \\
\text { Frippe }\end{array}$ & $\begin{array}{l}\text { VP Brands, Customer } \\
\text { Journey, Digital } \\
\text { Development \& } \\
\text { Innovation }\end{array}$ & Scandic & Hotel and travel \\
\hline Thörner, Tina & Founder & School4you & Education \\
\hline Torell, Anders & CEO & Kronans Apotek & Pharmacy \\
\hline Vahedi, Peyman & Principal & $\begin{array}{l}\text { Âdalsskolan, } \\
\text { Kramfors }\end{array}$ & Education \\
\hline $\begin{array}{l}\text { Waardahl, } \\
\text { Henrik }\end{array}$ & Co-Founder/CMO & MemoAR & Technology \\
\hline $\begin{array}{l}\text { Wennerholm } \\
\text { Kocken, Erik }\end{array}$ & CEO & Avarn Security & Security \\
\hline Ziemsky, David & CEO & Bellpall & Technology \\
\hline
\end{tabular}

\subsection{Study content}

This study presents global mega trends along with large and important consumer trends that we believe will influence the future Swedish welfare system, consumption patterns, and the ecosystem as a whole. This study also seeks to present separate ways in which the world might develop that affect the public sector, welfare services, private companies (including their business strategy), and market competition, as well as consumer preferences. Based on our aforementioned scenario analysis, and depending on how these aspects progress, we see four potential scenarios outlining how individuals would like to consume welfare services in the 
year 2030. In each scenario, we illustrate which triggers will enable the scenarios the most as well as which societal values and capabilities politicians and business leaders must strive to develop. The scenario names reflect the characteristics of how future citizens will consume welfare services. Specifically, these four scenarios are as follows: 1) data-driven state, 2) commercialized welfare, 3) efficiency game, and 4) global choice.

Readers of this chapter will thus gain an understanding of how to spot triggers that can change the development, while increasing the ability to assess how digitalization and sustainable development may change the society and the world at large. The scenarios can be used as an instrument to develop future-proofed strategies in each scenario. By understanding threats and opportunities in each scenario, companies can also distinguish a robust position and strategy that encompasses elements of several scenarios.

\section{Digitalization of Swedish welfare services is lagging behind}

Sweden has been known all over the world for its welfare system enabling all citizens to take part in schooling and health care in a safe society where institutions generally can be trusted. These welfare services have seen incremental development but have not changed much in 50 years compared to the development in the private sector. With digitalization, the public sector faces a major shift, which will force the sector to transform the foundation of the welfare system. The need to create excellent citizen experiences, automate processes and ways of working, become data-driven, and innovate business and financing models will be just as important in the public sector as anywhere else. From the customers' and citizens' point of view, the distinction between a service delivered by a public institution and one delivered by a private company will be blurred and customers will choose the service that meets their needs in the most relevant manner. Digitalization disrupts the way we pay for services, and this means that it will tear up value chains and monetize parts of the welfare system in a completely different way. Online/digital doctors, along with telemedicine/eHealth at large, are excellent examples (Evans, 2016; Wachter, 2015). Private actors define a need for a better experience, not having to spend precious hours at a care center, which means automating processes that are inefficient in the physical world and then getting instant advice and medication. New financing models will certainly emerge as services are refined and different levels of customer value are distinguished. An immense challenge related to digitalizing the public sector that Jenny Gejke, Head of Digital Channel Development at SJ, the Swedish state-owned passenger train operator, brings up is that we need significant investments in infrastructure from both the public and private actors - in as an extensive manner as was done 100 years ago - and that we are currently nowhere near that. This can become a major obstacle for Sweden and hold back our development in relation to the rest of the world. Sweden is used to being ahead, but right now many other countries are moving at a much faster pace. 
Some parts of the system, such as the Swedish Systembolaget, a governmentowned chain of liquor stores, and the Swedish National Tax Board, have already today managed to create services that the Swedish people are very satisfied with. But on the other hand, there are many examples of areas where the public sector is lagging in terms of digitalization and citizen centricity - especially when it comes to developing customer-focused solutions. Magdalena Gerger, CEO of Systembolaget, emphasizes how important it is to have a multistakeholder perspective and understand that, in the end, the citizens are the clients who must be satisfied with the service. Each cost needs to be evaluated with the effect of quality in mind. This, in turn, will be the key to success. Agreeing on the priority among purpose, cost, and quality of the services offered will be crucial. Systembolaget's specific challenge is to balance the appreciation of alcohol consumption with the potential risks and damages it causes to the individuals' health, to their families, and to society at large in terms of increased health care costs. They have focused on treating customers according to their own beliefs and values that taking a broader responsibility for people and society with care and respect for the individual will increase societal value creation and not merely function as an authority - controlling and inspecting people. This has played a major role in the journey toward becoming customer-centric and gaining both confidence and satisfaction in their services. This way of thinking could be translated into other areas such as health care and education, where citizen satisfaction with the service delivered is uneven or low. All areas partly or fully owned by the public sector will experience lobbying, competition, and pressure to change from the private sector.

Monica Lindstedt, Founder of Hemfrid, a household service company, argues there will be an increased focus on meeting consumer needs through offering consumers more complete services. Working full-time with a family of six, she longed for a service to help at home, available not only for a small, high-income segment but for a larger market. She established Hemfrid 20 years ago to meet the need for cleaning services at home. This service is today in most cases a once-aweek assignment but could likely turn into a full-responsibility "keep my home clean" service. Hemfrid is piloting a service with Electrolux where they bring their robot vacuum cleaners into people's homes to serve the daily need for cleaning that is not met in their own current service offering. Other services could be added; cleaners could, for example, receive and take care of groceries or other purchases. The smart home is happening now, and there will be an ecosystem of players wanting to get into people's homes with their products or services, with a more holistic, service-oriented offering, likely in collaboration with partners they have never thought of before.

\subsection{Health care is inefficient and new players are entering the scene}

Health care is an integrated and important element of almost every society. Swedish society's current development entails an increasing need for health care, combined with the challenges of financing high-quality health care with good 
availability for all citizens. The solution lies in the improved efficiency and productivity of the health care provided. Health care is on the brink of a paradigm shift whereby digitalization is opening up new ways of providing health care, for communication between patients and health care providers, and for patients to take control of their own health and treatment.

Today, long queues and waiting times to see a doctor and an inefficient process to get access to care drive the development of digital services such as KRY, Doktor24, and Doktor.se, among others. A recent OECD (2017) report stated that one Swedish doctor treats 692 patients a year, in comparison to the average of 2295 patients a year in OECD. In Germany alone, a doctor treats 2416 patients a year (OECD, 2017). This means that the long queues may not only depend on the scarcity of doctors, but also be due to inefficiency in the health care sector. At the same time, Sweden has among the highest costs for health care in OECD, while still garnering low levels of satisfaction from Swedish patients (OECD, 2017).

Many people today also expect flexibility and time efficiency when it comes to health care services, much like any other service. Daniel Kernell, CCO and CoFounder of Doktor24, a Swedish digital health care service, mentioned some of the greatest challenges facing Swedish health care today. Health care in Sweden is in general organized with productivity in mind, focusing on how to "optimize the production" instead of focusing on the patients and their journey. There is a logic to this, given that the Swedish health care system is publicly funded, but the lack of patient journey perspective has affected accessibility negatively. The Swedish referral system is also to a large extent mail based, resulting in long lead times in the patient journey. At the same time, people have gotten used to an increased service level in other industries through digitalization. This has led to higher expectations and a lower accepted "minimum care" within health care. Swedes in general agree to pay high tax rates because they feel they get a lot in return. However, the low accessibility and long lead times in health care, and the increase in service expectations, all risk reducing the popular trust in the publicly funded health care model. This is one of the reasons digital players are starting to take over parts of the value chain within the primary health sector in Sweden. From June 2016 to December 2017, there were almost 230,000 digital health care visits, and the numbers continue to grow. It is primarily families with young children $(0-4 \mathrm{y} / \mathrm{o})$ and young adults who tend to use the digital health care services (Blix and Jeansson, 2018).

According to Fredrik Bergström, CEO of Länsförsäkringar, a Swedish insurance company, the concern for our health has never been higher, and there is an explosion within the area of proactive health in the form of diets, gyms, sports, yoga, mental training, and so forth. He believes insurance companies could take on a much more active role in proactively promoting activities that lead to good health. One example of this is for companies to provide mental coaching in order to avoid stress and long sick leaves. He also believes insurance companies can use the data and insights they possess to a much greater extent. Assuming that this is handled in a trustworthy manner, consumers are not only willing to share data, but will also receive better services from insurance companies. 
Anders Torell, CEO of Kronans Apotek, a Swedish pharmacy chain, brings up the lack of consumer perspective in the health care sector. Today, consumers are left to handle their health care needs by themselves, seeking information, finding out who to contact for different matters and where to go - each and every step in the so-called "patient journey." He believes digitalization will enable major improvements to this experience and make it significantly more adapted to each individual. This will happen through smarter data usage and utilizing artificial intelligence, and it will increase transparency for the consumer. He shares Bergström's view that consumers are willing to share data if they are used for a good purpose, that is, improving the customer experience.

\subsection{Teacher scarcity and lack of control over student data}

When it comes to education, the system of today faces great challenges. We will see a scarcity of teachers in the coming years, and that will propel digitalization and push for increased efficiency in education according to Helen Melander, Associate Professor in Education at Uppsala University. Teachers must be able to educate more students in the same amount of time. We need to evaluate the role of teachers and how they interact with, and enhance the adaptation of, new technology in education.

When it comes to individualized support and managing student data, we need to solve how data can be shared between different parties, according to Peyman Vahedi, Principal at the senior high school Adalsskolan in the urban area of Kramfors. He regards this as the biggest challenge of today - that student data are owned and managed by two private actors in Sweden. Hence, the state is paying a lot of money to get access to relevant data such as name, address, guardians, and so on. He describes this as a major obstacle, since we cannot work with data until this information is owned and handled by the state. This implies we do not have full access to the infrastructure needed to develop relevant services for teachers, students, and parents. The school needs to be digitalized, but the limited access to data stands in the way.

Tommy Jarnemark, Chief Operational Officer at AcadeMedia, Northern Europe's largest education company, also brings up the importance of getting the right technology infrastructure in place for schools to become more digitalized and data driven. He believes teachers will still be a core component of a school, but they will work differently from today. We will not digitalize away teachers, but we may decrease the need for the physical location. Learning will be more real time based and we will need to continue learning through our whole lives. According to Jarnemark, this must be enabled by private actors, and the public sector can handle the foundation for everyone to get the same start. His opinion is that it is old fashioned to spend 12-16 years in school before we go to work for the rest of our lives. Instead we will switch between education and work several times during our lifetime.

The Swedish rally navigator and Founder of School4you (global education tools), Tina Thörner, describes the challenge in school today from the student's 
perspective - "children today are demotivated since we have an ancient school, far from the world they live in." The rewarding system does not meet their expectations of instant feedback, and they get bored and lose interest, instead of being motivated and inspired. She has a strong belief that schools must adapt to children and technology - and not the other way around.

\subsection{Increased need for security and safety solutions}

According to Torbjörn Ferndahl, Managing Director at Säkerhetsbranschen - a Swedish association for security companies - people in Sweden feel more insecure and have an increased need and demand for safety today, even though actual security levels are higher than ever before. International and local occurrences of terror threats are making us perceive the world as more dangerous than before, and the picture that media communicates makes us feel unsafe. The violence of today is perceived as more severe, probably because we have access to information in a completely different way than before and we tend to pay more attention to bad news than good news.

People satisfy the need for safety by investing in home alarms and other digital security products and services. We get to hear that community resources such as the police force are not being sufficient, and hence citizens start to "buy" their own safety. Torbjörn Ferndahl also adds that we are already starting to see gated communities, something he believes will be more common in the near future. The mission of the police is to fight crime in society, and therefore they will mobilize their resources to areas that need them the most, not patrolling in areas that are statistically "safe," even though the citizens might want them to. The police should be where the crime is, and citizens' perceived security needs will be handled by private actors. We see more and more cooperation between community services and private actors within the security sector, where, for instance, security guards are taking over some of the areas from the police. One example is the subway system in Stockholm (the Stockholm Metro), where security guards are tasked with maintaining safety rather than directly involving the police in the event that a threatening situation emerges. Digitalization among private actors is ahead of the public sector. Predictive analysis of certain behavioral patterns to prevent certain incidents is but one such example.

\section{Future thoughts on digitalization}

\subsection{Global developments are impacting future needs}

\subsubsection{Strong incentives for a digital transformation of public services}

The political incentives for improving efficiency, effectiveness, and governance of public services are clear. Governments look increasingly to digitalization as a strategic driver and tool to achieve the changes needed. Digitalization of some of the most workforce cost-heavy public welfare service areas, for example, 
education, health care, and protection has great potential that has yet to be realized (OECD, 2016).

\subsubsection{Changing demographic landscape}

One strong development trend affecting public services is the changing demographic composition. In the next 30 years, there will most likely be more retired people than there will be children and youth, at least in Sweden and other OECD countries. Due to this shift, dependency ratios are increasing, meaning that fewer citizens are contributing to growth. A smaller working population leads to lower GDP, a lower national income, and further strains on pension budgets (Gujral and Beer, 2015).

\subsubsection{Increasing chronic diseases highlight the need for preventive care}

The aging population has a significant impact on both the demand for and delivery of public services. Changes in the demography require flexibility and scalability in the delivery of, for example, education and health care services. Chronic diseases such as diabetes, obesity, and certain cardiovascular diseases are increasing and placing additional pressure on the health care sector, which stresses the need for preventive care (OECD, 2016).

\subsection{Consumer trends}

Consumer behavior and trends from the private sector will have an increasing impact on the consumption of welfare services. Citizens will make no difference between public or private services but demand simpler, faster, and cheaper access to welfare services. Adopting new technologies and getting better insights regarding customer experience, as well as developing the ability to build an ecosystem around consumer and citizen needs will be necessary to stay competitive and offer a customer-centric service.

\subsubsection{New user interfaces challenge the ownership of the relationship}

Screen usage, as our primary user interface, has evolved from computer screens to mobile screens. Within the next few years, voice, virtual reality, and augmented reality will most likely become our next primary interfaces because of convenience and efficiency. In addition, more and more objects will be connected and start collecting consumer data from real life. Cars, lamps, fridges, work desks, and so on will all be connected in the future, analyzing behaviors to recommend solutions that simplify or improve the lives of consumers. This will create new opportunities for innovative solutions and it will dramatically affect the growth of digital services. In the future, citizens will be able to keep better track of their 


\section{Charlotte Mattfolk and Lina Emfeldt}

health with interconnected devices such as smart bracelets, weight scales, and fridges. Citizens will expect service providers to present smart options for how to connect and leverage their personal data from devices with the services they provide. For instance, health service providers should be able to connect to the patient's fitness app or smartwatch and use the insights to give better health care. At the same time, there will be more solutions like the digital dietician and the digital doctor that help you get daily health advice and coaching. Voice control will probably be more integrated in daily routines and used, for instance, as an interface when asking for support in different welfare service errands. For welfare service providers to meet future citizen demand, it will not be enough to focus on providing the welfare service itself - they will need to start leveraging upcoming digital technologies in their service delivery and continuously find innovative ways to reach citizens using new interfaces and communication channels.

\subsubsection{The artificial relationship}

Primitive chatbots are already widely in use. They serve as substitutes to personal customer support for less complex questions and inquiries. Leading tech companies are all developing their own artificial personas (e.g., Siri, Alexa, Cortana, Google Now), making them even more intelligent and useful. Even though the level of sophistication is limited, the speed of improvement is increasing exponentially. In the very near future, the sophistication level is expected to be much higher. AI, chatbots, and personal assistants will be natural points of interaction for everyone. We will interact with our artificial assistants several times a day when we need help and assistance in a wide range of situations and with a multitude of tasks. This means that some of us will allow artificial intelligence to make decisions for us. While this will make our lives more convenient, it also means that we will hand over more power to whomever owns the intelligence. Trust will be key, and we as citizens and customers will not tolerate mistakes or bad service, lest we turn elsewhere. For incumbent welfare service providers to maintain their roles in this future, they will need to build capabilities, internally or through partnerships, to integrate AI and big data into their service delivery. If not, newcomers and global tech giants will likely take over large market shares in the welfare services market by leveraging $\mathrm{AI}$ and other technologies.

\subsubsection{The seamless customer flow}

Current expectations of great customer experiences will continue to grow. Giants, like Uber, Spotify and Netflix, with their core in customer experience and user interface technology, drive development as well as the market. They make us as citizens expect the same level of experience from local services, schools, and health care providers. A lot of companies and service providers have therefore focused on creating an omni-channel experience and being more customer centric. Now more and more companies and service providers are focusing on improving the overall experience throughout the whole customer flow. This starts from the 
first interaction point with the customer and ends with the last. The key is to look at service delivery from a service receiver point of view and provide a seamless flow throughout the entire journey, connecting different ecosystems with each other. The need to provide a seamless flow will be central in all value chains and service sectors, regardless of whether it is to get an appointment with the doctor, alert the police, or report to school that your child is sick - our expectations of a seamless experience will be extremely high. Welfare service providers need to think similarly to any other type of service provider when it comes to creating seamless experiences, because if citizens' demands are not met, we will not hesitate to switch to other service providers.

\subsubsection{Regulatory changes open for new innovations}

Changes in directives and regulations open new possibilities to create innovations based on new conditions for competition. In many industries, banking, for example, regulation is the foundation of trust for customers. New rules and regulations enable new players to compete on the same terms as incumbents. Three examples of directives and regulations that will have high impact on most businesses are Digital Single Market, Payment Service Directive 2 (PSD2), and General Data Protection Regulation. GDPR enables new innovations related to novel ways to manage data and create new ways to deliver services with less data available. These new regulations can also have an impact on the way we will consume welfare services, as data, payments, and digital solutions are evolving in this area.

\subsubsection{Public sector needs to become fast moving}

Changes in regulations and directives disrupt traditional industries, resulting in new competitive landscapes. Incumbents and the public sector have similar prerequisites and they will have to keep up with the pace of new entrants or see themselves lose ground to companies that offer what consumers really want. An example is digital health care companies such as Doktor24 and Kry, taking over as the first point of contact in the Swedish primary health care journey. While being small and new implies a disadvantage in terms of trust and scale, it is a competitive advantage not to be burdened by legacy. Incumbents struggling with old IT, old business or financing models, and non-agile ways of working will see their customer base shrink. They must realize that new competition will arise and that their historical advantage will not save them. Even public service providers need to adapt and be flexible to deliver the expected value to the taxpayers. Those who manage to adapt their operations to keep up with citizens' evolving demands will be able to compete with new players and use their scale and trust as an advantage.

\subsubsection{Integrity awareness}

A higher online presence for everyone, along with the digitalization of everything from government documentation to family photos, increases the need for control 


\section{6}

of one's own content. Both economic and legal aspects will drive higher security. GDPR is one example of how legislators address personal integrity and security online. A safe and sound handling of personal information is in fact becoming an increasingly important competitive advantage. GDPR will change the way business is done in the EU. As of May 25, 2018, every organization must meet the new data protection rules. Failure to comply will render a hefty fine (up to $€ 20$ million or up to 4 percent of the annual worldwide turnover of the preceding financial year in the case of an enterprise, whichever is greater.). Everyone needs to state when they are collecting data from a citizen, hence the importance of understanding which data are stored and processed will increase to comply with the new regulation.

\subsubsection{Increased expectations, wants, and needs}

Citizens are pampered with great innovations, better online customer service, and shorter delivery times. Thus, citizens have come to expect more from every encounter they have with a company, brand, or public institution. In addition, citizens have low tolerance for unsatisfactory services or products and are quick to switch to other service providers. In the upcoming years, citizen expectations will only increase, as people will expect solutions to be part of everyday life and work smoothly with their chosen lifestyles and day-to-day routines. Citizens will expect getting instant access to public services when needed, for instance, home delivery of pharmaceuticals and customized security solutions that can be integrated to their daily lives. Touch points will become more omniscient, and partnerships will allow for solutions with broader spans in services. If companies and public institutions manage to meet expectations well, they will gain an advantage over alternatives. To succeed, they must invest in becoming customer centric and strive to continuously meet changing demands.

\subsubsection{Diversity in diverging expectations between segments calls for more personalization}

With a rapidly growing population and increasing globalization, the citizen base is becoming more diverse than ever. This calls for a greater need for tailored services. For instance, differences in preferences and needs between generations cause dilemmas for service providers, both public and private, by making it difficult to know how to prioritize different demands. For public providers, this becomes increasingly challenging since they need to provide services that are accessible to the public and therefore cannot risk excluding any segments. When citizens expect public services to be accessible, transparent, and responsive, it is important to have a citizen-centric approach and solve the actual needs that citizens have. It is not enough to offer an online portal or call center, if these do not meet the expectations of the public (Dudley et al., 2015). Many citizen segments can, for example, be keen on physical meeting points, which means there is a challenge in satisfying both types of citizens and combining digital and physical 
experiences. The choice to go all digital is therefore not an obvious one. Even though understanding the new digital citizens is very important, neglecting the current citizen base would be a mistake. Tailoring services to fit both new and current segments will hence be a great but unavoidable challenge.

\subsubsection{Integration of services is necessary even in the public sector}

To compete with new innovative startups and meet the increased need for tailormade solutions, service providers have begun to integrate their services. For example, in 2015, Lloyds Pharmacy announced a cooperation with Kry and several logistical companies to enable everything from digital health care counseling to last-mile delivery of drugs (Dagens Apotek, 2015). This type of integration can help service providers offer services beyond their core offering without expanding their core operations. Enabling this type of collaboration across the public and private sectors will be necessary to meet the expectations from citizens, who will otherwise be forced to turn to private-sector providers. In the years to come, this trend will only further develop thanks to disruptive technologies, such as cloud computing and a new generation of people who expect greater transparency. This trend implies that both the private and public sectors need to look at how they can increase efficiency and generate greater service experiences through integration with other providers. This requires adopting a new organizational mind-set and breaking down barriers for collaboration. The next step for organizations is to identify assets that have complementary value to others, then find partners with offers that extend their own, experiment iteratively, and scale it once it works while maintaining the flexibility to change course at a later stage.

\subsubsection{David and Goliath: future friends or foes?}

We see partnerships between unlikely associates, both across and within industries and across the private and public sectors. This is likely to become more common due to the increasing complexity of the marketplace, calling for new and outside-the-box solutions in all parts of the value chain. To create synergies, large established incumbents, as well as public organizations, partner with innovative startups. Such partnerships enable both organizations to utilize each other's strengths, while still staying flexible by avoiding mergers. These types of partnerships are fragile and can be dissolved as soon as they become unproductive. However, if they are successful, the combination of sets of skills from different industries will benefit the involved parties and society by generating new services or products. Larger organizations, like public ones, struggle to adapt to fast-changing surroundings, so utilizing partnerships can help them to more quickly deliver improved services to citizens. Partnership is a cost-effective way to experiment with the market and to better understand citizen needs. 


\subsubsection{Evolving service models focusing on win-win-win value creation}

With an increasingly digital climate, new business and financing models emerge. Historically, making successful company partnerships has proven challenging, since parties seek to maximize their own profits. Partnerships between private and public parties can be challenging due to potentially misaligning objectives (profit-seeking vs. policy driven) and differences in decision-making processes. However, the increase in customer expectations forces both businesses and public organizations to evolve. Companies need to move away from "win - as much as possible for us" and start "winning" for the customer as well. Similarly, public organizations are pressured to change and provide more personalized services for their citizens as expectations increase. Beneficial partnerships that integrate services to increase the value for the service receiver enable a win-win-win situation for all involved. The rise of digital aggregators that do not own physical assets and that create a digital marketplace for merchants has started taking control over communication with citizens. By offering the possibility for citizens to compare service alternatives, from public and private actors alike, service providers are being pushed back behind the interface of the aggregators. The service consumer will therefore choose the provider with the most beneficial and customer-centric offer.

\subsubsection{Tech giants enter welfare services}

There is no doubt that large tech firms such as Google, Apple, Amazon, Facebook, Tencent, and Alibaba have substantial power and influence over people's lives through their products and services. They show no signs of slowing down in their mission to become our primary interface and platform. During the past decade, we have seen them develop services way beyond their core competences. Google, which probably is the role model for this trend, started as a search engine in 1998, but have since then launched several services that have little in common with the initial product. Like Google, other organizations now develop services way beyond their core. To name a few, the Chinese E-commerce giant Alibaba has now launched a new online bank, Amazon recently launched the food store Amazon Go to the public in January 2018, and it is rumored that Apple has been working on an electric car since 2014 (Jones, 2015). We even see this trend within welfare services, where Google have invested largely in EdTech and educational AI (Gartenberg, 2018). There are also indications that Amazon is taking more and more interest in the health care sector beyond prescription drugs and toward full-scale hospital services (Farr, 2018). What this will mean for the future of public-sector service providers, only time will tell.

\subsubsection{The digital era needs evolving regulations}

The topic of tech giants and the need for increased legislation is being raised more frequently than ever. The digital era causes new moral and ethical dilemmas to emerge and it calls into question what tech giants should and should not be able to 
do. Regulations are not keeping up with the technological advancements that are greatly influencing our society. This will have effects on the structure of the welfare services markets by creating an imbalance in freedom between different types of organizations. Public-sector organizations tend to be heavily regulated and policy driven, which in turn makes them less agile and makes it more challenging for them to respond quickly to changing citizen demands. Global tech companies, on the other hand, have been able to operate very freely due to slow-moving legislation processes and a lack of governmental technological prowess. A big challenge appears when global tech companies start to enter completely new sectors, such as providing welfare services on a global scale using digital solutions. Governments will need to adapt legislative processes to promote citizens' interests and to level the playing field for all market actors - by enabling the public sector to become more agile and putting necessary restraints on global technology companies.

\subsubsection{Governments and the public sector should be more digital}

At the media festival/conference South by Southwest (SXSW) in Austin, Texas, 2018, James Barbour, spokesperson and Head of Press Diplomacy at the EU Delegation to the United States and Shawn Powers, Executive Director at the US Advisory Commission on Public Diplomacy, spoke about the dilemma that politicians focus on the negative aspects of AI - the "dark side." They requested more discussions on productive ways of using AI and digitalization. How can we use technology to do better things?

An example is making digital IDs that can provide refugees with an ability to vote. Estonia is an example of a country that has digitalized government practices, for example, with digital passports. Today the time spent on manual administrative work in many public-sector organizations is high, which represents human resources that could be used to deliver faster or better services to citizens instead. During their speech, Barbour and Powers suggested that governments and the private sector should initiate more conversations. If they can come together, it will be easier to be more proactive, when it comes to legislation but also when it comes to understanding how new technology affects the development of society.

\section{Uncertainties about the future}

Uncertainties, unlike trends, describe areas where participants in this study have differing opinions or are unsure of where development is heading forward. The uncertainties we have discovered in this project concern citizens' demand for niched, customized services versus standardized services and whether we are willing to make a lot of effort in choosing our consumption versus preferring convenience and letting go of personal data to gain efficiency and more personalized services.

Our key question was:

What will future citizens demand and what will future solutions to their needs be like? 


\subsection{Uncertainty 1: will we prefer customized or standardized platform solutions?}

Customized or standardized platform accessibility results in variations of global and local limitations, AI status, privacy regulations, and logistical solutions. The term "customized" as we know it today will most likely be on a standardized scale by 2030 , so we need to consider what this new potential customized world will look like - and what and where the limitations will be. What will be possible from a legislative, technological, and consumer perspective? However, there is huge uncertainty regarding platform use and accessibility on a global scale for 2030.

Customized solutions mean lower platform dependency and specialized players. For this to work smoothly, the AI needs to be highly developed to function as a guiding tool between the many customized service offerings. Consumers are willing to pay for customized solutions since they offer exactly "what I want, when I want it, and where I want it."

Standardized solutions will entail a world dominated by few giant platforms that solve everything. In a standardized platform situation, an AI is not as customized to meet specific needs, but rather to create efficiencies and economies of scale within each platform. AI is a true competitive edge for platform players with the aim to dominate the market and make us dependent on their offerings.

\subsection{Uncertainty 2: will we prefer active choices or do we crave solutions that make decisions for us?}

These two ways of consumption result in completely different services, logistical solutions, and ecosystems. Depending on if we will see severe world events such as data hacking, climate change, and political instabilities that make us feel more insecure and unsafe - or if we experience reasonable peace and stability that make us confident letting someone else make decisions for us based on our data - it will affect our sense of what is "normal" in terms of sharing data.

I do it myself stands for the urge to make conscious decisions, purchasing locally and less, valuing high privacy, and taking part in a sharing economy lifestyle - thoughtful choices, trusted relations, and role models who spark communal efforts, true empathy, and care for other people and the locality.

Do it for me will embark on a more laid-back way of living, where sustainable consumption is sought, but not lived by - where comfort beats privacy. Consumers feel the pain of having too little time and want to make the most of the time they do have. Automation is key, along with full-on global services.

\section{Four scenarios describe development}

We have developed four different scenarios describing possible future outcomes. The names of the scenarios are data-driven state, commercialized welfare, efficiency game, and global choice.

Figure 15.1 illustrates the different scenarios and their main traits. 


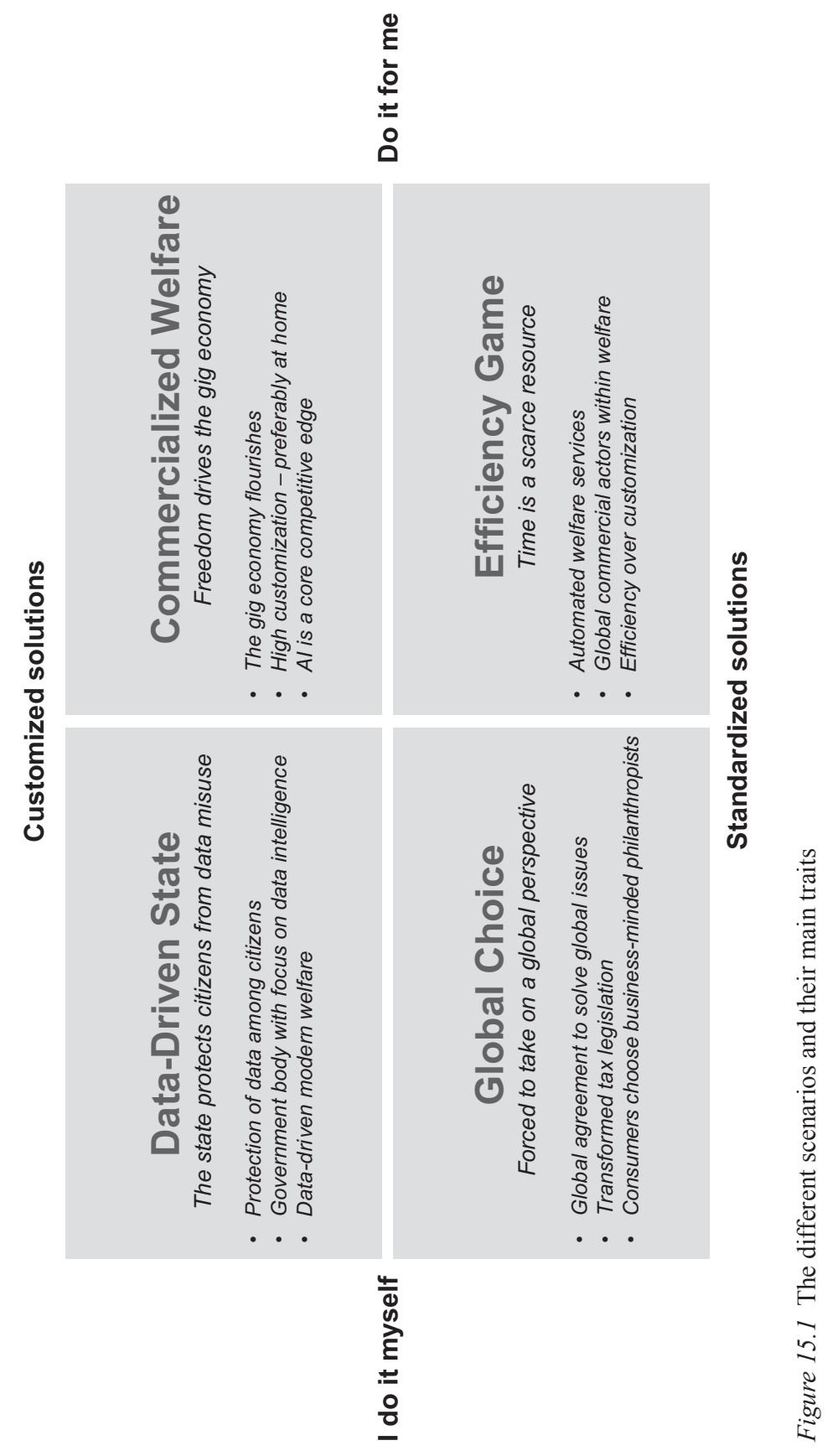




\subsection{Data-driven state}

\subsubsection{The state protects citizens from data misuse}

The world has experienced an increasing misusage of personal data, starting off with political elections and moving into increasingly sophisticated solutions that trick consumers into believing and buying into messages and choices where they have realized again and again that they are misled. There has been an explosion of content where politicians, businessmen and women, and celebrities are communicating "fake news" and people have been fooled to make choices based on false grounds. To halt this development, politicians have intervened and taken the role to protect citizens' data from misuse.

\subsubsection{Reluctance to share data}

In the data-driven state, citizens and consumers are reluctant to share their personal data with commercial players since they have experienced the downside of commercialized data. There has been an overflow of advertisements and breeches of handling data in a trustworthy way, and consumers choose to secure their personal data by not letting them out. This said, consumers still want the services and efficiency that sharing of data enables. Therefore, the state has taken on a role to handle personal data, being the quality assurance that citizens need to be able to share data in a much more controlled way.

\subsubsection{New government body with focus on data intelligence}

A new government body has been created with the mission to develop a stateof-the-art data-driven ability to handle citizens' personal data. This new body is the heart and core of the welfare system. The data belong to each citizen and can never be used without a citizen's consent. This is a major step forward from the personal numbers each Swedish citizen used to have. Each citizen profile consists of all data regarding school, health, income, criminal record, vehicle ownership, and so on. It will also know our geographical positioning. This feature will cause a lot of debate, but due to continuous terrorism and an increased demand for security, citizens will accept this to feel safer. Citizens can $\log$ in to their profiles and allow sharing of information between chosen parties. It can also be shared with employers and companies.

\subsubsection{Data-driven modern welfare}

The state is allowed to use the data on an aggregated level to be able to plan for the development of welfare services. This increases the efficiency in the welfare sector and enables a significant improvement in proactive arrangements to meet citizens' needs. Sweden re-establishes itself as a frontrunner in creating the next level of a modern welfare system, based on data and intelligence to serve its citizens' needs. This model is then exported to other countries. 


\subsubsection{Data-driven health}

Due to the great amount of data available on citizens and their health, health care institutions in Sweden can make sophisticated predictions of health issues at a population level. This is one of the reasons most individuals choose to share their data with the state. The state is optimizing for its citizens and provides short waiting lists for more advanced medical treatments and surgery, as well as great investments in research and development of new medicines and cures. The state benefits from healthy citizens and therefore provides them with free basic medical tools to keep at home. Health care is easily accessible for all people in Sweden, and machine learning is used to analyze data of medical histories to forecast health issues and risks at a country level. The potential for large savings due to reduced sickness among the population is the main argument for the state to invest heavily in this technology.

\subsubsection{Self-care centers at home}

Most diseases within the primary health care area will be cared for at home, with help from information and guidance from smart technology meters. In most people's homes, there will be a self-care center with all necessary tools for examining and treating individuals in a family. There will also be sensors installed in almost every room to generate information about a person's overall health, which will be alerted if something seems not normal or worrisome and you need to contact a health service provider. Besides providing warnings, the sensors will also provide information on genetic risks and current stress levels. Even though the technical solutions may be from a third-party service provider, all data are confidential and owned by the individual. However, these data are often shared with the state - to enable more preventative care.

\subsubsection{Health care is free of charge}

Sweden has few health centers for primary care, but several larger-sized and more advanced health care clinics for more complex and demanding care outside the home. All health care is free of charge for citizens of Sweden. Foreign patients can pay fees to get specialized treatments in Sweden as well - however, this is expensive since the state and health care institutions do not have all required information about the individual, which makes it more complicated to offer individualized care.

\subsubsection{Peer-to-peer learning}

In this scenario, the demand for trust is high and we turn to people that we confide in. To handle the scarcity of teachers, the system is transformed into a peer-topeer learning platform where students teach other students. Students no longer go to classes in their own age group, but rather with students with more or less knowledge than themselves in a certain topic, either to teach others or to be taught 


\section{Charlotte Mattfolk and Lina Emfeldt}

themselves. The logic behind this learning process is more similar to how knowledge is transferred in a company today, from more experienced to younger or less experienced colleagues within a certain topic.

\subsubsection{High-quality educational platforms}

Investments by the state have been significant to create a high-quality educational platform ensured by experts and recent research. Students access the platform through their digital student identity issued by the state. Initially, there is a limitation to the content of the platform, but it grows steadily as it develops over the years.

\subsubsection{Teachers are experts or coaches}

In this scenario, we see two types of teachers, experts and coaches. The experts contribute to the production of content to the educational platform. They are passionate about their subject and strive to find pedagogical ways of visualizing and distributing their knowledge. Other teachers become coaches. Through the educational platform, these "teacher-coaches" get a thorough understanding of each student's performance and potential. The teacher coaches the student to find the right selection of other students for learning and training of others in areas where this student excels or needs extra help.

\subsubsection{Security cameras everywhere}

In this scenario, we have a constant feeling of unsafety and insecurity and we also lack confidence in larger corporations and institutions. Companies that are trusted with guarding our neighborhood and monitoring our home deliveries have a strong local presence and are often structured as a peer-to-peer neighborhood watch. Security cameras are common goods and we share them with people we trust or in a trusted community. Not all neighbors are necessarily included unless we are confident that they are reliable. In order to get accepted and to prove your credibility to the community, a complex rating system applies. This is because data, other than what people freely share with you, are closely guarded by the government, and one way to ensure trust from people is by collectively gathering the communities' aggregated opinion of each individual. The classic proverb "it takes 20 years to build a reputation, but 5 minutes to ruin it" has never been more accurate. As such, it is difficult to get a second chance once your reputation has been thoroughly tarnished.

\subsection{Global choice}

\subsubsection{Forced to take on a global perspective}

National borders are less important, and we take on a global perspective to solve our planetary challenges. Climate change is a fact, and there is a burning platform 
for change. Severe instabilities among world leaders have nearly caused World War III. As the war has been averted at the last second, a global agreement comes into place with a common focus on solving the uneven distribution of resources among people in the world.

\subsubsection{Tax legislation is transformed and consumers choose business- minded philanthropists}

Large corporations have tricked the legal system by tax avoidance and caused a collapse of tax systems as we knew them. The need for a global tax system is inevitable given that almost every company acts on a global market. Digital giants such as Facebook, Amazon, Google, Apple, Alibaba, and Tencent have suffered from legislation hindering their rampage, and they have been struggling to transform their businesses. Only those with a strong focus on ethics and morals have succeeded to stay competitive. New giants arise with a combination of philanthropist and business perspective based on an ecosystem approach including consumers and their values in their own system.

\subsubsection{Consumers use their purchasing power}

Consumers in this scenario use their purchasing power to reward and distinguish good players from bad. They demand a full focus on the whole value chain with full information on how companies are delivering on the Sustainable Development Goals. The transparency is total and there is no way to hide misconduct.

\subsubsection{The state must find its global unique selling point}

The Swedish welfare state has met competition from a global arena, and citizens choose to use services where they are produced at a reasonable price with high quality and in a sustainable way rather than based on location. Since the state no longer has the power of regulating the tax system, it must secure its relevance by specializing in providing a world-class level of welfare services in chosen, specialized areas. Sweden has created a world benchmark and decided to focus on providing AI-based proactive health care promising record life length and education, with a focus on what makes society create a sustainable life. In this scenario, Sweden has invested in securing a strong focus on creating the most sustainable welfare services possible. It has increased costs, and to finance this development, the system has been opened up to global citizens who are able and willing to pay for services they can trust to be responsibly produced.

\subsubsection{A proactive view on health}

A proactive perspective on health and health care has been a major focus to diminish global costs and even out differences in knowledge about and accessibility to a healthy life. The world has experienced a substantial improvement in treating diseases early in their progress. We have programmed ourselves away from cancer 
and other similar diseases through combining our knowledge within medicine, biology, and technology. There have been intense discussions on how much we want to know in advance about our future health, but we have pushed our former beliefs into prioritizing knowledge over ignorance.

\subsubsection{Global schools serve global students}

Schools take part in global networks, and education is free to everyone. Philanthropic companies have focused on producing high-quality content and making it available to students all over the world. This way, they can pick out students with high levels of engagement and knowledge within their own specific focus areas. The ability to catch the highest level of talent is truly a global competitive advantage and the major difference from one company to another. The most prominent companies offer education as an integral part of their ecosystems.

\subsubsection{Data-driven education aimed toward sustainability goals}

Swedish schools have a long tradition of teaching sustainability awareness to children from a young age. The Swedish state decides to strengthen this focus even further into every subject and project. This makes the Swedish school a world leader in sustainability and attracts both students and teachers from all over the world who wish to develop and improve their competence within this area.

\subsubsection{Escalating terrorism drives technology development}

Escalating terrorism with creative new forms of attacks increasingly toward specifically vulnerable institutions, companies, and individuals has further increased the need for global measures. The aim of the attacks has been to shut down critical functions such as financial systems, utilities, media broadcasting, and so forth. The need for secure and robust systems is palpable and investments in developing, for instance, blockchain, technology enabling significantly safer transactions have been prioritized.

\subsubsection{Security firms - the National Security Agency of the future}

Since a more efficient and scalable way of hurting and robbing citizens is through hacking cars, homes, boats, and/or other belongings, security firms have developed a large anti-hacking service. Large corporations have the technical advantage and the leading anti-hacking solutions since our home is only based on one smart home platform built on solutions from companies like Google, Amazon, Facebook, Alibaba, and Tencent. Through their data and their philanthropic view of society, they have won the whole value chain, from protecting and monitoring your children and securing your home to bringing home the public procurement of predicting and protecting cities from riots based on search engine diagnostics. 
The big five have a stronger position in society than the governments around the world thanks to the combination of trust from the consumer, a sustainable approach toward the value chain, and the inefficiency and incompetence of our old institutions.

\subsection{Commercialized welfare}

\subsubsection{Freedom drives the gig economy}

The sense of freedom has a strong impact in this scenario, with financial and institutional as well as corporate freedom. We long for a life without a boss and being your own boss is highly valued. The gig economy flourishes and many switch between different commitments in just one day. Influential power is stronger than anything but requires much more specialization than in the early days when influencers entered the scene. True followers are hard currency and the only way to attract them is by staying exceptionally relevant to a specific target audience. The value of a low-interest mass market is gone. Companies, as well as institutions and politicians, look for influencers with strong engagement from their followers, but they have also developed their own capabilities to understand their target group better.

\subsubsection{High customization - preferably at home}

Consumers demand a high level of customization, preferably centered around their own living space. Time spent working at home has increased significantly, and people value the opportunity it gives to spend more time with children in the daytime - working flexible hours at all possible moments of the day. The notion of work hours from 9 to 5 is completely obsolete.

\subsubsection{Artificial intelligence is a core competitive edge}

In a commercialized welfare system, artificial intelligence is the backbone. It is necessary to customize services the way citizens want them. All of our personal data are made available, of course with our own consent, because we expect it to be used to make our lives easier. Behavioral and preference data must be shared across an ecosystem of different parties from the private and public sectors. Not all ecosystems look the same, so the challenge here is to design the most attractive service with the right set of partners.

\subsubsection{The new shape of an influencer - the direct influencer}

Everyone is an influencer. That means that the old characteristic of an influencer wanting to gather as many followers as possible is over. The hit rate for companies wanting to reach their potential audience by mass-market influencers is just as poor as broadcasting on TV. Every marketing effort is meticulously data 


\section{Charlotte Mattfolk and Lina Emfeldt}

driven, and small influencers with extremely relevant audiences rule. They influence their audiences directly and can move their thoughts and demand from one day to another. This is a challenge for politicians who want to reach the masses but need to be relevant to many smaller audiences. Many citizens are making their living as influencers, and technology and constant measurements are making this possible. It is a sensitive game where a bankruptcy or loss of confidence can occur overnight for a single influencer. But for politicians or companies, the risk can be spread among many different contributors.

\subsubsection{The state employs more robots than humans}

Commercialized welfare has implied severe competition from private actors and the state has been forced to cut down both its commitment in general and number of personnel. We see an extensive use of AI and robotics to handle administrative, caring, educational, and security issues. The role of the state is to automatically make predictions on citizen needs and make this information readily available to the ecosystems of actors that can solve these issues. The way of meeting different needs will be highly customized and delivered as a full-scale service. People turn to the ecosystem of companies that best treat a specific disease or teach a certain specialization, encompassing all aspects of life. If you have diabetes, you will be helped with everything from shopping for the right meals to getting the right medicine and suitable training - individually customized just for you.

\subsubsection{Daily and proactive recommendations for citizens}

Real-time information gathered by the sensors in the home will be translated into daily recommendations provided by digital assistants. For example, "Mr. Johnson, please reduce your coffee drinking as it will reduce your ability to sleep tonight," or "Mrs. Nordlind, I would recommend you to take Medicine X, instead of Medicine $\mathrm{Y}$ as it suits your body better for the moment." The recommendations are very much individualized and have a connection to online shops so that the data can be used in real time to make orders or automatically change a restaurant reservation for the evening.

\subsubsection{Me first-whatever it takes}

In this scenario, citizens expect instant health care - wherever they are. In case a citizen gets sick, the disease will be identified at an early stage, often before it is noticed. With help from an analysis made by intelligent cameras and sensors in your home that identifies the "healthy" you, you will be able to receive care quickly. Besides getting help very quickly, even the most complicated operations will be able to be carried out in your living room. A specialized doctor will "be there" virtually and, through robotic surgery, AR, and other technologies, will be able to serve you almost all types of health care in your home, whenever it suits you. 


\subsubsection{One issue, fact-based government with certifications to vote in a specific area}

In this scenario, you choose which areas are important for you to be able to influence politically. This is a one-issue, direct democracy society. But direct democracy cannot work if people are not educated and well prepared in a certain question. The risk of random beliefs is too great. Instead, you will need a certificate evaluated via the educational system to grant you the right to vote on a certain issue.

\subsubsection{Education on demand customized to each student's needs}

The notion of basic education that should be available to everyone is gone. This is not because it cannot be made available, but because it is considered irrelevant to spend too much time on "basic" knowledge. Students learn by identifying problems and dissecting them into facts and solutions. Subjects are handled increasingly simultaneously: languages and technology, mathematics and biology. Often we use the different perspectives in all sciences at once when looking at a single issue. A student can choose subjects freely since education is more about problem-solving than learning a certain foundation of facts. In this scenario, research has shown that previous categorization of sciences is irrelevant and even counteracts the ability to solve problems creatively. Students no longer become engineers, economists, journalists, biologists, or humanists. They are a mix of all these things, but focused on a specific topic or issue to solve.

\subsubsection{Gig teachers are the new influencers}

Teachers work sometimes by and for themselves, sometimes in loose networks. They take on the same role as today's influencers, building up their reputation online, combining digitalized preproduced content with live-streaming and interactive learning platforms. Some teachers may act in a national arena, but others are global with world-class content and a pedagogic approach. We will have "super-teachers" with millions of followers but also specialized "micro-teachers" with thousands of super-relevant and loyal followers.

\subsubsection{Security as a service}

In this scenario, everything comes as a service. Consumers do not buy food, they buy the service never to have an empty fridge. Consumers do not buy a vacuum cleaner, they buy a clean house service. To meet the demand for all services, home delivery during times when consumers are not home will be necessary. Inside monitoring with smart locks and alarms provides trust to the product-as-a-servicesystem. Companies enter into partnerships with security companies to be able to enter people's homes. Security companies also provide rigorous back ground checks for all employees to improve trust. Employment will be rendered impossible unless you share your data with these firms. To experience freedom in this 
gig economy society, you will be forced to give up your right to privacy. Security firms also partner with the health care sector to get access to the widely advanced security system.

\subsection{Efficiency game}

\subsubsection{Time is a scarce resource}

Getting the most out of every minute is of key importance in this scenario. We are struggling to keep our lives together, and we look for easy solutions in every situation. In reality, we do not have that little time, but our experience is that we are victims of technology and a society driving our lives. We spend enormous amounts of time in the digital world, either to socialize, consume media, work, or just make sure we are up to date with the world. We are obsessed with optimizing everything we do - and end up being quite inefficient.

\subsubsection{The welfare state as we know it is dead}

The Swedish welfare state has met competition from global commercial players and citizens choose to use services that are produced efficiently and meet their own demands reasonably well. Welfare is common goods, and the overall distribution of welfare in the world has evened out. Economies of scale have hit the welfare sector through commercial players. Common diseases, learning difficulties, or problems shared by many are easily handled or even programmed away. Abnormalities are harder to handle and are constantly met with lower priority. The state has a weak position, and the citizens do not care or consider whether there is a difference between the public sector and the private sector. To them, the part meeting their need most efficiently is the one they choose. The concept of offering welfare services to ensure the same service to all citizens is out of date.

\subsubsection{Global commercial actors within welfare}

Amazon opens hospitals worldwide, and to many people this is their first "go-to" whenever they feel sick or need some health advice or a very specialized surgery performed by the most intelligent robot available. Facebook is a major security player and has moved far beyond being the place to sign off as "safe" in terror attacks to taking care of one's whole security needs, irrespective of location - at home, at work, in school, en route, or in any other circumstance. Google has taken over education all over the world, and we now have a world standard for requirements at each educational level.

\subsubsection{Efficiency over customization}

Efficiency is king. Too much customization is costly, and it is simply not worth it. Citizens do not want to pay extra to get a personal treatment, individualized service, or anything that disturbs the automated efficiency game. 


\subsubsection{The Amazon clinic}

Hospitals by Amazon are available worldwide and are more common when you feel sick than primary health care institutions offered by the state. Amazon is more efficient and provides both digital health care advice and more complex operations in a physical space. Since Amazon has extreme amounts of data, it is able to forecast variations and predict times when citizens normally get sick, and make plans accordingly. It is also possible to receive your medicines at the door, in the same package as your other orders at Amazon. Efficiency is the keyword for health care in Sweden in this scenario, and hence citizens would rather go to Amazon than the few primary health care institutions that are still struggling to survive.

\subsubsection{Global platforms teach global citizens}

Schools no longer have national borders. The number of locally adjusted subjects is as limited as the number of truly local shops in big cities today. "The big chains" - in this case, the digital platforms with large volumes of data and knowledge, have taken over schooling and turned it into a lifelong commitment combining work and studies from an early age and lasting all life through. The global platforms will know what kind of capabilities will be important to develop, and they will steer students' choices in that direction.

\subsubsection{Blurring the border between education and work}

Digital giants do not consider the difference between education and work the same way as the national state and private companies used to. They utilize student projects for research, to collect data and gain insights. They give students assignments that improve their own or others' services. For this, they charge clients and incentivize students - increasing the efficiency in the educational system. Students are no longer a burden to society for 15-20 years of schooling. This development is met by resistance and fear for students being duped into playing the giants' game, losing their own individual choice and potential to find their passion in life. Given the vast educational possibilities and the lucrative system of getting through school with no or low student loans - with a promise to have chosen a future-proofed career, the resistance weakens and leaves room for this development to flourish.

\subsubsection{Real-time evaluation of student performance}

Digital players will base all education on their core capability - digitalization of all processes with a strong data-driven, student-centric approach. Students are evaluated in real time while they are passing on to new levels in the educational platform. The ability to answer questions and solve problems is registered, as well as their facial expressions to adjust to the student's level of competence. Gamification is widely used to keep students' interest, to encourage them to move on to higher levels and more knowledge. 


\subsubsection{Big brother is always watching}

"Big brother is watching you" is definitely present in this scenario. Everyone has the ability to know where you are at any given time. You may choose to "switch off" at certain times - but your everyday mode is fully connected and surveyed. Your personal security clearance automatically grants or denies access to different functions in society. The clearance is based on your personal data that you provide to large corporations in order to benefit from some of these functions even if you are rejected at other important institutions. Due to the continuous surveillance of our society, real-time updates are available for the big platforms, and we will know as soon as something happens as to which areas are unsafe. This enables you to navigate as a lone pedestrian almost as safely as in a car during the night. The widely implemented security systems in our cities may also alert or prevent us from entering certain areas in case of danger, or if you, based on behavior and historical data, are predicted to cause a danger to others within that area. Risky behavior is surveyed and "punished" by demoting you to lower access to services, support, and protection, as well as higher costs for you as an individual in society.

\section{Analytical summary}

We can already today see clear patterns emerging in our society that support the development in all four scenarios described in this chapter, although they are not yet developed all the way. The interviewees and workshop attendees all had different opinions on where we are today and where we should be heading. This is the strength of the scenario methodology since it encompasses different perspectives and still forces the participant to consider other aspects than their own point of view. It is our hope that these scenarios can be used for a further discussion to clarify what the choices our society makes - or does not make - will lead to in the long run. It is by analyzing the consequences and considering the vastly different outcomes that we can distinguish which decisions we make today will carry the most impact on tomorrow.

\subsection{Discussion}

Looking at Figure 15.1 presented in Section 5, the left side of the scenario cross requires stronger driving forces, such as a severely detrimental climate change and its subsequent consequences, in addition to significant data misuse and data intrusions. Politicians, scientists, and businesspeople strongly disagree on the impact and the possible outcomes of these events. Data are used either to prove or rebut climate change, but most of all the global discussion is characterized by opinions and prioritization of other objectives such as maximizing profits and sticking to current business models, ways of working, and value chains. Having said that, consumers are beginning to speak out and use their consumer power to promote companies that take substantial responsibility in society. The challenge is multifaceted; we have created strong habits in our consumption patterns, and even 
if certain citizens are willing to change in theory, the supply is in many cases not there, or not enough. Every day we are using environmentally unfriendly means of transportation; frivolously using antibiotics that, in the long run, may cause antibiotic resistance; or buying clothing produced in a questionable work environment and we may not even realize which choice could be better than the other. It is challenging to know what characterizes a "good choice" - when taking into account a much more complex view of the whole ecosystem of a society. Transparency, data collection, and measurements will be crucial to gain confidence among citizens and consumers, but also to make the right investments and drive change toward a more sustainable society and economy. There is a huge opportunity in closing this awareness and competence gap, where politicians, businesspeople, and consumers all can contribute better if there is trust and a common perspective.

Digitalization is a major contributor to enabling and empowering a sustainable change. Today we can collect data and distribute them on a massive scale. Historically, both politicians and companies have been able to filter data and adjust them to fit their own agenda - showing the good parts and holding back the more uncomfortable parts. Media and journalists have had a mission to uncover misconceptions or inaccuracies, but the lack of transparency has certainly hidden many faults. The digital transformation that we have seen in the private sector is lagging in the public sector, most certainly due to lower pressure to change. However, citizens are consumers and have gotten used to much more user friendly, automated, data driven, and innovative ways to meet their needs. This, in combination with an increased demand for services that are sustainable, with care for efficient utilization of resources, will force the public sector into a more dramatic digital transformation than we have seen until now. It will not be justifiable not to consider the opportunities and improvements that digitalization brings about when strategically implemented. Digitalization should be viewed as the most important area to improve and to build capabilities and knowledge among all employees in the public sector - to build a more sustainable society.

We have looked specifically into the three areas: health care, education, and security. We have analyzed the consequences on these areas if larger platforms such as Apple, Amazon, Alibaba, Google, Facebook, or Tencent (and similar newcomers with an ecosystem approach) increase their control and power. Then, we analyzed how these areas would develop if instead more niched players, focusing on solving specific needs, would gain market share. These niched players could either be serving a global market or a local market (solutions like Swish, a digital solution for instant money transfer via the mobile phone). In this category, we could count the whole public sector, which today is mainly focused on serving the national or local society, with the exceptions of some larger hospitals, universities, and colleges collaborating on a global basis.

All the mentioned types of players will most certainly have changed their positions significantly by 2030, and new players will have entered the market. The old generation of digital players will face transformation needs due to new legislation, new opportunities, new business models introduced by new entrants, and changing customer demands. In the scenarios, we have discussed the blurring 
borders between the private and public sector, and the lower part of the scenario cross in Figure 15.1 brings about further globalization and specialization of both schooling and health care whether it is due to stiff competition, citizen demands for efficiency, citizens feeling pressured for time - or simply due to a significantly increased overall pressure to become more sustainable. In both these scenarios, the public sector of today has become more specialized in handling specific citizen needs, such as unusual diseases, children and youth with special needs, or just citizens in general who crave more specialized attention. Needs that are frequently occurring and where large volumes of people need to be addressed, such as the flu, common types of cancer, or basic education, will be handled on a mass scale by large global actors. They will be able to efficiently meet a global demand, making only some local adjustments. This, in turn, will be possible through digitalization and AI.

In the two upper scenarios, the public sector can choose to take a niched role focusing on storing and distributing citizen data in a trustworthy way and being the best solution to preserving individual integrity and taking responsibility for ethical handling of data. The other option is that the public sector becomes a part of an increasingly commercialized society, where profitability governs, while the public sector is there to preserve regional or provincial services and ensure that schools, health care, and security systems are available even in locations where they are not profitable for a commercial actor.

\subsection{Conclusion}

We believe that to build a robust future-proof welfare system, we need to investigate the future and understand future citizen demands as well as the technology development enabling new ways to meet those needs. The scenarios describe very different outcomes for welfare services and roles for the Swedish state to take. While the scenarios will most likely co-exist, it becomes apparent that certain strategic choices must be made to ensure modernization of the current welfare system in Sweden. Citizen demands are changing, and the private sector is continuously increasing our expectations. Global digital players as well as niched startups will meet customer demands, ignoring the border between the private and public sector whenever and wherever that is possible. This is not a threat, it is a great opportunity to redefine the public sector and redistribute resources to areas where they have the best impact.

We are at a crossroads in terms of formulating and deciding on a vision and a strategy for the next level of citizen-centric, data-driven, digitalized welfare system based on future demands rather than on historic legacy. It is a great step forward for Sweden that the country now has an appointed Chief Digitalization Officer tasked to drive this transformation. Just as the private sector has experienced significant disruption, this will happen in the public sector, too. The challenge is to be part of the disruption, by anticipating and contributing to it. This takes an understanding of what new technology can do and a way to connect that knowledge to an overall strategic agenda of a modern welfare state, while 
maintaining a strong focus on the citizens' needs and experience. To this end, the use of digitalization has an immense potential to improve our future society by building a sustainable society.

\section{References}

Blix, M. and Jeansson, J., 2018. Nätläkare ger nya möjligheter - låt inte prestige stå i vägen [Online doctors offer new opportunities - do not let prestige stand in the way]. [online] Available at: <www.dn.se/debatt/natlakare-ger-nya-mojligheter-lat-inte-prestige-sta-ivagen $>$ [Accessed 5 Sep. 2019].

Cartina, 2017. The future of consumption patterns 2025. [online] Available at: $<$ https:// cartina.se/future-consumption-patterns $>$ [Accessed 12 Aug. 2019].

Cartina, 2018. Trend report SXSW 2018. [online] Available at: $<$ https://cartina.se/ sxsw2018> [Accessed 5 Sep. 2019].

Dagens Apotek, 2015. Lloyds Apotek startar samarbete med Kry.se på nätet [Lloyds Apotek starts new online collaboration with Kry.se]. [online] Available at: <www. dagensmedicin.se/artiklar/2015/06/16/1loyds-apotek-startar-samarbete-med-kry.se-panatet $>$ [Accessed 5 Sep. 2019].

Dudley, E., Lin, D-Y., Mancini, M. and Ng, J., 2015. Navigating the new digital divide. [online] Available at: <www.mckinsey.com/industries/public-sector/our-insights/imple menting-a-citizen-centric-approach-to-delivering-government-services $>$ [Accessed 5 Sep. 2019].

European Commission, 2011. The roadmap to a resource efficient Europe. [online] European Commission: Environment. Available at: <http://ec.europa.eu/environment/ resource_efficiency/about/roadmap/index_en.htm> [Accessed 5 Sep. 2019].

Evans, P., 2016. Your digital doctor will see you now - and provide a correct diagnosis. The Sunday Times. [online] Available at: $<$ www.thetimes.co.uk/article/your-digital-doctorwill-see-you-now-and-provide-a-correct-diagnosis-tm2n6t13f $>$ [Accessed 5 Sep. 2019].

Farr, C., 2018. As Amazon moves into health care, here's what we know - and what we suspect - about its plans. [online] Available at: <www.cnbc.com/2018/03/27/amazonsmoves-into-health-what-we-know.html $>$ [Accessed 5 Sep. 2018].

Gartenberg, C., 2018. Google wants to teach more people AI and machine learning with a free online course. [online] Available at: <www.theverge.com/2018/2/28/17063780/ google-ai-machine-learning-hub-crash-course-free $>$ [Accessed 5 Sep. 2019].

Government Offices of Sweden, 2016. The Swedish model. [online] EEAG Report on the European Economy. Available at: <www.government.se/4a5336/contentassets/8416c4ff 1410419090181fe503920390/the-swedish-model.pdf $>$ [Accessed 5 Sep. 2019].

Gujral, G. and Beer, M., 2015. Digital at depth. [online] Available at: <www.accenture. com/t20150523T033713Z__w__us-en/_acnmedia/Accenture/Conversion-Assets/ DotCom/Documents/Global/PDF/Dualpub_9/Accenture-Digital-at-Depth-for-Govern ment-Innovation.pdf $>$ [Accessed 5 Sep. 2019].

IIS, 2016. Svenskarna och Internet [Swedes and the internet]. [online] Stiftelsen för internetinfrastruktur. Available at: <https://internetstiftelsen.se/docs/Svenskarna_och_inter net_2016.pdf $>$ [Accessed 5 Sep. 2019].

IVA, 2016. Resource efficiency policy development towards 2025: A report from the IVA project resource efficient business models - greater competitiveness. [online] Available at: <www.iva.se/publicerat/resource-efficiency-policy-development-towards-2025> [Accessed 5 Sep. 2019]. 
Jones, C., 2015. Hitting the brakes on Apple's electric car. [online] Available at: <www. forbes.com/sites/chuckjones/2015/02/14/hitting-the-brakes-on-apples-electriccar/1\#3539e77b18ac> [Accessed 5 Sep. 2019].

Nationalencyklopedin, 2017. Välfärd - Uppslagsverk [Welfare - encyclopedia]. [online] Available at: <www.ne.se/uppslagsverk/encyklopedi/lång/välfärd> [Accessed 5 Sep. 2019].

OECD, 2016. Digital government strategies for transforming public services in the welfare areas. [online] OECD Comparative Study. Available at: <www.oecd.org/gov/digitalgovernment/Digital-Government-Strategies-Welfare-Service.pdf $>$ [Accessed 5 Sep. 2019].

OECD, 2017. Health at a glance 2017. [online] Available at: <www.oecd.org/health/ health-systems/health-at-a-glance-19991312.htm> [Accessed 5 Sep. 2019].

OECD, 2018. Digital government review of Sweden enabling government as a platform through a data-driven public sector. [online] Available at: $<$ www.oecd.org/gov/digitalgovernment/key-findings-digital-government-review-of-sweden-2018.htm $>$ [Accessed 5 Sep. 2019].

Porter, M. and Heppelman, J., 2017. A manager's guide to augmented reality. [online] Harvard Business Review. Available at: <https://hbr.org/2017/11/a-managers-guide-toaugmented-reality $>$ [Accessed 5 Sep. 2019].

$\mathrm{SCB}, 2018$. Sveriges framtida befolkning 2018-2070 [The future population of Sweden 2018-2070]. Stockholm, Sweden: Statistics Sweden.

Vartiainen, J., 2017. The future of the European welfare states: the intriguing role of demography? European View, 16(1), pp. 131-9.

Wachter, R.M., 2015. The digital doctor: hope, hype, and harm at the dawn of medicine's computer age. New York, NY: McGraw-Hill Education. 


\section{The trust revolution \\ Blockchain's potential to resolve institutional inefficiencies?}

Alejandro Moreno Puertas and Robin Teigland

\section{Introduction}

In 2008, Satoshi Nakamoto published on the Internet the paper "Bitcoin: A peerto-peer electronic cash system" that introduced one of the most secure protocols in the open web (Nakamoto, 2008). The protocol, termed blockchain, distributes the point of failure across a network of different nodes, which are devices connected to the network, and provides the nodes with incentives to keep the system secure. As of 2019, Bitcoin has reached a market capitalization of USD62 billion with over 200,000 transactions per day without a single hacking incident of the underlying technology (Blockchain.com, 2019; CoinMarketCap, 2019). The blockchain protocol has also been used by a large number of entrepreneurs and traditional incumbents, such as governments and global financial institutions, to provide secure processes in the digital world. As a result, the blockchain industry has grown at an outstanding pace in the past two years. As we can see in Figure 16.1, both traditional investors, such as venture capitalists and angel investors, and crypto-enthusiasts have invested large amounts of money through equity funding rounds and initial coin offerings (ICOs), which are a new type of fundraising system enabled by blockchain (CB Insights, 2018; Coinschedule, 2018).

Figure 16.1 illustrates the recent growth of blockchain technology through recent investments. Equity funding investments were obtained from CBInsights (2018), and ICO amounts were obtained from Coinschedule (2018).

The recent growth motivates us to investigate the potential impact of blockchain on institutions. Keeping this goal in mind, we first provide a brief explanation of blockchain, followed by how it relates to the emergence of trust in institutions. We then discuss three case scenarios in which blockchain can be applied to reduce certain institutional inefficiencies. Finally, we venture into a discussion of the conceivable benefits of a nation implementing blockchain technology.

\subsection{A brief explanation of blockchain}

Blockchain is, above all, a security protocol that provides an irreversible proof of a transaction conducted on a digital network. The network is governed by nodes that decide to approve a state transition based on predefined rules. In the case of 


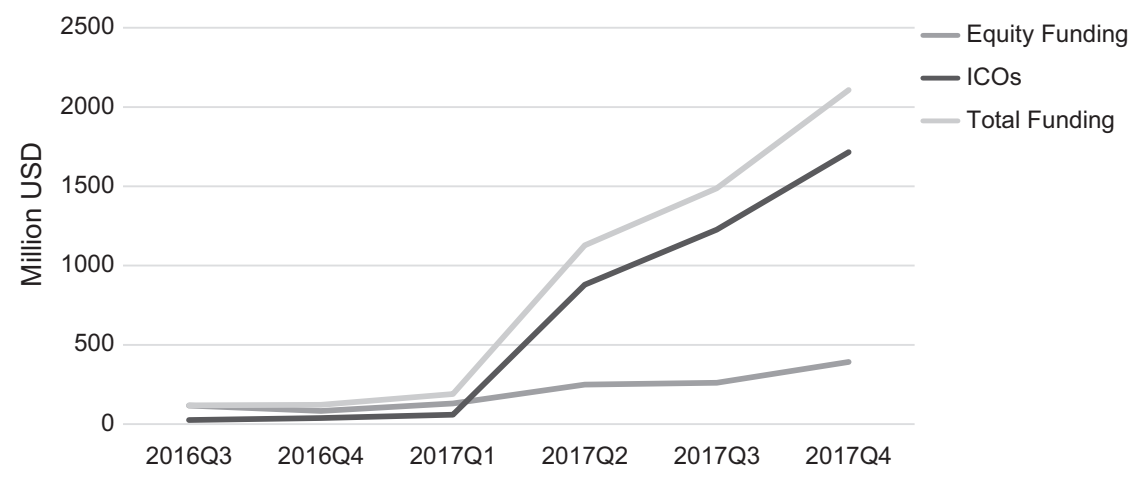

Figure 16.1 Blockchain investments

digital currencies, the network decides to approve a transaction by looking at the sender's transaction history. For instance, if Bob ${ }^{1}$ wants to send 5 BTC to another party, the network reviews the amount of BTC sent and received over Bob's lifecycle. If Bob received $10 \mathrm{BTC}$ and only spent $5 \mathrm{BTC}$, the network approves it. If Bob received $8 \mathrm{BTC}$ and spent $5 \mathrm{BTC}$, the network rejects it.

Another application of blockchain technology is smart contracts. With a smart contract, two or more parties agree on a series of predefined rules, which can be anything explicitly written in code, and the network approves the state transition depending on whether those predefined rules have been fulfilled. For instance, if Bob wants to buy a USD500 computer from Alice for delivery by UPS, they would both agree on defining a smart contract that has the following steps: ${ }^{2}$

1 A contract account is created.

2 Bob sends USD500 to the contract account.

3 Alice sends the UPS tracking number to the contract account.

4 If:

a UPS uploads in its tracking system that Bob has received the goods,

i The contract account releases the money to Alice.

b UPS does not upload in their tracking system that Bob has received the goods,

i The contract account releases the money back to Bob or, if Alice disputes it, a predefined court of preference decides where the money goes. ${ }^{3}$

Each step of the contract is completed after the majority of nodes approve that the condition is fulfilled. For instance, if Alice does not send a UPS tracking number or Bob does not receive the computer, the money will never be released to Alice. This process can be now performed at a near-zero cost through the blockchain 
instead of being performed through a trusted central party (e.g., a financial firm) in exchange for a small fee.

Blockchains can be divided into two types: private and public blockchains:

- $\quad$ Private blockchains have a finite set of trusted private nodes. Security is based on the private nodes not colluding to change the system as well as the difficulty of hacking the majority of them simultaneously.

- Public blockchains have a potentially infinite set of nontrusted public nodes that are motivated through a set of incentives. For example, public nodes have the option to "mine" blocks in exchange for cryptocurrencies. The cryptocurrencies that the miners receive can be either created by increasing the money supply or provided by the sender as transaction fees.

With the blockchain, and particularly smart contracts, code is "law" and anything that can be written in explicit code is possible (Moreno Puertas and Teigland, 2018). The resulting security that arises from distributing the decision-making process, which approves or rejects a state transition, is thus the most important feature of blockchain.

Although blockchain seems new, the protocol is based on the same principle that generated credible governments in the late 17th century - that of the distribution of power, which we discuss below.

\subsection{The emergence of trust in political institutions}

In the early 17 th century, the world was heavily reliant on centralized powers. Spain and France, the main superpowers, were governed by absolute monarchs, and both countries aimed to impose a strict Catholic regime around the world. Nevertheless, Britain was becoming increasingly aligned with the Protestant reform, which resulted in the Anglo-Spanish war (1585-1604).

Soon after the Spanish Armada was defeated in 1588, Britain decided to further sponsor its mercantile operations across the world in order to ensure survival. The expansion was eventually successful and resulted in the bourgeoisie class gaining economic power (Motley, 1892; Simon, 2017; Ulm, 2004).

In the 17 th century, Britain was involved in numerous wars, and its expenditures far exceeded its revenues. In order to keep financing its government, the Crown had to negotiate new sources of revenues, such as custom taxes and "forced loans," with the bourgeoisie class represented in the Parliament. In exchange for money, the Parliament requested the king to respect private property rights and cease monopolistic practices. However, the king had a tendency not to honor his promises and dissolve the Parliament if needed. Consequently, the emergent bourgeoisie class united to defeat the king. Over the century, through a series of civil wars culminating in the Glorious Revolution (1688), the bourgeoisie was able to establish politically aligned institutions (North and Weingast, 1989).

The new political institutions, as represented in the Parliament and independent courts, consisted of a diverse group of people. The distribution of power ensured 
that no group had too much power, thereby generating stability, as Douglass C. North, a 1993 co-recipient of the Nobel prize in economics, and Barry R. Weinstein $(1989$, p. 818$)$ stated in the following:

The new constitutional settlement endowed several actors with veto power, and thus created the beginnings of a division or separation of powers. Supplying private benefits at public expense now required the cooperation of the Crown, Parliament, and the court. ... The institutional and political changes significantly raised the predictability of the government ... [and] the government's ability to tap the resources of society increased.

As a result, the British government established credible property rights, became financially solvent, and increased borrowing to unprecedented levels. For instance, from 1630 to 1688 , the British government ran on average a total debt (obtained mostly through forced loans) of GBP1 million and had multiple defaults. In 1697, nine years after the Glorious Revolution, the British government raised its debt to GBP16.7 million (40 percent of GNP) without a significant increase in inflation. The ability to raise government debt allowed Britain to obtain enough resources to fight France in the Nine Years' War (1689-1697) and emerge as a superpower. Furthermore, with an independent judicial system and a strong parliament, the bourgeoisie class not only started to trust the government but also perpetuated the development of private debt markets (North and Weingast, 1989). Credit started to take a greater role in the economy as borrowers were able to put their guaranteed assets as collateral and lenders trusted their ability to claim them without government intermediation. Consequently, Britain experienced a financial revolution and a booming economy, acquiring global hegemony.

The distribution of power, which shifted the necessary trust from the king (central party) to the system (distributed parties) played a key role in this transition, as it enabled the British government to make credible promises, raise substantial amounts of debt, and develop its capital markets (North and Weingast, 1989). Today, almost every developed nation has implemented a similar system in order to foster economic growth and financial markets.

Blockchain is the enlargement of the already developed system present in modern economies to the open web. Blockchain brings different stakeholders into the equation and shifts trust from the centralized party to the distributed system. The protocol emerged as a solution to a series of failed attempts to create a new digital currency. Bitcoin, the first successful cryptocurrency, manages to stay resilient by providing incentives to users to participate in the decision-making process (Georgios, 2017). Today, the blockchain industry has evolved with many different types of governance, and the common denominator among them is, similarly to developed institutions, a distribution of power.

In the next sections, we are interested in how blockchain can diminish institutional inefficiencies that arise from centralized political elites. Nonetheless, in order to understand its potential impact, we must first understand why certain 
political elites are reluctant to distribute their power given its economic advantages and the consequences of a centralized government.

\section{Centralization of power}

Acemoglu, Johnson and Robinson (2005) argue that conflict of interest among various interest groups is the main cause that prevents central governments from implementing institutions that promote economic growth. Although a plausible solution to this is to negotiate the distribution of benefits among different groups (see Acemoglu's (2003) discussion on the political Coase theorem), the centralization of power incentivizes the political elites to choose institutions that satisfy their self-interests and do not constrain their future actions. Consequently, the decisions made by the government are not binding. This lack of commitment prevents groups from engaging in effective bargaining, thereby inhibiting improvements to the overall well-being of the country's citizens. Acemoglu, Johnson and Robinson (2005) discuss two main commitment problems: 1) political losers and 2) hold-ups.

\subsection{Political losers}

In many countries with centralized governments, the political elite obtains rents, incomes, and privileges through their power. For that reason, they evaluate every potential change based on its political consequences. This prevents them from promoting institutions that provide power to other groups, regardless of potential economic benefits. As we saw above in the financial revolution, Britain's support for mercantile expansion ended eventually with a ruling bourgeois class (North and Weingast, 1989).

This was also seen during the industrial revolution. As workers started to organize and demand rights in Britain, political elites in nearby countries, such as Russia and the Austro-Hungarian Empire, opposed building railways to prevent similar potential tumults. It was only after certain military defeats that they decided to engage in full-scale industrialization (Acemoglu, Johnson and Robinson, 2005).

\subsection{Hold-ups}

In hold-ups, there are two groups: the political elite and the investor who has no political power. The investor offers the political elite to make an investment in exchange for future returns.

- In ex-ante negotiations, both parties have bargaining power and are incentivized to cooperate. The political elite gains from the investment and the investor gains from the future returns.

- However, in ex-post negotiations, only the political elite has bargaining power. The investor has already made a sunk investment and depends on the political elite to enforce property rights and provide them with the returns. 
This problem has occurred many times throughout history. It is important to notice, as we explained in the financial revolution, that it was only after the merchant class obtained enough power that they were able to challenge the king and protect property rights (Acemoglu, Johnson and Robinson, 2005; North and Weingast, 1989). Furthermore, on many occasions, countries experience regime changes and the new political elites are not incentivized to honor any previous deals.

Except in rare cases of benevolent dictators, the distribution of power has thus been essential to promote the right economic institutions through effective bargaining. For that reason, a large part of the world, in which power tends to be concentrated, suffers from not having the desirable institutions, thereby depriving it of investment and long-term planning.

Nevertheless, with the emergence of the Internet, the world is becoming more digitalized and interconnected. Consequently, new opportunities are emerging to provide people from distant places with the right instruments to blossom in an ever-increasing digital world. Blockchain, with its security, is able to fill some of the gaps that arise from centralized governments by taking advantage of a global network to provide value-related services.

\section{The trust revolution}

In this section, we will focus on blockchain's potential to preserve private property and diminish the inefficiencies that arise from centralized political elites. We have divided this section into three parts: 1) digital currencies, 2) contracts and digital courts, and 3) tangible property rights.

\subsection{Digital currencies}

One of the main functions of a government is to establish a credible monetary system that enables its citizens to exchange goods and services. In most developed countries, the government sets up an independent central bank that is in charge of the money supply, thereby ensuring relatively stable exchange rates and price levels (e.g., EUR, USD) and, sometimes, other objectives such as high employment (e.g., USA). The central bank's independence is necessary in order to prevent governments from using their power to satisfy their short-term self-interests at the expense of their citizens' well-being.

However, in many less-developed countries with centralized power, the government has significant influence on the central bank, which results in a hold-up problem. In ex-ante negotiations, centralized governments promise to have the right monetary policies to encourage investments. However, once investments are made, the political elite has the power to print more money than expected in order to fund expenses and decrease debt.

This results in large price fluctuations and uncertainty that prevents households and firms from accurately forecasting future outcomes, such as cash payments (Poole and Wheelock, 2008; Barnes, Boyd and Smith, 1999; Tommasi, 1994). Furthermore, on many occasions, governments peg their national currencies at 
unrealistic fixed exchange rates, further hindering trade with other countries. As a result, black markets emerge for other stable currencies, which citizens buy at a premium (Investopedia, 2013).

Digital currencies transmitted through the blockchain have the potential to provide citizens with the opportunity to avoid the drawbacks from unreliable central banks. In this area "stablecoins," which are considered the "holy grail of cryptocurrencies," are of particular use. Stablecoins can be divided into two different types:

- Those that represent stable assets stored in a private location, for example, Tether (USD), DigiX (gold)

- Those that use a set of incentives to ensure price stability, for example, Maker and Havven

Stablecoins allow citizens to have easier access to parallel currency markets through the open web. For instance, lower-income countries receive large inflows of USD and EUR through remittances. These remittances tend to be expensive (on average a 7.13 percent transaction fee) and are converted through the official exchange rate, which reduces substantially the amount of money received (The World Bank Group, 2018; Beck and Martínez Pería, 2011). Eventually, it would be expected that parallel markets based on stablecoins would emerge to provide better mediums of exchange for local citizens. This would provide greater bargaining power, as citizens would have an alternative option to inefficient monetary policies.

\subsection{Contracts and digital courts}

An independent judicial system is essential to ensure that contracts, which are agreements between two or more parties, are enforced in accordance with the law (Merriam-Webster, 2018; Courts and Tribunals Judiciary, 2016). The foundations for the independence of the judicial system were laid out after the Glorious Revolution in 1688, which was discussed above with the financial revolution (Section 1.2). This system increased the level of cooperation in society, as people could rely on an independent judicial system to settle civil cases. This resulted in an economic boom, and other countries started to mimic the system. Today, most developed nations have a relatively independent judicial system.

However, this is not the case for many lower-income countries. Although a strong independent court system provides clear economic benefits (Keefer and Knack, 1997), many countries with centralized power structures are reluctant to set independent judicial bodies. This is an example of the political loser problem described earlier (Section 2.2). Political elites perceive an independent judicial system as a potential threat to their power and decide to enact suboptimal institutions to prevent it.

Blockchain has the potential to mitigate the problems that arise from dependent judicial systems through smart contracts. Smart contracts, as explained above, 
are programmable contracts that are self-enforced through a distributed network. With a smart contract, different parties agree on a set of predefined rules and the global node community accepts or rejects the state transition based on whether the predefined requirements have been fulfilled.

Currently, entrepreneurs are launching platforms that enable digital courts and provide clauses in case of disagreement. Digital courts are decided by the players within the networks and, usually, based on reputation. ${ }^{4}$ For instance, in Section 3.1, we explained the process of buying a computer through a smart contract. The fifth step contains an "else" function that allows, in the case of dispute, a court of preference to decide where the money will be moved. Once the court makes a decision, the global node community will move the digital currency to the desired destination.

In the blockchain world, digital courts are being promoted as parts of larger ecosystems that provide a digital landscape for individuals. Examples of such a system are 1) the Aragon Network and 2) Pangea. A brief explanation of both systems is included in the Appendix.

Smart contracts provide contract enforceability, and digital courts have rights over digital currencies. This diminishes, but does not eliminate, the need for a central party to supervise many commercial activities and enables cooperation among untrusted parties. Once again, the benefit of smart contracts and digital courts is that they provide alternatives to inefficient institutions. Unreliable courts prevent cooperation among untrusted parties, as they fear unjust verdicts in case of disputes. In the blockchain world, people can be assured that a contract will not be enacted if certain conditions have not been fulfilled and that any dispute will be solved in a digital court, which incentivizes cooperation among untrusted parties. For example, funds will not be moved unless the contract conditions are fulfilled, and, in the case of disputes, the funds will be dependent on the digital court's decision.

\subsection{Tangible property rights}

Property rights, which are a shared belief, have played a prominent role in the development of human civilization by promoting cooperation among humans. Nonetheless, for the vast majority of human history, this shared belief depended on a central party, which resulted in high volatility as the self-interests of the central party shifted over time. For instance, in medieval times, kings secured property rights for their people on many occasions but then later expropriated property if needed without a valid reason in the eyes of the common people (Acemoglu, Johnson and Robinson, 2005). The resulting volatility harmed cooperation, as people were never fully guaranteed that their property belonged to them. Only after a system of checks and balances was implemented, in which every decision required the approval of different independent bodies, did the financial industry emerge (North and Weingast, 1989). This system originated in the Netherlands and Britain and expanded across the current developed world. 
Yet, in countries with centralized power, the political elite still decides what can be expropriated. The resulting outcome is a hold-up problem. In the ex-ante situation, political institutions promise private property rights to encourage investment and stability. However, in the ex-post position, they have the ultimate power to expropriate assets when needed. This potential lack of commitment is accounted by investors and reduces their incentive to invest.

The blockchain may help to mitigate these problems by ensuring an adequate recording of every movement in a common distributed ledger. In the ex-ante situation, when both parties have bargaining power, the investor can require the use of blockchain technology in order to make an irreversible proof of every state movement, from any communication to payments. In the ex-post state, the centralized power will still have the power to expropriate, but the victim has an irreversible proof of every step conducted beforehand. This increases the likelihood of the victim recuperating their assets, as they have enough evidence to claim them in international courts or in future stable regimes.

However, the potential effect of blockchain technology on tangible property rights is not as high as in digital currencies and smart contracts. The reason is that tangible products, such as houses, cannot be physically moved through the open web, and their protection still relies on the government. Nonetheless, in the long term, the blockchain may help to reduce the incentives from central governments to expropriate, as they will always be accountable for their behavior.

\section{The hypothetical blockchain nation: going back to first principles}

In the previous sections, we have discussed the potential benefits of blockchain technology for currencies, contracts, and property rights. Each of these concepts is actually imaginary, or rather, an abstract idea provided by institutions to promote cooperation among ourselves (Soto, 2000).

- Currencies were created as an abstract medium of exchange that, compared to bartering, enhanced trade. Over time, currencies evolved from mint coins to bank notes to further increase the exchange of goods and services.

- Contracts originated as a set of promises and responsibilities attested by a group of witnesses. The enforcement of the contract tended to depend on centralized figures of power until the late 17th century, when courts started to become increasingly independent.

- $\quad$ Property rights were created as a framework to allocate resources. For most parts of human history, their allocation depended on the entities that had political power. In the late 17 th century, property rights evolved into fully guaranteed rights. The ability of citizens to exercise those rights enabled the development of the financial industry and long periods of economic growth.

Each of those abstract ideas requires trust in order to function properly. To maintain trust, governments have distributed power among a diverse group, ensuring 
that no person or entity has enough power to modify the pre-established concept (e.g., currencies, contracts, property rights). The resulting trust has allowed citizens to convert fixed assets into abstract forms and transact them at a low cost. For example, we can observe this abstraction when a company raises equity in exchange for US dollars:

- US dollars are an abstract concept that depends on an independent central bank, whose chairman is chosen by the president (executive power) and confirmed by the Senate (legislative power).

- The process of raising equity is done through a contract that is based on current laws (legislative power), which are enforced by the president (executive power) and in cases of dispute, judged by the courts (judicial power).

- The outcome, a stock, is a type of property right, which is protected by the executive, legislative power, and judicial power.

As we can see, each abstract concept depends on an agreement by a diverse group of people. Today, the total value of all stocks in all companies globally amounts to around USD80 trillion. These assets in their abstract form are constantly transacted in an imaginary financial world, which offers low transaction costs and results in an efficient allocation of capital.

This distribution of power, which guarantees trust, is also the basis of blockchain technology. Nonetheless, the abstract concept does not need to fully depend on the trust provided by an institution, which may or may not decide to distribute power, but on the trust provided by a global distributed network through the open web.

Having the aforementioned government services, relying on the open web can substantially diminish transaction and information costs, potentially resulting in another financial revolution. This would have an even greater impact in the developing world, as institutions have not yet managed to provide the trust needed to fully benefit from abstracting assets.

We can already see this disruption through the rise of initial coin offerings. Although studies have shown that more than 80 percent of ICOs are scams (Kelso, 2018), they have provided a clear medium of exchange between an abstract idea, usually represented in the form of a whitepaper, and an abstract digital currency. Since 2017, ICOs overtook venture capital funding, which is the traditional method for exchanging currencies for ideas, to blockchain startups by over 3.5 times, from USD1.3 billion to USD4.5 billion, respectively (Rowley, 2018). One of the main reasons behind this disruption is that digital currencies allow any person from anywhere to invest in an idea presented in the open web.

We can imagine a similar disruption occurring in the developing world if a government, or an independent society, decides to fully implement blockchain technology. For instance, imagine a hypothetical nation called SatoshiLand. SatoshiLand has implemented blockchain from the ground up:

- Every property is registered in the public ledger.

- Every property and currency movement needs to be accepted by the global set of nodes and is published in the public ledger. 
- Smart contracts regulate most contractual relations between different parties and have clauses that, in case of disagreements, allow a digital court chosen by the network to resolve the disputes based on available data.

SatoshiLand would provide international investors an irreversible proof of every transaction conducted. This would substantially reduce scams, given the recent success of behavioral analysis in fraud prevention. A firm may be able to bribe an auditor, but it is unlikely that it can mimic the behavior of a business, in terms of transactions and properties, over many years. Investors would also be able to transfer funds almost instantly from anywhere and monitor how the firm uses their funds.

For example, suppose that an imaginary firm in SatoshiLand wants to raise money from an international lender to increase its shoe production. In the current world, the lender would charge a high premium, as it experiences information asymmetries and mistrusts the local legal system. In SatoshiLand, the international lender would have access to the inflows and outflows of the company over the past years. This information could not be forged and would be extremely expensive to mimic. Furthermore, the investor could arrange a contractual agreement through the blockchain that specifies how the money is spent and adds clauses in case of dispute, which would allow a digital court to redistribute the remaining digital currency if the borrower is at fault. The result would be 1) a lower risk rate and 2) a larger supply of funds through the international sphere. Overall, international lenders would be able to accurately forecast risk and improve substantially the efficient allocation of capital, which would result in higher economic growth.

Furthermore, citizens would be able to engage in global savings schemes due to the free flow of capital. Economic literature emphasizes how people can maximize their utility by smoothing their consumption over their life cycle using financial instruments. Yet, a large portion of the world does not have access to these financial instruments. If they experience unexpected events, they have to reduce their consumption or rely on informal high interest rate networks (Kast and Pomeranz, 2014). Kast and Pomeranz (2014) showed that access to formal savings reduces substantially reliance on informal credit networks, thereby improving the welfare of the poor. With stable digital currencies, lower-income people would be able to access international saving schemes through the open web and increase their consumption smoothing. This enables them to be self-insured regardless of local government policies.

Finally, diminishing information asymmetries could also reduce government fraud and increase government efficiency. Several studies have shown that people are reluctant to pay higher taxes when their governments cannot be held accountable (Glaser and Hildreth, 1999; Ortega, Ronconi and Sanguinetti, 2016). This means that people who may want more government services are voting for budget reductions due to a lack of trust. In SatoshiLand, since every government expenditure post has a digital trace accessible in the open web, citizens would be able to audit their governments and vote accordingly. In the long term, we would expect a more effective government that matches citizens' preferences. Given that the willingness to pay taxes increases with government efficiency and accountability, we expect a greater role of the government under this potential scenario. 
Although the implementation of this type of digital nation seems far off, countries are already starting to use the blockchain for 1) registering properties and mortgage deeds, 2) increasing transparency, and 3) transacting digital currencies.

In our theoretical framework, the institutional spillovers arose from those nations that were able to adapt best to the emerging conditions. Blockchain technology enables a new type of irreversible digital trace that provides an unprecedented level of accurate information to both international investors and citizens. This would provide firms and citizens with access to international financial markets and governments with a greater source of revenues, potentially resulting in another financial revolution.

\section{Conclusion}

The distribution of power among a diverse group of people has formed the basis of credible governments and enables the emergence of financial markets. Blockchain brings this distribution of power to the digital landscape and creates trust in the open web. The benefits from this newly developed trust are still unclear. However, we see a tremendous potential in the developing world, as it enables their citizens to 1) access international financial resources and 2) provide an irreversible digital trace of their actions, which substantially mitigates information asymmetries. Nonetheless, our model is still in its nascent stage and has not discussed potential drawbacks (e.g., privacy concern) or the possible solutions to those concerns (e.g., zero knowledge proof or the decentralizing privacy model). We encourage future work in those areas and an empirical approach to measure the outcome of blockchain projects in developing countries. Our objective is not to justify our theory but to bring it as a starting point to discuss the potential benefit of blockchain technology in the institutional landscape. 


\section{Appendix}

\section{Aragon Network}

The Aragon Network is a decentralized autonomous organization and a blockchainbased ecosystem where companies, investors, and entrepreneurs can securely transact and enforce smart contracts. The Aragon Network aims to provide a hybrid between smart contracts and real-world business applications using a decentralized court system called the Aragon Network Jurisdiction (ANJ). Any person with an Aragon token (ANT) can create a bond, which is a call for arbitration. The judges are drawn from a sample of people/entities who also posted a bond. If the person/entity selected decides to not participate, it will be penalized.

The selected judges will then look at ANJ and at organization-specific rules to state a verdict. If all the judges have a unanimous vote, they all receive back the bond, which was created in order to request an arbitration. If the vote is not unanimous, the verdict that had the most votes will be chosen. The judges that voted for the verdict that had the minority of votes will be penalized. This aims to create a dynamic judicial court that is based on incentives.

The agent, if not satisfied, can request an upgrade to a marketplace in which all judges can participate. Finally, if the user is still not satisfied, they can take the case to the "Supreme Court," which is composed of nine judges chosen by the whole Aragon network.

If the judges feel that the user has not posted enough information to make a case, the judges have the right to dismiss it. However, if the user requests an upgrade and the case is then approved by a higher hierarchy, the low-tier judges will be penalized. This provides the incentive that 1) people spend time on giving a detailed and understandable case and 2) if judges decide to slack off, they will be penalized (Cuende and Izquierdo, 2017).

\section{BitNation}

BitNation is a global free market for governance services based on the Pangea Jurisdiction. The Pangea Jurisdiction is decentralized software that allows citizens to conduct peer-to-peer (P2P) arbitration and create nations. The whole system is based on irreversible reputation, which is gained through feedback similar to the Uber and Airbnb rating systems. 
Citizens are encouraged to develop smart contracts, reach agreements, and solve disputes through the Pangea Arbitration Token (PAT). The PAT contains both nontradable and tradable tokens.

Nontradable tokens serve to build reputation and are rewarded based on performance metrics (rated by AI) and user satisfaction (rated by other humans). There are three types of nontradable tokens:

- POA (Proof of Agreement): Given to users and arbitrators based on performance criteria with smart contract creation and execution.

- $\quad$ POC (Proof of Collective): Given to nations, user groups, and governance services based on users' satisfaction with collective contract creation and execution.

- $\quad$ PON (Proof of Nomic): Given to contracts, laws, and legal codes based on user satisfaction.

Tradable tokens (PATs) serve to pay for 1) arbitrators, judges, and juries and to 2) timestamping and executing smart contracts. PATs are rewarded to founders and contributors (32 percent), external stakeholders through a token sale (34 percent), and those who maintain high reputation scores (34 percent). A total of 42 billion tokens will be released through different stages (Tempelhof et al., 2017).

\section{Notes}

1 In reality, "Bob" is a public key.

2 This process is simplified to provide a clear explanation of the protocol.

3 Courts are a relatively new concept in the blockchain landscape. They are explained in detail in Section 3.2.

4 In the appendix, we have included two blockchain platforms that exemplify how courts are composed.

\section{References}

Acemoglu, D., 2003. Why not a political Coase theorem? Social conflict, commitment, and politics. Journal of Comparative Economics, 31(4), pp. 620-52.

Acemoglu, D., Johnson, S. and Robinson, J., 2005. Institutions as a fundamental cause of long-run growth. In: P. Aghion and S. Durlauf, eds. Handbook of economic growth volume 1A. Amsterdam, Netherlands: Elsevier, pp. 385-472.

Barnes, M., Boyd, J.H. and Smith, B.D., 1999. Inflation and asset returns. European Economic Review, 43(4-6), pp. 737-54.

Beck, T. and Martínez Pería, M.S., 2011. What explains the cost of remittances? An examination across 119 country corridors. The World Bank Economic Review, 25(1), pp. 105-31.

Blockchain.com, 2019. Confirmed transactions per day. [online] Available at: <www. blockchain.com/charts/n-transactions $>$ [Accessed 10 Sep. 2019].

CB Insights, 2018. Blockchain startups absorbed $5 X$ more capital via ICOs than equity financings in 2017. [online] Available at: <www.cbinsights.com/research/blockchainvc-ico-funding $>$ [Accessed 10 Sep. 2019]. 
CoinMarketCap, 2019. Bitcoin price, charts, market cap, and other metrics. [online] Available at: <https://coinmarketcap.com/currencies/bitcoin $>$ [Accessed 10 Sep. 2019].

Coinschedule, 2018. Cryptocurrency ICO statistics. [online] Available at: <www.coin schedule.com/stats.html?year=2017> [Accessed 12 Aug. 2019].

Courts and Tribunals Judiciary, 2016. Judiciary, the government and the constitution. [online] Available at: <www.judiciary.gov.uk/about-the-judiciary/the-judiciary-thegovernment-and-the-constitution/jud-acc-ind/independence $>$ [Accessed 10 Sep. 2019].

Cuende, L. and Izquierdo, J., 2017. Aragon Network a decentralized infrastructure for value exchange. [online] Available at: $<$ https://www.chainwhy.com/upload/default/2018 0705/49f3850f2702ec6be0f57780b22feab2.pdf> [Accessed 10 Sep. 2019].

Georgios, K., 2017. Understanding blockchain fundamentals, part 1: Byzantine fault tolerance. [online] Available at: <https://medium.com/loom-network/understandingblockchain-fundamentals-part-1-byzantine-fault-tolerance-245f46fe8419> [Accessed 12 Aug. 2019].

Glaser, M.A. and Hildreth, W.B., 1999. Service delivery satisfaction and willingness to pay taxes: citizen recognition of local government performance. Public Productivity \& Management Review, 23(1), pp. 48-67.

Investopedia, 2013. Currency trading on the black market. [online] Available at: <www. investopedia.com/articles/investing/031213/currency-trading-black-market.asp> [Accessed 12 Aug. 2019].

Kast, F. and Pomeranz, D., 2014. Saving more to borrow less: experimental evidence from access to formal savings accounts in Chile experimental evidence from access to formal savings accounts in Chile. No. [online] NBER Working Paper Series, No. 20239. Available at: <www.nber.org/papers/w20239> [Accessed 10 Sep. 2019].

Keefer, P. and Knack, S., 1997. Why don't poor countries catch up? A cross-national test of institutional explanation. Economic Inquiry, 35(3), pp. 590-602.

Kelso, E., 2018. New study: 80\% of ICOs are scams, only 8\% reach an exchange-Bitcoin News. [online] Available at: <https://news.bitcoin.com/80-of-icos-are-scams-only-8reach-an-exchange $>$ [Accessed 12 Aug. 2019].

Merriam-Webster, 2018. Contract | definition of contract. [online] Available at: <www. merriam-webster.com/dictionary/contract> [Accessed 12 Aug. 2019].

Moreno Puertas, A. and Teigland, R., 2018. Blockchain technology: the internet of value. In: R. Teigland, S. Siri, A. Larsson, A. Moreno Puertas and C. Ingram Bogusz, eds. The rise and development of FinTech: accounts of disruption from Sweden and beyond. London, UK: Routledge, pp. 276-308.

Motley, J., 1892. The rise of the Dutch republic: a history. New York, NY: Harper \& Brothers.

Nakamoto, S., 2008. Bitcoin: a peer-to-peer electronic cash system. [online] Available at: $<$ https://bitcoin.org/bitcoin.pdf $>$ [Accessed 12 Aug. 2019].

North, D.C. and Weingast, B.R., 1989. Constitutions and commitment: the evolution of institutions governing public choice in seventeenth-century England. The Journal of Economic History, 49(4), pp. 803-32.

Ortega, D., Ronconi, L. and Sanguinetti, P., 2016. Reciprocity and willingness to pay taxes: evidence from a survey experiment in Latin America. Economía, 16(2), pp. 55-87.

Poole, W. and Wheelock, D.C., 2008. Stable prices, stable economy: keeping inflation in check must be no. 1 goal of monetary policymakers. [online] Regional Economist. Available at: <www.stlouisfed.org/publications/regional-economist/january-2008/sta ble-prices-stable-economy-keeping-inflation-in-check-must-be-no-1-goal-of-monetarypolicymakers> [Accessed 10 Sep. 2019]. 
Rowley, J., 2018. ICOs delivered at least 3.5x more capital to blockchain startups than VC since 2017. [online] TechCrunch. Available at: <https://techcrunch.com/2018/03/04/ icos-delivered-at-least-3-5x-more-capital-to-blockchain-startups-than-vc-since-2017> [Accessed 12 Aug. 2019].

Simon, A., 2017. BBC - history - The Spanish Armada. [online] Available at: <www.bbc. co.uk/history/british/tudors/adams_armada_01.shtml $>$ [Accessed 12 Aug. 2019].

Soto, H. de, 2000. The mystery of capital: why capitalism triumphs in the west and fails everywhere else. New York, NY: Basic Books.

Tempelhof, S.T., Teissonniere, E., Tempelhof, J.F. and Edwards, D., 2017. Pangea jurisdiction and Pangea Arbitration Token (PAT): the internet of sovereignty. [online] Available at: <https:/github.com/Bit-Nation/Pangea-Docs/blob/master/BITNATION\%20 Pangea\%20Whitepaper\%202018.pdf $>$ [Accessed 12 Aug. 2019].

Tommasi, M., 1994. The consequences of price instability on search markets: toward understanding the effects of inflation. The American Economic Review, 84(5), pp. 1385-96.

Ulm, W., 2004. The defeat of the English Armada: a more detailed look at the Spanish Armada and its aftermath. [online] Available at: $<\mathrm{http}$ //wesulm.bravehost.com/history/ eng_armada.htm $>$ [Accessed 10 Sep. 2019].

The World Bank Group, 2018. Remittance prices worldwide. [online] Available at: $<$ https://remittanceprices.worldbank.org/sites/default/files/rpw_report_march2018.pdf $>$ [Accessed 10 Sep. 2019]. 


\title{
17 The future of the nation-state How the nation-state can find a way through digitalization
}

\author{
Mats Lewan
}

\section{Introduction}

It is commonly recognized that the Internet and digital technologies are bringing about a fundamental and sometimes disruptive change to businesses, society, and the lives of individuals (Kenney, Rouvinen and Zysman, 2015). The overall phenomenon is often referred to as digitalization, whereas the process of effectively adapting to digitalization is called digital transformation.

This chapter aims at investigating the potential future of the nation-state in the context of change brought about by the Internet and digitalization. Will the nationstate go through a process of digital transformation, altering its characteristics to be more in line with the conditions of a digitalized world and with the changed expectations of its citizens, maintaining their support? Or will it be completely disrupted and potentially replaced by some other organizational structure, better adapted to meet the future demands of people and organizations living together on our planet, in a world shaped by digital technologies?

\section{Methods}

The underlying theory that will be used in this chapter is a framework called the innovation loop, developed by the author, loosely inspired by evolutionary theories, mainly the concept of natural selection and the survival of the best adapted ${ }^{1}$ by Charles Darwin, and the theory of how innovations diffuse, presented by Everett Rogers in his seminal work Diffusion of Innovations (Rogers, 1962).

The basic principle of the innovation loop (see Figure 17.1) is that evolutionary steps in the biological system can be compared to human inventions and that, in a generalized sense, the evolution not only of species but also of technology, businesses, and society can be seen as a result of natural selection and survival of the best adapted - be it organic beings, individuals, products, services, processes, organizations, or societal structures.

A natural phase of the loop to start looking at is the point of an invention. Although human inventions are mostly made through human thinking, while biological evolutionary steps occur through random variations such as mutations, both are based on previous steps, and both, if favorable, diffuse gradually. 


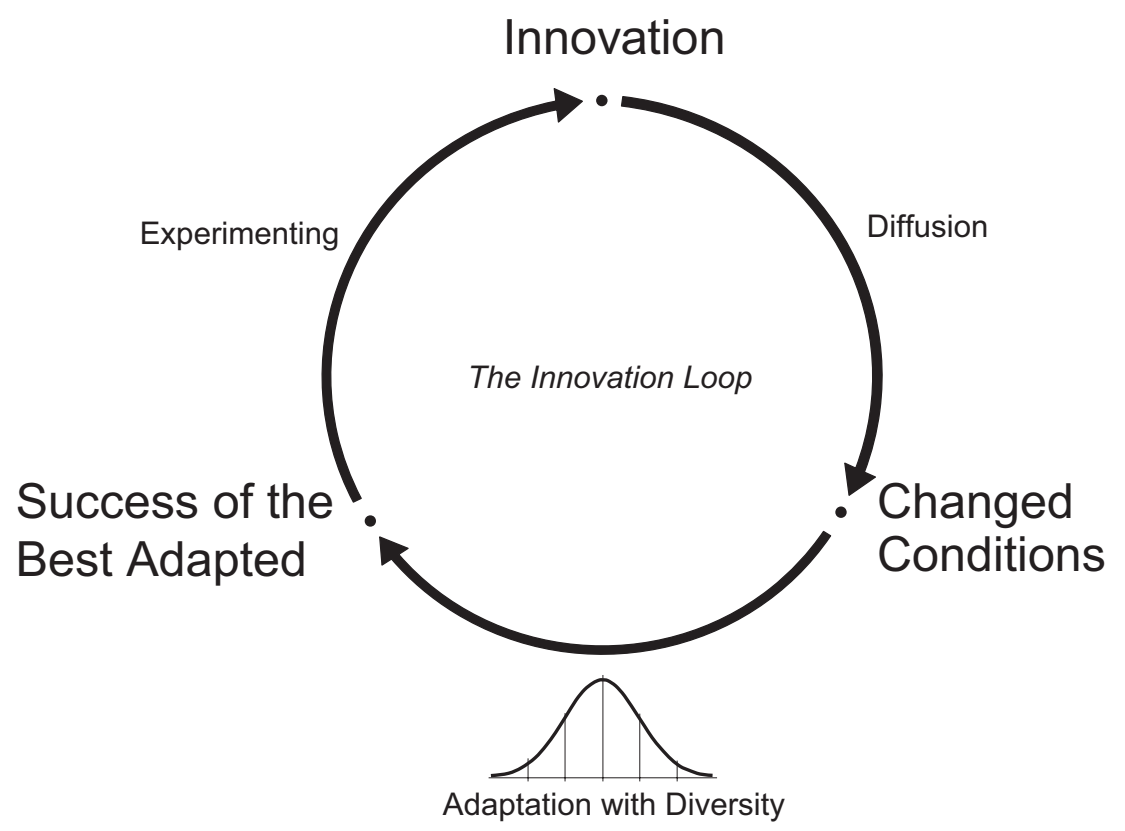

Figure 17.1 The innovation loop

Source: Model by the author.

Biological evolutionary steps diffuse through inheritance and natural selection and human inventions through individuals' varying tendency to adopt them, as described by Rogers with concepts such as early adopters, early majority, late majority, and laggards.

When a favorable evolutionary step or an invention reaches a certain level of diffusion, it starts changing the conditions for everything in the surrounding system. This is most notable for larger evolutionary steps and larger inventions, with examples ranging from sexual reproduction and sight to the wheel, the printing press, the steam engine, and the Internet.

As a consequence, organic beings, individuals, and organizations will have to adapt to the new conditions, and those who are best adapted will be the most successful. This is arguably also valid for products, services, and structures, which are being adapted by humans according to changed conditions. The adaptation process is similar in the biological system and in the innovation system, especially regarding behavioral adaptation, and it is effectively described through the concept of natural selection.

One recent example could be a person adapting to the availability of an Internet connection, starting to write emails instead of letters and searching for information on the web instead of in libraries and books. 
It is worth noting the importance of diversity in the process of adaptation - the less diversity, the less variety of ways to adapt. Moreover, the less variety of ways to adapt, the higher the risk of weak points being shared by various, multiple entities in the system. This would in turn make the system, as a whole, more vulnerable. To a certain extent this is also true for the diffusion phase, and altogether this is arguably the fundamental reason for striving for increased diversity of all sorts in all systems and in all situations since change and innovation occur continuously everywhere.

Once the initial adaptation process has been established, an extended form of adaptation takes place. This phase consists of various types of experimenting, for example, combining the initial invention or evolutionary step with others already existing in the system, or exploring opportunities to build inventions on top of the initial one. Humans do this through innovation, while nature uses random variations such as mutations. Since this phase leads to new inventions, it completes the cycle: innovation, changed conditions, and success of the best adapted.

An example of the last phase would be the combination of the Internet and of commerce, paving the way for E-commerce.

A few more observations can be made regarding the innovation loop:

- It's not a serial process. Many loops are running in parallel, interacting with each other.

- $\quad$ The result of each cycle can be described as increased self-organization and increased efficiency. This can be better observed looking at a large time span, billions of years back. Early life started with single-celled prokaryotes that evolved into multicellular eukaryotes, then into plants and animals - animals through reptiles and mammals, into apes, eventually walking on two legs, gaining intelligence, and evolving into homo sapiens, inventing the spoken language, agriculture, the wheel, the written language, the printing press enabling the scientific revolution, the steam engine enabling the industrial revolution, electricity, telephone, radio, the Internet, the World Wide Web, the smartphone, and further inventions now being developed. Unless there is a divine power influencing this evolution, what we are looking at is one single self-organizing system. Although the smartphone should hardly be considered the "crown of creation," efficiency is steadily increasing in the meaning that what can be achieved with a certain amount of energy, resources, and number of organic beings has never been more than today.

- The pace of change is constantly increasing, which can be concluded noting the time span between early evolutionary steps, for example, about two billion years from eukaryotes to prokaryotes, and comparing it to the time span between recent major inventions, for example, about 17 years from the World Wide Web to the smartphone. Ray Kurzweil has proposed an explanation for this increase in pace of change in his essay "The Law of Accelerating Returns," where he argues that "Evolution applies positive feedback in that the more capable methods resulting from one stage of evolutionary progress are used to create the next stage. As a result, the rate of progress of an 
evolutionary process increases exponentially over time. . . Biological evolution is one such evolutionary process. Technological evolution is another such evolutionary process" (Kurzweil, 2001, paras.11, 15, 16).

- The evolution described by the innovation loop will arguably continue, resulting in increased self-organization and increased efficiency at an everincreased pace of change until it potentially fails because of lost stability, for example, due to failure to balance available resources with consumption and recycling of resources.

The framework of the innovation loop will be used in this chapter to analyze the roots, the construction, and the development of the nation-state from the perspective of change brought about by inventions. Specifically, it analyzes the future evolution and the fate of the nation-state under the influence of the Internet and digital technologies - arguably the most important field of inventions of our time.

The invention-related analysis will be integrated with ideas and findings on the topic of the future of the nation-state presented in a number of articles and academic papers, and with opinions and ideas expressed in personal interviews with a series of people throughout April 2018 to May 2018.

\section{Results and discussion}

\subsection{Definitions}

Essential to this analysis is a definition of the nation-state. There is some common confusion about the use of the terms nation, state, nation-state, and nationalism. The definitions that will be used here are that nation is a cultural term referring to a body of people bound together by certain aspects that give them a sense of unity, making them feel that they have something in common and differ from other people; state is a political term, referring to a body of people who live on a definite territory and are unified under a set of institutional forms of governance, which possess monopoly of coercive power and demand obedience from people; and the nation-state is a merger of the two terms, implying that politics and culture support each other (Lu and Liu, 2018).

It must be noted that although nation is a cultural term, what gives people a sense of unity does not have to be a common history and a culture derived from a common descent or ethnicity. The source of unity might also be democracy and a common political will where the members have equal rights. These two approaches are commonly called the ethnic approach and the civic approach (Hutchinson, 2003; Lu and Liu, 2018).

This is also why the nation-state is not immediately related to the concept of nationalism, which could be seen as a strong emphasis on the ethnic approach of the nation, often better explained by the term ethno-nationalism.

Also, the state can be related to the two approaches. The ethnic approach argues that people's trust in the state derives from deeply rooted cultural values that are learned from an early age, leading to an interpersonal trust, which in its extended 
form builds trust in the state. The civic approach, on the other hand, maintains that the trust in the state is built on the performance of political institutions $(\mathrm{Lu}$ and Liu, 2018).

\subsection{Origins and development of the nation-state}

Looking at the nation-state from the perspective of innovations, its early roots can be considered to go far back in human history. Spoken language - one of humans' first and most important inventions, which is believed to have evolved between 50,000 and 200,000 years ago - changed the conditions for human interaction by introducing the oral tradition. This is arguably an important base for human culture and thus for building culture-based communities, which in turn are a building block for the nation according to the ethnic approach.

The invention of agriculture from about 10,000 years ago brought people closer together in villages, and a reasonable adaptation might have been improved methods for defining property and for resolving disputes. Another communications technology, written language, which was invented about 5000 years ago, probably helped in that matter. This could be seen as the early roots of the state.

Going ahead in history, there are different opinions among scholars whether the nation was formed as a consequence of the state or the contrary.

Early forms of modern states from the 13th century and onward are by some considered to have been formed through war, where warfare contributed to an increasingly centralized administration in order to impose taxes and enforce order (Hutchinson, 2003). Centralized and more complex administration was also developed due to improvements in agriculture productivity, which made it possible to sustain larger populations. Inventions and discoveries in other areas such as political economy, mercantilism, and cartography further strengthened the state, all leading to people in nations being more united, thus indicating that the nation emerged as a result of the state.

On the other hand, inventions such as the printing press gave rise to increased literacy, strengthening of national languages, and sharing of common knowledge, tales and culture, while it also led to increased reliability of trade for example, through the spreading of knowledge of techniques like double-entry bookkeeping, all entailing an increased interconnection between people, potentially building a sense of unity, which in turn could support the state. This consequently suggests that the state was built on the nation (Anderson, 1991).

Regardless of whether the nation led to the state or the other way around, or a combination of both - which might seem reasonable - another observation remains: inventions in fields such as warfare, agriculture, printing, trade, and communications all changed the conditions for people and society. Consequently, people and society had to adapt to these changed conditions in ways that gradually strengthened both the nation and the state.

The merger of the two, that is, the nation and the state, and the subsequent establishment of the nation-state in its modern form, is commonly considered to be a result of the Treaty of Westphalia in 1648 (Schwartzwald, 2017). Until then, 
many different powers, religious as well as civic, had an overlapping authority on nations, territories, and populations. The essential outcome of the Peace of Westphalia was that states were guaranteed sovereignty over a nation, its territory, and its population, thus forming a nation-state, and that other states would refrain from interfering with internal affairs in neighboring territories, for example, by supporting foreign co-religionists in conflict with their states.

The resulting international system of independent and sovereign nation-states has been compared to billiard-ball interactions - an anarchical society of external interactions between states (Thompson and Hirst, 1995).

From an internal perspective, it did not matter in this system whether states were empires or based on homogenous nations or if they were autocratic or democratic. But again, inventions influenced the evolutions of states. It has been argued, for instance, that improved communications technology - roads, rail, and the steam engine - made it technically possible to bypass local leaders and impose direct rule as opposed to indirect rule, thus ending the age of empires (Hechter, 2001; Hutchinson, 2003). Reasonably, other communications technologies - printing, telegraph, telephone, and radio - over time reinforced this trend. Such technologies also supported the spreading of information and the evolution of democratic systems. And, in fact, democracy is often considered to have given legitimacy to the sovereign power of the state, replacing a sovereign autocrat or king, eventually including citizens and binding them together and thus strengthening the nation-state (Thompson and Hirst, 1995).

Representative governments could also create uniform national systems for administration, education, and public health, again supporting increased inclusiveness and homogeneity of the population. During the 20th century, states also acquired the means to manage national economies - through state planning in the Communist world and by Keynesian measures in the Western world.

This is seen by many as the final glorious days of the nation-state before its demise under the pressure of globalization and digitalization. One early blow to the logic of a world composed by independent and autonomous nation-states was the end of the Cold War in 1989, when the Berlin Wall came down and when US President George H. W. Bush and Soviet General Secretary Mikhail Gorbachev met at the Malta Summit, making declarations of cooperation and peace. Already the Cold War in itself, emerging as a result of nuclear weapons technology, had destabilized the idea of independent nation-states, since the devastating power of nuclear weapons had made it essentially impossible for nuclear powers to win a war. The prospect of a nuclear conflict was unthinkable destruction on both sides, and thus the idea of settling disputes with war in the anarchical system of independent nation-states became impassable.

Yet, a nuclear attack remained a palpable threat and a possible scenario for many during the Cold War, making states necessary. With the end of the Cold War, however, this argument became more diffuse, while the effects of an increasingly global economy gained more attention.

A common view since then, summed up by the term globalization, is that in a global economy, market forces are stronger than any nation-state. Capital is 
mobile, while labor is not, meaning that capital moves where the conditions are most favorable, forcing nation-states to compete by providing such conditions. The nation-state thus has had to give up some of its autonomy and sovereignty the exclusive power to independently manage instruments such as national labor rights and monetary and fiscal policies. From this perspective, nation-states are becoming to the world what local authorities used to be to the state - providers of desired conditions for attracting businesses without the power to shape economy or employment within its territory.

This view, at least in its most far-reaching form, has been contested, for example, in the article "Globalization and the Future of the Nation-State" (Thompson and Hirst, 1995). The authors admit that there is some truth in the globalization view - states are less autonomous, they have less exclusive control over the economic and social processes within their territories, and they are less able to maintain national distinctiveness and cultural homogeneity.

Thompson and Hirst (1995) argue, however, that the changes are not as profound as they may seem for a series of reasons, among them that the number of genuine transnational companies (TNCs) is small, foreign trade flows and patterns of foreign direct investment are highly concentrated to advanced industrial states and a small number of newly industrialized countries, the thesis that capital is moving inexorably from high-wage advanced countries to low-wage developing countries is inaccurate in aggregate, and the evidence that world financial markets are beyond regulation is by no means certain.

An example of the last point is a series of international investigations, blacklists, and measures against tax havens in recent years, in order to reduce tax avoidance, estimated at $£ 506$ billion each year (Boffey, 2017).

Thompson and Hirst (1995) also argue that the reduced autonomy of the nation-state doesn't deprive it of an important role in a global system of governance. Instead, because of its relationship to territory and population, the role of a nation-state is pivotal as a source of legitimacy for transferring power both "above" it and "below" it - above through agreements with other states in various international organizations and bodies, and below it through a constitutional balance within its own territory among central, regional, and local governments, and also with publicly recognized private governments in civil society.

According to Thompson and Hirst (1995), nation-states can do this in a way no other agency can, because they provide legitimacy as the exclusive voice of a territorially bounded population. They admit that such representation is very indirect, but that it is the closest to democracy and accountability that international governance is likely to get.

\subsection{The impact of digitalization}

In the last decades, global mobility of technology has been added to that of capital. With the broad diffusion of the Internet, technology and information are vastly more mobile than they ever were before. 
From the perspective of the innovation loop, a few of the major changed conditions brought about by the Internet and by the first wave of digital technologies are that:

- Computer software can be used to effectively manage, process, and analyze most kinds of information and contents, making an increased level of automation possible.

- The cost of a digital copy is essentially zero - thus, once information, processes, contents, services, products, or even weapons have been digitalized, they can be copied at large scale at a minimal cost.

- The whole world can be reached with one click, not just with a phone call as through the telephone network, but with basically anything that can be digitalized.

- Once products and services have been digitalized, they can be mixed with other products and services much more easily than ever before.

- The Internet connects people peer-to-peer across the world, which means that horizontal structures for human activity, as opposed to hierarchical or vertical structures, which have been the norm for thousands of years, are becoming functional at a large scale.

Among the consequences or adaptations to these new conditions are:

- A major change in business models with a general shift from owning to accessing and from products to services, since what is digital can be copied almost infinitely and what is not digital can be shared efficiently on digital platforms (often referred to as the sharing economy), with a subsequent concentration of users to a few large digital platforms through the network effect ${ }^{2}$

- An increased reliance on horizontal structures such as social networks and informal networks for knowledge and news distribution, with partially unexpected effects such as trolling and fake news

- An increased focus on purpose in human activities - for example, in businesses where purpose may become as important as the basic requirement of long-term profitability - reasonably as a consequence of the opportunities the Internet offers for horizontal collaborative work with significant global impact at a scale that was only attainable by states and global corporations a few decades ago, for example, Wikipedia and open-source software

- An increased focus on customer experience since it is easier than ever to launch a product or a service offering with limited resources, targeting the whole world, and since this entails intensified competition for people's attention and steadily higher expectations among users and customers for ease, convenience, and transparency

- The emergence of a fourth military branch beyond Army, Air Force, and Navy - a cyber-warfare branch, along with a generally increased focus on cybersecurity in businesses and in society, as a consequence of the growing possibilities to perform highly effective cyberattacks, ranging from criminal 
activities aiming at economic gain, to state-supported activities with the purpose to inflict damage on enemy countries

The collective term for these phenomena is digitalization, whereas the ways in which businesses or public entities or agencies adapt in order to remain competitive and relevant in a digitalized world is often called digital transformation.

Although digitalization is regularly perceived as an established and stable ongoing process, it can be argued that it is only at its beginning, noting that most organizations, private or public, only just started their digital transformation.

Furthermore, before the first wave of digitalization has even reached its full power, a second wave is emerging with technologies such as AI and machine learning; natural language processing and cognitive computing, with effective voice interaction and human-like dialogue; the Internet of Things with networks of sensors and actuators - being to AI what our senses and limbs are to the brain; advanced automation also mastering mental work; and blockchain-based applications distributing a range of services and structures, potentially eliminating the need for controlling bodies and institutions such as banks, governmental agencies, and even courts.

Combining these technologies, the second wave will bring changed conditions that are difficult to anticipate, to say nothing of people's ways to adapt to such changes. As mentioned before, the pace of change is also increasing, which gives a hint about further inventions adding up to a third wave, and a fourth, and so forth.

The main question that this chapter aims at addressing is whether it will be possible for nation-states to remain relevant through digital transformation, and in that case how, or if they might be disrupted or become obsolete and replaced by some other structure for governing the world's populations and territories.

To understand how the nation-state can adapt to digitalization, it may first be useful to establish what the nation-state offers that is adaptable. From the initial definition, we find that the nation-state provides unity, a territory, and a form of governance. Through its institutions, it also supplies a number of services.

Out of these four aspects, both services and governance can be effectively adapted from a digital transformation perspective. Unity, in contrast, could be considered to depend on second-order effects of digital transformation, while territory is a physical aspect that turns out to remain important in a digitalized world. This will be discussed later.

Adaptation of services in a digitalized world involves not only services offered by the nation-state itself. Also, services offered by alternative providers must be taken into account, since digital technologies and the Internet, as noted before, make it possible for service providers to target the entire world, even with fairly limited resources.

The ways in which governance may be adapted to digitalization, on the other hand, depends largely on the form of governance. Noting that democracy is considered to have strengthened the nation-state through increased legitimacy, the question of governance will here be focused on adaptation of the democratic 
process, although effects of digitalization on authoritarian states will also be discussed further down.

Hence, from a digitalization perspective, there are three important aspects of digital transformation of the nation-state - efficiency of services offered by the state to citizens, alternative providers of those services, and the structure of the democratic process.

1 Among the main services offered to citizens are health care, child/elder/social care, education, infrastructure, law and order, and defense, all paid for by tax revenue.

Like any other service, all these can be made more efficient through digitalization. This is necessary since the expectations of individuals and organizations are increasing, while tax revenues will not grow substantially. The increased expectations derive partly from people's experience of the large range of various services offered online, with a significant increase in convenience and ease of use compared to only a decade ago, all at a low cost or for free (in exchange for access to people's personal data).

In this way, people have an indirect understanding of the quality improvements and efficiency gains that are possible through digitalization, using, analyzing, and combining data flows; providing well-designed user interfaces; and so on, and they naturally expect the same improvements in public services. In short - the conditions have changed and public services have to adapt in order to remain relevant, which also goes hand in hand with the increased focus on customer experience brought about by digitalization.

In many nation-states, the digital transformation of public services is ongoing, but since these services are normally not exposed to market competition, there is not any immediate risk of being outcompeted, and the driving force for change must, therefore, derive largely from an insight among leaders and those responsible.

An example of a country that is considered to have reached far in its efforts to digitally transform its services is Estonia (Heller, 2017). Apart from many services being accessible online, three technology-related aspects creating conditions for the Estonian digital welfare state are:

- A government-issued electronic ID for all citizens

- The "once only" principle, which means that no single piece of data should be entered or collected twice

- The governmental data platform X-Road, which links servers and systems to each other through encrypted connections

From a privacy and integrity point of view, it can be noted that any access to an individual's personal data by a public officer or a professional is recorded and reported.

Besides improving services and making them more efficient, there are also discussions about the possibility for the public sector to partner with alternative providers from the private sector and with civil society. An example is the Swedish 
Association of Local Authorities and Regions (commonly known internationally as "SALAR," or "SKL" in Swedish). ${ }^{3}$ Klas Danerlöv, Innovation Manager at SALAR, refers to the demographic challenge, to steadily increased expectations among citizens, and to the need for working in smarter ways due to lack of resources already visible in budgets, and he discusses a change in definition of the role of the public sector, from producer to facilitator, collaborating with private service providers and with civil society in areas such as digitalized health care and emerging mobility solutions. He explains that such a change depends partly on legislation since today's rules for procurement are rigid and prevent the public sector from cooperating with industry in a development-oriented manner. He also envisions that the fundamental responsibility of the public sector might become narrower, caring for exposed groups and for those not able to use digitalized services (K. Danerlöv, personal communication, April 16, 2018).

Regarding digitalization of national defence, it may be noted that with the emergence of cyber-weapons and of the military cyber-warfare branch, military activity is becoming increasingly digital since it is possible to inflict significant harm to enemy states by attacking essential infrastructure through digital networks and devices, with a minimal risk for human and material losses. Also, since it is also possible to make attacks without being directly exposed, it becomes less evident who the enemy really is, making warfare less effective for supporting national identity.

2 The aspect of alternative service providers goes further due to the Internet's global reach. Such providers can essentially be located anywhere in the world and, depending on local legislation, provide their services to citizens of various countries on a global market. The same goes for nation-states that can offer services to their own citizens worldwide, through the Internet and through collaboration agreements with local or global providers.

Interestingly, nation-states can also offer their services to citizens of other countries, which they already do. Estonia offers an e-Residency - a kind of limited citizenship in the form of a government-issued digital ID available to anyone in the world, offering the possibility to easily start and run a business in Estonia, which is part of the EU (Republic of Estonia, 2014).

Quite obviously though, the digital ID is not valid as a physical identification or a travel document, it does not serve as a residency permit, and it does not grant its holder the right of physical residency in Estonia. This aspect, regarding physical territory, people's physical movements, and the rule of law, will be discussed further below.

The concept of e-Residency is also related to private service offerings from alternative providers and to the question of how extended these offerings could eventually become. Let us say that a digital giant like Google, Apple, Amazon, or Microsoft puts together packages of social services such as online education, digitalized health care, cybersecurity, transportation as a service, and more, and combines these packages under the umbrella of a private digital citizenship - and in this way takes on the role of a private virtual state, PVS. At what extent would that be an alternative to a citizenship in an existing nation-state? 
Essentially, this comes down to two considerations:

1 First, the PVS offering the services will probably not have its own territory, and thus it will have its head office in some jurisdiction, having to obey the corresponding legislation. Potentially, it could acquire e-Residencies like the one offered by Estonia, for local branches in countries offering this opportunity, thus adapting to the local legislation in each country.

2 Second, users acquiring private citizenship will live in other territories. Either they will have a citizenship and a residency in the corresponding nation-state or the PVS will have to enter mutual agreements with nation-states, defining matters for users such as residency, work permits, taxation, and also the validity of some kind of passport or other travel document issued by the PVS.

Both considerations highlight an opportunity for nation-states to systematically offer extended versions of Estonia's e-Residency, targeted toward PVSs, paving the way for what could be called the State as a Platform, SaaP.

A PVS successfully concluding such agreements, attracting a large number of users, could be described as a popular state owning no territory, fitting into an often-cited pattern in digitalization: Uber, the world's largest taxi company, owns no vehicles. Facebook, the world's most popular media owner, creates no content. Alibaba, the most valuable retailer, has no inventory. Moreover, Airbnb, the world's largest accommodation provider, owns no real estate.

It also fits one of the main adaptations to digital technology mentioned above a general shift from owning to accessing.

However, a citizenship is different from a taxi ride or a night's accommodation. If Uber or Airbnb goes out of business, users might suffer a short inconvenience. But if this happens to a PVS, users might become stateless.

This would be acceptable only if there are a number of PVSs for users to immediately choose from, a situation that could possibly emerge after years of trial and error with pioneering PVSs offering services to early adopters who maintain their original citizenship as a back-up.

A number of PVSs for users to choose from would also in a way solve the issue with lacking democratic influence by citizens on a PVS. Since a PVS is a private company, it is essentially autocratic, being controlled by its owners who are not substituted through elections. If there are other PVSs available, users or citizens could simply "vote with their feet." If, on the other hand, one major PVS dominated, for example, due to the network effect, this would not be the case and the lack of a democratic process would become a serious issue.

Other aspects of the PVS scenario are economic, social, and political. Would PVSs paying for SaaP manage to provide citizenship and social services more efficiently than nation-states, at a lower cost than ordinary taxation? Or would they profile citizenship as a premium product for which people would be willing to pay more? If so, would such a selection be acceptable? Could PVSs over time become the partners that organizations such as Swedish SALAR envision, while 
nation-states take care of exposed groups? Or should PVSs, through international regulation, be obliged to receive all users, and if so, at what cost?

Adding to this is a final question - whether a PVS would need something corresponding to a nation, that is, a sense of unity among the users or the citizens, in order to survive. As will be discussed below, this is also a challenge for multicultural federations of nation-states, and for this reason, it's not obvious that a PVS could ever reach the stability of a nation-state, strong enough to keep it united in situations of crisis. Rather, also with regard to the issue of lacking democratic influence, PVSs are more likely to be what they are-commercial entities offering convenient and attractive services, entities that may come and go, with a limited long-term engagement from the users.

However, the PVS model also exposes an opportunity for nation-states to adapt and remain relevant to citizens with a growing interest in a cosmopolitan set of values. Building on the kind of agreements that PVSs would have to enter with nation-states, such agreements could also be made between nation-states in a systematic way, similar to the roaming agreements between mobile telephone operators in different countries that allow their users to continue using their mobile phone while traveling abroad, paying for the usage to their home operator.

In a corresponding way, citizen-roaming agreements between nation-states would allow citizens to move freely between the two countries, benefitting from social services and rights as local citizens, also paying local taxes and being answerable to local duties. It could be seen as an extended version of the freedoms in trade blocks such as the EU, with obvious challenges, not the least regarding interstate trust, but also with increased possibilities from an administrative point of view in a digitalized world, with conceivable digital entities such as clearing houses for citizen-roaming. As opposed to a PVS, a nation-state offering citizenroaming would be able to provide long-term stability and democratic influence, but whether one model would be better adapted than the other to future conditions in a digital world remains to be seen.

Related to this topic, leaving the physical world behind, are virtual worlds, which could be seen as a kind of private virtual reality states. Existing only in virtual reality, there's no need for agreements with states in the physical world nor for travel documents or for physical services such as health care, transportation, and so on.

Not providing for people's physical needs, virtual worlds can hardly be considered an alternative to nation-states. They may, however, have a certain influence on real-world economies - substantial economic transactions are already made for virtual goods in virtual worlds such as Second Life, and this may increase with improved technology for virtual reality. It is also likely that when virtual reality reaches a sufficiently high-quality experience, people will spend significant time in virtual worlds, both for work and for pleasure.

3 The third aspect mentioned above regarding the digital transformation of nation-states is the structure of the democratic process. Two issues emerge on this aspect. 
First, there seems to be a possibility to effectively manipulate individuals' opinions and worldviews through digital means, without people knowing it or noticing it. This would put democracy, as we know it, at risk.

Second, today's democratic systems have not yet adapted to the way the Internet and digital technologies have changed the conditions for information distribution, making geographic distances essentially irrelevant from an information perspective.

The first issue - manipulation of individuals - came to general attention in the late 2010s partly due to events regarding the company Cambridge Analytica. The company had reportedly collected massive amounts of personal data through Facebook, and built individual profiles from the data, relying on research in psychometrics. The profiles had then been used to expose individuals at a large scale through social networks to personally tailored political advertisements designed to activate a certain response, with the aim to move the electorate in a desired direction (Cadwalladr and Graham-Harrison, 2018).

Although not conclusively proved to be effective, the basic idea is in line with the capabilities of digital technology today - analysis of large amounts of data, personalization based on such analysis, and individual targeting through social networks, all at a massive scale. Exploiting the human nature with its fairly predictable responses to certain stimuli also seems to be viable, but possibly further progress has to be made - a few cycles in the innovation loop - until the method becomes effective.

Possible scenarios could include tuning the output from AI-based personal digital assistants or finely manipulating the search results of a large search engine - a plot that has been credibly described in the novel 11 Grams of Truth (Swe: 11 gram sanning) (Akenine, 2014).

Any such scenario becoming reality would be a significant threat against the democratic process and also to any nation-state that depends on democracy for its legitimacy.

One proposed model that could be resilient to such manipulation attempts is deliberative polling, which is a version of deliberative democracy, a term coined by Joseph M. Bessette in 1980, meaning that democratic decisions must be preceded by authentic deliberation - long and careful consideration or discussion not just voting (Bessette, 1980). The idea behind deliberative polling, which was proposed by James Fishkin (1988), is that rather than having a whole population of relatively uninformed people make decisions in a matter, it is better to have a random, representative sample of the population make an informed decision after thorough briefing and discussion. Such a deliberative process normally takes place at a physical meeting during a whole weekend, with the model having been tried out in a number of countries in the world on various occasions (Center for Deliberative Democracy, 2019).

The second issue - adaptation of the democratic process with regard to new conditions for information distribution - is connected with an often-expressed worry over a general decline in political activity and political interest in democratic states, particularly in younger generations. Although it is contested that 
Millennials are less politically active, it has also been found that a decline in voter turnout in established democracies during the last four decades coincides with decreasing levels of people's personal interest in politics and a declining trust in traditional democratic institutions as vehicles for personal fulfillment and well-being (Dalton, 2016). This decline in interest and trust can be effectively explained by a shift in priorities and values of Western citizens. As people have begun adapting to a higher material living standard, they are increasingly prioritizing autonomy and individual lifestyle choices over more basic economic necessities and class divisions, while traditional forms of community life and interaction have largely eroded, giving space to individualism and social isolation (Ferrini, 2012).

More specifically, from a digitalization perspective, it has been found that improved digital infrastructure and increased digital freedom in a country have opposite effects on people's trust in the state and their sense of unity as a nation, counterbalancing each other.

Improved digital infrastructure increases people's trust in the state for providing effective tools and services, while it also brings about social fragmentation and cultural individualization, which weakens national identity. On the other hand, digital freedom strengthens national identity since offering everyone an opportunity to speak constitutes an essential feature of democratic fairness, and democracy is found to serve as an ideological link to unite people into a nation. But digital freedom also has a negative effect on trust in the state since no institution in an open and free society can escape criticism from some segment of society.

According to these findings, the nation-state can reach increased strength through digitalization only if there is a balanced development of digital infrastructure and digital freedom ( $\mathrm{Lu}$ and $\mathrm{Liu}, 2018$ ).

The same study also finds that as a country becomes more Internet-connected, people's attachment to the nation-state tends to derive more from the universal appeal of democracy (the civic approach mentioned before) than from the particular appeal of ethnicity (the ethnic approach) (Lu and Liu, 2018).

Hence, the question we ask is how the democratic process could adapt with regard to:

- Internet-based information distribution, which has made geographic distances essentially irrelevant

- People tending to prioritize individual choices while yet placing great value on digital freedom and democracy as unifying aspects

It is probable that a democratic process offering citizens a more direct influence at regular occasions, from wherever they are located at the moment, would be a favorable adaption to such new Internet-related conditions.

One proposed model for democratic processes, which could fit this requirement, is liquid democracy, a system where voters can either vote directly or delegate their vote to other participants. Voters may select different delegates for 
different issues, and they are free to withdraw their delegation at any time. People who have received the right to vote for other voters can in turn delegate these votes to other delegates.

Even though this kind of voting system has roots going back to the 19th century, digital technology can help to make implementations of liquid democracy substantially more effective, flexible, and easy to use.

It is worth noting that digital voting through the Internet is generally met with significant skepticism, mainly for lack of transparency and for the risk of voters being exposed to coercion when voting at home or in other non-controlled environments. However, there are solutions to both these issues, which have been implemented, for example, in digital elections in Norway, but for such solutions to gain trust among voters, more time will probably be needed with successful experiments (Lewan, 2013).

Finally, regarding the aspect of the structure of the democratic process in a digital perspective, it can be noted that both deliberative polling and liquid democracy are in line with an increased reliance on horizontal structures and an increased focus on purpose, mentioned above as adaptations to new conditions brought by digitalization.

These three aspects of the digital transformation of the nation-state-efficiency of services, alternative providers of those services, and the structure of the democratic process - can be considered fields where the nation-state has to adapt in order to remain relevant to citizens or, in other words, successful.

A fourth aspect as a consequence of digitalization can be added - the issue of future taxation and revenue sources. Since one main part of today's tax revenues comes from income taxes, the main question here regards the future of work. Recent progress in AI and machine learning, specifically in the field of deep learning, has shown that increasingly advanced tasks that only humans used to be able to perform can be automated, not only physical work but also mental work. In many cases machines even outperform humans, and there's a general concern that machines eliminating human work will lead to high levels of unemployment.

However, efforts at predicting whether AI and automation will eliminate more jobs than they will create, or the contrary, provide results pointing in all directions and differing by tens of millions of jobs only in the US, indicating that it is difficult to know which effect will prevail (Winick, 2018). It is also true that rather than eliminating jobs, AI and automation are expected to eliminate tasks within jobs, while jobs will be transformed to focus on tasks that humans still do better than machines, such as creativity, convincing and motivating other people, empathy, and fine dexterity.

Thus, whether tax revenues from income tax will decrease drastically due to unemployment is unclear, but it is certain that the future of work will be different than work of today. In the case that unemployment would rise significantly, solutions such as negative income tax or unconditional basic income have been proposed as solutions for distributing resources to citizens. As for an alternative tax revenue base, different forms of increased sales taxes are often suggested, with generous tax deductions for consumption that can be connected with present 
or future professional activity, ranging from equipment to investments in education, as an adaption to the trend of increased self-employment in the gig economy.

\subsection{Threats from supra-states, localism, and cosmopolitanism}

Apart from changed conditions due to digitalization that force nation-states to adapt, the most commonly discussed threat to the nation-state is perhaps the combination of supra-state and intergovernmental institutions such as the EU on one hand, and localism with claims of independence by populations such as the Kurds and the Catalans and by regions such as Scotland and Quebec on the other.

As for the EU, which could be seen as the most advanced attempt at a modern federation of nation-states, there are different ways to explain the main reasons for building the union, ranging from national interests of gaining influence by being members of a larger player in world politics and international economy, to an effort for peace and collaboration, or a step toward a European state. The main question, however, is if it would be possible to build a sense of national unity among Europeans - either through the civic or ethnic approach - strong enough to mobilize the population to collective action in a crisis. This is effectively contested by Hutchinson (2003), who notes that the EU does not even possess a common language, let alone a bank of myths, memories, and symbols to convey a sense of belonging in a community of sentiment.

Referring to the United States, Australia, or Canada as successful models for building multicultural federations is of limited relevance for Europe since these are countries founded by immigrants who have found a common identity in the willingness to build a new culture in a new territory.

From a larger perspective, looking beyond "immigrant nations," it is also worth noting that what characterizes successful constructions of multicultural federations, as opposed to federations that keep suffering from fragmentation due to cultural divides, can be explained by three elements - first, building political alliances on already existing cross-cultural voluntary organizations, such as reading circles, trade unions, political clubs and so on; second, providing public goods in exchange for taxes across all regions of a country; and third, having a shared language with which individuals can communicate and converse (Wimmer, 2018). None of these could be considered viable for the EU, except maybe the second under the condition that a federal tax is introduced, which is a remote option as of today.

Rather than becoming a European state, the future role of the EU and other large federations is more likely to be in line with what Thompson and Hirst (1995) argue - trade blocks that, together with international organizations and bodies, can exercise some governance over international economic activities, labor market policies, social and environmental protection, and so on, based on legitimacy derived from national-states.

The threat posed to nation-states by localism is somewhat different. Although it might lead to a few more new small states, trying to build strong societies on a 
local homogeneous unity as an answer to what might be perceived as an increasingly hostile globalized world is essentially a dead end.

From the perspective of the innovation loop, it is undeniable that the world is becoming increasingly interconnected, multicultural, and diverse through steadily more efficient and pervasive communications technologies. Any attempt at modeling a society on cultural homogeneity and exclusiveness will therefore necessarily lead to a society that is less adapted to the changed conditions in the world, and thus less competitive. Furthermore, as already noted, the more a society becomes Internet-connected, the less people will feel attached to the nation-state based on ethnicity, in favor of the universal appeal of democracy (Lu and Liu, 2018). In other words, the wave of ethnic and nationalistic ideologies sweeping over the world during the mid-2010s - promoting harder delineations of national borders, tighter immigration controls, stronger trade barriers, stronger celebration of national symbols and of authoritarian regimes, more idealized depictions of nationalistic history, and so on, entailing increased racism and nationalist xenophobia, could be seen simply as a temporary swing of the pendulum of history.

If the innovation loop is a valid model for describing the origin of change, the pendulum could be expected to swing back and forth around a center that moves along the trajectory of continuous innovation and of adaptation to changed conditions. In that case, it is just a matter of time before ethno-nationalist and isolationist ideologies will turn out to be unsuccessful as a way to improve the workings of the nation-state, which in turn will make the pendulum swing back toward more open, interconnected, and multicultural societies. However, the attempt at turning back the clock with nationalist and separatist values is understandable, not only because of increased migration, which is often the main reason for making nation-states more closed. Some view the world as increasingly divided into two categories of people - one cosmopolitan with mostly urban people, sharing an international set of values, interests, and culture, communicating globally and, to some extent, also travelling globally, and another category of more locally rooted people, typically rural to a larger degree, and less able to harvest the opportunities offered by an increasingly interconnected world.

Since the latter category could be considered less adapted to new conditions emerging in a digitalized world, wanting to go back in time to a situation with more closed nation-states - the billiard balls mentioned before - is a natural reaction. Another important reason making many people wishing for time to stop is arguably a general fear of the future, which is vague to many, for natural reasons. While the pace of change is increasing, most political leaders themselves have vague ideas about the future, and credible, long-term, positive visions for a future world are clearly lacking.

This is not to say that the opinions expressed by the second category mentioned above are not important. On the contrary, what is important, and in everyone's interest, is keeping society united, learning from diversity, and helping everyone to take part in the ongoing digitalization process since high tensions in society will be unfavorable for everyone. 
On the other hand, one may ask whether the cosmopolitan category has such values and motivations that people in this group would rather abandon the nationstate in favor of some global alternative state, such as a PVS, uniting, for example, people living in large urban environments across the world.

Anthropologist Ulf Hannerz (2004), investigating the nature of cosmopolitanism, sketches a wide range of different flavors and origins. The range of these flavors and origins stretches from the international elite working in global organizations, moving across the world, to a Pakistani villager, not particularly well-educated, but a member of a Sufi cult and formerly a migrant laborer in the highly mobile, heterogeneous society of the Gulf, there picking up a series of foreign languages. Hannerz further notes that cosmopolitanism has two faces; one side aesthetic and intellectual with a happy face, and one political side with a worried face.

He raises the question of whether there could be a "thick" cosmopolitanism, corresponding to the unity required for building a national identity, and without coming to an answer, he observes that while cosmopolitans are often seen as rootless, cosmopolitanism can also be seen as the "privilege of those who can take a secure nation-state for granted" (Hannerz, 2004, p. 78).

It is thus not obvious whether a growing cosmopolitan tendency could be seen as a threat to the nation-state, or even as a support. It's also clear that the number of far-reaching ideological cosmopolitans in the world is dwarfed by the sheer number of involuntary cosmopolitans - international migrants - reaching 258 million worldwide in 2017, up from 220 million in 2010 (United Nations, 2017).

The increasing international migration thus appears as a stronger threat to nation-states, not only since it is a main reason for the backward-aiming forces striving for closed and isolated countries, poorly adapted for the world's changing conditions. Migration is also likely to continue growing since the interconnectedness of the world lets information flow more easily, making the differences and the injustice in the world more apparent to everyone. This is further enforced since cultural homogeneity will be increasingly difficult to use by advanced states as an argument for exclusion, and closed borders will thus appear as what they are, a mere refusal of entry based on the lottery of birth.

Such a world order will become untenable, and it will remain a major threat to advanced nation-states unless the differences decrease. Just like within Western nation-states, where improved communications technologies over time made a leveling of resources and opportunities between classes inevitable in order to avoid unsustainable tensions in society, it is unlikely that the world's poor will passively accept their poverty, and a leveling of resources in the world will become necessary.

Apart from limiting the migration pressure on advanced nation-states, such a leveling would also strengthen the opportunities for the concept of citizen-roaming mentioned before, through improved conditions for interstate trust, and thus support nation-states in more than one way. 


\section{Mats Lewan}

\subsection{The rule of law}

The final consideration to be made on the nation-state is the rule of law. A declining autonomy for nation-states to exclusively decide over internal politics does not diminish the importance of the state's monopoly as a lawmaker in its territory. On the contrary, in a world that is more complex and interconnected on the one hand, and more individual and diversified on the other, the rule of law as a guarantee of stability, limiting the harm that individuals, companies, and the government itself can do, is of increased importance. The rule of law is also necessary for a structure of global governance to be effective, as a way for transforming international agreements into national laws and imposing such laws on the citizens. And although cities are often considered to be the main future actors of global collaboration since a majority of all people in the world now live in cities, nation-states are important for making cities and regional governments accountable according to the rule of law.

Apart from this, however, the rule of law is also a tool of power in the hands of the nation-state, which eventually comes down to the monopoly of coercive power and to the fact that, even in a digitalized world, all individuals have a physical body and all cables and servers that make up the Internet have a physical location.

The combination of the monopoly of coercive power and the control of a physical territory gives the nation-state a significant power over individuals and their movements, and also of the organizations they make up, which together with digital tools such as surveillance cameras, facial recognition, data analysis and so on, is strengthened rather than weakened. The power can be used by authoritarian states for control and oppression. However, also in democracies, even where the level of corruption is low, it remains a strong foundation for the nation-state to build its survival on, even when challenged.

We can look at the cryptocurrency Bitcoin as an example of such a challenge. Although the future of Bitcoin today is unclear, not the least for the unsustainable level of energy consumed by the Bitcoin system and for the low transaction speed, future versions might offer interesting opportunities for international peer-to-peer transactions without the need for controlling parties such as banks or financial institutions. Crypto-libertarians and/or crypto-anarchists, ${ }^{4}$ however, often consider Bitcoin one of the tools that could make the nation-state irrelevant, due to its distributed, noncentralized nature.

Also, the underlying database technology, the blockchain, may offer attractive distributed applications in a wide range of contexts, eliminating the influence and bias of controlling parties, but again, crypto-libertarians and/or crypto-anarchists see many of these opportunities as ways to subvert the state and its institutions.

Confronted with such a challenge, before it reaches critical levels, the nationstate could use the rule of law to effectively defend itself by drastically limiting the use of such applications. It is true that software applications through virtualization can be made to jump seamlessly in real time between physical servers across the world, but eventually, the ability of the state to reduce the usage is significant. 
In the context of rule of law and digital technologies, a special note may be made on what could become a global competition between liberal democracy and digital authoritarianism (Wright, 2018). Digital technologies, in particular the latest evolution of artificial intelligence, have turned out to offer authoritarian regimes - for the first time in decades - a possible way to sustain long-term economic growth while controlling their citizens. China is by many considered to lead this development with large-scale Internet censoring and widespread surveillance through technologies such as face recognition, and with machine learning tools in combination with a "social credit system," which according to the Chinese government will be rolled out nationwide for every citizen by 2020 (Munro, 2018).

Many AI-based machine-learning technologies depend on access to large amounts of data for training. Authoritarian regimes like China therefore have a significant advantage over liberal democracies in using such technology for analyzing and controlling citizens' behavior, being able to access and combine people's personal data with few restrictions and privacy concerns.

The official scope of the "social credit system" is to increase trust and to decrease the level of corruption and fraud in Chinese society. This is admittedly needed and some citizens also welcome it, but it is also clear that citizens will have limited opportunities, if any, to challenge the system.

It is an open question whether citizen control realized through digital authoritarianism will make countries like China more competitive and better adapted than liberal democracies to a digitalized world, but it is undeniable that China will give it a try. According to a recent report by the US government-financed democracy watchdog Freedom House, China is also actively spreading its methods and technology in this area to tens of other countries (Shahbaz, 2018).

Speaking against the success of digital authoritarianism is the aforementioned finding, that is, that the nation-state can reach increased strength through digitalization only if there is a balanced development of digital infrastructure and digital freedom (Lu and Liu, 2018).

However, as described by the innovation loop, neither democracies nor authoritarian states, will, in the long run, be able to resist necessary adaptations to new technologies changing the conditions for their existence; otherwise, they will collapse and be disrupted. Yet, the rule of law will give nation-states substantial capabilities to delay such a development, providing extended time for implementing change.

On the other hand, there is already another strong technology trend, apart from Bitcoin and the blockchain, hinting at a more decentralized model of society: local energy production with renewables such as solar and wind, but also with yet unexplored small-scale energy sources such as low-energy nuclear reactions (LENRs). If such energy sources over time can make wide-area power grids unnecessary, they will also bring the advantage of making societies less vulnerable to cyberattacks and cyberwarfare, which typically target crucial infrastructure systems.

In a distant future, distributed technologies such as blockchain and hyperlocal energy production may one day provide the basis for a completely decentralized 


\section{Mats Lewan}

world order, akin to nature itself where all individuals and entities are independent of any state structure and free to interact globally, but where - in a difference from nature - an AI-based rule of law is built in to the decentralized system, limiting the harm individuals and organizations can do and thus avoiding the cruel aspects of the law of the jungle. However, it is only when humans may merge with machines (making it possible to transcend the physical body) that the power over physical territories will eventually lose its importance.

\section{Conclusion}

In an increasingly globalized, digitalized, and interconnected world, with mobility for capital and technology and for digital services and products, the nationstate is challenged but may remain a fundamental building block for governance and international collaboration. Nation-states are losing some of their sovereignty regarding exclusive control over economic and social processes within their territories, and they are less able to maintain national distinctiveness and cultural homogeneity. On the other hand, their role as a source of legitimacy for agreements made in international institutions, organizations, and bodies is becoming more important, as well as for ensuring accountability of cities and regional governments. From an innovation perspective, losing independence and gaining another role in an increasingly interconnected world can be seen as a natural evolution, being a consequence of steadily improved communications technologies through human history.

In order to remain relevant to citizens and to the world, however, nation-states need to adapt to new conditions posed by digitalization. These adaptations can be found in three fields - efficiency of services offered by the state to citizens, alternative providers of those services, and the structure of the democratic process.

Efficiency of services needs to increase through digital transformation, in order to address a combination of increased expectations and limited resources. The increased expectations derive partly from people's experience of the large range of various services offered online, with a significant increase in convenience and ease of use compared to only a decade ago.

Alternative providers of social services may partner with public agencies that in turn may transform their role from producer to facilitator of services. Such service providers could also extend their offerings into a private virtual state eventually providing an alternative to traditional citizenship. However, since a PVS will depend on legislation in the nation-state where it is registered as a company, it will need to enter agreements with nation-states where its users live and work, and it will need to solve the issue of lacking democratic influence on the owners. Meanwhile, nation-states could offer services to PVSs through concepts such as State as a Platform, and nation-states could also make agreements with other nation-states for citizen-roaming, allowing their citizens to live and work in other countries.

The structure of the democratic process needs to adapt to decreased political involvement and to the risk of advanced manipulation of people's opinions on one hand, and to the fact that geographic distances have become irrelevant on the 
other. Two possible models addressing those issues are deliberative polling and liquid democracy.

It is also found that the nation-state can reach increased strength through digitalization only if there is a balanced development of digital infrastructure and digital freedom.

Another question related to digitalization regards a future base of tax revenue in the case that AI and automation would lead to massive unemployment and to reduced tax revenues from income taxes. Although it is unclear whether automation will eliminate more jobs than it creates, an often-suggested alternative tax base is increased sales taxes, while alternative ways of distributing resources to citizens are negative income tax or unconditional basic income.

Nation-states are also considered to be threatened by a combination of suprastates, localism, and cosmopolitanism. However, since it will be hard for a supra-state to build a national identity strong enough to keep it united in crisis, the nation-state will likely have a role as a source of legitimacy for larger international structures, as mentioned before. Localism, on the other hand, will, in the long run, have limited opportunities to be successful due to the increasingly interconnected nature of the world. Specifically, with regard to ethnic homogeneity, it has been found that as a country becomes more Internet-connected, people's attachment to the nation-state tends to derive more from the universal appeal of democracy than from the particular appeal of ethnicity. Regarding cosmopolitanism, it is not clear whether a growing cosmopolitan tendency could be seen as a threat to the nation-state, or even as a support. However, the increased number of involuntary cosmopolitans - international migrants constitutes an increasing threat to nation-states, reinforced by improved communications technologies highlighting the injustice of the lottery of birth, and, eventually, the only way to remediate this threat is through a leveling of resources in the world.

Even though it is difficult to define a valid alternative that would threaten or disrupt the nation-state, the need for the nation-state to adapt as described above in order to remain relevant is urgent since digitalization is a process that arguably has just started and since the pace of change is accelerating. Not adapting is not an alternative since no entity can avoid adaptation to new conditions brought about by inventions without collapsing or being disrupted. However, the combination of the rule of law, the monopoly of coercive power, and the control of a territory gives significant power to the nation-state even in a digitalized world, which eventually comes down to the fact that all humans have a physical body and that the Internet is built on servers and cables that all have a physical location. This power gives nation-states substantial capabilities to delay any challenging development, providing extended time for implementing change.

\section{Ethical considerations}

The persons interviewed and named throughout this chapter (wherever applicable) have all provided their informed consent to appear in-text. 


\section{Mats Lewan}

\section{Acknowledgments}

The author would like to thank the following persons for providing their views on this topic in personal interviews through April and May 2018: Anders Sandberg, Carl Heath, Darja Isaksson, Jan Nolin, Jan Söderqvist, Klas Danerlöv, Leif Edvinsson, Matthew Zook, and Stefan Fölster.

\section{Notes}

1 The term "best adapted" is a more accurate, and less problematic, representation of the source material than the popularly used term "fittest."

2 Network effect: a phenomenon whereby a product or service gains additional value as more people use it.

3 Swe: Sveriges kommuner och Landsting.

4 Crypto-anarchists or crypto-libertarians refer to people who use cryptographic software striving for total or a high degree of anonymity, freedom of speech, and freedom to trade.

\section{References}

Akenine, D., 2014. 11 gram sanning [11 grams of truth]. Stockholm, Sweden: Hoi Förlag AB.

Anderson, B.R.O., 1991. Imagined communities: reflections on the origin and spread of nationalism. 2nd ed. New York, NY: Verso.

Bessette, J.M., 1980. Deliberative democracy: the majority principle in republican government. In: R.A. Goldwin and W.A. Schambra, eds. How democratic is the constitution? Washington, DC: American Enterprise Institute for Public Policy Research, pp. 102-16.

Boffey, D., 2017. EU blacklist names 17 tax havens and puts Caymans and Jersey on notice. The Guardian. [online] Available at: <www.theguardian.com/business/2017/ dec/05/eu-blacklist-names-17-tax-havens-and-puts-caymans-and-jersey-on-notice $>$ [Accessed 5 Sep. 2019].

Cadwalladr, C. and Graham-Harrison, E., 2018. Revealed: 50 million Facebook profiles harvested for Cambridge Analytica in major data breach. The Guardian. [online] Available at: $<$ www.theguardian.com/news/2018/mar/17/cambridge-analytica-facebook-influ ence-us-election $>$ [Accessed 5 Sep. 2019].

Center for Deliberative Democracy, 2019. What is deliberative polling? [online] Center for Deliberative Democracy, Stanford University. Available at: $<$ http://cdd.stanford.edu/ what-is-deliberative-polling $>$ [Accessed 5 Sep. 2019].

Dalton, R., 2016. Why don't Millennials vote? The Washington Post. [online] Available at: $<$ www.washingtonpost.com/news/monkey-cage/wp/2016/03/22/why-dont-millennialsvote> [Accessed 5 Sep. 2019].

Ferrini, L., 2012. Why is turnout at elections declining across the democratic world? [online] E-International Relations. Available at: <www.e-ir.info/2012/09/27/why-isturnout-at-elections-declining-across-the-democratic-world $>$ [Accessed 5 Sep. 2019].

Fishkin, J.S., 1988. The case for a national caucus: taking democracy seriously. Atlantic Monthly, Aug., pp. 16-18.

Hannerz, U., 2004. Cosmopolitanism. In: D. Nugent and J. Vincent, eds. A companion to the anthropology of politics. Oxford, UK: Blackwell Publishing Ltd, pp. 69-85.

Hechter, M., 2001. Containing nationalism. New York, NY: Oxford University Press. 
Heller, N., 2017. Estonia, the digital republic. The New Yorker. [online] Available at: $<$ www.newyorker.com/magazine/2017/12/18/estonia-the-digital-republic> [Accessed 5 Sep. 2019].

Hutchinson, J., 2003. The past, present, and the future of the nation-state. Georgetown Journal of International Affairs, 4(1), pp. 5-12.

Kenney, M., Rouvinen, P. and Zysman, J., 2015. The digital disruption and its societal impacts. Journal of Industry, Competition and Trade, 15(1), pp. 1-4.

Kurzweil, R., 2001. The law of accelerating returns. [online] Kurzweil Accelerating Intelligence. Available at: <www.kurzweilai.net/the-law-of-accelerating-returns $>$ [Accessed 5 Sep. 2019].

Lewan, M., 2013. E-röstning kan testas om 5 år [E-voting can be tested in 5 years]. [online] Ny Teknik. Available at: <www.nyteknik.se/digitalisering/e-rostning-kan-tes tas-om-5-ar-6403323> [Accessed 5 Sep. 2019].

Lu, J. and Liu, X., 2018. The nation-state in the digital age: a contextual analysis in 33 countries. International Journal of Communication, 12, pp. 110-30.

Munro, K., 2018. China's social credit system "could interfere in other nations' sovereignty." The Guardian. [online] Available at: <www.theguardian.com/world/2018/ jun/28/chinas-social-credit-system-could-interfere-in-other-nations-sovereignty> [Accessed 5 Sep. 2019].

Republic of Estonia, 2014. E-residency. [online] Available at: $<$ https://e-resident.gov.ee $>$ [Accessed 5 Sep. 2019].

Rogers, E.M., 1962. Diffusion of innovations. 1st ed. New York, NY: Free Press of Glencoe.

Schwartzwald, J.L., 2017. The rise of the nation-state in Europe. Jefferson, NC: McFarland.

Shahbaz, A., 2018. Freedom on the net 2018: the rise of digital authoritarianism. [online] Freedomhouse.org. Available at: $<$ https://freedomhouse.org/report/freedom-net/free dom-net-2018/rise-digital-authoritarianism > [Accessed 5 Sep. 2019].

Thompson, G. and Hirst, P., 1995. Globalization and the future of the nation state. Economy and Society, 24(3), pp. 408-42.

United Nations, 2017. International migration report 2017: highlights (ST/ESA/SER.A 1404). New York, NY.

Wimmer, A., 2018. How nations come together. [online] Aeon.co. Available at: $<$ https:// aeon.co/essays/why-some-countries-come-together-while-others-fall-apart> [Accessed 5 Sep. 2019].

Winick, E., 2018. Every study we could find on what automation will do to jobs, in one chart. [online] MIT Technology Review. Available at: <www.technologyreview. $\mathrm{com} / \mathrm{s} / 610005 /$ every-study-we-could-find-on-what-automation-will-do-to-jobs-in-onechart> [Accessed 5 Sep. 2019].

Wright, N., 2018. How artificial intelligence will reshape the global order. [online] Foreign Affairs. Available at: <www.foreignaffairs.com/articles/world/2018-07-10/howartificial-intelligence-will-reshape-global-order> [Accessed 5 Sep. 2019]. 


\title{
18 Digitalization has changed the foundation of the democracy
}

\author{
Olle Wästberg
}

Most of the power of authoritarianism is freely given. In times like these, individuals think ahead about what a more repressive government will want, and then offer themselves without being asked. A citizen who adapts in this way is teaching power what it can do.

- From Timothy Snyder (2017, p. 17): “On Tyranny"

\section{Introduction}

Democracy is obviously far more than majority rule. To a great extent, democracy is about the dialogue between citizens and their democratically elected representatives as well as the participation in the political process. Developments in recent decades have brought drastic change: the political parties are just a remnant of what they once were and civil discourse has largely been replaced by confrontation and conflict.

This dramatic change is taking place globally and is largely due to the digitalization of the political process and organizations, as well as of methods for shaping public opinion and disseminating mass media.

Digitalization has, however, not only had negative effects. Rather, it has also liberated forces that work for democracy. There were the young activists with cell phones who rebelled against some of the Arab world's worst dictatorships during the "Arab Spring." It was with cell phones that pictures were taken of tortured prisoners in the US-based Abu Ghraib camp. And cell phones were used to take pictures of Neda Agha-Soltan, who was shot dead during the demonstrations against the Iranian regime in 2009.

The research conducted in this chapter is chiefly based on the author's professional experience and reading on the topic discussed in this study, as well as on the research conducted by the Swedish Government's Democracy Commission (Government Offices of Sweden, 2016b) and the work of the Government's Digitalization Investigation (Government Offices of Sweden, 2016a).

\section{The transformation of American politics}

Donald Trump (2019) - with his more than 64 million followers on Twitter (he himself follows 47 people as of mid-2019) - shows how digitalized public opinion 
formation now dominates. Trump has three TV screens in his bedroom; turns them on for the morning shows when he wakes up and reacts to what he sees with tweets (Wolff, 2018). These tweets then dominate the news cycle in the US - and subsequently often across the globe.

The fact that Trump was elected president is largely a result of how he and his campaign made use of social media. Trump's tweets dominated the political news. Because US network television lives off advertising revenue and advertisers pay in proportion to the numbers of viewers viewing these ads, TV networks want to have Trump on screen. He dominates the news, and news about him draws viewers. Because of his savvy exploitation of mass media, the Trump campaign was probably the least expensive in modern political history (Confessore and Yourish, 2016).

The Swedish US-based journalist Martin Gelin wrote in an article in the Swedish daily newspaper Dagens Nyheter that it is hard to fully comprehend how influential the alternative digital media have been for Trump, both in his candidacy and his presidency (Gelin, 2017). This is especially true regarding his ability to reach younger voters through these media channels. These influential alternative media channels would not exist without the Internet. A print magazine with the same content would probably only be purchased by a core group of supporters and, like pornography, would not be sold openly. As an example, because of its web presence, the far-right news organization Breitbart was during summer 2016 able to attract 31 million unique visitors and was one of the largest news sites in the United States. Trump realized early on the power of alternative media and hired Breitbart publisher Steve Bannon to head up his campaign during the summer of 2016.

In addition, Trump supporters used social media to mobilize potential voters and to make Hillary Clinton's potential voters stay home. Journalists from both The Guardian and Dagens Nyheter reported from Macedonia on how teenagers fabricated and disseminated "news" through social media on behalf of groups on the extreme right and were paid according to clicks and shares (Nevéus, 2016; Cadwalladr, 2016).

During the election campaign, many false claims circulated online and were shared tens of thousands of times. That the Pope supported Trump was one such claim. The most provocative example is the story, spread through the Infowars web site among others, claiming that Hillary Clinton and her campaign manager John Podesta from the basement of a Washington, DC pizzeria were running a pedophile ring with enslaved children (Farhi, 2017). The pizzeria was identified in the story. The story, later known as Pizzagate, led to the pizzeria employees being threatened, while an armed man stormed the pizzeria intending to shoot the employees and free the children. The story had been shared to more than ten million people, and according to an opinion poll from Yougov, 45 percent of Trump's supporters believed that it was true (Gelin, 2017).

In a survey done by the Pew Research Center, every fourth American stated that they had, intentionally or not, shared a fake news story (Barthel, Mitchell and Holcomb, 2016).

Trump, of course, was not the first to take advantage of the digital revolution. Barack Obama's presidential campaign organized through Meet-up, a site 
the campaign used to bring supporters together and to engage them in actively supporting the candidate.

What was new in the Trump campaign, however, was the extent to which it used "big data." In 2018, Cambridge Analytics was in the news for its methods of gathering and exploiting personal data (Hern, 2018). It also sold access to groups of individuals with certain desirable, identifiable traits. Big data collects what people in social media share and what they follow, as well as their answers to popular polls of the type "If you were an animal, what would you want to be?" Often, you can capture individual consumer patterns, map voters, and then target them with the right message. Identifying, gathering, and grouping this type of data is sometimes called "psychometrics" (Reed, 2018).

On the day before the US presidential election in 2016, I met with a consultant in Washington who had become especially skilled at using a specific app that could be used to organize, identify, and exploit personal data garnered from Facebook. He showed me how easy it was to find, for example, gay Wisconsin men who were still in the closet. He accomplished this by mapping networks of individuals and monitoring their searches on Facebook.

Of course, it is easy to find homophobes and those who are not, or to find xenophobes and those who are not. In addition, though, it is possible to map individuals' personalities and attitudes in minute detail and ensure that they are getting posts to their timeline tailored to their interests and personality.

Facebook's own review shows that 126 million Facebook users in the US may have been reached by posts from Russian trolls (White, 2017). It is unclear if this was significant enough to be a factor in Trump's victory, but it does show how wide-open and vulnerable democracies are to Russian influence.

The Obama campaign was first to use data gathering through Facebook to target and mobilize potential supporters (Shapiro, 2018). But since then, so much more has happened. The Trump campaign was able to send tailored - often contradictory - messages to tens of thousands of people in key states (Grassegger and Krogerus, 2017).

Donald Trump's influence within the Republican Party is also based on his Twitter usage. Because he is in direct contact with his followers, Trump can command Republican loyalty by implying on Twitter that he is switching support to a different candidate should the incumbent not fall in line behind Trump. That turned out to be guiding for the republican candidates in the 2018 midterm election.

During December 2017, a directive from the White House to leaders in the various departments of the federal government banned the use of seven words in the departments' budget applications. The words were: "vulnerable," "entitlement," "diversity," "transgender," "fetus," "evidence-based," and "sciencebased." That all official documents (including budget applications) are now available in digital form has made it possible to track the usage of banned terms and thus affect censorship. Through the digital revolution, the new administration has, more than ever, before the ability to view and control all public activities (Sun and Eilperin, 2017). 


\section{The Five Star Movement - a digital party}

Donald Trump's campaign is by no means unique. Following the Italian general elections of March 2018, the Five Star Movement gained the largest representation in the Italian parliament, even though it is not a party in the conventional sense, but rather a movement organized and directed through digital media.

The Five Star Movement ran its campaign mostly using social media. Using the app "Rousseau," members of the movement could guide its work, voting on which political issues the Movement should focus on in the campaign and selecting which candidates would represent the Movement.

Part of the Five Star Movement's goal was also to work toward the establishment of a comprehensive, online-based direct democracy.

In the election, the Five Star Movement had its greatest success in the poorest southern parts of Italy. There, traditional media as well as traditional political parties are weak. But with the new communication platform of the Internet, the Five Star Movement was able to reach voters directly.

\section{China - a new, digitally founded, imperialism}

In April 2018, Chinese president Xi Jinping led a national working conference on cybersecurity and computerization. The purpose was twofold: China wanted to become world leading in digital technology. At the same time, the president also wanted to ensure continued control of the Internet and strengthening of the party dictatorship.

China's 800 million network users are behind the "Golden Shield," the censorship wall blocking Facebook, Google, and hundreds of thousands of other sites (among them my personal site, www.wastberg.se).

China has also become leading in the use of big data and facial recognition to control the population and prevent the coordination of public opinion supporting dissident groups. The government's goal is to make it possible for each Chinese person to be digitally identified in three seconds (Wong, 2018). The Chinese regime also uses the Internet for international control. As part of its global foreign influence campaign, the Chinese Communist Party is applying censorship abroad and is punishing companies and citizens in other countries that step out of line. Beijing's claim is that any criticism of the Communist Party, anywhere around the world, is a violation of Chinese sovereignty and an offense committed against the Chinese people (Rogin, 2018).

\section{Radically changed Swedish politics}

In 1993, US political scientist Robert Putnam and two of his Italian colleagues wrote a well-received book about how democracy had grown in Italy. They showed that the reason democracy had deep roots in northern Italy, in contrast to southern Italy, could not be explained by the fact that people in the North were 
economically stronger. Instead, the reason was that those in the North had access to greater social capital (Putnam, Leonardi and Nanetti, 1993). People trusted each other and their public institutions. The people of the North had begun issuing and amassing social capital by having a collective mind-set: joining their fellow human beings in non-profit associations like choirs and sports associations. Putnam showed how social activity through clubs and associations are important to the emergence of a strong democracy. A decade later, Putnam (2000) came out with a study: Bowling Alone. He said that Americans who had previously organized themselves in bowling clubs now chose to bowl alone. They cared less about the collective or community aspect. This was a symptom of a trend in US society where, for example, fewer are active in non-profit organizations. This trend has contributed to a devaluation of social capital. This contributes to the crisis of our present moment, since social capital is a ground on which democracy is built.

Bowling has never been an important pastime in Sweden, but few countries in the world have the same level of participation in collective activities as Sweden. Nearly three out of four Swedes are members of the Swedish Church or of unions, three million are members of sports clubs, and nearly 600,000 Swedes sing in choirs (Nordström and Skjöld, 2009). We are still a people of members, but as in the United States, our associations are losing members. According to Statistics Sweden (SCB), every second Swede was active in a club in the early 1990s, but now it is down to every third (Vogel et al., 2003). Several researchers point to the fact that organizations such as the Boy/Girl scouts, the temperance societies, the free churches, and the unions are all losing members. This is combined with the trend toward individualization and the ever-increasing dominance of the Internet; fewer and fewer people seem to want to congregate together in clubs and associations. Who wants to gather around a coffee table in the clubroom to discuss societal problems when you can tweet or like a post on Facebook?

At the same time, the established political parties in Sweden have chosen not to use the Internet as a way to engage members and enable them to influence the direction that the party takes. Research that looked at party members' attitudes toward internal democracy shows that dissatisfaction is high. A third of the party members felt that they had no more influence than non-members. Nearly twothirds of the members of established political parties want to be able to vote on the Internet for their party leadership; however, none of the parties has yet adopted this approach (Government Offices of Sweden, 2015b).

The social scientist Tobias Harding describes how traditional associations are dying out, while newer movements are taking over (Harding, 2012). These new associations function more often as informal networks that enlist people in more short-term and spontaneous commitments. We join campaigns and respond to calls to action that are launched through social media, but we are less interested in extended board meetings that require voting according to protocol and writing minutes that have to be adjusted.

The perishing of collective associations is thus of great concern for democracy, as associations are democracies in microcosm. Like the cabinet of a democratic government, an association has its board and board officers. And, like a 
democracy, associations make decisions through voting and debate. Associations also act as training grounds for democratic participation and cooperation. When we stop meeting to try to solve problems together, the community's capacity to create the social capital that democracy depends on disappears.

Few things have changed so quickly through digitalization as political parties and the process of shaping public opinion. As voters have lost confidence in political parties, their members have left. In Sweden during the early 1980 s, political parties had about one and a half million members. Today approximately 260,000 Swedes are members of one of the eight parties represented in parliament (Kölln, 2015). This means that while some 40 years ago, 20 percent of eligible voters were members of a political party, only 2.5 percent of the voters are members today.

The political youth federations are now just remnants of what they once were. Fifty years ago, the Center Party Youth League was Sweden's largest, with nearly 200,000 members. Today they have about 2000 (SVT, 2018).

There are many examples of how traditional association-based work in shaping public opinion continues to be replaced by the use of social media. The Swedish Government's Democracy Commission, which I led, showed that the overwhelming majority of first-time voters in the 2014 election had Facebook as their main source of information (Government Offices of Sweden, 2015b).

Even with regard to the culture of politics in Sweden, digitalization has brought about tremendous change. The Swedish journalist Olle Svenning worked at Sweden's Prime Minister Tage Erlander's office in the mid-1960s. In his biography, he describes the Prime Minister's Office in the 1960s as being a continuous seminar, where staff exchanged articles and papers and discussed and commented on their reading (Svenning, 2018). Today, almost all such communication takes place via email, or in an equivalent online manner. Previously, members of parliament sat and paged through documents relevant to the proceedings and made notes in the margins. Now, most of the documents are read online, and the parliament is lit by computer screens while voting is ongoing.

Thus, it seems as though not many ponder how digitalization has changed politics, in spite of the fact that it has clearly contributed to the erosion of political parties and to widen the gap between the voters and their elected representatives.

\section{From face to face to Facebook: the relocation of political dialogue}

In the past, a young person seeking to be politically active might have joined a party's youth league, begun attending meetings, have distributed flyers, have attended training sessions, and so on.

This path to political activism has drastically changed.

In fact, young people are more interested in politics now than ever before, but they have chosen a different forum for engagement: the Internet. The path to activism described above meant that the budding activist met and debated with others who shared the same basic ideas and interests. Now, though political engagement 
has relocated online, a person who engages through social media will still end up matched with a cohort that shares his or her interests and values. In other words, groups and algorithms in social media build community the way that social interaction once did.

It is worth noting that the far-right dominates in social media. According to a recent survey by Retriever, a media analysis firm, the far-right party, the Sweden Democrats, has the most dominating presence on social media of all Sweden's political parties (Rosenbaum, 2018).

Retriever's head of social media commented that it is not so much that the Sweden Democrats are overrepresented, but that other parties are underrepresented. He also notes that the Sweden Democrats have an understanding of how social media work and a sophisticated social media strategy in contrast to the other political parties.

There are political opinions far more extreme than the Sweden Democrats that possess a large and frequent presence on social media. A strategy among rightwing activists is to insert themselves into online dialogue and influence the tone on various Internet forums. A highly visible case was in December 2016 when the Swedish department store Åhléns used an image in its holiday advertisements of a young black boy as Lucia. In the ensuing reactions were comments consisting largely of hate speech that were posted in a closed Facebook group facilitated by right-wing extremists and Neo-Nazis. Within a few hours, the comments from the closed group spread to several other groups on the Internet as well as to Åhlén's Facebook page, where about 500 such disparaging comments ended up.

There are several closed Facebook groups like the one described above. With content and posts being shared among these groups and their members, the members get the impression that there are many who think like them and that they represent the true will of the people.

Online activists affect what is shared and to what extent. Much material that is posted online reaches many more readers through the sharing of content than it ever would have through its original published channel. As an example, Jimmie Åkesson and Mattias Karlsson (respective party leader and group leader of the Sweden Democrats) wrote an article posted in the Wall Street Journal on February 22, 2017, where they expressed support for a recent statement by President Donald Trump that seemingly implied that the recent influx of immigrants to Sweden had been the cause of the recent increase in violent crimes. This article was shared online several million times. However, the corrective issued by Swedish Minister of Justice Morgan Johansson (also in the Wall Street Journal) was shared only a few thousand times. It is telling who dominates the online narrative.

An explanation for this asymmetrical sharing of opinions and opinion pieces on social media is that the lack of confidence in the traditional media channels is most present on the right end of the political spectrum. Thus, those on the political right tend to first turn to online information and are consequently more active in sharing what they find.

Perhaps the most important difference between an activist on the right and mainstream politicians is that they do not only post to "friends" or profiles that 
they follow, rather they actively seek out discussion forums that cater to their perspectives and insert themselves in other online conversations to agitate and provoke a response.

\section{The political dialogue}

Digitalization has changed the political dialogue - in both positive and negative ways. Groups that previously stayed out of the political conversation have now found their way via the Internet. This applies both to people who have previously been more passive, and, for example, to people with disabilities. Information provided by municipal governments and local forums for information exchange is continually being shifted from traditional to digital media.

According to a study carried out on behalf of the government's Digitalization Investigation, those that have traditionally been less politically active are now more politically active online (Government Offices of Sweden, 2015a). These include young men, those lacking post-secondary education, and those who are foreign born. These groups can express their political views online through social media more easily than they can organize themselves in political parties and opinion groups. The outcome is that the Internet actually leads to more equal participation in the formation of public opinion. Even those who are already active in the community engage online. Thus, the Internet can revitalize democracy by increasing the representation of demographic diversity and introducing a wealth of opinions into the political conversation.

In the governmental Democratic Commission - which I was appointed to head - one of the principal recommendations was "The Citizens' Initiative" (Swe: Folkmotion), an idea imported from Finland (Wästberg and Lindvall, 2016; Population Register Centre, 2006; Eduskunta, 2017). If 1 percent of the voters in a municipality, county council, or the country as a whole sign a proposal, it is introduced as a proposition to the city council, county council, or parliament. This would be a way to use the Internet to expand and strengthen democracy.

Previously, when a government investigation logged hundreds of written responses, these would be difficult to access for interested citizens. As a young journalist in the 1960s, one of my jobs was to sit for days in government offices reading reports on current governmental investigations. Now anyone can easily search them on the government's website.

The fact that the Internet has succeeded in engaging people who are not active in political organizations and community groups can also have a negative effect. There is a risk that while we have a formal party or association-based activism that is visible and where representatives are held accountable for their views and actions, we will also have anonymous Internet activity where there is no public responsibility taken. The Internet enables the emergence of a new social movement where the exchange of opinions takes place in closed forums and where all manner of claims can stand unchallenged. It is not uncommon that things communicated on the Internet may take on extreme expressions, simply because they are communicated reflexively to a computer screen rather than to a human face that 
reacts. This type of activism is governed by social pressure and promotes a herd mentality. It may draw strength from its outsider status and tend to express itself through hate speech and aggression. Finally, this type of activism risks becoming a force that erodes rather than builds up social capital.

Social media have become increasingly important for political dialogue. For the young, social media have become the main forum for political participation. For political parties, social media platforms have become increasingly important as forums for communication with voters. According to the Democratic Commission (which I headed) survey, more than half of all party organizations now use the Internet to communicate with voters. Social media are also considered the most important channel for recruiting new party members. Through their online presence, parties gain access to those who have not participated in or been responsive to party politics. On social media, the debate on local issues can be more dynamic, which may help in forging contacts with new electoral groups.

\section{The transformation of the media}

Through digitalization, media have been transformed dramatically. The Newspaper Publishers' Association reported in 2018 that revenue growth for traditional newspapers is now primarily through digital publishing (TU, 2018). Since 2014, digital subscriptions to morning papers have increased by over 260 percent.

Advertising in digital media also accounted for more than half - 51 percent - of the total media investments in 2017. According to surveys from the Institute for Advertising and Media Statistics (IRM), advertising investment in Sweden amounted to a total of SEK 37.7 billion, a new record. Advertising in digital media increased 21 percent from the previous year, accruing sales of SEK 19.2 billion. The areas that grew the fastest were social networking and online video (in addition, advertising on television increased by about 2 percent in 2017). Finally, just 14 percent of total advertising investments is allotted to print news media (IRM, 2017).

Swedish public service media (SR, UR, SvT) is increasingly moving toward digital platforms. Several commercial TV channels are planning to abandon traditional terrestrial broadcasts in favor of completely switching to digital broadcasting.

Not since the days of Gutenberg and the invention of the printing press have we seen a revolution on this scale of methods for dissemination and cheap communication. This is a revolution that not only transforms radio and television, but, in equal measures, also the printed press. That is to say, most local newspapers can now also be found online and many of them store their content behind a paywall.

We are being drowned in information in a way that was not possible before the breakthrough of digitalization. Over 90 percent of all data produced in human history have come into existence since 2012 (Brynjolfsson and McAfee, 2014, p. 16).

We face a development that has prompted many analysts to talk about the imminent death of print newspapers. And yes, the next step is that newspapers 
will entirely skip their printed editions. What we are seeing is that the supply of information and news no longer is managed by the media, but by the individual's selection. Even when people are consuming the same media, there is an increased fragmentation of the group of readers when their reading is done digitally instead of on paper. When people read print newspapers, everyone is exposed to the same content; when reading is done digitally, it is guided by topics that are of special interest for the reader. It is also guided by the popularity of certain stories, as determined by the number of times it has been shared via social media. If you read a print newspaper, you are exposed to the content in its entirety. If instead, you read a newspaper digitally, you will be exposed to separate articles.

\section{There's no turning back}

Political opinion formation and public information have in this way as much as been taken over by the digital media. It is not the first time that a society has been transformed through the media's technological revolution

The development of the printing press in the late 1400s gave Martin Luther the basis for a revolution that would not otherwise have been possible.

The complaint that people are no longer able to handle the flow of information and no longer justify what they read is hardly new: During the first half of the 19th century, a shift from intensive to extensive reading took place. "Multi-reading" was seen as destructive and non-intensive (Jarlbrink, 2010, p. 52).

The Nazis' success was partly a result of how well the National Socialists understood the new medium: the radio. And the crucial debate between Richard Nixon and John Kennedy in the presidential election campaign of 1960 was sometimes described as a new form of drama that manipulated the public opinion. The face of the politicians took over from the political positions (Sorensen, 2010).

"The core of post-truth politics," wrote the Dutch-British author Joris Luyendijk, is that "the individual's freedom to express their own opinion has become the freedom to choose their own facts" (Luyendijk, 2016, para.1). Today, we choose, to a greater extent than before, how we want to get the news or if we want to be informed at all. The Internet allows us to consume only the news that confirms our own worldview and deselect information that questions it. Many end up in echo chambers, media bubbles. We do not even need to actively avoid news that does not fit our worldview; the search engines we choose offer preferences and give us headlines based on what an algorithm thinks we want.

Digitalization of media and debate has great advantages in terms of accessibility and search opportunities. At the same time, the drawbacks are obvious: it has never been easier to spread "fake news." Political polarization increases sharply when people can stay in their Internet bubbles. Politics is increasingly becoming a matter of digging trenches.

To like or not like online is binary, either/or; thus, dialogue and compromise disappear.

The numbers of threats and hatred that thrive on the outskirts of the public debate has grown sharply in a time when politicians and journalists are digitally 
accessible. At the same time, it is easier to hide one's online activity. The Dark Net is used not only for criminal transactions but also the activity conducted by extremist groups.

\section{The way forward}

However, the future cannot be separated from digital information; everyone has to adapt to the new reality. While serving as director of the Swedish Institute (a government agency that provides information about and strengthens the image of Sweden) I discovered that the digital "world" Second Life had grown to include many millions of members (as avatars) and that tens of thousands were in Second Life at any time of the day. Since the Swedish Institute invested in maintaining a presence in places with fewer residents, I decided to open a Swedish Embassy in Second Life. At this "digital embassy," you could obtain forms for visas and passport renewals. You could sit in digital sofa groups from Swedish furniture manufacturers such as IKEA and Lammhult and look at paintings found at Nationalmuseum (the Swedish National Museum of Fine Arts) hanging on the walls. In addition, you could order Swedish food and participate in the Midsummer celebration. In this way, we showed that a public authority could renew its activities through digital opportunities. The Swedish Embassy in Second Life got extensive publicity all over the world. However, since then, the active user-base of Second Life has dwindled considerably.

In her book Desktop Warriors (2013), Swedish journalist Lisa Bjurwald notes that the Alt-Right were pioneers on the net. She suggests that since the first hate sites appeared in the 1990s, the Alt-Right has created a veritable online university for prospective extremists. Many have learned how to "throw torches" to enflame public opinion, and how to formulate the kind of extreme claims that attract shares. As this is disseminated on the web, it has a completely different effect than when politicians write debate articles in the traditional media (Ahlström, 2016).

Elected politicians have only minimally familiarized themselves with these new forms of communication. In Sweden, there is hardly a member of parliament who would not take a long-distance train to a rural town to speak to 20 party members. However, it is very unlikely that the same person would spend 2-3 hours a day engaging in discussions on social media.

There are many reasons as to why extremist views thrive, but it is a fact that an ever-increasing group of voters feel neglected and forgotten in the political decisionmaking process and are therefore attracted by new nationalist movements. Certainly, one factor is the gap between urban and rural areas. The disenchanted always have social media as a natural forum. And yet, traditional politicians have almost no familiarity with the digital space.

The digitalization of politics and democratic dialogue also provides a forum for destructive forces. Russia has in many ways been at the center of this. The journalist Peter Pomerantsev discusses in his book Nothing Is True and Everything Is Possible (2016) how Russia, in recent years, has had the strategy of creating a 
kind of information chaos in the West. The purpose has been to reduce confidence in democratic institutions and their elected leaders.

An example of how a Russian channel can play a role is the Russian counterpart to Facebook, VKontakte (VK). Here, the Swedish Nordic Resistance Movement (SMR) has posted entries - which are not regulated as they often are on, for example, Facebook. During the electoral campaign of 2018, images of Prime Minister Stefan Löfven behind bars and the agrarian Centre Party leader Annie Lööf wearing a hijab were created and posted on VK. These "memes" were then shared many times over across the Internet (SvD, 2018).

The Swedish survey the "Youth Barometer" (Swe: Ungdomsbarometern) shows that today, around 20 percent of individuals under the age of 25 believe in popular conspiracy theories like "The world is ruled by a secret society/organization" or "an American or Jewish conspiracy plotted the September 11 attacks." The survey also shows that those who believe in conspiracy theories are mostly young men who sympathize with the far-right or have their roots in the Middle East. Of those who believe in conspiracy theories, a significant number use alternative media sites (Poohl and Simonsson, 2015).

As the number of citizens avoiding traditional news media grows, the need for expertise in source criticism and critical scrutiny is becoming increasingly important. The National Agency for Education has stressed the importance of learning how to review and critically assess information. Having these skills equips the individual to safely use the Internet for knowledge retrieval, including gaining the knowledge necessary for participating in democracy. However, a survey from the Swedish National Agency for Education (Swe: Skolverket) indicates that a third of all high school students never get training in source criticism.

According to the Swedish Media Council (Swe: Statens Mediaråd), teacher training on Internet use and source criticism is very uneven. Bo Jansson, former chairman of the Teachers' National Union, wrote that today's students are an easy target for malicious actors who want to destabilize our society. He contends that training in source criticism and critical thinking are too important a part of how students are trained to be members of a democratic society to be made optional due to "a lack of resources" (Jansson, 2015). Today's students do not use print newspapers to access information. Instead, they use the Internet.

\section{The Swedish general election of 2018}

The 2018 Swedish general elections became the first to be characterized by the use of digital media to shape public opinion. Political debates were still broadcast on public service channels. Many were also or instead made available on the network websites. In addition, the tabloids organized political debates that were shared on their own digital television channels.

Certainly there were election posters in towns and along the roads, but political parties invested more than ever in social media, and the media controlled on specific sites what was said in politics. In the Swedish general elections of 2018, the far-right party the Sweden Democrats (Swe: Sverigedemokraterna) dominated 
on social media (Mounk, 2018). The party's official Facebook account received more likes and was shared more times than all the other Swedish political parties together. It totaled approximately several hundred thousand interactions during the election campaign.

In the Swedish election of 2018, digitalization was an underlying factor. In Sweden - just as in the United States - the dwindling faith in the future plays a significant political role. And the fear of future development is likely to be due to the fear that digitalization and AI will lead to greater unemployment. One of the political parties has pitted globalization (driven by digitalization) against the Swedish welfare society. Traditionally, the Swedish election campaign has always begun with Politikerveckan (Eng: "Politician's Week"), in an otherwise annual event taking place during the 27th week of the year, in and around Almedalen, a park in the city of Visby on the Swedish island Gotland. The event typically attracts more than 40,000 visitors attending 4300 events. In 2018, nearly a thousand of these touched upon the digital development. During this event, a special series consisting of 26 seminars was characterized as "Digidalen."

The question of whether the Swedish election process can become digitalized by means of e-voting has been subject to much debate throughout the years. In Estonia, citizens have the ability to vote online, a right exercised by a large number of voters (Alpman, 2018). Following the US election of 2016, this issue has been all but rejected in Sweden. The risk of hacking the e-voting system, as well as the mere suspicion of its occurrence, is enough to diminish the legitimacy of any electoral results.

What was unique for the 2018 election was how the Swedish Civil Contingencies Agency devoted considerable resources to controlling and mapping the attempts by foreign powers to influence the Swedish election by hacking sites, anonymously participating in online debate, and disseminating "fake news."

As recently as during the 2014 elections, hardly anyone could have predicted this. All we know about the future is that it will be different.

\section{References}

Ahlström, K., 2016. Nätet har blivit grogrund för högerextrema [The net has become a hotbed for far-right extremists]. [online] Dagens Nyheter. Available at: <www.dn.se/ kultur-noje/natet-har-blivit-grogrund-for-hogerextrema> [Accessed 10 Sep. 2017].

Alpman, M., 2018. Vågar vi rösta på internet? [Do we dare to vote on the Internet?]. [online] Forskning \& Framsteg. Available at: <https://fof.se/tidning/2018/2/artikel/ vagar-vi-rosta-pa-internet $>$ [Accessed 10 Sep. 2019].

Barthel, M., Mitchell, A. and Holcomb, J., 2016. Many Americans believe fake news is sowing confusion. [online] Pew Research Center. Available at: <www.journalism. org/2016/12/15/many-americans-believe-fake-news-is-sowing-confusion> [Accessed 10 Sep. 2019].

Bjurwald, L., 2013. Skrivbordskrigarna: Hur extrema krafter utnyttjar Internet [Desktop warriors: how extreme forces exploit internet]. Stockholm, Sweden: Natur och Kultur.

Brynjolfsson, E. and McAfee, A., 2014. The second machine age: work, progress, and prosperity in a time of brilliant technologies. New York, NY: W.W. Norton \& Company. 
Cadwalladr, C., 2016. Tech is disrupting all before it - even democracy is in its sights. The Guardian. [online] Available at: <www.theguardian.com/technology/2016/nov/06/ technology-disruption-infects-political-system $>$ [Accessed 2 Sep. 2019].

Confessore, N. and Yourish, K., 2016. \$2 billion worth of free media for Donald Trump. The New York Times. [online] Available at: <www.nytimes.com/2016/03/16/upshot/meas uring-donald-trumps-mammoth-advantage-in-free-media.html $>$ [Accessed 2 Sep. 2019].

Eduskunta, 2017. Parliament of Finland. [online] Eduskunta: The Parliament of Finland. Available at: <www.eduskunta.fi/FI/tietoaeduskunnasta/esitemateriaalit/Docu ments/2017_Eduskunta_perusesite_ENGLANTI_web.pdf $>$ [Accessed 2 Sep. 2019].

Farhi, P., 2017. A conspiratorial tale of murder, with Fox News at the center. [online] The Washington Post. Available at: <www.washingtonpost.com/lifestyle/style/a-conspir atorial-tale-of-murder-with-fox-news-at-the-center/2017/05/17/6a4d1f5a-3b14-11e7a058-ddbb23c75d82_story.html?utm_term $=$. a43472c127b9> [Accessed 2 Sep. 2019].

Gelin, M., 2017. Mediekrigaren Alex Jones och hans plattform Infowars leder Donald Trumps stödtrupper [The media warrior Alex Jones and his platform infowars are leading Donald Trump's supporting forces]. [online] Dagens Nyheter. Available at: <www.dn.se/ nyheter/varlden/mediekrigaren-leder-trumps-stodtrupper> [Accessed 2 Sep. 2019].

Government Offices of Sweden, 2015a. Gör Sverige i framtiden - digital kompetens [Making Sweden in the future - digital competency]. [online] SOU 2015:28. Available at: $<$ www.regeringen.se/rattsliga-dokument/statens-offentliga-utredningar/2015/03/sou201528> [Accessed 2 Sep. 2019].

Government Offices of Sweden, 2015b. Låt fler forma framtiden! Forskarantologi [Let more shape the future! researcher anthology]. [online] SOU 2015:96. Available at: $<$ www.regeringen.se/rattsliga-dokument/statens-offentliga-utredningar/2016/01/sou201596> [Accessed 2 Sep. 2019].

Government Offices of Sweden, 2016a. För digitalisering i tiden [For digitalization in time]. [online] SOU 2016:89. Available at: <www.regeringen.se/rattsliga-dokument/ statens-offentliga-utredningar/2016/12/sou-201689> [Accessed 2 Sep. 2019].

Government Offices of Sweden, 2016b. Lăt fler forma framtiden! [Let more shape the future!]. [online] SOU 2016:5. Available at: <www.regeringen.se/rattsliga-dokument/ statens-offentliga-utredningar/2016/01/sou-20165> [Accessed 2 Sep. 2019].

Grassegger, H. and Krogerus, M., 2017. The data that turned the world upside down. [online] Motherboard. Available at: $<$ https://motherboard.vice.com/en_us/article/ mg9vvn/how-our-likes-helped-trump-win $>$ [Accessed 2 Sep. 2019].

Harding, T., 2012. Framtidens civilsamhälle. Underlagsrapport 3 till Framtidskommissionen [Civil society of the future. Background report 3 to the Swedish future commission]. Stockholm, Sweden: Government Offices of Sweden.

Hern, A., 2018. Far more than $87 \mathrm{~m}$ Facebook users had data compromised, MPs told. The Guardian. [online] Available at: <www.theguardian.com/uk-news/2018/apr/17/ facebook-users-data-compromised-far-more-than- $87 \mathrm{~m}$-mps-told-cambridge-analytica $>$ [Accessed 2 Sep. 2019].

IRM, 2017. Ny milstolpe: Internet mer än halva mediekakan 2017 [New milestone: internet is has more than half of the media pie]. [online] The IRM Institute for Advertising and Media Statistics. Available at: <www.irm-media.se/nyheter/2018/ny-milstolpe-internetmer-an-halva-mediekakan-2017> [Accessed 2 Sep. 2019].

Jansson, B., 2015. Elevernas kunskap vårt främsta försvar [The students' knowledge is our best defense]. In: J. Bergenäs and M. Ögren Wanger, eds. Kan Sverige försvaras - mot vad?: En antologi om svensk säkerhetspolitik [Can Sweden be defended-against what? An anthology on swedish security policy. Falun, Sweden: Ekerlids Förlag, pp. 150-9. 


\section{Olle Wästberg}

Jarlbrink, J., 2010. Lässcener: Publik och medier på café och sockenbibliotek [Reading scenes: audiences and media at the café and parish library]. In: J. Harvard and P. Lundell, eds., 1800-talets Mediesystem [Media systems of the 1800s]. Stockholm, Sweden: Kungliga Biblioteket, pp. 43-64.

Kölln, A-K., 2015. Det sjunkande antalet partimedlemmar och demokratin [The dwindling number of party members and the democracy. [online] Available at: $<$ https://partifor skning.gu.se/digitalAssets/1565/1565259_kc3b6lln-sjunkande-partimedlemskap-ochdemokratin-version-slutversion.pdf $>$ [Accessed 2 Sep. 2019].

Luyendijk, J., 2016. Nu lever vi i en tidsålder efter sanningen [We are now living in a posttruth age]. [online] Dagens Nyheter. Available at: <www.dn.se/kultur-noje/nu-lever-vii-en-tidsalder-efter-sanningen $>$ [Accessed 2 Sep. 2019].

Mounk, Y., 2018. The people vs. democracy: why our freedom is in danger and how to save it. Cambridge, MA: Harvard University Press.

Nevéus, I., 2016. Målet är att sprida misstro mot medier [The goal is to spread distrust toward media]. [online] Dagens Nyheter. Available at: <www.dn.se/arkiv/varlden/ malet-ar-att-sprida-misstro-mot-medier $>$ [Accessed 2 Sep. 2019].

Nordström, G. and Skjöld, C., 2009. Fritid 2006-07. Levnadsförhållanden [Living conditions] Report 111, Örebro, Sweden: Statistics Sweden.

Pomerantsev, P., 2016. Ingenting är sant och allting är möjligt: Det nya Rysslands surrealistiska själ [Nothing is true and everything is possible: the new Russia's surreal soul]. Stockholm, Sweden: Ordfront Förlag.

Poohl, D. and Simonsson, U., 2015. DN Debatt. 'Alltför många bär på djup misstro mot statsmakten' [DN. debate 'too many bear a deep sense of distrust toward the state power']. [online] Dagens Nyheter. Available at: <www.dn.se/debatt/alltfor-manga-barpa-djup-misstro-mot-statsmakten $>$ [Accessed 2 Sep. 2019].

Population Register Centre, 2006. Finnish citizens' initiative. [online] Available at: $<$ https:// web.archive.org/web/20130918001435/http://vrk.fi/default.aspx?id=706> [Accessed 10 Sep. 2019].

Putnam, R.D., 2000. Bowling alone: the collapse and revival of American community. New York, NY: Simon \& Schuster.

Putnam, R.D., Leonardi, R. and Nanetti, R., 1993. Making democracy work: civic traditions in modern Italy. Princeton, NJ: Princeton University Press.

Reed, M., 2018. What you need to understand about Facebook and Cambridge Analytica. New York Magazine. [online] Available at: <http://nymag.com/selectall/2018/03/whatis-cambridge-analytica-and-who-is-christopher-wylie.html $>$ [Accessed 2 Sep. 2019].

Rogin, J., 2018. Then they came for Peppa Pig. The Washington Post. [online] Available at: <www.washingtonpost.com/opinions/global-opinions/then-they-came-for-peppapig/2018/05/03/172b7af6-4f0e-11e8-b725-92c89fe3ca4c_story.html $>$ [Accessed 2 Sep. 2019].

Rosenbaum, J., 2018. Sverigedemokraterna utklassar i sociala medier [The Sweden democrats are outperforming in social media]. [online] Retriever Press Release. Available at: <www.retriever.se/pressrelease/sverigedemokraterna-utklassar-i-sociala-medier> [Accessed 2 Sep. 2019].

Shapiro, B., 2018. What's genius for Obama is scandal when it comes to Trump. [online] The Hill. Available at: <http://thehill.com/opinion/technology/379245-whats-geniusfor-obama-is-scandal-when-it-comes-to-trump $>$ [Accessed 2 Sep. 2019].

Snyder, T., 2017. On tyranny: twenty lessons from the twentieth century. New York, NY: Tim Duggan Books. 
Sorensen, T., 2010. When Kennedy met Nixon: the real story. The New York Times. [online] Available at: <www.nytimes.com/2010/09/26/opinion/26sorensen.html > [Accessed 2 Sep. 2019].

Sun, L.H. and Eilperin, J., 2017. CDC gets list of forbidden words: fetus, transgender, diversity. [online] The Washington Post. Available at: <www.washingtonpost.com/ national/health-science/cdc-gets-list-of-forbidden-words-fetus-transgender-diver sity/2017/12/15/f503837a-e1cf-11e7-89e8-edec16379010_story.html> [Accessed 2 Sep. 2019].

SvD, 2018. Så använder NMR ryska trollens metoder på nätet [This is how the NMR use the Russian trolls' methods on the Internet]. [online] Svenska Dagbladet. Available at: <www.svd.se/sa-anvander-nmr-ryska-trollens-metoder-pa-natet> [Accessed 2 Sep. 2019].

Svenning, O., 2018. Ar med Erlander [My years with Erlander]. Stockholm, Sweden: Albert Bonniers Förlag.

SVT, 2018. Svårt att locka nya medlemmar till partiernas ungdomsförbund [Difficult to attract new members to the parties'youth leagues]. [online] SVT Nyheter. Available at: $<$ www.svt.se/nyheter/inrikes/statsvetare-mycket-star-pa-spel-om-for-fa-engagerar-sigi-de-politiska-ungdomsforbunden $>$ [Accessed 2 Sep. 2019].

Trump, D.J., 2019. Donald J. Trump (@realDonaldTrump). [online] Twitter. Available at: $<$ https://twitter.com/realdonaldtrump $>$ [Accessed 10 Sep. 2019].

TU, 2018. Så utvecklades morgonpressens annonsintäkter under årets första kvartal [How the ad revenue of the morning press developed during the first quarter]. [online] Internetbarometern, Press Statement. Available at: $<\mathrm{http}: / /$ tu.se/pressmeddelanden/sautvecklades-morgonpressens-annonsintakter-under-arets-forsta-kvartal $>$ [Accessed 2 Sep. 2019].

Vogel, J., Amnå, E., Munck, I. and Häll, L., 2003. Föreningslivet i Sverige: Välfärd, Socialt kapital, Demokratiskola [Voluntary associations in Sweden: welfare, social capital, democracy school]. Sociologisk forskning, 40(2), pp. 53-89.

Wästberg, O. and Lindvall, D., 2016. Låt folket lägga förslag till riksdag och kommun [Let the people issue proposals to the parliament and municipalities]. [online] Dagens Nyheter. Available at: <www.dn.se/debatt/lat-folket-lagga-forslag-till-riksdag-och-kom mun $>$ [Accessed 2 Sep. 2019].

White, J.B., 2017. Facebook says 126 million Americans may have been exposed to Russia-linked US election posts. The Independent [online] Available at: $<$ www.independent. co.uk/news/world/americas/us-politics/facebook-russia-adverts-americans-exposedtrump-us-election-2016-millions-a8028526.html> [Accessed 10 Sep. 2019].

Wolff, M., 2018. Fire and fury: inside the Trump White House. New York, NY: Henry Holt and Company.

Wong, O., 2018. Kina stärker censur - it-jättar växer ändå [China tightens censorship IT-giants continue growing]. [online] Svenska Dagbladet. Available at: $<\mathrm{https} / / \mathrm{www}$. svd.se/kina-starker-kontroll-och-censur--it-jattar-vaxer-anda> [Accessed 10 Sep. 2019]. 


\title{
19 Conclusion \\ Digital welfare - now and forever?
}

\author{
Anthony Larsson and Robin Teigland
}

\section{Introduction}

The digital transformation of public services is by and large depicted as a "disruptive" development inasmuch that it fundamentally alters the way individuals in society receive welfare services and how welfare providers supply them. More than that, it has also opened up a venue for private/non-governmental actors to claim market shares in an area in which the state has in the past century or so, for all intents and purposes, exercised exclusive control and been the sole "incumbent." That is to say that the public-sector bodies have traditionally been monopolies by their very nature, but it is a monopoly that is steadily losing its grip. To this end, the digital transformation and digitalization process has also had a disruptive effect on the state as an incumbent, inasmuch that it has provided a possibility for the state to automatize its services to a greater extent, and encourage "self-help" among the citizens (Kucuk, 2016). For instance, patients may now (in certain places) conduct doctor's appointments online by their own devices, which saves time and resources from the caregiver from having to do so at the patient's behest. Still, as digital transformation is rarely a simple task, it is especially daunting for public-sector organizations for a number of different reasons.

For starters, the complexities surrounding the public sector are invariably far more advanced than the corresponding complexities found in private "disruptive" companies (Farrell and Goodman, 2013; Bryson and Edwards, 2017). Publicsector organizations are often tasked with wide and far-reaching goals that are dependent on a range of external technical, political, and socio-economic factors, such as schools seeking to "educate people."

A second problem is that the public sector covers many different areas. This book has outlined three major welfare areas: health and social care, education, and citizen protection. Even so, all of these areas are, in and of themselves, vast areas that often carry relevance mainly to various country-specific needs. Thus, it is a daunting, if not to say a near-impossible, task to get a full understanding of all the technology used throughout all of these welfare areas. Moreover, the diversity of technology used in each area makes it extremely difficult to identify all the digital opportunities that could potentially carry a wider societal impact. 
A third problem is that it is sometimes difficult to identify the actual customer of the public-sector welfare (Alford, 2002). Is it the taxpayers whose funds are used to deliver the welfare? Is it the institutions receiving the funds from the state to deliver the welfare? Is it the people who are the beneficiaries of welfare? Is it the policy-makers who are to adopt digital transformation strategies? Or is it society at large? Invariably, various labels such as "customer," "consumer," "user," "client," "stakeholder," "taxpayer," "citizen," or even "the public" often circulate in regard to the public sector (Thomas, 2013; Alford, 2002). While digital transformation often places emphasis on the customer experience, there is rarely the same kind of clarity in the public-sector environment as to who the customer is, as opposed to other business environments. To that end, there may also be difficulties in gauging the value of public goods provided to the customers of public-sector organizations, as opposed to the commercial sectors, where revenue from consumers is a clear and direct measure of success.

A fourth problem is that the public sector has a tradition of suffering from resistance to change (Fronda and Moriceau, 2008; Barton Cunningham and Kempling, 2009). The public sector is not profit driven and procures most of its funding through the tax system (Asquer, 2018). For that reason, there is not the same inherent incentive always to be a trailblazer of innovative, cutting-edge technology and methods, but rather tested and cost-effective solutions are favored. This in turn may lead to the organization becoming insular and, if not resistant to change, then at least inert. The processes are by and large bureaucratic and ingrained, which invariably favors the status quo. Thus, introducing innovation to a public-sector organization often becomes a big undertaking, especially so for an organization that is accustomed to moving at a measured pace.

However, the disruption caused by the new actors; a new technological awareness among citizens, along with greater political interest in the digital technology; and a growing need to serve larger volumes of people is now reshaping entire welfare industries. Concepts considered "a bonus" (at most) just a decade or so ago (such as mobile apps or websites) has now become such a basic service that is has come to be more or less expected from almost any service provider. While this shift may have accelerated in the private sector, its impact has come to seep over to the public sector as well, as citizens now expect the same level of service in this area. Naturally, this means the public sector will need to reconsider the way they interact with consumers, patients, citizens, business, and society at large. To that effect, the public sector needs to possess the ability to innovate, adapt, and respond in a swift manner and foster an environment that seeks to take on intelligent risks that will bring innovative and efficient solutions to the forefront that benefit the public sectors as well as the citizens.

The difficulty with disruption and innovation overall is that projects and programs can take months or years to budget for and build (Fuchs, Nowicke and Strube, 2017). The risk is therefore that they may become irrelevant before they even launch due to sudden shifts in conditions. Examples of this could be a change in the ruling party in government, large-scale terror attacks, a serious breach of cybersecurity, a sudden financial crisis, or any other factor that carries serious 
ramifications on a larger scale. Notwithstanding, business transformation generally tends to be a complex and unwieldy beast to implement in full. Technology evolves at breakneck speed, which in turn pressures organizations to keep an even pace or risk falling by the wayside. To that end, organizations today generally face two main challenges in connection to digital transformation. First, they must put digital transformation/digitalization on their roadmap. Second, they must ensure that they possess the agility to deploy new technologies before they become obsolete. As digital and technological disruptors are fundamentally altering the necessitated mode of operation for the public sector, the need to keep an even pace with digital developments will be more important than ever.

Throughout this volume, a team of researchers have investigated various areas of the welfare sector, how they are affected by digital transformation/digitalization, and what the overall ramifications may be for society at large. This chapter will thus seek to elaborate on the conclusions drawn by the authors through their respective chapters, while endeavoring to build up an overall conclusion based on the findings and predictions made.

\section{Chapter summaries}

The following section will seek to elaborate upon the conclusions drawn by the different chapters in regard to the different welfare areas of the public sector as outlined by this book's structure.

\section{Health and social care}

Welfare in health care will likely see a rise in the use of telemedicine (most notably so in Sweden, but possibly also soon in other digitalized nations). As such, telemedicine has the potential to alleviate the lack of accessibility of primary care, and digitalization of the healthcare sector by and large enables the possibility of more care to be provided at home or remotely, which in turn serves to reduce the costs of hospital care (Blix and Jeansson, Chapter 2, this volume; Larsson, Elf, Gross, and Elf, Chapter 3, this volume). Still, even though telemedicine is a major disruption to the conventional type of health care, the findings suggest that the public sector exudes a more reactive than proactive stance toward market shaping. That is to say that although the public sector generally expressed positive attitudes toward the emergence of telemedicine, given its perceived potential to enhance productivity and ability to propel the innovation abilities of the public sector, there is decidedly some apprehension from the public sector. Specifically, the public sector appears wary that development toward telemedicine will ignore quality assurances. This, in turn, prompts the need to introduce more standardized quality measurements of telemedicine. Interestingly, the public sector appears interested in collaborating more with the "disruptors," but, at the same time, collaboration seems unlikely for the foreseeable future due to, among other things, their vastly contrasting value bases (Larsson, Elf, Gross, and Elf, Chapter 3, this volume). 
We may also see a future development toward electronic health records/data for use in the health care sector and for research purposes on a larger scale, but also for individual use. As discussed by Essén and Ekholm (Chapter 4, this volume), there is a need to share health data for learning purposes on a wider scale in a much more accessible manner. The governance arrangement of today's statebased health information exchanges may be enhanced with the use of more decentralized, possibly blockchain-based, HIEs.

Interestingly, the overall inert digital technological uptake by the public sector has led to some clinicians (and even patients) independently developing services and applications (Øvretveit, Chapter 5, this volume). This has been a development that has been recurrent not only in Scandinavia, but in many welfare nations around the world. In this way, we see that the inherent inertia by the public sector does little to stymie the digital/technological advancement and that people active in the public sector may in fact partake in this development even if it is done outside of the public sector's purview. Some of these developments are being developed in public-private partnerships, such as subsidized primary care remote physician consultations. To this end, we may expect to see an increase of patient advocacy and patient organizations championing this cause in the future (Øvretveit, Chapter 5 , this volume).

Given the fact that public health care organizations by and large tend to be change resistant, it is actually likely that if any fundamental change to the health care sector is to happen, it will be impelled through changed consumer behavior (Edwards and Saltman, 2017). To this end, Wänn (Chapter 6, this volume) argues that the growing need for better data management, especially from a patient perspective, has prompted a consumer-powered, automated system relying on AI to deliver predictive, preventative, and actionable advice directly to the end user. Along with a growing user base, more data sources covering aspects such as genomics, wearables, and behavioral data will successively help optimize the system's reliability and usefulness while empowering patients to take better preemptive care of their health. Hence, there will be a need for publicly funded health care to transform their business models as the growing AI platforms will run a risk of outcompeting some of the extant health care services, such as acute primary care, while at the same time complementing others, such as treatment of patients with chronic conditions. Wänn (Chapter 6, this volume) suggests that a solution to this issue would be for the providers of the electronic health platforms to team up with the national agencies responsible for providing health care. This could in no uncertain terms cause a disruption of the current health care model, but, on the other hand, this could also allow for a personalized, predictive, and preventative platform that has the ability to benefit patients, health care service, and politicians (by enabling more cost-effective and pre-emptive medical care).

This need to provide cost-effective, high-quality care in addition to reducing waste has also been a lingering issue within dental health care for some time. The issue is becoming more pressing, as the number of dentists in the workforce is diminishing rapidly. Larsson and Sabolová (Chapter 7, this volume) argue that digital dentistry in the form of a combination of different technologies such as 3D 
printing, as well as virtual reality and augmented reality, could be instrumental in combating the problem. However, at the same time, the authors caution that awareness must be raised among policy-makers in order to ensure the right preconditions in facilitating this digital technology so that it is used as intended and reaches its full potential.

In the social care sector, new forms of collaboration may be in the making. Drawing upon the Swedish example, Laya and Markendahl (Chapter 8, this volume) argue that the current structure of the social care sector stymies social care innovation based on digital solutions. The authors contend that while it is not likely for non-governmental actors to overrun the public sector in terms of social care services, there will be an increased need for collaboration between private companies and disruptors who can supply innovative solutions. The reason is in part due to regulation, but also as a mean of combining expertise. This may in turn create external pressure on the public sector to adopt and accept innovation more swiftly and to a greater extent.

\section{Education}

Education is an area that is likely to see much disruption due to digital innovation (McGrath and Åkerfeldt, Chapter 9, this volume; Mahaley, Chapter 10, this volume). As emphasized by Mahaley (Chapter 10, this volume), there is an ongoing debate regarding the legislation of the privatization of education and the future policies of digital transformation of the educational sector in order to meet the needs of the millions of learners globally. In order to reach out and meet the growing need in an efficient manner, educational technology will most certainly continue to play a pervasive role in the educational system in the years to come. Even more so, the use of EdTech will likely find its way to a younger target group in preschools and compulsory and secondary schools, as well as in higher education. It is no doubt that EdTech has had a disruptive and transformative impact on the extant educational environment and will continue to have so even in the future. However, as pointed out by McGrath and Åkerfeldt (Chapter 9, this volume), universities appear to lack a dedicated digital learning strategy. The authors have also found that laws regulating public procurement of services, in addition to data regulation laws, constitute major obstacles to EdTech ventures. To that effect, new strategies are needed, both from the universities and from the policy-makers. The concept of EdTech undoubtedly raises the question of the future role of educators. A take-away from McGrath and Åkerfeldt (Chapter 9, this volume) is that that future opportunities for educators should not be less favorable, even if EdTech becomes more widespread. Rather, educators should be viewed as creators of knowledge who possess the ability to dissect knowledge into comprehensible components that can be disseminated, questioned, and built upon further. Thus, the way forward for educators is for them to be cocreators of intellectual output and on-demand solutions. In that way, they may not only enhance their own teaching efforts, but also the learning efforts of the students with whom they interact. 
Mahaley (Chapter 10, this volume) contends that digital transformation will bring about much future change in a multitude of areas. From the side of learning administration and credentialing, the application of AI can be expected to gain a greater foothold, arguing that this change may occur either by design or by default, but that it is, notwithstanding, inevitable. As more resources become available and accessible via the Internet, the tracking of completion of various coursework and qualifications will likely no longer reside in formal institutions, but rather in individually held, publicly recognized repositories. The author argues that blockchain technology has great potential in this space, as it provides the possibility of having services that can provide individuals with the continuity of verified learning. In this regard, the public sector would have to keep itself and its policies attuned to new technologies that promote learning sciences in new, unconventional ways.

\section{Citizen protection}

Citizen protection is essentially divided into two different aspects. There is the more "physical"-type protection on the one hand that keeps the individual and the nation safe from direct, physical threats, and then there is the "digital" type of security that safeguards the individual and societies from various forms of cyberthreats. Drawing upon the US example, Conley and Nakkawita (Chapter 11, this volume) argue that although citizen protection efforts have traditionally fallen under the purview of the state/public sector, governments have been collaborating with private entities since the early 20th century in their efforts to promote citizen security for various reasons, ranging from financial efficiency to technological superiority. As new technology is constantly evolving at a rapid pace and financial incentives have changed, the consumer market for innovation has surpassed the public sector, which has resulted in governments no longer being the primary drivers of the innovation agenda. For that reason, Conley and Nakkawita (Chapter 11, this volume) have argued that research supports the notion of citizen support for an increased private role along with a decreasing public role in delivering safety and security. To this end, a future development in this space would be the public-private partnership, which is a growing hybrid model where private organizations master digital innovations and apply them toward public citizen protection missions. The authors contend that this model shows a lot of potential to gain traction in public opinion, as citizens trust government capabilities and intentions.

Given the notion that innovations in "physical" security are primarily propelled by other actors than the public sector, it is important to determine how digitalization itself can work toward making societal security more agile and resilient while also increasing the learning abilities of society at large in terms of security issues. Norlander (Chapter 12, this volume) contends that digitalization and digital transformation can both add new and reinforce existing capabilities for the protection of both society and its citizens. Digitalization/digital transformation can accomplish this by 1) expanding the number and variety of societal security approaches an entity can choose among (a larger, more diverse organizational and technological "toolkit"); 2) enabling entities to select and adopt the most appropriate societal 
security approach given the situation-specific circumstances; and 3) making individual approaches and the systems that support them more responsive, versatile, flexible, and resilient and making individuals and organizations more adaptive and innovative.

Threats, however, can also come in digital forms, thus prompting the needs of cybersecurity.

In exploring the different models that have emerged in terms of data management systems and identity management, Ingram Bogusz (Chapter 13, this volume) has assessed their strengths and weaknesses, in addition to comparing them to existing identity and data use systems. The chapter concludes that there is an ongoing struggle between control and transparency on the one hand and convenience on the other. The key determinant is implementation, which in turn decides which business model should be used and if it is advantageous to set up a common ground for the different identity verification and data management services. If users were to prioritize control and transparency over convenience, it is possible that there would be a market for data management systems that are far more interoperable and nuanced than those presently available. It is important to remember that the market is already to a large extent saturated with several established contenders competing for the larger market shares; thus, the window of opportunity for new entrants would appear slim at best. The costs of bringing a new large-scale product to fruition that aspires to take on extant giants like Facebook, Google, Spotify, Apple, Amazon, Alibaba, and so on would in most cases be insurmountable, and the attempts that have been made thus far have more often than not had limited to no success.

Thus, the public sector and policy-makers will need to consider in which direction they wish to steer the identity management issue, as there are many possible ways to go. To this end, it is also important to garner an awareness of the fact that while "effective policy" may be devised in numerous areas, such policy also has the potential to affect the very future of identity management solutions. As explained by Ingram Bogusz (Chapter 13, this volume), many countries have had a long history of making adjustments to account for externalities and supporting markets for services that are considered to serve the public interest, such as identity management services. In that way, it is possible that digital transformation/ digitalization will affect policy issues far beyond the remits for a particular welfare area, quite possibly affecting the very essence of the state itself.

\section{Future of the welfare state}

Eriksson and Sandhill (Chapter 14, this volume) argue that there is a growing policy development in various welfare states, and especially so in the case of Sweden, to reduce the amount of cash in society in favor of "cash-free" payment alternatives. This includes alternatives such as credit/debit cards, money transfer, and, more popularly in recent years, mobile payments. The contention is that this development alters the balance of power from both the individuals and from the welfare services provided by the state to global, private actors. In this way, 
unchecked digitalization may in fact in the future pose a threat to the state as we know it inasmuch that private organizations may utilize it to consolidate their power and control (whether it is direct or indirect) over the state itself. Thus, the authors posit that it is incumbent on national governments to take decisive action in order to ensure the survival of the analog payment system alongside the digital alternatives, should they wish to retain full control even in the future.

Conversely, Mattfolk and Emfeldt (Chapter 15, this volume) discuss the future possibilities for the welfare sector in a digitalized society. The point of departure is that digitalization will likely prompt the consumption of welfare services to take on similar traits to those of the consumption of any other kind of service. That is to say that future citizen demand, in addition to technological development, will likely dictate the development of new welfare solutions that are quite distinct from the way in which they are presently offered. The authors map out four different scenarios using Swedish welfare as an example. Each of these scenarios describes markedly different outcomes for welfare services and what role (if any) the national state could take in each scenario, given the corresponding type of citizen and their individual consumer preferences. While the authors argue that it is not a case of "either-or," as the different scenarios will most likely coexist with one another, they also contend that there will be a need for different strategic choices in order to modernize the welfare system in a way that is in line with consumers' behavior and demands. To this end, the private sector is invariably always one step ahead of the public sector, with global digital players and niched startups possessing the ability to meet customer demands by blurring the lines between the private and public sector whenever and wherever possible. The authors emphasize that the development in itself is not a threat, but an opportunity to redefine the future public sector so that resources may be redistributed to areas where they may carry the greatest impact.

Digital transformation also affects the welfare state in the developing parts of the world. Approaching the impact on political institutions, Moreno Puertas and Teigland (Chapter 16, this volume) conclude that the distribution of power between diverse groups of people has traditionally been formed as a basis of credible governments, and that it is this form of distribution that has enabled the emergence of financial markets. The authors contend that blockchain technology brings this distribution of power to the digital landscape and creates trust in the open web. They argue that there is much potential to be had in the political institutions of the developing world inasmuch as blockchain technology could enable their citizens to access international financial resources while also providing an irreversible digital trace of the actions carried out by said political institutions.

Lewan (Chapter 17, this volume) takes the debate concerning digital transformation and its impact on society to a deeper, philosophical level by developing a theoretical model called the innovation loop, wherein the author argues that evolutionary steps in the biological system can be compared to human inventions, and that evolution in this sense also concerns technology, businesses and society, and so on. The author argues that the development of the modern nation-state should be viewed from the perspective of major human inventions and that in 
order to remain relevant to citizens and to the world, nation-states need to adapt to the new conditions set forth by digitalization. The same also applies to welfare and public services, which will also need to adapt in order to remain relevant to citizens, much in line with the increased focus on customer experience brought about by digitalization (Lewan Chapter 17, this volume). The chapter concludes by deducing that the nation-state will continue to be an important concept even in a future international governance system, but this is contingent on its ability to make the necessary changes to accommodate for a change in consumer behavior.

On this note, Wästberg (Chapter 18, this volume) contends that the future democratic welfare state, as we know it, may actually be in jeopardy. The author brings up topical examples from the United States and Sweden, as well as other European nations, of how the digital revolution has provided citizens with an abundance of data as well as the power to act and react online. While empowering citizens, this development has also led to a polarization of the political climate, while also altering the habits of how people consume their information. Print media is being increasingly replaced by digital media, and the news is spread worldwide instantaneously, usually in a matter of seconds, and often by word of mouth. This development makes news reports more susceptible to disinformation or misrepresentation of facts, which can in turn be exploited for more nefarious political purposes. The new means of spreading information is an inevitable fact that all citizens must reconcile themselves to sooner or later, as the future cannot be separated from digital information. To that end, the author concludes that the future safety of welfare is incumbent on society's ability to educate its population at an early age in source criticism and critical thinking.

\section{Concluding comments}

As mentioned in the introductory chapter (Larsson and Teigland, Chapter 1, this volume), this book endeavored to explore the ramifications of the development of the digital transformation and digitalization processes and its effect on welfare and the future role of the public sector. The overall results of the studies have concluded that the digital transformation of the welfare/public sector is a fact and that it has only just begun. Its societal impact will be profound and extensive, but it will come with benefits as well as costs. As information becomes more detailed and freely accessible, citizens' awareness will increase, as will their demands and expectations of what services to expect. The public sector as we have known it will not have the resources and the policy framework to be able to accommodate all of the future demands placed on it by citizens, such as around-the-clock availability, swift and simple access to welfare, and personalized welfare that accounts for individual needs. This has left an opening for new actors to step in and provide new services in ways that the public sector cannot. Technology and automation may be used to lessen bureaucracy and shorten lead times in the health care sector. It is even technically possible to provide some health care (and to some extent even social care) remotely. The same also applies for education to a large extent. Increasingly, education is accessible via remote applications, lessening the need 
of being physically confined to any particular place in order to partake in knowledge sharing. Via advanced technology, private initiatives can proffer security services to individuals in ways that the public sector is unable to accommodate, giving people an increased sense of security.

Needless to say, the overwhelming risk that this development carries is that the concept of "welfare" becoming commoditized. This is to say that different welfare services may be ascribed an economic (or other) value that contains distinguishable attributes within their own set of welfare type. That is to say that it would become far more commonplace with different types of welfare services according to what one as a consumer is willing to pay. Thus, this commodification of welfare would entail a shift from welfare given on a basis of "need" to one that is given on a basis of purchase power. This would also allow for a greater customization of welfare services. Perhaps it may be possible to purchase various "subscription plans" of welfare services much in the same manner that one purchases different types of insurance plans? In such a scenario, it may also be possible for welfare services to transcend national borders so that a customer preferring the welfare solutions offered by provider organizations in one particular country could purchase a plan that would allow for them to opt for that type of welfare at a particular station or hub set up in a different country. In this instance, only those who have a subscription with the organization offering that type of welfare would be served at that station/hub.

What would then remain of the future role of the public sector? As outlined in some of the chapters, digital transformation may in and of itself fundamentally alter the entire structure of the public sector. However, this does not mean to say that the state should resign itself to merely providing for essential functions such as security and infrastructures and/or road maintenance, and so on. Rather, as illustrated in some of the chapters (e.g., Conley and Nakkawita, Chapter 11, this volume), the state and the public sector enjoy a level of credibility and trustworthiness that is rivaled by few, if by anyone at all. As such, the public sector will continue to play an essential function even in a future, digitalized world. However, it would seem likely that the public sector would come to shift its priorities and provide welfare to a much lower extent in certain areas than what it is currently doing (especially so in the field of health care and social care), exercising increasingly "elective" procedures from its selection, and rather opting to focus on the bare essential, life-saving procedures. It is also possible for the public sector to eventually enter some type of collaboration with the "disruptors," establishing clear standards and guidelines and so on and taking on a more regulatory function that would oversee the quality of welfare being distributed in these areas. The public sector could, of course, decide to act in a completely contrary manner and decide that it seeks to contend with all the "disruptors" and operate in a manner that is as agile and accommodating as citizens demand their welfare to be, although that would most certainly require extensive legal reform and vastly more funding, which in itself would be a topic for political contention.

Hence, as digitalization progresses, it is difficult to see the hands of time being turned back and welfare returning to the way "it once was." Through a series of 


\section{Anthony Larsson and Robin Teigland}

analytical accounts provided by several experts in their respective fields, this book has provided an anthology of potential future scenarios and developments for welfare areas. Thus, a discussion of the future role of the public sector as the undisputed welfare provider and its function in digitalized society must be broached by politicians and policy-makers. The time has come for a proper debate on the future of the public sector and what direction it should take.

\section{References}

Alford, J., 2002. Defining the client in the public sector: a social-exchange perspective. Public Administration Review, 62(3), pp. 337-46.

Asquer, A., 2018. Public sector revenue: principles, policies and management. London, UK: Routledge.

Barton Cunningham, J. and Kempling, J.S., 2009. Implementing change in public sector organizations. Management Decision, 47(2), pp. 330-44.

Bryson, J. and Edwards, L.H., 2017. Strategic planning in the public sector. [online] Oxford research encyclopedias: business and management. Available at: <http:// oxfordre.com/business/view/10.1093/acrefore/9780190224851.001.0001/acrefore9780190224851-e-128> [Accessed 11 Sep. 2019].

Edwards, N. and Saltman, R.B., 2017. Re-thinking barriers to organizational change in public hospitals. Israel Journal of Health Policy Research, 6(1), pp. 8, 1-11.

Farrell, D. and Goodman, A., 2013. Government by design: four principles for a better public sector. [online] McKinsey \& Company. Available at: <www.mckinsey.com/ industries/public-sector/our-insights/government-by-design-four-principles-for-a-bet ter-public-sector $>$ [Accessed 11 Sep. 2019].

Fronda, Y. and Moriceau, J., 2008. I am not your hero: change management and culture shocks in a public sector corporation. Journal of Organizational Change Management, 21(5), pp. 589-609.

Fuchs, S., Nowicke, J. and Strube, G., 2017. Navigating the digital future: the disruption of capital projects. [online] McKinsey \& Company. Available at: <www.mckinsey.com/ industries/capital-projects-and-infrastructure/our-insights/navigating-the-digital-futurethe-disruption-of-capital-projects> [Accessed 11 Sep. 2019].

Kucuk, S.U., 2016. Consumerism in the digital age. Journal of Consumer Affairs, 50(3), pp. 515-38.

Thomas, J.C., 2013. Citizen, customer, partner: rethinking the place of the public in public management. Public Administration Review, 73(6), pp. 786-96. 


\section{Afterword}

\section{Technology - the solution to all welfare challenges?}

One of the surest things we can say about technological development is that barriers to technology due to cost will always drop to acceptable levels for adoption. There is essentially no technology that was expensive when created that has not eventually reached the majority of people, either through market pressure to undersell or through efficiencies of production. So it has been with cars, phones, housework technology, computers, and mobile devices. Welfare services in health care/social care, education, and protection services follow this trend, and so it is inevitable that all the technological advances we see today as prohibitive and cutting edge will eventually be cheap and mundane. It is simply a matter of time before it is possible that data-driven tracking systems, dynamically adjusting assignments, virtual reality, augmented systems, artificial intelligence-driven evaluations, and multimedia creation tools can be ubiquitous in welfare institutions across the public sector.

What does not automatically advance is design. As has been clear from the introduction of video technology, data-driven approaches, and personal computers, the fact that the technology can arrive in schools does not mean that it will be integrated into schools effectively, nor that it will live up to its potential. Some of this has to do with the technical savvy of the institution itself - often, schools rely on the limited resources of IT or computer science instructors to handle all of the technical implementation decisions. The need for schools to be critically evaluating processes and learning about technologies and their potential pedagogic effects means that more staff members have to develop technical producing skills as part of their work to make sure not only that smart decisions are made about how acquired technologies are made part of the school experience, but which technologies are even appropriate for schools to have and how they can be modified or designed to maximize educational impact. This is a need that goes far beyond education, as there is no aspect of work that is not benefited by staff that have this critical approach to process and an eye on what technology can do and offer.

But what is even more critical is how technology does not override basic inequity. Too many attempts have been made to introduce computers into struggling schools, only to recognize that their mere presence does not fundamentally change the basic dynamics of the school. A gamified system of tracking student progress 
to create meaningful challenge could be a wonderful system to encourage learning and help students succeed, but only if there are the resources for teachers and students to make use of it. If students continue to lack basic needs such as food or safety, or if teachers are not given time to interface with systems or support with integration, we will see the exact same half-uses of technology we see today individual teachers creating ad hoc processes that squeeze the new things into the hard limits of classroom time, teachers spending their own money to introduce new elements to class, and pointless exercises of bureaucracy to track data that no one looks at and are never processed. As much as there is an inevitability in the introduction of technology, there is an inevitability that limited-resource institutions will underuse and in fact waste the technology by not having the support to integrate it to its full potential.

So now, as always, we find ourselves at a crossroads in welfare services in general and in education in particular. Coming technologies and designs based around those technologies are giving us access to the truest manifestation of individualized learning we have ever had. Gamified systems of uniquely tailored challenges; holistic data capture of student performance that informs intervention and/ or acceleration; synchronized communication of student progress between the student, teacher, and parent; extensive multimedia objects that allow new access to information in virtual, augmented, and hands-on ways - all of these are possible right now, and all of them provide means to help low-performing students improve, mid-performing students accelerate, and high-performing students soar. This can be done for all income levels, in all communities, and the technology can be an equalizer between disparities. We have more potential than ever to have schools be a place where privilege is leveled and opportunities are built around individual achievement, preference, and ability.

But if we assume that technology will do this automatically, and ignore the systemic issues of inequality and privilege that allow for disparate experiences in welfare institutions, then we will simply continue to replicate the wide gulf between the well and poorly supported. We will see high-resource, high-performing schools as wonderlands of individually guided learning, hands-on exercises, and transparent information display. That will truly be a miracle of educational possibility. But, at the same time, we will see the very same technologies applied in a slapdash and improvised way in low-resource, lower-performing schools, where technology is siloed, student creativity is stifled, and data are under- or completely unused due to the basic demands the schools have to meet. It would be tragic to see those things that work magic in other schools neglected in these institutions, but the realities of the needs of these schools will surely do so if they are not addressed first. This bifurcation of education will simply replicate itself on any technological advance until a design is introduced to specifically combat the bifurcation.

Technology alone never solves problems; well-intentioned design that uses technology can. We must be vigilant that as we think about how new kinds of media, data, processing, and communication can be used to enhance experience that their application take into consideration the systemic biases and inequities 
that currently exist, and that the design of how these technologies are integrated into institutions works specifically to counteract those systemic issues. We have decades of experience with technology in education and other welfare institutions to show us that unless a holistic approach is taken, thinking about the new technical approaches as part of a larger reform project, the core injustice of inequality will not change. It is incumbent upon us to see the technologies as what they are tools - capable of enabling us to make great change, but only if we wield them with wisdom in the right places and the right ways.

Nicholas Fortugno 


\section{Index}

Note: Page numbers in italic indicate a figure, page numbers in bold indicate a table, and page numbers followed by an " $n$ " indicate a note on the corresponding page.

accessibility 336; and dentistry 119 ; of

health care 27 ; and welfare services 256 activism $323-25$

adaptation $293-96,301-2$

adherence 88

advertising 25,326

agile organizations 201, 201-2, 203

agility 199-206, 209, 255

Ahlquist, Magnus 246

AI see artificial intelligence (AI)

Airbnb 304

alarms 103, 134, 137n2, 252, 269

Alibaba 258, 265, 273

alt-right 328

Amazon 258, 265, 271, 273

ambulances 89

analytics $2,97,101,103,112,129,144$, $151,158,162$

antibiotics 16, 19-20, 26-27

Apple 101, 104, 136, 265, 273

apps 15, 21, 21, 36, 43, 67, 88, 102, 162, 165

Aragon Network 284, 289

artificial intelligence (AI) 2-3, 69-70,

$74-75,88,267$; and education

162, 163-64; and educational

technology (EdTech) 144, 147-48;

and personalized health care 97-99;

and predictive diagnostics 104-5; and

predictive platforms $99-103,106-13$;

and prevention 105-6; and wearables

103-4; and welfare services 254, 260

assessment of learning 149, 271

associations $322-23$

ATMs 237

at-risk populations 86 augmented reality (AR) 120-22, 162

autonomous vehicles 206

BankID 17, 62, 76n1, 217, 217, 218-19

banks 236

Bannon, Steve 319

Barbour, James 259

behavioral data 102, 112

Berg, Ylva 246

Bergström, Fredrik 246, 250

big data 97, 144, 163, 254, 320, 321

Bitcoin 277-78, 312; see also blockchains

BitNation 289-90

blockchains 4, 9, 58-61, 60, 76n5, 277-80, 278, 285-88, 339; challenges of 70-75; and data storage $76 \mathrm{n} 3,76 \mathrm{n} 4$; and innovation 61-70; see also health information exchanges (HIEs)

Blockstack 224

bots 227

bowling 322

Breitbart 319

Brexit 239

Brown v. Board of Education 159

business data 222

business ecosystems $128-29,137$

CAD/CAM see computer-aided design/ computer-aided manufacturing $(\mathrm{CAD} /$ CAM)

cancer 16

care management 88, 207

cars 206; see also autonomous vehicles

cash 5, 8, 235-40, 340

cell phones 318 ; see also smartphones 
centralization: and blockchains $61,74-75$; of power 281-82

charter schools 161

chatbots 254

children 20, 22-23

China 313, 321

citizen protection 179-86, 182, 209, 339-40; definition of 171-73, 195n1; and police 190-91; and protective language 192; in the United States 173-79; and US Central Intelligence Agency 189; and US Department of Defense 187; and US Department of Energy 188; and US Department of Homeland Security 188; and US Department of Justice 189; and US Department of State 187-88; and US Federal Bureau of Investigation 190; and US judiciary 190; and US National Security Administration and Central Security Service 189; see also security, societal

citizen-roaming agreements 305

climate change 264-65, 272-73

Clinton, Hillary 319

cloud computing 85

clubs 322

Coala Heart Monitor 103

co-care 84, 90-93

coercion 207-8

Cold War 298

collaboration 37, 37-39, 49, 49

Columbine massacre 178

commerce 215-16

commodification 343

computer-aided design/computer-aided manufacturing (CAD/CAM) 119-20

consent 214-16, 219-25, 220, 229, 229, 246, 262; see also permissions

conspiracy theories 329

consumer behavior 253-54

contracts $283-84$

cookies 214

corporate education 154

cosmopolitanism 9, 311, 315

crisis management operations (CMO) 202-3

crisis response 207

crypto-anarchists $312,318 \mathrm{n} 4$

cryptocurrencies 65,70

crypto-libertarians $212,318 \mathrm{n} 4$

currency 244; see also cash

customer experiences 254-55, 300

customer service 249

customization $267,270-71$ cystic fibrosis (CF) 91

Czech Republic 119

Danerlöv, Klas 303

DApps 224

data control 220, 226, 226

data cooperatives 223, 225, 226

data-for-services model 226-27, 229, 229

data management $8,29,62-63,99$, 216-20

data marketplaces 222-23, 225, 226

data mining 2

data protection $100-101$

data sharing 62-64, 108

decentralization: and blockchains 61 , 74-75; of data 225-28, 226; and protection 186

deliberative polling 306

democracy 5, 9, 269, 306-8, 342; and activism 323-25; and China 321; and dialogue 325-26; and digital media 326-29; and education 158; and Italy 321; and Sweden 321-23, 329-30; and United States 318-20

Denmark 143

dentistry $6,117-19,123-24$; and computer-aided design 119-20; and $3 \mathrm{D}$ printing $120-21$; and virtual reality 121-22

diagnosis 19, 20, 26-27, 86-87, 104-5

digital connected devices 7

digital currencies 282-83, 285

digital exams $148-50$

digital health technologies (DHTs) 84-85, 93

digital learning resources (DLR) 160

digital light processing (DLP) 121

digital locks 135

digitally enabled learning health system 84

digital services and technologies (DST) 6 , 84, 90-91, 93

digital technology application (DTA) 84

digital transformation 301-8, 334-36, 339

digital welfare $33,334-36,342-44$

dignity 34

diplomatic protection 174

$3 \mathrm{D}$ printing $120-21$

dynamic organizations (DOs) 201

EdTech see educational technology (EdTech)

education 7, 158-66, 263-64, 338-39; global 266, 271; on-demand 269; and student data $251-52$ 
educational technology (EdTech) 4, 7, $143-54,153,338$

efficiency $270-71,295,302,308,314$

eHealth 35-36, 76n2, 128, 137n4

Ehle, Petra 246

Ekstedt, Anders 246

elderly $17,20,27-28$

electronic health see eHealth

electronic health records (EHRs) 84

electronic intensive care units (EICUs) 206-7

electronic medical records (EMRs) 61, 84-85

emergency care 24

England 118, 279-80

Enigma Data Marketplace 224

e-Residency 303-4

Estonia 60, 207-8, 218, 259, 303-4

evolution 293-96

Facebook 226-27, 265, 273, 304, 320; see also social media

fake news $262,318-19,327,330$

falls 103

Farestam, Stefan 246

Ferndahl, Torbjörn 246, 252

Finland 143

Five Star Movement 321

flipped classrooms 144

forest fires 207-8

for-profit universities 161

Forslund, Daniel 246

frames 40

fraud 214-15

Gejke, Jenny 246

General Data Protection Regulation 215

genomics 69, 99, 100, 102-3, 104, 105, 112,337

Gerger, Magdalena 246, 249

Germany 119

gig economy 267, 269

globalization 9, 20, 238, 256, 274, 298-99, 330

Glorious Revolution 279-80, 283

glucose monitoring devices 87,103

Golan, Jonas 246

gold standard 236

Google 226-27, 258, 265, 273

Google Docs 145

governments 111

Grandt, Anna 246
Gullström, Annelie 246

guns $177-78$

Hafstad, Joachim 246

health care 33-37, 249-51, 336-38; and market frames 43-44; and market reshaping 39-41; and metrological devices 44-45; and nations 45-46; and private providers $46-50$; and Sweden 35; and telemedicine 37-38; and welfare services $36-37$; see also telemedicine

health information exchanges (HIEs) 6, 58-63, 69-75, 76n5; see also blockchains

Hellqvist, Linda 247

Hemfrid 249

HIEs see health information exchanges (HIEs)

hold-ups 281-82

Holgersson, Tom 247

home security 177

identification 214-16, 220, 228-31; and data control 220-25; and data management 216-20; and policy concerns 225-28

identity theft $214-15$

identity verification $8,67-68$

immigration 188, 309-10, 324

India 60

industry data 222

inequality $109-10$; and citizen protection 184-85; and education 159-60

Inera $35, \mathbf{6 0}, 61,135,137 \mathrm{n} 4$

influencers 267-68

information and communication technologies (ICT) 127-28

information systems (IS) 59; see also blockchains; health information exchanges (HIEs)

infrastructure 248

initial coin offerings (ICOs) 286

innovation 36-37, 38-39, 335; and artificial intelligence (AI) 107; and blockchains 61-70; in health care 50-51; and social care 133; in social care 127-29

innovation loops 293-96, 294, 300, 310, 313,341

insurance 18, 22, 84, 111, 117-19, 343

integrity $255-56$ 
intensive care units 206-7

interactive whiteboards (IWBs) 145-46

international protection 176

Internet 2

intraoral cameras (IOCs) 120

inventions 297-98

Italy $321-22$

Jarnemark, Tommy 247, 251

Källsholm, Joachim 247

Kanter, Theo 247

Kernell, Daniel 247, 250

Krés, Ulrica 247

krona 236

Kry 17, 18, 21, 22, 36, 255

law of freedom-of-choice (LOV) 18

laws: and cash 236; and data 73; and health information exchanges (HIEs)

63; and public-private collaborations (PPCs) 38; and taxes 265; see also regulations

learning $72-73,145-47$; see also education

Lindstedt, Monica 247, 249

Linguistic Inquiry and Word Count (LIWC) 180-81

LinkedIn 165

liquid democracy 307

localism 9, 309, 315

LOV see law of freedom-of-choice (LOV) loyalty 3-4

machine learning 2, 88-89, 148

market frames 34, 43-44, 51

markets 39-40, 41

massive open online courses (MOOCs) see MOOCs

medical advice 100, 105-6, 109, 111

medications 29, 88, 92, 99, 105, 127, 248

MedTech devices 103-4

Melander, Helen 247, 251

metrological devices 44-45, 52

mHealth 36,128

military protection $174-75,186$; see also

US Department of Defense

Min Doktor 17, 18, 21, 22, 29, 36, 42

mobile devices 33, 36, 347; see also cell

phones; smartphones

mobile health see mHealth

MOOCs 144, 150-52 multiple choice quizzes (MCQs) 149

MyData 224

Nakamoto, Satoshi 277

national identity 307

nationalism 296

nations $45-46$

nation-states 9, 293-97, 299-309, 314-15; origins of 297-99; and rule of law 312-14; threats to 309-12

Nazis 327

Netherlands, the 118

network effect $300,318 \mathrm{n} 2$

neural network software 148

newspapers 326-27

Norway 119

nuclear power 188

nuclear weapons 188, 298

Nybell, Karl-Johan 247

Obama, Barack 319-20

Ocean Protocol 224

open data 72

organizational agility $201-2$

Pangea 284, 289-90

Parkland shooter 178-79

ParkWell 92

passwords 214, 219, 221

patient-accessible electronic health record

(PAEHR) 84

patient associations 87

patient histories 88

patient knowledge 91

patient pathways 89

patient portals $61,87,98$

peace $177,238,239$

peer-to-peer learning 263-64

permissions 71, 221-22; see also consent

personal computers (PCs) 84-85

personal health records (PHRs)

$101-2,112$

personalized health care 6,97-99

person-centered integrated care (PCIC) 91

phishing 214

PIN codes $217-18$

Pizzagate 319

police $178-79,190-91,252$

political losers 281

population health 97,111

poverty 118

Powers, Shawn 259 
predictive analytics 2

predictive diagnostics $100,104-5$

predictive modeling 2

primary health care $16,18-19,24,27$,

$117-18$

private commercial security $176-77$

private individual protection $177-78$

private protection $172-73$

private schools 161

private virtual states (PVSs) 303-5, 314

property rights $279-80,284-85$

public education 158-59; see also

education

public keys 221

public opinion 323

public-private collaborations (PPCs)

$37-38,49,52,131,133-34,257$

public protection $172-73$

public universities 161; see also education

Putnam, Robert 321-22

racism 310

regulations 52, 231, 255, 258-59; data 73, $76 \mathrm{n} 2,100,108,153,165$; and education 161 ; and health care 52, 62, 105;

and telemedicine 25, 44; and welfare services 255; see also laws

reimbursement 17-18, 129, 131, 131-32

remuneration $17-18,24-26$

robots $2-3,89-90,163,244,268$

rule of law $312-13,315$

rural residents $27-28,87$

Russia 208, 328-29

SALAR 16, 42, 135-36

Salmeling, Merete 247

SatoshiLand 286-87

school performance 161

school shootings 178

Second Amendment 177-78, 183

Second Life 328

security, personal 7-8, 252, 269-70; see also citizen protection

security, societal 8, 198-200, 208-11; and agility 200-206; and autonomous vehicles 206; and coercion 207-8; and crisis response 207; and intensive care units 206-7; see also citizen protection security cameras 264

security firms 266

self-care 91-92, 99-100, 127, 263

self-sovereign identities (ssIDs) 67-69, $73,221-22$
Sellström, Johan 247

sensor-augmented insulin pumps 104

sick-pay 24

simulations 149

Skype 42

Slovakia 119

smart contracts $65,68-70,71,278-79$, $283-85,287,289-90$

smart homes 249

Smart IDs 218

smartphones 2, 215, 219; see also cell phones

social care $3,7,10 \mathrm{n} 1,127-29, \mathbf{1 3 3}$, 336-38; current challenges in 129-33; and government guidelines 135-36; and innovation 136-37; and private companies 133-34

social media 100, 102, 214, 222-23, 319-30, 323-26; see also Facebook; Twitter

source criticism 329

stablecoins 283

Stenberg, Frippe 247

stereolithography (SLA) 121

strategic human resource management

(SHRM) 201

suicide bombers 183; see also terrorism surgery $89,122,263,268,270$

surveillance 176, 264, 272

sustainability $265-66$

Sweden 4, 5; and blockchains 60; and cash 8, 235-40; and democracy 9, 321-23, 329-30; and digital health technologies 83-86; and educational technology 143,145 ; and health care $34-35,35$, 50, 76n2; and health care apps 21; and health information exchanges (HIEs) 61-63; and identification 218-19; and patient health care records 107-8; and social care 127-37; and societal security 198-99; and telemedicine 15-18, 21-23, 22; and welfare services 243 , 248-52

Swedish Association of Local Authorities and Regions see SALAR

Swedish National Bank 236

Systembolaget 249

taxes $265,308-9$

teaching $145-47,264,269$

telemedicine 4, 6, 27-29, 33, 37-38, $53 \mathrm{n} 1,53 \mathrm{n} 2,128,336$; and collaboration with public sector $43-46,51-52$; 
criticisms of 19-20; and health care accessibility $16-17$; and primary health care 18-19; and privatization 20-21; and productivity 52 ; quality of $23-27$; in Sweden 15-16, 17-18, 21-23, 22; and visits 23, 23; see also health care terrorism 182-83, 189, 266

textbooks 144,159

Thörner, Tina 247, 251-52

three-dimensional printing see 3D printing time-based one-time password algorithm (TOTP) 219

Torell, Anders 247, 251

trace data 214

Treaty of Westphalia 297-98

Trump, Donald 318-21, 324

trust 105, 279-81, 282-85; and nations 296-97; and US government 175-76 Twitter 319-20

Uber 254, 304

UK: and blockchains 60 ; and health care apps 21

uncanny valley 2

United States: and blockchains 60; and democracy 9, 318-20; and education 158-63; and health care apps 21; and military defense 192-93; and trust in government 193

US Central Intelligence Agency (CIA) 172,189

US Department of Defense (DOD) 172, $173,185,187$

US Department of Energy (DOE) 173, $188,195 \mathrm{n} 2$

US Department of Homeland Security (DHS) 173, 188

US Department of Justice (DOJ) 173, 189

US Department of State (DOS) 173, 187-88 user interfaces 253-54

US Federal Bureau of Investigation (FBI) 190

US National Security Administration and Central Security Service 172, 189

Vahedi, Peyman 247, 251

video calls 18, 21; see also telemedicine

virtual health rooms $87-88$

virtual reality (VR) 120-22, 162, 164, 305

Vision for eHealth 35

voice control 254

von Bismarck, Otto 1

voting 269

vulnerable groups $110,112,113 \mathrm{n} 2$; see also elderly; inequality

Waardahl, Henrik 247

waiting times 17

warfare 238, 239, 297

weapons 175

wearables 99-100, 103-4, 109, 112, 128, 254

welfare services $9,272-75,341$; and commercialized welfare 260,261 , 267-70; consumption of 243-48; and data-driven states 260,261 , 262-64; and efficiency $243-44,260$, $261,270-72$; future of $259-60$; and global choice 260, 261, 264-67; and globalization 252-59; and Sweden 248-52

welfare states $1,340-42$

well-being 127-37

Wennerholm Kocken, Erik 247

Wibson 224

wicked problems 204

Ziemsky, David 247 


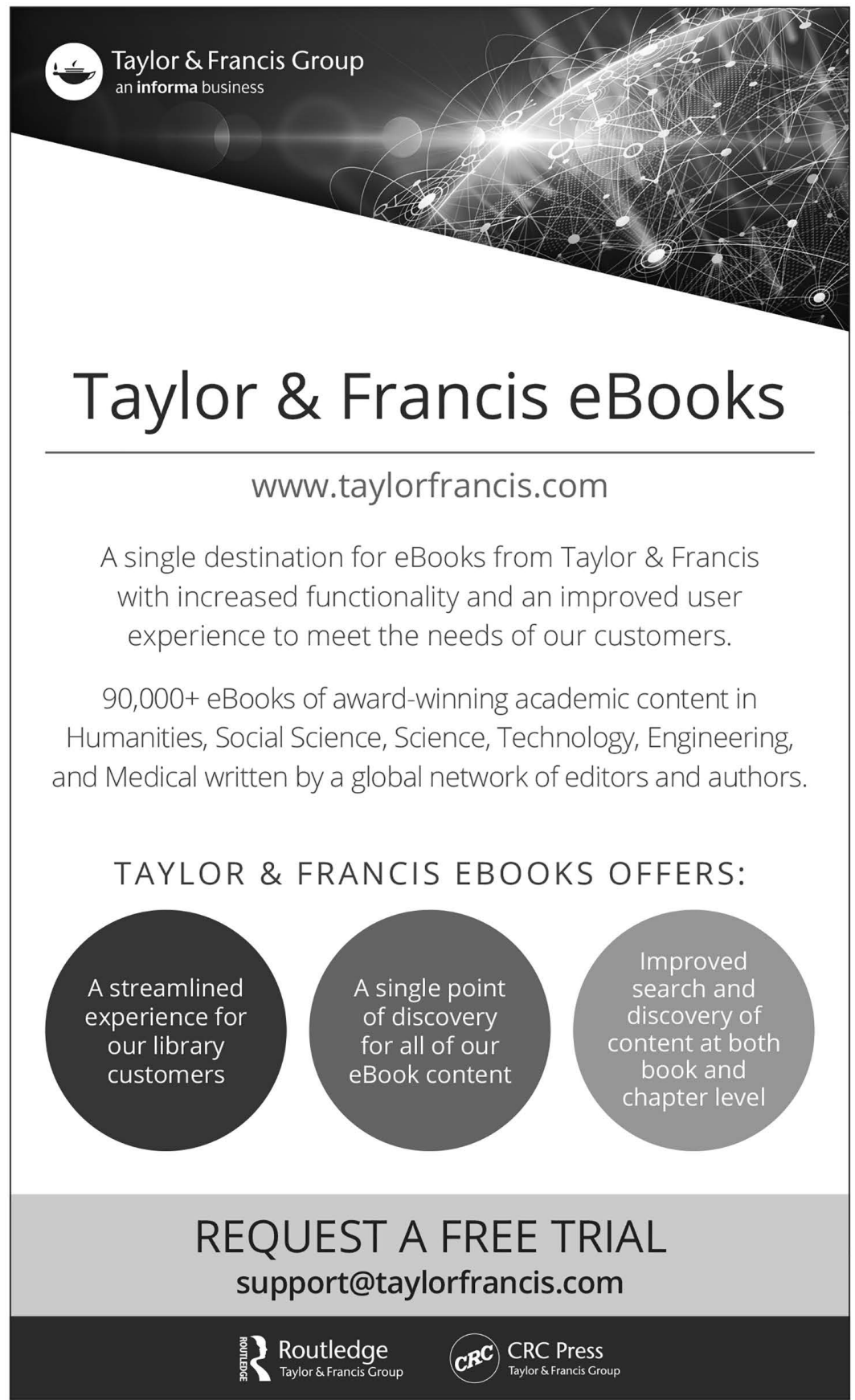

